UNIVERSIDADE DE SÃO PAULO

FACULDADE DE EDUCAÇÃO

KILWANGY KYA KAPITANGO-A-SAMBA

\title{
HISTÓRIA E FILOSOFIA DA CIÊNCIA NO ENSINO DE CIÊNCIAS
}

NATURAIS: o consenso e as perspectivas a partir de documentos oficiais, pesquisas e visões dos formadores 


\section{HISTÓRIA E FILOSOFIA DA CIÊNCIA NO ENSINO DE CIÊNCIAS NATURAIS: o consenso e as perspectivas a partir de documentos oficiais, pesquisas e visões dos formadores}

Versão Revisada

Tese apresentada ao Programa de PósGraduação em Educação da Faculdade de Educação, da Universidade de São Paulo, para obtenção do Título de Doutor em Educação.

Área de Concentração: Ensino de Ciências e Matemática

Orientador: Prof. Dr. Elio Carlos Ricardo 
Autorizo a reprodução e divulgação total ou parcial deste trabalho, por qualquer meio convencional ou eletrônico, para fins de estudo e pesquisa, desde que citada a fonte.

\author{
Catalogação na Publicação \\ Serviço de Biblioteca e Documentação \\ Faculdade de Educação da Universidade de São Paulo
}

371.12(81) Kapitango-a-Samba, Kilwangy kya

K17h História e Filosofia da Ciência no Ensino de Ciências Naturais: o consenso e as perspectivas a partir de documentos oficiais, pesquisas e visões dos formadores / Kilwangy kya Kapitango-a-Samba ; orientador Elio Carlos Ricardo. - São Paulo, 2011.

$384 p$ : il., tabs.

Tese (Doutorado - Programa de Pós-Graduação em Educação. Área de Concentração: Ensino de Ciências e Matemática) - Faculdade de Educação da Universidade de São Paulo.

1. Formação de Professores - Ciências Naturais 2. Documentos Oficiais - Brasil 3. Professores de Ensino Superior - Percepções 4. Ciência - Ensino 5. Filosofia da Ciência 6. História da Ciência I. Ricardo, Elio Carlos, orient. 


\section{FOLHA DE APROVAÇÃO}

Nome: KAPITANGO-A-SAMBA, Kilwangy kya

Título: História e Filosofia da Ciência no Ensino de Ciências Naturais: o consenso e as perspectivas a partir de documentos oficiais, pesquisas e visões dos formadores.

Tese apresentada ao Programa de PósGraduação em Educação da Faculdade de Educação, da Universidade de São Paulo, para obtenção do título de Doutor em Educação (Ensino de Ciências e Matemática).

Aprovado em:

\section{Banca Examinadora}

Prof. Dr. Elio Carlos Ricardo Instituição: FE-USP Julgamento: Assinatura:

Prof. Dr. Luis Carlos de Menezes Instituição: IF-USP Julgamento: Assinatura:

Prof ${ }^{a}$. Dr ${ }^{a}$. Marcia Helena Mendes Ferraz Instituição: PUC-SP Julgamento: Assinatura:

Prof ${ }^{a}$. Dr ${ }^{a}$. Maria Elice de Brzezinski Prestes Instituição: IB-USP Julgamento: Assinatura:

Prof ${ }^{a}$. Dra ${ }^{\mathrm{a}}$. Thais Cyrino de Mello Forato Instituição: UNIFESP Julgamento: Assinatura: 


\section{DEDICO}

Aos meus pais, em memória, com afeto, estima e profunda gratidão por me terem trazido à experiência e pela educação recebida.

À Simone Regina de Souza, Albertina Francisco Guerra, Weza Kissanga, Aísha Aminatah e Kilwangy Kidi com amor e profunda admiração pelo apoio e pela compreensão recebida ao longo do período de estudos e pesquisa, que exigiram de mim ausências constantes. 


\section{AGRADEÇO}

À minha família pela sua compreensão nos momentos de minha ausência.

Ao Prof. Dr. Nilson José Machado pelo diálogo e indicação do Prof. Elio para orientação.

Ao Prof. Dr. Elio Carlos Ricardo pela atenção e dedicação com que assumiu a orientação da pesquisa, pela sua capacidade de diálogo aberto, crítico, construtivo e proativo.

Às $\operatorname{Prof}^{\mathrm{a}}{ }^{\mathrm{s}} \mathrm{Dr}^{\mathrm{a}} \mathrm{s}$ Márcia H. M. Ferraz e Maria E. B. Prestes pelas contribuições críticas recebidas durante a Banca de qualificação.

Aos Docentes da USP (FE, IF, IB, IQ, FFLCH) pela colaboração ao responderem às entrevistas semiestruturadas. 
A ciência é sem dúvida uma tarefa importante e nobre, mas não é a única forma de investigação intelectual com valor. Não devemos abraçar a ideia de que uma pergunta ou é científica ou coisa nenhuma.

Colin McGinn, 2007¹.

1 Como se Faz um Filósofo. Lisboa: Bizâncio, 2007. Disponível em: <http://criticanarede.com/fm_01.html>. Acesso em: 08 dez. 2009. 


\section{RESUMO}

KAPITANGO-A-SAMBA, Kilwangy kya. História e Filosofia da Ciência no Ensino de Ciências Naturais: o consenso e as perspectivas a partir de documentos oficiais, pesquisas e visões dos formadores. 2011. $384 \mathrm{f}$. Tese (Doutorado) Faculdade de Educação, Universidade de São Paulo - USP, São Paulo, 2011.

A análise do distanciamento entre as orientações teóricas das instâncias decisórias (ID) sobre a inclusão da abordagem dos aspectos da História e Filosofia da Ciência no Ensino de Ciências Naturais (HFCrECN) constitui o nosso objetivo de investigação, cujo problema foi identificar as ID e saber em que elas se distanciavam entre si em relação à $\mathrm{HFC}$ ECN. Para tal, delimitamos o estudo de caso único qualitativo, tendo o Brasil como unidade caso sob o aspecto da HFCrECN, cujas múltiplas unidades de análise foram as ID. Para coleta e análise de dados utilizamos a entrevista semiestruturada com especialistas, a análise de conteúdo e a análise documental. Da investigação resultou a identificação de quatro ID em relação à HFCrECN, das quais três foram analisadas e identificamos que elas apresentam desconexão/discrepância metodológica e epistemológica de perspectivas diferentes, portanto, a convergência entre as ID está longe de ocorrer na realidade material do sistema educacional, o que pode inviabilizar a efetiva HFCrECN. Os regulamentos oficiais apontam para a contextualização externa (sociocultural) e as pesquisas parecem assumir a HFC como conteúdo no ensino de ciências naturais, porém, dos 72 trabalhos de pesquisa analisados, 34 apontam para contextualização interna; 16, criticidade; 9, motivação; 8 , contextualização externa. Na formação docente, a maioria das disciplinas aponta para contextualização interna (7); as percepções dos docentes formadores apontam para instrumentação didática e criticidade e uma abordagem da HFC enquanto perspectiva de reflexão crítica. As três ID constituem seus próprios cenários ontológico, político e decisório, formam uma constelação bicondicional com rupturas de sequência comunicativa e tomada de decisões. A realidade escolar não tem sido considerada enquanto instância decisória e nem consultada o suficiente para tomada de decisões e prescrições das três ID. Finalmente, apresentamos algumas reflexões e perspectivas propositivas sobre 0 tema.

Descritores: História e Filosofia da Ciência. Ensino de Ciências Naturais. Formação de Professores. Documentos Oficiais. Parâmetros e Diretrizes Curriculares. Instâncias Decisórias. 


\begin{abstract}
KAPITANGO-A-SAMBA, Kilwangy kya. History and Philosophy of Science in Teaching of Natural Sciences: the consensus and the perspectives from official documents, research and teachers' viewpoints. 2011. 384 pp. Thesis (Ph.D.) School of Education, University of São Paulo - USP, São Paulo, 2011.
\end{abstract}

Our research goal is to analyze the detachment of the theoretical orientations from the decision-making institutions (DMIs) with regards to the inclusion of aspects of the approach of History and Philosophy of Science in the Teaching of Natural Sciences (HPS-TNS), in order to identify the decision-making institutions and learn where they distanced themselves from each other regarding HPSrTNS. Thus, a single qualitative case was delimited, using Brazil as a study unit under the HPSrTNS aspect and the DMls as multiple analyses units. To collect and examine the data, semi-structured interviews with experts, content and documentation analysis were used. The outcome of the research was the identification of four decision makers related to HPS-TNS, of which three were analyzed. We concluded that they exhibit methodological and epistemological disconnection/discrepancy with different perspectives, therefore, the convergence between the DMls is far from occurring in the educational system's actual material, rendering unfeasible the effective HPS-TNS. The official rules point to an external contextualization (social-cultural) and the research appears to assume the HPS as the natural science teaching content. However from the 72 research papers analyzed: 34 showed internal contextualization; 16, criticisms; 9, motivations; and 8, external contextualization. In teacher education, most of the courses point to the internal context (7), the teachers' perceptions indicate didactic instrumentation, and criticism is an HPS approach as a perspective of critical reflection. The three DMls constitute their own ontological, political and decision-making scenario, they form a bi-conditional constellation with communicative sequence and decision making disruptions. The school reality has not been considered as a Decision-Making Institution nor sufficiently consulted for the recommendations of decisions and directives of those three (DMIs). Finally, we offer some reflections and proactive perspectives on the subject.

Keywords: History and Philosophy of Science. Education of Natural Sciences. Teacher Education Training. Official Documents. Parameters and Curriculum Guidelines. Decision-Making Institutions. 


\section{LISTA DE FLUXOGRAMAS}

Fluxograma 1 - Zonas de Interface Metacientífica HFC e HFSC …................................. 53

Fluxograma 2 - Zona de Interface Supercomplexa ECN.................................................... 55

Fluxograma 3 - Zonas de Interface Hipercomplexa HFC/HFSCrECN .............................. 56

Fluxograma 4 - Estrutura Funil Dedutiva do Estudo de Caso ............................................ 67

Fluxograma 5 - Carga Prescritiva: processo decisório prescritivo das ID implicadas na HFSCrECN ................................................................................. 303 


\section{LISTA DE TABELAS}

Tabela 1 -

Argumentos Categorizáveis em relação à $\mathrm{HCrECN}$ 44

Tabela 2 -

Argumentos Categorizáveis em relação à $\mathrm{FC} r \mathrm{ECN}$ 45

Tabela 3 -

Argumentos Categorizáveis em relação à tendência HFCrECN

Tabela 4 -

Argumentos Categorizáveis em relação à HFSCrECN 47

Tabela 5 Das Categorias de Análise

Tabela 6 -

Competências e Habilidades do Contexto sociocultural . 86

Tabela 7 Competências e Habilidades em Representação e Comunicação 92

Tabela 8 Competências e Habilidades em Investigação e Compreensão .93

Tabela 9 Competências de Contextualização Sociocultural 95

Tabela $10-$ Competências e habilidades específicas de contextualização sociocultural na aprendizagem da Biologia

Tabela $11-$ Competências e habilidades específicas de contextualização sociocultural na aprendizagem da Física

Tabela $12-$ Competências e habilidades específicas de contextualização sociocultural na aprendizagem da Química .... 102

Tabela 13

Conhecimentos e habilidades de História e Filosofia da Química 121

Tabela 14 Símbolos e abreviações usadas nas tabelas de revistas e eventos 131

Tabela 15 Caderno Brasileiro de Ensino de Física 137

Tabela 16 -

Revista Brasileira de Ensino de Física 142

Tabela 17 Química Nova 143

Tabela 18

Química Nova na Escola .

Tabela 19

Revista de Ensino de Biologia 146

Tabela 20

Alexandria - Revista de Educação em Ciência e Tecnologia 146

Tabela 21 -

Ciência \& Educação 164

Tabela 22 -

Ciência \& Ensino 165

Tabela 23 -

Ensaio - Pesquisa em Educação em Ciências 174

Tabela 24 Investigações em Ensino de Ciências 180

Tabela 25 Filosofia e História da Biologia 181

Tabela 26 História da Ciência e Ensino: construindo interfaces 182

Tabela 27 -

Revista Brasileira de História da Ciência 182

Tabela 28 -

Revista Brasileira de Pesquisa em Educação em Ciências 183

Tabela 29 Artigos por Categorias de Análise 184

Tabela 30 -

Encontro de Pesquisa em Ensino de Física 202

Tabela 31 -

Simpósio Nacional de Ensino de Física 221

Tabela 32 -

Encontro Nacional de Ensino de Química 229

Tabela 33 -

Encontro Nacional de Ensino de Biologia 231

Tabela 34 -

Encontro de Filosofia e História da Biologia 233 
Tabela 35 - Encontro Nacional de Pesquisa em Educação em Ciência ........................... 242

Tabela 36 - Trabalhos de Eventos por Categorias de Análise ........................................ 242

Tabela 37 - Disciplinas com Aproximação à HFCrECN por Categorias ........................... 255

Tabela 38 - Incidências das Percepções dos Docentes Formadores nas Categorias ..... 296 


\section{LISTA DE ABREVIATURAS E SIGLAS}

\begin{tabular}{|c|c|}
\hline AAAS & American Association for Advancement of Science \\
\hline ACt & Análise de Conteúdo \\
\hline ADt & Análise Documental \\
\hline APS & American Physical Society \\
\hline AQC & Análise qualitativa de conteúdo \\
\hline BAAS & British Association for the Advancement of Science \\
\hline BSCS & Biological Science Curriculum Study (EUA) \\
\hline BSHS & British Society for the History of Science \\
\hline CAPES & Coordenação de Aperfeiçoamento de Pessoal de Nível Superior \\
\hline CEB & Câmara da Educação Básica (do CNE) \\
\hline CNE & Conselho Nacional de Educação \\
\hline CES & Câmara de Ensino Superior (do CNE) \\
\hline DCNEM & Diretrizes Curriculares Nacionais para o Ensino Médio \\
\hline CTS & Ciência, Tecnologia e Sociedade \\
\hline DCNCG & Diretrizes Curriculares Nacionais para os Cursos de Graduação \\
\hline DF & Docentes Formadores (isto é, que atua na formação docente) \\
\hline DO & Documentos Oficiais \\
\hline ECN & Ensino de Ciências Naturais \\
\hline FC & Filosofia das Ciências \\
\hline ENEM & Exame Nacional do Ensino Médio \\
\hline ETDRD & Estratégia de Trabalho Didático em Rede Disciplinar (e Docente) \\
\hline FE-USP & Faculdade de Educação da Universidade de São Paulo \\
\hline FC-UNESP & Faculdade de Ciências da Universidade Estadual Paulista \\
\hline FIOCRUZ & Fundação Osvaldo Cruz \\
\hline $\mathrm{HC}$ & História das Ciências \\
\hline HFC & História e Filosofia da Ciência \\
\hline HFSC & História, Filosofia e Sociologia da Ciência \\
\hline \multirow[t]{2}{*}{ HFCrECN } & Uso/Aplicação/Inclusão da abordagem Histórico-Filosófica das Ciências no \\
\hline & Ensino de Ciências Naturais \\
\hline \multirow[t]{2}{*}{ HFSCrECN } & Uso/Aplicação/Inclusão da abordagem Histórico-Filosófico-Sociológica das \\
\hline & Ciências no Ensino de Ciências Naturais \\
\hline HSS & History of Science Society (EUA) \\
\hline ID & Instância/s Decisiva/s \\
\hline INEP & Instituto Nacional de Estudos e Pesquisas Educacionais Anísio Teixeira \\
\hline LDBEN & Lei de Diretrizes Básicas de Educação Nacional \\
\hline MEC & Ministério da Educação (Brasil) \\
\hline NCC & National Curriculum Council (do Reino Único) \\
\hline
\end{tabular}


OCEM Orientações Curriculares para o Ensino Médio

PCN

Parâmetros Curriculares Nacionais

PC

Pesquisa Científica

$\mathrm{PCN}+$

Orientações Educacionais Complementares aos Parâmetros Curriculares

Nacionais

PCNEM Parâmetros Curriculares Nacionais para o Ensino Médio

PDE

Prática Didática Escolar

PUC-SP

Pontifica Universidade Católica de São Paulo

RO

Regulamentos Oficiais

SAEB

Sistema Nacional de Avaliação do Ensino Médio

SBHC

Sociedade Brasileira de História da Ciência

SEB

Secretaria de Educação Básica (MEC)

SEMT

Secretaria de Educação Média e Tecnológica (MEC)

UNICAMP

Universidade Estadual de Campinas

VOSTS

Views on Sciencie-Technology-Society 


\section{SUMÁRIO}

1 INTRODUÇÃO

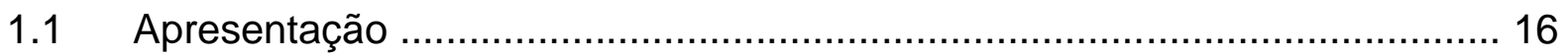

1.2 Cenário Internacional e Projetos de Inclusão ............................................ 16

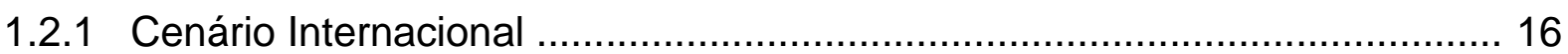

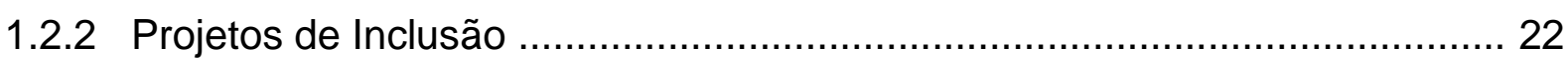

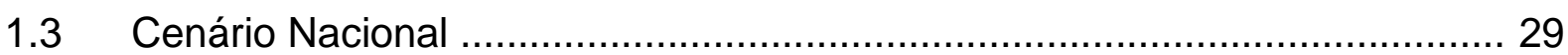

1.4 Categorias Temáticas e Analíticas ................................................................ 39

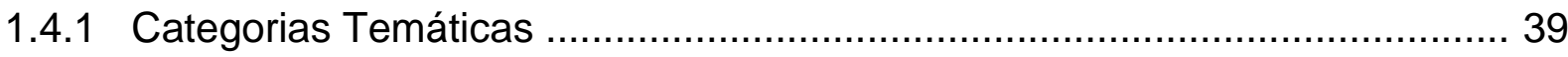

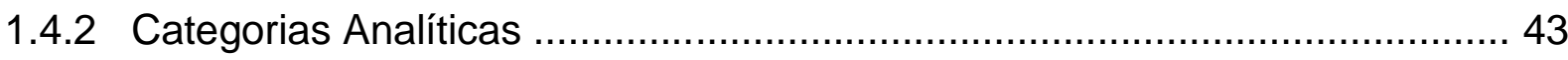

1.5 Problema de Pesquisa ................................................................. 49

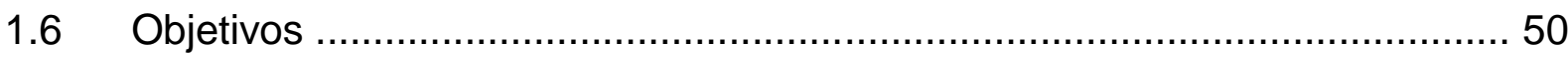

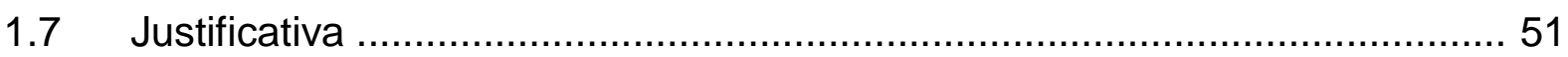

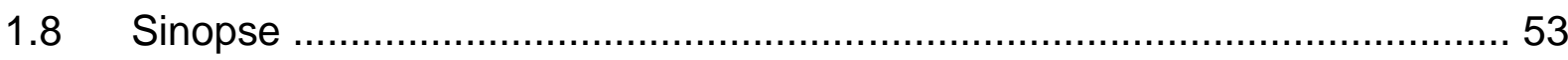

2 PROCEDIMENTOS METODOLÓGICOS …............................................. 58

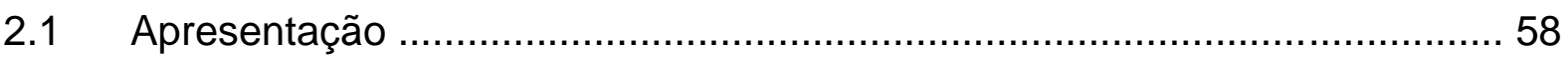

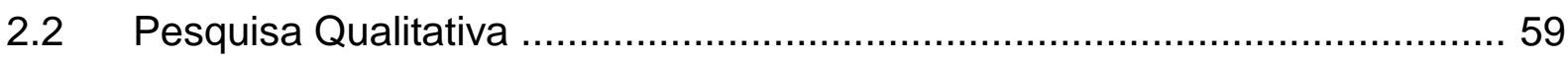

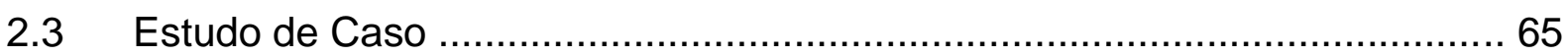

2.4 Técnicas de Coleta e Análise de Dados ....................................................... 68

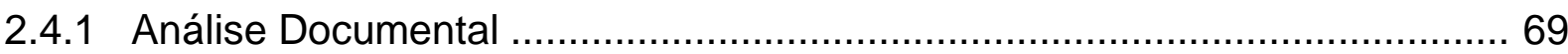

2.4.2 Entrevista Semiestrutura com Especialistas ……................................... 71

2.4.3 Análise de Conteúdo ......................................................................... 74

3 HCrECN NOS REGULAMENTOS OFICIAIS .......................................... 76

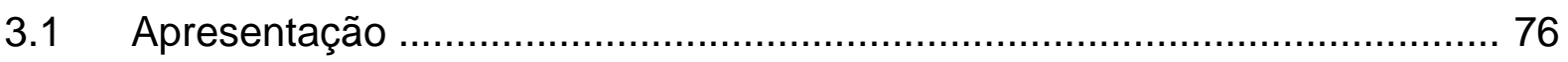

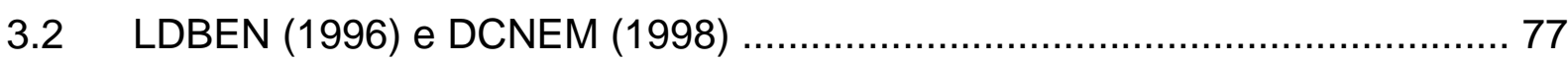

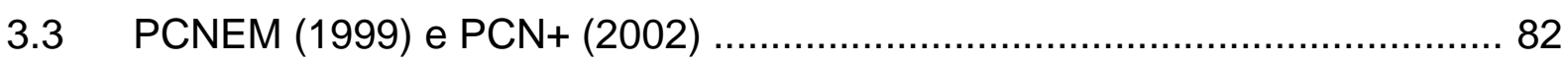

3.4 Matrizes Curriculares de Referência para o SAEB (1999) …...................... 105

3.5 Diretrizes Curriculares Nacionais para os Cursos de Graduação ................ 111

3.6 Orientações Curriculares para o Ensino Médio (2006) ............................... 116

3.7 Matriz de Referência do ENEM (2009) .................................................. 123

4 HCrECN NAS PESQUISAS NACIONAIS (1999 a 2010) ......................... 127

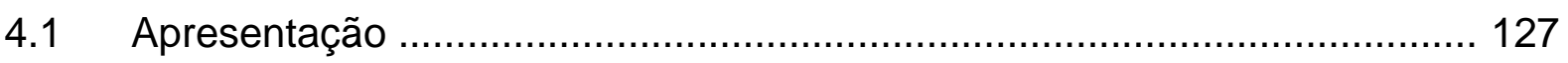

4.2 HFCrECN nas Pesquisas Publicadas em Periódicos (1999 a 2010) ......... 129

4.2.1 Periódicos da Área de Ensino de Física ................................................. 131 
4.2.2 Periódicos da Área de Ensino de Química ............................................ 143

4.2.3 Periódicos da Área de Ensino de Biologia ............................................... 146

4.2.4 Periódicos da Área de Ensino de Ciências Naturais .................................. 146

4.3 HFCrECN nos Resumos de Eventos Científicos (1999 a 2010) ................ 185

4.3.1 Eventos da Área de Ensino de Física .................................................... 186

4.3.1.1 Encontro de Pesquisa em Ensino de Física .............................................. 186

4.3.1.2 Simpósio Nacional de Ensino de Física .................................................... 202

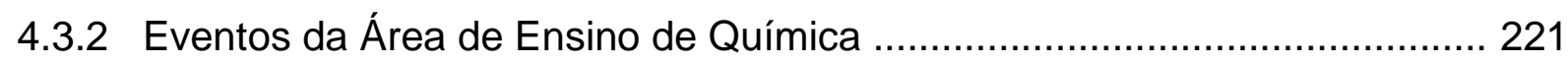

4.3.2.1 Encontro Nacional de Ensino de Química ............................................... 222

4.3.3 Eventos da Área de Ensino de Biologia ................................................... 229

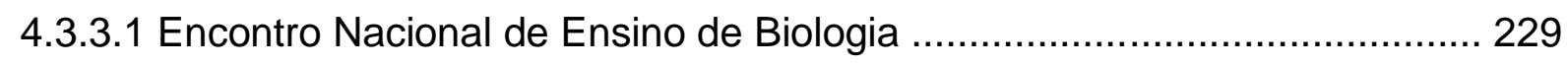

4.3.3.2 Encontro de Filosofia e História da Biologia ............................................ 231

4.3.4 Eventos da Área de Ensino de Ciências Naturais ...................................... 233

4.3.4.1 Encontro Nacional de Pesquisa em Educação em Ciência ....................... 234

5 HCrECN NA FORMAÇÃO INICIAL DOCENTE: Caso USP ..................... 246

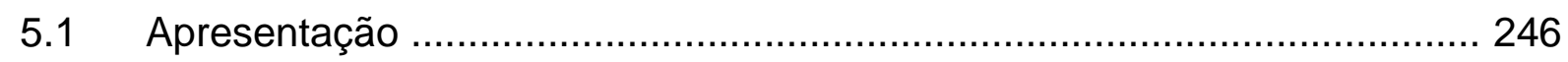

5.2 HFCrECN nos Planos Disciplinares ………….................................. 246

5.2.1 Na Licenciatura em Física ………………................................... 247

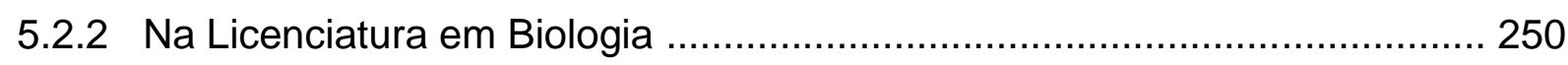

5.2.3 Na Licenciatura em Química ........................................................... 252

$5.3 \quad \mathrm{HFC} r E C N$ vista pelos Docentes Formadores …....................................... 256

5.3.1 Percepções acerca da Aproximação da HFC ao ECN ……….................... 258

5.3.2 Percepções acerca da HFCrECN na Formação Inicial Docente .................. 268

5.3.3 Percepções acerca da HFCrECN no Ensino Médio .................................. 285

6 CONSIDERAÇÕES, REFLEXÕES E PERSPECTIVAS ............................. 297

a) À Guisa de Considerações Finais ....................................................... 297

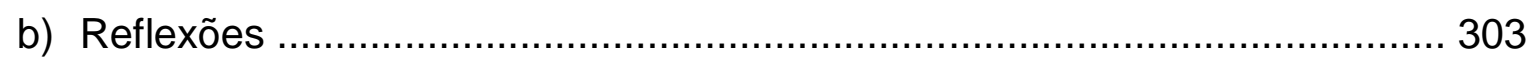

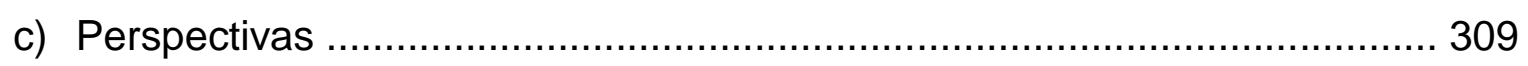

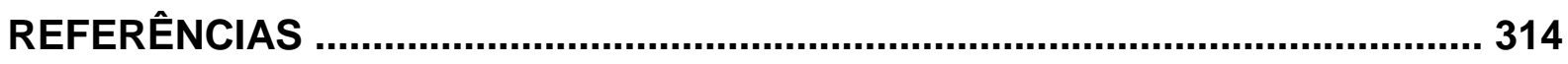

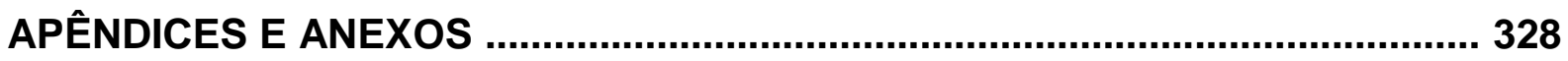

Apêndice Termo de Consentimento Livre e Esclarecido ........................................ 329

Anexo 1ํㅡㄹ Ementário das Disciplinas de Licenciatura em Física ............................. 330

Anexo 2ํㅡㄹ Ementário das Disciplinas de Licenciatura em Biologia ......................... 342

Anexo 3ํㅡㄹ Ementário das Disciplinas de Licenciatura em Química ......................... 365 


\section{1 - INTRODUÇÃO}

Tudo aquilo que se nos depara na história do pensamento científico está bem longe de servir efetivamente a evolução desse pensamento.

Gaston Bachelard. A Epistemologia, 2001, p. 167.

\section{1 - Apresentação}

Antes de apresentarmos os nossos objetivos e o problema da pesquisa, consideramos ser necessário analisar o cenário do movimento internacional que advoga a inclusão (uso/aplicação) da abordagem de aspectos da História e Filosofia da Ciência (HFC) no Ensino de Ciências Naturais (ECN) em que o problema se situa. Antes, porém, convém esclarecer que a História e Filosofia da Ciência no Ensino de Ciências Naturais constitui uma área de interseção/interface secundária antecedida de interseções primárias que ocorreram entre a HC e FC de um lado e do outro, entre a Física, Química e Biologia, de ambas resultou áreas de formação pós-graduada e investigação científica denominadas História e Filosofia da Ciência, no primeiro caso, e Ensino de Ciências Naturais ${ }^{2}$, no segundo. E é destas duas áreas de interseções que surgiu a interface terciária, chamada de HFC no ECN.

\section{2 - Cenário Internacional e Projetos de Inclusão}

\subsection{1 - Cenário Internacional}

$\mathrm{Na}$ análise dos cenários tomamos como objetivo ilustrar a dinâmica da literatura* acerca da aproximação da HFC ao ECN, neste caso, o enfoque é dado ao âmbito internacional, para demonstrar o enquadramento do cenário nacional e deduzir deste o objeto de pesquisa. Nos cenários também há certo consenso sobre a temática ou a necessidade de incluir a HFC no ECN.

\footnotetext{
${ }^{2}$ Conhecida , comumente, como Ensino de Ciências. A esta área, às vezes, tem sido acrescentada a Matemática, como ocorreu nos PCN: Ciências da Natureza, Matemática e suas Tecnologias.

* A grande maioria desta literatura está em inglês.
} 
Nos últimos 20 anos, a inclusão da abordagem dos aspectos da HFC no ECN (HFCrECN) ou, mais genérica, inclusão da abordagem dos aspectos da HFSC (HFSCrECN) - tem sido temática e área de investigação em crescimento e de prescrições das políticas públicas educacionais. Ela tem se tornado "inspiradora" de ações em que se objetiva a implementação de projetos didáticos ou paradidáticos com a finalidade de introduzir, no ensino de ciências naturais, a abordagem de alguns aspectos histórico-filosófico-sociológicos implicados na produção (e divulgação) do conhecimento científico, fenômeno que ocorre tanto no cenário internacional quanto no nacional ${ }^{4}$, o que lhe garante, em princípio, o "status" de movimento internacional investigativo e prescritivo na interface entre a $\mathrm{HFC}^{-\mathrm{HFSC}^{5} \mathrm{e}}$ o ECN.

No entanto, neste movimento é possível identificar uma oscilação conceitual identitária entre HC, HFC e HFSC. Fato é que a tendência do movimento está para uma unificação maior das metaciências, para também fortificar sua identidade e ampliar a consistência de suas abordagens, tanto nesta zona de intersecção epistêmica: ensino de ciências naturais escolares e formação docente (ou também ensino de ciências sociais e humanas) quanto na sua própria área de constituição História, Filosofia e Sociologia da Ciência (estudando as ciências como um todo (sociais/humanas, naturais, da saúde, etc.), em seus aspectos metacientíficos (intra e extra). Resulta daí o fato de ser amplamente apropriada e plausível a expressão identitária HFSC.

\footnotetext{
${ }^{3}$ Trata-se de inclusão/uso/aplicação de aspectos histórico-filosóficos. A expressão História, Filosofia e Sociologia da Ciência (HFSC), que também tem sido utilizada com pouca frequência, constitui a forma ampliada deste movimento internacional, que, de certo modo, nele também está subjacente a tendência denominada Ciência, Tecnologia e Sociedade (CTS). Houve também uma perspectiva metacientífica de antropologia da ciência e psicologia da ciência, porém, esses projetos não tomaram rumos significativos quanto os anteriores. No entanto, a área de Política Científica tem tido prosperidade, apensar de não estar vinculada ao movimento aqui referido, porque se estuda mais política pública de ciência e tecnologia, mas também ainda está em pouca expansão acadêmica, são raríssimos os programas de formação pós-graduada em economia e política científica. Podemos citar alguns exemplos: no Brasil temos os cursos de mestrado e doutorado em Política Científica e Tecnológica do Instituto de Geociências da Universidade Estadual de Campinas (Unicamp). No exterior existem alguns como o mestrado e doutorado em Política Científica e Tecnológica (MSc/PhD in Science and Tecnology Policy) da University of Sussex (Inglaterra); doutorado em Política Científica e Tecnológica da George Washington University (Estados Unidos da América); doutorado em Política Científica e Tecnológica da National Graduate Institute for Policy Studies (Japão) e doutorado em Estudos de Ciência e Tecnologia (PhD in Science and Technology Studies (STS)) da School of Social and Policital Science da University of Edinburgh (Inglaterra).

${ }^{4}$ No que se refere ao âmbito nacional retomaremos este assunto ao analisarmos os documentos oficiais brasileiros e a literatura nacional, nos capítulos $3^{\circ}$, $4^{\circ}$ e $5^{\circ}$.

${ }^{5}$ É comum encontrar expressões $H C$ ou HFC e, raramente, HFSC no ensino de ciências naturais escolares (Física, Química e Biologia), em virtude do caráter do trabalho, utilizamos o conceito HFC, que não exclui em si o componente da análise social, que é histórica e filosófica.
} 
Não obstante, entre as duas últimas décadas do século 20 e a primeira do século 21, começou a tornar-se mais expressiva - como veremos adiante - este movimento da HFCrECN, sob a alegação de introduzir uma abordagem crítica da natureza da ciência e contextualista, isto é, dos aspectos históricos, sociais, econômicos e políticos, entre outros, envolvidos na produção científica e na distribuição de seus resultados.

Ademais, é preciso ressaltar que este foi o período histórico em que a própria $\mathrm{HC}$ começava ainda a tornar-se autônoma, como bem descreve Thomas $\mathrm{S}$. Kuhn, em sua obra A Tensão Essencial (1989, p. 143):

\begin{abstract}
Como disciplina profissional independente, a história da ciência é um novo campo emergindo ainda de uma pré-história longa e variada. Só desde 1950 e, inicialmente, apenas nos Estados Unidos é que a maioria, mesmo dos seus praticantes mais jovens, se especializou ou empenhou numa carreira escolar a tempo completo neste campo. Dos predecessores, a maioria dos quais eram historiadores apenas por entretenimento e assim derivavam os seus objectivos e valores principalmente de qualquer outro campo, esta geração mais jovem herdou uma constelação de objetivos, por vezes irreconciliáveis. As tensões resultantes, embora tenham afrouxado com a crescente maturidade da profissão, ainda são perceptíveis, sobretudo nas variadas audiências principais a que continua a dirigir-se a literatura da história da ciência.
\end{abstract}

Em poucas palavras, Kuhn destaca a juventude da $\mathrm{HC}$, o grau da sua maturidade e a complexidade historiográfica e filosófica que a cerca. $E$, as tensões de caráter filosófico e historiográfico a que ele se refere não findaram, estão presente no próprio ofício de historiador e/ou filósofo da ciência.

Podemos dizer que a história é a tentativa de reconstrução do passado a partir da perspectiva filosófica, sociocultural e ideológica do historiador, institucionalizada no presente em que se "imagina" ou se pensa o passado, a partir das "evidências" fragmentadas pressupostas como colaboradoras da hermenêutica de reconstrução. Assim, a história teria feição dos olhos e das mentes dos seus feitores, daí, talvez, a razão da paráfrase lakatiana, de que a 'HC sem a FC é vazia e a FC sem a HC é cega', para tentar quebrar a acriticidade, de um lado, e a ahistoricidade, do outro!

Historicamente, as origens do movimento internacional da HFCrECN estão nas aproximações ou nos reconhecimentos da relevância da $\mathrm{HC} / \mathrm{HFC}$ no ensino que podem ser constatadas já no século 19 - até onde se tem informações 
históricas - no Reino Unido ${ }^{6}$, ou seja, muito antes de a HC constituir-se em um campo de pesquisa e de formação profissional amadurecida.

Segundo Jenkins (1990, p. 274), em 1855, em Glasgow (Escócia), durante o encontro da British Association for the Advancement of Science (BAAS), o presidente da BASS, Duque de Argyll, em sua mensagem, teria se pronunciado nestes termos: o que se deseja - no ensino de ciências para os jovens - não é tanto a mera obtenção dos resultados, mas, dos métodos e, sobretudo, da história da ciência, isto se o processo educacional for muito bem direcionado e estruturado poderia, então, resultar no alcance de grandes metas (JENKINS, 1990, p. 274).

Esta manifestação põe em evidência a necessidade do domínio da metodologia das ciências e do conhecimento do seu contexto histórico e chama atenção da sua relevância no processo de ensino e aprendizagem, de tal forma que corrobore para que os objetivos educacionais (de seu tempo) sejam alcançados.

Ora, é possível inferir, na citação acima, a intenção de fazer com que seja compreendido o processo experimental (métodos) e o contextual (sócio-histórico, político, econômico, cultural) em que se produziu o conhecimento que está sendo ensinado aos discentes, contrariamente à simples apresentação dos resultados. Verifica-se que os métodos e a HC são substantivados, o que confere caráter de objetivos formativos a estas duas áreas, para então, supostamente, ativar, nos discentes, o entendimento da feitura do conhecimento científico (KAPITANGO-ASAMBA, 2005, p. 17).

Jenkins (op. cit.) afirma igualmente que, durante a conferência de 1917, a BAAS teria retomado uma aproximação semelhante, ao ressaltar que a $\mathrm{HC}$ ofereceria condições para dissolver a barreira artificial erguida pelo horário escolar com fins de distanciar os estudos literários das ciências. ${ }^{7}$ Esta afirmação contém certa coerência ainda hoje, se pensarmos nas estruturas dos programas (cursos) de graduação em ciências naturais, quão ausente é a presença de estudos linguísticos e das humanidades, a recíproca também é verdadeira.

E, no ano seguinte, em 1918, segundo Matthews (1992, p. 30) constava da British Thomson Report o reconhecimento de que o conhecimento da HFC devesse fazer parte da bagagem intelectual de todos os docentes de ciências das

\footnotetext{
${ }^{6}$ Mas também, talvez seja possível encontrar vestígios em Augusto Comte, na França, e no pensamento marxista.

Também referenciado em Matthews, 1992, p. 15.
} 
escolas secundárias.

Além do mais, o movimento da HFCrECN conta com aproximações advindas também da própria FC. Ernest Mach (1838-1916) ${ }^{8}$ foi quem afirmara que: $\left.1^{\circ}\right)$ a compreensão de determinado conceito teórico é, necessariamente, histórica e que; $\left.2^{\circ}\right)$ a pesquisa histórica sobre 0 desenvolvimento da ciência seria extremamente necessária, para que os princípios da ciência não sejam meros amontoados de 'sistema de preceitos parcialmente compreendidos, ou o que é ainda pior, um sistema de pré-conceitos.' (MACH, $1883^{9} / 1960$, p. 316 apud MATTHEWS, 1992, p. 15).

Resulta, então, que a investigação histórica da construção do conhecimento científico não promoveria apenas a compreensão do que existe no presente, mas, sobretudo, visaria a apresentar a oportunidade de vislumbrar novas possibilidades, perspectivas e novos horizontes no fazer, no ensinar e no aprender ciências.

Outra aproximação da HC ao Ensino que encontramos em Mach (op. cit.) está relacionada à sua concepção de que indivíduos que conhecem ou buscam conhecer com profundidade o percurso do desenvolvimento da ciência, poderão julgar de forma mais livre e correta o significado de quaisquer movimentos científicos atuais que aqueles indivíduos limitados aos seus pontos de vista centenários e, simplesmente, contemplam as tendências dos atuais eventos intelectuais ( $\mathrm{MACH}$, 1960, p. 8-9 apud MAIENSCHEIN, 2000, p. 334-344).

O conhecimento do percurso histórico das ciências é tido, então, como "garantia" de entendimento e da capacidade de julgar os eventos científicos em seu significado. Conhecendo-se o percurso da ciência (portanto, sua história) ter-se-ia uma capacidade julgadora mais aguçada e autônoma, ao contrário, a reprodução acrítica, a falta de visão da conjuntura e de futuro. Isto seria evidente naqueles que contemplam os conhecimentos atuais, desconhecendo-Ihes o passado e as relações envolvidas na sua produção, o que pode habilitá-los a não projetar uma intervenção teórico-prática.

Em relação à FC, Matthews (1992, p. 28) ressalta que o filósofo que mais contribuiu relevantemente para a interface da FC com o ECN, foi o filósofo

\footnotetext{
${ }^{8}$ Físico e filósofo austríaco.

${ }^{9}$ A obra que Ernest Mach publicou em 1883 denomina-se Die Mechanik in ihrer Entwicklung (A Ciência da Mecânica), há uma tradução inglesa The Science of Mechanics, publicada em LaSalle pela Open Court Publishing Company, em 1960.
} 
estadunidense Michael L. Martin. Ele dedicou uma obra cujo tema é Concepts of Science Education: a Philosophical Analysis, publicado pela primeira vez em 1972, pela Scott-Foresman, em Chicago, Estados Unidos da América. Para este filósofo estadunidense a FC poderia esclarecer o pensamento dos docentes de ciências naturais sobre a investigação científica e ainda sugerir-lhes novas idéias. Portanto, trata-se de uma concepção da Filosofia como propulsora de pensamento crítico e criativo.

Também é possível encontrar aproximações da HC ao ensino em Sarton (1884-1956) - fundador da revista Isis e da Sociedade de História da Ciência e sua institucionalização na Universidade de Harvard, EUA ${ }^{10}$ - para quem, segundo Maienschein (2000), a HC deve ser reguladora de consciências, coadjuvar os indivíduos (cientistas, filósofos, entre outros) a não serem "complacentes, arrogantes ou otimistas demais pelo sucesso", mas serem gratos e esperançosos para continuarem desempenhando, ativamente, suas atividades.

Assim, a HC não deveria ser considerada como importante simplesmente porque seria fonte de sabedoria e humanismo, mas por ser um "regulador de consciências"11 e - embora a história seja, como diz Bachelard (2001, p. 167), por princípio, hostil ao juízo normativo - torna-se necessário assim proceder se quisermos "julgar a eficácia de um pensamento" ou conhecimento.

É neste sentido que também se enquadra a concepção de Ernest Mayr ${ }^{12}$ de que a HC teria relevância na compreensão crítica de conceitos fundamentais e para quem, também, os conceitos estão carregados de um longo desenvolvimento histórico que influencia o atual estado conceitual ou semântico.

Ora, mas há que transcender a história interna, pensemos conceitos tais como "espécie”, "adaptação", "evolução", "raça”, "ideologia”, "substância”, "massa”, "matéria", "força", "energia", "progresso", "bomba nuclear", "energia nuclear", "alimentos transgênicos", "melhoramento genético", entre tantos outros, que são transmitidos e perpetuados de forma errônea sem a devida análise filosófica,

\footnotetext{
${ }^{10}$ Para mais informações vide Allen G. Debus. Ciência e história: o nascimento de uma nova área. In ALFONSO-GOLDFARB e BELTRAN (Org.). Escrevendo a história da ciência: tendências, propostas e discussões historiográficas, 2004, p. 31ss.

${ }_{11}$ George Sarton (The History of Science and The New Humanism, 1931, pp. vix, 190), apud MAIENSCHEIN, Jane. Why Study History for Science?, Biology and Philosophy, 2000, p. 342-343.

${ }^{12}$ Biólogo e historiador das ciências biológicas alemão. Vide MAIENSCHEIN, Jane. "Why Study History for Sciencie?", Biology and Philosophy, p. 343. Neste mesmo artigo, a autora apresenta algumas informações sobre a visão de Thomas Edison, de que muitas das ideias atuais (novas) não passam de adaptações espertas das ideias antigas.
} 
sociopolítica e histórica, desconsiderando-se assim a dinâmica dos processos produtivos e sócio-históricos inerentes às atividades humanas (entre elas, a produção de teorias e conceitos científicos).

Portanto, podemos afirmar que é da natureza de toda teoria ou conceito inerir a sua contextualização sócio-histórica, cultural, econômica, político-militar e sua fundamentação crítica (FC), pois, não podemos admitir fazer HFSC apenas com a história da construção conceitual (interna), mas também é necessário considerar o entorno produtivo, os fatores intervenientes e a fundamentação subjacente (externa), trata-se, ou seja, trata-se de uma atenção dialética da construção do conhecimento científico e tecnológico. Para tal, os dois contextos são filosoficamente importantes para estudos das e sobre as ciências (seu processo, seus produtos e atores, suas conseqüências e seus benefícios). Qualquer insistência em apenas uma das margens desse processo dialético constituirá um fundamentalismo e reducionismo, uma postura improdutiva, seca e sega. A análise integrativa ou holística que busca considerar todas as margens do processo é mais relevante e rica.

Por outro lado, no cenário internacional, podemos observar que alguns países como Grã-Bretanha, EUA e Dinamarca apresentam um avanço nas discussões, no planejamento, na execução de projetos curriculares e parâmetros ou medidas prescritivas em que se enfatiza o uso de temas de HC ou HFC no ensino de ciências naturais (Matthew, 1992, 1994, 1997, 2009; Jenkins, 1990; Nielsen e Thomsen, 1990; Maienschein, 2000; entre outros). Entretanto, a expansão do movimento para outros países é, também, um fenômeno que tem sido verificado ultimamente, sobretudo, a partir da década de 1980.

\subsection{2 - Projetos de Inclusão}

Em termos de projetos ou programas de intervenção curricular ou de divulgação, há alguns dados históricos apresentados por Jenkins (1990); Nielsen e Thomsen (1990); Maienschein (2000) e, sobretudo, Matthews (1992; 1994; 1997; 2009) que nos permitem a descrição seguinte.

Segundo esses autores, no Reino Unido, o National Curriculum Council (NCC) tem criado parâmetros nos quais tem se contemplado a inclusão da abordagem de temas da história, filosofia e sociologia das ciências no sistema curricular nacional daquele país, com objetivo de apresentar a evolução dos 
conceitos científicos historicamente e como a natureza e o uso de tais conceitos são influenciados pelos aspectos sociais, morais, espirituais, culturais, políticos e econômicos do contexto histórico da época em que eles foram produzidos. E, logo depois da guerra de 1939-1945, em 1946, criou-se a British Society for the History of Science (BSHS) (JENKINS, 1990, p. 274-281).

No entanto, na década anterior à criação da BSHS, em 1931, ocorreu, em Londres, um congresso na área de $\mathrm{HC}^{13}$, do qual participou uma delegação soviética que suscitou a discussão que fazia incidir sobre a produção científico-tecnológica a influência dos fatores externos (econômicos, sócio-culturais, políticos, ideológicos, geográficos ou até religiosos). Esta posição ficou conhecida como "visão externa" (ou externalismo), em contrapartida à "visão interna" dos cientistas (ou internalismo). É bem provável que a visão contextualista que assumiria a nova historiografia da ciência ou HFC, sobretudo, a partir da década de 1950, encontre o seu gérmen naquele histórico episódio!

Durante as décadas de 1970 e 80, a Associação Britânica para o Ensino da Ciência elaborou projetos sobre a inclusão de temas de HFC no currículo das ciências naturais, por intermédio dos seus relatórios (Alternativas para ensino de ciências - 1979 e Educação por meio das ciências - 1981) (MATTHEWS, 1992, p. $15)$.

Nos EUA, a Harvard University tornou-se uma referência histórica na aproximação da $\mathrm{HC}$ ao ensino de ciências experimentais e tal fato deve-se à iniciativa do professor James Bryant Conant ${ }^{14}$, ex-presidente da Harvard University (1933 a 1953). Ele promoveu a introdução da HC como disciplina no currículo de graduação daquela universidade e publicou três obras decorrentes de tal experiência, sendo que a última, editada em 2 vols, tornou-se o livro-texto universitário mais popular na sua época sobre o tema, nos USA. A abordagem de estudo de caso de Conant teria influenciado os projetos futuros.

Os projetos mais conhecidos foram: Harvard Project Physycs ${ }^{15}$ (remonta à

\footnotetext{
${ }_{14}^{13}$ ALFONSO-GOLDFARB, Ana Maria. O que é História da Ciência. 1994, p. 76 ss.

${ }^{14}$ Foi pró-reitor geral e presidente (1933 a 1953) da Harvard University. Da sua experiência com projetos de abordar casos de HC, publicou algumas obras, a saber: On Understanding Science: $\mathrm{Na}$ Historical Approach (Compreendendo a Ciência: uma abordagem história, 1947), General Education in a Free Society (Educação Geral na Sociedade Livre, 1945) e Harvard Case Histories in Experimental Science (Estudo de Casos de Harvard sobre História nas ciências Experimentais, 1957, 2 vol.).

${ }^{15}$ Alguns nomes ligados a tal projeto: Gerald Holton, Stephen Brush, Fletcher Watson e James Rutherford.
} 
década de 1960), Project 2061 (1985, sob direção de James Rutherford); "Science as a Liberal Art' Project e Benchmarks for Science Literacy (1993) os quatro lançados pela American Association for Advancement of Science (AAAS), bem como as iniciativas projetuais da Biological Science Curriculum Study-BSCS (proposta "Curriculum Framework"), cujos objetivos eram oferecer fundamentos históricos, culturais e filosóficos das ciências ao currículo escolar. Outras manifestações institucionais próximas dizem respeito à criação, em 1970, da seção de História da Física pela American Physical Society (APS) e ao mesmo tempo em que era estabelecido o Comitê de Educação pela History of Science Society $\left(\mathrm{HSS}^{16}\right)$, além de outras propostas em Ciência, Tecnologia e Sociedade desenvolvidas tanto nos USA e no Canadá (MATTHEWS, 1992; 1994, p. 35ss).

O Harvard Project Physics ${ }^{17}$ foi um projeto nacional da área de desenvolvimento curricular do ensino de Física na escola secundária, dos Estados Unidos da América. Ele foi desenvolvido entre 1962-1972, por meio dele produziu-se uma série de material didático (textos) usado no ensino de Física, sobretudo, nas décadas de 1970 e 1980. Estava lotado na Harvard University, porém, teve participação de outras universidades, escolas e professores de vários estados daquele país.

Segundo Matthews, nos Estados Unidos, a HC tem sido menos significativa nas escolas que na Grã-Bretanha. Ressalta que na década de 1920 alguns químicos e, posteriormente, Holmyard ${ }^{18}$, defenderam uma abordagem histórica no ensino da ciência e uma série de textos foi escritos com orientação histórica (MATTHEWS, 1994, p. 54).

Nielsen e Thomsen (1990, p. 308-309) afirmam que, em 1987, o parlamento dinamarquês realizou uma extensa reforma do sistema nacional de ensino básico, em que se enfatizou um ensino da Física como atividade social humana, com o objetivo de ultrapassar o modelo conteudista e compreender essa

${ }^{16}$ A HSS (Sociedade de História da Ciência dos Estados Unidos), fundada em 1924 por professores George Sarton e Joseph Lawrence Henderson. A HSS é considerada a principal associação profissional de estudos acadêmicos da HC. Mantém duas revistas da área: a revista Ísis (trimestral) e a Osiris (anual), a Ísis foi iniciada em 1912 pelo Sarton. Atualmente é presidida por Jane Maienschein, docente da Arizona State University (Arizona, USA).

${ }_{17}$ Projeto coordenado por F. James Rutherford, Departamento de Ciências da Educação da New York University; Gerald Holton, Departamento de Física da Harvard University e Fernando G. Watson, da Harvard Graduate School of Education.

${ }^{18}$ Eric John Holmyard (1891-1959), inglês, foi professor de ciências na Clifton College e historiador da ciência e tecnologia. Autor de livros didáticos de ciências naturais com abordagem de aspectos históricos, um dos seus livros chama-se Química Elementar de 1925. 
disciplina como uma das ferramentas para a compreensão do mundo.

A ênfase foi concentrada na redução quantitativa dos fatos ou conceitos físicos no currículo e na introdução de cinco novas abordagens ao ensino de física, a saber:

a) a Física e o mundo a sua volta;

b) a cosmovisão dos físicos ou as concepções que os cientistas físicos têm do mundo;

c) a inclusão de exemplos da moderna Tecnologia;

d) a inclusão de temáticas referentes às relações entre Física, Tecnologia e Sociedade;

e) a inclusão de temas de História e Filosofia da Física.

Pressupôs-se que a inclusão destes temas possibilitaria convencer os discentes a respeito da importância dos estudos da Física e ampliar a cultura geral.

$\mathrm{Na}$ Holanda (ou Países Baixos), também houve iniciativa semelhante de projetos nacionais, como é o caso do Projeto PLON ${ }^{19}$ : a Physics Curriculum Development Project for General Secondary Education in the Netherlands, que teria tido início por volta de 1972, com o objetivo de modernizar e atualizar o ensino e o currículo de Física produzindo material didático destinado ao ensino médio e superior. Trata-se de materiais didáticos baseados em situações de sala de aula e nas experiências de docentes e discentes e nos aspectos sociais da época, realçavam-se aspectos aproximativos à HFC, sobretudo, à CTS ao Ensino, foco dado na década 80.

Em outras palavras, focava-se na produção de materiais que fossem significativos para os discentes de física, esta relacionada ao cotidiano, às vidas dos discentes, ao foco na relação entre a física e a sociedade, considerando as diferenças individuais e concentrando-se sobre as formas como os discentes resolvem problemas.

Entre outros países, com algumas iniciativas, podemos destacar ainda a Dinamarca, Itália, Espanha, Japão, etc.

Porém, recentemente, determinados para buscar estratégias que melhor possibilitassem aproximar a HFCrECN, alguns pesquisadores de 10 instituições de pesquisa e universidades parceiras de 08 países, dos quais 07 europeus e 01

\footnotetext{
${ }^{19}$ Também referenciado em Matthews (1992, p. 38, nota 2).
} 
asiático, a saber: Portugal, Itália, Polônia, Alemanha, Reino Unido, Hungria, Grécia e Israel, assumiram o compromisso de desenvolver um projeto macro denominado "History and Philosophy in Science Teaching", ou, simplesmente, "Projeto HIPST". Ele foi iniciado em 01/01/2008 para ser finalizado em 31/07/201020. Participaram do Projeto HIPST as seguintes instituições:

1. Gesellschaft für Technische Zusammenarbeit, Alemanha;

2. Institute for Science Education, Universidade de Bremen, Alemanha;

3. Department for Physics Education and History and Philosophy of Science, Universidade de Oldenburg, Alemanha;

4. School of Primary Education, Universidade Aristóteles, Grécia;

5. Institute of Education, Universidade de Reading, Grã-Bretanha.

6. Department of Philosophy and History of Science, Universidade de Tecnologia e Economia de Budapeste, Hungria;

7. Instituto Tecnico Toscano e Fondazione Scienza e Tecnica, Itália;

8. Institute of Physics, Universidade Nicolaus Copernicus, Polónia;

9. Faculdade de Ciências, Universidade de Lisboa, Portugal;

10.Science Teaching Center within the Faculty of Mathematics and Natural Sciences, Universidade de Jerusalém, Israel;

O Projeto HIPST é o maior projeto já concebido pelo movimento da HFCrECN e, pela sua magnitude, tornou-se o primeiro projeto internacional da área $^{21}$ já conhecido. Ele teve seus objetivos focados no ensino médio com a possibilidade de estender os resultados para o ensino fundamental, por meio do desenvolvimento de novos fundamentos teóricos ou teorias e novos materiais sobre o ensino das ciências naturais com base na HFC.

O Projeto HIPST surgiu como resposta ao problema grave do sistema educacional atual, tornado público pelos sistemas de avaliação, tais como o Programme for International Student Assessment (PISA) e outros, bem como respostas à outros problemas relacionados à aprendizagem efetiva e a diminuição do interesse dos jovens pelas ciências, o que caracteriza a falta de eficiência no

\footnotetext{
${ }^{20}$ O Projeto HIPST conta com financiamento do $7^{\circ}$ Programa Quadro da União Européia. Para mais informações, consultar o site do Projeto HIPST em: <http://hipst.eled.auth.gr/index.htm>, ou ainda, em: <http://didaktik.physik.uni-kl.de/hipst/about\%20HIPST.html>. Acesso em: 11 mar. 2010.

${ }^{21}$ O Comitê Assessor do Projeto HIPST tem tido a participação brasileira, por intermédio da Prof-a Dr $^{\mathrm{a}}$ Cibele Celestino Silva, do Instituto de Física da Universidade de São Paulo, em São Carlos.
} 
ensino $^{22}$. Com esse projeto esperou-se que possibilitasse 0 aumento da compreensão pública das relações entre Ciência, Tecnologia e Sociedade (CTS) nos países integrantes do projeto.

$\mathrm{Ou}$, especificamente, como previsto no Projeto HIPST ${ }^{23}$ constituem seus objetivos:

1. Aumentar a inclusão da história e filosofia da ciência no ensino de ciências para o benefício de literacia científica;

2. Melhorar as estratégias de desenvolvimento e implementação do domínio de materiais relevantes e técnicas de ensino na prática educativa;

3. Reforçar a cooperação e estabelecer uma infraestrutura permanente do trabalho em rede sustentável de todos os intervenientes no domínio da literacia científica e a compreensão pública da ciência, em colaboração com professores do ensino de ciências naturais, museólogos e pesquisadores.

O Projeto HIPST constitui uma rede de sustentação entre os seus parceiros no desenvolvimento e intercâmbio de know-how e experiências em inclusão da abordagem histórico-filosófica no ensino de ciências naturais. Os resultados esperados formarão um conjunto de material didático, desenvolvido especificamente para HFCrECN. Tais materiais serão adaptados pelos professores das equipes nacionais de cada país parceiro e incluirão equipamentos experimentais.

Porém, além de projetos, a partir da década de 1980, as discussões sobre a aproximação da HFC ao ensino se aceleraram e passaram a ocupar espaços nos eventos e periódicos científicos com mais precisão, sobretudo em alguns países europeus e nos EUA. Por exemplo, em 1980 (09 a 11/out.), ocorreu na Universidade de Nantes um colóquio sobre o ensino da $\mathrm{HC}$ para cientistas, cujos anais teriam sido editados por J. Dhombres, sob o título: Actes du Colloque "Enseignement de l'histoire des sciences aux scientifiques" (ARBOLEDA, 1984, p. 194, nota 4. Bibliografia).

A HC no ensino passou a figurar nas programações ou a ser objeto

${ }^{22}$ Conforme consta da Theoretical basis of the HIPST Project. Material recebido, no dia 18/03/2009, por e-mail enviado pelo professor Ricardo Lopes Coelho da Secção Autónoma de História e Filosofia das Ciências, da Universidade de Lisboa e integrante do Projeto HIPST.

${ }^{23}$ Para mais dados vide: HIPST em <http://hipst.eled.auth.gr>. Acesso em: 11/03/2010. 
central de alguns eventos, com frequência, a partir da década de 1980. E foi nesta época que a European Physical Society patrocinou uma série de conferências sobre HC e ensino da Física em 1983 (Pávia, Itália); 1986 (Munique); 1988 (Paris) e em 1990 (Cambridge).

Com objetivo semelhante, a Universidade de Oxford realizou, em 1987, a conferência "História da Ciência e o Ensino de Ciências", com apoio financeiro da British Society for the History of Science. Em 1989, a Florida State University promoveu também uma conferência internacional sobre HFC e ensino de ciências naturais. Para Matthews, essas iniciativas teriam originado cerca de 300 estudos acadêmicos sobre HFC e ensino de ciências naturais e muito material didático com inclusão de aspectos histórico-filosóficos (MATTHEWS, 1992, p. 12).

Foi, ainda, nessa mesma década de 1980 que a American National Science Foundation criou dois programas com o objetivo de promover a HFC no ensino de ciências naturais na Educação Básica. Segundo Matthews (1992, p. 12), nessa mesma época, nos EUA, o Estado da Flórida tornou a HFC uma disciplina obrigatória nos programas de formação docente nas áreas de ciências naturais, cuja conclusão era condição sine qua non para se obter a licenciatura em ciências naturais. E, a criação da revista Teaching the History of Science - em 1989, na Inglaterra - é considerada como uma consequência direta dos eventos ocorridos sobre a HC e ensino de ciências naturais na Inglaterra desde 1986 (MARTINS, 2000, p. 48, notas 19 e 20).

Portanto, internacionalmente, existe uma produção crescente de publicações, que vão desde artigos, constituição de periódicos específicos da área de ensino de ciências naturais e livros à Handbook voltados para área de interface em construção (sobretudo no eixo Inglaterra-EUA-França). Para mais informações sobre o tema e o movimento da HFCrECN, no cenário internacional, pode-se consultar periódicos tais como: Enseñanza de las Ciencias ${ }^{24}$; Revista de Enseñanza de la Fisica; Revista Eletrónica de Enseñanza de las Ciencias; Science Education; Science \& Education ${ }^{25}$; Internacional Journal of Science Education; The Electronic

${ }^{24}$ Entre autores que tratam o tema podemos citar, entre outros: M. Valera et al (1983), R. Gagliardi e A. Giordan (1986), R. Gagliardi (1988), D. Gil Pérez (1993), V. Mellado e D. Carracedo (1993), José A. Gallegos (1996), J. Solbes e M. J. Traver (1996), O. I. Lombardi (1997), Agustín Adúriz-Bravo et al (2002).

${ }^{25}$ Alguns autores como: Martin Monk e Jonathan Osborne (1997), Peter Machamer (1998), J. Solbes e M. Traver (2003), Peter Davson-Galle (2004), Hayati Seker e Laura C. Welsh (2006), Vicente Mellado et al. (2006), J. Solbes e M. Traver (2007), Sibel Erduran et al. (2007), Don Metz et al. (2007), 
Journal of Science Education; Journal of Science Education and Tecnology ${ }^{26}$; Journal of Scence Teacher Education. Pode-se consultar também o International History, Philosophy, and Science Teaching Group ${ }^{27}$, coordenado por Michael R. Matthews. Enfim, passemos agora a analisar, brevemente, o cenário nacional.

\section{3 - Cenário Nacional}

Interessa-nos aqui fazer um panorama genérico no cenário nacional, nos capítulos $2^{0}$ e $3^{\circ}$ haverá uma análise específica dos documentos oficiais e das pesquisas nacionais dentro do período delimitado.

O movimento da HFCrECN chegou ao Brasil, nos finais da década de 1980, época, também, da criação da Sociedade Brasileira de História da Ciência (SBHC), em 1983.

Em 2005, durante a minha pesquisa de mestrado em História da Ciência, fiz um levantamento - constituindo na fase inicial da atual pesquisa de tese e serviu como prelúdio para a compreensão do que chamei de "institucionalização da HC no Brasil" - que me permitiu analisar o aparecimento (presença) da HC nos documentos oficiais, nos programas de formação inicial e a ocorrência da interface $\mathrm{HC}$ e Ensino nas licenciaturas em ciências naturais e matemática, bem como a existência de programas de formação pós-graduada em HC.

De tal levantamento resulta que, em termos de prescrições das políticas educacionais, o movimento brasileiro de aproximação ou o reconhecimento político da relevância da HC no ensino pode ser constatado a partir da década de 1930, que segundo Sicca e Ferraz (1995) consta do Decreto o 19890 de 18/4/193128 - que estabelece o Programa e Instruções Metodológicas para o Ensino de Química - que:

\footnotetext{
Ao professor compete ainda referir, abreviadamente, a propósito das descobertas mais notáveis da Química, a evolução dos seus conceitos fundamentais através dos tempos, revelando aos alunos os grandes vultos da sua história, a cuja tenacidade e intuição deve a civilização contemporânea, além da satisfação espiritual de dilatar o conhecimento do mundo objetivo, o concurso dos processos químicos em benefício da saúde, das comodidades da vida, da defesa e do desenvolvimento das nações.
}

Harry Collins (2007), Stephen Klassen (2007), Kira Padilla e Carles Furio-Mas (2008), Stein Dankert Kolsto (2008).

${ }^{26}$ Por exemplo: Steve Masson e Jesús Vázquez-Abad (2006).

${ }^{27}$ Este grupo pode ser acessado on-line: < http://ihpst.net/>.

${ }^{28}$ Do Ministro Francisco Campos. 
E segundo as mesmas autoras, outra recomendação semelhante a anterior se encontra no Programa e Instruções Metodológicas para o Ensino de Química, Portaria ํㅡ 1045 de 14/12/195129, em que se recomenda que:

Cumpre ao professor mostrar, sobretudo no curso clássico, a evolução histórica das descobertas e dos conceitos mais notáveis da química, a obra dos grandes vultos que contribuíram nesse domínio, para acentuar o saber humano, o papel que representa na civilização contemporânea a educação científica.

Porém, embora a visão historiográfica dos dois enunciados legais seja tradicionalista ou historiograficamente ultrapassada, por apresentar uma abordagem linear e transmitir a imagens de personagens tidos como geniais ("grandes vultos" ou "mais notáveis"), o que interessa aproveitar aqui é a demonstração do marco histórico do reconhecimento da relevância da $\mathrm{HC}$ no ensino e a responsabilidade reconhecida e dada ao docente para introduzir a abordagem histórica do conhecimento científico (KAPITANGO-A-SAMBA, 2005, p. 41).

Ademais, o marco legal mencionado introduz - talvez, pela primeira vez, até onde sabemos e de acordo com as fontes disponíveis, na história da educação científica brasileira - a relevância da HC, nesse caso, no ensino e aprendizagem da Química ${ }^{30}$. Porém, é interessante verificar que a Química é a área com menos aproximações com a HFC para o seu ensino no Brasil, isto é, com pouca produção sobre $o$ assunto.

Entretanto, é nas décadas de 1990 e 2000 que aparecem novos instrumentos normativos nacionais expressivos em relação ao tema, como é o caso dos Parâmetros Curriculares Nacionais para Educação Básica, das Orientações Curriculares e das Diretrizes Curriculares Nacionais que oferecem procedimentos organizacionais dos programas formativos, inclusive, dos cursos de graduação (licenciatura) em Física, Química, Biologia e Matemática. A aproximação da HC ou HFC ao ECN também foi constatada nas Propostas Curriculares locais, como as do Estado de São Paulo. ${ }^{31}$

\footnotetext{
${ }^{29}$ Do Ministro Clemente Mariano.

${ }^{30}$ Faltaram-nos informações de Programas e Instruções Metodológicas para o Ensino de outras disciplinas, tais como Física e Biologia, nesse período.

${ }_{31}$ Por exemplo, a Proposta Curricular para o Ensino de Química - 20 Grau, 1988. De autoria de FERRAZ; HINO; SICCA (KAPITANGO-A-SAMBA, 2005).
} 
Assim, esses instrumentos oficiais foram objetos de análise no capítulo 2 , em que fizemos a análise das razões conceituais ou categorias justificativas. Por enquanto, vejamos os achados em relação a $\mathrm{HC}$ no campo universitário. A institucionalização da HC como disciplina acadêmica pode ser constatada a partir de 1934, logo depois da publicação do Decreto no 19890 de 18/4/1931 que estabelece o Programa e Instruções Metodológicas para o Ensino de Química.

A HC aparece no curso de Sciencias Physicas da Faculdade de Philosophia, Sciencias e Letras $^{32}$, da Universidade de São Paulo. Inicialmente, estava configurada no quadro curricular, sob a denominação de Teorias Físicas e História da Física, obrigatória no último ano $\left(3^{\circ}\right)$, sob a responsabilidade do Professor Gleb Wataghin ${ }^{33}$. Observe-se que o curso de Sciencias Physicas tinha a duração de três anos (isto é, de 1934 a 1936) para as duas modalidades formativas (bacharelado e licenciatura), porém, para a obtenção do título de licenciado, era obrigatório frequentar o "Curso de Formação Pedagógica do Professor Secundário", do então Instituto de Educação, que se localizava na Praça da República (em São Paulo) (PRADO, 1980, p. 1ss).

Com a criação da Faculdade Nacional de Filosofia, em 1939, a Faculdade de Philosophia, Sciencias e Letras da USP se adapta ao modelo nacional e o curso de Sciencias Physicas passa para quatro anos. Em 1942, a disciplina Teorias Físicas e História da Física desapareceu do quadro curricular e, em 1967, reaparece no quarto ano do curso, sob a denominação de História das Ciências Físicas, oferecida para as duas modalidades formativas.

Entretanto, especula-se que o reaparecimento veio "refletir uma tendência oposta às principais modificações de caráter pragmático que o currículo sofreu no período, com a inclusão da Física Aplicada (1946) e de Física Tecnológica (1966)." (PRADO, 1980, p. 2, 4, 6-7, 13).

Com a reforma universitária de 1969, a disciplina História das Ciências Físicas é transferida do Departamento da Física para o de História, da nova Faculdade de Filosofia, Letras e Ciências Humanas (FFLCH), mas segundo Prado (1980, p. 14) a

\footnotetext{
${ }^{32}$ Procuramos manter a grafia antiga, conforme citada por Prado (1980).

${ }^{33}$ Russo, naturalizado italiano, que teria contribuído na elaboração da estrutura inicial de ensino e pesquisa em Física no Brasil.
} 
História das Ciências Físicas é um caso particular. Com a implantação da Reforma Universitária, a disciplina ficou afeta ao Departamento de História; [porém] como havia interesse por parte do Departamento de Física em manter a disciplina sob sua responsabilidade, criou-se a Evolução dos Conceitos da Física para substituí-la, uma vez que, com essa denominação, a disciplina ficaria vinculada ao Departamento [de Física].

Este conflito de vinculação da disciplina, entre os departamentos, demonstra as situações do que podemos chamar de conflito político de organização (acadêmica) curricular (CPOC), que - de qualquer modo - acabou por favorecer a multiplicação da $\mathrm{HC}$, ofertada a partir daí em, pelo menos, dois departamentos e que viria a expandir-se para outras universidades, como é o caso da Universidade Estadual de Campinas (Unicamp), em que aparece no curso de Física, também sob a denominação de Evolução dos Conceitos da Física, em 1973.

Porém, é a partir da década de 1980 e, sobretudo, a de 1990, que a área é renovada com a criação de espaços específicos de pesquisa, tais como: Centro Simão Matias de Estudos em História da Ciência (PUC-SP) e Centro Interunidade de História da Ciência (USP) e surgem programas específicos de formação pósgraduada, como, por exemplo: História da Ciência (PUC-SP); História das Ciências da Saúde (FIOCRUZ); História das Ciências, das Técnicas e Epistemologia (UFRJ); Ensino, Filosofia e História das Ciências (UFBA e UEFS).

O tema também passou a ocupar espaços nos periódicos e eventos acadêmicos e pesquisas de pós-graudação. Entretanto, em relação à FC no Brasil, não encontramos informações sobre as origens das aproximações da FC ao ensino de ciências naturais.

Nas últimas décadas de 1990 a 2010, nas publicações brasileiras, a defesa feita pelo movimento da HFCrECN tem se demonstrado crescente, ainda que de forma tímida, teórica e isolada, tem crescido o número de dissertações, teses e artigos em periódicos e trabalhos em eventos, nos quais se discutem, geralmente, casos ou aspectos históricos e como a abordagem de tais casos poderia contribuir para o ensino; tem crescido sobremaneira, também, a análise de livros didáticos (identificando erros conceituais e supressões históricas).

Pode-se encontrar relatos de algumas experiências de docentes sobre inclusão de HFC na sua prática docente e pesquisa, geralmente no ensino superior, em autores como: Luiz O. Q. Peduzzi (2001); Marcelo A. Barros e Anna Maria P. de Carvalho (1998); Anna Maria P. de Carvalho e Andréa I. Vannuchi (2000); Olival 
Freire Jr (2002); Osvaldo Pessoa Jr (2002); Fernanda A. Maeglhioratti et al. (2005); César S. dos Santos e João J. Caluzi (2005); Charbel N. El-Hani (2006); Lilian AlChueyr P. Martins e Ana Paula O. P. M. Brito (2006); Alberto Villani (2007); Charbel N. El-Hani $(2007)^{34}$.

Uma novidade recente, no cenário nacional, foi a criação, em 2010, de um periódico específico da zona de interface, na Pontifícia Universidade Católica de São Paulo, denominado História da Ciência e Ensino: construindo interface. Embora não se integre aí a Filosofia da Ciência e Sociologia da Ciência ${ }^{35}$ que formam a tríplice metacientífica HFSC, já é um passo para a desejada interface.

Observa-se, também, uma divulgação do tema na área de ensino de ciências naturais e o surgimento de subáreas, mesas de debates ou sessões de HFSC nas sociedades científicas e nos eventos, por exemplo, o Encontro Nacional de Pesquisa em Educação em Ciências, tem tido uma sessão de História, Filosofia e Sociologia da Ciência no Ensino.

$\mathrm{Na}$ literatura, alguns autores argumentam que a HFC é um instrumento que colabora para revelar a realidade da construção do conhecimento científico e das suas implicações políticas, sociais, econômicas e ambientais, ou seja, apresentar os aspectos reais da realidade humana implicadas na produção e divulgação do conhecimento científico, feita por homens falíveis e passíveis às influencias políticas, ideológicas e culturais do seu tempo ou do passado. Ou também advoga-se o uso da HFC como estratégia didática, ou ainda, para os defensores da alfabetização científica, como Chassot (2003), ela é tida como

\footnotetext{
${ }^{34}$ Os textos destes autores podem ser localizado em: BARROS, Marcelo A.; CARVALHO, Anna Maria Pessoa de. A História da Ciência lluminando o Ensino de Visão. Ciência \& Educação, 1998, v. 5, n. 1, p.55-72; 73-81; 83-94. BASTOS, Fernando. História da Ciência e Ensino de Biologia: a pesquisa médica sobre a febre amarela (1881-1903). 1998. Tese (Doutorado em Educação) - Faculdade de Educação da Universidade de São Paulo. São Paulo, 1998. BORGES, Regina Maria Rabelo (Org). Filosofia e História da Ciência no Contexto da Educação em Ciências: vivências e teorias. Porto Alegre: EDIPUCRS, 2007. p. 113-140. CALDEIRA, Ana Maria de Andrade; CALUZI, João José (Orgs.). Filosofia e História da Ciência: contribuições para o ensino de ciências. Ribeirão Preto/Bauru: Kayrós/Cá Entre Nós, 2005. p. 11-28; 103-114. CARVALHO, Anna Maria Pessoa de; VANNUCHI, Andréa Infantosi. History, Philosophy and Science Teaching: Some Answers to "Haw?". Science \& Education, v. 9, n. 5, 2000, p. 427-448. NARDI, Roberto (Org.). A Pesquisa em Ensino de Ciências no Brasil: alguns recortes. São Paulo: Escrituras Editora, 2007. p. 293-315. PIETROCOLA, Maurício (Org.). Ensino de Física: conteúdo, metodologia e epistemologia numa concepção integradora. Florianópolis/Brasília: Editora da UFSC/INEP, 2001. p. 151-170). SILVA, Cibelle Celestino (Org.). Estudos de História e Filosofia das Ciências: subsídios para aplicação no ensino. São Paulo: Editora Livraria da Física, 2006. p. 3-21; 245-264. SILVA FILHO, Waldomiro José da el al. Epistemologia e Ensino de Ciências. Salvador: Arcádia, 2002. p. 13-30; 259-277.

${ }^{35}$ Toda a história/historiografia pretendida a ser o mais coerente possível em sua tecelagem do passado, precisa baseiar-se numa fundamentação crítica, filosófica e sociológica, para não ser um conjunto de narrativas obliterantes epistêmicas.
} 
coadjuvante da na formação de cidadãos críticos.

\author{
No ensino e aprendizagem a HFC possibilitaria ao intelecto o \\ desenvolvimento das capacidades de analisar a complexidade que envolve 0 \\ processo de construção do conhecimento científico, como afirma Oliveira (2003, p.
}

134) que as

\begin{abstract}
Análises histórica-epistemológicas revelam que o conhecimento científico é fruto de um complexo processo de construção. A prospecção do mundo natural é feita sob a tutela da razão, da experimentação, da criatividade, das emoções, das influências culturais e sociais, das crenças mais diversas sobre a vida, o futuro, o universo etc. esta variedade de fatores concorre na produção de uma simples lei científica, embora recitos ingênuos sobre a ciência acabem por limitar esta complexidade a uma racionalidade autoevidente.

Considerações de natureza histórica sobre as etapas de elaboração do conhecimento podem facilitar a tarefa de ensino-aprendizagem das ciências, pois através delas pode-se compreender por que não é simples compreender. A negação da trivialidade sobre o compreender se torna pedra de toque de um ensino revigorado, pois é através de análises com perfil histórico que se pode abarcar a dimensão do complexo que envolve a prática científica e o conhecimento por ela produzido. Um ensino de ciências pode melhorar se situar no campo das construções do intelecto humano com o auxilio dos estudos históricos, iluminando conteúdos que de outra tendem a ser entendidos sob o clichê da realidade evidente, da objetividade imediata, da verdade absoluta. Sem um verdadeiro compromisso com a compreensão dos processos históricos que permitiram ao intelecto humano produzir os conhecimentos, e que hoje nos permitem entender e agir em face de uma realidade que nos ultrapassa, somos como cegos tateando no universo educacional e induzindo nossos alunos a uma falsa imagem deste mundo.
\end{abstract}

Com a HFC seria ilustrar-se-ão os conteúdos científicos porque, também, existem problemas estruturais que interferem no processo de compreensão histórico-filosófica do conhecimento científico, tais problemas se manifestam desde os programas de formação, onde as falsas imagens e compreensões das ciências são proliferadas e perpetuadas no próprio sistema educativo, o que requer uma autocrítica, pois segundo Oliveira (2003, p. 137-138):

Nos cursos de ciências em geral, o ensino das teorias é raras vezes acompanhado por discussões históricas que enfoquem seu processo de construção. Quando o fazem, apelam para um ingênuo processo de revelação a partir da observação sistemática dos fenômenos, onde cientistas superdotados são capazes de "vê" aquilo que é ocultado dos demais seres humanos. A dinâmica história da atividade científica é substituída por um monótono encadeamento linear de fatos observados e leis inferidos. A descrição da ciência escolar se revela atemporal e marcada por reconstruções históricas que expurgam a dúvida, o debate, o erro e a revisão que constituem a essência da atividade científica. Nesta pseudohistória, valoriza-se a clarividência de poucos em detrimento da capacidade 
de todos.

Assumindo-se o conhecimento da ciência como a-histórico, nega-se a possibilidade de inseri-lo dentro de um contexto de construção, onde a aceitação das teorias seja fruto de um processo lento de maturação e adequação das formas de entendimento aos fenômenos estudados. Nesta visão, o conhecimento não é entendido como meio para alcançar um objetivo, mas muitas vezes um fim em si próprio.

Outros ainda, baseando-se em suas experiências didáticas em Ensino Básico, reclamam, e com razão, dos problemas trazidos pelos manuais e pelas práticas didáticas e fazem uma defesa em prol dos discentes que estes devem sim conhecer o formalismo matemático da física, no entanto, o contexto históricofilosófico no qual os conceitos científicos foram produzidos não tem sido discutidos, quer nos livros textos quer no ensino em salas de aulas, afirmando que se tem apresentado aos discentes um conjunto de verdades tidas como "bem encadeadas sobre a natureza" aguardando-se que os discentes usem tais conhecimentos de modo prático. E que perante tal utilitarismo,

[...] parece anacrônico falar em historicizar a Física, já que hoje o seu corpo de conhecimentos não precisa de justificativas para ser aceito. O que se faz no ensino de Física é reproduzir na sala de aula a realidade árida dos "papers", que só aos iniciados no formalismo matemático é permitido o acesso. No entanto poderíamos nos perguntar: será isso correto? Servirá este tipo de ensino aos alunos? Que valor terá o domínio de um grande formalismo matemático para a compreensão do mundo cotidiano? (GUERRA et al. 1998, p. 190).

Diante desta situação de excesso de formalismo, a-historicidade e acriticidade no processo de formação escolar ou universitária e diante do aspecto caricatural da história das ciências veiculada, ao vislumbrar outras perspectivas corroborativas, os atores do movimento da HFCrECN tentam contrapor-se ao status quo e afirmam, por exemplo, que "A dimensão temporal do conhecimento manifestase quando se toma consciência que as teorias não são fruto de revelações, mas de um complexo processo histórico de construção" (OLIVEIRA, 2003, p. 137).

O que vale dizer que no processo de ensino descrito anteriormente ainda se está distante de se alcançar uma consciência crítica, em virtude do formalismo excessivo, das imagens e estereótipos perfilhados no ensino. Este estado "mórbido", fechado, rígido e determinista favorece o desconhecimento e a incompreensão do espaço e tempo como dimensões fundamentais para o desenvolvimento das capacidades de entendimento das atividades de produção científica e seu caráter 
dialético: suas contribuições/avanços, consistências, contradições, limites e inconsistências.

Considerar o caráter dialético da produção científica e do seu ensino e aprendizagem permite que se analise o quê, quem e com quem, como, onde, porquê e outras variáveis intervenientes no processo e na dinâmica histórica e social do empreendimento científico e didático. Se assim concordarmos, então, encontra suficiência a afirmação de Guerra et al. (2003, p. 191, destaque do original) de que "Muitas vezes a preocupação excessiva com o entendimento de como os alunos aprendem os conceitos pode levar ao esquecimento do porquê se deve aprender os conceitos."

Ora, se se compreendesse as ciências e tecnologias como partes inerentes à nossa cultura, não haveria razões convencíveis e defensáveis para desvincular aquele empreendimento da sua historicidade e da de construções sociais; historicidade em que também se situam os seus atores e as variáveis intervenientes.

Assim, a hipótese de que a HFC permite a desdogmatização da produção do conhecimento científico e compreender os mecanismos subjacentes à atividade científica está também presente na literatura nacional ${ }^{36}$, como bem o afirma Oliveira (2003, p. 141), em narrativa de sua experiência didática com o tema, e afirma que: "As contextualizações histórico-epistemológicas permitiram desdogmatizar o fazer científico, mostrando sua evolução conceitual através da história." Mas o dogmatismo imiscui-se também no ensino que exalta o conteúdo e a aprendizagem mecânica das ciências, isto exige um redirecionamento processual didático e não só,

Para que os alunos possam compreender a ciência enquanto um processo
histórico, e não apenas como um produto acabado (seus conceitos atuais),
temos que mudar a visão conteudista (que se preocupa demasiadamente
com a quantidade do programa a ser cumprido) e exageradamente
matemática que impera no ensino de Física. Será preciso elaborar uma
nova abordagem da Física que, sem anular completamente a linguagem
matemática, trate os temas a partir de uma visão HSITÓRICO-
FILOSÓFICA. Nesta visão cada tema selecionado deve ser abordado em
função de sua importância em termos da construção das grandes estruturas
conceituais e de suas relações com as questões fundamentais de cada
época.
[...].
Por outro lado, não pode negar que o conhecimento científico é hoje peça-
chave no jogo de poder das modernas sociedades. Não é possível

${ }^{36}$ É necessário ressaltar que na grande maioria da produção de artigos trata-se de literatura de revisão bibliográfica, geralmente, de autores europeus e estadunidenses. 
compreender a sociedade atual sem um mínimo conhecimento da ciência e da tecnologia (GUERRA et al., 1998, p. 191).

Este estado de desabafo da situação a que se chegou no ensino de ciências, talvez tenha contribuído para levar Chassot (2008, p. 93-94 e 108) a chamar de "império perverso do conteudismo" nas escolas - e diga-se nas universidades também, para sermos realistas - e, então, vê (com certo romantismo) na FHC o recurso, o instrumento de luta contra esse "império" e eliminar o seu imperador e seu sistema imperial ou imperialista!

$\mathrm{E}$, Chassot ao verificar que o ensino é feito de forma a-histórica e que os docentes não apresentam preocupações com a dimensão histórica do conhecimento ensinado, ver na $\mathrm{HC}$ o instrumento para ultrapassar as "barreiras artificiais" que provocam a "segmentação dos conteúdos". Para tal, Chassot defende a busca do ensino de base histórica como uma alternativa oposicional ao "nefasto conteudismo", mas como defensor da alfabetização científica, sua visão volta-se para esta, reduz seu objetivo da HC para que "[...] catalise propostas transdisciplinares para fazer alfabetização científica. [...] a História da Ciência pode ser uma facilitadora para que se transgrida as rígidas fronteiras das disciplinas" (CHASSOT, 2008, p. 93).

Às vezes, parece observarmos um estado saturado das coisas e um "desespero" em encontrar o instrumento "salva-vidas" do ensino e aprendizagem das ciências naturais, mas talvez, a tamanha indignação inflame as mentes desejosas de mudança!

Ademais, no campo da história das aproximações da HFCrECN, verificamos certa ausência de textos em relação à Filosofia da Ciência e Sociologia da Ciência $^{37}$ propriamente ditas e suas aproximações ao ensino das ciências naturais.

De modo geral, as aproximações são feitas mais em relação à e a partir da $\mathrm{HC}$ e ensino de ciências naturais, em Física (frequentemente), Biologia (um pouco) e Química (raramente), o que enfraquece a construção de uma identidade tricomposta e abordagem integrada metacientífica (HFSC).

Embora se verifique a pretensão de fortalecimento da identidade, há poucos filósofos, sociólogos ou cientistas engajados na área e uma predominância

37 Circunscrevemo-nos, precisamente, no cenário nacional, porém, há sim algumas pequenas contribuições da Filosofia da Ciência a pensar o ensino de ciências naturais, em outros países, como EUA, França, Inglaterra e outros. Para mais informações pode-se consultar Matthews (1992; 1994). 
de educadores (docentes) das ciências naturais (físicos, biólogos ou químicos) e os parcos recém formados historiadores da ciência.

O que suscita a indagação seguinte: por que os filósofos e sociólogos da ciência não estão preocupados com o ensino de ciências? Esta é uma questão interessante para uma eventual investigação de modo a auscultar as concepções desses profissionais em relação ao tema.

De fato, isso parece demonstrar, talvez, ou o "desinteresse" ou as "dificuldades" da maioria daqueles profissionais em refletir sobre o ensino das ciências naturais ${ }^{38}$. Se assim for, a afirmação de Ennis, de algum modo, tem ainda coerência: "Com algumas exceções, os filósofos da ciência não mostraram muito interesse explícito nos problemas do ensino de ciências" (ENNIS, ${ }^{39} 1979$, p. 138 apud MATTHEWS, 1992, p. 28).

Essa ausência assemelha-se a que levou Ernest Mayr (2008, p. 9-17) a se debruçar sobre a HFC na Biologia, como ele mesmo o afirma em Isto é Biologia: a ciência do mundo vivo, depois de ter verificado que havia uma lacuna na literatura de HFC da biologia ou para uma HFC ampla.

A Filosofia da Ciência possui um cabedal forte de ferramentas para análise contextual da produção, divulgação e consumo do conhecimento científico, pois na FC participam as seguintes análises: ontológica, da constituição dos entes, conceitos, teorias, sistemas ou ciências; lógica, das proposições argumentativas e coerência interna (formal) das teorias científicas; metodológica, da consistência dos procedimentos e sua validade interna e externa; epistemológica, da natureza do conhecimento científico; axiológica, dos valores sociais (valor social do empreendimento científico) e epistêmicos; política, do ordenamento da ação e poder que representa a produção científica e; social, das relações sociais dos atores e seus produtos com os diversos entes sociais. Portanto, em síntese, esse é o modus operandi filosófico que precisa ser levado em consideração, não apenas se restringir à natureza da ciência que é apenas um pequeno fragmento do pensamento crítico e sua prática.

Portanto, o que também nos interpela no cenário nacional é a questão de saber por que não houve, até hoje, no Brasil, um projeto de intervenção (micro ou

${ }^{38} \mathrm{O}$ que levaria também a debruçar-se sobre o ensino das ciências sociais, humanas e da própria filosofia.

${ }^{39}$ ENNIS, R. H. Research in Philosophy of Science Bearing on Science Education, in ASQUITH, P. D. \& KYBUR, H. E. (Eds). Current Research in Philosophy of Science, PSA, East Lansing, pp. 138-170. 
macro) que tratasse da inclusão da HFC/HFSC no ensino de ciências naturais? Esta é uma pergunta que a comunidade inclusionista do movimento da HFCrECN precisa responder com ações práticas e sair do consenso teórico para experimentação da hipótese defendida.

Enfim, o que tem havido no Brasil são iniciativas individuais de docentes universitários ou de pequenos grupos de pesquisa. Neste sentido, do exposto passamos então para apresentar algumas categorias de análise advindas do cenário internacional que poderão ser identificadas ou não no cenário nacional a ser analisado no estudo de caso (Capítulos $3^{\circ}, 4^{\circ}$ e $5^{\circ}$ ).

\section{4 - Categorias Temáticas e Analíticas}

A delimitação das categorias temáticas e analíticas advindas do cenário internacional é de extrema importância nesta pesquisa, porque elas constituem o arcabouço do referencial teoricometodológico, em que nos apoiamos para fazer a análise do material e diagnosticar as categorias nas orientações das instâncias do cenário nacional em estudo, assim temo-las a seguir.

\subsection{1 - Categorias Temáticas}

A categoria pode ser compreendida como um conjunto de conceitos ou conceito geral e fundamental que abrange noções ou ideias afins para orientar o raciocínio ou a ação (razões conceituais e de práxis).

Essa definição é colaborativa diante dos argumentos apresentados em prol da HFC-ECN, isto pode ser verificado, por exemplo, em Matthews (1994, p. 3), para quem a inclusão da HFC ao ensino de ciências não depende apenas de uma visão liberal da educação científica, pois uma boa educação científica/técnica requer a integração dos conhecimentos de história e filosofia ao seu programa de estudos. Além do mais, o conhecimento da ciência envolve tanto o conhecimento dos fatos científicos, leis, teorias - os produtos da ciência, quanto o dos processos das ciências - os meios técnicos e intelectuais em que as ciências se desenvolvem e testam suas hipóteses.

E, além do mais, argumenta Matthews (1994, p. xiv-xv) que uma parte da contribuição da HFC é vincular os temas das disciplinas científicas com outros de 
outras áreas, tais como a matemática, filosofia, literatura, psicologia, história, tecnologia, comércio e teologia, com o objetivo de demonstrar as interconexões entre ciência e cultura - as artes, ética, religião, política, de forma ampla. Mesmo porque - sustenta o autor e com razão - as ciências não se desenvolvem desvinculadas do desenvolvido de outras áreas, mas sim se desenvolvem em conjunto.

Ora, há uma interdependência mútua. As ciências se desenvolvem e são praticadas dentro de um amplo contexto cultural e social. Estas interligações e interdependências poderiam ser adequadamente exploradas no ensino de ciências baseado em HFC, desde a escola básica até à pós-graduação - pensa o autor. Assim, o resultado será muito mais gratificante para os discentes em virtude dos temas desconexos com que têm sido ensinadas as ciências e conclui citando comentário de um discente que teria comparado o ensino desnexo a "marchas forçadas para um país desconhecido, sem tempo para olhar para os lados" (MATTHEWS, 1994, p. xiv-xv).

Entretanto, a autora do "Por que estudar História da Ciência?", Maienschein (2000, p. 342), apresentou cinco áreas em que, segundo ela, os argumentos tradicionalmente têm sido apresentados e vincula alguns autores a cada área:

Auto-aperfeiçoamento de nós mesmos como cientistas e humanos (George Sarton ${ }^{40}$ );

Eficiência, a HC como fonte de prevenção de repetição de erros do passado e os erros como fonte de aprendizagem (Ernest Mayr ${ }^{41}$ );

Perspectiva, a HC fornece uma elucidação panorâmica que permite aos cientistas julgar melhor o seu trabalho e o dos outros (Ernest Mach ${ }^{42}$ );

Imaginação, oferecer amplo repertório de ideias para poder escolher (Thomas Edison ${ }^{43}$ );

Educação, a HC teria a tarefa de promover o entendimento público da

${ }^{40}$ SARTON, George. The History of Science and the New Humanism, Indiana, Bloomingtion. 1931, p. vix, 190.

${ }^{41}$ MAYR, Ernest. The Growth of Biological Thought. Diversity, Evolution, and Inheritance. Harvard, Cambridge, 1982, p. 20.

${ }^{42} \mathrm{MACH}$, Ernest. The Science of Mechanics. Tradução de T. J. McCormack. Open Court, La Salle, ILUSA, 1960.

${ }^{43}$ WACHHORST, W. Thomas Alva Edison. MIT, Cambridge, 1982. 
ciência e da literacia científica (Hilton, Brush ${ }^{44}$ ).

Assim, da análise dos argumentos do conteúdo textual dos dois cenários que orientam o pensamento e as ações do movimento internacional da HFCrECN inferimos categorias de análise e registramos posteriormente a frequência geral de sua ocorrência no estudo de caso restrito aos capítulos $3^{\circ}$, 4ํ e $5^{\circ}$.

As categorias de análise identificadas inicialmente são passíveis de modificação ao longo do processo, em virtude do que a inferência na análise do corpus de dados do conteúdo textual apontar; bem como passíveis de comparação com os que resultarão do estudo de caso e contribuirão para a reflexão sobre o problema de investigação. Pois, além do mais, as categorias constituem as razões explicativas representativas de sentido, por meio das quais, por exemplo, o movimento da HFCrECN apresenta, em seu discurso, prescrições acadêmicas ou políticas que justificam a reflexão e a ação investigativa e projetual na práxis educativa.

Praticamente, observa-se a existência de duas grandes categorias temáticas; perfeitamente, podemos classificá-las como duas tendências, que descrevem perspectivas, variações temáticas e de interesses de ação investigativa e de intervenção projetual, na complexa zona de interface entre a HFC e o ensino de ciências naturais, e podemos assim distinguir tais tendências: ensino da própria HFC e Inclusão da abordagem dos aspectos da HFC no Ensino de Ciências Naturais ${ }^{45}$.

Na categoria temática/tendência ensino da própria HFC advoga-se o ensino da HFC como disciplina acadêmica autônoma no quadro de tantas outras, com estatuto específico e reconhecimento próprio no campo universitário, garantindo assim a plenificação da sua institucionalização e expansão acadêmica curricular e política, bem como a divulgação da profissionalização em HFC.

As variações que podem ocorrer ou têm ocorrido aqui, isto é, no âmbito curricular, são apenas regionais (História da Biologia/Física/Química ou Filosofia da Biologia/Física/Química ou juntos História e Filosofia da Biologia, ou ainda, HFC, por exemplo, como veremos na análise dos ementários no capítulo $4^{\circ}$ ). Essa grande categoria temática não interessa, em princípio, ao problema de nossa pesquisa, que

\footnotetext{
${ }^{44}$ Vide Maienschein, op. cit. P. 345.

${ }^{45}$ Embora não seja objeto de estudo neste trabalho, à Matemática pode-se também aplicar esta análise.
} 
se localiza na segunda categoria temática da HFCrECN, no entanto, referimo-nos a ela por razões informativas.

Porém, na tendência inclusão da abordagem dos aspectos da HFC no Ensino de Ciências Naturais defende-se o uso de casos de HFC e contextualizações como possíveis fontes de inspiração para o ensino e a aprendizagem dos conteúdos/conceitos científicos ou como estratégia de abordagem didática daqueles conteúdos, portanto, enquanto procedimento metodológico-didático reflexivo e prescritivo para o campo escolar. No entanto, a segunda categoria temática tem duas subcategorias temáticas, quais sejam:

- HFC no Ensino Superior (especificamente as licenciaturas ${ }^{46}$, porém, há pouca produção e faltam (no país) projetos experimentais para testar nas praáticas educativas a hipótese da relevância da HFCrECN e, sobretudo, a contribuição da HFC na aprendizagem significativa das ciências). A literatura sobre tais experiências didáticas ou em que se apresentam propostas de abordagem didática para a prática educativa é a que nos interessou levantar nas pesquisas nacionais em periódicos e eventos científicos pesquisados.

- HFC na Educação Básica (é nesta que a maioria das pesquisas acadêmicas e de prescrições políticas se inscreve; focando-se, geralmente, as séries do Ensino Fundamental II (5 $5^{\text {a }}$ a 9 ${ }^{\underline{a}}$ Série), o Ensino Médio e a análise dos livros didáticos, também faltam projetos experimentais).

$\mathrm{E}$, neste sentido, podemos constatar que as investigações do movimento da HFCrECN têm sido direcionadas, geralmente, para as seguintes categorias subtemáticas de investigação ${ }^{47}$ :

a) - apresentação teórica de casos tópicos em que a HFC possa servir de fonte inspiracional para estruturar conteúdos e estratégias de ensino de ciências naturais;

b) - análise de casos de HC veiculados nos livros didáticos - avaliando a contextualização histórico-social, as questões ideológicas, erros históricoconceituais, a natureza da ciência, a imagem da ciência e a dos cientistas divulgada naqueles textos didáticos. Segundo Bastos (1998, p. 46) os textos didáticos são criticados por, entre outras razões, não apresentarem

\footnotetext{
${ }^{46}$ Mas também interessaria ao Bacharelato. Uma terceira subárea seria o da Pós-Graduação, por exemplo.

${ }^{47}$ As alíneas a), b), c), f) e g) foram adaptadas a partir de Bastos (1998, p. 43-52).
} 
[...] as relações entre Ciência e sociedade (ou então fazem apenas afirmações gerais do tipo 'interesses econômicos, políticos e militares estimularam sobremaneira a pesquisa sobre doenças tropicais', sem explicar concretamente como é que isso ocorreu). Diante desse tipo de problema, pesquisadores em Ensino de Ciências têm-se dedicado à produção de relatos de História da Ciência que consigam contemplar simultaneamente os diferentes temas considerados relevantes para a formação do aluno da escola fundamental e média.

c) - produção de casos ou relatos de $\mathrm{HC}$ que colaborem com o ensino de ciências naturais;

d) - Estudo das concepções de discentes ou docentes sobre a natureza da ciência;

e) - HFC na formação de docentes de ciências naturais;

f) - produção e avaliação experimental de projetos curriculares fundamentados em HFC.

g) - produção de materiais didáticos específicos, fundamentados histórica, filosófica e sociologicamente, que sirvam de meios de apoio ao ECN. É o caso dos Projetos Harvard e HIPST.

O descrito nas alíneas b) e d) não constituiu objeto vinculado a esta investigação, por não se focalizar de modo direto na abordagem inclusiva, mas não negamos sua importância temática, pois os docentes podem servir-se deles e fazer vinculações com práxis didática em ciências naturais. Assim, demonstradas algumas das categorias e subcategorias temáticas do movimento, passamos, então, à apresentação de algumas das categorias propulsoras que estão subjacentes às investigações.

\subsection{2 - Categorias Analíticas}

Para identificar as categorias que explicam os motivos para a HFCrECN, propomos a seguinte interrogação que supomos ser subjacente: por que a HFC interessa ao ensino de ciências naturais? O movimento tem apresentado vários argumentos categorizáveis que descrevem razões elucidativas e tendem a assegurar hipoteticamente as contribuições da HFC ao ensino. Para tal efeito nos servimos dos argumentos categorizáveis coligidos em Matthews (1992, 19940, Maienscheim (2000), principalmente. 
Nas primeiras quatro tabelas a seguir apresentamos os argumentos categorizáveis, isto é, a serem reduzidos a categorias de análise, tais argumentos têm sido apresentados pelos defensores da HFCrECN. Foram apresentados em Matthews (1992, 1994), na base teórica do HIPST Project (europeu), na síntese feita por Maienschein (2000) e também têm sido apresentada na literatura nacional. Estes argumentos estão apresentados separadamente por áreas, em conformidade com a sua ocorrência ou referência dada pelos autores.

Para os defensores da HFCrECN, a HFC (ou ainda HFSC) não tem resposta para todas as questões que afetam tanto o ensino quanto a aprendizagem das ciências naturais, no entanto, ela pode auxiliar como se segue:

Tabela 1 - Argumentos Categorizáveis em relação à $\mathrm{HCrECN}$

\begin{tabular}{|c|c|c|}
\hline № & DESCRIÇÃO DOS ARGUMENTOS & AUTORES \\
\hline 1 & A HC motiva e atrai os discentes. & $\begin{array}{l}\text { Matthews, 1992, p. } \\
17-18\end{array}$ \\
\hline 2 & A HC humaniza a matéria [conteúdo disciplinar]. & Id., Ibid., loc. cit. \\
\hline 3 & $\begin{array}{l}\text { A HC promove uma compreensão melhor dos conceitos científicos } \\
\text { porque delineia seu desenvolvimento e aperfeiçoamento. }\end{array}$ & Id., Ibid., loc. cit. \\
\hline 4 & $\begin{array}{l}\text { Existe um valor intrínseco na compreensão de certos episódios } \\
\text { fundamentais na } \mathrm{HC} \text {, como a revolução científica, o darwinismo, etc. }\end{array}$ & Id., Ibid., loc. cit. \\
\hline 5 & $\begin{array}{l}\text { A HC demonstra que as ciências são mutáveis e instáveis, razão } \\
\text { pela qual o pensamento científico atual está sujeito a } \\
\text { transformações. }\end{array}$ & Id., Ibid., loc. cit. \\
\hline 6 & $\begin{array}{l}\text { A HC demonstra que tais transformações opõem-se à ideologia } \\
\text { cientificista. }\end{array}$ & Id., Ibid., loc. cit. \\
\hline 7 & $\begin{array}{l}\text { A HC permite uma compreensão mais profícua do método científico } \\
\text { e apresenta os padrões de mudança na metodologia vigente. }\end{array}$ & Id., Ibid., loc. cit. \\
\hline 8 & $\begin{array}{l}\text { A HC constitui-se em veículo natural para demonstrar como a } \\
\text { subjetividade afeta a ciência. }\end{array}$ & Id., Ibid., p. 22 \\
\hline 9 & $\begin{array}{l}\text { A HC pode auxiliar a compreensão dos docentes para chegarem } \\
\text { próximo dos resultados da ciência. }\end{array}$ & Id., Ibid., p. 26 \\
\hline 10 & $\begin{array}{l}\text { A HC promove uma melhor compreensão dos conceitos e métodos } \\
\text { científicos. }\end{array}$ & $\begin{array}{l}\text { Matthews. 1994, p. } \\
\text { 49-50 }\end{array}$ \\
\hline 11 & $\begin{array}{l}\text { Abordagens históricas ligam o desenvolvimento do pensamento } \\
\text { indivual com o das ideias científicas. }\end{array}$ & Id., Ibid., loc. cit. \\
\hline 12 & $\begin{array}{l}\text { A HC é intrinsecamente valiosa, porque torna familiar aos discentes } \\
\text { os episódios importantes da história da ciência e da cultura, tais } \\
\text { como: a Revolução Científica, o darwinismo, a descoberta da } \\
\text { penicilina e assim por diante. }\end{array}$ & Id., Ibid., loc. cit. \\
\hline 13 & A HC é necessária para compreender a natureza da ciência. & Id., Ibid., loc. cit. \\
\hline 14 & $\begin{array}{l}\text { A HC neutraliza o cientificismo e o dogmatismo que são comumente } \\
\text { encontrados nos livros didáticos e [perpetuados] em salas de aulas. }\end{array}$ & Id., Ibid., loc. cit. \\
\hline 15 & $\begin{array}{l}\text { A HC, por inspecionar a vida e a época individual dos cientistas, } \\
\text { humaniza o conteúdo da ciência, tornando-o menos abstrato e mais } \\
\text { envolvente para os discentes. }\end{array}$ & Id., Ibid., loc. cit. \\
\hline 16 & $\begin{array}{l}\text { História permite que as conexões sejam feitas dentro dos tópicos e } \\
\text { das disciplinas científicas, bem como com outras disciplinas } \\
\text { acadêmicas, ela mostra a natureza integrada e interdependente das } \\
\text { realizações humanas. }\end{array}$ & Id., Ibid., loc. cit. \\
\hline 17 & HC mostra as influências de inúmeros fatores de natureza cultural, & Theoretical \\
\hline
\end{tabular}




\begin{tabular}{|c|c|c|}
\hline & filosófica, tecnológica e social. & $\begin{array}{ll}\text { of the HIPST } \\
\text { Project }\end{array}$ \\
\hline 18 & $\begin{array}{l}\text { HC esclarece o significado da ciência para a geração } \\
\text { contemporânea e apresenta a tradição científica em suas várias } \\
\text { cores. }\end{array}$ & Id. \\
\hline 19 & $\begin{array}{l}\text { HC revela que o conhecimento científico é um conhecimento } \\
\text { coletivo. }\end{array}$ & Id. \\
\hline 20 & $\begin{array}{l}\text { O uso da HC fornece aos estudantes uma compreensão mais } \\
\text { profunda do conteúdo científico gerando uma aprendizagem } \\
\text { significativa. }\end{array}$ & Id. \\
\hline 21 & $\begin{array}{l}\text { HC suaviza o conteúdo seco e introduz o discente à complexidade } \\
\text { do conhecimento a ser aprendido. }\end{array}$ & Id. \\
\hline 22 & $\begin{array}{l}\text { Estudo de casos de HC pode criar nos alunos uma imagem realista } \\
\text { da ciência como um processo em que pessoas normais estão } \\
\text { envolvidas com os seus sentimentos, problemas, hesitações, erros, } \\
\text { esperança, devoção e decisões. }\end{array}$ & Id. \\
\hline 23 & $\begin{array}{l}\text { Abordagem da HC desmistifica a opinião vulgar sobre os cientistas } \\
\text { vistos como uma raça especial de pessoas, masculinos, estranhos, } \\
\text { exotéricos, trabalhando isolados com coisas perigosas e lutando por } \\
\text { suas descobertas. }\end{array}$ & Id. \\
\hline 24 & $\begin{array}{l}\text { Estudos de casos de HC mostram a ciência autêntica como } \\
\text { atividade humana e os cientistas como ocupados com atividades } \\
\text { atrativas e desafiadoras e enfrentando problemas importantes para } \\
\text { a sociedade. }\end{array}$ & Id. \\
\hline 25 & $\begin{array}{l}\text { Estudos de casos de HC mostram que, independentemente de sua } \\
\text { raça ou classe social, os cientistas trabalham internacionalmente, } \\
\text { em comunidades mistas, mantendo o discurso humano ao longo de } \\
\text { gerações e civilizações. }\end{array}$ & Id. \\
\hline 26 & $\begin{array}{l}\text { HC ilumina a ciência e a torna melhor', mostra que 'a ciência é uma } \\
\text { atividade humana, enfatiza a criatividade especial do homem e a } \\
\text { humanidade', 'HC como fonte de sabedoria e humanismo e } \\
\text { reguladora de consciências.' }\end{array}$ & $\begin{array}{l}\text { Sarton, } 1931, \quad \text { p. } \\
\text { vix, } 190, \text { apud } \\
\text { Maienschein, } \\
\text { 2000, p. 342. }\end{array}$ \\
\hline 27 & $\begin{array}{l}\text { O conhecimento histórico proporciona evitar a repetição dos erros } \\
\text { do passado, aprendendo com os nossos erros. }\end{array}$ & $\begin{array}{l}\text { Mayr, } 1982, \text { p. } 20, \\
\text { apud Maienschein, } \\
2000, \text { p. } 342-343 .\end{array}$ \\
\hline 28 & $\begin{array}{l}\text { HC fornece uma perspectiva, elucidação e permite que os cientistas } \\
\text { julguem melhor o seu trabalho e o dos outros. }\end{array}$ & $\begin{array}{l}\text { Mach, } 1960, \text { apud } \\
\text { Maienschein, } \\
2000, \text { p. 342-344. }\end{array}$ \\
\hline 29 & A HC oferece amplo repertório de ideias que permite fazer escolhas. & $\begin{array}{l}\text { Thomas Edison; } \\
\text { Maienschein, } \\
2000, \text { p. } 342 \text { e } 345 \text {. }\end{array}$ \\
\hline 30 & $\begin{array}{l}\text { A HC promove o entendimento público da ciência e da literacia } \\
\text { científica (alfabetização científica). }\end{array}$ & $\begin{array}{l}\text { Hilton e Brush } \\
\text { apud Maienschein, } \\
2000, \text { p. } 342 \text { e } 345 .\end{array}$ \\
\hline
\end{tabular}

Tabela 2 - Argumentos Categorizáveis em relação à $\mathrm{FCrECN}$

\begin{tabular}{|l|l|l|}
\hline № & \multicolumn{1}{|c|}{ DESCRIÇÃO DOS ARGUMENTOS } & \multicolumn{1}{|c|}{ AUTORES } \\
\hline 1 & $\begin{array}{l}\text { A FC pode auxiliar os professores a interpretar os resultados das } \\
\text { pesquisas científicas. }\end{array}$ & $\begin{array}{l}\text { Matthews, 1992, p. } \\
26\end{array}$ \\
\hline 2 & $\begin{array}{l}\text { A FC pode esclarecer o pensamento dos docentes de ciências } \\
\text { naturais sobre a investigação científica e sugerir novas idéias. }\end{array}$ & Martin, 1985, p. 1 \\
\hline 3 & $\begin{array}{l}\text { FC fornece um significado global do conhecimento científico e } \\
\text { determina a imagem da ciência em sala de aula. }\end{array}$ & $\begin{array}{l}\text { Theoretical basis } \\
\text { of the HIPST } \\
\text { Project }\end{array}$ \\
\hline
\end{tabular}


Tabela 3 - Argumentos Categorizáveis em relação à HFCrECN

\begin{tabular}{|c|c|c|}
\hline № & DESCRIÇÃO DOS ARGUMENTOS & AUTORES \\
\hline 1 & $\begin{array}{l}\text { A HFC pode dar às idealizações em ciências uma dimensão mais } \\
\text { humana e compreensível e podem explicá-las como artefatos dignos } \\
\text { de serem apreciados por si mesmos. }\end{array}$ & $\begin{array}{l}\text { Matthews, 1992, p. } \\
27-28\end{array}$ \\
\hline 2 & $\begin{array}{l}\text { A HFC possibilita o docente a auxiliar os discentes a entenderem, } \\
\text { exatamente, como a ciência apreende e não apreende o mundo } \\
\text { real, vivido e subjetivo. }\end{array}$ & $\begin{array}{l}\text { Matthews, 1992, p. } \\
28\end{array}$ \\
\hline 3 & $\begin{array}{l}\text { HFC contribui para [que os docentes tenham] a compreensão da } \\
\text { terminologia [científica]; }\end{array}$ & $\begin{array}{l}\text { Matthews, 1992, p. } \\
31\end{array}$ \\
\hline 4 & $\begin{array}{l}\text { HFC contribui para [que os docentes] compreendam os objetivos } \\
\text { conflitantes e a dimensão cultural e histórica da ciência [que } \\
\text { ensinam]. }\end{array}$ & Id., Ibid., loc. cit. \\
\hline 5 & $\begin{array}{l}\text { HFC contribui para desenvolver a capacidade de compreensão mais } \\
\text { profunda e crítica dos conceitos do discurso científico. }\end{array}$ & $\begin{array}{l}\text { Matthews, } 1992, p . \\
31, \quad \text { citando } \\
\text { MILLER, } 1983\end{array}$ \\
\hline 6 & $\begin{array}{l}\text { HFC pode humanizar as ciências e conectá-las às questões } \\
\text { pessoais, éticas, culturais e políticas. Há evidências de que isso faz } \\
\text { com que os programas de ciências e engenharia sejam mais } \\
\text { atraentes para muitos estudantes e, especialmente, as meninas, que } \\
\text { atualmente abandonam-nos. }\end{array}$ & $\begin{array}{l}\text { Matthews, 1994, p. } \\
7\end{array}$ \\
\hline 7 & $\begin{array}{l}\text { HFC, pode tornar as aulas desafiantes e aprimorar o raciocínio e as } \\
\text { habilidades de pensamento crítico, particularmente, os exercícios } \\
\text { básicos lógicos e analíticos. }\end{array}$ & Id., Ibid., loc. cit. \\
\hline 8 & $\begin{array}{l}\text { HFC pode contribuir para melhorar a compreensão do conteúdo } \\
\text { científico e a superar o "mar de falta de sentido", como disse certa } \\
\text { vez Joseph Novak, em que fórmulas e equações são recitadas sem } \\
\text { o conhecimento do que elas significam ou a que se referem. }\end{array}$ & Id., Ibid., loc. cit. \\
\hline 9 & $\begin{array}{l}\text { HFC pode melhorar a formação dos professores, auxiliando-os a } \\
\text { desenvolver uma compreensão mais rica e mais autêntica da ciência } \\
\text { e seu lugar no esquema intelectual e social das coisas. Isto tem um } \\
\text { fluxo de efeito, como há muita evidência de como a epistemologia } \\
\text { dos professores ou as suas concepções sobre a natureza da ciência } \\
\text { afetam a comunicação científica [informações] que transmitem aos } \\
\text { estudantes. }\end{array}$ & Id., Ibid., loc. cit. \\
\hline 10 & $\begin{array}{l}\text { HFC pode ajudar os professores a avaliar [ser sensível e estimular] } \\
\text { as dificuldades de aprendizagem dos discentes, porque a HFC os } \\
\text { alerta para as dificuldades históricas do desenvolvimento científico e } \\
\text { para a mudança conceitual. [...] Através dos estudos históricos os } \\
\text { professores podem perceber que algumas das dificuldades } \\
\text { intelectuais e conceituais ocorreram também nos períodos iniciais do } \\
\text { desenvolvimento das disciplinas científicas. Este conhecimento pode } \\
\text { auxiliá-los na organização do currículo e do ensino das aulas [de } \\
\text { ciências]. }\end{array}$ & Id., Ibid., loc. cit. \\
\hline 11 & $\begin{array}{l}\text { HFC pode contribuir para a avaliação mais nítida de muitos debates } \\
\text { educacionais contemporâneos que envolveram professores de } \\
\text { ciências e planejadores de currículos. Muitos desses debates - } \\
\text { sobre os métodos de ensino construtivista, a educação científica } \\
\text { multicultural, ciência feminista, ciência ambiental, a aprendizagem } \\
\text { por inquérito, ciência-tecnologia-sociedade nos currículos, entre } \\
\text { outros - fizeram reivindicações e suposições sobre a história e } \\
\text { epistemologia da ciência ou sobre a natureza do conhecimento } \\
\text { humano e sua produção e validação. Sem uma base de } \\
\text { conhecimento em HFC, os professores podem ser facilmente } \\
\text { levados por ideias que estejam na moda, por parecerem úteis no } \\
\text { momento. }\end{array}$ & Id., Ibid., loc. cit. \\
\hline 12 & $\begin{array}{l}\text { HFC pode ser fonte de inspiração de estratégias metodológicas para } \\
\text { abordagem dos conteúdos científicos no ensino de ciências. }\end{array}$ & $\begin{array}{l}\text { Literatura como um } \\
\text { todo }\end{array}$ \\
\hline 13 & Materiais à base da HFC podem fornecer ao discente aprendizagem & Theoretical \\
\hline
\end{tabular}




\begin{tabular}{|c|l|l|}
\hline & $\begin{array}{l}\text { contextualizada e revelar que a ciência está indissociavelmente } \\
\text { mesclada com a sociedade, economia, ecologia e cultura. }\end{array}$ & $\begin{array}{l}\text { of the HIPST } \\
\text { Project }\end{array}$ \\
\hline 14 & $\begin{array}{l}\text { Conteúdo baseado em HFC é importante para os docentes } \\
\text { reviverem os debates e as experiências históricas, revelando como } \\
\text { a ciência funciona e familiarizando-os com experiências que muitas } \\
\text { vezes faltam nos materiais [didáticos]. }\end{array}$ & Id. \\
\hline 15 & $\begin{array}{l}\text { HFC mostra que o conhecimento científico é provisório, não fixo, } \\
\text { baseia-se em teorias anteriores e evidências empíricas. }\end{array}$ & Id. \\
\hline 16 & $\begin{array}{l}\text { O conhecimento advindo da HFC aumenta a capacidade dos da } \\
\text { docentes para orientar o ensino e as discussões em sala de aula, } \\
\text { permitindo compreender melhor as contribuições dos discentes. }\end{array}$ & Id. \\
\hline
\end{tabular}

Tabela 4 - Argumentos Categorizáveis em relação à HFSCrECN

\begin{tabular}{|c|c|c|}
\hline № & DESCRIÇÃO DOS ARGUMENTOS & AUTORES \\
\hline 1 & $\begin{array}{l}\text { A HFSC podem humanizar as ciências e aproximá-las às questões } \\
\text { pessoais, éticas, culturais e políticas; }\end{array}$ & $\begin{array}{l}\text { Matthews, 1992, p. } \\
11-12\end{array}$ \\
\hline 2 & $\begin{array}{l}\text { A HFSC podem tornar mais desafiadoras e reflexivas as aulas de } \\
\text { ciências, possibilitando o desenvolvimento do pensamento crítico; }\end{array}$ & $\begin{array}{l}\text { Matthews, 1992, p. } \\
11-12\end{array}$ \\
\hline 3 & $\begin{array}{l}\text { A HFSC podem contribuir para o entendimento mais integral do } \\
\text { conteúdo científico, isto é, podem contribuir para superar o mar de } \\
\text { falta de significado que tem inundado as salas de aulas de ciências, } \\
\text { em que as fórmulas e equações são recitadas sem que muitos } \\
\text { cheguem a saber o que significam; }\end{array}$ & $\begin{array}{l}\text { Matthews, 1992, p. } \\
11-12\end{array}$ \\
\hline 4 & $\begin{array}{l}\text { A HFSC podem melhorar a formação de professores auxiliando o } \\
\text { desenvolvimento de uma epistemologia da ciência mais rica e } \\
\text { autêntica, em outras palavras, de uma maior compreensão da } \\
\text { estrutura das ciências bem como do espaço que elas ocupam no } \\
\text { sistema intelectual das coisas. }\end{array}$ & $\begin{array}{l}\text { Matthews, 1992, p. } \\
11-12\end{array}$ \\
\hline
\end{tabular}

Segundo Matthews (1992, p. 12), os defensores da inclusão da HFC no ensino de ciências e na formação de professores têm defendio, em parte, uma abordagem contextualista do ensino de ciências. Trata-se de um ensino de ciências situado no seu contexto social, histórico, filosófico, ético e tecnológico; diríamos no contexto existencial. Portanto, relembra ele, trata-se de retomada de um argumento já antigo, o do ensino de e sobre ciências, ou seja, ampliando-o, formação em e sobre ciência e tecnologia.

Neste sentido, como os argumentos apresentados nas quatro tabelas, às vezes, repetem-se e traduzem as mesmas ideias, na quinta tabela a seguir reduzimo-los e formamos as categorias de análise subjacentes à HFCrECN. E, considerando a tendência à abordagem unificada HFC/HFSC para formação de uma identidade e de uma área na zona de interface, optamos por apresentar uma síntese integrada (HFSC). 
Tabela 5 - Das Categorias de Análise

\begin{tabular}{|c|c|c|}
\hline \multicolumn{3}{|c|}{ CATEGORIZAÇÃO } \\
\hline № & $\begin{array}{l}\text { ARGUMENTOS CATEGORIZADOS } \\
\end{array}$ & CATEGORIA \\
\hline 1 & $\begin{array}{l}\text { Tab.1: } 2,11,12,15,20,22,24,25,26 \\
\text { Tab.3: } 1,6 \\
\text { Tab.4: } 1\end{array}$ & $\begin{array}{l}\text { Autoaperfeiçoamento* } \\
\text { (inclui argumentos de humanização } \\
\text { e aprendizagem) } \\
\text { *este sinal caracteriza os termos } \\
\text { aproveitados de Maienschein, } 2000 .\end{array}$ \\
\hline 2 & $\begin{array}{l}\text { Tab.1: 9, 28, } \\
\text { Tab.2: 2, } \\
\text { Tab.3: 2, 16, }\end{array}$ & $\begin{array}{l}\text { Elucidação } \\
\begin{array}{l}\text { (inclui } \\
\text { "Perspectiva"*) }\end{array}\end{array}$ \\
\hline 3 & $\begin{array}{l}\text { Tab.1: 6, 8, 13, 23, 27, } \\
\text { Tab.2: 1, 3, } \\
\text { Tab.3: 7, 8, 9, 10, 11, } \\
\text { Tab.4: 2, 3, }\end{array}$ & $\begin{array}{l}\text { Criticidade } \\
\text { (argumentos de Hermenêutica ou } \\
\text { interpretação, Desmistificação, } \\
\text { Resignificaçãa e "Eficiência"*) } \\
\end{array}$ \\
\hline 4 & $\begin{array}{l}\text { Tab.1: 3, 4, 7, 10, } \\
\text { Tab.3: 3, 5, }\end{array}$ & $\begin{array}{l}\quad \begin{array}{c}\text { Contextualização } \\
\text { Interna** }\end{array} \\
\text { (argumentos vinculados ao contexto } \\
\text { interno, metodológico e cognitivo) }\end{array}$ \\
\hline 5 & $\begin{array}{l}\text { Tab.1: 5, 14, 17, 18, 19, 29, } \\
\text { Tab.3: 4, 13, 14, }\end{array}$ & $\begin{array}{l}\text { Contextualização } \\
\text { Externa* } \\
\text { (argumentos vinculados ao contexto } \\
\text { externo histórico, das relações } \\
\text { socioculturais, } \\
\text { políticas, etc.) }\end{array}$ \\
\hline 6 & $\begin{array}{l}\text { Tab.1: 16, 21, } \\
\text { Tab.4: } 4\end{array}$ & \begin{tabular}{l}
\multicolumn{2}{c}{ Sistemicidade } \\
(argumentos em que se expõe \\
relações \\
Inter/Multi/Transdisciplinaridade, \\
remetendo a um sistema integrado)
\end{tabular} \\
\hline 7 & Tab.3: 15, & $\begin{array}{l}\text { Falibilidade Epistêmica } \\
\text { (argumentos em que se ressaltam } \\
\text { os limites do conhecimento } \\
\text { científico-tecnológico) }\end{array}$ \\
\hline 8 & $\begin{array}{l}\text { Tab.1: 1, } \\
\text { Tab.3: 12, }\end{array}$ & $\begin{array}{l}\quad \text { Motivacional } \\
\text { (argumentos em que se exprime a } \\
\text { ideia de que a HFC seria fonte de } \\
\text { motivação, } \\
\text { inspiraçãol"imaginação"*) }\end{array}$ \\
\hline 9 & Tab.1: 30 & $\begin{array}{l}\text { Socialização Epistêmica } \\
\text { (argumentos voltados para } \\
\text { divulgação, literacia científica, } \\
\text { formação do cidadão (cidadania) ) }\end{array}$ \\
\hline
\end{tabular}

** Alguns autores poderão ficar atônitos ao verem seus artigos ou trabalhos incluídos em uma dessas categorias, isto em virtude do preconceito que se tem sobre ser internalista ou externalista, os trababalhos incluíndos nessas categorias é porque apresenta aspectos de abordagem interna (hisória e filosofia conceitual) ou externa (social, econômica, política, religiosa, militar, por exemplo). Não julgamos o mérito nem as razões das abordagens, cada deve ter feito como lhe foi possível proceder e conforme a forte influência de sua formação básica, os recursos ou a sua ideologia didática. O leitor pode também reler o que já afirmamos sobre essas duas margens de considerar o processo de construção do conhecimento científico na página 22 e em outras partes deste trabalho.

O quadro acima estão sintentizadas as categorias básicas, com as quais opramos inicialmente, no entanto, ao logo da pesquisa foi necessário elaborar outras categorias que emergiram da analise dos dados. A cada cada introdução de novas categorias apresentamos o novo quadro alargado. 


\section{5 - Problema de Pesquisa}

O problema de investigação surge no campo temático da HFCrECN em que concorrem quatro instâncias decisórias (ID), elas poder ser assim descritas:

$4^{\mathrm{a}}-\mathrm{a}$ dos regulamentos oficiais $(\mathrm{RO})$;

$3^{2}-$ a das pesquisas científicas (PC);

$2^{\mathrm{a}}$ - a da formação docente (FD);

$1^{\text {a }}$ - a da prática didática escolar (PDE).

$\mathrm{E}$, disto surge a questão central da pesquisa: em que as instâncias decisórias (ID-RO, ID-PC e ID-FD) se distanciam entre si em relação à inclusão (aplicação/uso) da abordagem dos aspectos histórico-filosóficos no ensino de ciências naturais? E como cada ID responde à questão da HFCrECN? Esta questão secundária compreende a saber: $1^{\underline{a}}-O$ que os documentos oficiais regulamentam em relação à $\mathrm{HFC}$ ECN? 2 ${ }^{\mathrm{a}}$ - $\underline{\text { O que, experimentalmente, revelam as }}$ pesquisas nacionais sobre a HFCrECN, veiculadas através de periódicos e eventos científicos, a partir da publicação dos PCN (1999)? 3" - Como está configurada ou planejada a HFCrECN nos ementários curriculares das disciplinas nos programas de formação inicial docente, no caso específico da USP? $4^{\text {a }}$ - Quais as percepções dos docentes formadores sobre a HFCrECN, no caso da USP?

Esta forma de apresentar as questões está adequada ao paradigma metodológico da pesquisa qualitativa, pois, segundo Creswell:

\footnotetext{
Em um estudo qualitativo, os investigadores mencionam as questões de pesquisa, e não seus objetivos (ou seja, metas específicas para pesquisa) ou suas hipóteses (ou seja, previsões que envolvem várias variáveis e testes estatísticos). Essas questões de pesquisa assumem duas formas: uma questão central e subquestões associadas. (CRESWELL, 2007, p. 117)
}

Concordamos em parte com Creswell em relação à apresentação das questões de pesquisa e aos aspectos quantitativos, porém fizemos questão de apresentar a tese base e os objetivos da pesquisa adiante, por tencionarmos ao "controle" racional dos rumos ou das intenções da investigação.

Assim, as questões levantadas fundamentam-se na tese de que embora haja confluência de objetivos gerais (consenso) sobre a relevância da HFC $r E C N$ entre as orientações das ID, em alguns aspectos representativos tais orientações apontam para perspectivas diferentes cuja convergência não é simples na prática 
didática. Há, portanto, desconexão metodológica e epistemológica de perspectivas em que as instâncias decisórias se divergem e este fato gera situações complexas que inviabilizam a materialização, na prática didática, da inclusão da abordagem dos aspectos histórico-filosóficos pretendida no ensino de ciências naturais.

\section{6 - Objetivos}

Em termos genéricos tencionamos:

$\checkmark$ Estudar as orientações teóricas dos documentos oficiais brasileiros, artigos da literatura nacional e as concepções de docentes formadores sobre a HFCrECN.

Para, então, especificamente:

1) - Analisar - no campo político - as orientações dos RO/DO para o ensino médio e formação docente, no que concerne à HFCrECN, respectivamente: a Lei 9.394 de 20 de dezembro de 1996, que estabelece as Diretrizes e Bases da Educação Nacional (LDBEN); as Diretrizes Curriculares Nacionais para o Ensino Médio (DCNEM, Parecer № 15/1998 CEB/CNE e Resolução no 3/1998 CEB/CNE); os Parâmetros Curriculares Nacionais para O Ensino Médio (PCNEM: Parte III - Ciências da Natureza, Matemática e suas Tecnologias, 1999); as Matrizes Curriculares de Referência para o SAEB (1999); as Diretrizes Curriculares Nacionais para os Cursos de Graduação (DCNCG, 2001/2: Física: Parecer № 1.304/2001 e Resolução № 09/2002 CES/CNE, Biologia: Parecer no 1.301/2001 e Resolução no 07/2002 CES/CNE e Química: parecer no 1.303/2001 e Resolução no 08/2002 CES/CNE); as Orientações Educacionais Complementares aos Parâmetros Curriculares Nacionais ( $\mathrm{PCN}+$ 2002); Orientações Curriculares para o Ensino Médio, vol. 2: Ciências da Natureza, Matemática e suas Tecnologias (OCEM, 2006); a Matriz de Referência do ENEM (2009).

2) -

Analisar as orientações das pesquisas experimentais/intervencionistas, que trata de experimentos, testes pou ropostas experimentais de inclusão da abordagem dos aspectos histórico-filosóficos no ECN, divulgadas nos periódicos 
científicos nacionais $^{48}$ e nos cadernos de resumos/anais de eventos científicos ${ }^{49}$ da área de ensino de ciências naturais e inferir categorias de análise ${ }^{50}$;

3) - Analisar os ementários curriculares das disciplinas em que se objetiva introduzir a HFC na formação inicial docente: caso USP e inferir categorias de análise;

4) - Analisar as percepções de docentes formadores dos cursos de licenciatura em Química, Física e Biologia: caso USP e inferir categorias de análise;

5) - Contribuir para com os estudos de interface entre HFC e o ECN, em especial, para Formação Docente.

\section{7 - Justificativa}

Cabe agora debruçarmo-nos sobre o porquê da realização desta pesquisa, ou melhor, responder à questão: por que razão desenvolver esta pesquisa?

Não podemos falar em razão, mas sim em razões que advém de variáveis diferentes em termos de relevância da pesquisa, pois vejamos: a pertinência do tema de pesquisa - análise de três das quatro instâncias ${ }^{51}$ implicadas no campo temático, especificamente, as orientações teóricas dos documentos oficiais; das pesquisas brasileiras sobre a HFCrECN e a formação inicial docente - é congruente tanto com a dinâmica do campo temático no cenário internacional e nacional quanto

48 Periódicos: Alexandria - Revista de Educação em Ciência e Tecnologia (UFSC); Caderno Brasileiro de Ensino de Física (UFSC); Ciência e Educação (Unesp); Ciência \& Ensino (Unicamp); Ensaio - Pesquisa em Educação em Ciências (FAE-UFMG); Filosofia e História da Biologia (ABFHiB); História da Ciência e Ensino: construindo interfaces (PUCSP); Investigações em Ensino de Ciências (UFRGS); Química Nova (SBQ); Química Nova na Escola (SBQ); Revista Brasileira de Ensino de Física (SBF); Revista Brasileira de Pesquisa em Educação em Ciências (ABRAPEC-FAE-UFMG); Revista da Sociedade Brasileira de História da Ciência (SBHC); Revista de Ensino de Biologia (SBEnBio).

${ }^{49}$ Eventos: Encontro de Filosofia e História da Biologia (ABFHiB); Encontro Nacional de Ensino de Biologia (ENEBIO); Encontro de Pesquisa em Ensino de Física (EPEF); Simpósio Nacional de Ensino de Física (SNEF); Encontro Nacional de Ensino de Química (ENEQ); Encontro Nacional de Pesquisa em Educação em Ciência (ENPEC);

${ }^{50}$ Os periódicos e eventos específicos da HFC não foram objetos de estudos, porque o foco da pesquisa foi a área de ECN no que tange a inclusão da HFC. Não ignoramos que, eventualmente, possa aparecer em tais periódicos e eventos alguns temas relacionados ao ensino, mas toda a pesquisa precisa de delimitação do foco/objeto.

${ }^{51}$ A análise da quarta instância decisiva não pode ser feita no âmbito desta investigação em virtude do seu caráter, mas talvez em outra oportunidade. 
com a dinâmica do campo das instâncias decisórias (as investigações científicas e as regulamentações em políticas públicas de educação).

Portanto, a pertinência temática garante e demonstra o não-isolamento da presente investigação, além do mais, trata-se de um tema novo cuja reflexão e exploração remontam à etapa anterior (mestrado em História da Ciência) e que se enquadra nos debates atuais sobre a HFCrECN.

O tema de pesquisa e a sua delimitação nos objetivos e no problema de investigação demonstram a lacuna existente na literatura sobre o assunto. Esta lacuna pode ser descrita, especificamente, como sendo a desconexão ou o distanciamento entre os pressupostos teóricos das orientações (pesquisas e documentos oficiais) e a formação inicial de docentes sobre a HFCrECN. Esta lacuna se reflete na práxis educativa e gera incerteza profissional na tomada de decisões didáticas nos docentes.

Assim, o desenvolvimento da pesquisa corrobora a necessidade de suprir a lacuna e contribui para a área temática, à linha de pesquisa (Ensino de Ciências e Matemática) e à formação profissional docente e para repensar os programas de formação inicial, objetivos da HFCrECN na interrelação entre as ID, nisto está o contributo social e acadêmica da pesquisa.

Ou, dito de outra forma, o recorte feito não isola a pesquisa das demais linhas de investigação na área de interface entre a HFC e o ECN, bem como, a área de Ensino de Ciências, mas aproxima-a delas, enquanto estudo de análise teóricoempírica, concentrada em questões epistemológicas e metodológicas. É neste sentido, também, que procuramos fortalecer as discussões acerca do tema, já que o uso de conteúdos da HFC tem sido considerado, por alguns pesquisadores e docentes, como portador de contribuições para a superação das crises e incertezas no processo de ensino das ciências naturais na escola e na universidade. Ademais, a delimitação dada ao tema e aos procedimentos metodológicos confere a originalidade inquiritiva para a pesquisa e as condições procedimentais propostas para sua execução são viáveis. 


\section{8 - Sinopse}

Apresentamos neste capítulo a delimitação temática e do problema revisando os cenários internacional e nacional, no entanto, a delimitação estende-se aos capítulos seguintes. Situamos também o tema no âmbito específico em que se localiza, apresentando o problema, objetivos e sua justificativa. E, a partir da revisão bibliográfica do cenário internacional (sobretudo) e nacional identificamos e especificamos as categorias temáticas e inferimos as categorias básicas de análise, cuja finalidade é epistemológica e metodológica, para dinamizar a análise e a discussão de dados.

Assim, podemos esclarecer que o tema de investigação não se localiza na HFC nem no ENC enquanto especificidades autônomas, mas sim na zona de interseção temática entre ambas as áreas de interfaces primárias. Esta zona de interseção confere-lhe a especificidade de abordagem temática e problemática.

E para uma ilustração da delimitação da mesma zona apresentamos uma forma de visualização gráfica, que ilustra a dinâmica da estrutura sistêmica e o seu enquadramento delimitativo temático como se segue.

Fluxograma 1 - Zonas de Interface Metacientífica HFC e HFSC:

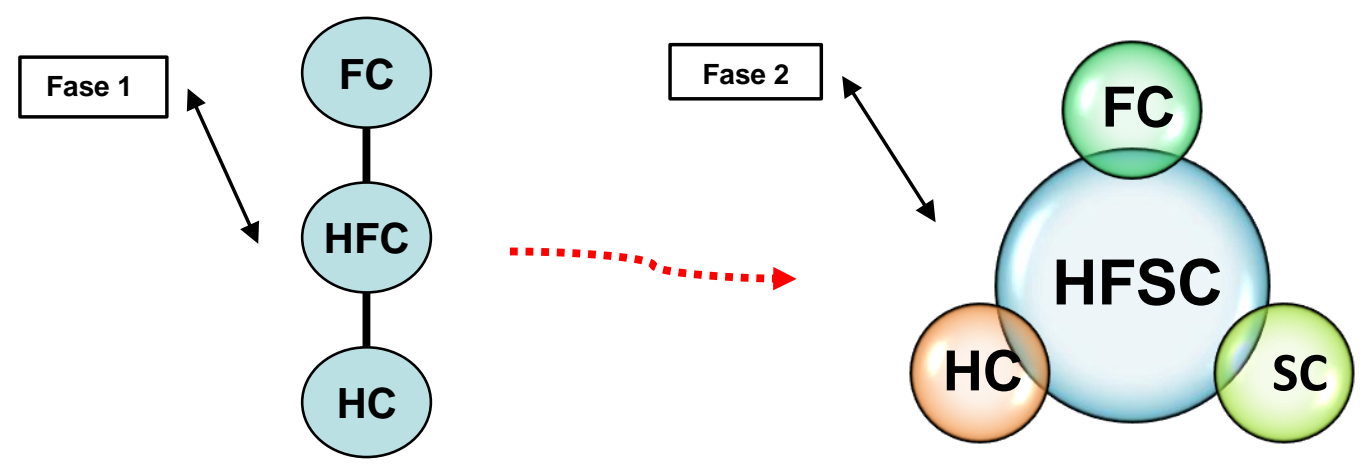

Essas duas áreas de intercepções apresentam, respectivamente, graus de complexidade Básica (fase 1) e Alta (fase2). A integração da HC e FC já foi alvo de observações por Lakatos (1978/1998, p. 21), ao parafrasear a máxima kantiana "A filosofia da ciência sem a história da ciência é vazia; a história da ciência sem a filosofia da ciência é cega", esta interrelação anunciada constitui uma interdependência sistêmica do engajamento do raciocínio histórico-filosófico. 
Mas a que avançar mais, segundo Lakatos a FC forneceria os procedimentos normativos (metodologias) com os quais o historiador da ciência operaria no processo de reconstrução da "história interna" da ciência e deste modo apresentar elucidação racional da evolução do conhecimento científico (objetivo).

$\mathrm{E}$, se dois procedimentos (metodologias) estiverem em competição podemos analisá-las filosoficamente com auxilio da história. No entanto, quaisquer reconstruções racionais (filosóficas) da história precisarão ser suplementadas por uma história externa empírica (sociopsicológica), portanto, chegamos assim a segunda representação de uma HFSC, da qual a psicologia ou psicanálise bachelardiana reivindica uma análise metacientífica psicanalítica. O que requererá um alargamento do espectro metacientífico!

Por outro lado, há um reforço na interdependência ente $\mathrm{HC}$ e FC na análise bachelardiana, ao afirmar que

Certos conhecimentos, mesmo sendo justos, fazem cessar demasiado cedo
pesquisas úteis. O epistemólogo tem, assim, de fazer uma triagem dos
documentos recolhidos pelo historiador. Deve julgá-los do ponto de vista da
razão, e mesmo do ponto de vista da razão evoluída, porque só nos nossos
dias é que podemos julgar plenamente os erros do passado espiritual. Aliás,
mesmo nas ciências experimentais, é sempre a interpretação racional que
situa os factos na sua posição justa. É no eixo experiência-razão e no
sentido da racionalização que se encontram a um tempo o risco e o
sucesso. Só a razão dinamiza a pesquisa, pois só ela sugere, para além da
experiência comum (imediata e especiosa) a experiência científica (indirecta
e fecunda). É o esforço de racionalidade e de construção que deve reter a
atenção do epistemólogo. Podemos ver aqui o que distingue o trabalho do
epistemólogo do do historiador das ciências. O historiador das ciências tem
de tomar as ideias como factos. O epistemólogo tem de tomar os factos
como ideias, inserindo-os num sistema de pensamento. Um facto mal
interpretado por uma época continua a ser um facto para o historiador. Para
o epistemólogo, constitui um obstáculo, um contrapensamento. (Bachelard,
1971/2001, p.167-168)

Ora, ao distinguir a atividade do filósofo da ciência a do historiador da ciência, Bachelard reafirma indiretamente a necessidade da complementaridade entre $\mathrm{FC}$ e $\mathrm{HC}$, tanto no engajamento do raciocínio epistemológico quanto na narrativa ou descrição reconstrutiva da história.

As duas formas de compreensão do fato mal interpretado ora como fato (histórico) ou como obstáculo (epistêmico) são dialeticamente "necessárias" no processo de compreensão da atividade científica, de seus empreendimentos e contextos diversos, uma espécie de necessidade nietzscheana de viver entre o histórico e o a-histórico, isto em prol do bem-estar: "o histórico e o a-histórico são na 
mesma medida necessários para a saúde de um indivíduo, um povo e uma cultura." (Nietzsche, 2003, p. 11), uma engrenagem dialética que ocorre também no "eixo experiência-razão" para racionalizar ao mesmo tempo "o risco e o sucesso", ou seja, a descrição histórica e análise epistemológica ou sociológica que está na base da interseção HFC/HFSC. A seguir temos a zona de interface primária para ECN.

Fluxograma 2 - Zona de Interface Supercomplexa ECN:

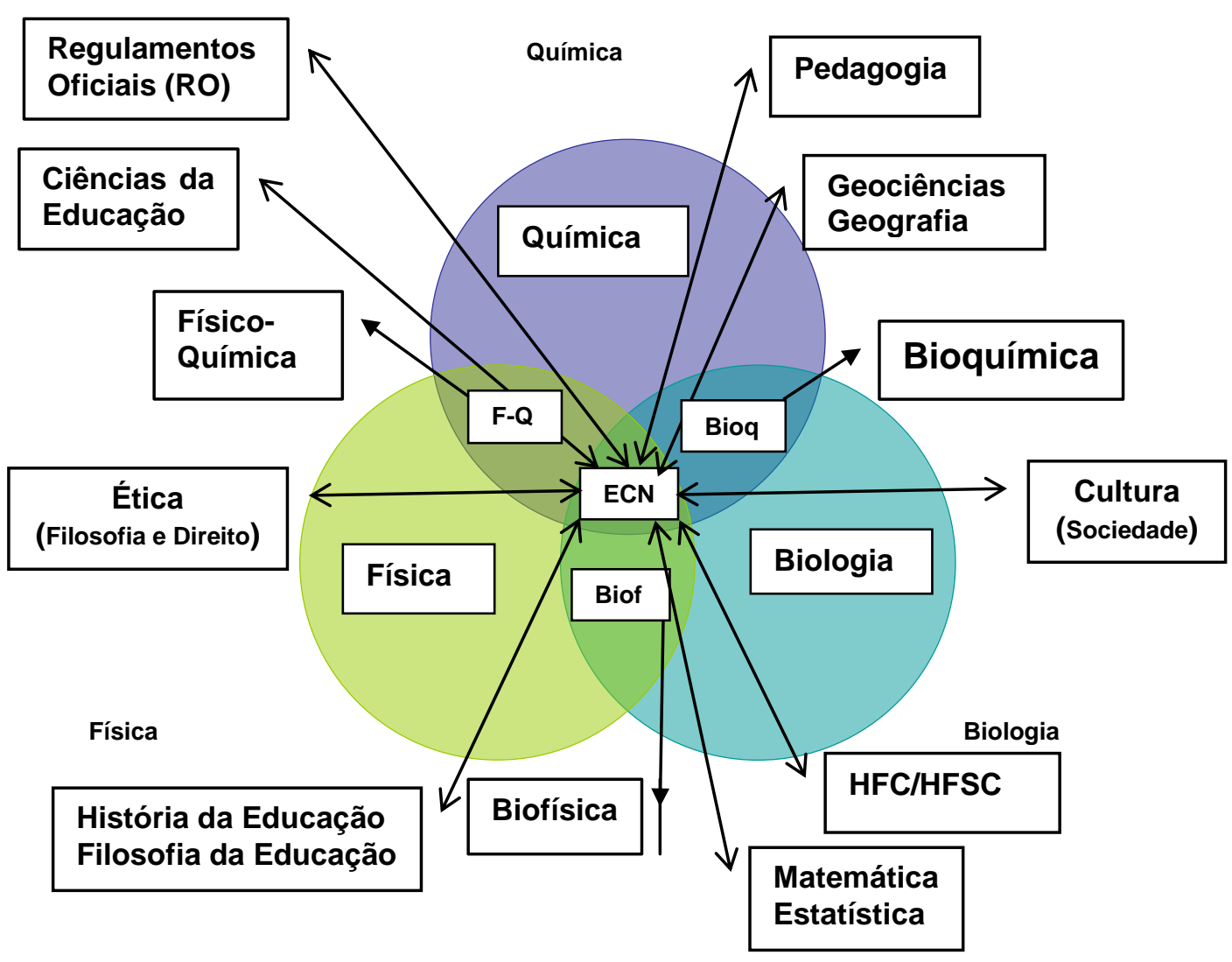

Este fluxograma ilustra a segunda interseção primária em que a engrenagem supercomplexifica-se, como podemos perceber além das subinterfaces (internas) há também as confluências externas de outras áreas, que deveria ser em forma de diálogo contínuo. Desse todo emaranhado de interrelações surge a área de interface HFCrECN que pode ser visualizada abaixo. 
Fluxograma 3 - Zonas de Interface Hipercomplexa HFCrECN / HFSCrECN:

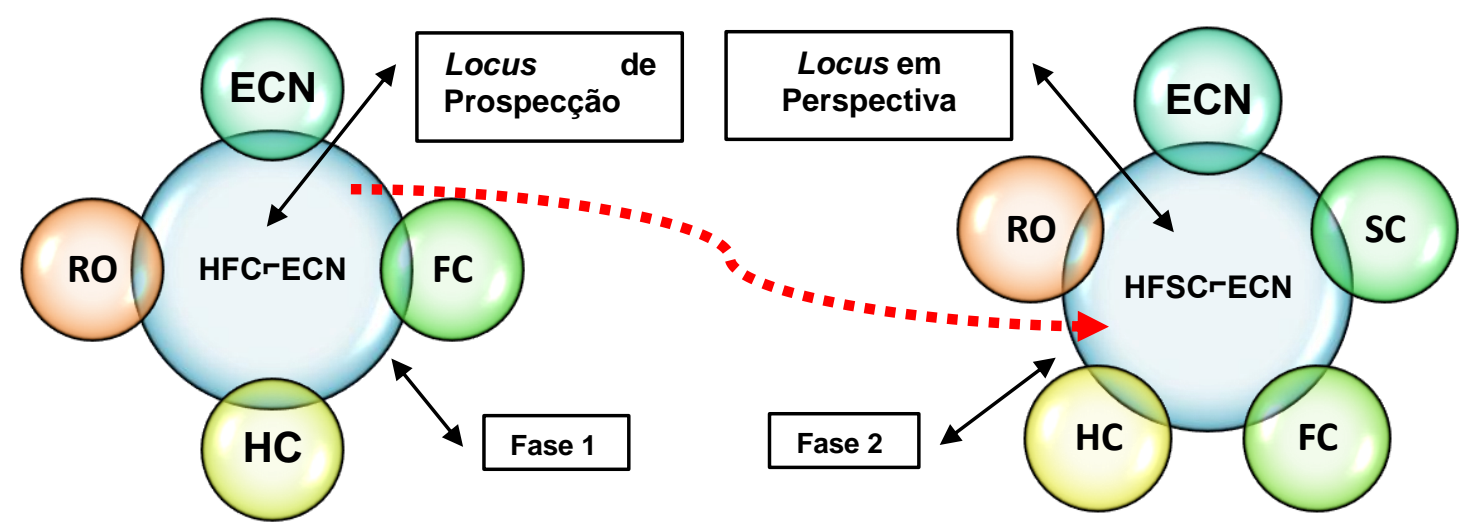

A fase 1 do fluxograma 3 indica o processo evolutivo da área de interface pretendida entre as áreas metacientíficas ${ }^{52}$ no ECN, ampliando a área de investigação e formação, na busca do foco ou objeto, materialização dos objetivos e descrição do seu percurso de integração enquanto ferramenta dinamizadora da criticidade, eticidade, historicidade, elucidação e policontextualização subjacente ao processo teórico-prático do ECN e não meramente como conteúdo em si a ser introduzido no ECN.

Assim, o trabalho, que apresentamos, está composto de quatro capítulos, o primeiro é dedicado à descrição dos fundamentos metodológicos adotados como referência para pesquisa; o segundo, à análise de dados das orientações teóricas dos documentos oficiais; o terceiro, à análise das orientações teórico-práticas - isto é, produções, relatos e avaliações experimentais de casos e propostas curriculares fundamentados em HFC no ensino de ciências naturais - presentes nas pesquisas nacionais, veiculadas nos periódicos brasileiros e eventos científicos da área de ensino de ciências naturais, selecionados por especificidade e pertencimento à esta área e o grau de representatividade no âmbito nacional. Para tal fim, determinamos o período de 11 anos (1999 a 2010) para coleta de dados, tendo como marco temporal e histórico a publicação dos PCN.

O quarto capítulo está dedicado a análise da HFCrECN na formação inicial, por meio da análise dos ementários curriculares das disciplinas em que se

52 O trabalho do filósofo da ciência francês Bruno Latour tem sido considerado como trabalho de sociologia da ciência, o que me parece não ser tão correta essa classificação, por exemplo, a pesquisa que resultou na obra mais falada (Vida de Laboratório) foi uma pesquisa etnográfica, então, dir-se-ia de um trabalho antropológico, mas que no fundo é um trabalho de engajamento filosófico! 
visa abordar o tema e à análise das concepções dos docentes formadores sobre o problema, o critério de seleção de docentes foi: pertencer ao quadro docente da unidade caso de estudo, estar a lecionar em pelo menos um curso de licenciatura de uma das ciências naturais (Física, Química, Biologia).

$\mathrm{E}$, finalmente, ressaltamos que em virtude dos objetivos e do problema de investigação os textos da área de FHC no ECN em que: se analisam os aspectos históricos nos livros didáticos; se comentam as contribuições de alguns autores (e. g. alguns filósofos) quanto à relevância de suas teorias no ensino de ciências (e. g. a contribuição epistemologia de Bachelard para o ensino de ciências naturais, etc.) ou aqueles em que se trata das concepções de discentes ou docentes sobre a natureza da ciência ou sobre quaisquer coisas, estes textos não foram contemplados na análise de nossa pesquisa, por entendermos que diferem do objeto de nosso estudo, pois não tratam metodologicamente o problema da HFCrECN de forma experimental e inclusionista (com propostas) na práxis didática, ou seja, eles não nos permitiriam verificar a ocorrência da HFCrECN nas práticas educativas escolares ou universitárias, a partir da divulgacão dos trabalhos científicos analisados. No entanto, isto não invalida o valor de tais textos teóricos, para a compreensão da relevância da HFC no ENC, pois fazem parte da problemática, apenas não ao problema deste trabalho. É neste sentido que devemos ser entendidos quando nos referimos a alguns trabalhos não fazerem parte do tema aqui delimitado, mas que pertencem à temática. 


\title{
2 - PROCEDIMENTOS METODOLÓGICOS
}

\begin{abstract}
Nenhuma [das modalidades tradicionais de abordagem metodológicas: quantitativa ou qualitativa] é melhor que a outra, simplesmente são diferentes caminhos para se chegar a um mesmo fim: alcançar os objetivos de pesquisa e responder às questões do estudo para gerar conhecimento. Freqüentemente são complementares, sem dúvida nenhuma, sempre que escolhemos uma delas incorporamos elementos da outra [ainda que estes elementos não são explicitados, permanecem latentes como interpelações]. (SAMPIERI, 2006, p. 515)
\end{abstract}

\section{1 - Apresentação}

A estratégia de investigação proposta para execução da pesquisa é o Estudo de Caso Único, cuja unidade-caso é o Brasil. Na concepção tradicional de Estudo de Caso, a unidade-caso era definida como um indivíduo num determinado contexto. Porém, este conceito foi ampliado, de tal forma que, segundo Gil (2010, p. 118) pode referir-se a uma família, um grupo social, uma organização, comunidade, nação ou a uma cultura - é óbvio, sob um determinado aspecto que especifica o objeto de investigação em profundidade. É sob esta concepção alargada que entendemos o Brasil como unidade-caso, do ponto de vista do contexto da HFCrECN manifesto nas fontes primárias (documentos oficiais nacionais $e$ ementários disciplinares e entrevistas semiestruturadas com docentes formadores) e secundárias (literatura das pesquisas nacionais). Trata-se do Brasil da HFCrECN e não outro, este é o aspecto que o especifica e caracteriza como unidade-caso de estudo.

Esta estratégia central (estudo de caso) é coadjuvada pelo estudo bibliográfico, que fornece referências teóricas das produções bibliográficas, especificamente, por meio da análise dos periódicos e anais ou resumos de eventos nacionais da área de ensino de ciências naturais, previamente, selecionados.

As múltiplas técnicas de investigação no estudo de caso - análise bibliográfica, análise documental, entrevistas semi-estruturas e análise de conteúdo - justifica-se por considerarmos ser o caminho adequado para se obter dados que 
nos permitam acessar o cerne do tema-problema e possibilitar uma reflexão aprofundada. Neste sentido, lidamos com dados qualitativos textuais, logo, a investigação segue a abordagem qualitativa.

\section{2 - Pesquisa Qualitativa}

Metodologicamente, a denominação pesquisa qualitativa é uma classificação dos tipos/estratégias de pesquisa decorrente do fato de lidar com dados qualitativos (escritos, orais, iconográficos), contrariamente à pesquisa quantitativa que lida com dados quantitativos (numéricos), ou ainda, de dados mistos.

Segundo Flick (2009) e Bogdan e Biklen (1994) - que traçam um breve histórico deste paradigma metodológico de investigação, na Alemanha e EUA -, a pesquisa qualitativa remonta às origens das pesquisas em antropologia, sociologia, psicologia, história (história de vida, biografias, etc.) e até mesmo à psicanálise (estudo de caso (individual) clínico, por exemplo).

Porém, a expressão pesquisa qualitativa é de uso recente que passa a predominar a partir da década de 1970, antes se usava outras expressões que hoje constituem estratégias ou métodos de pesquisa com dados qualitativos. Bogdan e Biklen (1994) afirmam que as outras expressões que têm sido usadas para designar a "investigação qualitativa" são: "interaccionismo simbólico, perspectiva interior, Escola de Chicago, fenomenologia, estudo de caso, etnometodologia, ecologia, descritivo", ou ainda, "investigação de campo" ou "trabalho de campo" e "etnografia".

Flick (2009) acrescenta mais três denominações, a saber: estruturalismo, psicanálise, construtivismo. Segundo este autor, nos EUA esta modalidade teve seu período tradicional por volta de 1900-1945 e na Alemanha os primeiros estudos começariam no final do século 19 e início do século 20, porém, a grande produção é dos EUA, e, esta influenciou a germânica na década de 1970. No entanto, Bogdan e Biklen (1994) remontam-na no final do século 19 nos EUA, por volta da década de 1890 e cerca de 1850 a 1880 na Inglaterra e França e que a partir de 1900 em diante a pesquisa qualitativa estadunidense começa a evoluir, sobretudo com a Escola Sociológica de Chicago.

Entretanto, o seu aparecimento na educação ocorre em virtude do transporte de métodos qualitativos do campo da antropologia, sociologia e psicologia 
para o da investigação educacional, já que não há propriamente uma disciplina científica/ciência por excelência que tenha a educação por objeto de estudo e que possa produzir métodos específicos. O campo educacional é multidisciplinar e este fato contribui para a confluência de várias áreas com diferentes métodos de investigação.

Bogdan e Biklen (1994, p. 25 e 29) fazem um breve histórico do aparecimento da pesquisa qualitativa na educação nos EUA a partir de 1898, com os artigos de Franz Boas (1858-1942) sobre antropologia e educação e da Nina Vandewalker (Some Demands of Education upon Anthropology in American Journal of Sociology, 1898) e do início da Sociologia da Educação em 1915, quando foi inaugurado o primeiro curso desta disciplina sociológica. E, que em 1926 surgiu o primeiro periódico desta disciplina: o Journal of Educational Sociology.

Porém, o enfoque era quantitativo/experimental em virtude do complexo da época de que para uma disciplina ser ciência tinha que basear-se em métodos experimentais, levando ao "movimento de medida da escola científica"; contrariamente à metodologia inicial da então Escola de Chicago ${ }^{53}$ que seguia os métodos qualitativos na época. Por muito tempo os chamados "estudos científicos da escola" tomaram conta das pesquisas educacionais.

Por outro lado, no Brasil carecemos de material sobre o assunto, praticamente os primeiros indícios de trabalhos sobre pesquisa qualitativa em educação aparecem na década de 1980. Os primeiros de pesquisa qualitativa em educação parecem ser os da Marli E. D. A. Andre ${ }^{54}$ e os do R. Stake ${ }^{55}$. E mesmo hoje há pouquíssimas obras de métodos qualitativos na pesquisa educacional no país.

Para tanto, interessa agora saber o que se entende, afinal, por pesquisa qualitativa? Esta pesquisa é, geralmente, muito mais caracterizada do que definida, em todo caso procuramos entender por pesquisa qualitativa (e suas estratégias de investigação) baseando-nos em Lüdke (1986), Bauer e Gaskell (2008), Bogdan e

\footnotetext{
${ }^{53}$ Apelido dado a alguns docentes e discentes pesquisadores do Departamento de Sociologia, da Universidade de Chicago. Departamento fundado, em 1892, por Albion Small.

${ }^{54}$ A abordagem etnográfica: uma nova perspectiva na avaliação educacional in Tecnologia Educacional, ABT, 24, set./out. 1978; Estudo de caso: seu potencial na educação, in Cadernos de Pesquisa, 49, mai. 1984. Vide Lüdke (1986).

${ }^{55}$ Estudo de caso em pesquisa e avaliação educacional, in Educação e Seleção, São Paulo: Fundação Carlos Chagas, 7, jan./jun. 1983; Pesquisa qualitativa/naturalista: problemas epistemológicos, in Educação e Seleção, São Paulo: Fundação Carlos Chagas, 7, jan./jun., 1983. Vide Lüdke (1986).
} 
Biklen (1994), Creswell (2007), Gaskell (2008), Flick (2009), Silverman (2009) e GIL (2010) conforme se segue.

Para Flick (2009, p. 36),

\begin{abstract}
A pesquisa qualitativa não se refere apenas ao emprego de técnicas e de habilidades aos métodos, mas inclui também uma atitude de pesquisa específica. Essa atitude está associada à primazia do tema sobre os métodos, à orientação do processo de pesquisa e à atitude com que os pesquisadores deverão alcançar seus "objetivos".
\end{abstract}

Ou ainda, segundo o mesmo autor "a pesquisa qualitativa dirige-se à análise de casos concretos em suas peculiaridades locais e temporais, partindo das expressões e atividades das pessoas em seus contextos locais." (FLICK, 2009, p. 37). Pois, "Geralmente em estudos qualitativos, as questões estão sob revisão e reformulação contínua [...]" (CRESWELL, 2007, p. 119). E, para Silverman "[...], a pesquisa qualitativa tende a definir seus problemas de pesquisa de uma maneira que faz sentido imediato para profissionais e administradores" (SILVERMAN, 2009, p. 311). Portanto, "A finalidade da pesquisa qualitativa não é contar opiniões ou pessoas, mas ao contrário, explorar o espectro de opiniões, as diferentes representações sobre o assunto em questão" (GASKELL, 2008, p. 68).

Podemos dizer que se trata de uma investigação cuja finalidade

[...] não é contar opiniões ou pessoas, mas ao contrário, explorar o espectro de opiniões, as diferentes representações sobre o assunto em questão. Em um meio social específico, digamos, na profissão [...] [docente], o que nós estamos interessados em descobrir é a variedade de pontos de vistas no assunto em questão, por exemplo, [...] [as percepções sobre a HFCrECN] e especificamente o que fundamenta e justifica estes pontos de vistas. (BAUER e GASKELL, 2008, p. 68)

Alguns autores apresentam algumas características da pesquisa qualitativa, que julgamos ser necessário apresentá-las de forma sintética por descreverem aquilo que se compreende, genericamente, por este enfoque metodológico de investigação. Bogdan e Biklen (1994, p. 47-50) apresentam cinco características, ei-las:

1. Na investigação qualitativa a fonte directa de dados é o ambiente natural, constituindo o investigador o instrumento principal.

2. A investigação qualitativa é descritiva. 
3. Os investigadores interessam-se mais pelo processo do que simplesmente pelos resultados ou produtos.

4. Os investigadores qualitativos tendem a analisar os seus dados de forma indutiva.

5. O significado é de importância vital na abordagem qualitativa.

E, afirmam ainda que os pesquisadores qualitativos educacionais estão sempre a questionar os sujeitos da pesquisa, visando perceber "aquilo que eles experimentam, o modo como eles interpretam as suas experiências e o modo como eles próprios estruturam o mundo social em que vivem" (PSATHAS, 1973 apud BOGDAN e BIKLEN, 1994, p. 51). O processo de investigação qualitativa ocorre como um diálogo entre o investigador e os sujeitos participantes, uma vez que estes não são abordados de forma neutra (BOGDAN e BIKLEN, 1994. P. 51).

Por outro lado, Creswell cita oito características baseadas em Rossman e Rallis (CRESWELL, 2007, p. 186-187), vejamo-las:

1. A pesquisa qualitativa ocorre em cenário natural.

2. A pesquisa qualitativa usa métodos múltiplos que são interativos e humanísticos.

3. A pesquisa qualitativa é emergente em vez de estritamente préconfigurada. No decorrer da investigação diversos aspectos surgem, as questões podem mudar e serem refinadas, o processo de coleta de dados também pode mudar.

4. A pesquisa qualitativa é fundamentalmente interpretativa.

5. O pesquisador qualitativo vê os fenômenos sociais holisticamente.

6. O pesquisador qualitativo reflete sistematicamente sobre quem é ele na investigação e é sensível à sua biografia pessoal e à maneira como ela molda o estudo.

7. $O$ pesquisador qualitativo usa um raciocínio complexo multifacetado, interativo e simultâneo.

8. O pesquisador qualitativo adota e usa uma ou mais estratégias de investigação como um guia para os procedimentos no estudo qualitativo. 
Porém, tais características não são determinantes do que seja esta investigação, elas são notas descritivas que indicam o que ou como têm sido as pesquisa qualitativas, portanto, uma determinada pesquisa qualitativa pode ou não apresentar tais características.

A pesquisa qualitativa é fundamentalmente interpretativa e toda a interpretação é interpretação de alguém de/sobre algo, obedecendo às regras sistematizadas. Na interpretação visa-se (mira-se) o fenômeno e não o fato, porque o fato é a configuração do fenômeno em quantum. Assim, se a pesquisa qualitativa solicita descrições e compreensões é para responder às questões tais como: por quê?, porquê?, como?, o que?, entre outras. Que não são respondidas ao se trabalhar com dados numéricos.

Assim, as estratégias de pesquisa utilizadas na investigação qualitativa são diversas, entre elas estão os vários tipos de estudos de caso. Dentre estes delimitamos um tipo de estudo de caso: estudo de caso único, de múltiplas unidades de análise.

A questão da validade (confiabilidade) segundo Creswell não tem a conotação igual como na investigação quantitativa e nem vem acompanhada de confiabilidade na pesquisa qualitativa. A validade dos resultados ocorre em todos os momentos do processo investigativo. Confiabilidade e generalização têm papel muito menor na pesquisa qualitativa (CRESWELL, 2007, p. 199).

Além do mais a validade da pesquisa com dados textuais (documentos, entrevistas) é conferida também pelo método e pelas fontes usadas que sejam acessíveis a outros investigadores e que possam testar os resultados. A análise de conteúdo é um método que confere segurança ao pesquisador e aos resultados. Pois, possibilita ao pesquisador a pragmática da autenticidade, integridade, credibilidade e criticidade.

Segundo Creswell (2007, p. 200) a validade "é vista como um ponto forte da pesquisa qualitativa, mas é usada para determinar se os resultados são acurados do ponto de vista do pesquisador, do participante ou dos leitores de um relato" e apresenta oito estratégias básicas para validação:

1. Fazer triangulação de diferentes fontes de informações de dados, examinando as evidências de fontes.

2. Usar conferência de membros para determinar a precisão dos 
resultados qualitativos, levar o relatório final aos participantes para que avaliem sua precisão.

3. Usar descrição rica e densa para transmitir os resultados.

4. Esclarecer os vieses que o pesquisador traz para o estudo.

5. Apresentar informações negativas ou discrepantes que vão contra os temas.

6. Passar um tempo prolongado no campo.

7. Usar interrogatório de pares para aumentar a precisão do relato.

8. Usar um auditório externo para rever o projeto todo.

Por outro lado, sobre o mesmo assunto, Gil (2010, p. 122-123) sugere alguns cuidados para garantir a credibilidade no estudo de caso, a saber:

1) Verificar a representatividade dos participantes. Participantes devem ser apropriados ao tema específico para garantir informações relevantes.

2) Verificar a qualidade dos dados. Ela está relacionada com os informantes selecionados.

3) Controlar os efeitos do pesquisador. Presença do pesquisador entre informantes pode criar estranheza e desconfiança. Reconsiderar as influências do pesquisador na análise $e$ interpretação.

4) Fazer triangulação. Confrontar informações obtidas de uma fonte com as outras.

5) Obter feedback dos participantes. Adequar os resultados com os pontos de vistas dos participantes.

6) Obter avaliação externa. Parecer de outros pesquisadores.

Os critérios apresentados por Creswell (2007) e Gil (2010) serviram de base a essa pesquisa, a fim de assegurar, tanto quanto possível, sua validade. 


\section{3 - Estudo de Caso}

O estudo de caso ilustra por que uma dependência de métodos puramente quantitativos pode negligenciar a construção social e cultural das "variáveis" que a pesquisa quantitativa procura correlacionar. (SILVERMAN, 2009, p. 47)

O Estudo de caso é uma estratégia de investigação polivalente, podendo ser qualitativa ou quantitativa, nesse sentido melhor seria chamá-lo de estratégia do terceiro paradigma misto (quantiqualitativo)! Adotamos aqui o estudo de caso qualitativo que se subdivide em vários tipos de estudos de caso: único, múltiplos, comparados, comunitários, histórico-organizacionais, caso situacional, de observação, entre outros (GIL, 2010, p. 118ss; BOGDAN e BIKLEN, 1994, p.89ss). Com o estudo de caso objetiva-se a exploração do processo ou como diz Gil:

[...], os propósitos do estudo de caso não são os de proporcionar o conhecimento preciso das características de uma população, mas sim o de proporcionar uma visão global do problema ou de identificar possíveis fatores que o influenciam ou são por ele influenciados. (Gil, 2010, p. 38)

Assim como na pesquisa qualitativa, para o estudo de caso qualitativo Lüdke (1986, p. 18-20) apresenta algumas características que esta estratégia de pesquisa pode apresentar em suas diversas modalidades, a saber:

1. Os estudos de caso visam à descoberta.

2. Os estudos de caso enfatizam a "interpretação em contexto".

3. Os estudos de caso buscam retratar a realidade de forma completa e profunda.

4. Os estudos de caso usam uma variedade de fontes de informação.

5. Os estudos de caso revelam experiência vicária e permitem generalizações naturalísticas. ${ }^{56}$

6. Estudos de caso procuram representar os diferentes e às vezes conflitantes pontos de vista presentes numa situação social.

7. Os relatos do estudo de caso utilizam uma linguagem e uma forma mais acessível do que os outros relatórios de pesquisa.

${ }^{56}$ Entre os pesquisadores qualitativistas, a investigação qualitativa em educação tem sido também denominada de naturalista, segundo Lüdke (1986, p. 18). 
Portanto, dentre os vários tipos de estudo de caso, elegemos o Estudo de Caso Único com múltiplas unidades de análise, pois, nos permite o conhecimento aprofundado do problema de estudo e a descoberta das perspectivas das orientações das instâncias decisórias em estudo. Segundo Gil, no estudo de caso é possível usar várias técnicas de coleta de dados: entrevista, observação, análise de documentos (GIL, 2010, p. 118-121).

Mas, por que estudo de caso único? Porque ao estudar o movimento da HFCrECN no cenário nacional sob plano de trabalho estabelecido, delimitamos o Brasil como unidade-caso de estudo - enquanto circunscrição ou entidade política, sob o aspecto da HFCrECN, já referido anteriormente. E as diversas instâncias de análise (documentos oficiais, produção acadêmica que relata experiências ou propostas inclusionistas, formação docente) descrevem esferas nacionais que representam as unidades de análise da unidade-caso de estudo, pois são elementos que o compõem sob o aspecto deste estudo (recorte temático).

Especificamente, as esferas/unidades de análise são representadas pelo: Ministério da Educação (regulamentos oficiais: LDB, PCN, Orientações e Diretrizes Curriculares em relação à HFCrECN); Comunidade Acadêmica (produção científica sobre HFCrECN) e a USP enquanto unidade formadora de futuros docentes, que supostamente materializa os objetivos dos regulamentos nacionais sobre HFCrECN.

A USP é o locus da análise de ementários curriculares na formação inicial de docentes e da coleta de dados por meio de entrevistas semiestruturadas com especialistas para o aprofundado do estudo. Sua escolha foi intencional, porque na experiência da pesquisa anterior constatamos ter sido nela que se iniciou o uso da HC na graduação e por ser uma instituição formadora de referência nacional (e internacional), além de ser o espaço do processo de formação e desenvolvimento desta pesquisa, garante 0 tempo de pesquisa, o acesso aos informantes especializados e à coleta de documentos ou dados qualitativos presentes nos currículos de formação docente. Além do mais, a USP sedia as sociedades científicas das áreas de ensino de ciências naturais, em cujos periódicos e eventos fizemos coleta de dados das pesquisas nacionais.

A estrutura apresentada assemelha-se a do funil no estudo de caso descrito por Bogdan e Biklen (1994), partindo de uma análise genérica (Documentos Oficiais) passando pela menos genérica (Pesquisas Acadêmicas) chega-se a uma 
análise específica (Ementários e Concepções de Docentes Formadores), que caracterizam o Brasil como unidade caso. Bogdan e Biklen afirma a respeito que:

O plano geral do estudo de caso pode ser representado como um funil. Num estudo qualitativo, o tipo adequado de perguntas nunca é muito específico. O início do estudo é representado pela extremidade mais larga do funil: os investigadores procuram locais ou pessoas que possam ser objecto do estudo ou fontes de dados e, ao encontrarem aquilo que pensam interessarIhes, organizam então uma malha larga, tentando avaliar o interesse do terreno ou das fontes de dados para os seus objetivos. Procuram indícios de como deverão proceder e qual a possibilidade de o estudo se realizar. [...]. à medida que vão conhecendo melhor o tema em estudo, os planos são modificados e as estratégias seleccionadas. [...]. a área de trabalho é delimitada. A recolha de dados e as atividades de pesquisa são canalizadas para terrenos, sujeitos, materiais, assuntos e temas. De uma fase de exploração alargada passam para uma área mais restrita de análise dos dados coligidos. [...]. (BOGDAN e BIKLEN, 1994, p. 89-90, Destaque nosso)

Podemos assim representar a estrutura funil dedutiva do estudo de casoúnico, com unidades de análise ${ }^{57}$ :

Fluxograma 4 - Estrutura funil dedutiva do estudo de caso-único

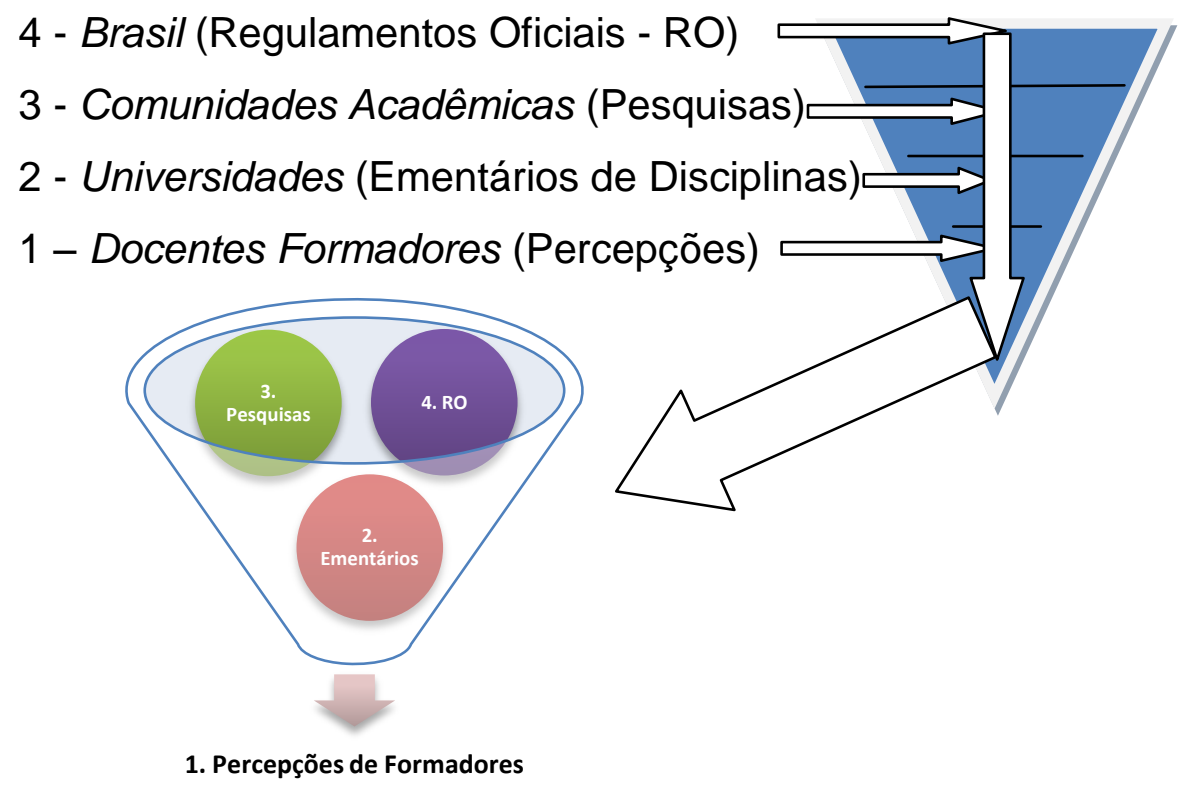

Finalmente, para a coleta e análise de dados elegemos os seguintes métodos: análise documental, entrevista semiestruturada com especialistas e

57 É necessário levar em consideração que esta estrutura também reflete interrelações ou retroalimentação, isto é, as concepções de docentes formadores podem estar presentes nos documentos oficiais, uma vez que a sua elaboração tenha contado com a participação destes profissionais. 
análise de conteúdo, etapas que passamos a abordar a seguir.

\section{4 - Técnicas de Coleta e Análise de Dados}

Dado é um conceito que precisa também ser esclarecido no âmbito desta investigação, pois tem havido uma confusão em relação a este conceito. Alguns autores de textos de metodologia científica significam-no como informação não tratada, portanto, em estado natural como matéria prima. Para outros ele significa informação já tratada, lapidada. Então como entendê-lo na pesquisa qualitativa? Para este fim, preferimos trabalhar com a definição de Bogdan e Biklen por ser mais adequada ao nosso labor, ei-la:

\footnotetext{
O termo dado refere-se aos materiais em bruto que os investigadores recolhem do mundo que se encontram a estudar; são os elementos que formam a base da análise. Os dados incluem materiais que os investigadores registam activamente, tais como transcrições de entrevistas e notas de campo referentes a observações participantes. Os dados também incluem aquilo que outros criaram e que o investigador encontra, tal como diários, fotografias, documentos oficiais e artigos de jornais.

Dados são simultaneamente as provas e as pistas. (BOGDAN e BIKLEN, 1994, p. 149)
}

Este conceito de dado é amplo, rico e compreende os dados pertinentes a esta pesquisa, cuja coleta e análise estão delimitadas a três métodos adotados na "[...] na suposição de que a coleta de diversos tipos de dados garante um entendimento melhor do problema de pesquisa" (CRESWELL, 2007, p. 38).

Bogdan e Biklen (1994, p. 149 e 205) salientam que os dados englobam os elementos necessários para pensarmos adequada e profundamente sobre os aspectos do objeto a ser explorado e que a análise de dados constitui um processo de coleta e organização sistemático de transcrição de entrevistas e de outros materiais acumulados ao longo da busca, com a finalidade de ampliar a compreensão de tais materiais e permitir ao investigador apresentar os achados da pesquisa; ela envolve trabalho com dados, sua organização, divisão em unidades manipuláveis, síntese, busca de padrões/categorias e descoberta de outros aspectos relevantes e daquilo que deve ser aprendido e decidido para transmitir.

Por seu turno a análise de dados é um ato processual que apresenta relevância fundamental para a investigação. Tem razão Creswell ao afirmar que: 
O processo de análise de dados consiste de extrair sentido dos dados de texto e imagem. Envolve preparar os dados para análise, conduzir análises diferentes, aprofundar-se cada vez mais no entendimento dos dados, fazer representação dos dados e fazer uma interpretação do significado mais amplo dos dados. (CRESWELL, 2007, p. 194)

Podemos perceber que a ocorrência deste processo está implícita desde a coleta e, em certa medida, evolui durante o tratamento de dados e a interpretação para transformação das informações em conhecimento. Tal processo exige preparar, organizar, captar sentido, refletir, codificar para criação de categorias, descrever, inferir, deduzir e induzir, interpretar e divulgar os resultados da investigação.

\subsection{1 - Análise Documental}

É necessário registrar primeiro o que se entende por documento. $\mathrm{O}$ conceito documento engloba vários artefatos, registros (iconográficos, textuais) e imagens de diferentes formas que constituem fontes primários de investigação.

Flick (2009, p. 230-231) afirma que essas fontes ainda que não tenham sido produzidas para finalidades investigativas, elas e as suas informações podem ser utilizadas para pesquisa. E que os documentos não são meramente representações dos fatos ou da realidade, eles foram produzidos por alguém que tinha um objetivo prático e com um uso e acesso destinados. Portanto, este é o campo da Análise Documental (ADt $)^{58}$. A ADt pode ser utilizada como método exclusivo ou com a complementaridade de outro método (como é o caso da Análise de Conteúdo) ou outra técnica de coleta de dados, como é o caso da entrevista, entre outras.

Os documentos selecionados para esta pesquisa possuem uma tipicidade das entidades que os produziu, que garante a sua representatividade; sua originalidade confere-lhes a autenticidade; pressupomos não possuírem erros/distorções, o que garante a sua credibilidade; que são compreensíveis porque feitos para serem entendidos pelos cidadãos, fato que lhes confere a significação.

$\mathrm{Na}$ ADt alguns cuidados são necessários para uso de documentos tal como FLICK (2009, p. 234) referencia a advertência de Wolff $\left(2004 b^{59}\right)$ no qual este

\footnotetext{
${ }^{58}$ ADt usamos essa notação para distingui-la da AD (Análise do Discurso), a ADt é uma técnica que pode ser tanto quantitativa quanto qualitativa e compõe os métodos não intrusivos. Neste trabalho foi dado foco qualitativo.

${ }^{59}$ Obra referida: Wolff, S. "Analysis of Documents and Records", in FLECK, U.; KARDORFF, E. v.;
} 
teria recomendado que:

[...] não se deva partir de uma noção da existência de uma realidade factual nos documentos comparada às opiniões subjetivas presentes nas entrevistas. Os documentos representam uma versão específica de realidades construídas para objetivos específicos. É complicado utilizá-los para validar as afirmações obtidas em entrevistas. Os documentos devem ser vistos como uma forma de contextualização da informação. Em vez de usá-los como "contêineres de informação", devem ser vistos como dispositivos comunicativos metodologicamente desenvolvidos na construção de versões sobre eventos.

Por sua vez, para Lüdke (1986, p. 39) os documentos constituem fonte poderosa de que se pode retirar evidências que fundamentam afirmações e declarações do pesquisador. Não são apenas fontes de informação contextualizada, por surgirem num dado contexto, fornecem informações sobre o tal contexto. E que o processo de investigação na ADt segue a seleção de documentos e, depois, passa-se para a análise propriamente dita, com efeito, afirmam as autoras, é possível recorre ao uso da Análise de Conteúdo $\left(\mathrm{ACt}^{60}\right)$ para detectar unidades e proceder à codificação (categorização).

Gil (2010, p. 68) apresenta os seguintes processos para análise e interpretação de dados em pesquisa documental:

1) Definição dos objetivos ou hipótese.

2) Constituição de um quadro de referência.

3) Seleção de documentos para análise.

4) Construção de um sistema de categorias e indicadores.

5) Definição de unidades de análise.

6) Definição de regras de enumeração.

7) Teste de validade e fidelidade.

8) Tratamento de dados.

9) Interpretação de dados.

Segundo o autor, esses passos podem variar conforme o tipo de pesquisa. No entanto, poderia ser operacionalizada para:

STEINKE, I. (Eds). A Companion to Qualitative Research. London, SAGE, 2004, p. 284-290.

60 Preferimos introduzir a notação ACt para distinguir a Análise de Conteúdo da Análise da Conversação, cuja notação é $A C$. 
1) - Seleção, compilação e organização de documentos.

2) - Estudo aprofundado dos documentos, descrição analítica (detectar unidades e categorias de análise).

3) - Tratamento e interpretação.

Para esta pesquisa foram utilizados documentos oficiais produzidos pelo Governo Federal e os documentos oficiais dos programas de formação inicial produzidos pela Universidade que constitui subunidade caso de estudo (USP).

No campo político educacional foram analisados os seguintes documentos educacionais oficiais: a Lei 9.394 de 20 de dezembro de 1996, que estabelece as Diretrizes e Bases da Educação Nacional (LDBEN); as Diretrizes Curriculares Nacionais para o Ensino Médio (DCNEM, Parecer no 15/1998 CEB/CNE e Resolução no 3/1998 CEB/CNE); os Parâmetros Curriculares Nacionais para o Ensino Médio (PCNEM: Parte III - Ciências da Natureza, Matemática e suas Tecnologias, 1999); as Matrizes Curriculares de Referência para o SAEB (1999); as Diretrizes Curriculares Nacionais para os Cursos de Graduação (DCNCG, 2001/2: Física: Parecer oㅜ 1.304/2001 e Resolução № 09/2002 CES/CNE, Biologia: Parecer no 1.301/2001 e Resolução oㅡ 07/2002 CES/CNE e Química: parecer no 1.303/2001 e Resolução no 08/2002 CES/CNE); as Orientações Educacionais Complementares aos Parâmetros Curriculares Nacionais ( $\mathrm{PCN}+, 2002)$; Orientações Curriculares para o Ensino Médio, vol. 2: Ciências da Natureza, Matemática e suas Tecnologias (OCEM, 2006); a Matriz de Referência do ENEM (2009).

E, no campo universitário foram analisados os documentos seguintes: ementários das disciplinas da área de Metodologia de Ensino de Química/Física/Biologia e os das de HFC (nas licenciaturas em Química/Física/Biologia), respectivamente.

\title{
2.4.2 - Entrevista Semiestruturada com Especialistas
}

\author{
Podemos dizer com Gaskell (2008, p. 65) que
}

O primeiro ponto de partida é o pressuposto de que o mundo social não é um dado natural, sem problemas: ele é ativamente construído por pessoas em suas vidas cotidianas, mas não sob condições que elas mesmas 
estabeleceram. Assume-se que essas construções constituem a realidade essencial das pessoas, seu mundo vivencial. $O$ emprego da entrevista qualitativa para mapear e compreender o mundo da vida dos respondentes é o ponto de entrada para o cientista social que introduz, então, esquemas interpretativos para compreender as narrativas dos atores em termos mais conceptuais e abstratos, muitas vezes em relação a outras observações. A entrevista qualitativa, pois, fornece os dados básicos para 0 desenvolvimento e a compreensão das relações entre os atores sociais e sua situação. O objetivo é uma compreensão detalhada das crenças, atitudes, valores e motivações, em relação aos comportamentos das pessoas em contextos sociais específicos.

Bogdan e Biklen afirmam que na pesquisa qualitativa a entrevista pode ser a técnica predominante na coleta de dados ou auxiliada por análise documental ou observação, ou por outra técnica ainda, entretanto, a entrevista é aplicada para coletar dados "descritivos na linguagem do próprio sujeito", o que permite ao pesquisador desenvolver ideias sobre o modo como "os sujeitos interpretam aspectos do mundo". Afirmam ainda, os autores, que nessa modalidade de entrevista "fica-se com a certeza de se obter dados comparáveis entre os vários sujeitos, embora se perca a oportunidade de compreender como é que os próprios sujeitos estruturam o tópico em questão." Entretanto, o que importa nessa modalidade é que a sua eleição baseia-se no objetivo e problema da investigação e para isso, mesmo que haja conflito entre pontos de vista do pesquisador e dos participantes, o investigador tem o papel fundamental de não "modificar os pontos de vista, mas antes compreender os pontos de vista dos sujeitos e as razões que os levam a assumi-los", ele tem de ser e agir como detetive reunindo partes de várias fontes de dados na tentativa de "compreender a perspectiva pessoal do sujeito" participante (BOGDAN; BIKLEN, 1994, p. 134-139).

A relevância da entrevista está na flexibilidade de sua integração com outros métodos de coleta de dados, como é o caso da análise documental que desempenha um papel complementar recíproco. É esta flexibilidade que Gaskell (2008, p. 65) chama de "papel vital" da entrevista "na combinação com outros métodos."

Dentre os tipos de entrevistas utilizadas na investigação qualitativa e em virtude da especialização dos sujeitos participantes optamos por um tipo de entrevista semiestrutural introduzido por Meuser e Nagel, segundo Flick (2009, p. 158), e denominada por estes autores de Entrevista com Especialista. Segundo os autores, trata-se de uma modalidade específica de aplicar a entrevista semiestruturada a sujeitos especialistas, que, no nosso caso, são os docentes 
formadores. Neste sentido, podemos chamar de Entrevista Semiestruturada com Especialistas.

Flick (2009, p. 158) afirma que na entrevista com especialistas o interesse pela pessoa do entrevistado é menor, foca-se mais na sua capacidade de especialista em um determinado campo de atividade. As informações fornecidas por especialistas têm um foco mais restrito, preciso e amplia o grau de sua relevância devido ao nível de especialização dos participantes. No entanto, a entrevista semiestruturada não dispensa o guia de entrevista, porém, nesta modalidade ele assume a função diretiva específica.

No entanto, Flick (2009, p. 158) aponta também alguns problemas que podem ocorrer: 0 investigador pode restringir a entrevista e o entrevistado para 0 foco de interesse, isso porque os especialistas tendem a bloquear o rumo da entrevista ao perceber que não têm domínio do tema (difícil admitir o desconhecimento); pode envolver o entrevistador em conflitos internos da área de conhecimento ou de trabalho, em vez de falar sobre o tema em pauta; pode oscilar entre o especialista e o pessoal, informando mais sobre ele que sobre a especialidade; os especialistas tendem a fazer palestra sobre o que sabem fugindo do jogo de inquérito (perguntas e respostas). No entanto, é possível o entrevistador superar esses fatos, estabelecendo as regras do jogo logo de princípio.

Além do mais, é característica das entrevistas semiestruturadas a preferência pelo direcionamento ao tema e ser conduzida de forma direta às questões específicas (Flick, 2009, p. 195).

A eleição desta modalidade de entrevista deve-se ao fato de permitir que a fluidez, a flexibilidade na obtenção de dados, por não ser fixa nem presa ao roteiro e sem oferecer abertura para o participante, mas manter o grau de controle lógico da investigação. É necessário dar liberdade ao participante para que o investigador possa explorar alguns aspectos importantes para a pesquisa, mas mantendo o controle do foco.

Por outro lado, Flick (2009, p. 143) ratifica a nossa justificativa ao afirmar que na investigação qualitativa

As entrevistas semi-estruturadas, em particular, têm atraído interesse e passaram a ser amplamente utilizadas. Este interesse está associado à expectativa de que é mais provável que os pontos de vistas dos sujeitos entrevistados sejam expressos em uma situação de entrevista com um planejamento aberto do que em uma entrevista padronizada ou em um 
questionário.

As entrevistas foram aplicadas a alguns docentes da USP, selecionados pelos seguintes critérios: ser docente do quadro efetivo desta universidade; atuar na graduação na modalidade licenciatura em Biologia, Física e Química; ministrar uma das disciplinas da área de metodologia de ensino (de Física, Química, Biologia) ou de HFC nas licenciaturas citadas e; aceitar participar da pesquisa. Os docentes foram contatados previamente e informados dos objetivos da investigação e agendamos as datas para entrevista.

E, durante as entrevista foi entregue aos docentes formadores o Termo de Consentimento Livre, assinado pelo pesquisadores e por eles próprios, seu fomulário consta dos anexos. A amostra foi de nove (9) docentes formadores, assim distribuídos: 3 de Metodologia de Ensino (Química: 1, Biologia: 1 e Física: 1) e 6 de HFC nas licenciaturas (Química e Biologia: 4, Física: 2). As entrevistas foram gravadas e transcritas. Os dados das entrevistas foram tratados por meio da análise de conteúdo qualitativa. A opção pela aplicação da entrevista aos docentes formadores deve-se ao fato de se esperar deles o aprofundamento na compreensão do problema por parte de um dos grupos dos atores, neste caso, os da $2^{\mathrm{a}}$ ID.

\subsection{3 - Análise de Conteúdo}

Análise de Conteúdo (ACt) é uma técnica de análise de dados verbais (textuais ou orais). No âmbito desta investigação trata-se de dados textuais coletados por meio de entrevistas semiestruturadas com especialistas. A ACt tem sido utilizada tanto na investigação quantitativa quanto na qualitativa.

$\mathrm{Na}$ ACt quantitativa os investigadores estabelecem um conjunto de categorias e contam a frequência/incidência numérica de cada categoria. $\mathrm{Na}$ pesquisa qualitativa utiliza-se outra modalidade (ACt qualitativa) "em que se relatam trechos (não-tabulados) que ilustram categorias em particular" (SILVERMAN, 2009, p. 149 e 151). No entanto, exige-se que a categoria seja precisa para capacitar a outros pesquisadores chegarem ao mesmo resultado quando consultarem o mesmo corpus de material.

A análise qualitativa de conteúdo proporciona a compreensão e a codificação das categorias dos dados textuais tanto dos documentos oficiais quanto 
das entrevistas em relação ao problema da HFCrECN, tais categorias descrevem/representam as perspectivas das ID sobre a HFCrECN. A ACt permite analisar não apenas o texto per se, mas também, os detalhes que o contexto dos dados oferece, porque o importante é não se restringir à descrição simples dos conteúdos, se

\footnotetext{
Deseja-se inferir sobre o todo da comunicação. Entre a descrição e a interpretação interpõe-se a inferência. Buscam-se entendimentos sobre as causas e antecedentes da mensagem, bem como seus efeitos e conseqüências. (MARTINS; THEÓPHILO, 2007, p. 96)
}

A ACt é uma técnica de análise de dados sistemática para reduzir dados quantitativos ou qualitativos, adequada aos estudos de questões ligadas ao ensino e à aprendizagem; aos documentos, às concepções dos atores no sistema educacional e entre outros sistemas.

Em nossa pesquisa optamos por aplicar uma das três técnicas de análise qualitativa de conteúdo (AQC) conforme proposta por Mayring, de acordo com a explicação de Flick (2009, p. 291-294), metodologicamente, Mayring apresenta a AQC em três técnicas: $1^{\text {a }}$ Síntese da Análise de Conteúdo; $2^{-a}$ Análise Explicativa do Conteúdo; 3a Análise Estruturadora de Conteúdo. Selecionamos a primeira técnica, que consiste em redução de conteúdo para criar categorias.

Na Síntese da Análise de Conteúdo procede-se à "omissão" racional dos trechos e paráfrase com significados iguais = $1^{\text {a }}$ redução; e depois as paráfrases semelhantes são condensadas e resumidas $=2^{\mathrm{a}}$ redução. Os textos-fonte são parafraseados, reduzidas pelas omissões racionais dos enunciados que se sobrepõem no nível da generalização.

Ainda segundo o julgamento de Flick, o procedimento específico de Mayring "[...] parece menos ambíguo e mais fácil de controlar do que os outros métodos de análise de dados. Isso ocorre também devido à possível redução do material anteriormente delineado." E que "[...]. a formalização do procedimento dá origem a um esquema uniforme de categorias, facilitando a comparação dos diferentes casos através dos quais ele se aplica." (FLICK, 2009, p. 294). 


\title{
3 - HFCrECN NOS REGULAMENTOS OFICIAIS
}

\begin{abstract}
A História é também história do conhecimento científicotecnológico e matemático, e ainda história da cultura, em todos os sentidos dessa palavra, desde cultura da alimentação, do vestuário e de regras de convívio, até cultura literária, artística e humanista.

[...].

Em termos gerais, a contextualização no ensino de ciências abarca competências de inserção da ciência e de suas tecnologias em um processo histórico, social e cultural e o reconhecimento e discussão de aspectos práticos e éticos da ciência no mundo contemporâneo [...].

MEC. SEMT. PCN+ Ensino Médio, 2002, p. 18 e 31.
\end{abstract}

\section{1 - Apresentação}

O objetivo nosso neste capítulo é analisar como aparece a HFCrECN nas regulamentações educacionais nacionais com implicação direta na organização do sistema curricular e na formação docente. Neste campo político educacional foram analisados os seguintes documentos educacionais oficiais:

* a Lei 9.394 de 20 de dezembro de 1996, que estabelece as Diretrizes e Bases da Educação Nacional (LDBEN);

* as Diretrizes Curriculares Nacionais para o Ensino Médio (DCNEM, Parecer no 15/1998 CEB/CNE e Resolução no 3/1998 CEB/CNE);

* os Parâmetros Curriculares Nacionais para o Ensino Médio (PCNEM: Parte III - Ciências da Natureza, Matemática e suas Tecnologias, 1999); as Matrizes Curriculares de Referência para o SAEB (1999);

* as Diretrizes Curriculares Nacionais para os Cursos de Graduação (DCNCG, 2001/2: Física: Parecer № 1.304/2001 e Resolução no 09/2002 CES/CNE, Biologia: Parecer oํ 1.301/2001 e Resolução no 07/2002 CES/CNE e Química: parecer ํo 1.303/2001 e Resolução ㄲo 08/2002 CES/CNE);

* as Orientações Educacionais Complementares aos Parâmetros Curriculares Nacionais (PCN+, 2002); 
* as Orientações Curriculares para o Ensino Médio, vol. 2: Ciências da Natureza, Matemática e suas Tecnologias (OCEM, 2006);

* a Matriz de Referência do ENEM (2009).

\section{2 - LDBEN (1996) e DCNEM (1998)}

A Lei 9.394 de 20 de dezembro de 1996 que estabelece as Diretrizes e Bases da Educação Nacional (doravante $\operatorname{LDBEN}^{61}$ ), que foram produzidas numa época em que os temas e problemas advogados pelo movimento da HFCrECN já se encontravam em discussões há muito tempo, internacionalmente, bem como as discussões sobre a formação por competências que levará ao surgimento no Brasil dos PCN.

O objetivo do ato de legislar consiste em regular os fenômenos sociais normatizáveis, sob aspecto jurídico, em uma determinada sociedade ou grupo social e em dada época. Entre os fenômenos sociais reguláveis está a educação formal. Assim, analisar a lei que regula o sistema educacional é verificar a interpenetração entre os problemas/fatos, sem, porém, exigir que a lei contemple, necessariamente, as reivindicações dos movimentos e tendências educacionais ou pedagógicas.

Neste sentido, em relação à HFCrECN na LDBEN não encontramos uma referência específica ao assunto, mas é possível deduzir, genericamente, que quando se definem as finalidades do Ensino Médio apresenta-se uma pequena aproximação com os domínios da HFC.

De uma forma muito ampla ao regular os objetivos deste grau de ensino, em seu Art. 35ํㅡㄹ inciso IV, consta que o Ensino Médio terá como finalidades, entre outras: "IV - a compreensão dos fundamentos científico-tecnológicos dos processos produtivos, relacionando a teoria com a prática, no ensino de cada disciplina." (BRASIL, 1996) [destaque nosso]. Ou ainda, como se determina no Art. 36ํㅡㄹ inciso I, que o currículo do Ensino Médio deverá observar diretrizes entre as quais está a seguinte:

I - destacará a educação tecnológica básica, a compreensão do significado da ciência, das letras e das artes; o processo histórico de transformação da sociedade e da cultura; a língua portuguesa como instrumento de comunicação, acesso ao conhecimento e exercício da

61 Às vezes, usa-se LDB, nós preferimos usar a referência completa: LDBEN. 
cidadania; (BRASIL. 1996) [destaque nosso]

É possível inferir do texto normativo três aspectos interessantes que podem interessar aos defensores da HFCrECN: $1^{\circ}$ a compreensão dos "fundamentos científico-tecnológicos dos processos produtivos", $2^{\circ}$ a compreensão do "significado da ciência" e $3^{\circ}$ a compreensão do "processo histórico da transformação da sociedade e da cultura".

A compreensão dos fundamentos científico-tecnológicos dos processos produtivos se localiza no contexto interno, mas com interdependência no espaço e tempo em que ocorreram ou ocorrem as relações de produção e de significação, deduzindo-se ser também necessário compreender o contexto externo que localiza a produção dentro dos problemas históricos, filosóficos e sociopolíticos implicados nos processos de produção, significação e dos seus recortes ou suas delimitações. Então, ratifica-se que a compreensão da ciência é também a compreensão de sua dimensão filosófica, histórica, política, socioeconômica e cultural.

Em outras palavras, à compreensão do que significa a ciência está subjacente $\mathrm{o}$ entendimento dos aspectos metodológicos, epistemológicos e, portanto, histórico-sociais tanto dos processos produtivos quanto do significado e da delimitação dos problemas de investigações ou da natureza da ciência e da tecnologia. Ao destacar o processo histórico das transformações sociais e culturais as contribuições das ciências e tecnologias são contempladas, pelo que elas têm proporcionado a esse processo.

E, além do mais, a compreensão histórica das transformações da sociedade e cultura implica compreender os impactos positivos ou negativos da ciência e tecnologia que influem nessas transformações, às vezes, as transformações científico-tecnológicas são causas de mudanças socioculturais, como é o caso das ciências da informação e comunicação (e. g. computação/internet) e da genética molecular ${ }^{62}$ que impulsionou uma mudança científico-tecnológica (e. g. ciência e engenharia de regeneração tecidual) e sociocultural por repercutir fortemente nas mentalidades (consequentemente nos comportamentos) e na economia (indústria farmacêutica, indústria hospitalar, política econômica e científico-tecnológica).

${ }^{62}$ Hoje já se fala em ciências moleculares, inclusive, formam-se profissionais nestas ciências a caminho de institucionalização. A USP mantém um curso de graduação em ciências moleculares. 
Portanto, não há uma aproximação direta das prescrições da LDBEN à HFCrECN, entretanto, pode-se dizer que nela é possível inferir duas categorias: a da contextualização externa (subcategoria: historicidade) e da criticidade (subcategoria: dimensão epistemológica) para possível fundamentação da HFCrECN a partir daquelas prescrições legais supracitadas.

Por outro lado, o Parecer no 15/1998 e a Resolução n 3/1998, ambos do CEB/CNE, estabelecem as Diretrizes Curriculares Nacionais do Ensino Médio (DCNEM) tendo como base a LDBEN de 1996. Nesses dois instrumentos normativos educacionais regulamenta-se a base nacional do currículo e da organização do Ensino Médio. Neles constam dois conceitos que, a princípio, podem nos induzir a supor sua aproximação com o movimento da HFCrECN. Tais conceitos são: interdisciplinaridade e contextualização.

No entanto, nos dois documentos, a concepção e a sua projeção para práxis didática estão distantes das aproximações ao movimento da HFCrECN, mas também, com criatividade, nada impediria ao docente servir-se dos dois conceitos para desenvolver uma metodologia integrada que the possibilitasse abordar aspectos da HFCrECN, mesmo porque a interdisciplinaridade é compreendida como não sendo uma mera justaposição e diluição de disciplinas em generalidades, mas como uma prática pedagógica e didática a ser adequada aos objetivos do Ensino Médio, que deve ocorrer como "possibilidade de relacionar as disciplinas em atividades ou projetos de estudos, pesquisa e ação" (BRASIL. MEC, SEMT, 2000, p.75).

A concepção da interdisciplinaridade como processo relacional introduz a compreensão de que todo conhecimento é um processo de diálogo perpétuo, entre outras formas de conhecimento "que pode ser de questionamento, de confirmação, de complementação, de negação, de ampliação, de iluminação de aspectos não distinguidos" (BRASIL. MEC, SEMT, 2000, p.75).

A compreensão de interdisciplinaridade poder ser mais captável no texto seguinte:

É importante enfatizar que a interdisciplinaridade supõe um eixo integrador, que pode ser o objeto de conhecimento, um projeto de investigação um plano de intervenção. Nesse sentido, ela deve partir da necessidade sentida pelas escolas, professores e alunos de explicar, compreender, intervir, mudar, prever, algo que desafia uma disciplina isolada e atrai a atenção de mais de um olhar, talvez vários. Explicação, compreensão, intervenção são processos que requerem um conhecimento que vai além da descrição da realidade e mobiliza competências cognitivas para deduzir, tirar inferências ou 
fazer previsões a partir do fato observado.

A partir do problema gerador do projeto, que pode ser um experimento, um plano de ação para intervir na realidade ou uma atividade, são identificados os conceitos de cada disciplina que podem contribuir para descrevê-lo, explicá-lo e prever soluções. Dessa forma, o projeto é interdisciplinar na sua concepção, execução e avaliação, e os conceitos utilizados podem ser formalizados, sistematizados e registrados no âmbito das disciplinas que contribuem para o seu desenvolvimento. O exemplo do projeto é interessante para mostrar que a interdisciplinaridade não dilui disciplinas, ao contrário, mantém sua individualidade. Mas integra as disciplinas a partir da compreensão das múltiplas causas ou fatores que intervêm sobre a realidade e trabalha todas as linguagens necessárias para a constituição de conhecimentos, comunicação e negociação de significados e registro sistemático de resultados. (BRASIL. MEC, SEMT, 2000, p.76) [destaque do original]

Recapitulamos que de modo específico não há na prescrição algo que possa ser relacionado, concretamente, ao debate sobre a HFCrECN, mas serve para ilustrar o que foi dito anteriormente.

A contextualização também segue o mesmo grau de distanciamento em relação à $\mathrm{HFC}-\mathrm{ECN}$, pois ela é referida ao conteúdo a ser aprendido no Ensino Médio e sua relação com o mundo do trabalho e a cidadania (mundo social). Tratase de contextualizar o conteúdo, ou seja, transpô-10 ${ }^{63}$ para o âmbito do trabalho e da cidadania, ora, trata-se, portanto, de fazer uma transposição didática.

A interdisciplinaridade e a contextualização (juntamente com identidade, diversidade e autonomia) são propostas na condição de princípios pedagógicos que estruturariam o currículo do Ensino Médio com o fim de atender ao que preceitua a LDBEN quando às competências e que as DCNEM seguem-na (BRASIL. MEC, SEMT, 2000, p. 93 e 102).

Esses contextos são diferentes dos contextos advogados pelo movimento da HFCrECN, neste movimento trata-se do entorno sócio-histórico da produção do conhecimento científico que estaria silenciado na sua divulgação, comercialização e consumo, somando-se-Ihe os problemas filosóficos e sociológicos, tais como: os aspectos econômicos e ideológicos subjacentes, os interesses político-militares, os conflitos internos à produção científica, a natureza das ciências, as questões éticas, as razões de escolhas metodológicas, quem são os cientistas, a participação feminina, os interesses dos financiadores das pesquisas, quem são as cobaias humanas, entre outros.

Esta concepção de contextualização está além da concepção da

63 Estão subjacentes às DCNEM as concepções das teorias de Transposição Didática e Aprendizagem Significativa. 
contextualização como transposição do conhecimento aprendido na Escola para os contextos próximos ou próprios dos discentes escolares: o do trabalho; o da vida cotidiana, pessoal e de convivência comunitária e o do meio ambiente, corpo e saúde.

Neste sentido, as disciplinas foram agrupadas em três grandes grupos de áreas de conhecimento: Linguagens e Códigos, Ciências Humanas, Ciências da Natureza e Matemática e as respectivas tecnologias que seguem as três grandes áreas. Em relação às Ciências Naturais justificou-se que foram aglutinados com o objetivo de

[...] contribuir para a compreensão do significado da ciência e da tecnologia na vida humana e social, de modo a gerar protagonismo diante das inúmeras questões políticas e sociais para cujo entendimento e solução as Ciências da Natureza são uma referência relevante. (BRASIL. MEC, SEMT, 2000, p. 93)

Organizada a base curricular nacional em áreas de conhecimento, as Ciências Naturais são "convocadas" a contribuir na construção de competências e habilidades que devem permitir aos discentes escolares:

- compreender as ciências como construções humanas, entendendo como elas se desenvolvem por acumulação, continuidade ou ruptura de paradigmas, relacionando o desenvolvimento científico com a transformação da sociedade. (BRASIL. MEC, SEMT, 2000, p. 95, 104)

A esta percepção de autoaperfeiçoamento das ciências acrescenta-se a compreensão das relações com os seus contextos sociais que também se refletem no processo de autoaperfeiçoamento humano:

- entender a relação entre o desenvolvimento das Ciências Naturais e o desenvolvimento tecnológico, e associar as diferentes tecnologias aos problemas que se propuseram e propõem solucionar.

- entender o impacto das tecnologias associadas às Ciências Naturais na sua vida pessoal, nos processos de produção, no desenvolvimento do conhecimento e na vida social. (BRASIL. MEC, SEMT, 2000, p. 96, 105)

Ao menos, aqui encontramos algumas prescrições que se apropinguam ao movimento da HFCrECN e que podem possibilitar inferências didáticas que proporcionem ao docente fazer uma abordagem cuja aproximação é perceptível nas 
referências ao objetivo de aglutinação das ciências naturais, bem como nas competências e habilidades, o que nos leva a localizar tais prescrições nas categorias de contextualização externa, criticidade e sistemicidade.

Enfim, o modo prescritivo de compreender as ciências naturais e as suas relações contextuais no processo de ensino e aprendizagem vai aparecer também nos Parâmetros Curriculares Nacionais para o Ensino Médio (PCNEM) e nas suas Orientações Complementares, como se segue.

\section{3 - PCNEM (1999) e PCN+ (2002)}

Os Parâmetros Curriculares Nacionais para o Ensino Médico (PCNEM) tiveram sua primeira versão em 1997 - logo após a publicação da LDBEN/1996 - e a segunda em 1999, é esta última edição que utilizamos na análise, pelo seu caráter de atualidade.

Do ponto de vista da relação entre a regulamentação educacional e as aproximações da história e filosofia da ciência ao ensino de ciências naturais os PCN surgem como os primeiros instrumentos nacionais a darem ênfase à HFCrECN, pois

Os objetivos explicitamente atribuídos à área de Ciências e Matemática incluem compreender as Ciências da Natureza como construções humanas e a relação entre conhecimento científico-tecnológico e a vida social e produtiva; objetivos usualmente restritos ao aprendizado das Ciências Humanas. [...]. (BRASIL. MEC, SEMT, [1999 ou 2000], p. 11)

Constata-se aqui uma aproximação dos objetivos das ciências naturais à competência de contextualização sócio-cultural e histórica da ciência e tecnologia, que tradicionalmente estava vinculada à Filosofia e às Ciências Humanas (entre elas as sociais). Este fato pode ser interpretado como mais um aspecto inovador no âmbito das prescrições educacionais no país.

Nesta macrocompetência da contextualização sócio-cultural da ciência e tecnologia está prescrita a pretensão de que os discentes do ensino médio possam "Compreender e utilizar a ciência, como elemento de interpretação e intervenção, e a tecnologia como conhecimento sistemático de sentido prático" (BRASIL. MEC, SEMT, [1999 ou 2000], p. 13) e para isso espera-se que tenham competências e habilidades, entre outras, tais como as de: 
1. Reconhecer o sentido histórico da ciência e da tecnologia, percebendo seu papel na vida humana em diferentes épocas e na capacidade humana de transformar o meio.

2. Compreender as ciências como construções humanas, entendo ${ }^{64}$ como elas se desenvolveram por acumulação, continuidade ou ruptura de paradigmas, relacionando o desenvolvimento científico com a transformação da sociedade.

3. Entender a relação entre o desenvolvimento de Ciências Naturais e o desenvolvimento tecnológico e associar as diferentes tecnologias aos problemas que se propuser e se propõe solucionar.

4. Entender o impacto das tecnologias associadas às Ciências Naturais, na sua vida pessoal, nos processos de produção, no desenvolvimento do conhecimento e na vida social. (BRASIL. MEC, SEMT, [1999 ou 2000], p. 13).

A inserção destas "competências e habilidades" no instrumento normativo aproxima a HFC ao ensino médio e indiretamente à formação docente. É assim que a concepção da historicidade das ciências perpassa pelas justificativas que sustentam as competências e aparece nas postulações sobre as três disciplinas que compõem o tronco das Ciências Naturais escolares (Biologia, Física e Química).

O reconhecimento da relevância da HFC no ensino de ciências naturais aparece de forma a justificar as competências referentes à contextualização histórica da produção do conhecimento científico, tal como em relação ao conhecimento da Biologia afirma-se que:

Ao longo da história da humanidade, várias foram as explicações para o surgimento e a diversidade da vida, de modo que os modelos científicos conviveram e convivem com outros sistemas explicativos como, por exemplo, os de inspiração filosófica ou religiosa. O aprendizado da Biologia deve permitir a compreensão da natureza viva e dos limites dos diferentes sistemas explicativos, a contraposição entre os mesmos e a compreensão de que a ciência não tem respostas definitivas para tudo, sendo uma de suas características [é] a possibilidade de ser questionada e de se transformar. Deve permitir, ainda, a compreensão de que os modelos na ciência servem para explicar tanto aquilo que podemos observar diretamente, como também aquilo que só podemos inferir; que tais modelos são produtos da mente humana e não a própria natureza, construções mentais que procuram sempre manter a realidade observada como critério de legitimação.

[Neste sentido] Elementos da história e da filosofia da Biologia tornam possível aos alunos a compreensão de que há uma ampla rede de relações entre a produção científica e o contexto social, econômico e político. É possível verificar que a formulação, o sucesso ou o fracasso das diferentes teorias científicas estão associados a seu momento histórico. (BRASIL. MEC, SEMT, [1999 ou 2000], p. 14)

Essa postura de entender a HFC como elemento de compreensão dos

${ }^{64}$ Assim consta no original, talvez fosse "entendendo". 
conteúdos (conhecimento) científicos nos seus contextos de produção e nas suas relações com os contextos social, econômico, político, militar e até religioso e com a perspectiva analítico-crítica (filosófica) pode ser interpretado como uma postura que possibilita a capacidade de os discentes compreenderem a complexa rede de relações e de fundamentos subjacentes à produção, comercialização e consumo do conhecimento científico. Trata-se, então, de uma perspectiva que busca superar a tradicional visão e prática didática predominante no ensino, na aprendizagem, nos livros didáticos das ciências naturais e instituições de ensino, que tem obnubilado o desenvolvimento das capacidades criativas na aprendizagem (formação) científica.

Por outro lado, espera-se também, da escola média, que o conhecimento da Física, por exemplo, seja elucidado enquanto processo histórico sujeito a mudanças contínuas e às relações com outros sistemas de produção e manifestação das culturas humanas:

\begin{abstract}
A Física percebida enquanto construção histórica, como atividade social humana, emerge da cultura e leva à compreensão de que modelos explicativos não são únicos nem finais, tendo se sucedido ao longo dos tempos, como o modelo geocêntrico, substituído pelo heliocêntrico, a teoria do calórico pelo conceito de calor como energia, ou a sucessão dos vários modelos explicativos para a luz. O surgimento de teorias físicas mantém uma relação complexa com o contexto social em que ocorrem.

Perceber essas dimensões históricas e sociais corresponde também ao reconhecimento da presença de elementos da Física em obras literárias, peças de teatro ou obras de arte. (BRASIL. MEC, SEMT, [1999 ou 2000], p. 27)
\end{abstract}

Tal percepção do conhecimento da Física seria uma condição necessária para promover uma consciência de "responsabilidade social e ética."

$E$, para analisar e interpretar a natureza (ou o mundo) outro conhecimento necessário é o da Química, na sua dinamicidade e historicidade:

Assim, o conhecimento químico não deve ser entendido como um conjunto de conhecimentos isolados, prontos e acabados, mas sim [como] uma construção da mente humana, em contínua mudança. A História da Química, como parte do conhecimento socialmente produzido, deve permear todo o ensino de Química, possibilitando ao aluno a compreensão do processo de elaboração desse conhecimento, com seus avanços, erros e conflitos.

A consciência de que o conhecimento científico é assim dinâmico e mutável ajudará o estudante e o professor a terem a necessária visão crítica da ciência. Não se pode simplesmente aceitar a ciência como pronta e acabada e os conceitos atualmente aceitos pelos cientistas e ensinados nas escolas como "verdade absoluta". (BRASIL. MEC, SEMT, [1999 ou 2000], p. 31) 
A dimensão processual do conhecimento científico é necessariamente uma dimensão histórico-filosófica, como tal a HFC é, por natureza, inerente à produção do conhecimento científico, ou seja, as ciências têm história, cultura e problemas filosóficos (nos planos diversos: axiológico, lógico, epistemológico, metodológico, ontológico, político e estratégico), que não devem ser ignorados no processo refinado da divulgação do conhecimento a ser apreendido.

Podemos inferir que esta dimensão processual do conhecimento científico proporcionaria situar o conhecimento científico no espaço e tempo social e mental (conceitual). Possibilitaria, também, compreender o caráter falível do conhecimento científico, que não deveria ser dogmático, mas dinâmico/dialético: lançando as mentes a uma cultura de criticidade necessária para analisar e interpretar as implicações socioculturais, éticas, econômicas, político-militares e estratégicas das ciências e tecnologias.

Assim, a elucidação da dimensão histórico-filosófica no ensino das ciências naturais pode ocorrer em vários momentos da evolução curricular desde o seu planejamento estratégico à sua materialização na prática didática, tal como no momento de estudos:

* de leis e teorias genéticas (clonagem, melhoramento genético, transgenia, regeneração tecidual e suas implicações éticas e interesses político-militares, econômicos e ideológicos);

* da dinâmica ambiental (interesses político-econômicos, ecossistemas, biomas, mudanças climáticas, aquecimento global);

* da diversidade das espécies (adaptação, seleção natural, origem das espécies, evolução ou criação?);

* das teorias geológicas (evolução geológica da terra e as cosmovisões);

* das teorias astronômico-cosmológicas (geocentrismo, heliocentrismo);

* das teorias do atômico (evolução conceitual e natureza do átomo);

* das transformações da energia (fontes e formas de produção nos diversos contextos sócio-históricos e os interesses econômicos, político-militares);

* a teoria da gravitação; 


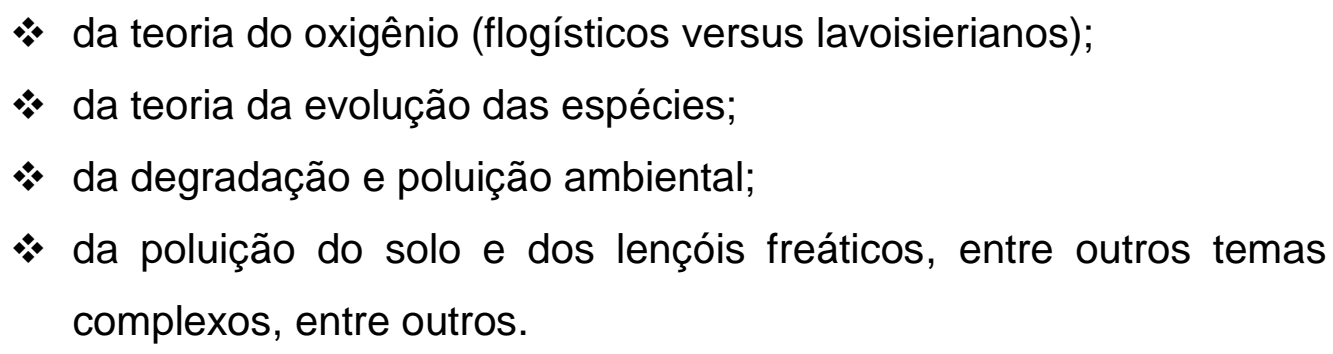

Em todos esses momentos do processo didático far-se-ia necessário uma abordagem contextual-crítica, da história e natureza dos eventos ou objetos de estudos.

Entre as competências e habilidades prescritas para serem desenvolvidas pelos discentes da escola média, na aprendizagem das ciências naturais, em relação ao contexto sócio-cultural do conhecimento científico, estão:

Tabela 6 - Competências e Habilidades do contexto sociocultural

\begin{tabular}{|c|c|c|}
\hline $\begin{array}{c}\text { Para a Biologia } \\
\text { (BRASIL. MEC. SEMT, [1999 } \\
\text { ou 2000], p. 21): }\end{array}$ & $\begin{array}{c}\text { Para a Física } \\
\text { (BRASIL. MEC. SEMT, [1999 } \\
\text { ou 2000], p. 29): }\end{array}$ & $\begin{array}{c}\text { Em relação à Química } \\
\text { (BRASIL. MEC. SEMT, [1999 } \\
\text { ou 2000], p. 39): }\end{array}$ \\
\hline $\begin{array}{l}\text { Reconhecer a Biologia como } \\
\text { um fazer humano e, portanto, } \\
\text { histórico, fruto da conjugação } \\
\text { de fatores sociais, políticos, } \\
\text { econômicos, culturais, } \\
\text { religiosos e tecnológicos. }\end{array}$ & $\begin{array}{l}\text { Reconhecer a Física } \\
\text { enquanto } \\
\text { humana, aspectos de sua } \\
\text { história e relações com o } \\
\text { contexto cultural, social, } \\
\text { político e econômico. }\end{array}$ & 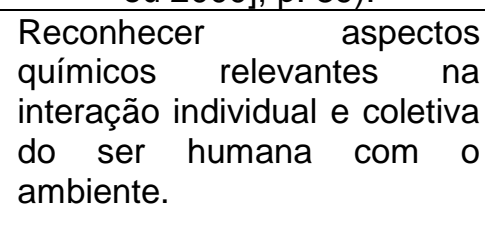 \\
\hline $\begin{array}{l}\text { Identificar as relações entre o } \\
\text { conhecimento científico e o } \\
\text { desenvolvimento tecnológico, } \\
\text { considerando a preservação } \\
\text { da vida, as condições de vida } \\
\text { e as concepções de } \\
\text { desenvolvimento sustentável. }\end{array}$ & $\begin{array}{l}\text { Reconhecer o papel da Física } \\
\text { no sistema produtivo, } \\
\text { compreendendo a evolução } \\
\text { dos meios tecnológicos e sua } \\
\text { relação dinâmica com a } \\
\text { evolução do conhecimento } \\
\text { científico. }\end{array}$ & $\begin{array}{l}\text { Reconhecer as relações } \\
\text { entre o desenvolvimento } \\
\text { científico e tecnológico da } \\
\text { Química e aspectos sócio- } \\
\text { político-culturais. }\end{array}$ \\
\hline & $\begin{array}{l}\text { Estabelecer relações entre o } \\
\text { conhecimento físico e outras } \\
\text { formas de expressão da } \\
\text { cultura humana. }\end{array}$ & $\begin{array}{l}\text { Reconhecer os limites éticos } \\
\text { e morais que podem estar } \\
\text { envolvidos no } \\
\text { desenvolvimento da Química } \\
\text { e da tecnologia. }\end{array}$ \\
\hline & $\begin{array}{l}\text { Ser capaz de emitir juízos de } \\
\text { valor em relação a situações } \\
\text { sociais que envolvam } \\
\text { aspectos físicos e/ou } \\
\text { tecnológicos relevantes. }\end{array}$ & \\
\hline
\end{tabular}

Prescreveu-se nos PCNEM que a compreensão da relação entre a aprendizagem científica e as questões de alcance social constitui, ao mesmo tempo, "meio para o ensino e objetivo da educação", isto carece de verificação ou evidencia, talvez, pudesse advir do desenvolvimento de atividades em projetos coletivos de 
produção e divulgação do conhecimento, ou então, por meio da análise histórica do processo de desenvolvimento das ciências.

Portanto, a HC é vista - nos PCNEM - como um recurso didático de extrema importância para a aprendizagem científica, porque oferece análise conceitual além das relações sociais estabelecidas no processo de produção científica, isto é, ela teria relevância na aprendizagem porque "transcende a relação social" e "ilustra também o desenvolvimento e a evolução dos conceitos a serem aprendidos" (BRASIL. MEC. SEMT, [1999 ou 2000], p. 54), esse reconhecimento descreve, de certa forma, uma HC imbricada na FC, logo uma HFC.

Em 2002, um novo projeto amplia o que fora prescrito nos PCN, surge assim as Orientações Educacionais Complementares aos Parâmetros Curriculares Nacionais, conhecidos como $\mathrm{PCN}+$, para o Ensino Médio, e, nas três áreas de conhecimento em que foram elaborados os PCN (Ciências Naturais, Matemática e suas Tecnologias; Ciências Humanas e suas Tecnologias; Linguagem, Códigos e suas Tecnologias).

Os $\mathrm{PCN}+{ }^{65}$ são um conjunto prescritivo de orientações dirigidas aos profissionais da educação, respectivamente: docentes, coordenadores e diretores escolares do ensino médio, responsáveis pela formação continuada e pelas redes de educação básica. Eles são destinados objetivamente a: facilitar a organização do trabalho escolar; explicitar a articulação das competências gerais que se pretende promover com os conhecimentos disciplinares; apresentar sugestões de práticas educacionais e organizacionais dos currículos que estabelecem temas estruturadores do ensino disciplinar e abrir perspectivas para formação continuada nas Escolas. (BRASIL. MEC. SEMT, 2002, p.7).

Percebe-se que, nestas orientações, a hipótese inicial tomada é de que se pretende formar para a vida, numa época de transformações contínuas, então, isto impõe os seguintes requisitos como premissas:

Saber se informar, comunicar-se, argumentar, compreender e agir;

Enfrentar problemas de diferentes naturezas;

Participar socialmente, de forma prática e solidária;

Ser capaz de elaborar críticas ou propostas; e,

Especialmente, adquirir uma atitude de permanente aprendizado. (BRASIL. MEC. SEMT, 2002, p. 9)

65 Usaremos $\mathrm{PCN}_{+}$ou orientações para nos referirmos às Orientações Educacionais Complementares aos Parâmetros Curriculares Nacionais. 
Essas premissas poderiam ser operacionalizadas por intermédio de recursos e condições que proporcionassem aos discentes da escola média o desenvolvimento de competências, tais como:

\author{
Comunicar-se e argumentar; \\ Defrontar-se com problemas, compreendê-los e enfrentá-los; \\ Participar de um convívio social que lhes dê oportunidades de se realizarem \\ como cidadãos; \\ Fazer escolhas e proposições; \\ Tomar gosto pelo conhecimento, aprender a aprender. (BRASIL. MEC. \\ SEMT, 2002, p. 9).
}

A defesa do desenvolvimento destas competências seria em virtude de que aproximaria a formação dos discentes da Escola média aos contextos reais; às perspectivas profissionais, sociais e individuais; aos problemas e desafios da sociedade. E, que tais competências impulsionariam a participação do estudante na construção social e a prática didática dos docentes na definição de conteúdo e adoção de procedimentos metodológicos e mobilização de outros recursos didáticos, dentro de uma perspectiva interdisciplinar e de contextualização histórica, social, cultural, política e econômica do conhecimento, porque "a própria competência de dar contexto social e histórico a um conhecimento científico é um exemplo que não está restrito nem às ciências, nem à história, nem a uma soma delas" (BRASIL. MEC. SEMT, 2002, p. 15). Isto significa que a contextualização sócio-histórica transcende os âmbitos disciplinares, em virtude de sua vinculação ontológica ao campo metadisciplinar.

Os PCN estabeleceram três competências genéricas, a saber, comunicar e representar, investigar e compreender e contextualizar socialmente, no entanto, nos PCN não há uma explanação desses conjuntos de competências genéricas em específicas e habilidades como ocorre nos $\mathrm{PCN}+\mathrm{e}$, ao se proceder desta forma, articularam-se as áreas anteriormente delimitadas nos PCN e a aproximação à HFC torna-se mais evidente nos $\mathrm{PCN}+$ que nos $\mathrm{PCN}$, embora não tão explicita como poderia ter sido, porque a HFCrECN já é um tema mundialmente discutido e implementado em um número significativo de países, dos quais os pesquisadores nacionais mantêm contatos formativos ou investigativos.

A articulação entre as áreas - que favorece a abordagem ou a defesa da HFCrECN - é justificada, de certo modo, porque 
Explicitamente, disciplinas da área de linguagens e códigos e da área de ciências da natureza e matemática devem também tratar de aspectos histórico-geográficos e culturais, ingredientes da área humanista, e, viceversa, as ciências humanas devem também tratar de aspectos científicotecnológicos e das linguagens. (BRASIL. MEC. SEMT, 2002, p. 15-16)

Essa compreensão amplia também a noção do conceito contexto nos $\mathrm{PCN}_{+}$, porque não se trata mais do contexto convivencional ou cotidiano dos discentes ou da cidadania ${ }^{66}$ (como nos PCN), mas englobando este e transcendendo-o trata-se da compreensão do contexto histórico, social, econômico, político e cultural da produção do conhecimento científico, a ser proporcionada na operacionalização das competências que funcionam como engrenagens de articulação entre as diversas áreas do conhecimento (interdisciplinaridade) e os contextos (contextualização).

Entretanto, em termos de identidade da $\mathrm{HC}$, contrariamente à visão que tem predominado ultimamente entre os pesquisadores da $\mathrm{HC}$ ou historiadores da ciência e do movimento da HFCrECN, ontologicamente, nos DO a HC é entendida enquanto subárea da História e da História Econômica e Social, na seguinte sequência lógico-dedutiva: a História ao assumir por objeto de estudo a evolução econômica e social pode apresentar a História da Ciência e Técnica, ou seja,

${ }^{66}$ Conceito não tão bem elucidado nos instrumentos da política educacional em análise. A sua complexidade, no entanto, está no fato de ser um conceito político, jurídico, sociológico e filosófico que encontra nestas áreas maior vinculação às ciências sociais, humanidades e filosofia e menos nas ciências naturais, assim a consistência e efetividade da sua abordagem estão onde é inerente por natureza epistemológica, para a economia curricular e eficiência do planejamento didático.

Cidadania é um conceito que avulta os discursos de todos os tipos (dos palanques políticos às mídias, das organizações às salas de aulas, passando pelos movimentos sociais e pelo cotidiano). É um conceito compreendido, geralmente - enquanto adjetivo - como qualificativo que descreve ou traduz estado político de um indivíduo (cidadão) dentro do Estado e - enquanto substantivo - como gozo de direitos civis (ter vida, liberdade, igualdade legal, propriedade), político-econômicos (votar, ser votado, pagar impostos, consumir) e sociais (ter educação, trabalho, salário, saúde, aposentadoria, velhice, morte e enterro digno) dentro de um Estado e como exercício de deveres para com esse Estado, cujo vínculo se dá pelo fato de possuir documentos que prescrevam o controle do indivíduo.

Sob as compreensões de cidadania subjazem os ideais da revolução francesa, a Declaração dos Direito Humanos das Nações Unidas, as regulações do mercado, além dos valores culturais e religiosos que têm estado na base de ações humanas na forma de prescrições simbólicas.

Ademais, o exercício da cidadania é, vulgarmente, tido como trabalhar para consumir e pagar tributos, o que reduz o ser cidadão ao estar cidadão, pois, se uma vez desprovido de trabalho, que significa não consumir nem pagar tributos, o sujeito perde o status de cidadão.

Entretanto, os processos ou sistemas de escolarização científica podem contribuir para a prática da cidadania, até certo ponto, mas enquanto participação organizada das realizações sociais que perpassam pela organização dos processos mentais ou das próprias mentalidades. $E$, neste sentido, é de certa forma válida a introdução da abordagem do conceito de cidadania no ensino das ciências naturais na medida em que é possível esperar que, a partir do seu ensino, os discentes adquiram uma literacia que lhes permita exercer o pensamento analítico e apoiado em evidências suficiente e "útil" para as aplicações na vida cotidiana, mas também que possa permitir que se lancem para a formação e/ou o exercício do ofício científico. 
dedutivamente: História > História Econômica e Social > História da Ciência e Técnica, está é uma compreensão possibilitada e perceptível na afirmação seguinte:

\begin{abstract}
A disciplina de História, pertencente à área de Ciências Humanas, ao estudar o desenvolvimento econômico e social na modernidade, pode apresentar um panorama amplo da história das ciências e das técnicas nos últimos quatrocentos ou quinhentos anos, revelando em que medida a concentração de riqueza, em determinadas nações e em certos períodos, determinou sua capacidade de investimento científico-cultural e, vice-versa, em que medida sua cultura científica constitui vantagem estratégica. (BRASIL. MEC. SEMT, 2002, p. 18)
\end{abstract}

Além da polêmica questão identitária de vinculação da $\mathrm{HC}$ à História ou às Ciências ou ainda à Filosofia - questão de fronteira política e epistemológica e de garantia ontológica e problema comum nas áreas multi/inter/transdisciplinares constata-se que há um reconhecimento de que o estudo da $\mathrm{HC}$ possibilitaria compreender as relações entre a produção do conhecimento e as questões macros (históricas, sociais, econômicas, políticas e militares).

\begin{abstract}
Ao estabelecer-se um paralelismo possível entre poder político ou econômico e desenvolvimento científico-tecnológico e cultural, desde a Renascença até a presente "era do conhecimento", incluindo, portanto, as três revoluções, se estaria descortinando, ao longo do tempo, o cenário global em que o complexo científico-tecnológico se originou e evoluiu. (BRASIL. MEC. SEMT, 2002, p. 18)
\end{abstract}

A busca do entendimento da ciência como construção humana tem sido uma das premissas de defesa da HFCrECN para poder ilustrar a complexa realidade por detrás da produção científico-tecnológica, desmistificando a suposta neutralidade científica e apresentando as nuances que estão na base das decisões sobre a investigação científica, a política de financiamento e a divulgação ou comercialização do produto consequente. Assim, se o estudo de aspectos da HFC for feito:

Tanto no aprendizado de história quanto no de ciências é possível compreender como, em determinados períodos e circunstâncias, o conhecimento técnico-científico se mostrou mais determinante para o domínio militar, discutindo até mesmo aspectos éticos dos meios de destruição em massa, e como, em outros períodos, foi mais essencial para a hegemonia econômica, ou como, em geral, ambos esses domínios freqüentemente se sobrepõem. As máquinas térmicas, na revolução industrial inglesa, a tecnologia nuclear, na segunda guerra mundial e na "guerra fria", os semicondutores e a informática, na terceira revolução industrial, são só alguns exemplos. Esse exercício histórico daria aos 
estudantes uma oportunidade de questionar e compreender melhor processos sociais, econômicos e culturais passados e contemporâneos e, além disso, auxiliaria a construir uma visão das Ciências da Natureza associada a outras dimensões da vida humana. (BRASIL. MEC. SEMT, 2002, p. 18).

Neste sentido, a HFC assumiria aqui um papel de suporte para fomentar capacidades críticas e compreensivas dos problemas implicados na geração do conhecimento e de elucidar as relações contextuais do passado e do presente para repensar as novas práticas.

A noção de história é ampliada nos $\mathrm{PCN}+$, pois nos seus preceitos considera-se que:

A História é também história do conhecimento científico-tecnológico e matemático, e ainda história da cultura, em todos os sentidos dessa palavra, desde cultura da alimentação, do vestuário e de regras de convívio, até cultura literária, artística e humanista. (BRASIL. MEC. SEMT, 2002, p. 18)

Essa generalização da história talvez ilustre a razão pela qual a dimensão histórica das ciências naturais esteja realçada nos $\mathrm{PCN}_{+}$, sobretudo, na competência de contextualização sócio-cultural.

As ciências naturais são consideradas - nestes instrumentos prescritivos - como componentes da "cultura científica e tecnológica" que, por sua vez, é "resultado e instrumento da evolução social e econômica" ao longo da história humana. Elas são apresentadas como sendo "construções históricas, com participação permanente no desenvolvimento social, econômico e cultural" da humanidade (BRASIL. MEC. SEMT, 2002, p. 23), no entanto, essa compreensão é reforçada por meio de estabelecimento de relações de abordagem interdisciplinar com as ciências humanas.

E, neste sentido, a contextualização sócio-cultural é considerada como a competência geral já que "o conhecimento disciplinar é, em qualquer caso, recurso essencial para um desígnio humano comum" e além do mais,

As fases distintas das diferentes especialidades, em termos da história dos conceitos ou de sua interface tecnológica, não impedem que a história das ciências seja compreendida como um todo, dando realidade a uma compreensão mais ampla da cultura, da política, da economia, no contexto maior da vida humana. Por tudo isso, a contextualização sócio-cultural das ciências e da tecnologia deve ser vista como uma competência geral, que transcende o domínio específico de cada uma das ciências. (BRASIL. MEC. SEMT, 2002, p. 25) 
De igual modo, os $\mathrm{PCN}+$ foram desenvolvidos à base dos mesmos três grupos de competências que aparecem nos PCN, a saber: "representação e comunicação" (pela qual as ciências naturais se interligam com as linguagens e códigos), "investigação e compreensão" (que mantém inerência às competências e habilidades lógicas e metodológicas das ciências naturais, logo à FC, de certo modo) e a "contextualização sócio-cultural" (que interliga as ciências naturais às ciências humanas, logo à HFC).

Esses conjuntos são compostos de subcompetências e habilidades específicas a que convém reproduzirmos seus três esquemas representativos, para que seja possível, verificar a aproximação à temática da HFCrECN. Neles se descrevem as competências a serem adquiridas na área de ensino de ciências naturais, a partir deles prescreveu-se competências disciplinares. No conjunto de representação e comunicação encontram-se as seguintes especificações de competências:

Tabela 7 - Competências e Habilidades em Representação e Comunicação (BRASIL. MEC. SEMT, 2002, p. 27).

\begin{tabular}{|c|}
\hline REPRESENTAÇÃO E COMUNICAÇÃO \\
\hline $\begin{array}{l}\text { [Em relação à:] Símbolos, códigos e nomenclaturas } \\
\text { [O discente deve saber:] Reconhecer e utilizar adequadamente na forma oral e escrita } \\
\text { símbolos, códigos e nomenclatura da linguagem científica. }\end{array}$ \\
\hline $\begin{array}{l}\text { Articulação dos símbolos e códigos } \\
\text { Ler, articular e interpretar símbolos e códigos em diferentes linguagens e representações: } \\
\text { sentenças, equações, esquemas, diagramas, tabelas, gráficos e representações geométricas. }\end{array}$ \\
\hline $\begin{array}{l}\text { Análise e interpretação de textos e outras comunicações } \\
\text { Consultar, analisar e interpretar textos e comunicações de ciência e tecnologia veiculados por } \\
\text { diferentes meios. }\end{array}$ \\
\hline $\begin{array}{l}\text { Elaboração de comunicações } \\
\text { Elaborar comunicações orais ou escritas para relatar, analisar e sistematizar eventos, } \\
\text { fenômenos, experimentos, questões, entrevistas, visitas, correspondências. }\end{array}$ \\
\hline $\begin{array}{l}\text { Discussão e argumentação de temas de interesse } \\
\text { Analisar, argumentar e posicionar-se criticamente em relação a temas de ciência e tecnc }\end{array}$ \\
\hline
\end{tabular}

Verifica-se que a última competência guarda relação com a FC no que tange às questões lógicas de análise, argumentação e crítica das proposições científicas e tecnológicas.

No conjunto de investigação e compreensão encontramos as competências específicas seguintes: 
Tabela 8 - Competências e Habilidades em Investigação e Compreensão

(BRASIL. MEC. SEMT, 2002, p. 30).

\begin{tabular}{|c|}
\hline INVESTIGAÇÃO E COMPREENSÃO \\
\hline $\begin{array}{c}\text { [Em relação à:] Estratégias para enfrentamento de situações-problemas } \\
\text { [O discentes deve saber:] ldentificar em dada situação-problema as informações ou variáveis } \\
\text { relevantes e possíveis estratégias para resolvê-la. }\end{array}$ \\
\hline $\begin{array}{l}\text { Interações, relações e funções; invariantes e transformações } \\
\text { Identificar fenômenos naturais ou grandezas em dado domínio do conhecimento científico, } \\
\text { estabelecer relações; identificar regularidades, invariantes e transformações. }\end{array}$ \\
\hline $\begin{array}{l}\text { Medidas, quantificações, grandezas e escalas } \\
\text { Selecionar e utilizar instrumentos de medição e de cálculo, representar dados e utilizar } \\
\text { escalas, fazer estimativas, elaborar hipóteses e interpretar resultados. }\end{array}$ \\
\hline $\begin{array}{c}\text { Modelos explicativos e representativos } \\
\text { Reconhecer, utilizar, interpretar e propor modelos explicativos para fenômenos ou sistemas } \\
\text { naturais ou tecnológicos. }\end{array}$ \\
\hline $\begin{array}{l}\text { Relações entre conhecimentos disciplinares, interdisciplinares e interáreas } \\
\text { Articular, integrar e sistematizar fenômenos e teorias dentro de uma ciência, entre as várias } \\
\text { ciências e áreas de conhecimento. }\end{array}$ \\
\hline
\end{tabular}

Neste conjunto as duas últimas competências também guardam aproximação à $\mathrm{FC}$ pelas razões já expostas anteriormente.

Porém, é no conjunto de contextualização sócio-cultural que encontramos aproximação mais específica à abordagem da HFC no ensino que em outros conjuntos anteriores. A abordagem contextual é integrada à interdisciplinar para elucidação de temas, conceitos e problemas como os dos impactos ambientais, energéticos ou econômicos na história e suas consequências no presente.

\begin{abstract}
De uma perspectiva histórica, o estudo da energia pode discutir a importância da invenção das rodas d'água, dos moinhos de vento e do aperfeiçoamento dos arreios de animais de tração para o acúmulo de produção no período medieval, ou o papel da máquina a vapor para impulsionar a primeira revolução industrial, ou do motor elétrico, da iluminação elétrica e da eletroquímica para a segunda revolução industrial e daí para a frente, até alcançar a enorme rede de oferta e demanda de insumos energéticos, dos quais depende tão profundamente a vida contemporânea. Esses tratamentos de aspectos geográficos, sociais e históricos podem ser feitos articuladamente com as demais áreas, mas não é preciso que sejam deixados para a área de ciências humanas, por conta da "natureza do conteúdo". Pelo contrário, precisamente por sua natureza humanista, esses aspectos são significativos para dar contexto sóciocultural a disciplinas científicas como a Biologia, a Física e a Química, e às linguagens matemáticas de que fazem uso, propiciando assim um aprendizado mais eficaz. (BRASIL. MEC. SEMT, 2002, p. 31)
\end{abstract}

A contextualização sócio-cultural integrada à abordagem interdisciplinar dos conteúdos possibilitaria a abertura de discussão para a questão identitária desta 
área de interseção epistêmica: mas a quem caberá fazê-lo? Às ciências naturais ou humanas? A interpelação atinge também a identidade da própria $\mathrm{HC}$ : a quem a $\mathrm{HC}$ pertence, à História ou às Ciências das quais ela é história?

Vimos, anteriormente, nos próprios $\mathrm{PCN}+$, a vinculação da $\mathrm{HC}$ à História. Vimos também que, com a implantação da reforma universitária na USP, a disciplina "História das Ciências Físicas" foi transferida do Departamento de Física para o de História, no entanto, este fato não eliminou o interesse do departamento anterior pela disciplina, que resolveu replicar denominado-a "Evolução dos Conceitos da Física".

Parecem questões meramente de nomenclaturas, mas tudo isso demonstra o sério problema identitário por que passa a $\mathrm{HC}$, e quanto associada à FC e à Sociologia da Ciência, de fato o problema aumenta o seu grau de complexidade. Então, não se trata de questão de nomenclatura, mas de questões políticas, epistemológicas e metodológicas.

Mas, para além das identidades primárias (História, Ciências Naturais, Filosofia, Sociologia), o fato é que esta interface fez surgir uma nova área de conhecimento que vem construindo sua identidade: História, Filosofia e Sociologia da Ciência (HFSC), para qual convergem cientistas naturais, sociais, historiadores e filósofos interessados nos problemas científicos e tecnológicos, nas relações com a sociedade e nos impactos de seus produtos, etc.

No âmbito do ensino, essas questões introduzem ou exigem mudanças conceituais e organizações dos sistemas e processos formativos e da ação didática. Evidentemente são os físicos, químicos e biólogos a ensinarem física, química e biologia na Educação Básica, mas carecem de suporte de competências para a materialização da abordagem e do desenvolvimento de competências e habilidades de contextualização sócio-cultural das ciências naturais, isto em virtude de a formação atual desfavorecer esse aspecto de estudos sociais e filosóficos.

Portanto, estamos diante de uma exigência que transcende às mudanças estruturais organizacionais para alcançar as mudanças de mentalidades, pois as mentalidades precisam mudar primeiro, para depois definir os rumos das ações didáticas, organizacionais para uma congruência de perspectivas, porque competências de inserção da ciência e de suas tecnologias em um processo histórico, social e cultural e o reconhecimento e discussão de 
aspectos práticos e éticos da ciência no mundo contemporâneo, como sinaliza e exemplifica o quadro seguinte. (BRASIL. MEC. SEMT, 2002, p. 31)

Portanto, trata-se de uma concepção mais ampla de contextualização, não restrita às tradicionais análises da HFC, mais ampliada para uma inter/multidisciplinar, multitemático e multisetorial. Vejamos então o quadro do conjunto de competências de contextualização sócio-cultural (BRASIL. MEC. SEMT, 2002, p. 32):

Tabela 9 - Competências de Contextualização Sociocultural

\begin{tabular}{|c|}
\hline CONTEXTUALIZAÇÃO SÓCIO-CULTURAL \\
[Em relação á:] Ciência e tecnologia na história \\
[O discente deve saber:] Compreender o conhecimento científico e o tecnológico como \\
resultados de uma construção humana, inseridos em um processo histórico e social. \\
Ciência e tecnologia na cultura contemporânea \\
Compreender a ciência e a tecnologia como partes integrantes da cultura humana \\
contemporânea.
\end{tabular}

O contexto é ontologicamente transdisciplinar, portanto, sua abordagem não representaria obstáculo tanto no âmbito das disciplinas particulares quanto nos projetos didáticos coletivos, se existirem nas escolas.

As competências do conjunto de contextualização sócio-cultural foram inseridas e ampliadas em cada área disciplinar, desta feita, a contextualização não está restrita ao ambiente do cotidiano e da cidadania dos discentes como nos PCN, portanto, houve uma extrapolação significativa da noção de contextualização social e cultural da produção do conhecimento científico-tecnológico.

Por questão de pertinência temática, vamos verificar de forma mais específica este conjunto de competências prescritas no interior de cada disciplina: Biologia, Química e Física. Quanto a outros dois conjuntos de competências apenas faremos referência a eles quando houver imediata aproximação à contextualização do tema.

Assim, do ensino e aprendizagem da Biologia espera-se um 
desenvolvimento de competências e habilidades específicas que proporcionem aos discentes uma compreensão histórica, social e filosófica dos temas e conteúdos apreendidos, a elegibilidade desses temas e conteúdos obedece à sua importância científica, social, ao seu significado histórico e atual, bem como, às expectativas, os interesses e as necessidades dos discentes (BRASIL. MEC. SEMT, 2002, p. 40). Porém, resta saber se essas expectativas, necessidades e interesses dos discentes serão aquelas percebidas pelos docentes ou os discentes terão de manifestá-los? A quem cabe defini-los, selecioná-los?

A aproximação à abordagem dos aspectos da HFC ao ensino da Biologia aparece nas competências específicas prescritas para esta disciplina, vejamos o quadro seguinte.

Tabela 10 - Competências e habilidades específicas de contextualização sociocultural na aprendizagem da Biologia (BRASIL. MEC. SEMT, 2002, p. 39-40).

\begin{tabular}{|c|c|}
\hline \multicolumn{2}{|c|}{ Contextualização sócio-cultural } \\
\hline $\begin{array}{l}\text { [Competências a serem desenvolvidas na } \\
\text { área de ciências naturais e matemática.] }\end{array}$ & $\begin{array}{l}\text { [Competências a serem desenvolvidas no } \\
\text { processo de aprendizagem da Biologia.] }\end{array}$ \\
\hline \multicolumn{2}{|c|}{ [Em relação à] ciência e tecnologia na história } \\
\hline $\begin{array}{l}\text { Compreender o conhecimento científico e o } \\
\text { tecnológico como resultados de uma } \\
\text { construção humana, inseridos em um } \\
\text { processo histórico e social. }\end{array}$ & $\begin{array}{l}\mathbf{1}^{67} \text { - Perceber os conhecimentos biológicos } \\
\text { como interpretações sobre o funcionamento e } \\
\text { as transformações dos sistemas vivos } \\
\text { construídos ao longo da história e } \\
\text { dependentes do contexto social em que foram } \\
\text { produzidos. } \\
\mathbf{2} \text { - Analisar idéias biológicas como a teoria } \\
\text { celular, as concepções sobre a } \\
\text { hereditariedade de características dos seres } \\
\text { vivos, ou, ainda, as teorias sobre as origens e } \\
\text { a evolução da vida como construções } \\
\text { humanas, entendendo como elas se } \\
\text { desenvolveram, seja por acumulação, } \\
\text { continuidade ou ruptura de paradigmas. }\end{array}$ \\
\hline \multicolumn{2}{|c|}{ Ciência e tecnologia na cultura contemporânea } \\
\hline $\begin{array}{l}\text { Compreender a ciência e a tecnologia como } \\
\text { partes integrantes da cultura humana } \\
\text { contemporânea. }\end{array}$ & $\begin{array}{l}1 \text { - Reconhecer a presença dos } \\
\text { conhecimentos biológicos e da tecnologia no } \\
\text { desenvolvimento da sociedade. Perceber, por } \\
\text { exemplo, que eles contribuíssem para } \\
\text { preservar e prolongar a vida ao possibilitarem } \\
\text { a produção de medicamentos, vacinas, } \\
\text { tecnologia para diagnóstico e tratamento, } \\
\text { conservação de alimentos. } \\
2 \text { - Reconhecer as formas pelas quais a } \\
\text { Biologia está presente na cultura nos dias de }\end{array}$ \\
\hline
\end{tabular}

${ }^{67}$ A inserção numérica nesta e nas próximas tabelas é nossa. 


\begin{tabular}{|c|c|}
\hline & $\begin{array}{l}\text { hoje, seja influenciando visão de mundo, seja } \\
\text { participando de manifestações culturais, } \\
\text { literárias, artificiais. }\end{array}$ \\
\hline \multicolumn{2}{|c|}{ Ciência e tecnologia na atualidade } \\
\hline $\begin{array}{l}\text { Reconhecer e avaliar o desenvolvimento } \\
\text { tecnológico contemporâneo, suas relações } \\
\text { com as ciências, seu papel na vida humana, } \\
\text { sua presença no mundo cotidiano e seus } \\
\text { impactos na vida social. }\end{array}$ & $\begin{array}{l}1 \text { - Relacionar os avanços científicos e } \\
\text { tecnológicos com a melhoria das condições } \\
\text { de vida das populações, como, por exemplo, } \\
\text { o uso de vacinas com a conseqüente queda } \\
\text { nas taxas de mortalidades infantil; o } \\
\text { saneamento básico e a redução na incidência } \\
\text { de doenças infecto-contagiosas. } \\
2 \text { - Analisar a distribuição desigual pela } \\
\text { população dos efeitos positivos decorrentes } \\
\text { da aplicação dos conhecimentos biológicos e } \\
\text { tecnológicos na medicina, na agricultura, na } \\
\text { indústria de alimentos. } \\
3 \text { - Perceber os efeitos positivos, mas } \\
\text { também perturbadores, da ciência e } \\
\text { tecnologia na vida moderna como, por } \\
\text { exemplo, reconhecer o papel dos antibióticos } \\
\text { na preservação da vida e, ao mesmo tempo, } \\
\text { as alterações que esses medicamentos vêm } \\
\text { introduzindo nas populações microbianas e } \\
\text { as conseqüências dessas modificações para } \\
\text { a manutenção da saúde dos indivíduos ou, } \\
\text { ainda, compreender a importância do uso de } \\
\text { defensivos agrícolas para a produção de } \\
\text { alimentos e os efeitos danosos dessas } \\
\text { substâncias nos ecossistemas. }\end{array}$ \\
\hline \multicolumn{2}{|c|}{ Ciência e tecnologia, ética e cidadania } \\
\hline $\begin{array}{l}\text { Reconhecer e avaliar o caráter ético do } \\
\text { conhecimento científico e tecnológico e } \\
\text { utilizar esses conhecimentos no exercício da } \\
\text { cidadania. }\end{array}$ & $\begin{array}{l}1 \text { - Reconhecer a importância dos } \\
\text { procedimentos éticos na aplicação das novas } \\
\text { tecnologias para o diagnóstico precoce de } \\
\text { doenças e do uso dessa informação para } \\
\text { promover a saúde do ser humano sem ferir a } \\
\text { sua privacidade e dignidade. } \\
2 \text { - Avaliar a adequação do uso de } \\
\text { procedimentos invasivos para o tratamento de } \\
\text { determinadas disfunções. } \\
3 \text { - Avaliar a importância do aspecto } \\
\text { econômico evolvido na utilização da } \\
\text { manipulação genética em saúde: o problema } \\
\text { das patentes biológicas e a exploração } \\
\text { comercial das descobertas das tecnologias de } \\
\text { DNA. }\end{array}$ \\
\hline
\end{tabular}

Percebe-se neste quadro um efetivo reconhecimento da relevância dos estudos metacientíficos (HFSC), que possibilitam, a nosso ver, levantar questões:

* éticas (problemas sérios na área de reprodução humana, da regeneração tecidual, o uso de seres humanos para experimentos científicos, o aborto e a esterilização forçada e não consentida, 
etc.);

* referentes à manipulação econômica e política das ciências e suas tecnologias (questão dos transgênicos e das indústrias farmacêuticas);

* de impactos benéficos e maléficos para a sociedade: no ambiente (poluição, contaminação de solos e de lençóis de água (freáticos ou artesianos)), na alimentação e na saúde das populações;

* de distribuição e consumo desigual dos benefícios das ciências e tecnologias e;

* da necessidade de formação de mentalidades investigativas, críticas e responsáveis socialmente.

Ademais, argumenta-se que o estudo dos aspectos histórico-filosóficos do conhecimento biológico contribuiria, por exemplo, para compreender e identificar concepções pré-mendelianas de hereditariedade; compreender as concepções ideológicas e políticas subjacentes ao desenvolvimento da genética (eugenia); compreender as concepções espontâneas ou culturais, filosóficas e científicas da origem do universo e da vida (se acidental/evolução molecular ou se de projeção intencional por um suposto ente extraterrestre, por exemplo), entre outros temas estratégicos.

O ensino e a aprendizagem da Física são compreendidos como um processo construído ao longo da história da humanidade, influenciado por questões culturais, econômicas e sociais e estas questões também influenciadas, por sua vez, pelo desenvolvimento da ciência física.

A aproximação à abordagem dos aspectos da HFC no ensino da Física aparece nas competências específicas prescritas no interior desta disciplina, como se segue: 
Tabela 11 - Competências e habilidades específicas de contextualização sociocultural na aprendizagem da Física (BRASIL. MEC. SEMT, 2002, p. 67-68).

\begin{tabular}{|l|l|}
\hline \multicolumn{2}{|c|}{ Contextualização sócio-cultural ${ }^{68}$} \\
\hline $\begin{array}{l}\text { [Competências a serem desenvolvidas na } \\
\text { área de ciências naturais e matemática.] }\end{array}$ & $\begin{array}{l}\text { [Competências a serem desenvolvidas no } \\
\text { processo de aprendizagem da Física.] }\end{array}$ \\
\hline
\end{tabular}

[Em relação à] Ciência e tecnologia na história

Compreender o conhecimento científico e o 1 1 - Compreender a construção do tecnológico como resultados de uma conhecimento físico como um processo construção humana, inseridos em um histórico, em estreita relação com as processo histórico e social. condições sociais, políticas e econômicas de uma determinada época. [...].

2 - Compreender o desenvolvimento histórico dos modelos físicos para dimensionar corretamente os modelos atuais, sem dogmatismo ou certezas definitivas.

3 - Compreender o desenvolvimento histórico da tecnologia, nos mais diversos campos, e suas consequências para o cotidiano e as relações sociais de cada época, identificando como seus avanços foram modificando as condições de vida e criando novas necessidades. Esses conhecimentos são essenciais para dimensionar corretamente 0 desenvolvimento tecnológico atual, através tanto de suas vantagens como de seus condicionantes. Reconhecer, por exemplo, o desenvolvimento de formas de transporte, a partir da descoberta da roda e da tração animal, ao desenvolvimento de motores, ao domínio da aerodinâmica e à conquista do espaço, identificado a evolução que vem permitindo ao ser humano deslocar-se de um ponto ao outro do globo terrestre em intervalos de tempo cada vez mais curtos e identificando também os problemas decorrentes dessa evolução.

4 - Perceber o papel desempenhado pelo conhecimento físico no desenvolvimento da tecnologia e a complexa relação entre ciência e tecnologia ao longo da história. Muitas vezes, a tecnologia foi precedida pelo desenvolvimento da Física, como no caso da fabricação de lasers, ou, em outras, foi a tecnologia que antecedeu o conhecimento científico, como no caso das máquinas térmicas.

\section{Ciência e tecnologia na cultura contemporânea}

Compreender a ciência e a tecnologia como 1 - Compreender a Física como parte partes integrantes da cultura humana contemporânea. integrante da cultura contemporânea, identificando sua presença em diferentes âmbitos e setores, como, por exemplo, nas

${ }^{68}$ No texto original está escrito "Investigação e compreensão" ao invés de "Contextualização sóciocultural", talvez por um lapso de digitação. 


\begin{tabular}{|c|c|}
\hline & $\begin{array}{l}\text { manifestações artísticas ou literárias, em } \\
\text { peças de teatro, letras de músicas etc., } \\
\text { estando atento à contribuição da ciência para } \\
\text { a cultura humana. } \\
2 \text { - Promover e interagir com meios culturais e } \\
\text { de difusão científica, por meio de visitas a } \\
\text { museus científicos ou tecnológicos, } \\
\text { planetários, exposições etc., para incluir a } \\
\text { devida dimensão da Física e da ciência na } \\
\text { apropriação dos espaços de expressão } \\
\text { contemporâneos. } \\
3 \text { - Compreender formas pelas quais a Física } \\
\text { e a tecnologia influenciam nossa } \\
\text { interpretação do mundo atual, condicionando } \\
\text { formas de pensar e interagir. Por exemplo, } \\
\text { como a relatividade ou as idéias quânticas } \\
\text { povoam o imaginário e a cultura } \\
\text { contemporânea, conduzindo à extrapolação } \\
\text { de seus conceitos para diversas áreas, como } \\
\text { para a Economia ou Biologia. }\end{array}$ \\
\hline \multicolumn{2}{|c|}{ Ciência e tecnologia na atualidade } \\
\hline $\begin{array}{l}\text { Reconhecer e avaliar o desenvolvimento } \\
\text { tecnológico contemporâneo, suas relações } \\
\text { com as ciências, seu papel na vida humana, } \\
\text { sua presença no mundo cotidiano e seus } \\
\text { impactos na vida social. }\end{array}$ & $\begin{array}{l}1 \text { - Acompanhar o desenvolvimento } \\
\text { tecnológico contemporâneo, por exemplo, } \\
\text { estabelecendo contato com os avanços das } \\
\text { novas tecnologias na medicina, por meio de } \\
\text { tomografias ou diferentes formas de } \\
\text { diagnóstico; na agricultura, nas novas formas } \\
\text { de conservação de alimentos com o uso das } \\
\text { radiações; ou, ainda, na área de } \\
\text { comunicações, com os microcomputadores, } \\
\text { CDs, DVDs, telefonia celular, tevê a cabo. }\end{array}$ \\
\hline \multicolumn{2}{|c|}{ Ciência e tecnologia, ética e cidadania } \\
\hline $\begin{array}{l}\text { Reconhecer e avaliar o caráter ético do } \\
\text { conhecimento científico e tecnológico e } \\
\text { utilizar esses conhecimentos no exercício da } \\
\text { cidadania. }\end{array}$ & $\begin{array}{l}1 \text { - Compreender a responsabilidade social } \\
\text { que decorre da aquisição do conhecimento, } \\
\text { sentindo-se mobilizado para diferentes ações, } \\
\text { seja na defesa da qualidade de vida, da } \\
\text { qualidade de infra-estrutura coletivas, ou na } \\
\text { defesa de seus direitos como consumidor. } \\
2 \text { - Promover situações que contribuam para } \\
\text { a melhoria das condições de vida da cidade } \\
\text { onde vive ou da preservação responsável do } \\
\text { ambiente, conhecendo as estruturas de } \\
\text { abastecimento de água e eletricidade de sua } \\
\text { comunidade e dos problemas delas } \\
\text { decorrentes, sabendo posicionar-se, } \\
\text { argumentar e emitir juízos de valor. } \\
3 \text { - Reconhecer que, se de um lado a } \\
\text { tecnologia melhora a qualidade de vida do } \\
\text { homem, do outro ela pode trazer efeitos que } \\
\text { precisam ser ponderados quanto a um } \\
\text { posicionamento responsável. Por exemplo, o } \\
\text { uso de radiações ionizantes apresenta tanto } \\
\text { benefícios quanto riscos para a vida humana. } \\
4 \text { - Reconhecer, em situações concretas, a } \\
\text { relação entre Física e ética, seja na definição }\end{array}$ \\
\hline
\end{tabular}




\begin{tabular}{|l|l|}
\hline & de procedimentos para a melhoria das \\
condições de via, seja em questões côo do \\
desarmamento nuclear ou em mobilizações \\
pela paz mundial. \\
Reconhecer que a utilização dos produtos da \\
ciência e da tecnologia nem sempre é \\
democrática, tomando consciência das \\
desigualdades e da necessidade de soluções \\
de baixo custo, como por exemplo, para \\
ampliar o acesso à eletricidade.
\end{tabular}

A contextualização que contempla o desenvolvimento das competências na aprendizagem da ciência física requer compreender esta ciência como integrante da cultura social, que contribui para o seu desenvolvimento multissetorial, mas também, que gera impactos que ameaçam a vida social, o que colabora com o estudo da dimensão histórica da física (global ou local), para compreender as relações e os fatores implicados na produção do seu conhecimento e seus usos. Assim, advoga-se que pesquisar e resgatar a história da evolução do conhecimento técnico-científico "[...] pode também ser uma estratégias significativa na direção do estabelecimento de uma visão da ciência enquanto atividade humana e social" (BRASIL. MEC. SEMT, 2002, p. 85).

Subentende-se que a apreensão e o conhecimento da dimensão história das ciências - e de certa forma, política, social, econômica, ideológica e filosófica passaria pelo domínio das competências e habilidades prescritas na área de contextualização sociocultural. Por esta dimensão demonstrar-se-ia aos discentes como o conhecimento científico, as pesquisas e os paradigmas explicativos têm sido desenvolvidos e modificados ao longo da história do conhecimento científico e tecnológico e das condições sociais da época.

Assim, por exemplo, os modelos explicativos da teoria da constituição da matéria por elementos indivisíveis na filosofia atomista e na física atômica moderna não são iguais nem respondem às mesmas perspectivas ou expectativas. Ao estudar o conhecimento da física atômica seria de suma importância elucidar a dimensão histórica das transformações conceituais da filosofia atomística até chegar à atual teoria atômica.

O mesmo vale para os modelos explicativos no conhecimento científico da química, como o caso dos fluídos/gases ou da teoria do calórico (abandonada em virtude da insuficiência explicativa da massa nula do calórico). Ao estudar estes temas sua contextualização histórico-social seria, então, um instrumento de 
significação dos conteúdos e estabelecimento de relações com outras áreas de conhecimento: significação contextual e interdisciplinaridade no processo de aprendizagem científica.

As competências e habilidades específicas na aprendizagem da química foram, então, assim descritas:

Tabela 12 - Competências e habilidades específicas de contextualização sociocultural na aprendizagem da Química (BRASIL. MEC. SEMT, 2002, p. 92-93).

\begin{tabular}{|c|c|}
\hline \multicolumn{2}{|c|}{ Contextualização sócio-cultural ${ }^{69}$} \\
\hline $\begin{array}{l}\text { [Competências a serem desenvolvidas na } \\
\text { área de ciências naturais e matemática.] }\end{array}$ & $\begin{array}{l}\text { [Competências a serem desenvolvidas no } \\
\text { processo de aprendizagem da Química.] }\end{array}$ \\
\hline \multicolumn{2}{|c|}{ [Em relação à] Ciência e tecnologia na história } \\
\hline $\begin{array}{l}\text { Compreender o conhecimento científico e o } \\
\text { tecnológico como resultados de uma } \\
\text { construção humana, inseridos em um } \\
\text { processo histórico e social. }\end{array}$ & $\begin{array}{l}1 \text { - Reconhecer e compreender a ciência e } \\
\text { tecnologia químicas como criação humana, } \\
\text { portanto inseridas na história e na sociedade } \\
\text { em diferentes épocas; por exemplo, identificar } \\
\text { a alquimia, na Idade Média, como visão de } \\
\text { mundo típica da época. } \\
2 \text { - Perceber o papel desempenhado pela } \\
\text { Química no desenvolvimento tecnológico e a } \\
\text { complexa relação entre ciência e tecnologia } \\
\text { ao longo da história; por exemplo, perceber } \\
\text { que a manipulação do ferro e suas ligas, } \\
\text { empírica e mítica, tinha a ver, no passado, } \\
\text { com o poder do grupo social que a detinha, e } \\
\text { que hoje, explicada pela ciência, continua } \\
\text { relacionada a aspectos políticos e sociais. }\end{array}$ \\
\hline \multicolumn{2}{|c|}{ Ciência e tecnologia na cultura contemporânea } \\
\hline $\begin{array}{l}\text { Compreender a ciência e a tecnologia como } \\
\text { partes integrantes da cultura humana } \\
\text { contemporânea. }\end{array}$ & $\begin{array}{l}1 \text { - Identificar a presença do conhecimento } \\
\text { químico na cultura humana contemporânea, } \\
\text { em diferentes âmbitos e setores, como os } \\
\text { domésticos, comerciais, artísticos, desde as } \\
\text { receitas caseiras para limpeza, propagandas } \\
\text { e uso de cosméticos, até em obras literárias, } \\
\text { músicas e filmes. } \\
2 \text { - Compreender as formas pelas quais a } \\
\text { Química influencia nossa interpretação do } \\
\text { mundo atual, condicionando formas de } \\
\text { pensar e interagir; por exemplo, discutir a } \\
\text { associação irrefletida de "produtos químicos" } \\
\text { com algo sempre nocivo ao ambiente ou à } \\
\text { saúde. } \\
3 \text { - Promover e interagir com eventos e } \\
\text { equipamentos culturais, voltados à difusão da } \\
\text { ciência, como museus, exposições científicas, } \\
\text { peças de teatro, programas de tevê. }\end{array}$ \\
\hline
\end{tabular}

${ }^{69}$ No texto original está escrito "Investigação e compreensão" ao invés de "Contextualização sóciocultural”, talvez por um lapso de digitação. 


\section{Ciência e tecnologia na atualidade}

Reconhecer e avaliar o desenvolvimento tecnológico contemporâneo, suas relações com as ciências, seu papel na vida humana, sua presença no mundo cotidiano e seus impactos na vida social.
1 - Reconhecer o papel do conhecimento químico no desenvolvimento tecnológico atual, em diferentes áreas do setor produtivo, industrial e agrícola; por exemplo, na fabricação de alimentos, corantes, medicamentos e novos materiais.

2 - Reconhecer aspectos relevantes do conhecimento químico e suas tecnologias na interação individual e coletiva do ser humano com o ambiente, por exemplo, o uso de CFC - cloro-flúor-carbono -, de inseticidas e agrotóxicos, de aditivos nos alimentos, os tratamentos de água e de lixo, a emissão de poluentes que aumentam o efeito estufa na atmosfera.

3 - Articular, integrar e sistematizar o conhecimento químico e o de outras áreas no enfrentamento de situações-problemas; por exemplo, identificar e relacionar aspectos químicos, físicos e biológicos da produção e do uso de metais, combustíveis e plásticos, além de aspectos sociais, econômicos e ambientais.

\section{Ciência e tecnologia, ética e cidadania}

\begin{tabular}{|l|l|l|l|l}
$\begin{array}{l}\text { Reconhecer e avaliar o caráter ético do } \\
\text { conhecimento científico e tecnológico e e } \\
\text { utilizar esses conhecimentos no exercício da } \\
\text { cidadania. }\end{array}$ & $\begin{array}{l}\mathbf{1} \text { - Reconhecer as responsabilidades sociais } \\
\text { decorrentes da aquisição de conhecimento na } \\
\text { defesa da qualidade de vida e dos direitos do } \\
\text { consumidor; por exemplo, para notificar } \\
\text { órgãos responsáveis diante de ações como } \\
\text { destinações impróprias de lixo ou de produtos } \\
\text { tóxicos, fraudes em produtos alimentícios ou } \\
\text { em suas embalagens. } \\
2 \text { - Compreender e avaliar a ciência e } \\
\text { tecnologia química sob o ponto de vista ético } \\
\text { para exercer a cidadania com } \\
\text { responsabilidade, integridade e respeito; por } \\
\text { exemplo, no debate sobre fontes de energia, } \\
\text { julgar implicações de ordem econômica, } \\
\text { social, ambiental, ao lado de argumentos } \\
\text { científicos para tomar decisões a respeito de } \\
\text { atitudes e comportamentos individuais e } \\
\text { coletivos. }\end{array}$ \\
\hline
\end{tabular}

O conjunto das competências e habilidades específicas prescritas como as esperadas dos discentes da Escola média apresentam conexões aproximativas às propostas da HFCrECN. Tal aproximação se verifica pela perspectiva contextual culturalista, que concebe a cultura como gênero das produções humanas em suas especialidades. A produção científico-tecnológica é uma espécie de tais produções culturais. 
genérica nos $\mathrm{PCN}+$, não tanto quanto nos $\mathrm{PCN}$, mas em termos de indicações específicas ou concretas da inserção da abordagem dos aspectos da HFC ainda permaneceu-se distante, embora se reconheça a dimensão histórica ou sociocultural das ciências naturais e suas interrelações e impactos positivos e negativos das suas tecnologias na sociedade, pela qual se prescreveu as ciências como sendo integrantes da cultura humana, não se fez uma aproximação com a literatura que trata da HFCrECN, talvez subliminarmente, mas não de forma objetiva. Se isso fosse feito talvez proporcionasse estratégias de planejamento didático aos docentes tanto escolares quanto universitários. Em relação às universidades seria de práxis reverem os seus programas de formação docente inicial em conformidade com as recomendações dos órgãos reguladores, dos objetivos nacionais da educação e com aquilo que é de inerência metodológica fazer.

Parece-nos predominar nos PCN como um todo, noção de contextualização como aproximação ao cotidiano, como transferência ou transposição dos processos e conteúdos e adaptação dos procedimentos de ensino à realidade sociocultural local dos sujeitos da aprendizagem. Fato é que não há um consenso no uso e operacionalização do conceito contextualização ou contexto, o que também já fora diagnosticado por Ricardo (2005, p. 120) num exaustivo trabalho de pesquisa com os formuladores dos PCN e docentes formadores,

\footnotetext{
A noção de contextualização também se apresenta sobre vários aspectos nas concepções dos formadores. Uma delas, mais como, é a associação direta com o cotidiano dos alunos. Assim como ocorreu com as competências e a interdisciplinaridade, a compreensão plena dessa noção e qualquer perspectiva de consenso estão longe de acontecer.
}

Finalmente, a contextualização tida como aproximação à realidade sociocultural dos discentes, ao seu ambiente, diferencia-se de uma contextualização sociocultural da produção científica, pois essa é local, nacional e internacional e conjuga-se - de forma analítica e crítica - do presente ao passado e do passado ao presente da produção do conhecimento científico, diagnosticando as variáveis que interferem no processo produtivo e subjacentes à divulgação e ao consumo. 


\section{4 - Matrizes Curriculares de Referência para o SAEB (1999)}

O Sistema Nacional de Avaliação do Ensino Médio (SAEB) foi aplicado inicialmente em 1990, sua frequência é de dois em dois anos e é restrita apenas a duas disciplinas escolares (Português e Matemática). Trata-se de uma avaliação amostral aplicada aos discentes finalistas de $4^{\underline{a}}$ e $8^{\underline{a}}$ [9aํ $^{\text {a }}$ séries do ensino fundamental e do $3^{\text {o }}$ ano do ensino médio. Eles são avaliados em Língua Portuguesa, mensurando suas capacidade de leitura, e em Matemática, verificando a capacidade de resolução de problemas matemáticos. Participam dela discentes das escolas públicas e privadas.

Entretanto, a avaliação do SAEB de 1999 não foi restringida apenas à língua portuguesa e matemática, incluíram nela as disciplinas de ciências naturais (Ciências, Química, Física, Biologia), razão pela qual a sua matriz foi alvo de análise no âmbito desta investigação. Mantendo o mesmo objetivo de diagnosticar as aproximações à HFCrECN nas Matrizes, considerando as competências e habilidades específicas de contextualização sociocultural presentes nos PCN, pelas quais esses encontram vinculação às abordagens de HFC.

O objetivo das Matrizes Curriculares é "[...] identificar o conjunto de descritores do desempenho desejável dos alunos em cada disciplina ao longo da educação básica, para orientar a elaboração de itens que compõem as provas do SAEB" (INEP, 1999, p. 9). Tenciona-se assim associar os conteúdos às competências cognitivas e habilidades instrumentais próprias apresentadas em forma de descritores do desempenho dos discentes.

Nas Matrizes (INEP, 1999, p. 10-11) as competências cognitivas foram distribuídas em três níveis: básico $(B)$, operacional $(O)$ e global $(G)$. Em relação à Física no Ensino Médio há uma advertência de que é importante compreender que as

[...] três categorias de competências em Física não devem se restringir ao plano ao plano [sic] abstrato-formal, pois cada uma delas igualmente se revela em aspectos práticos, culturais, tecnológico, sociais e ambientais. Reconhecendo esses aspectos, os descritores são apresentados, sempre que possível, com sentido prático e contextualizado, de forma que elementos de tecnologia se encontram distribuídos por todos os temas e tópicos, lado a lado com ênfases interdisciplinares envolvendo ambiente, Química, Biologia, etc. (INEP, 1999, p. 108) 
No entanto, ao analisarmos os descritores em busca de competências relacionados à contextualização sociocultural (portanto, histórica, social e filosófica) apenas encontramos dois descritores de nível global em que, genericamente, poderíamos inferir uma relação de aproximação distante, sob o título de temas gerais e física moderna, vejamos:

D94 - Classificar as diferentes fontes de energia de uso social mais difundido, em termos de suas características (convencionais ou alternativas, renováveis ou não, etc.), e apontar seus eventuais impactos ambientais. (G) $[\ldots]$

D96 - Compreender que visões simultâneas de planetas e estrelas correspondem a eventos separados por milhões de anos. $(G)$

$[\ldots]$

D100 - Descrever utilizações industriais e médicas de radiações nucleares, identificando seus riscos. (G) (INEP, 1999, p. 112)

Percebe-se, por esses três descritores, a suposição de que se avalia, minimamente, as competências sociais, históricas e dos problemas filosóficos postos pela investigação em Física e que os discentes teriam aprendido durante os três anos de sua formação média.

Em relação aos conhecimentos da ciência química a hipótese de base para formulação dos descritores avaliativos foi considerá-la enquanto uma

[...] interpretação humana da natureza. Tal interpretação encontra-se sujeita a modificações, falhas e revisões, pois o conhecimento científico só poder ser gerado no interior da sociedade e, portanto, mantém vínculos com esferas da técnica, da produção, da cultura, da política. (INEP, 1999, p. 115)

De fato, tanto a química como quaisquer outras formas de conhecimento nunca deixaram de ser interpretações humanas daquilo que os sentidos ou as intuições nos fornecem. Mas, em conformidade com tal hipótese, aconselha-se que

[...] os itens de um processo de avaliação da compreensão do conteúdo químico, competências cognitivas e habilidades instrumentais do aluno devem privilegiar a análise de situações de seu cotidiano. Porém não se pode conceber o cotidiano como sendo apenas o vivido pelo aluno, o próximo em relação ao espaço e tempo, pois estamos vivendo um processo de mudança estrutural caracterizado pela globalização da economia, mudança cultural e impacto tecnológico baseado nas tecnologias de informação/comunicação que permitem uma ampliação da velocidade de divulgação das mesmas. (INEP, 1999, p. 115)

${ }^{70} \mathrm{Na}$ expressão D94, o $D$ significa Descritor, 94 é o número do descritor na ordem numera de seu ordenamento lógico. O (G) indica o nível de competência a que o descritor pertence, nesse caso o nível global. 
E, de acordo com tais diretrizes, espera-se do discente finalista da formação média que seja capaz de reter e processar uma compreensão que o leve a, entre outras coisas: "reconhecer a Química como uma construção humana, compreendendo os aspectos históricos de sua produção e suas relações com o contexto cultural, socioeconômico e político"; "proceder a processos simples de investigação científica"; "comunicar os resultados de processos investigativos" (INEP, 1999, p. 116). Mas, também, precisa desenvolver uma consciência crítica que o permita "avaliar as implicações de processos químicos para o ambiente e para a saúde pública" (INEP, 1999, p. 116).

E como ficaram os descritores avaliativos depois de apresentar as competências contextuais supracitadas? Ora, apenas um (01) descritor foi avaliado como aproximado àquelas competências apropinguadas à abordagem histórica, filosófica e social. Trata-se do descritor 80 , que se refere ao tema de reações nucleares, como segue:

D80 - Reconhecer no cotidiano algumas aplicações importantes e implicações sociais acerca do uso da energia nuclear: na Medicina, na Agricultura, na Arqueologia, na fabricação de armas nucleares, nas unsinas Angra I e II, bem como analisar os acidentes de Chernobyl e de Goiânia. (O) (INEPE, 1999, p. 122)

Com este descritor se pressupõe o conhecimento da história da energia nuclear no Brasil e das suas consequências econômicas, sociais, político-militares e científicas. Uma história recente e não acessível facilmente que, como se sabe, teria se iniciado na década de 1950, quando, em 1953, o Almirante Álvaro Alberto da Mota e Silva, teria importado duas ultra-centrifugadoras da Alemanha, para enriquecer o urânio no Brasil. Apenas em 1969 se decidiu implementar uma usina termonuclear, tarefa delegada à empresa Furnas Centrais Elétricas SA e, aparentemente, seduzia à compreensão de que os objetivos eram de dominar a nova tecnologia e substitui a energia hidráulica, mas o contextos social, político e militar da época (Governo Militar) demonstravam que os objetivos incluíam o desenvolvimento de submarinos nucleares e armas atômicas ${ }^{71}$.

$\mathrm{E}$, finalmente, quanto à Biologia atentou-se a ancorar à teoria da

\footnotetext{
${ }^{71}$ Nuclear Tecnologia e Consultoria. (vide em referências). Empresa integrada por ex-funcionários da Furnas Centras Elétricas AS.
} 
evolução, ao afirmar-se que o seu estudo devesse "[...] possibilitar a compreensão de que a vida se organizou, através do tempo, sob a ação de processos evolutivos, o que resultou numa diversidade de formas, sobre as quais continuam atuando as pressões seletivas" (INEP, 1999, p. 128).

Em todo caso, ressalta-se que uma atenção deve ser dada ás "[...] relações estabelecidas pelos seres humanos, considerando a especificidade de seu potencial de interferência. Em tal abordagem, os conhecimentos biológicos não se dissociam das questões sociais, políticas, econômicas e culturais" (INEP, 1999, p. 128).

No âmbito do ensino postulou-se que é importante oportunizar aos discentes o desenvolvimento de competências tais como, entre outras:

\footnotetext{
- buscar e encontrar a informação de maneira autônoma, crítica e criativa;

- compreender os fundamentos científicos e tecnológicos dos processos produtivos, relacionando a teoria com a prática;

$[\ldots]$

- avaliar o impacto da produção científica e tecnológica na real melhoria da qualidade de vida da população;

- reconhecer a relatividade (histórica e cultural) dos saberes e das crenças; (INEP, 1999, p. 128)
}

Pretende-se com isso que a formação não seja enciclopédica, mas que fomente a reflexão, a análise e a valoração, de tal modo que

[...] a maior parte das situações de aprendizagem deve procurar envolver a resolução de um problema, por meio de uma investigação documental e/ou experimental, a partir da qual os alunos, ao interagirem com os objetos e com os indivíduos servindo-se de diferentes linguagens (textos, gráficos, tabelas, etc.). tais situações devem estar, preferencialmente, fundadas na vida real, o que implica ter em conta as experiências, os interesses e os contextos socioculturais dos alunos. (INEP, 1999, p. 128)

Logo, os descritores parecem como elementos que possibilitam o planejamento das avaliações, ao descreverem as competências a ser diagnosticadas nos discentes em relação ao processo de aprendizagem. $E$, entre os descritores da área de biologia, estão aqueles que se aproximam ao diagnóstico das competências de contextualização sociocultural, pelas quais é possível aproximar a abordagem de HFC:

- Em relação ao conhecimento da biologia humana: "D43 - Compreender os fundamentos biológicos e sociais da sexualidade humana (O)" (INEP, 1999, p. 
131).

- Quanto à organização funcional dos ecossistemas:

-D59 - Compreender o ecossistema como um conjunto vivo com relativa auto-suficiência, resultante da interação entre comunidades de seres vivos, fatores físicos e químicos. ( $\mathrm{O}$ )

-D60 - Analisar as relações de interdependência entre os componentes de ecossistemas naturais e diretamente modificados pelo ser humano: níveis tróficos, fluxo de energia, ciclo da matéria e outras relações ecológicas entre os seres vivos. (G) (INEP, 1999, p. 131)

Tanto a compreensão dos problemas que afetam os ecossistemas e as interações dos seres vivos, entre eles os humanos quanto a análise das interdependências entre os elementos dos vários ecossistemas pode requer a compressão histórica, filosófica e sociológica dessas relações dos seres vivos entre si, sobretudo entre os seres humanos e os ecossistemas, sobretudo, a compreensão histórica das ações humanas sobre o ambiente natural, os problemas de devastação e recuperação de florestas, a poluição atmosférica, a contamina do solo e da água, a estinção de animais em virtude da ação humana. Essas questões têm suas dimensões históricas e filosóficas (éticas, políticas, ontológicas (coexistência), econômicas).

- No que se refere à distribuição da vida na terra: "D69 - Analisar as modificações da cobertura vegetal no Brasil, nos vários tipos de registros produzidos em diferentes épocas: mapas, fotografias, desenhos, esboços, dados estatísticos e documentos históricos. (G)" (INEP, 1999, p. 132).

- E no que tange ao desenvolvimento e meio ambiente:

D74 - indicar os principais problemas ambientais brasileiros: questões relativas a habitação, saneamento, saúde, educação, distribuição de terras e renda, uso do solo, planejamento urbano, poluição do ar e da água, desmatamento e extinção de espécies biológicas. (B)

D75 - Analisar problemas ambientais brasileiros a partir da leitura crítica de diferentes fontes: textos jornalísticos, informativos, relatórios institucionais, RIMAs e outros. (G) (INEP, 1999, p. 132).

Os problemas levantados nestes descritores assemelham-se aos comentado quanto dos descritores D59 e D60. Referem-se tanto aos problemas históricos, sociais e políticos e filosóficos que tangem à ecologia humana ou animal, 
ecologia de populações, ecologia vegetal, terrestre ou aquática, etc.

- Quanto ao conhecimento das bases da hereditariedade: "D76 Reconhecer, através dos trabalhos de Mendel, o mecanismo de transmissão de características hereditárias. (B)" (INEP, 1999, p. 132).

- Sobre a evolução, em suas bases biológicas:

D88 - Analisar textos históricos, para identificar as idéias evolucionistas, em particular as de Lamarck e de Darwin. (G)

D89 - Explicar a transformação das espécies ao longo do tempo através dos mecanismos de: mutação, recombinação gênica e seleção natural. (G) (INEP, 1999, p. 133)

- E, ainda, sobre a evolução, mas no que diz respeito à gênese da vida e suas trajetórias evolutivas:

D96 - Analisar as idéias sobre a origem da vida, a partir da leitura de textos históricos. (G)

D97 - Indicar a linha evolutiva dos vertebrados, demonstrando a relação de ascendência. (B)

D98 - Apontar algumas características dos animais que permitiram a transição da vida na água para o ambiente terrestre. (B)

D99 - Representar a história da vida na Terra em escala temporal, indicando os seguintes acontecimentos: surgimento da vida, das plantas terrestres, dos vertebrados, dos mamíferos e da espécie Homo sapiens. (G)

D100 - Compreender que o processo evolutivo humano resulta da interação de mecanismos biológicos e culturais. (O) (INEP, 1999, p. 133)

Nos descritores da área de Biologia constata-se uma compreensão evidente da aproximação dos descritores orientadores do planejamento de avaliações às competências de contextualização sociocultural das prescrições, ou seja, indiretamente à abordagem da HFC e, por sua vez, à HFCrECN.

Portanto, podemos ver que as Matrizes Curriculares do SAEB apontam de certa forma para os diagnósticos de algumas competências de contextualização sociocultural que aparece nos PCN ou PCN+, porém de uma forma muito limitada e genérica, sobretudo, no caso da Física e Química, o que pode dificultar o alcance dos objetivos, porque o planejador dos instrumentos de avaliação, a partir dos descritores, tende a selecionar aqueles que ele considerar prioritários ou convenientes, a partir da sua "ideologia" de avaliação educacional e de ciência. 


\section{5 - Diretrizes Curriculares Nacionais para Cursos de Graduação}

As Diretrizes Curriculares Nacionais para os Cursos Graduação encontram-se nas Resoluções (e pareceres) da Câmara do Ensino Superior do Conselho Nacional de Educação (CNE/CES), respectivamente: Parecer no 1.304/2001 e Resolução no 09/2002 CES/CNE: Física; Parecer no 1.301/2001 e Resolução no 07/2002 CES/CNE: Biologia e; Parecer no 1.303/2001 e Resolução no 08/2002 CES/CNE: Química.

A aproximação mais evidente da HFC ao ensino, nestes instrumentos reguladores, está prescrita nas competências e habilidades esperadas dos futuros licenciados (ou bacharéis). Tais prescrições estão mais nos Pareceres que dispõem sobre as diretrizes nacionais para os cursos de graduação em Física, Química e Biologia.

Em relação à formação em Física está recomendado que se leve em consideração tanto os aspectos tradicionais da atuação profissional dessa área quanto os novos que vão emergindo na realidade social. Regulamentou-se que a formação em Física, tanto em licenciatura (Físico-educador) quanto em bacharelado (Físico-pesquisador, Físico-tecnólogo e Físico-interdisciplinar) fosse necessária uma qualificação profissional básica comum expressa em cinco (05) "competências essenciais", das quais a quinta competência expressa uma dimensão históricofilosófica da ciência, qual seja, a de

\footnotetext{
desenvolver uma ética de atuação profissional e a conseqüente responsabilidade social, compreendendo a Ciência como conhecimento histórico, desenvolvido em diferentes contextos sócio-políticos, culturais e econômicos. (MEC. CNE/CES Parecer no 1.304/2001, p. 4)
}

Recomenda-se aqui que o futuro docente de física (ou o Físico-educador, em conformidade com a norma) apresente desenvolvida a análise crítica - os valores (ética) e a responsabilidade social na e para atuação profissional - e a análise histórica das relações do contexto de produção científica - que ocorre em "contextos sócio-políticos, culturais e econômicos" diversos, e que podem influir nos processos de ensino e aprendizagem, portanto, há que saber situar o desenvolvimento científico no tempo e espaço de forma crítica para compreender suas dimensões filosóficas (axiológica, ontológica, epistemológica, lógica e 
sociopolítica).

Por outro lado, o instrumento normativo apresenta nove habilidades gerais prescritas para serem incluídas em quaisquer modalidades de formação inicial em Física. Entre estas, na oitava habilidade recomenda-se que os físicos em formação possam, ao final, "reconhecer as relações do desenvolvimento da Física com outras áreas do saber, tecnologias e instâncias sociais, especialmente contemporâneas" (MEC. CNE/CES Parecer nำ1.304/2001, p. 4).

Este reconhecimento passaria necessariamente pelo conhecimento histórico-filosófico que possibilitaria o conhecimento e a análise crítica das interrelações que se estabeleceram ou se estabelecem entre a evolução da física e a das tecnologias e "instâncias sociais".

No entanto, ao especificar a prescrição das habilidades e competências específicas para cada modalidade formativa, a aproximação à HFC, no que se refere à licenciatura em Física, desaparece e prescreve-se uma dimensão didáticometodológica, ao restringir que "as habilidades e competências específicas devem, necessariamente, incluir também":

1. o planejamento e o desenvolvimento de diferentes experiências didáticas em Física, reconhecendo os elementos relevantes às estratégias adequadas;

2. a elaboração ou adaptação de materiais didáticos de diferentes naturezas, identificando seus objetivos formativos, de aprendizagem e educacionais; (MEC. CNE/CES Parecer no 1.304/2001, p. 5)

O regulador desculpa-se que, em virtude das mudanças constantes no mercado, não seria oportuno particularizar as habilidades específicas naquele instante normativo, pois elas dependem das áreas de atuação, mas parecer se olvidar que estava prescrevendo para diversos âmbitos de atuação do físico, o que não retira a possibilidade de caracterizar o que se pretenderia com as habilidades específicas para cada saída de formação profissional do Físico.

Finalmente, ao regular sobre a estrutura e os conteúdos curriculares do curso, a aproximação à HFC é localizada no núcleo de formação comum que remete a autoaperfeiçoamento, conforme está prescrito: "O núcleo comum é caracterizado por conjuntos de disciplinas relativos à física geral, matemática, física clássica, física moderna e ciência como atividade humana. [...]" (BRASIL, MEC. Parecer CNE/CES no $1.304 / 2001$, p. 6) [destaque nosso]. E, isto aparece então caracterizado 
na parte das disciplinas complementares à parte específica da formação do físico, como se segue:

O núcleo comum precisa ainda de um grupo de disciplinas complementares que amplie a educação do formando. Estas disciplinas abrangeriam outras ciências naturais, tais como Química ou Biologia e também as ciências humanas, contemplando questões como Ética, Filosofia e História da Ciência, Gerenciamento e Política Científica, etc. (MEC. CNE/CES Parecer ํo 1.304/2001, p. 7)

Vemos aqui uma recomendação tácita para a inclusão de disciplinas de HFC na estrutura curricular dos programas formativos do físico, portanto, reflexo da compreensão da física como uma prática que deva ser situada no contexto sociocultural e conceitual, isto é, na história e na análise e compreensão das implicações filosóficas, políticas e gerenciais envolvidas na produção do conhecimento e na sua divulgação.

Este parecer introduz um diferencial inovador, inseriu-se nele a preocupação com os processos de gerenciamento da ciência e da política científica, áreas importantes que, geralmente, são ignoradas nos programas de formação inicial ou pós-graduada. Porém, sua presença no instrumento político-legal não é, ainda, uma garantia de ocorrência material na práxis formativa. Carece do papel dos formadores universitários, o de adotarem os princípios dos instrumentos reguladores.

Quanto à formação em Química argumenta-se inicialmente, a partir do discente, que a nova estrutura orientacional ou o "novo paradigma" introduzido pela LDBEN exige que

O estudante deve ter tempo e ser estimulado a buscar o conhecimento por si só, deve participar de projetos de pesquisa e grupos transdisciplinares de trabalhos, de discussões acadêmicas, de seminários, congressos e similares; deve realizar estágios, desenvolver práticas extensionistas, escrever, apresentar e defender seus achados. E mais: aprender a "ler" o mundo, aprender a questionar as situações, sistematizar problemas e buscar criativamente soluções. (MEC. CNE/CES Parecer no 1.303/2001, p. 2)

É interessante ressaltar que o discente é convocado a aprender a fazer leitura do mundo, a inquirir situações, sistematizar problemas e buscar a resolução de problemas de forma criativa, o que exige uma postura e ação docente de calibre filosófico, para corresponder às expectativas postuladas, para isso o docente de 
Química deve apresentar capacidades e habilidades, tais como as transcritas abaixo, entre outras, conforme contas no Parecer 1.303/01 (MEC. CNE/CES Parecer № 1.303/2001, p. 6,7 e 8):

- Particularmente deve "Ter uma visão crítica com relação ao papel social da Ciência e à sua natureza epistemológica, compreendendo o processo históricosocial de sua construção".

- E ao buscar compreender esta ciência deverá reconhecê-la enquanto consequência da "[...] construção humana e compreender os aspectos históricos de sua produção e suas relações com o contexto cultural, socioeconômico e político". E ainda,

- "Compreender e avaliar criticamente os aspectos sociais, tecnológicos, ambientais, políticos e éticos relacionados às aplicações da Química na sociedade".

- Ao ensinar a Química o docente deve: a) "Compreender e avaliar criticamente os aspectos sociais, tecnológicos, ambientais, políticos e éticos relacionados às aplicações da Química na sociedade" e b) "Conhecer os fundamentos, a natureza e as principais pesquisas de ensino de Química".

Ou seja, espera-se ao final do ciclo formativo do docente que deva guiar suas competências e habilidades compreensivas da Química, também, pela óptica da HFC.

E, quanto à organização do currículo formativo deste docente regulou-se, também, a inclusão de conteúdos complementares e

Sugerem-se, para este segmento curricular, conteúdos de filosofia, história, administração, informática, instrumental de língua portuguesa e línguas estrangeiras, dentre outros. A elaboração de monografia de conclusão do curso será inserida também nestes conteúdos. (MEC. CNE/CES Parecer no $1.303 / 2001$, p. 9)

A Filosofia e a História sugeridas, no texto normativo, não são especificas do âmbito da HFC, o que não orienta os formuladores de currículos para inferir a extensão à caracterização histórico-filosófica da ciência, porque tradicionalmente a disciplina de Filosofia tem sido inserida em currículos, com caráter geral e histórico, não refletindo os problemas filosóficos das ciências, mas sim discutindo temas de história da filosofia.

Em relação à licenciatura em Ciências Biológicas, o parecer está focado para o bacharelado, quanto à formação docente, o documento remete-se aos 
conteúdos delineados pelas diretrizes gerais para a formação de professores da Educação Básica.

Inicialmente, recomenda-se que o estudo destas ciências biológicas possibilite a compreensão de que "[...] a vida se organizou através do tempo, sob a ação de processos evolutivos, tendo resultado numa diversidade de formas sobre as quais continuam atuando as pressões seletivas" (MEC. CNE/CES Parecer no $1.301 / 2001$, p. 1).

$E$, dentre as competências e habilidades prescritas para o bacharel (aplicáveis ao licenciado) e que servem para o movimento da HFCrECN e apresentam maior proximidade com a abordagem contextualista estão:

f) entender o processo histórico de produção do conhecimento das ciências biológicas referente a conceitos/princípios/teorias;

g) estabelecer relações entre ciência, tecnologia e sociedade;

$[\ldots]$.

$\mathrm{m})$ avaliar o impacto potencial ou real de novos conhecimentos/tecnologias/serviços e produtos resultantes da atividade profissional, considerando os aspectos éticos, sociais e epistemológicos; (MEC. CNE/CES Parecer no 1.301/2001, p. 4)

Quando à estrutura dos programas de formação inicial, no âmbito do instrumento normativo em análise, regulou-se que a estruturação do curso fosse baseada em princípios tais como: o de "levar em conta a evolução epistemológica dos modelos explicativos dos processos biológicos" (MEC. CNE/CES Parecer no $1.301 / 2001$, p. 5) e, por conseguinte, tal programa deve alicerçar-se em alguns princípios, tais como os de:

garantir um ensino problematizado e contextualizado, assegurando a indissociabilidade entre ensino, pesquisa e extensão;

[...];

levar em conta a evolução epistemológica dos modelos explicativos dos processos biológicos; (MEC. CNE/CES Parecer no 1.301/2001, p. 5)

Também insiste-se, ainda, que dos conteúdos básicos, dos programa formativos das duas modalidades, deve constar os

FUNDAMENTOS FILOSÓFICOS E SOCIAIS: Reflexão e discussão dos aspectos éticos e legais relacionados ao exercício profissional. Conhecimentos básicos de: História, Filosofia e Metodologia da Ciência, Sociologia e Antropologia, para dar suporte à sua atuação profissional na sociedade, com a consciência de seu papel na formação de cidadãos. (MEC. CNE/CES Parecer no 1.301/2001, p. 6) [Nosso destaque] 
Veja-se que há uma mudança de configuração dos elementos e aumento do grau de aproximação da HFCrECNM, pois que a "História, Filosofia e Metodologia da Ciência" devem constar dentre os conhecimentos básicos necessários para a formação profissional do biólogo, independentemente de modalidade do programa formativo (bacharelado ou licenciatura).

Neste sentido, vê-se que as regulamentações das estruturas dos programas formativos apresentam indícios que servem para inferência e base para a defesa da inclusão da HFCrECNM, pelo movimento que a advoga.

\section{6 - Orientações Curriculares para o Ensino Médio (2006)}

As Orientações Curriculares para o Ensino Médio (OCEM) surgem em 2006, publicadas pela Secretaria de Educação Básica do Ministério da Educação (por intermédio do Departamento de Políticas do Ensino Médio), com o objetivo de contribuir para a reflexão e o diálogo entre o docente e a Escola sobre a prática docente, em virtude da política educacional decorrente dos PCN e PCN+.

A análise proposta para esse documento consistiu em verificar se nas orientações descritas aparece a aproximação ao tema HFCrECN, ou mesmo, se os docentes são orientados sobre como proceder para operacionalizar a abordagem integradora da temática ao conteúdo e às práticas disciplinares em ciências naturais. Como documento elucidador dos PCN e PCN+ esperou-se encontrar aproximações via recorrência às competências da contextualização sociocultural.

No entanto, o entendimento dado a esse conceito tem sido diverso, no conhecimento biológico, por exemplo, é tido como possibilidade de ação em que se estabelece uma relação entre o conteúdo e a realidade, isto é, "o contexto da realidade do aluno e da escola", ou ainda,

Se a realidade dos alunos, seus conhecimentos e vivências prévias, forem considerados como ponto de partida, o ensino da Biologia fará sentido para o aluno e a compreensão dos processos e fenômenos biológicos será possível e efetiva. Concorre a favor da contextualização o fato de que estamos inseridos em um mundo biológico, mais do que isso, fazemos parte dele. Além disso, em um mundo cada vez mais globalizado, acontecimentos distantes podem afetar diretamente a vida do aluno e constituir pontos de partida para tornar os conteúdos biológicos mais atraentes. (MEC. SEB, 2006, p. 34) 
No entanto, há uma ressalva de que a contextualização de que se trata não se restringe a exemplificação de situações vividas pelos discentes ou como assessoria à informação, mas "como ponto de partida para o aprendizado" (Brasil, 2006 , p. 34). Ainda que permaneça a ambiguidade, percebe-se o esforço de compreender a contextualização, ou o contexto, enquanto cotidiano discente e escolar, que serve para fazer transposição didática e criação de ancoras.

A nosso ver, tanto o contexto discente quanto o contexto escolar são diferentes do contexto sócio-histórico e filosófico da produção do conhecimento científico-tecnológico a ser ensinado e aprendido, que é o contexto reivindicado pelo movimento da HFCrECN, que é mais abrangente e tende a contribuir mais com o processo educativo em ciências naturais (especificamente). Porém, tais contextos não são, a princípio, incompatíveis no que for possível para convergi-los, de tal modo que se possa melhor elucidar e significar o ensino e aprendizagem das ciências naturais.

Todavia, ao associar a contextualização à interdisciplinaridade, afirma-se que a História (isto é, a disciplina História, num trabalho interdisciplinar) "[...] pode permitir que o aluno entenda o processo das descobertas científicas como fruto de contextos históricos e sociais" (MEC. SEB, 2006, p. 37). De fato, isto exige um trabalho colaborativo entre os docentes de História e os das Ciências Naturais escolares e pode ser um passo para engrenar a abordagem histórica que lança para HFC, se os docentes forem preparados para tal abordagem. Também não é salutar fazer sempre trabalho colaborativo durante todo o calendário escolar em que se desenvolve os trabalhos disciplinares. Portanto, isso indica o caráter de uma abordagem eventual e não constante.

A indicação de temas para que os docentes possam fazer uma exploração da dimensão filosófica pode ser inferido das observações seguintes:

A formação ética e o pensamento crítico podem ser estimulado, em Biologia, pela exposição do aluno a questões como: produzir ou não em larga escala organismos geneticamente modificados; quais os riscos e benefícios da utilização de transgênicos; apoiar ou não uma lei que prevê o desmatamento de um trecho da Amazônia para a produção de alimentos e a geração de empregos; apoiar ou não a destruição de uma área de mangue para a construção de casas populares; usar ou não, terapeuticamente, células-tronco embrionárias. São situações-problema em que o aluno, explicitamente, é obrigado a tomar decisões fundamentadas em conhecimentos científicos e relacionadas aos seus valores pessoais ou sociais. (MEC. SEB, 2006, p. 38-39) 
Percebe-se que as orientações do conhecimento biológico estão limitadas ao que se refere às competências do contexto histórico, sociocultural, logo a aproximação à HFCrECN.

Porém, partindo do pressuposto de que a formação por competência visa possibilitar ao indivíduo posicionar-se de forma crítica, isto - no caso do conhecimento da Física escolar - pode ser proporcionado aos discentes debatendo temas que englobem aspectos históricos, filosóficos, sociológicos e econômicos, político-militares (e psicológicos, se necessário for), tais como: clonagem/clonagem terapêutica, uso de pesticidas agrícolas, transgênicos e uso da energia nuclear/atômica em virtude dos perigos envolvidos nesses assuntos, que a história já registrou (e. g. Hiroshima) (MEC. SEB, 2006, p. 47).

Reconhece-se ainda que no ensino escolar de Física,

Um tratamento didático apropriado é a utilização da história e da filosofia da ciência para contextualizar o problema, sua origem e as tentativas de solução que levaram à proposição de modelos teóricos, a fim de que o aluno tenha noção de que houve um caminho percorrido para se chegar a esse saber. (MEC. SEB, 2006, p. 50)

Temos aqui uma recorrência indicativa à $\mathrm{HFC}$ de que resulta a compreensão de uma concepção da HFC como sendo recurso de apoio didático para contextualizar o conteúdo ou conhecimento científico. Neste sentido, a noção de contextualização muda de posição ontológica, porque é vinculada ao contexto de que trata o movimento da HFCrECN, pois,

[...] não se pretende com a contextualização partir do que o aluno já sabe e chegar ao conhecimento científico, pois esse não é apenas polimento do senso comum. O que se pretende é partir da reflexão crítica ao senso comum e proporcionar alternativas para que $o$ aluno sinta a necessidade de buscar e compreender esse novo conhecimento.

Os conhecimentos prévios dos alunos, e a exploração de suas contradições e limitações pelo professor, exigem que este elabore situações e problemas que 0 aluno não faria sozinho e que tenham o potencial de levar à aquisição de um conhecimento que o educando ainda não possui, mas que passará a ter significância dentro dos esquemas conceituais do aluno. Ao mesmo tempo em que os conhecimentos prévios dos alunos são problematizados, deve-se fazer a contextualização história dos problemas que originaram esse conhecimento científico e culminaram nas teorias e modelos que fazem parte do programa de conteúdos escolares a ser apreendido pelo aluno, ampliando a visão do seu mundo cotidiano. (MEC. SEB, 2006, p. 51)

Mas, a mudança de posição ontológica parece inconstante, pois ainda permanece a forte tendência para o contexto da realidade vivencial do discente. Isto 
pode ser percebido ao se argumentar - logo na sequência da citação acima - que

A contextualização como recurso didático serve para problematizar a realidade vivida pelo aluno, extraí-la do seu contexto e projetá-la para análise. Ou seja, consiste em elaborar uma representação do mundo para melhor compreendê-lo. Essa é uma competência crítico-analítica e não se reduz à mera utilização pragmática do conhecimento científico. (MEC. SEB, 2006, p. 51)

Tal inconstância parece subtrair a presença do enfoque do contexto da realidade da produção do conhecimento, que aparece muito pouco nas orientações, tendo em vista o atual estado de arte e a importância que tem sido atribuída à HFC no ensino de ciências naturais, a contar pelos próprios documentos oficiais, inclusive pelas orientações em análise, pois podemos constatar, entre os vários exemplos já citados, na seguinte afirmação:

O estudo da gravitação é uma excelente oportunidade para discutir temas da astronomia em seus aspectos físicos, históricos e filosóficos. A física térmica pode ser estruturada a partir dos princípios da termodinâmica, associada às máquinas térmicas e a aspectos econômicos e socais, no contexto da Revolução Industrial. (MEC. SEB, 2006, p. 56)

E, além do mais, a secção "conhecimentos da física" é a única, entre as três disciplinas componentes das ciências naturais, que contém uma subsecção dedicada - de forma ligeira, porém, significativa - à HFC, no âmbito destas orientações curriculares.

Ao dissertar sobrec como recorrer ao uso da $\mathrm{HC}$, o objetivo de tal uso é entendido como enriquecimento do ensino da Física e atrativo para a sua aprendizagem, porque ao aproximar "[...] os aspectos científicos dos acontecimentos históricos, possibilita a visão da ciência como uma construção humana" e, na sequência, argumenta-se que o uso da $\mathrm{HC}$ estaria em conformidade com o desenvolvimento da competência geral de contextualização sociocultural ao permitir "[...] compreender a construção do conhecimento físico como um processo histórico, em estreita relação com as condições sociais, políticas e econômicas de uma determinada época" (MEC. SEB, 2006, p. 64).

O mesmo valeria dizê-lo em relação ao desenvolvimento da história da tecnologia, nas suas diversas áreas, épocas, sociedades e sua vinculação com as relações sociais e com a modificação das condições de vida, criação de novos artefatos e necessidades. 
Quanto à FC afirmou-se apenas que ela "[...] tem maior importância, para o professor, na construção de sua concepção de ciência, com reflexos na hora de abordá-la em sala de aula" (MEC. SEB, 2006, p. 64). Sem mais outras orientações, portanto, há uma predominância de referenciação à $\mathrm{HC}$.

E, finalmente, no que tange aos conhecimentos de Química, nas orientações há entendimento de que, de modo geral, o ensino de química deve ser

[...] praticado nas escolas não está propiciando ao aluno um aprendizado que possibilite a compreensão dos processos químicos em si e a construção de um conhecimento químico em estreita ligação com o meio cultural e natural, em todas as suas dimensões, com implicações ambientais, sociais, econômicas, ético-políticas, científicas e tecnológicas. (MEC. SEB, 2006, p. 107)

Esta constatação estaria baseada na experiência da Sociedade Brasileira de Química (SBQ), que à época da edição das orientações perfazia os seus 25 anos de existência institucional. A constatação seria instigadora para projetar mudanças que provoquem aproximações com aquelas dimensões constatadas como relegadas no ensino. Não obstante, reconhece-se que

\begin{abstract}
A discussão de aspectos sociocientíficos articuladamente aos conteúdos químicos e aos contextos é fundamental, pois propicia que os alunos compreendam o mundo social em que estão inseridos e desenvolvam a capacidade de tomada de decisão com maior responsabilidade, na qualidade de cidadão, sobre questões relativas à Química e à Tecnologia, e desenvolvam também atitudes e valores comprometidos com a cidadania planetária em busca da preservação ambiental e da diminuição das desigualdades econômicas, sociais, culturais e étnicas. (MEC. SEB, 2006, p. 119)
\end{abstract}

No mais, repete-se as orientações dadas nos PCN+ de que se deve considerar a química como construção humana, sujeita aos processos de produção e reconstrução sociocultural, portanto, o desenvolvimento das suas teorias e conceitos ocorre "no confronto com os dados experimentais e com idéias cotidianas" em situações reais na busca pela compreensão conceitual daquilo que está além das aparências e impressões imediatas. Os conceitos e as teorias não são descobertas, mas criações/construções "[...] históricas, dinâmicas, processuais, com antecedentes, implicações e limitações" (MEC. SEB, 2006, p. 124), portanto, tais teorias e conceitos são provisórios. 
Assim, é preciso que a abordagem dos conceitos e dos conteúdos de Química seja coerente com a visão atualizada desses, contemplando avanços tanto no conhecimento químico quanto nas concepções da Química como ciência, sua historicidade e suas implicações sociais, sendo essencial a busca sistemática de novas referências e de novas e diversificadas fontes de informação. (MEC. SEB, 2006, p. 111)

Reproduzirmos, a seguir, a íntegra do quadro que está apresentado nas orientações em relação aos conhecimentos e habilidades de História e Filosofia da Química (MEC. SEB, 2006, p. 115), extremamente interessante e único nesses documentos analisados:

Tabela 13 - Conhecimentos e habilidades de História e Filosofia da Química

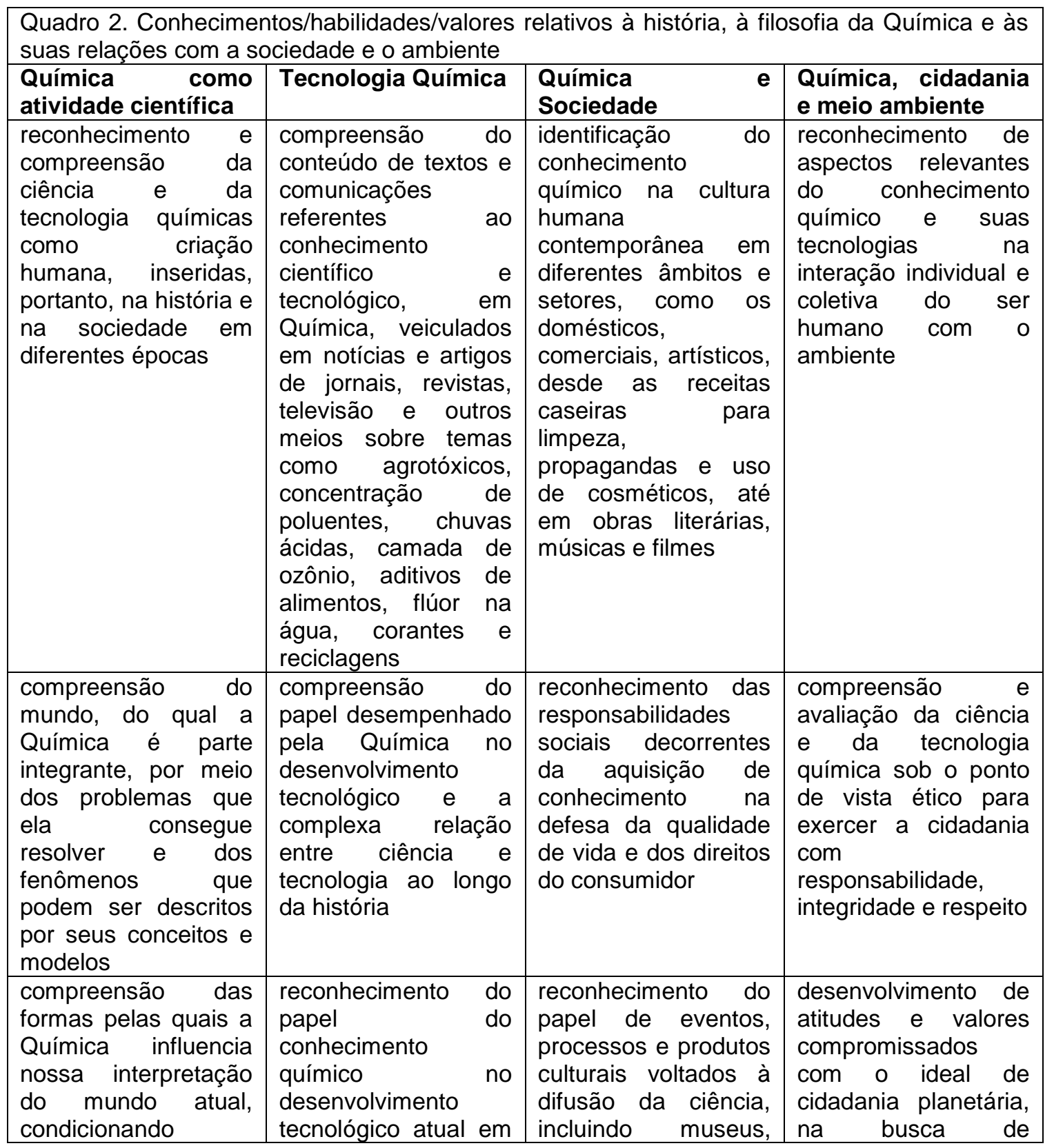




\begin{tabular}{|c|c|c|c|}
\hline $\begin{array}{l}\text { formas de pensar e } \\
\text { interagir }\end{array}$ & $\begin{array}{ll}\text { diferentes } & \text { áreas do } \\
\text { setor } & \text { produtivo, } \\
\text { industrial e agrícola }\end{array}$ & $\begin{array}{l}\text { exposições } \\
\text { científicas, peças de } \\
\text { teatro, programas de } \\
\text { televisão, vídeos, } \\
\text { documentários, } \\
\text { folhetos de } \\
\text { divulgação científica } \\
\text { e tecnológica }\end{array}$ & $\begin{array}{l}\text { preservação } \\
\text { ambiental do ponto } \\
\text { de vista global de } \\
\text { ações de redução } \\
\text { das desigualdades } \\
\text { étnicas, sociais e } \\
\text { econômicas }\end{array}$ \\
\hline $\begin{array}{l}\text { compreensão dos } \\
\text { limites da ciência e o } \\
\text { significado das suas } \\
\text { dimensões sociais e } \\
\text { políticas }\end{array}$ & $\begin{array}{lr}\text { compreensão dos } \\
\text { aspectos } \\
\text { caracterizam que } \\
\text { prática tecnológica: } \\
\text { técnico (know-how), } \\
\text { organizacional } \\
\text { cultural }\end{array}$ & $\begin{array}{l}\text { reconhecimento da } \\
\text { influência da ciência } \\
\text { e tecnologia sobre a } \\
\text { sociedade e desta } \\
\text { última sobre o } \\
\text { progresso científico e } \\
\text { tecnológico e as } \\
\text { limitações } \\
\text { possibilidades de se } \\
\text { usar a ciência e a } \\
\text { tecnologia para } \\
\text { resolver problemas } \\
\text { sociais }\end{array}$ & $\begin{array}{l}\text { desenvolvimento de } \\
\text { ações engajadas na } \\
\text { comunidade para a } \\
\text { preservação } \\
\text { ambiental }\end{array}$ \\
\hline $\begin{array}{l}\text { reconhecimento da } \\
\text { ciência não como um } \\
\text { corpus rígido e } \\
\text { fechado, mas como } \\
\text { uma atividade aberta, } \\
\text { que está em contínua } \\
\text { construção, a qual } \\
\text { não é justificada } \\
\text { somente por critérios } \\
\text { racionais } \\
\text { cognitivos, pois } \\
\text { esses critérios são } \\
\text { também construídos } \\
\text { socialmente }\end{array}$ & $\begin{array}{lr}\text { compreensão } & \text { da } \\
\text { interdependência } & \\
\text { entre } & \\
\text { desenvolvimento } & \\
\text { científico } & \text { e } \\
\text { tecnológico } & \text { e } \\
\text { desenvolvimento } & \\
\text { tecnológico } & \text { e } \\
\text { sociedade } & \end{array}$ & \begin{tabular}{l}
\multicolumn{2}{l}{ compreensão das } \\
interações entre a \\
ciência e a tecnologia \\
e os sistemas \\
políticos e do \\
processo de tomada \\
de decisão sobre \\
ciência e tecnologia, \\
englobando defesa \\
nacional e políticas \\
globais
\end{tabular} & \\
\hline $\begin{array}{l}\text { reconhecimento do } \\
\text { caráter provisório e } \\
\text { incerto das teorias } \\
\text { científicas, das } \\
\text { limitações de um } \\
\text { modelo explicativo e } \\
\text { da necessidade de } \\
\text { alterá-lo, avaliando } \\
\text { as aplicações da } \\
\text { ciência e levando em } \\
\text { conta as opiniões } \\
\text { controvertidas dos } \\
\text { especialistas }\end{array}$ & & 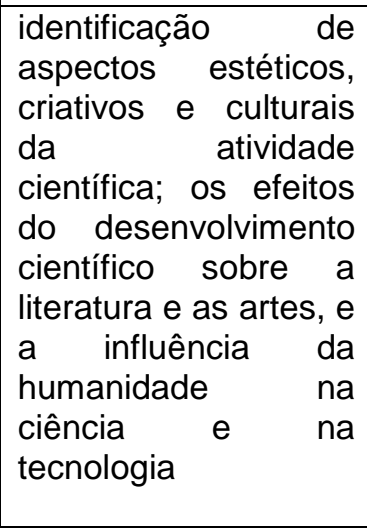 & \\
\hline
\end{tabular}

Esses conhecimentos/habilidades/valores descritos nas orientações apresentam certo avanço em relação àquilo que fora regulado nos PCN e PCN+ sobre o conhecimento químico no âmbito escolar, porém, como todas as outras orientações, também carecem de instrumentação didática para criar ou recriar orientações sobre como inseri-los no processo didático pelo professor. 


\section{7 - Matriz de Referência do ENEM (2009)}

O Exame Nacional do Ensino Médio (ENEM) é um instrumento de avaliação de discentes, inclusive para o ingresso no Ensino Superior. A sua Matriz de Referência apresenta referências, orientações e lista de objetos de avaliação sobre conteúdos cuja aprendizagem se espera dos discentes concluintes do ensino médio, nas áreas de linguagens; ciências naturais; ciências humanas e matemática. Para este trabalho selecionamos a nova matriz de 2009, para análise.

Nela delimitam-se cinco eixos cognitivos comuns às áreas de conhecimento que compõem o processo avaliativo, quais sejam: $1^{\circ}$ - dominar diferentes linguagens; $2^{0}$ - compreender fenômenos; $3^{0}$ - enfrentar situaçõesproblemas; $4^{\circ}$ - construir argumentação; $5^{\circ}$ - elaborar propostas.

O 2º $4^{\circ}$ e $5^{\circ}$ eixo são três eixos com possível aproximação à abordagem de contextualização sócio-histórica e análise histórico-filosófica, porque no primeiro $\left(2^{\circ}\right)$ dos três, refere-se à construção e aplicação de conceitos de diferentes áreas de conhecimento com o objetivo de compreender os fenômenos naturais, os processos sociais, históricos, geográficos, culturais e da produção tecnológica e artística; no segundo $\left(4^{\circ}\right)$, visa-se "relacionar informações, representadas em diferentes formas, e conhecimentos disponíveis em situações concretas, para construir argumentação consistente." No último dos três eixos ( $\left.5^{\circ}\right)$, trata-se de "recorrer aos conhecimentos desenvolvidos na escola para elaboração de propostas de intervenção solidária na realidade, respeitando os valores humanos e considerando a diversidade sociocultural" (MEC. INEP, 2009).

De modo preciso, a Matriz constitui um conjunto de competências (que se compõem de habilidades, para cada área, e. g., Ciências Naturais e suas Tecnologias, como também, para cada disciplina específica) e objetos de conhecimento associados (lista de conteúdos de cada disciplina escolar), para avaliação do conhecimento.

Ao analisar a Matriz de Referência de Ciências da Natureza e suas Tecnologias constatamos algumas competências que congregam habilidades que remetem à análise histórico-filosófica, trançando possíveis relações com a HFCrECN, embora, às vezes, de forma muito distante, tais são: 
Competência de área 1 - Compreender as ciências naturais e as tecnologias a elas associadas como construções humanas, percebendo seus papéis nos processos de produção e no desenvolvimento econômico e social da humanidade. (MEC. INEP, 2009 , destaque do original)

Esta competência congrega quatro habilidades esperadas no processo

avaliativo:

H1 - Reconhecer características ou propriedades de fenômenos ondulatórios ou oscilatórios, relacionando-os a seus usos em diferentes contextos.

H2 - Associar a solução de problemas de comunicação, transporte, saúde ou outro, com o correspondente desenvolvimento científico e tecnológico.

H3 - Confrontar interpretações científicas com interpretações baseadas no senso comum, ao longo do tempo ou em diferentes culturas.

H4 - Avaliar propostas de intervenção no ambiente, considerando a qualidade da vida humana ou medidas de conservação, recuperação ou utilização sustentável da biodiversidade. (MEC. INEP, 2009, negritos do original)

As outras habilidades aparecem nas seguintes competências que apresentamos na sequência (MEC. INEP, 2009, destaques do original):

Competência da área 3 - Associar intervenções que resultam em degradação ou conservação ambiental a processos produtivos e sociais e a instrumentos ou ações científico-tecnológicos. [sic]

[...]

H10 - Analisar perturbações ambientais, identificando fontes, transporte e (ou) destino dos poluentes ou prevendo efeitos em sistemas naturais, produtivos ou sociais.

H11 - Reconhecer benefícios, limitações e aspectos éticos da biotecnologia, considerando estruturas e processos biológicos envolvidos em produtos biotecnológicos.

H12 - Avaliar impactos em ambientes naturais decorrentes de atividades sociais ou econômicas, considerando interesses contraditórios.

[...]

Competência de área 5 - Entender métodos e procedimentos próprios das ciências e aplicá-los em diferentes contextos.

[...]

H19 - Avaliar métodos, processos ou procedimentos das ciências naturais que contribuam para diagnosticar ou solucionar problemas de ordem social, econômica ou ambiental.

Ou então, localizando as habilidades em cada disciplina escolar tem-se:

Competência de área 6 - Apropriar-se de conhecimentos da física para, em situações problemas, interpretar, avaliar ou planejar intervenções científico-tecnológicas.

[...]

H22 - Compreender fenômenos decorrentes da interação entre a radiação e a matéria em suas manifestações em processos naturais ou tecnológicos, 
ou em suas implicações biológicas, sociais, econômicas ou ambientais.

H23 - Avaliar possibilidade de geração, uso ou transformação de energia em ambientes específicos, considerando implicações éticas, ambientais, sociais e/ou econômicas.

Competência de área 7 - Apropriar-se de conhecimentos da química para, em situações problemas, interpretar, avaliar ou planejar intervenções científico-tecnológicas.

[...]

H25 - Caracterizar materiais ou substâncias, identificando etapas, rendimentos ou implicações biológicas, sociais, econômicas ou ambientais de sua obtenção ou produção.

H26 - Avaliar implicações sociais, ambientais e/ou econômicas na produção ou no consumo de recursos energéticos ou minerais, identificando transformações químicas ou de energia envolvidas nesses processos.

H27 - Avaliar propostas de intervenção no meio ambiente aplicando conhecimentos químicos, observando riscos ou benefícios.

Competência de área 8 - Apropriar-se de conhecimentos da biologia para, em situações problemas, interpretar, avaliar ou planejar intervenções científico-tecnológicas.

H29 - Interpretar experimentos ou técnicas que utilizam seres vivos, analisando implicações para o ambiente, a saúde, a produção de alimentos, matérias primas ou produtos industriais.

H30 - Avaliar propostas de alcance individual ou coletivo, identificando aquelas que visam à preservação e a implementação da saúde individual, coletiva ou do ambiente. (MEC. INEP, 2009, destaque do original)

Como podemos verificar, na Matriz do ENEM, há indícios evidentes da política de educação por competências e habilidades presente nos PCN e PCN+, inclusive ela apresenta, compreensivelmente, a aproximação à competência geral de contextualização sociocultural presente nos PCN e PCN+. Isto é demonstrativo de uma perspectiva (política de continuidade) no processo de normalização e avaliação da sua conformidade, quando couber!

Porém, a verificação ou constatação da conformidade destas habilidades do reflexo cognitivo dos discentes no processo da avaliação - além de fatores psicológicos, que não são objeto deste estudo - depende muito do labor fundamental dos docentes e da adesão discente, do significado que cada um atribui à aprendizagem. O labor docente também depende dos formadores e do aparato teórico que conduz às suas práticas didáticas, sobretudo, no que tange a pautar os discursos e as práticas didáticas numa abordagem integrada, que ressalte a dimensão social e histórico-filosófica, implicada no fazer ciências e tecnologias e suas relações de diversos âmbitos.

Os objetos de avaliação das Matrizes disciplinares não remetem de imediato às competências de contextualização sociocultural, é com muito esforço que em alguns descritores podemos verificar expressões temáticas, e.g. (MEC. INEP, 2009, destaques nossos): 
> ao se tratar - na Física - do movimento, do equilíbrio e da descoberta das leis física, constatamos apenas um tema: "A hidrostática: aspectos históricos e variáveis relevantes", ou então, ao referir-se à mecânica e funcionamento do Universo, o tema é: "Concepções históricas sobre a origem do universo e sua evolução."

na Biologia, o objeto mais próximo à abordagem sócio-histórica e filosófica se refere à questões da qualidade de vida humana: "Aspectos biológicos da pobreza e do desenvolvimento humano. Indicadores sociais, ambientais e econômicos. Índice de desenvolvimento humano. [...]. Aspectos sociais da biologia: uso indevido de drogas".

No que tange à Química não constatamos algum objeto da Matriz que remeta a aproximação ao tema de pesquisa. Porém, se forçarmos, os objetos podem ser passíveis de abordagem histórica, sociológica e filosófica, o que recai na "dependência" da formação e autoformação docente.

Finalmente, percebe-se que quanto à HFC há um desligamento entre os regulamentos por áreas específicas, em Física há certa predominância em considerar a HFC, na Biologia um pouco e na Química muito pouco. Essa situação torna os regulamentos divergentes entre si, o que se refletem negativamente na materialização da proposta da HFCrECN no sistema escolar e fragiliza a motivação e confiança dos docentes. Existe um prosseguimento teórico prescritivo que foi alargando-se, sobretudo, desde os PCN, no entanto, há oscilação entre um e outro documento, entre uma e outra área específica. Constata-se a existência de pouco rigor propositivo metodologicamente e falta de fundamentação epistemológica nos regulamentos. Em termos gerais, a $\mathrm{HC}$ é tida mais como elemento motivacional ao possibilitar a contextualização e menos como estratégia metodológica para ensino e aprendizagem científica e perspectiva de análise crítica. 


\section{HFCrECN NAS PESQUISAS NACIONAIS (1999 a 2010)}

\section{1 - Apresentação}

Neste capítulo analisamos as orientações das pesquisas nacionais da área de ensino de ciências naturais (e, eventualmente, da área de HFC apropinquadas ao tema-problema HFCrECN): produções, relatos e avaliações experimentais de casos e propostas curriculares baseadas em HFC, publicadas em periódicos nacionais representativos da área. Para esse mesmo fim, diagnosticamos, também, os trabalhos apresentados em eventos científicos. Os trabalhos analisados foram localizados nas categorias de análise ou permitiram criar novas categorias analíticas.

Para tal fim, determinamos o período de 11 anos (1999 a 2010) para coleta de dados, tendo como marco histórico o ano de 1999, quando da publicação da edição dos PCN, marco oficial do reconhecimento da relevância da HFCrECN. Verificamos, consequentemente, a repercussão das orientações oficiais nas pesquisas, buscando diagnosticar o diálogo entre as instâncias decisórias em torno da HFCrECN.

Para eventos computamos apenas trabalhos (comunicações orais ou painéis) consequentes de pesquisas cujos resumos foram achados, porém constatando não haver como aprofundar a análise dos resumos pelo seu caráter artificial (sinopse para indexação) - o que significa que os resumos somente não ofereceriam os elementos completos do trabalho de pesquisa - levantamos os trabalhos completos da grande maioria dos resumos analisados, exceptos os poucos que não foram localizados, por falta de disponibilidade dos mesmos pelas entidades promotoras.

As conferências não foram computadas como trabalhos a serem analisados porque constatamos que, no geral, estão desprovidas de resumos, essa postura justifica-se porque não se trata de uma pesquisa de levantamento quantitativo de números de trabalhos apresentados, mas trata-se de análise qualitativa, pela qual buscamos diagnosticar e compreender os experimentos $\mathrm{e}$ testes de inclusão da abordagem dos aspectos histórico-filosóficos no ensino e aprendizagem das ciências naturais. 
Igualmente, os mini-cursos e oficinas, às vezes, têm uma descrição indicativa do ementário e objetivos que, metodologicamente, trazem poucas informações passíveis de análise e categorização no âmbito desta pesquisa, por essa razão também não foram computados.

Alguns cadernos de resumos (ou anais) de certos eventos não foram localizados nem mesmo consultando as sociedades científicas respectivas, é o caso, por exemplo, dos eventos da Sociedade Brasileira de Química. Verificamos que muitos organizadores de eventos têm adotado a gravação dos resumos e/ou anais em CD, o que dificulta a localização posterior, por parte dos pesquisadores, os CDs são de distribuição e porte pessoal e dificilmente chegam às bibliotecas e quebram facilmente.

Para efeitos da análise levamos em estrita consideração os seguintes critérios de seleção de periódicos: representatividade e pertinência à área de ensino de ciências naturais; maior circulação e condições de acesso aos docentes de Educação Básica ou discentes das licenciaturas, e. g., disponibilização digital (online) que possibilita a circulação e o acesso fácil e rápido e; aproximação ao tema HFCrECN.

Ou seja, os periódicos de acesso restrito aos assinantes não se enquadram na categoria de material de fácil acesso aos professores e, bem como, aqueles que não dispõem de versões digitais, não consultáveis via internet. É de conhecimento da maioria dos pesquisadores que as Escolas de Ensino Médio ou Fundamental do nosso país, no geral, não dispõem de serviços de assinaturas de periódicos científicos nem "obrigação" de que seus docentes participem dos eventos científicos. Ademais, também não é costume dos docentes da Educação Básica ou discentes graduandos assinarem periódicos científicos.

A seleção dos trabalhos publicados em periódicos ou cadernos de resumos de eventos obedeceu ao seguinte critério: pertinência aos objetivos deste capítulo e ao tema-problema que consiste na apresentação tanto de relatos de experiências e propostas de inclusão da HFC na práxis didáticas no ECN quanto de argumentos que indiquem a inserção do trabalho nas categorias de análise.

Neste sentido, reafirmamos que aqueles trabalhos em que:

$>$ se analisam os aspectos históricos (ou filosóficos) nos livros didáticos de ciências naturais verificando "erros" históricos apresentados nesses materiais; 
$>$ se apresentam as contribuições de alguns autores ou sobre a relevância de suas teorias ao ensino de ciências naturais;

se trata das concepções de discentes ou docentes sobre a natureza da ciência, mas que, tais trabalhos não se originam de propostas de pesquisa didática ou experimental, sobre a inclusão da abordagem dos aspectos histórico-filosóficos no ensino e aprendizagem científica;

Estes trabalhos não foram contemplados na análise, por se diferirem do objeto e problema de investigação e da sua delimitação temática, ou seja, em tais trabalhos não se objetivou a discussão metodológica para a HFCrECN. No entanto, eles guardam sua grande importância no âmbito do movimento e da defesa da inclusão da HFC no ECN.

Analisamos aqueles trabalhos em que se tencionou investigar, discutir e apresentar propostas ou estratégias metodológicas (e fundamentação epistemológica) de inclusão da HFC no ensino de Física, Química ou Biologia (na Escola média ou nas Licenciaturas). O movimento da HFCrECN já conta com uma vasta literatura com postulações teóricas. Alguns trabalhos não analisados e constatados nos periódicos e resumos de eventos foram coletados, estudados e não selecionados para a análise por serem direcionados a propósitos diferentes

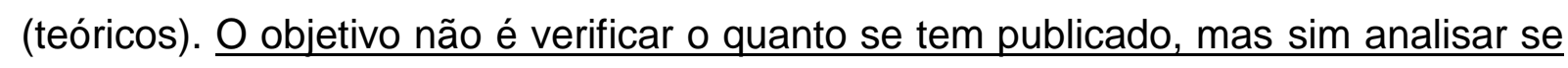
o que se tem publicado implica ou se reflete metodologicamente a HFCrECN, a partir dos resultados das pesquisas da área.

Finalmente, procedemos a uma análise situada, trabalho por trabalho. $O$ período de coleta de material em periódicos, resumos de eventos foi até 30 de dezembro de 2010 (e houve uma retomada de busca online em janeiro de 2011), antecedida da aplicação das entrevistas semiestruturadas entre outubro e novembro de 2010.

\section{2 - HFCrECN nas Pesquisas Publicadas em Periódicos (1999 a 2010)}

Em relação aos trabalhos analisados nos periódicos, alguns critérios reforçaram a seleção do material durante a coleta: não foram computados para o total de trabalhos publicados no periódico aqueles que constam das secções de "Editorial", "Resumos de dissertações/teses" e "Resenhas". Isto por entendermos 
que um artigo é um trabalho consequente de reflexão e/ou investigação científica ou filosófica em que se apresentam um (no mínimo) objeto/problema de estudo, indicação do processo metodológico (métodos, técnicas e estratégias de investigação), dos respectivos resultados alcançados para resolução do problema posto e da sua conclusão e seu referencial.

Foram selecionados catorze (14) periódicos nacionais da área de ensino de ciências naturais e alguns da de HFC com proximidade à HFCrECN, em destaque estão as abreviaturas utilizadas para referir-se à revista ao analisar os artigos nela coletados, a saber:

1. Alexandria - Revista de Educação em Ciência e Tecnologia (Alexandria) da UFSC;

2. Caderno Brasileiro de Ensino de Física (CBEF) da UFSC;

3. Ciência e Educação (C\&Ed) da UNESP;

4. Ciência \& Ensino (C\&Ens) da UNICAMP;

5. Ensaio - Pesquisa em Educação em Ciências (Ensaio) da UFMG;

6. Filosofia e História da Biologia (FHB) da ABFHiB;

7. História da Ciência e Ensino: construindo interfaces (HC\&Ens) da PUC-SP;

8. Investigações em Ensino de Ciências (IEC) da UFRGS;

9. Química Nova $(\mathbf{Q N})$ da SBQ;

10. Química Nova na Escola (QNE) da SBQ;

11. Revista Brasileira de Ensino de Física (RBEF) da SBF;

12. Revista Brasileira de Pesquisa em Educação em Ciências (RBPEC) da ABRAPEC;

13. Revista da Sociedade Brasileira de História da Ciência (RSBHC) da SBHC;

14. Revista de Ensino de Biologia (REB) da SBEnBio.

Para facilitar o processo de expressão de alguns aspectos foi necessário criar alguns símbolos ou abreviatura que apresentamos na tabela a seguir. 
Tabela 14 - Símbolos e abreviações usadas nas tabelas de revistas e eventos

\begin{tabular}{|c|l|}
\hline $\begin{array}{c}\text { SÍMBOLO / } \\
\text { ABREVIATURA }\end{array}$ & \multicolumn{1}{|c|}{ SIGNIFICADO NO CONTEXTO DO TRABALHO } \\
\hline Ext. & $\begin{array}{l}\text { Antecede ao numeral, significa artigo/s vindo/s do exterior, que não } \\
\text { refletem a realidade brasileira. }\end{array}$ \\
\hline$\sim$ & $\begin{array}{l}\text { Antecede ao numeral, significa total aproximado de artigos } \\
\text { computados em um Periódico analisado, isto ocorre em Revista com } \\
\text { várias seções, incluídos seções como "comentários", "notas", etc. que } \\
\text { não apresentam nelas artigos científicos. }\end{array}$ \\
\hline$\sim P$ & $\begin{array}{l}\text { Volume e/ou número do Periódico não publicado até a data da coleta } \\
\text { de dados. }\end{array}$ \\
\hline- & $\begin{array}{l}\text { Antecede ao numeral, significa "pouca relação ou aproximação ao } \\
\text { tema HFCrECN"; por exemplo: -2 (= há pouca aproximação ao tema } \\
\text { nos dois artigos) ou 1, -1 (dos dois trabalhos, na mesma edição, o } \\
\text { segundo apresenta pouca aproximação) ou -B-CBEF artigo com pouca } \\
\text { aproximação. }\end{array}$ \\
\hline+ & $\begin{array}{l}\text { Antecede ao numeral, significa que deve haver mais artigos ou } \\
\text { trabalhos que a quantidade mencionada na coluna da totalidade de } \\
\text { trabalhos computados em um periódico ou evento, e. g.: + 146 = mais } \\
\text { de 146 trabalhos. }\end{array}$ \\
\hline
\end{tabular}

Seguimos uma ordem não alfabética, mas que parte do estudo de periódicos das áreas específicas Física, Química e Biologia aos dos periódicos da área genérica de ECN. Os trabalhos analisados foram enquadrados nas categorias de análise. A ordem de apresentação dos artigos em cada periódico analisado obedece ao critério de prioridade em termos de pertinência temática. Depois da análise de cada periódico apresentamos uma tabela ilustrativa. Metodologicamente não é improcedente apresentar alguns elementos quantitativos em pesquisa qualitativos a título de ilustração e melhor visualização, o que não significa fazer pesquisa quantitativa, isto também não deve preocupar o pesquisador qualitativo, pois a complementaridade é relevante na investigação. Não somos partidários do fundamentalismo e reducionismo metodológico que vê as pesquisas qualitativas e quantitativas como irreconsiliáveis e não complementares.

\subsection{1 - Periódicos da Área de Ensino de Física}

No Caderno Brasileiro de Ensino de Física (CBEF) durante o período de 1999 a 2010 foram publicados 322 artigos, dos quais sete aparentemente pareciam ter aproximação ao tema, mas ao procedermos a uma análise mais acurada em relação ao tema-problema da pesquisa verificamos que dos sete artigos apenas um se enquadrava nos prósitos da pesquisa.

Os outros, ainda que tenham apresentado ou feito referência à $\mathrm{HC}$ ou 
HFC nos títulos ou palavras-chave, a abordagem dada é diferente, referindo-se a uma discussão teórico-histórica dos temas, comum no movimento que defende uso da HFC no ensino, contrapondo-se alguns aspectos dos livros didáticos, referindo-se às concepções (representações) ou ao ensino baseado em problemas com uso de demonstrações de situações experimentais sem, no entanto, incluir ou relatar, metodologicamente, uma abordagem histórico-filosófica dos eventos, problemas ou situações no processo de ensino e aprendizagem, apontando com isso a propósitos diferentes, isto foi verificado no conjunto do material coletado em todas as revistas e cadernos de resumos de eventos.

Eis os artigos achados no CBEF:

A-CBEF - GUERRA, Andreia; REIS, José C.; BRAGA, Marco. Uma Abordagem Histórico-Filosófica para o Eletromagnetismo no Ensino Médio. Caderno Brasileiro de Ensino de Física, Florianópolis, v. 21, n. 2, p. 224-248, ago., 2004.

B-CBEF - LONGHINI, Marcos D.; NARDI, Roberto. Como age a pressão atmosférica? Algumas situações-problemas tendo como base a História da Ciência e pesquisa na área. Caderno Brasileiro de Ensino de Física, Florianópolis, v. 26, n. 1, p. 7-23, abr., 2009.

Daqui em diante nos referiremos aos artigos a partir das letras alfabéticas que ocupam na ordem de sua apresentação, seguida da abreviatura da revista.

No artigo A-CBEF os autores se propuseram a selecionar um tema (fenômenos eletromagnéticos ou eletromagnetismo) e período histórico que vai do experimento de Hans Christian Oersted (1777-1851) acerca do efeito do conflito elétrico sobre a agulha magnética, em 1820, à divulgação da obra de Michael Faraday (1891-1867) em 1832, sobre a indução eletromagnética, período em que os autores descrevem o contexto histórico do tema "eletromagnetismo" para abordá-lo histórica e filosoficamente numa proposta curricular no ensino médio, em uma Escola do Rio de Janeiro. Os autores justificam que

É fundamental, então, que as salas de aulas sejam espaços abertos a discussões a respeito dos limites e possibilidades dos conhecimentos construídos pelos homens ao longo da história. Isso implica na criação de espaços em que os alunos possam estudar a história da construção de tais conhecimentos, de forma a refletir sobre as questões por eles respondidas através do tempo, assim como as soluções encontradas e os caminhos trilhados na produção destas. (GUERRA; REIS; BRAGA, 2004, p. 225)

Por isso, seria relevante o estudo da História e Filosofia da Ciência e Tecnologia de tal forma que os discentes pudessem conhecer o passado e as 
"angústias, preocupações, dificuldades e certezas" pelo que passaram os cientistas e conhecer o processo de construção da ciência e tecnologia percebidas como produções culturais, localizados no tempo e espaços determinados. Os autores retomam a defesa do movimento da HFCrECN ao afirmarem que a $\mathrm{HC}$ para alcançar o seu papel no ECN precisa ultrapassar a dimensão factual, episódica, biográfica e valorização apenas das teorias aceitas atualmente, essa retomada pode ser verificada na afirmação seguinte:

\begin{abstract}
Para que a história da ciência cumpra o papel destacado, é necessário que, ao enfocá-la, seja ultrapassada a história factual, baseada apenas em curtas biografias dos autores das leis e das teorias atualmente aceitas. Ela será um instrumento eficaz na construção de um espaço propício à reflexão, quando, paralelamente ao estudo do histórico desenvolvimento interno dos conceitos e experimentos científicos e tecnológicos, discuta-se como o desenvolvimento desses conhecimentos se inseriu na história das sociedades. Deve-se, então, salientar as controvérsias científicas, as inquietações filosóficas dos que construíram a ciência, e também as interfaces entre esta e outras produções culturais. (GUERRA; REIS; BRAGA, 2004, p. 226)
\end{abstract}

Em relação à proposta curricular afirmam os autores que "um currículo dinâmico e producente é aquele construído pelos professores junto com os alunos no cotidiano escolar." Essa proposição pode dar margem a interpretação que a localiza num certo construtivismo que levanta sérias interpelações: como elaborar com discentes de educação básica ou mesmo superior a proposta curricular, ou seja, ou que ensinar? Até que ponto os discentes podem assegurar o que é necessário ser ensinado e aprendido de/sobre ciências? O que eles podem afirmar do desconhecido?

A questão de saber que coisas devem ser ensinadas é fundamentalmente filosófica (Filosofia da educação) e implica em maturidade para tomada de decisão estratégica para escolha curricular. Por outro lado, o que ensinar também implica em conhecer os objetivos da educação prescritos em leis e costumes de uma determinada sociedade. Assim, o currículo torna-se, pertinentemente, um elemento do planejamento estratégico refinado.

O currículo é um plano para a implementação de objetivos educacionais. [...].

[...] o currículo é, talvez, mais bem definido se considerado como aquele conjunto de atividades planejadas cuja elaboração almeja a implementação de um objetivo educacional particular - ou um conjunto de objetivos educacionais -, em termos do conteúdo daquilo que deve ser ensinado bem 
como do conhecimento, das habilidades e das atitudes que devem ser deliberadamente fomentadas. Como um todo, o currículo deve ser diferenciado do plano de ensino e da aula. O primeiro engloba a descrição do conteúdo e a estrutura de alguns "temas" ou "assuntos" no âmbito do currículo, por exemplo, ciências. A segunda diz respeito à porção de tempo na qual o conteúdo do plano de ensino é implementado. (WINCH, 2007, p. 59-60)

Assim, o currículo como projeto estratégico do processo didático, então, tem de ser necessariamente dinâmico, não há outra forma de sê-lo, porque planejado de forma aberta e cuja materialização leva a construção do conhecimento de forma não unilateral, mas sim na interdependência que se estabelece entre o docente, os discentes e os entes da sociedade (comunidades, Estado, organizações). Na formação escolar (inicial ou continuada) o currículo processa-se numa relação dialética entre a prática docente de um lado e a prática discente, do outro, ou como dizia Paulo Freire, em A Pedagogia da Autonomia, "não há docência sem discência" e, reforcemos que, a recíproca também é equivalente. No enanto, as duas práticas são mediadas pela instituição escolar, sociedade e pelo Estado.

Neste sentido, verificarmos que a proposta descrita no artigo A-CBEF se enquadra mais em uma proposta de ensino que uma proposta curricular, como os autores afirmam em seu trabalho. $O$ que pode ser confirmado no plano por eles estabelecido sobre o tema (eletromagnetismo) desenvolvido, dividido em unidades de ensino:

- na primeira trataram dos antecedentes do eletromagnetismo em que abordaram as questões filosóficas do iluminismo e mecanicismo desenvolvidas em parceria com docentes de Artes, História, Filosofia e Literatura para compreender o contexto cultural dos séculos 17 e 18 em que se localizam os experimentos de Oersted, Ampère, Faraday, Leyden e Galvani, com uso de recursos visuais e imagens históricas, além das aulas expositivas.

- a segunda unidade, "unidade central da proposta curricular" dos autores, foi dedicada ao nascimento do eletromagnetismo, estudando-se a corrente filosófica da "Naturphilosophie" relacionada ao romantismo literário. GUERRA; REIS; BRAGA, (2004, p. 241) afirmam que

Esse trabalho foi muito rico, e a parceria com os professores de História, Filosofia, Literatura e Artes (mesmo que restrita à retomada de temas discutidos por esses professores) permitiu explorar recursos nem sempre usados na educação científica, como leitura de poesias, contos, discussão de filmes e peças de teatro. Fora a exploração desses recursos, esse tipo 
de parceria permitiu ao aluno, de forma mais completa, compreender o contexto cultural em que o eletromagnetismo nasceu e as questões histórico-filosóficas e culturais com as quais os cientistas que construíram aquele saber se defrontaram.

O relato evidencia a complexidade metodológica e epistemológica implicada na HFCrECN, a constante necessidade de colaboração, que é difícil de ocorrer ao longo do desenvolvimento das atividades didáticas disciplinares, durante o período letivo.

No entanto, os autores relatam que houve, por exemplo, estudo de textos originais, análise e contextualização do gerador e motor elétrico e que foi apresentado uma proposta de construção de um motor elétrico aos discentes, essa atividade de transpor o modelo para um construto (artefato) em funcionamento teria colocado os discentes diante de problemas técnicos relevantes para a formação técnico-científica.

A terceira unidade fora destinada ao eletromagnetismo após Faraday, com discussão do conceito de campo elétrico/magnético/eletromagnético, ondas eletromagnéticas, transmissões de sinais de radio e televisão. A quarta, sobre circuitos elétricos com estudos da eletrodinâmica (enfatizando a lei de Ohm e aplicações): exploração da resistência e resistividade elétricas e suas unidades no sistema internacional.

Portanto, em virtude do exposto, nota-se que houve um esforço interessante de inserir um tratamento histórico dos temas elegidos, neste sentido podemos, então, afirmar que o artigo A-CBEF se enquadra em duas categorias: Contextualização Externa (duas primeiras unidades trabalhadas) e Contextualização Interna (duas últimas). Portanto, trata-se de uma tentativa integrada de contextualização.

Finalmente, na revista $\mathrm{CBEF}$, encontramos um artigo que pelo tratamento dado aos experimentos não se localiza na delimitação do tema-problema, mas que merece uma referência, trata-se do artigo B-CBEF de Longhini e Nardi (2009).

Embora os autores (LONGHINI; NARDI, 2009, p. 9) se apóiem na literatura do movimento da HFCrECN no momento em que afirmam que

A História da Ciência também foi um pressuposto que subsidiou a elaboração das atividades, e isto porque ela pode se constituir em rica fonte de informações sobre como o tema em estudo se desenvolveu no decorrer dos tempos, os impasses e as dificuldades experimentadas por outras 
pessoas em diferentes épocas para explicar fenômenos relacionados à mesma temática.

Ao longo do trabalho não há uma descrição ou ilustração de como os aspectos históricos foram, metodologicamente, inseridos ou abordados durante a atividade didática, diferente da forma como ficou compreensível a descrição feita no artigo A-CBEF, no artigo em questão refere-se ao ensino de fenômenos atmosféricos (pressão atmosférica), a didática do evento apresentado ocorreu por meio de apresentação de problemas em que se reproduziam alguns experimentos, depois algumas perguntas sobre o evento eram feitas aos discentes, vejamos, por exemplo, o primeiro eixo das atividades dos autores referia-se à questão de que a "variação do volume de um recipiente fechado influencia na manifestação da pressão atmosférica sobre este mesmo recipiente", entre os experimentos exercitados estão os do "canudinho" e das "placas de vidro":

\begin{abstract}
A maior parte das pessoas já deve ter experimentado tomar suco ou refrigerante utilizando um canudo plástico, e a partir dessa situação cotidiana, sugerirmos solicitar aos alunos que expliquem por que o líquido sobe através do canudo neste processo.

[...].

Quando duas placas de vidro, perfeitamente lisas, são molhadas e colocadas uma sobre a outra, elas ficam unidas entre si. Uma situaçãoproblema pode surgir quando solicitamos aos alunos que respondam: por que as placas se mantém unidas?
\end{abstract}

Os autores relatam que tinham por objetivo verificar nos discentes se atribuiriam a explicação ao ar externo e que os exercícios foram elaborados com base em discussões advindas da historicidade do conceito de pressão atmosférica, porém, sem oferecer dados historiográficos da história da pressão atmosférica e os problemas filosóficos implicados no seu desenvolvimento. A estratégia estaria dentro da didática do uso de experimentos no ensino de ciências, as perguntas feitas também não são filosóficas senão inerentes a curiosidade de evento, no caso as concepções prévias dos discentes (licenciandos) submetidos ao teste, em virtude disto poder-se-ia alocar mais ou menos na categoria Motivacional.

A proposta é interessante, em virtude de tentar recorrer a outra ferramenta ou linguagem, como uso de experimento ou teorias de aprendizagem, para abordar a HFC, talvez Ihe tenha faltado uma afinação histórico-filosófica, já que foi anunciada no título como fundamento da atividade. Porém, nem toda pergunta é história ou filosófica. A FC atualiza a HC para que seja ratificada, de tal forma que os 
problemas históricos sejam necessários no desenvolvimento da mentalidade e investigação científica.

Tabela 15 - Caderno Brasileiro de Ensino de Física / ISSN 2175-7941

Universidade Federal de Santa Catarina -UFSC

Home Page: http://www.periodicos.ufsc.br/index.php/fisica/index

\begin{tabular}{|c|c|c|c|}
\hline \multirow[t]{2}{*}{$\begin{array}{c}\text { VOLUME, NÚMERO E } \\
\text { DATA }\end{array}$} & \multirow{2}{*}{$\begin{array}{l}\text { Total de Artigos } \\
\text { Publicados na } \\
\text { Revista }\end{array}$} & \multicolumn{2}{|c|}{$\begin{array}{l}\text { Artigos relacionados ao Tema da } \\
\text { Pesquisa conforme delimitado }\end{array}$} \\
\hline & & $\begin{array}{l}\text { Referentes à } \\
\text { HFCrECN }\end{array}$ & $\begin{array}{ll}\text { Referentes } & \text { à } \\
\text { HFCrECN nos RO }\end{array}$ \\
\hline Vol. 16 N. 11999 & 9 & 0 & 0 \\
\hline Vol. 16 N. 21999 & 11 & 0 & 0 \\
\hline Vol. 16 N. 31999 & 7 & 0 & 0 \\
\hline Vol. 17 N. 12000 & 8 & 0 & 0 \\
\hline Vol. 17 N. 22000 & 7 & 0 & 0 \\
\hline Vol. 17 N. 32000 & 8 & 0 & 0 \\
\hline Vol. 18 N. 12001 & 9 & 0 & 0 \\
\hline Vol. 18 N. 22001 & 8 & 0 & 0 \\
\hline Vol. 18 N. 32001 & 8 & 0 & 0 \\
\hline Vol. 19 N. 12002 & 8 & 0 & 0 \\
\hline Edição Especial jun. 2002 & 7 & 0 & 0 \\
\hline Vol. 19 N. 22002 & 8 & 0 & 0 \\
\hline Vol. 19 N. 32002 & 8 & 0 & 0 \\
\hline Vol. 20 N. 12003 & 8 & 0 & 0 \\
\hline Vol. 20 N. 22003 & 5 & 0 & 0 \\
\hline Vol. 20 N. 32003 & 5 & 0 & 0 \\
\hline Vol. 21 N. 12004 & 8 & 0 & 0 \\
\hline Vol. 21 N. 22004 & 7 & 1 & 0 \\
\hline Edição Especial Nov. 2004 & 43 & 0 & 0 \\
\hline Vol. 21 N. 32004 & 8 & 0 & 0 \\
\hline Vol. 22 N. 12005 & 7 & 0 & 0 \\
\hline Vol. 22 N. 22005 & 6 & 0 & 0 \\
\hline Vol. 22 N. 32005 & 6 & 0 & 0 \\
\hline Vol. 23 N. 12006 & 5 & 0 & 0 \\
\hline Vol. 23 N. 22006 & 7 & 0 & 0 \\
\hline Vol. 23 N. 32006 & 7 & 0 & 0 \\
\hline Vol. 24 N. 12007 & 8 & 0 & 0 \\
\hline Vol. 24 N. 22007 & 6 & 0 & 0 \\
\hline Vol. 24 N. 32007 & 6 & 0 & 0 \\
\hline Vol. 25 N. 12008 & 9 & 0 & 0 \\
\hline Vol. 25 N. 22008 & 8 & 0 & 0 \\
\hline Vol. 25 N. 32008 & 10 & 0 & 0 \\
\hline Vol. 26 N. 12009 & 11 & -1 & 0 \\
\hline Vol. 26 N. 22009 & 10 & 0 & 0 \\
\hline Vol. 26 N. 32009 & 10 & 0 & 0 \\
\hline Vol. 27 N. 12010 & 7 & 0 & 0 \\
\hline Vol. 27 N. 22010 & 9 & 0 & 0 \\
\hline Vol. 27 N. 32010 & $\sim \mathbf{P}$ & 0 & 0 \\
\hline Total & 322 & 2 & 0 \\
\hline
\end{tabular}

Na Revista Brasileira de Ensino de Física (RBEF) foram publicados 672 artigos no período de 1999 a 2010 (até o primeiro volume deste ano, os outros, não tinham sido publicados até o período da coleta neste periódico (31 dezembro de 
2010). Do total, quatro haviam sido coletados, mas apenas dois artigos apresentam uma aproximação ao tema-problema de estudo:

A-RBEF - MAGALHÃES, Murilo de F.; SANTOS, Wilma M S.; DIAS, Penha M. C. Uma Proposta para Ensinar os Conceitos de Campo Elétrico e Magnético: uma aplicação da História da Física. Revista Brasileira de Ensino de Física, v. 24, n. 4, p. 489-496, dez., 2002.

B-RBEF - ROCHA, José F. Moura. O Conceito de «campo» em sala de aula: uma abordagem histórico-conceitual. Revista Brasileira de Ensino de Física, v. 31, n. 1, p. 489-496, dez., 2002.

No artigo A-RBEF, os autores (MAGALHÃES; SANTOS; DIAS, 2002, p. 490) tiveram por objetivo formular uma proposta didática alternativa para o ensino dos conceitos de campo elétrico e magnético. Utilizando a História da Física, inspiraram-se na teoria de aprendizagem significativa ${ }^{72}$; sua proposta foi desenvolvida no terceiro ano de uma escola média do Rio de Janeiro.

Os autores acreditam que a "História da Física pode ser um elemento facilitador de uma aprendizagem significativa, na medida em que funciona como organizador prévio," e o uso da teoria é para tornar compreensível o "papel da História da Física como organizador prévio, o que, também, explica seu sucesso no ensino de Física" (MAGALHÃES; SANTOS; DIAS, 2002, p. 490).

Defendem ainda que a História da Física possibilitaria apresentar problemas que levaram à formulação de conceitos científicos e que revelaria os ingredientes, lógicos ou empíricos, que teriam sido importantes no processo da formulação conceitual, ou seja, ela tornaria compreensível os conceitos, revelandoIhes o significado.

Do ponto de vista do uso da teoria da aprendizagem significativa, a História da Física, por revelar significados, seria um legítimo organizador prévio porque se adequaria ao papel de fazer superar os limites entre o que os discentes conhecem e o que precisam conhecer ainda, antes de aprender a tarefa que lhes será apresentada. Na teoria de aprendizagem significativa centra-se na interação entre o conhecimento prévio do discente e o conteúdo de aprendizagem.

Para que a nova aprendizagem ocorra é necessário o uso de âncoras (organizadores prévios) que proporcionam a aprendizagem, a HC funcionaria como âncora para a aprendizagem da Física, ou no caso em pauta, dos conceitos de

72 Desenvolvida por David Ausubel e aperfeiçoada por Joseph Novak: AUSEBEL, D.; NOVAK, J. D.; HANESIAN, H. Educational Psycology, a Cognitive View. Holt: Reinhart and Wiston, 1978. 
campo elétrico e magnético porque os organizadores prévios seriam "materiais introdutórios apresentados antes do próprio material a ser aprendido" e sua função seria de "servir de ponte entre o que o aprendiz já sabe e o que ele deve saber, a fim de que o material possa ser aprendido de forma significativa" (MOREIRA; MASINI, 1982, p. 11).

No entanto, antes os autores aplicaram um questionário (com seis questões) a 120 discentes com objetivo de diagnosticar conhecimentos prévios sobre o conceito de campo, a partir daí implementaram o estudo de caso de campo eletromagnético em sala aula, a partir desse conhecimento planejaram estratégias de ensino tencionando gerar, nos discentes, uma aprendizagem significativa.

Esse tipo de levantamento de dados de aprendizagem exige uma aplicação do instrumento de coleta antes, durante e depois para verificar até que ponto o uso da estratégia introduzida - a teoria de aprendizagem significativa e abordagem de temas da história do campo eletromagnético - favoreceu ou não a aprendizagem e com qual grau. Porém, não é o que tem ocorrido. As propostas não têm sido efetivamente experimentais, por várias razões, os autores do artigo ARBEF alegam que

\footnotetext{
Nem foi possível aplicar o questionário, de novo, ao término do curso, por razões meramente burocráticas. No entanto, os alunos prestaram exames de conclusão da disciplina que, embora nos moldes tradicionais, teve suas questões baseadas nas do questionário. Assim, devido ao alto índice de aprovação entre os alunos, consideramos que as respostas forneceram alguma indicação. (MAGALHÃES; SANTOS; DIAS, 2002, p. 492)
}

A conclusão hipotética é compreensível, até plausível, embora deixe dúvidas por não ter havido uma turma de controle e/ou por não ter completado a sequência do teste antes-durante-depois, para poder comparar os resultados e extrair conclusões. Se houve uma aprovação significativa nada nos garante que a estratégia tenha sido a causa, pode ter havido outra variável interveniente.

Esses são os problemas que se enfrentam ao realizar experiência nas instituições de ensino, como é perceptível na lamentação dos pesquisadores pelo fato de não ter sido possível aplicar o questionário no final das atividades por questões burocráticas, instrumentos pelas quais se impendem avanços que poderiam ser significativos para o processo e sistema educacional.

Os autores (MAGALHÃES; SANTOS; DIAS, 2002, p. 496) ressalvam que 
De um lado, ressaltamos que o uso de conhecimentos prévios dos alunos para introduzir novos conceitos ou até mesmo teorias é uma prática que deve ser explorada enfática e sistematicamente; isso torna-se, ainda, muito mais fundamental, quando da iniciação ao estudo da Física, o que se dá no ensino Médio. Por outro lado, a abordagem histórica parece ser uma ferramenta muito eficiente, pois possibilita melhor organização da estrutura conceitual, na medida em que revela as concepções que fundamentam um conceito ou até teorias.

De fato, a estratégia é plausível - e mereceria replicação atualizada - por tentar reunir teorias educacionais plausíveis para abordar historicamente a temática conceitual, por esta razão, o artigo A-RBEF se localiza na categoria de Contextualização Interna, por abordar a história conceitual do campo eletromagnético.

Já no artigo B-RBEF há uma extensa retomada bibliográfica sobre o campo (elétrico/magnético), encontramos poucas informações referentes a aproximação ao tema-problema de nossa pesquisa: HFCrECN, ou seja, como teria sido abordado, metodologicamente, o tema, no entanto, o trabalho é consequente de uma experiência docente do autor - no segundo ano de Licenciatura em Física, que se insurge contra o formalismo matemático que predomina no ensino da Física em contrapartida a uma abordagem histórica dos conceitos físicos. O que é evidente nas palavras do autor em relação ao ensino da eletricidade e magnetismo, ele afirma que

[...] a minha experiência pessoal era a de apresentar o assunto ou capítulo "campo elétrico" nos marcos de uma abordagem matemático-conceitual [...]. As razões que nos levavam a este tipo de abordagem geralmente estavam relacionadas com o excesso de tópicos a serem cobertos dentro da carga horária da disciplina. A isto se somava a necessidade reclamada pelos alunos de se fazer um número razoável de exercícios em sala de aula, envolvendo cálculo diferencial e integral, no que geralmente se gastava muito tempo. Esta maneira de apresentar o assunto poderia até resultar num bom "treinamento" para alunos dos cursos de engenharia, por exemplo, mas certamente não é a melhor maneira de abordar o tema, especialmente no que se refere aos alunos de cursos de Licenciatura em Física. (ROCHA, 2002, p. 13)

De fato, há uma predominância do formalismo matemático no ensino da Física o que oblitera a abordagem experimental, sócio-histórica, epistemológica dos problemas postos pela Física. Que são importantes para formação docente enquanto elementos subjacentes às habilidades e como capacidade do próprio docente. $\mathrm{O}$ autor ressalta que a abordagem histórico-conceitual - favorecida por ter 
constado tacitamente na ementa da disciplina a inclusão da História da Física - teria favorecido o surgimento de questões interessantes em sala de aula, que tais questões estariam relacionadas diretamente às "interações eletromagnéticas, descritas por campos elétricos e magnéticos", tais questões seriam, segundo Rocha (2002, p. 13):

O que é mesmo o campo elétrico? A presença de uma carga muda realmente as propriedades do espaço em sua volta? O campo elétrico é algo real, ele existe de fato? Não é apenas um recurso útil para descrever os fenômenos físicos? Podemos falar de interação (repulsão ou atração) entre campos (criados por bobinas ou imãs, por exemplo)? Qual a diferença essencial entre o conceito de campo usado na linguagem cotidiana, a exemplo de campo de influência política, e o conceito científico de campo físico?

Essas são questões de caráter filosófico que se referem à semântica conceitual que, aparentemente, oscila entre a significação no cotidiano e na ciência. A compreensão dessas questões é relevante para distinguir o engajamento vulgar do filosófico-científico, a abordagem vulgar, ou outra, da filosófico-científica dos fenômenos/eventos. Como bem reconhece o autor à guisa de conclusão: "Bem, se ficássemos restritos ao caso do campo eletrostático, a discussão desses problemas não seria do plano filosófico" (Rocha, 2002, p. 14).

Isto porque os fundamentos dessas questões não se encerram na semântica conceitual simples, alcançam o "status" ontológico dos fenômenos ou eventos que os conceitos designam ou referenciam. Definir o campo elétrico seria atribuir-lhe um estatuto ontológico em que se circunscreve as notas características, os atributos que distinguem, individualizam/singularizam este evento e a garantia de sua existência ou não, pois, ser por ser não é garantia de existir.

Assim, podemos localizar o artigo B-RBEF em duas categorias de análise, a da Criticidade, em virtude da abordagem problematizadora de questões epistemontológicas e a Contextualização Interna por abordagem históricoconceitual, como demonstra a defesa do autor (Rocha, 2002, p. 16):

Em razão do exposto, defendemos que, em sala de aula, a proposta de abordagem histórico-conceitual do campo físico, junto com seus aspectos matemáticos, é mais apropriada para uma boa formação do aluno que aquela que enfatiza apenas os aspectos matemáticos deste conceito.

Finalmente, esta conclusão, embora apresente coerência lógica, é, 
porém, metodologicamente, hipotética, carece do ônus da prova, que não foi descrito no artigo estudado, diferentemente dos artigos anteriores cujos autores descreveram as experiências realizadas e tentativas de mensuração do aprendizado (avaliação) em virtude da abordagem introduzida. A ausência de evidências enquadra a proposição defendida no domínio teórico, já predominante no movimento que defende a HFCrECC.

Tabela 16 - Revista Brasileira de Ensino de Física ISSN 1086 - 9126 On Line Sociedade Brasileira de Física Instituto de Física da Universidade Federal do Rio Grande do Sul Home Page: http://www.sbfisica.org.br/rbef/ojs/index.php/rbef/index

\begin{tabular}{|c|c|c|c|}
\hline \multirow{2}{*}{$\begin{array}{c}\text { VOLUME, NÚMERO E } \\
\text { DATA }\end{array}$} & \multirow{2}{*}{$\begin{array}{l}\text { Total de } \\
\text { Artigos } \\
\text { Publicados } \\
\text { na Revista }\end{array}$} & \multicolumn{2}{|c|}{$\begin{array}{l}\text { Artigos relacionados ao Tema da } \\
\text { Pesquisa }\end{array}$} \\
\hline & & $\begin{array}{l}\text { Referentes à } \\
\text { HFCrECN }\end{array}$ & $\begin{array}{ll}\text { Referentes } & \text { à } \\
\text { HFCrECN nos DO }\end{array}$ \\
\hline Vol. 21 N. 1 mar. 1999 & 27 & 0 & 0 \\
\hline Vol. 21 N. 2 jun. 1999 & 13 & 0 & 0 \\
\hline Vol. 21 N. 3 set. 1999 & 16 & 0 & 0 \\
\hline Vol. 21 N. 4 dez. 1999 & 13 & 0 & 0 \\
\hline Vol. 22 N. 1 mar. 2000 & 15 & 0 & 0 \\
\hline Vol. 22 N. 2 jun. 2000 & 10 & 0 & 0 \\
\hline Vol. 22 N. 3 set. 2000 & 21 & 0 & 0 \\
\hline Vol. 22 N. 4 dez. 2000 & 15 & 0 & 0 \\
\hline Vol. 23 N. 1 mar. 2001 & 15 & 0 & 0 \\
\hline Vol. 23 N. 2 jun. 2001 & 14 & 0 & 0 \\
\hline Vol. 23 N. 3 set. 2001 & 11 & 0 & 0 \\
\hline Vol. 23 N. 4 dez. 2001 & 10 & 0 & 0 \\
\hline Vol. 24 N. 1 mar. 2002 & 8 & 0 & 0 \\
\hline Vol. 24 N. 2 jun. 2002 & 22 & 0 & 0 \\
\hline Vol. 24 N. 3 set. 2002 & 11 & 0 & 0 \\
\hline Vol. 24 N. 4 dez. 2002 & 14 & 1 & 0 \\
\hline Vol. 25 N. 1 mar. 2003 & 13 & 0 & 0 \\
\hline Vol. 25 N. 2 jun. 2003 & 10 & 0 & 0 \\
\hline Vol. 25 N. 3 set. 2003 & 10 & 0 & 0 \\
\hline Vol. 25 N. 4 dez. 2003 & 10 & 0 & 0 \\
\hline Vol. 26 N. 1 mar. 2004 & 13 & 0 & 0 \\
\hline Vol. 26 N. 2 jun. 2004 & 12 & 0 & 0 \\
\hline Vol. 26 N. 3 set. 2004 & 12 & 0 & 0 \\
\hline Vol. 26 N. 4 dez. 2004 & 15 & 0 & 0 \\
\hline Vol. 27 N. 1 mar. 2005 & 17 & 0 & 0 \\
\hline Vol. 27 N. 2 jun. 2005 & 16 & 0 & 0 \\
\hline Vol. 27 N. 3 set. 2005 & 22 & 0 & 0 \\
\hline Vol. 27 N. 4 dez. 2005 & 16 & 0 & 0 \\
\hline Vol. 28 N. 1 mar. 2006 & 13 & 0 & 0 \\
\hline Vol. 28 N. 2 jun. 2006 & 13 & 0 & 0 \\
\hline Vol. 28 N. 3 set. 2006 & 15 & 0 & 0 \\
\hline Vol. 28 N. 4 dez. 2006 & 17 & 0 & 0 \\
\hline Vol. 29 N. 1 mar. 2007 & 19 & 0 & 0 \\
\hline Vol. 29 N. 2 jun. 2007 & 14 & 0 & 0 \\
\hline Vol. 29 N. 3 set. 2007 & 18 & 0 & 0 \\
\hline Vol. 29 N. 4 dez. 2007 & 21 & 0 & 0 \\
\hline Vol. 30 N. 1 mar. 2008 & 17 & 0 & 0 \\
\hline
\end{tabular}




\begin{tabular}{|l|c|c|c|}
\hline Vol. 30 N. 2 jun. 2008 & $\mathbf{1 1}$ & 0 & 0 \\
\hline Vol. 30 N. 3 set. 2008 & $\mathbf{1 8}$ & 0 & 0 \\
\hline Vol. 30 N. 4 dez. 2008 & $\mathbf{1 5}$ & 0 & 0 \\
\hline Vol. 31 N. 1 mar. 2009 & $\mathbf{1 3}$ & $\mathbf{1}$ & 0 \\
\hline Vol. 31 N. 2 jun. 2009 & $\mathbf{1 4}$ & 0 & 0 \\
\hline Vol. 31 N. 3 set. 2009 & $\mathbf{1 5}$ & 0 & 0 \\
\hline Vol. 31 N. 4 dez. 2009 & $\mathbf{1 7}$ & 0 & 0 \\
\hline Vol. 32 N. 1 mar. 2010 & $\mathbf{2 1}$ & 0 & 0 \\
\hline Vol. 32 N. 2 jun. 2010 & $\sim \mathbf{P}$ & 0 & 0 \\
\hline Vol. 32 N. 3 set. 2010 & $\sim \mathbf{P}$ & 0 & 0 \\
\hline Vol. 32 N. 4 dez. 2010 & $\sim \mathbf{P}$ & 0 & 0 \\
\hline total & $\mathbf{6 7 2}$ & $\mathbf{2}$ & 0 \\
\hline
\end{tabular}

\subsection{2 - Periódicos da Área de Ensino de Química}

No periódico Química Nova (QN) foram publicados 2866 no período de 1999 a 2010, dentre estes havíamos coletado um artigo, porém após um estudo verificamos o seu não enquadramento ao problema.

Tabela 17 - Química Nova / ISSN 1678-7064 On Line Sociedade Brasileira de Química - SBQ

Home Page: http://www.sbq.org.br / http://quimicanova.sbq.org.br/index.php

\begin{tabular}{|l|c|c|c|}
\hline \multicolumn{1}{|c|}{$\begin{array}{c}\text { VOLUME, NÚMERO E } \\
\text { DATA }\end{array}$} & $\begin{array}{l}\text { Total de } \\
\text { Artigos } \\
\text { Publicados } \\
\text { na Revista }\end{array}$ & $\begin{array}{l}\text { Artigos relacionados ao Tema da } \\
\text { Pesquisa }\end{array}$ \\
\cline { 3 - 4 } & $\begin{array}{l}\text { Referentes à } \\
\text { HFCrECN }\end{array}$ & $\begin{array}{l}\text { Referentes à } \\
\text { HFCrECN nos Do }\end{array}$ \\
\hline Vol. 22 N. 1 jan./fev. 1999 & $\mathbf{2 4}$ & 0 & 0 \\
\hline Vol. 22 N. 2 mar./abr. 1999 & $\mathbf{2 3}$ & 0 & 0 \\
\hline Vol. 22 N. 3 mai./jun. 1999 & $\mathbf{2 6}$ & 0 & 0 \\
\hline Vol. 22 N. 4 jul./ago. 1999 & $\mathbf{2 2}$ & 0 & 0 \\
\hline Vol. 22 N. 5 set./out. 1999 & $\mathbf{2 1}$ & 0 & 0 \\
\hline Vol. 22 N. 6 nov./dez. 1999 & $\mathbf{2 1}$ & 0 & 0 \\
\hline Vol. 23 N. 1 jan./fev. 2000 & $\mathbf{2 3}$ & 0 & 0 \\
\hline Vol. 23 N. 2 mar./abr. 2000 & $\mathbf{2 2}$ & 0 & 0 \\
\hline Vol. 23 N. 3 mai./jun. 2000 & $\mathbf{2 2}$ & 0 & 0 \\
\hline Vol. 23 N. 4 jul./ago. 2000 & $\mathbf{2 3}$ & 0 & 0 \\
\hline Vol. 23 N. 5 set./out. 2000 & $\mathbf{2 2}$ & 0 & 0 \\
\hline Vol. 23 N. 6 nov./dez. 2000 & $\mathbf{2 1}$ & 0 & 0 \\
\hline Vol. 24 N. 1 jan./fev. 2001 & $\mathbf{2 5}$ & 0 & 0 \\
\hline Vol. 24 N. 2 mar./abr. 2001 & $\mathbf{2 0}$ & 0 & 0 \\
\hline Vol. 24 N. 3 mai./jun. 2001 & $\mathbf{2 2}$ & 0 & 0 \\
\hline Vol. 24 N. 4 jul./ago. 2001 & $\mathbf{1 9}$ & 0 & 0 \\
\hline Vol. 24 N. 5 set./out. 2001 & $\mathbf{1 9}$ & 0 & 0 \\
\hline Vol. 24 N. 6 nov./dez. 2001 & $\mathbf{3 0}$ & 0 & 0 \\
\hline Vol. 25 N. 1 jan./fev. 2002 & $\mathbf{2 4}$ & 0 & 0 \\
\hline Vol. 25 N. 2 mar./abr. 2002 & $\mathbf{2 3}$ & 0 & 0 \\
\hline Vol. 25 N. 3 mai./jun. 2002 & $\mathbf{2 6}$ & 0 & 0 \\
\hline Vol. 25 N. 4 jul./ago. 2002 & $\mathbf{2 7}$ & 0 & 0 \\
\hline Vol. 25 Suplemento N. 1 & $\mathbf{1 2}$ & 0 & 0 \\
\hline Especial, jul. 2002 & & 0 & 0 \\
\hline Vol. 25 N. 5 set./out. 2002 & $\mathbf{2 4}$ & 0 & 0 \\
\hline Vol. 25 N. 6A nov./dez. 2002 & $\mathbf{2 3}$ & 0 & 0 \\
\hline & & & 0 \\
\hline
\end{tabular}




\begin{tabular}{|c|c|c|c|}
\hline Vol. 25 N. 6B nov./dez. 2002 & 24 & 0 & 0 \\
\hline Vol. 26 N. 1 jan./fev. 2003 & 24 & 0 & 0 \\
\hline Vol. 26 N. 2 mar./abr. 2003 & 25 & 0 & 0 \\
\hline Vol. 26 N. 3 mai./jun. 2003 & 24 & 0 & 0 \\
\hline Vol. 26 N. 4 jul./ago. 2003 & 28 & 0 & 0 \\
\hline Vol. 26 N. 5 set./out. 2003 & 24 & 0 & 0 \\
\hline Vol. 26 N. 6 nov./dez. 2003 & 32 & 0 & 0 \\
\hline Vol. 27 N. 1 jan./fev. 2004 & 28 & 0 & 0 \\
\hline Vol. 27 N. 2 mar./abr. 2004 & 32 & 0 & 0 \\
\hline Vol. 27 N. 3 mai./jun. 2004 & 25 & 0 & 0 \\
\hline Vol. 27 N. 4 jul./ago. 2004 & 26 & 0 & 0 \\
\hline Vol. 27 N. 5 set./out. 2004 & 25 & 0 & 0 \\
\hline Vol. 27 N. 6 nov./dez. 2004 & 29 & 0 & 0 \\
\hline Vol. 28 N. 1 jan./fev. 2005 & 28 & 0 & 0 \\
\hline Vol. 28 N. 2 mar./abr. 2005 & 32 & 0 & 0 \\
\hline Vol. 28 N. 3 mai./jun. 2005 & 30 & 0 & 0 \\
\hline Vol. 28 N. 4 jul./ago. 2005 & 31 & 0 & 0 \\
\hline Vol. 28 N. 5 set./out. 2005 & 35 & 0 & 0 \\
\hline $\begin{array}{l}\text { Vol. } 28 \text { Suplemento nov./dez. } \\
2005\end{array}$ & 21 & 0 & 0 \\
\hline Vol. 28 N. 6 nov./dez. 2005 & 29 & 0 & 0 \\
\hline Vol. 29 N. 1 jan./fev. 2006 & 30 & 0 & 0 \\
\hline Vol. 29 N. 2 mar./abr. 2006 & 36 & 0 & 0 \\
\hline Vol. 29 N. 3 mai./jun. 2006 & 34 & 0 & 0 \\
\hline Vol. 29 N. 4 jul./ago. 2006 & 43 & 0 & 0 \\
\hline Vol. 29 N. 5 set./out. 2006 & 39 & 0 & 0 \\
\hline Vol. 29 N. 6 nov./dez. 2006 & 41 & 0 & 0 \\
\hline Vol. 30 N. 1 jan./fev. 2007 & 38 & 0 & 0 \\
\hline Vol. 30 N. 2 mar./abr. 2007 & 47 & 0 & 0 \\
\hline Vol. 30 N. 3 mai./jun. 2007 & 41 & 0 & 0 \\
\hline Vol. 30 N. 4 jul./ago. 2007 & 48 & 0 & 0 \\
\hline Vol. 30 N. 5 set./out. 2007 & 54 & 0 & 0 \\
\hline $\begin{array}{l}\text { Vol. } 30 \text { N. } 6 \text { comemorativo } \\
30 \text { anos SBQ, } 2007\end{array}$ & 18 & 0 & 0 \\
\hline Vol. 30 N. 7 nov. 2007 & 50 & 0 & 0 \\
\hline Vol. 30 N. 8 dez. 2007 & 48 & 0 & 0 \\
\hline Vol. 31 N. $12008^{*}$ & 32 & 0 & 0 \\
\hline Vol. 31 N. 22008 & 46 & 0 & 0 \\
\hline Vol. 31 N. 32008 & 40 & 0 & 0 \\
\hline Vol. 31 N. 42008 & 36 & 0 & 0 \\
\hline Vol. 31 N. 52008 & 59 & 0 & 0 \\
\hline Vol. 31 N. 62008 & 53 & 0 & 0 \\
\hline Vol. 31 N. 72008 & 53 & 0 & 0 \\
\hline Vol. 31 N. 82008 & 51 & 0 & 0 \\
\hline Vol. 32 N. 12009 & 45 & 0 & 0 \\
\hline Vol. 32 N. 22009 & 45 & 0 & 0 \\
\hline Vol. 32 N. 32009 & 23 & 0 & 0 \\
\hline Vol. 32 N. 42009 & 43 & 0 & 0 \\
\hline Vol. 32 N. 52009 & 46 & 0 & 0 \\
\hline Vol. 32 N. 62009 & 55 & 0 & 0 \\
\hline Vol. 32 N. 72009 & 48 & 0 & 0 \\
\hline Vol. 32 N. 82009 & 42 & 0 & 0 \\
\hline Vol. 32 N. 92009 & 47 & 0 & 0 \\
\hline Vol. 33 N. 12010 & 39 & 0 & 0 \\
\hline Vol. 33 N. 22010 & 43 & 0 & 0 \\
\hline Vol. 33 N. 32010 & 50 & 0 & 0 \\
\hline Vol. 33 N. 42010 & 44 & 0 & 0 \\
\hline Vol. 33 N. 52010 & 38 & 0 & 0 \\
\hline
\end{tabular}




\begin{tabular}{|c|c|c|c|}
\hline Vol. 33 N. 62010 & 36 & 0 & 0 \\
\hline Vol. 33 N. 72010 & 34 & 0 & 0 \\
\hline Vol. 33 N. 82010 & 34 & 0 & 0 \\
\hline Vol. 33 N. 92010 & 32 & 0 & 0 \\
\hline Vol. 33 N. 102010 & 43 & 0 & 0 \\
\hline Total & 2840 & 0 & 0 \\
\hline
\end{tabular}

Na revista Química Nova na Escola (QNE), suplementar da Química Nova, 324 foi o número de artigos publicados de 1999 a 2010, dois haviam sido coletado, porém não se enquadram ao problema conforme delimitação feita para esta análise.

Tabela 18 - Química Nova na Escola ISSN 2175-2699 On Line Sociedade Brasileira de Química - SBQ

Home Page: http://www.sbq.org.br / http://qnesc.sbq.org.br/online/

\begin{tabular}{|c|c|c|c|}
\hline \multirow{2}{*}{$\begin{array}{l}\text { VOLUME, NÚMERO E } \\
\text { DATA }\end{array}$} & \multirow{2}{*}{$\begin{array}{l}\text { Total de } \\
\text { Artigos } \\
\text { Publicados } \\
\text { na Revista }\end{array}$} & \multicolumn{2}{|c|}{$\begin{array}{l}\text { Artigos relacionados ao Tema da } \\
\text { Pesquisa }\end{array}$} \\
\hline & & $\begin{array}{l}\text { Referentes à } \\
\text { HFCrECN }\end{array}$ & $\begin{array}{l}\text { Referentes à } \\
\text { HFCrECN nos Do }\end{array}$ \\
\hline Vol. 09 mai. 1999 & 11 & 0 & 0 \\
\hline Vol. 10 nov. 1999 & 14 & 0 & 0 \\
\hline Vol. 11 mai. 2000 & 10 & 0 & 0 \\
\hline Vol. 12 nov. 2000 & 11 & 0 & 0 \\
\hline Vol. 13 mai. 2001 & 11 & 0 & 0 \\
\hline Vol. 14 nov. 2001 & 11 & 0 & 0 \\
\hline Vol. 15 mai. 2002 & 9 & 0 & 0 \\
\hline Vol. 16 nov. 2002 & 11 & 0 & 0 \\
\hline Vol. 17 mai. 2003 & 12 & 0 & 0 \\
\hline Vol. 18 nov. 2003 & 13 & 0 & 0 \\
\hline Vol. 19 mai. 2004 & 12 & 0 & 0 \\
\hline Vol. 20 nov. 2004 & 12 & 0 & 0 \\
\hline Vol. 21 mai. 2005 & 11 & 0 & 0 \\
\hline Vol. 22 nov. 2005 & 11 & 0 & 0 \\
\hline Vol. 23 mai. 2006 & 12 & 0 & 0 \\
\hline Vol. 24 nov. 2006 & 11 & 0 & 0 \\
\hline Vol. 25 mai. 2007 & 11 & 0 & 0 \\
\hline Vol. 26 nov. 2007 & 11 & 0 & 0 \\
\hline Vol. 27 fev. 2008 & 9 & 0 & 0 \\
\hline Vol. 28 mai. 2008 & 10 & 0 & 0 \\
\hline Vol. 29 ago. 2008 & 10 & 0 & 0 \\
\hline Vol. 30 nov. 2008 & 12 & 0 & 0 \\
\hline Vol. 31 N. 1 fev. 2009 & 10 & 0 & 0 \\
\hline Vol. 31 N. 2 mai. 2009 & 11 & 0 & 0 \\
\hline Vol. 31 N. 3 ago. 2009 & 10 & 0 & 0 \\
\hline Vol. 31 N. 4 nov. 2009 & 10 & 0 & 0 \\
\hline Vol. 32 N. 1 fev. 2010 & 10 & 0 & 0 \\
\hline Vol. 32 N. 2 mai. 2010 & 10 & 0 & 0 \\
\hline Vol. 32 N. 3 ago. 2010 & 10 & 0 & 0 \\
\hline Vol. 32 N. 4 nov. 2010 & 8 & 0 & 0 \\
\hline Total & 324 & 0 & 0 \\
\hline
\end{tabular}




\subsection{3 - Periódicos da Área de Ensino de Biologia}

Vinte e sete (27) é a quantidade de artigos publicados na Revista de Ensino de Biologia (REB), de 2007 a 2009, também nenhum artigo constatado.

Tabela 19 - Revista de Ensino de Biologia ISSN 1982-1867 On Line Sociedade Brasileira de Ensino de Biologia - SBEnBio Home Page: http://www.sbenbio.org.br/

\begin{tabular}{|l|l|c|c|}
\hline \multirow{2}{*}{$\begin{array}{c}\text { vOLUME, NÚMERO E } \\
\text { DATA }\end{array}$} & $\begin{array}{l}\text { Total de } \\
\text { Artigos } \\
\text { Publicados } \\
\text { na Revista }\end{array}$ & $\begin{array}{l}\text { Artigos relacionados ao Tema da } \\
\text { Pesquisa }\end{array}$ \\
\cline { 3 - 4 } & $\begin{array}{l}\text { Referentes à } \\
\text { HFCrECN }\end{array}$ & $\begin{array}{l}\text { Referentes à } \\
\text { HFCrECN nos Do à }\end{array}$ \\
\hline N. 0 ago. 2005 & $\mathbf{5}$ & 0 & 0 \\
\hline N. 1 ago. 2007 & $\mathbf{8}$ & 0 & 0 \\
\hline N. Especial nov. 2007 & $\mathbf{5}$ & 0 & 0 \\
\hline N. 2 nov. 2008 a out. 2009 & $\mathbf{9}$ & 0 & 0 \\
\hline Total & $\mathbf{2 7}$ & 0 & 0 \\
\hline
\end{tabular}

\subsection{4 - Periódicos da Área de Ensino de Ciências Naturais}

Na Alexandria - Revista de Educação em Ciência e Tecnologia (Alexandria) dos 50 artigos publicados de 2008 (data da 1ª edição) a 2010, um artigo fora coletado, mas não tem proximidade com problema.

Tabela 20 - Alexandria - Revista de Educação em Ciência e Tecnologia. ISSN 1982-5153 On Line

Home Page: http://www.ppgect.ufsc.br/alexandriarevista/

\begin{tabular}{|l|c|c|c|}
\hline \multirow{2}{*}{$\begin{array}{c}\text { VOLUME, NúMERO E } \\
\text { DATA }\end{array}$} & $\begin{array}{l}\text { Total de } \\
\text { Artigos } \\
\text { Publicados } \\
\text { na Revista }\end{array}$ & $\begin{array}{l}\text { Artigos relacionados ao Tema da } \\
\text { Pesquisa }\end{array}$ \\
\cline { 3 - 4 } & $\begin{array}{l}\text { Referentes à } \\
\text { HFCrECN }\end{array}$ & $\begin{array}{l}\text { Referentes à } \\
\text { HFCrECN nos Do }\end{array}$ \\
\hline Vol. 1 N. 1 mar. 2008 & $\mathbf{9}$ & 0 & 0 \\
\hline Vol. 1 N. 2 jul. 2008 & $\mathbf{5}$ & 0 & 0 \\
\hline Vol. 1 N. 3 nov. 2008 & $\mathbf{5}$ & 0 & 0 \\
\hline Vol. 2 N. 1 mar. 2009 & $\mathbf{6}$ & 0 & 0 \\
\hline Vol. 2 N. 2 jul. 2009 & $\mathbf{1 1}$ & 0 & 0 \\
\hline Vol. 2 N. 3 nov. 2009 & $\mathbf{5}$ & 0 & 0 \\
\hline Vol. 3 N. 1 mai. 2010 & $\mathbf{5}$ & 0 & 0 \\
\hline Vol. 3 N. 2 jul. 2010 & $\mathbf{4}$ & 0 & 0 \\
\hline Total & $\mathbf{5 0}$ & 0 & 0 \\
\hline
\end{tabular}

De 2000 a 2010 foram publicados 307 artigos na revistas Ciência \& 
Educação (C\&Ed), dos quais treze haviam sido, inicialmente, coletados. Depois de um estudado mais aprofundado, quatro foram selecionados para análise, pela proximidade ao tema-problema, ei-los:

A-C\&Ed - GATTI, Sandra Regina; NARDI, Roberto; SILVA, Dirceu da. A História da Ciência na Formação do Professor de Física: subsídios para um curso sobre o tema atração gravitacional visando às mudanças de postura na ação docente. Ciência \& Educação, Bauru-SP, v. 10, n.3, p. 491-500, 2004.

B-C\&Ed - OKI, Maria da C. Marinho; MORADILLO, Edílson Fortuna de. O Ensino de História da Química: contruindo para a compreensão da natureza da ciência. Ciência \& Educação, Bauru-SP, v. 14, n. 1, p. 67-88, 2008.

C-C\&Ed - SORPRESO, Thirza P.; ALMEIDA, Maria José P. Monteiro de. Discursos de Licenciandos em Física sobre a Questão Nuclear no Ensino Médio: foco na abordagem histórica. Ciência \& Educação, Bauru-SP, v. 16, n. 1, p. 37-60, 2010.

D-C\&Ed - GUIMARÃES, Márcio T.; CARVALHO, Washington I. P. de; OLIVEIRA, Mônica Santos. Raciocínio Moral na Tomada de Decisões em Relação a Questões Sociocientíficas: o exemplo do melhoramento genético. Ciência \& Educação, Bauru-SP, v. 16, n. 2, p. 465-477, 2010.

O planejamento de um curso com o fim de evidenciar o desenvolvimento histórico do conceito de atração gravitacional, com base nas concepções alternativas comuns na literatura, nas noções diagnosticadas entre docentes de Física de ensino médio e nas sugestões obtidas nas pesquisas recentes sobre o ensino e aprendizagem de ciências naturais foi o objetivo dos autores do artigo AC\&Ed.

A pesquisa foi feita em um curso de Licenciatura em Física da UNESP, no primeiro semestre de 2003, em que os autores (GATTI; NARDI; SILVA, 2004, p. 492) procuraram

[...] inserir a discussão sobre a inserção da História da Ciência no ensino de Ciências na disciplina de Prática de Ensino de Física, a partir de um curso para a formação de professores, tendo como pano de fundo o desenvolvimento histórico do tema atração gravitacional. A proposta procurava evidenciar as dificuldades para a mudança de postura na ação docente, além de propor um modelo de formação que favorecesse a adoção de metodologias de ensino mais voltadas para a construção do conhecimento.

Justificaram a inserção da HC em virtude dela

[...] a) proporcionar uma visão mais adequada de Ciência enquanto processo de construção; b) servir como base de elementos de reflexão na definição de temas fundamentais; c) revelar os obstáculos epistemológicos por meio da semelhança entre concepções alternativas e concepções 
relativas a teorias científicas do passado, quando possível e d) superar os modelos de ensino cujo foco principal seja a mera transmissão dos "produtos" da Ciência. (GATTI; NARDI; SILVA, 2004, p. 492-493)

Para tal fim, eles procederam a um levantamento inicial, em que fizeram o diagnóstico de concepções prévias dos licenciandos sobre a atração gravitacional; levantamento sobre a visão de ciência que os licenciandos tinham e, didaticamente, serviram-se da "conversação avaliativa", trata-se de um procedimento de ensino proposto por Duschl $(1995, \text { p. } 5)^{73}$ em que se estabelece um diálogo, em cinco passos instrucionais - numa dinâmica de acordo e desacordo -, entre docente e discente, esta dinâmica possibilitaria avaliar a "informação útil" gerada durante o processo de ensino e aprendizagem dialogal.

O ensino é baseado na solução de problemas reais e que tenham sentido. Dá-se autonomia aos discentes para participarem do processo de produção de solução do problema e construção de argumentos significados à estruturação do conhecimento. Esses procedimentos utilizados no curso possibilitaram o trabalho coletivo, debates e sínteses de textos.

Para o desenvolvimento da pesquisa em sala de aula, relatam os autores do artigo A-C\&Ed (GATTI; NARDI; SILVA, 2004, p. 495) que procederam, primeiramente, ao:

Diagnóstico das concepções dos docentes sobre o tema atração
gravitacional, a partir da utilização de questões presentes na literatura;
Levantamento da visãa de Ciência dos docentes através de questões
baseadas no VOSTS ${ }^{74}$ (Viwes on Science-Technology-Society).
Entrevistas do tipo Grupo focal (focus group) com o objetivo de revelar as
concepções dos participantes sobre as possibilidades da inserção da
História da Ciência no ensino, além de sensibilizar o grupo, criando
necessidades para o desenvolvimento do tema.
Questionário de concepções sobre os processos de ensino e aprendizagem.

${ }^{73}$ DUSCHL, R. A. Más allá del conocimiento: los desafíos epistemológicos y sociales de la enseñanza mediante el cambio conceptual. Enseñanza de las Ciencias, Espanha, v.13, n.1, p. 3- 14, 1995. Os cinco passos da avaliação conversação avaliativa de Duschl (op. cit., p. 10) são:

1. Fazer com que os sujeitos ou grupos participem das tarefas que produzam uma diversidade ou gama de resultados.

2. Conduzir apresentações em público para dar uma idéia precisa da diversidade de esforços e significados.

3. Analisar e discutir as características de tal diversidade concentrando-se no objetivo.

4. Síntese em grupo: Empregar discussões para, na medida do possível, obter uma opinião consensual ou ao menos uma diminuição da diversidade original, fazendo uso dos critérios do objetivo da tarefa.

5. Aplicar o que foi aprendido em uma situação diferente. Analisar novamente uma tarefa já realizada ou empregá-la a outras novas.

${ }^{74}$ AIKENHEAD, G. S.; RYAN, A. G. Student's preconceptions about the epistemology of science. Science Education, V. 76. N. 6, 1992, p. 599-580. 
No segundo momento, passaram para as discussões dos trabalhos sugeridos e o curso proposto para inclusão da abordagem histórica da atração gravitacional foi desenvolvido em três partes dinâmicas (GATTI; NARDI; SILVA, 2004, p. 495), a saber:

“1) Atividades de conhecimento epistemológico/científico" - panorama geral do desenvolvimento histórico da atração gravitacional e diagnósticos das concepções alternativas, apoiando-se nos textos de autores, entre outros, como Aristotéles, Ptolomeu, Copérnico, Galileu; cuja avaliação ocorreu por meio da discussão da produção individual e coletiva, exposições e construção de sínteses.

“2) Atividades de reflexão acerca dos referenciais teóricos sobre a aprendizagem e a aprendizagem em Ciências", que consistiram no debate de textos e pesquisas atuais em ECN, que possibilitaria a ocorrência de mudança conceitual e reflexão crítica nos participantes e;

“3) Atividades de síntese das idéias debatidas" form solicitadas a cada licenciando que elaborasse uma espécie de memorial retrospectivo com destaque para questões debatidas, tidas como relevantes e as mudanças de postura autopercebidas. Assim como a elaboração dos minicursos destinados para discentes da Escola média sobre atração gravitacional:

O minicurso desenvolvido pelos estudantes foi inicialmente apresentado sob a forma de um seminário para os demais participantes e posteriormente aplicado em situações reais de sala de aula no Ensino Médio, durante as atividades de estágio no segundo semestre letivo de 2003. (GATTI; NARDI; SILVA, 2004, p. 496)

Subjacentemente, proposta inclusionista foi permeiada pela teoria construtivista de ensino e aprendizagem, perceptível no formato organizacional e nas suas intenções expressas ao afirmarem que com os temas discutidos tencionavam o "desenvolvimento de um modelo construtivista de ensino e à articulação entre a teoria e prática através da elaboração e aplicação do minicursos" (GATTI; NARDI; SILVA, 2004, p. 496). E a história da ciência como o elemento motivador de fundo dos debates:

Nesta proposta, a História da Ciência ocupa um de destaque, constituindo o pano de fundo sobre o qual as discussões foram realizadas. [...] Ao propor momentos de reflexão sobre como o conceito de gravidade foi elaborado 
historicamente, ampliamos a discussão, não apenas centrada no conhecimento em si, mas também nas dificuldades enfrentadas em sua elaboração e nas diversas condicionantes presentes no contexto, que interferem no processo de construção do conhecimento científico. (GATTI; NARDI; SILVA, 2004, p. 498)

No entanto, os autores não apresentaram os resultados finais do projeto de intervenção para a HFCrECN, afirmam - em seu texto - que "Os resultados da intervenção deverão ser objeto de outra comunicação" (GATTI; NARDI; SILVA, 2004, p. 498).

Portanto, embora se trata de apresentação parcial do trabalho, pelo que foi demonstrado no artigo A-C\&Ed, ele pode ser localizado em duas categorias, a primeira, da Contextualização Interna, já que o estudo histórico encerrou-se aos textos dos autores que se debruçaram sobre o conceito e não em contexto macro do desenvolvimento sociocultural, econômico, político do conceito atração gravitacional; a segunda, Criticidade, por inserir na abordagem com os textos os debates, seminários e discussões em grupos, respectivamente.

$\mathrm{O}$ artigo B-C\&Ed é consequente de um estudo de caso em que os autores (OKI; MORADILLO, 2008, p. 67) tencionaram "explorar as potencialidades de aproximação entre História e Filosofia da Ciência da educação científica mediante utilização do ensino de História da Química" com a finalidade de auxiliar os discentes a compreenderem a natureza da ciência e aprender os conceitos químicos. Tal estudo ocorreu no âmbito de uma disciplina História da Química, na licenciatura em Química da Universidade Federal da Bahia, num período de um ano letivo. Os dados foram coletados em sala de aula, sendo que o estudo piloto foi feito no primeiro semestre.

A pesquisa didática realizada foi de caráter exploratório de abordagem qualitativa, com aplicação de técnicas tais como questionário "de perguntas abertas", entrevistas semiestruturadas, gravação de discussões em grupos, registro de observações e anotações de aulas. As categorias de análise foram pré-definidas. Os autores procederam primeiro ao levantamento para a identificação de concepções prévias dos discentes sobre conteúdos da FC, esses dados foram coletados por meio de um questionário de perguntas abertas; em seguida procederam a um trabalho de contextualização histórica dos conceitos químicos e avaliação da sua influência no processo de compreensão conceitual.

Apoiaram-se na literatura de HFC, cujo tema principal foi "as controvérsias 
envolvendo atomistas e anti-atomistas relativas à aceitação do atomismo no século XIX", apoiando-se na leitura, discussão de textos e reuniões em grupos para avaliar a recepção e retenção de conhecimento.

Os autores constataram também que sob a égide do sistema tradicional não se tem permitido uma interligação entre a $\mathrm{HC}$ e $\mathrm{FC}$, o que efetivamente empobrece o debate e o desenvolvimento de uma visão crítica e de uma autocrítica na seleção de aspectos da $\mathrm{HC}$ e os momentos didáticos de sua inserção e abordagem coerente, quando não dogmatizados e ideologizados, a percepção da disparidade entre HC e FC podemos constatá-lo da expressão seguinte dos autores que corrobora o que já afirmamos anteriormente, sobretudo, ao falarmos sobre a identidade da HFC:

Ainda que a valorização desses campos na formação profissional tenha crescido, a inclusão desses temas nos currículos ainda segue um modelo tradicional, no qual, geralmente, disciplinas específicas abordam os conteúdos e a articulação com a didática é extremamente frágil. Tradicionalmente, o ensino da História das Ciências por disciplinas específicas não busca fazer uma ampla articulação com conteúdos da Filosofia da Ciência. (OKI; MORADILLO, 2008, p. 69).

Ora, são dois problemas levantados aqui: o primeiro refere-se ao que já mencionamos anteriormene: a falta ou parca integração entre HC e FC, vamos mais além, entre HC, FC e SC, numa projeção de integração metacientífica ampliada: HFSC (embora falte-Ihe a análise psicológica do comportamento dos cientista, mas, por ora, essa análise pode ser suprida via análise filosófica e sociológica do comportamento).

O segundo problema está relacionado às deficiências nos planejamentos curriculares, é com razão que o segundo momento de interconexão entre áreas para o alcance do suposto objetivo da HFCrECN, talvez, não seja efetivamente alcançado, além de outras implicações, sem uma vinculação eficiente à didática, isto é, ancorar-se à teorias de ensino e aprendizagem validadas, consistentes e flexíveis para incorporação da abordagem de aspectos histórico-filosófico-sociológicos das ciências e tecnologias.

Voltando ao artigo B-C\&Ed, os autores afirmam que - talvez, em virtude da pesquisa didática - o planejamento das aulas fora feito de tal forma que as "[...] diversas dimensões epistemológicas pudessem ser adequadamente contempladas" (OKI; MORADILLO, 2008, p. 71). 
Entretanto - embora para a nossa compreensão tenha faltado algumas informações sobre como e quais resultados foram obtidos em relação à rediscussão das controvérsias entre atomistas e não-atomistas no século 19 - os autores (OKI; MORADILLO, 2008, p. 84) afirmam que

\begin{abstract}
O trabalho realizado na disciplina História da Química, fundamentado numa abordagem explicita de conteúdos da Filosofia da Ciência, possibilitou algum ganho em relação aos conhecimentos epistemológicos detectados, inicialmente, entre os alunos pesquisados. Concepções mais elaboradas e menos ingênuas foram identificadas nos momentos posteriores ao trabalho didático realizado em cada aula, uma vez que detectou-se o aparecimento de novas categorias que refletiam posições mais racionalistas e contextualizadas sobre o conhecimento científico e a ciência.
\end{abstract}

Além do mais, verificou-se também o que podemos chamar de fenômeno de regressão epistemológica no processo da desobstaculização epistêmica, um retrocesso às concepções vulgares que supostamente haviam sido consideradas dissipadas:

\begin{abstract}
Entretanto, ao final do curso, alguns alunos ainda associavam o átomo a uma parte da realidade, fazendo afirmações carregadas de certo realismo ingênuo. Considera-se que esta seja uma questão complexa que evidencia a grande penetração de realismo ingênuo no ensino de Química, em especial em relação às representações químicas. (OKI; MORADILLO, 2008, p. 84)
\end{abstract}

Este fenômeno de regressão ilustra a persistência dos obstáculos epistemológicos - nos moldes descritos por Bachelard (1996, p. 17; 1971/2001, p. 168-169) - e a complexidade dos processos de ensino e aprendizagem, para Bachelard implicariam na necessidade de mudança cultural (da cultural vulgar para cultural científica), o que não significa, para nós, que seja necessário fazer uma guerra da eliminação da cultura vulgar, porque as duas culturas não precisam ser consideradas como antagônicas, mas como diferentes, com perspetivas e objetivos diferentes.

Em outras palavras, ao contrário da mudança de cultura preferimos o desenvolvimento cultural, pelo que a cultura do senso comum não precisa ser eliminada para desenvolver a cultura científica. À regressão que representa a inércia, estagnação, acomodação da mentalidade às concepções da primeira cultura experimental (senso comum) o engajamento epistemológico contrapõe 0 desenvolvimento cultural, em prol da formação de mentalidade filosófico-científica e 
considerando a alteridade entre as culturas.

O desenvolvimento de uma cultura qualquer que seja não é razão para eliminação da outra. $O$ desenvolvimento da cultura científica e filosófica não precisa da morte da cultura popular, muito menos de promoção de uma guerra contra o senso comum, a existência desta em nada importa à mentalidade filosóficocientífica, mas faz-se necessário atualizar o indivíduo que busca a cultura filosóficocientífica, considerando suas dimensões policulturais e ao atualizá-lo refinar seu estatuto ontológico de ser fautor epistemológico.

Portanto, o desenvolvimento da cultura científica ou filosófica contribui para a distinção e uso coerente das dimensões policulturais da riqueza gnosiológica do patrimônio cultural humano. O desenvolvimento da cultura científica não deve tencionar uniformizar os indivíduos, para não correr o risco de fazer da ciência uma espécie de religião.

De volta ao artigo, para os autores o resultado contribuiu para confirmar a relevância da disciplina (História da Química) para dissipar concepções simplistas e contextualizar o conhecimento científico e a compreensão da sua natureza, constataram - nos discentes participantes da pesquisa - as dificuldades em superar obstáculos, tais como: as "concepções realistas ingênuas fortemente enraizadas em suas visões epistemológicas” (OKI; MORADILLO, 2008, p. 67-68).

Ou ainda, para Oki e Moradillo "[...] o referencial histórico-epistemológico contribuiu para que os estudantes de Química envolvidos neste trabalho adquirissem uma imagem de ciência mais contextualizada e melhor formação inicial." $E$, na sequência, afirmam estes autores que o desenvolvimento da pesquisa na disciplina "[...] possibilitou, em especial, o reconhecimento da ciência como uma atividade humana sujeita a erros e conflitos, além da percepção do caráter provisório do conhecimento científico e da complexidade envolvida no contexto da justificação de novas teorias científicas" (OKI; MORADILLO, 2008, p. 68 e 85).

Ademais, fora atendida, também, a expectativa inicial dos pesquisadores em relação à possibilidade de abordar questões de FC na HC (Química) no contexto de ensino - interdependência entre FC e HC já fora discutida por Lakatos e Bachelard $^{75}$-, Oki e Moradillo (2008, p. 70) chamam atenção ao considerarem que "[...] a opção didática pela História da Ciência deve acontecer de forma articulada

${ }^{75}$ Para ambos vide obras referenciadas neste trabalho. 
com a Filosofia da Ciência, a fim de ajudar na análise crítica do conhecimento científico produzido e na transposição didática dos conteúdos."

Entretanto, eles reconhecem - com toda razão - que

Apesar de algumas divergências detectadas nos resultados das pesquisas envolvendo concepções sobre a natureza da ciência, um aspecto consensual é o reconhecimento da importância da História e Filosofia da Ciência no aprimoramento das concepções de alunos e professores, em especial mediante estratégias de formação que fazem uso de abordagens explícitas, as quais têm se mostrado mais eficientes. Oki e Moradillo (2008, p. 71)

Eles fazem uma advertência de extrema relevância metodológica, epistemológica, de planejamento curricular e até política, para sobrevivência dos argumentos teóricos do movimento da HFCrECN, se se considera a sua inclusão válida e necessária ao ensino, então, há que perceber, como uma condicio sine qua non, que "[...] necessita-se de maior número de investigações empíricas para que seja avaliada a influência deste tipo de abordagem e sua maior ou menor eficácia na formação inicial", além do mais, "[...] outros espaços curriculares precisam ser identificados para que as lacunas relativas à dimensão epistemológica sejam preenchidas" (OKI e MORADILLO, 2008, p. 71 e 85). [destaque em negrito nosso]

Este reconhecimento dos autores não pode ser reduzido meramente à consequência da inexistência no currículo da disciplina FC, ou então, que a disciplina fosse HFC/HFSC para que a abordagem fosse naturalmente integrada o suficiente. A mera junção terminológica ou conceitual não é garantia ou certidão ontológica para a aventura e engajamento na complexidade do ensinar e aprender ciência ou quaisquer coisas que seja útil filosoficamente aprender ou ensinar. Ser por ser não é razão suficiente para existir na realidade efetiva.

Percebemos nos autores um esforço - defensável - de advogar uma questão cuja importância vai além da justificação teórica, pois, interpela e reclama de uma validação, uma espécie de apresentação do ônus da prova material (empírica) além da expeculação inclusionista, e isto é muito sério, porque se trata, afinal de contas, de uma implicação metodológica e epistemológica fundamental da/para HFCrECN, já que o ensino e a aprendizagem não se fazem com especulação teórica ad aeternum.

Além da necessidade de investigações em que se testa a HFCrECN em 
sala de aula com demonstração de resultados efetivos de aprendizagem - ou seja, comprovação da hipótese de que baseando o ensino e aprendizagem em abordagem dos aspectos histórico-filosóficos melhora-se o aprendizado científico -, há também que se partir para outra empreitada, a da produção de livros didáticos em conformidade com os fundamentados da HFC/HFSC aplicáveis ao ensino e validados na prática didática em sala de aula. Nesse último caso, e. g., sabe-se que o Projeto HIPST (referido anteriormente) teve objetivos voltados para geração de material didático experimentado! Neste sentido, percebe-se que não se trata mais de condicio sine quan non, mas sim de condicionis sine quibus non ${ }^{76}$.

Finalmente, percebemos que o artigo B-C\&Ed pode ser localizado em três categorias, a Contextualização Interna, por se tencionar ao contextual conceitual do atomismo; Criticidade pela abordagem epistemológica, na tentativa de romper com os obstáculos epistemológicos (concepções ingênuas), o propiciamente de círculos de debates, discussões em grupos, leituras para desenvolvimento de reflexão crítica; Autoaperfeiçoamento - a busca pelo entendimento de que a ciência é uma das atividades humanas, portanto, sujeita a erros e conflitos e, por fim, Falibilidade Epistêmica - por se tencionar também às questões da percepção do caráter provisório do conhecimento científico e da complexidade envolvida no contexto da justificação de novas teorias científicas.

No artigo C-C\&Ed, Sorpreso e Almeida (2010), analisaram discursos de dois licenciandos que elaboraram uma proposta de ensino fundamentado em HFC, a partir da necessidade de introduzir a $\mathrm{HC}$ - projetada pela segunda autora - em sala de aula, na disciplina Prática de Ensino de Física e Estágio Supervisionado, para licenciatura em Física, desenvolvida na Faculdade de Educação, da Universidade Estadual de Campinas, durante o primeiro semestre de 2005 e considerando as mudanças no currículo de Física do ensino médio e suas implicações na formação docente. Evidentemente, essas mudanças são as provocadas pelos PCN, PCN+, DCEM.

Do ponto de vista das estratégias de pesquisa didática, as autoras adotaram a Análise do Discurso ${ }^{77}$ como referencial para análise de dados coletados.

\footnotetext{
${ }^{76}$ Forma plural da expressão anterior, às vezes, também grafado como conditiones sine quibus non.

${ }^{77} \mathrm{Na}$ versão francesa de Michel Pêcheux, vulgarizada no Brasil por Eni P. Orlandi. Nos textos: Análise do Discurso: princípios e procedimentos. Campinas: Pontes, $2005 \mathrm{e}$ _. Paráfrase e Polissemia: a fluidez nos limites do simbólico. In: Rua: Revista do Núcleo de Desenvolvimento da Criatividade, Campinas, v.4, n.1, 1998, p. 9-19.
} 
Elas afirmam ter se apoiaram no conceito de imaginário como referencial para poder compreender as posições dos docentes em formação no que concerne ao uso da HC no ensino de Física, em nível médio.

O tema foi escolhido coletivamente entre a docente (segunda autora) e os discentes (licenciandos): "'questão nuclear".

Sorpreso e Almeida (2010, p. 46) relatam que os futuros docentes em formação foram divididos em duplas, a cada dupla foi atribuído o planejamento e a apresentação de um seminário relacionado à questão nuclear enfocando uma abordagem específica, entre as abordagens estava o enfoque histórico (HC). Relatam que em relação à apresentação do seminário, havia sido previsto: a explicação da abordagem e apresentação de um episódio de ensino sobre questão nuclear.

Para Sorpreso e Almeida (2010, p. 47), o objetivo seria o de fazer com que o licenciando pudesse conhecer e refletir sobre os

[...] aspectos da cotidianidade do ensino médio, com foco no ensino de Física, a partir de observações em escolas, pesquisas publicadas, recursos didáticos destinados a esse ensino e documentos oficiais como os parâmetros curriculares; discuta e se posicione quanto a concepções de ciência e de ensino veiculadas em recursos didáticos, pensando o seu funcionamento em estratégias específicas de ensino; compreenda elementos da pesquisa educacional sobre educação em ciências e procure relacioná-los com a prática pedagógica em aulas de Física do ensino médio e reflita sobre elementos do planejamento escolar do Ensino Médio.

É interessante notar que as autoras fizeram questão de contemplar a rede das orientações que concorrem prescritivamente para o campo educacional pesquisas, DO e recursos didáticos, em relação a estas últimas orientações, em especial, os livros didáticos, estes têm se tornado as únicas orientações adotadas na prática didática escolar, sobretudo. Os DO - no caso da atual reforma: PCN, DCEM, etc. - nem sempre são conhecidos pela grande maioria dos docentes escolares (até mesmo universitários ${ }^{78}$ ).

${ }^{78}$ Em 2005 quanto da nossa pesquisa para a conclusão do mestrado, em visita à algumas Escola em São Paulo, encontramos os PCN amontoados em condições de abandonos, nos recantos de bibliotecas ou salas de leituras, em algumas escolas, sobretudo, as interioranas nem sempre dispões dessas orientações. Em 2007 constatamos os mesmo problema em Mato Grosso (interior) e São Paulo (Capital), durante um levantamento sobre a relevância da HC na formação docente. $\mathrm{Na}$ Universidade, em nossa experiência docente, tanto na licenciatura e quanto no bacharelado, temos percebido o grande desconhecimento das orientações oficiais, inclusive as diretrizes dos cursos, por uma parte significativa de docentes tanto os atuantes na formação de licenciados quanto na dos bacharéis, o que tem gerado muitas dificuldades no planejamento de propostas curriculares dos 
As atividades da pesquisa didática foram divididas em três momentos que permitiram analisar o imaginário da dupla de licenciandos responsável pela abordagem histórica da questão nuclear, ipsis verbis:

\begin{abstract}
O primeiro momento refere-se à análise de um questionário respondido pelos licenciandos na primeira aula da disciplina. Nesse momento encontramos elementos presentes nos discursos dos licenciandos bastante relacionados à sua memória discursiva, sem a interferência das condições de produção [do conhecimento científico] que fizeram parte das ocorrências durante a disciplina, já que se tratava do primeiro dia de aula.

No segundo momento analisamos os discursos referentes aos planejamentos do seminário e episódios de ensino em que podemos notar indícios das condições imediatas da disciplina nos discursos dos licenciandos. Nesse segundo momento os licenciandos leram, utilizaram e discutiram publicações da área de ensino de ciências.

Por fim, no terceiro momento, apresentamos os discursos relacionados ao seminário e episódio de ensino apresentados, em que analisamos o resultado final do trabalho dos licenciados e o que mais se aproximaria de uma situação de ensino da questão nuclear com abordagem histórica pelos licenciandos. Para a elaboração dos episódios de ensino, os licenciandos não se restringiram à bibliografia presente no plano de curso; a professora fez sugestões de periódicos de pesquisa em ensino de ciências e levou, para a sala de aula, livros e textos como sugestão para a preparação dos seminários, além de outros recursos, como notícias de jornal. (SORPRESO; ALMEIDA, 2010, p. 47)
\end{abstract}

Porém, no inicio das aulas, foi feito um questionário para diagnosticar as expectativas em relação à disciplina e o imaginário dos discentes sobre o ensino de ciências, sem, no entanto, mencionar a HC e a Física Nuclear.

No entanto, nós pensamos que teria sido útil, também, para a pesquisa didática feita se fosse diagnosticado que discursos tinham antes, durante e depois, o que favoreceria a verificação da mudança e da evolução ou não da instrução da memória discursiva.

A análise do questionário inicial permitiu às autoras obter informações dos discentes sobre as visões de professor de Física e sobre como planejaria as suas aulas, nos discursos dos dois licenciandos estudados apareceu a menção à "história da Ciência" e à "história, prática e seus conceitos" do conteúdo planejado.

Pelo diagnóstico das autoras a noção de $\mathrm{HC}$ advindo dos imaginários dos discentes estava relacionada mais à $\mathrm{HC}$ presente nos livros didáticos e textos de divulgação científica na mídia e na escola, portanto, distante ou diferente daquela $\mathrm{HC}$ presente nas pesquisas.

cursos, às vezes, o currículo de um curso é entendido e reduzido apenas a um conjunto aglomerado de disciplinas. Este fenômeno, do desconhecimento de orientações oficiais, não se restringe a um determinado grupo, nível ou região, é comum na educação básica e superior. 
Constataram que os discentes consideravam a ciência como processo investigativo e criativo, a cujo processo de formação vinculavam a abordagem histórica, ao que as autoras inferiram que os discentes preferiam abordar processos de formação e não resultados da ciência. No entanto, ao longo da pesquisa didática, foram constatadas oscilações nos discursos dos licenciandos cuja memória discursiva estava em análise, pois: "[...] a História da Ciência passa a ser não apenas um instrumento motivador, mas também uma forma de auxiliar os alunos a compreenderem o processo de produção da ciência e, também, a se desenvolverem enquanto cidadãos" (SORPRESO; ALMEIDA, 2010, p. 50).

As autoras - ao analisarem as respostas dos licenciandos - relatam ter percebido que estes apresentavam uma concepção de $\mathrm{HC}$ semelhante à divulgada nos livros didáticos, preso às datas e descobertas consideradas "mais importantes", eles apresentavam oscilações decisórias em termos de seleção temática e de concepção da HC no ensino, isto porque num primeiro momento haviam apresentado indícios de que ensinar HC não envolve Física, indício que não aparece no momento seguinte da pesquisa didática, porque durante o seminário os licenciandos apresentaram oscilação em relação à idéia anterior: "[...] ensinar História da Ciência seria também ensinar Física e, ainda, utilizar a História da Ciência seria uma forma de aquisição de conhecimento, e não crenças" (SORPRESO; ALMEIDA, 2010, p. 51), ou ainda,

[...] pudemos identificar conflitos nos imaginários dos estudantes. Por exemplo, nos momentos iniciais da disciplina, houve indícios de que ensinar História da Ciência não seria também um meio de ensinar Física, e esse aspecto tornou-se conflituoso no decorrer da disciplina, existindo momentos em que apareceram indícios de que, em seus imaginários, ensinar história da Ciência seria um meio para que os estudantes aprendessem Física. Notamos que esses aspectos pareceram se relacionar com a condição de produção de tratarem genericamente da abordagem ou do trabalho efetivo no Ensino Médio. Ou seja, quando falavam genericamente da abordagem, possivelmente recorrendo às publicações em ensino que revisaram, a História da Ciência seria meio para ensinar Física; já durante a apresentação do episódio de ensino, a Física não foi abordada através da História da Ciência. (SORPRESO; ALMEIDA, 2010, p. 56)

O descrito acima nos interpela e faz refletir sobre as implicações metodológicas e epistemológicas na $1^{1}$ ID e necessidade da instrumentação didática dos docentes na formação inicial.

Para Sorpreso e Almeida (2010, p. 51) as oscilações ou para usar a 
expressão deles, os

[...] deslocamentos e conflitos no imaginário dos licenciandos, ocorreram pelo contato com publicações em ensino de Ciências durante as aulas da disciplina, ou mesmo em suas pesquisas para preparação do seminário e episódio de ensino, ou ainda devido a discussões e atividades da própria disciplina, que contrastavam com a História dos livros didáticos e ensino tradicional.

Este fenômeno descrito demonstra a dificuldade em mudança de cultural experimental (Bachelardiana), desenvolvimento da cultura científica e em tomada de decisão estratégica no campo didático, tal fato demonstra que as prescrições das orientações oficiais e de pesquisa - em termos de sua efetivação na práxis - sem uma instrumentação didática ${ }^{79}$ apropriada transformam-se em processo de geração de obstáculos de diversas ordens, que tendem mais a dificultar a aprendizagem e o ensino que contribuir para sua melhoria.

As oscilações de tomada de decisão estratégica epistêmico-didática-que se manifestam nos "deslocamentos e conflitos" - são, fenomenologicamente, demonstrações do quão necessário é a abordagem da HFC na formação docente, antes de quaisquer pretensões de levá-la aos bancos da Escola básica. Elas são, de fato, dificuldades (obstáculos) no processo de tomada de decisão estratégica epistêmico-didática que define a adesão docente (autoconvencimento), por isso, geram o que chamo de incerteza profissiona ${ }^{\beta 0}$. Se se optar permanecer na não instrumentação didática dos docentes em formação, para a HFCrECN, dificilmente se passará de ações anódinas que não terão efetividade na práxis educativa de formação científica.

A mudança de cultura experimental, ou melhor, o desenvolvimeno de cultura científica não é tarefa fácil que pode ocorrer em um processo rápido, trata-se de uma mudança lenta, para ilustrarmos o que afirmamos, vejamo o que Sorpreso e

\footnotetext{
${ }^{79}$ A instrumentação didática é uma categoria que criamos a partir do artigo C-C\&Ed, para localizá-lo no quadro das categorias de análise. No entanto, a instrumentação didática ocorre no processo de profissionalização docente e evolui na educação contínua ou ao longo do desenvolvimento profissional, em que a teoria se embate com a prática profissional. Daí ela ser, também, o momento adequado para a adesão docente em relação à HFCrECN.

${ }^{80}$ Incerteza Profissional entendo-a, no momento, como uma categoria conceitual que representa e pelo que se descreve o estado provisório ou constante das carências de condições epistêmicas dinâmicas e proativas no exercício das atividades profissionais de um indivíduo. Ela pode ser compreendida como o fac-símile da inatividade, um bloqueador, ou mesmo, uma "toxina" da ação organizada competente em situações nas quais se requer a tomada de decisão. A incerteza profissional pode afirmar-se, então, como obstáculo obliterante da criatividade na ação profissional teórico-prática, logo, pode reduzir o indivíduo à inação na razão e na práxis.
} 
Almeida (2010, p. 51) descrevem - em relação ao terceiro momento da sua pesquisa didática: seminário, afirmam ter observado que

[...] há bastante influência do discurso da pesquisa em suas falas. Por outro lado, a apresentação do seminário constitui-se de elementos mais próximos de uma História 'tradicional', marcando novamente contradições entre sua memória discursiva e as condições de produção imediatas.

Em relação à abordagem pretendida, observaram que

\begin{abstract}
Inicialmente, ela era tratada como algo que aumentaria o interesse dos alunos, provavelmente pelo gosto dos licenciandos pela abordagem. Nos momentos de planejamento, ela passou a ser também algo que ajudaria no desenvolvimento da cidadania. Por fim, no momento do seminário, a justificativa foi fundamentada por reflexões presentes em publicações em ensino de ciências, como, por exemplo: sua utilização dependeria dos objetivos e das concepções de ensino do professor. (SORPRESO e ALMEIDA, 2010, p. 56)
\end{abstract}

Ademais, as tentativas de mudança estão na demonstração da intenção de aprendizagem dos licenciandos participantes da pesquisa didática. Neste sentido, a pesquisa didática (na formação docente) pode servir de instrumento para diagnosticar situações de intervenção e possibilitar a criação de condições e estratégias para intervir no processo de profissionalização docente na formação inicial.

Porém, Sorpreso e Almeida (2010, p. 55), de certa forma, atentaram a essa ponderação ao afirmarem que, em virtude das oscilações em tomada de decisões por licenciandos:

Talvez eles tenham interpretado os artigos de pesquisa com base em sua história de vida e de formação no Ensino Médio ou, mesmo, no Superior. Ou seja, talvez eles tenham considerado que a apresentação da evolução de fatos históricos relacionados à física nuclear, tal como apresentaram no seminário, seria de fato uma abordagem histórica tal qual aquela proposta pela pesquisa em ensino de Ciências.

Provavelmente, pouco tempo de pesquisa e trabalho com a abordagem, durante a disciplina, não foi suficiente para que ocorressem maiores deslocamentos com relação à prática de aspectos da abordagem que os licenciandos consideraram relevantes. Ou ainda, sob determinadas condições de produção, as memórias discursivas do Ensino Básico e Superior dos licenciandos tiveram peso preponderante na produção de seus discursos. 
[...] no imaginário dos licenciandos, o significado das diferentes abordagens históricas (externalista e internalista), ou mesmo o significado da própria abordagem histórica, não convergiria com aquele delineado pela pesquisa em ensino. Esse aspecto ficou mais evidente no seminário, pois, durante a apresentação da abordagem, os licenciandos demonstraram a intenção de pôr em prática, em seu episódio de ensino, diversas recomendações retiradas de publicações sobre a abordagem, mas de fato não as realizaram na apresentação do episódio. Por exemplo, afirmaram que dariam um tratamento histórico externalista ao episódio de ensino, o que de fato não foi feito. Os licenciandos pareceram assimilar e reproduziram o que diziam os estudos pesquisados sobre História da Ciência, mas talvez não tenham compreendido como colocar em prática essas recomendações.

Também devemos considerar que, provavelmente, o imaginário desses licenciandos estivesse mais vinculado a uma História da Ciência relacionada a datas, fatos e cientistas importantes, devido às suas vivências pessoais como alunos do Ensino Médio, e até Superior, nos quais tiveram contato com livros didáticos, divulgação da mídia etc. (SORPRESO e ALMEIDA, 2010, p. 57)

Enfim, Sorpreso e Almeida (2010, p. 57) concluiram:

Se o pouco tempo de realização da disciplina não foi suficiente para discussões, reflexões e realização de outras atividades com a abordagem histórica da questão nuclear, de forma a provocar maiores deslocamentos no imaginário desses licenciandos; e se a memória discursiva dos licenciandos, enquanto ainda eram estudantes do Ensino Básico, tem considerável influência em suas produções, poderíamos supor que esses licenciandos, pois de formados e atuando em sala de aula, sujeitos às condições de produção do ensino brasileiro (que são as mesmas em que se originou tal memória discursiva [...]), teriam oportunidade, tempo e condições de modificar o ensino por eles mesmos, criticado em seus seminários?

De fato, temos de considerar que toda a mudança exige tempo suficiente para sua ocorrência, a mudança precisa alcançar seu ponto de maturidade para ocorrer, só assim se efetiva o desenvolvimento cultural, sobretudo quando se trata de mudança ou desenovlivmento de mentalidade e cultura científica e filosófica. A recorrência da regressão ao estado cômodo é muito forte e atrativo, abandonar o já conhecido para aventurar-se no desconhecido não é tarefa fácil.

Detectar essas dificuldades é passo para "fundamentar os rudimentos da psicanálise da razão" já que a "cultura científica deve começar [...] por uma catarse intelectual e afetiva”, "[...] dialetizar todas as variáveis experimentais, oferecer enfim à razão razões para evoluir" (BACHELARD, 1996, p. 24).

No entanto, há que se considerar que uma pesquisa didática instrucional feita em um semestre letivo traz indicações que não podem nos levar precipitadamente - a fazer conclusões que sejam consistentes sobre o processo de aprendizagem, devido a complexidade desta. Considerando o caráter da proposta 
das autoras de submeter os licenciados à pesquisa, planejamento e execução de seminário para discussões e episódio didático (aula) fez-nos criarmos uma nova categoria de análise em que o artigo C-C\&Ed pode ser localizado: Instrumentação Didática para a HFCrECN.

Por fim, encontramos ainda, na revista Ciência\&Educação, o artigo DC\&Ed de autoria de Guimarães, Carvalho e Oliveira (2010, p. 465 e 467), em cuja proposta de pesquisa didática compreensiva buscaram entender "como estudantes de ensino médio percebem e interpretam questões relacionadas à manipulação genética em seres humanos," ou seja, como eles tomam "decisões em relação a questões sociocientíficas." Para alcançar tal objetivo discutiram com os discentes problemas relacionados à "biotecnologia, melhoramento genético e questões levantadas em um filme de ficção científica."

Guimarães, Carvalho e Oliveira (2010, p. 467 e 468) entrevistaram estudantes do ensino médio que participaram de um curso de 40h, denominado: "Encontrando parentesco entre seres vivos" em que foi abordado o uso de cladogramas $^{81}$ para ensino de evolução. Em tal curso foram discutidos temas biotecnológicos tais como:

[...] a resistência de plantas a pragas, produção de insulina humana por bactérias, e manipulação genética em humanos, em especial relacionada à doença de Huntington ${ }^{82}$. O conteúdo científico por trás de cada tema também foi explorado. Ao final das discussões, os estudantes assistiram, e em seguida debateram, o filme GATTACA ${ }^{83}$ : a experiência genética.

${ }^{81}$ Segundos os autores "Cladogramas sãos diagramas que mostram a relação de parentesco entre seres vivos, tendo como pressuposto a sua origem comum, ou seja, a evolução dos organismo é considerada como fator importante nas classificações." (Guimarães; Carvalho; Oliveira, 2010, p. 467, nota 40.

${ }^{82}$ A doença de Huntington (já foi chamada de coréia de Huntington) é um distúrbio hereditário que afeta o sistema nervoso central. Uma doença autossômica dominante. Seu nome advém do médico estadunidense (Estado de Ohio) George Huntington, que descreveu este distúrbio neurológico em 1872. Provoca movimentos involuntários e rápidos nos membros superiores e inferiores e nos rosto. Em 1993 foi descoberto o gene causador da doença. Causada por mutação genética nos nucleotídeos, isto é, ocorrem repetições anormais da sequência de nucleotídeos: citosina, adenina e guanina (CAG), que são responsáveis pela codificação da glutamina. As repetições podem chegar a mais de 36 vezes, contra de 20 , o normal.

${ }^{83}$ Trata-se de um filme de ficção científica do neozelandês Andrew Niccol, retrata futuristicamente uma sociedade alicerçada na estratificação sociobiológica e institucionalização da discriminação por melhoramento genético de seres humanos. O enredo gira em torna do futuro de um jovem (Vincent) nascido naturalmente, fora do domínio da engenharia genética (concepção artificial), colocando em risco sua sobrevivência, numa sociedade baseada em código genético, na seleção do "melhor" patrimônio genético dos pais, para erradicar as doenças hereditárias e possíveis "imperfeições" e prolongar da duração biológica da vida humana. A programação genética introduz novos valores e desvalores. 
São estratégias diferentes que permitem abordar questões da FC - como um prisma a ser desenvolvido sob diversas faces que o compõem - sob aspectos diversos, nesse caso o aspecto ético, tratando problemas de ética aplicada. Guimarães, Carvalho e Oliveira (2010) identificaram que a moral expressa em argumentos dos estudantes era uma "moral consequencialista", pela qual uma ação é julgada correta ou incorreta se as suas consequências forem boas ou más. Os motivos religiosos levaram alguns discentes a rejeitarem quaisquer tipos de manipulação genética em seres humanos. As convicções religiosas - por sua natureza - não conferem autonomia de pensamento crítico e autocrítico aos indivíduos sob sua base, mas subordinam-nos. Esta subordinação pode gerar obstáculo no processo de aprendizagem dependendo de como as relações discentedocente ocorrerem.

$\mathrm{Na}$ situação vivida pelos estudantes dessa pesquisa, podemos ver isso claramente. A diferença de perspectivas ao abordar a questão da manipulação genética em humanos mostra como as representações sociais ou visões de mundo podem afetar a avaliação de questões científicas e, consequentemente, seu aprendizado formal. Os estudantes mais ligados à religião não separam a ciência de seu mundo e ela é avaliada a partir deste. Uma educação científica que desconsidere esse fenômeno e, simplesmente, tome os alunos como incapazes de aprender conteúdos científicos está incompleta.

Por outro lado, há negociação sobre alguns aspectos do conhecimento científico, e não há sobre outros. O nosso exemplo da manipulação genética em humanos mostrou que alguns estudantes eram favoráveis à manipulação genética com fins terapêuticos, mas todos foram contrários à manipulação estética. Esta contrariedade em relação à eugenia positiva comporia o núcleo central dessas representações, ou seja, aquela representação mais resistente a mudanças. (GUIMARÃES; CARVALHO; OLIVEIRA, 2010, p. 475)

Tal "negociação" deve-se ao fato de os estudantes participantes da pesquisa didática axiológica terem sido divididos em dois grupos de perspectivas diferentes: a religiosa e a não religiosa. Durante as discussões, os autores constataram que os dois grupos negaram a realização da manipulação genética para fins estéticos ("eugenia positiva") nos seres humanos. Em relação à manipulação terapêutica, o grupo de perspectiva religiosa proibiu-a enquanto que foi permitida pelo grupo não religioso.

A manipulação genética envolve questões polêmicas da tecnologia filosófica (como chama Mário Bunge a ética): os seres humanos podem interferir no seu processo evolutivo e dos seres ao seu entorno? Essa pergunta foi respondida 
em 1944 com a descoberta do papel do DNA e a resposta aperfeiçoada, cada vez mais, em 1953 com a descoberta da estrutura do DNA, em 1970 com bactérias manipuladas, em 1980 com a geração da cobaia transgênica e em 1986 com a terapia genética em humanos e daí em diante os cientistas não pararam mais.

E agora? As questões polêmicas não findam com a resposta acima, ela faz surgir outras questões. Quais os fins da manipulação genética em humanos, plantas e animais? Todos os fins possíveis são plausíveis? A quem cabe, em última análise, a definição de sua plausibilidade? Os riscos são previsíveis e contornáveis? Como? Com qual grau de eficiência? Qual é o grau de toxidade em manipulação genética de animais e plantas alimentares? Até que ponto é plausível a segurança dos alimentos transgênicos? Como fica a questão de genes de resistência a antibióticos? O uso de cobaias humanas: quem, por quê? Entre outras questões.

Portanto, o resultado descrito por Guimarães, Carvalho e Oliveira em sua pesquisa didática de caráter axiológico era de se esperar que os estudantes de perspectiva religiosa negassem quaisquer tipos manipulação genética e, em virtude de algum ganho que vem sendo obtido em terapias genéticas com humanos, haja pelo menos alguns indivíduos sensibilizados com as possibilidades de cura das enfermidades de outros, submetidos a esses tratamentos. Tais crenças são, também, consequentes da cultura social que rege as mentalidades dos indivíduos.

A discussão trazida pelos autores do artigo D-C\&Ed leva-nos também a introduzir uma nova categoria de análise: Eticidade.

Tabela 21 - Ciência \& Educação ISSN 1980-850X On Line Programa de Pós-Graduação em Educação para a Ciência Faculdade de Ciências da Universidade Estadual Paulista - Campus de Bauru. Home Page: http://www2.fc.unesp.br/cienciaeeducacao/

\begin{tabular}{|c|c|c|c|}
\hline \multirow{2}{*}{$\begin{array}{c}\text { VOLUME, NÚMERO E } \\
\text { DATA }\end{array}$} & \multirow{2}{*}{$\begin{array}{l}\text { Total de } \\
\text { Artigos } \\
\text { Publicados } \\
\text { na Revista } \\
\end{array}$} & \multicolumn{2}{|c|}{$\begin{array}{l}\text { Artigos relacionados ao Tema da } \\
\text { Pesquisa }\end{array}$} \\
\hline & & $\begin{array}{l}\text { Referentes à } \\
\text { HFCrECN }\end{array}$ & $\begin{array}{l}\text { Referentes à } \\
\text { HFCrECN nos DO }\end{array}$ \\
\hline 1999 não há edição & 0 & 0 & 0 \\
\hline Vol. 6 N. 12000 & 7 & 0 & 0 \\
\hline Vol. 6 N. 22000 & 7 & 0 & 0 \\
\hline Vol. 7 N. 12001 & 8 & 0 & 0 \\
\hline Vol. 7 N. 22001 & 9 & 0 & 0 \\
\hline Vol. 8 N. 12002 & 10 & 0 & 0 \\
\hline Vol. 8 N. 22002 & 10 & 0 & 0 \\
\hline Vol. 9 N. 12003 & 10 & 0 & 0 \\
\hline Vol. 9 N. 22003 & 10 & 0 & 0 \\
\hline Vol. 10 N. 12004 & 10 & 0 & 0 \\
\hline Vol. 10 N. 22004 & 10 & 0 & 0 \\
\hline
\end{tabular}




\begin{tabular}{|c|c|c|c|}
\hline Vol. 10 N. 32004 & 20 & 1 & 0 \\
\hline Vol. 11 N. 12005 & 12 & 0 & 0 \\
\hline Vol. 11 N. 22005 & 12 & 0 & 0 \\
\hline Vol. 11 N. 32005 & 12 & 0 & 0 \\
\hline Vol. 12 N. 12006 & 8 & 0 & 0 \\
\hline Vol. 12 N. 22006 & 8 & 0 & 0 \\
\hline Vol. 12 N. 32006 & 8 & 0 & 0 \\
\hline Vol. 13 N. 12007 & 8 & 0 & 0 \\
\hline Vol. 13 N. 22007 & 8 & 0 & 0 \\
\hline Vol. 13 N. 32007 & 12 & 0 & 0 \\
\hline Vol. 14 N. 12008 & 12 & 1 & 0 \\
\hline Vol. 14 N. 22008 & 12 & 0 & 0 \\
\hline Vol. 14 N. 32008 & 15 & 0 & 0 \\
\hline Vol. 15 N. 12009 & 12 & 0 & 0 \\
\hline Vol. 15 N. 22009 & 12 & 0 & 0 \\
\hline Vol. 15 N. 32009 & 15 & 0 & 0 \\
\hline Vol. 16 N. 12010 & 15 & 1 & 0 \\
\hline Vol. 16 N. 22010 & 15 & 1 & 0 \\
\hline Vol. 16 N. 32010 & $\sim \mathbf{P}$ & 0 & 0 \\
\hline Total & 307 & 4 & 0 \\
\hline
\end{tabular}

Na revista Ciência \& Ensino (C\&E) foram publicados 74 artigos de 1999 a 2008. Em 2008, apenas um volume foi publicado, deste período em diante não foram mais publicadas novas edições do periódico. No entanto, nenhum trabalho foi constatado próximo do tema-problema delimitado.

Tabela 22 - Ciência \& Ensino ISSN 1980-8631 On Line

Grupo de Estudo e Pesquisa em Ciência \& Ensino - GEPCE da Faculdade de Educação da Unicamp Grupo de Pesquisa em Educação Aplicada às Geociências - GPEAG do Instituto de Geociências/Unicamp

Grupo de Pesquisa em Discursos da Ciência e da Tecnologia na Educação - DICITE/UFSC Home Page: http://www.ige.unicamp.br/ojs/index.php/cienciaeensino

\begin{tabular}{|c|c|c|c|}
\hline \multirow{2}{*}{$\begin{array}{c}\text { VOLUME, NÚMERO E } \\
\text { DATA }\end{array}$} & \multirow{2}{*}{$\begin{array}{l}\text { Total de } \\
\text { Artigos } \\
\text { Publicados } \\
\text { na Revista }\end{array}$} & \multicolumn{2}{|c|}{$\begin{array}{l}\text { Artigos relacionados ao Tema da } \\
\text { Pesquisa }\end{array}$} \\
\hline & & $\begin{array}{l}\text { Referentes à } \\
\text { HFCrECN }\end{array}$ & $\begin{array}{l}\text { Referentes } \\
\text { HFCrECN nos Do }\end{array}$ \\
\hline N. 61999 & 4 & 0 & 0 \\
\hline N. 71999 & 4 & 0 & 0 \\
\hline N. 82000 & 5 & 0 & 0 \\
\hline N. 92000 & 5 & 0 & 0 \\
\hline N. 102001 & 5 & 0 & 0 \\
\hline N. 112001 & 5 & 0 & 0 \\
\hline N. 122002 a 2004 & 3 & 0 & 0 \\
\hline \multicolumn{4}{|l|}{2005 sem edição } \\
\hline Vol. 1 N. 12006 & 8 & 0 & 0 \\
\hline Vol. 1 N. 22007 & 6 & 0 & 0 \\
\hline Vol. 1 N. Especial 2007 & 17 & 0 & 0 \\
\hline Vol. 2 N. 12007 & 6 & 0 & 0 \\
\hline Vol. 2 N. 22008 & 6 & 0 & 0 \\
\hline \multicolumn{4}{|l|}{ Sem mais edições } \\
\hline Total & 74 & 0 & 0 \\
\hline
\end{tabular}


De 1999 a 2010 foram publicados 171 trabalhos no Ensaio - Pesquisa em Educação em Ciências (Ensaio), dos quais dois artigos foram coletados por apresentar aproximação ao tema-problema, ei-los:

A-Ensaio - HÜLSENDEGER, Margarete J. V. C. A História da Ciência no Ensino da Termodinâmica: um outro olhar sobre o ensino de Física. Ensaio - Pesquisa em Educação em Ciências, Belo Horizonte, v. 9, n. 2, p. 191-205, 2007.

B-Ensaio - SILVA, Paulo Sérgio Araújo da; CHAVES, Sílvia Nogueira. Epistemologia, Ética e Política na Formação de Professores de Ciências. Ensaio - Pesquisa em Educação em Ciências, Belo Horizonte, v. 11, n. 2, p. 230-244, 2009.

No artigo A-Ensaio, Hülsendeger apresenta um trabalho consequente de um projeto desenvolvido em sala de aula. $\mathrm{O}$ seu objeto foi analisar como a $\mathrm{HC}$ poderia ser utilizada no ensino da Física, com o fim de "favorecer a aprendizagem dos conceitos estudados na Termodinâmica." No objetivo a autora descreve um projeto didático experimental que the aproxima dos demais materiais pesquisados nesta parte do nosso trabalho, porque se trata de uma proposta (teste) didática.

Hülsendeger (2007, p. 2 [192]) relata que a realização do projeto ${ }^{84}$ cobriu um período de 120 dias e incluiu uma execução em parceria de três áreas de conhecimento ou disciplinas: Física, História e Redação. Trinta alunos do primeiro ano do ensino médio participaram do projeto. $O$ projeto inclui as seguintes atividades realizadas por discentes: "pesquisa escrita sobre $\mathbf{o}$ surgimento $\mathbf{e}$ desenvolvimento da máquina a vapor, a leitura e interpretação de textos e a resolução de questões objetivas e dissertativas sobre os conceitos abordados em sala de aula", e a $\mathrm{HC}$ foi tida como "[...] uma ferramenta importante no entendimento dos fenômenos estudados na Física" (HÜLSENDEGER, 2007, p. 6 $\left[196^{85}\right]$ destaque nosso).

Essa estratégia ilustra a razão da mobilização dos docentes das três disciplinas para poderem trabalhar juntos para auxiliar a compreensão história da termodinâmica, mas por quê? Porque para compreender os contextos do desenvolvimento dessa parte da Física, era necessário que os discentes fizessem pesquisa e para isso é necessário fazer leituras interpretativas e escrita coerente, a isso se ocupou a docente de Redação: "deixou-se claro que seria valorizada a redação própria e não a cópia" (HÜLSENDEGER, 2007, p. 6 [196]).

\footnotetext{
${ }^{84}$ Projeto desenvolvido num Colégio particular de Porto Alegre.

${ }^{85}$ Corresponderia a página na sequência geral das edições do periódico.
} 
Concomitantemente, à aprendizagem da redação para desenvolver a pesquisa sobre o tema, na disciplina Física, fez-se trabalhos de diagnóstico para averiguar o conhecimento dos discentes sobre o tema "[...] e de que forma se poderia aproveitar esse conhecimento para desenvolver os conceitos tratados na Termodinâmica" (HÜLSENDEGER, 2007, p. 6 [196]). Atividade que envolvia a discussão de concepções sobre trabalho, maquinas térmicas e relações com outras máquinas. Enquanto isso na História aprendia-se sobre revolução industrial e mudanças ocorridas nas ciências, na política, na sociedade e nas concepções de mundo.

Segundo Hülsendeger (2007, p. 7 [197]) "os debates, muitas vezes, começavam na aula de Física e terminavam na de História" ou ainda que

[...] sempre que possível eram sugeridas tarefas que permitissem aos alunos buscar as respostas sozinhos, e sempre com o compromisso de apresentá-las aos seus colegas. Foi assim, por exemplo, com uma atividade de pesquisa sobre as transformações gasosas. Organizou-se a aula de forma que os alunos, reunidos em grupos, recebessem uma única transformação para pesquisar, devendo ao final expor ao restante da turma o que haviam compreendido. Houve, portanto, uma troca de conhecimentos, permitindo uma interação maior do aluno com o conteúdo que estava sendo trabalhado. Por essa razão, esse mesmo tipo de trabalho também foi desenvolvido na disciplina de História, em momentos cujo objetivo era auxiliar aos alunos [a] avançarem na pesquisa que estavam realizando sobre a Revolução Industrial e a Máquina a Vapor.

Todas essas atividades procuraram desenvolver a autonomia e a capacidade de pesquisar, pois os alunos buscavam, na maioria das vezes, as informações necessárias sem a tutela constante do professor. Além disso, buscou-se desenvolver uma consciência mais crítica sobre os assuntos que estavam sendo abordados nas disciplinas de Física e História, conferindo a esses temas um caráter mais dinâmico. (HÜLSENDEGER, 2007 , p. 7 [197])

De fato, o tipo de pesquisa desenvolvida por esses alunos é diferente daquela desenvolvida nas universidades ou centros/institutos de pesquisa. As razões são várias, primeiro que os próprios docentes escolares não são profissionalizados para investigação científica, quer nas escolas ou fora delas, não foram instruídos durante a sua formação inicial o suficinte para tal. Esse fato remete a possíveis inconsistências metodológicas e epistemológicas no planejamento das propostas, na execução e consequentemente na validação dos resultados do que se chama de pesquisar na educação básica.

O que também não significa que se deva menosprezar a iniciativa escolar à investigação didática, porque é possível fazer quaisquer tipos de pesquisa nas 
Escolas, desde as pesquisas de complexidade básica às de alta complexidade, estas últimas exigiriam recursos e condições técnicas, infraestrutura e capacitação docente.

O levantamento bibliográfico e a verificação das opiniões são pesquisas que podem ser feitas nas escolas em conjunto com os discentes, inclusive os experimentos e testes didáticos (por docentes escolares). É com base no levantamento bibliográfico que se situa a proposta desenvolvida por Hülsendeger (2007), na tentativa de incluir a abordagem histórica da termodinâmica.

Por outro lado, os esforços e a estratégia utilizada por Hülsendeger, de mobilizar outros dois colegas de Redação e História, para em parceria trabalhar aspectos da Física historicamente, demonstra primeiro a possibilidade de trabalho didático cooperado entre docentes, extremamente importante. Do outro lado, demonstra a dificuldade em incluir a abordagem dos aspectos histórico-filosóficos na educação básica por fatores variados que vão desde a falta de formação docente adequada para tal fim; a impossibilidade de que os estudos de Física sempre ocorram dessa formam cooperada durante todas as aulas, fazendo com que as propostas inclusionistas sejam meramente eventualidades. Isto compromete a eficiência e efetividade da HFCrECN. Logo, corrobora a instrumentação didática dos docentes, no processo de profissionalização, para tal inclusão.

Ademais, à primeira análise parece que o trabalho didático desenvolvido estava restrito a questões conceituais, o que faria com que se localizasse na categoria da contextualização interna, porém, ao analisar o plano didático verifica-se elementos de contextualização externa descritos nos objetivos da unidade de ensino/aprendizagem: levar os discentes a compreender: a) fatores sociais, econômicos e políticos que contribuirão para o desenvolvimento da maquina a vapor (no século 18) e; b) a relação ocorrida entre o aperfeiçoamento dessa maquina e a evolução dos conceitos da termodinâmica.

Paralelamente a isso, a preparação dos discentes para trabalho em grupos, a leitura e interpretação de textos, a facilitação da autonomia e a interdisciplinaridade fizeram parte do elenco dos objetivos. Estrategicamente, para alcançar esses ideais a atividade foi desenvolvida - segundo Hülsendeger (2007, p. 6 [196]) - com base na "[...] pesquisa, escrita, discussão, crítica, contextualização, compreensão dos fenômenos físicos e apresentação dos resultados."

Uma das justificativas que predominam no movimento da HFCrECN é o 
de que o uso de HFC no ECN seria importante porque motivaria os discentes a compreenderem os mecanismos pelos quais o conhecimento científico e os artefatos tecnológicos são produzidos e a aprenderem sobre ciências: não se tem aprendido a fazer ciência nas escolas, até mesmo nas universidades, raramente, aprende-se a fazer ciência. A grande massa dos estudantes é diplomada por ter aprendido fragmentos de ciências: sabe resolver exercícios já resolvidos, chegar a conclusões já concluídas. Logo, o ensino é demonstrativo do passado. E a aprendizagem é a apropriação do passado. Mas não era para ser assim!

A HFC pode ser sim um excelente motivador tanto para aprender a ciência, isto é, fazê-la quanto para aprender sobre ciência. No geral tem predominado a última tese: a aprender sobre ciência. E neste sentido Hülsendeger (2007, p. 12 [202]) parece ter alcançado esta dimensão motivadora na sua tentativa de inserir a abordagem contextual ( $\mathrm{HC}$ ) no ensino de Física (termodinâmica), pois, segundo a autora, observou que "muitos alunos" estavam

[...] começando a romper com a visão ingênua de que a máquina a vapor "surgiu do nada", passando a compreender que ela, como qualquer outro produto do conhecimento humano, é o resultado do esforço e da pesquisa, não de uma única pessoa, mas de várias ao longo do tempo. Segundo um aluno, esse trabalho foi "uma oportunidade de ficar sabendo coisas que a gente não tinha nenhuma idéia e de entender melhor muitas coisas. A gente teve sorte".

Da mesma forma, outro aluno também reconheceu que, ao pesquisar e ler os textos oferecidos durante as aulas, pode compreender melhor a relação existente entre as leis da termodinâmica e o desenvolvimento das máquinas térmicas. Compreendeu inclusive, que "os homens, mexendo na máquina, descobriram coisas importantes e que influenciaram bastante nas leis da termodinâmica e até criou algumas".

Outro argumento remete à justificativa de que HFC contribui para apresentar aos discentes os diversos contextos da produção científica e as relações estabelecidas entre ciência, tecnologia e outros sistemas sociais das sociedades humanas (cultura, religião, economia, política, etc.). Quer-se dizer com isso, também, que a HFC pode servir como elemento de demonstrar a organização ou dinâmica sistêmica do desenvolvimento dos conceitos científicos, dos seus artefatos tecnológicos e das organizações sociais.

Em sua proposta de experiência didática Hülsendeger (2007, p. 14 [204]) descreve que 
apesar das dificuldades, o trabalho permitiu que se relacionasse "uma matéria com a outra, um assunto com o outro. E isso é para o resto da vida, a gente sempre vai ter de saber relacionar uma coisa com a outra, não é só Física, ou só História, misturou e eu achei isso interessante". E, ao "misturar-se" algo que nunca esteve separado, a não ser em nossas mentes e nos livros escolares, foi possível uma maior compreensão dos fenômenos que estavam sendo tratados em sala de aula, adquirindo um maior sentido e, por que não?, colorido no imaginário do aluno.

Trata-se de uma declaração forte da discente e expressa sobremaneira o valor educativo do uso de trabalhos colaborativos. Embora esta estratégia não possibilite um contínuo didático, dificuldade inerente à proposta do movimento da HFC-ECN, porque o trabalho contínuo desta inclusão requer atividades disciplinares individualizadas em cada conteúdo ou unidade de ensino e aprendizagem, ao logo do desenvolvimento do plano de ensino da disciplina (Física, Química ou Biologia).

Entretanto,

[...] mesmo que as dificuldades de se implementar esse tipo de trabalho sejam inúmeras, causando, muitas vezes, desânimo frente a elas, é importante ressaltar o papel dos professores, não só de Física, na exploração das diferentes possibilidades de utilização da História da Ciência. Devemos preocupar-nos em oferecer ao aluno a oportunidade de desenvolver um olhar crítico em relação à realidade que o cerca e em relação a si, superando-se a idéia de uma Ciência "senhora da verdade", proprietária de saberes inquestionáveis e absolutos.

Portanto, ao longo do projeto, constatou-se que o trabalho com a História da Ciência pode ser tornar uma ferramenta importante para auxiliar o aluno não só na compreensão dos fenômenos estudados na Física, mas principalmente uma forma de possibilitar o entendimento de que todo o conhecimento está interligado, e que a divisão instaurada pelas disciplinas é mera ilusão, podendo, com algum esforço, ser superada. E ao acreditar - 0 aluno - que não existe uma única verdade, estará mostrando-se pronto para vivenciar e exercitar o espírito científico, admitindo o questionamento e a crítica. (Hülsendeger, 2007, p. 14-15 [204-205]).

Neste sentido, a partir do analisado e descrito acima, podemos localizar a inserção do artigo A-Ensaio, respectivamente, nas seguintes categorias de análise:

\section{Contextualização Externa, Contextualização Interna, Motivacional,}

Sistemicidade e Criticidade, porque permitiu a contextualização conceitual (termodinâmica) e social (história da Revolução Industrial e criação de máquinas a vapor, etc.), a motivação para aprendizagem discente e a percepção não ingênua, mas refletida e sistêmica, da realidade de produção do conhecimento científico e das relações entre os assuntos e suas respectivas disciplinas.

A HFC, na sua face filosófica da ciência e tecnologia, inclui, além de questões epistemológicas, a análise de questões ontológicas, lógicas, éticas, 
políticas, estratégicas e ideológicas implicadas na ou suscitadas pela produção científica e tecnológica. $O$ artigo B-Ensaio se incorpora na análise de questões éticopolíticas implicadas na produção científica. O trabalho de SILVA e CHAVES foi consequente de uma pesquisa didática realizada no âmbito da formação continuada de docentes de ciências naturais (incluindo ciências, do ensino fundamental), em nível de especialização em uma universidade pública. Tratou-se de uma pesquisa narrativa cujo objetivo foi:

[...] investigar que tipos de reflexões os sujeitos-professores constroem a partir da introdução de discussões relativas ao processo de produção, validação e apropriação social do conhecimento científico e as relações que estabelecem com suas histórias de atuação e formação pessoal e profissional. (SILVA; CHAVES, 2009, p. 230)

Os participantes da pesquisa, depois de discussões, redigiram seus memoriais em que narraram suas reflexões críticas em relação às atividades científicas e suas relações com as ações políticas. Silva e Chaves (2009, p. 233) afirmam que

\footnotetext{
A análise do conjunto de materiais produzidos sinaliza que a ação recursiva da memória, estimulada a partir de discussões epistemológicas, no presente, potencializou as reflexões docentes em quatro dimensões principais: Ético-política, Curricular, Metodológica e Afetiva.
}

No trabalho os autores propuseram-se a analisar apenas da dimensão ético-política: "A análise do material empírico produzido sinaliza que dentre os aspectos nos quais o debate epistemológico estimulou reflexões, está a dimensão ético-política da ciência" (SILVA; CHAVES, 2009, p. 230). E ressaltam ainda que a sua "[...] investigação incidiu privilegiadamente sobre a dimensão ideacional, conceitual e não propriamente sobre as condutas profissionais desencadeadas pelas discussões epistemológicas travadas durante o processo formativo" (SILVA; CHAVES, 2009, p. 233).

A problematização do mito ou dogmática da ciência: neutralidade científica. Alguns dos docentes participantes da pesquisa narrativa apresentaram relatos que levantam questões ético-políticas ou biopolíticas, como dizia Foucault, tais como, depois das discussões e lembrando-se de episódio do filme " $E$ a vida Continua ..." um docente participante descreveu um outro lado da ciência que não era aquele de uma atividade direcionada para resolver problemas que afetam a 
humanidade para gerar condições melhores, mas percebeu que "[...] Ela também tem seu lado político, capitalista, burocrático, e até mesmo, mesquinho [...]" (referenciado em SILVA; CHAVES, 2009, p. 234, destaque dos autores).

Esta é uma das tarefas da FC: fazer com que os indivíduos percebam de forma crítica e dialeticamente as relações e os processos, no nosso caso, os de produção do conhecimento científico. Significa dizer que a FC tem a tarefa de suscitar mentalidades críticas, e isto é testemunhada na narrativa seguinte:

\begin{abstract}
Essas discussões e reflexões [no curso de especialização] me ajudaram a perceber que: cabe a nós, professores, mostrar que a ciência é uma atividade humana, feita coletivamente, não está alheia a fatos históricos, sociais e políticos, é feita por homens (mulheres) que têm por trás de suas ações, interesses nem sempre éticos. (Mara, memorial) (referenciado em SILVA; CHAVES, 2009, p. 234)
\end{abstract}

Ao mesmo tempo em que tais debates suscitaram questões de autoaperfeiçoamento (a ciência é feita por homens: passível de acertos e erros, falível e não absoluta, e, outras dicotomias caras à existência humana) e que as atividades humanas constituem redes sistêmicas de processos produtivos, o que faz perceber as relações com os seus contextos: histórico e sociopolítico, isto é, que as atividades científicas não se realizam fora da sociedade, mas, dentro da sociedade influenciada por elas e da qual também elas recebem suas influências. Assim, alguns participantes descrevem o que ou em que a introdução da abordagem lhe favoreceu, os destaques sãos de Silva e Chaves (2009, p. 234):

\footnotetext{
Estas experiências [na disciplina] me deixaram com algumas impressões. Elas me fizeram refletir sobre o papel do professor no mundo atual. Vivemos uma época marcada por um desenvolvimento acelerado da ciência. Mas também uma época marcada por uma crise de valores humanos que tende a desrespeitar cada vez mais a vida. Senti que isso ficou subjacente nas aulas da disciplina. Ficou claro para mim que, como professor de ciências, tenho um papel a desempenhar e que este papel deve iniciar em minha prática de ensino, que devo apresentar a ciência como atividade humana sujeita a falhas, acertos e limitações, pois a ciência não se desenvolve num espaço social e cultural vazio, mas condicionada a fatores externos. (Diogo, memorial, destaques nosso [sic]).
}

Os autores afirmam que "Tais discussões que pensam e propõem a educação como transformação pressupõe um processo de desalienação da ciência como conhecimento dogmático, inquestionável" (SILVA; CHAVES, 2009, p. 234). De fato isto é perceptível nas descrições memoriais dos docentes que participaram da 
pesquisa narrativa, como consta em Silva e Chaves (2009, p. 241) [as aspas aberta e não fechadas constam assim no original]:

\begin{abstract}
O mundo está mergulhado nesse contexto científico e eu preciso dizer se eu quero isso, ou não quero aquilo, e para eu saber não tenho que confiar nos outros, eu tenho que entender sim, tenho que entender o que é fibra ótica, entender para dizer "olha! Eu não quero essa tecnologia porque se essa tecnologia me traz conforto, mas ela pode trazer prejuízo ambientais [sic] para mim e para as gerações futuras, mas não conseguimos fazer isso. Por quê? Porque a escola está afastada dessa discussão, ensinamos fórmulas, definições, ensinamos um monte de coisas e essas coisas importantes ficam fora da escola. [...] (F).
\end{abstract}

As discussões epistemológicas parecem ter suscitando um desenvolvimento cultural nos docentes em formação continuada: "Após a discussão percebi (...) não podemos delegar à ciência o papel de decidir o que é bom para nós (Rafael)" (SILVA; CHAVES, 2009, p. 242). Esta percepção ou declaração parece consequente da desilusão com as práticas científicas e suas relações com os sistemas de dominação (descrevendo relações de poder).

Os autores do artigo B-Ensaio, Silva e Chaves (2009, p. 245 e 246) concluíram que:

[...] com base nas problematizações acerca da concepção de ciência dogmática neutra, impulsionadas pelas discussões epistemológicas, emergiu a reflexão ético-política no âmbito da prática educativa. A emergência de tal reflexão significou para os sujeitos se admitirem como ativistas políticos no campo da Educação em Ciências [...].

E que:

Por meio dessas memórias, os professores participantes puderam rever criticamente seus processos de formação. Fizeram relações entre a produção da ciência e sua necessária ancoragem em critérios éticospolíticos de validação, como também submeteram a análise de suas próprias práticas educativas a esses critérios, de tal modo que suas narrativas de formação passaram a apontar necessidade de inclusão de outras concepções de ciência, ensino e educação para serem incorporadas na re-construção de suas identidades docentes.

Pedagogicamente, pareceu-nos estarem subjacentes as teorias de mudança conceitual e análise das representações/concepções alternativas.

Em todo caso, em virtude de sua dimensão epistemológica e do enfoque dado às discussões durante a pesquisa narrativa em contexto didático, podemos verificar a localização deste artigo B-Ensaio nas seguintes categorias de análise, 
respectivamente: Criticidade, Sistemicidade, Eticidade e Falibilidade Epistêmica.

Tabela 23 - Ensaio - Pesquisa em Educação em Ciências ISSN 1983-2117

Centro de Ensino de Ciências e Matemática (Cecimig)

Programa de Pós-Graduação da Faculdade de Educação (FAE) Universidade Federal de Minas Gerais (UFMG)

Home Page: http://www.portal.fae.ufmg.br/seer/index.php/ensaio

\begin{tabular}{|c|c|c|c|}
\hline \multirow{2}{*}{$\begin{array}{c}\text { VOLUME, NÚMERO E } \\
\text { DATA }\end{array}$} & \multirow{2}{*}{$\begin{array}{l}\text { Total de Artigos } \\
\text { Publicados na } \\
\text { Revista }\end{array}$} & \multicolumn{2}{|c|}{$\begin{array}{l}\text { Artigos relacionados ao Tema da } \\
\text { Pesquisa }\end{array}$} \\
\hline & & $\begin{array}{l}\text { Referentes à } \\
\text { HFCrECN }\end{array}$ & $\begin{array}{l}\text { Referentes } \\
\text { HFCrECN nos DO }\end{array}$ \\
\hline Vol. 1 N. 11999 & 5 & 0 & 0 \\
\hline Vol. 2 N. 12000 & 5 & 0 & 0 \\
\hline Vol. 2 N. 22000 & 5 & 0 & 0 \\
\hline Vol. 3 N. 12001 & 5 & 0 & 0 \\
\hline Vol. 3 N. 22001 & 5 & 0 & 0 \\
\hline Vol. 4 N. 12002 & 5 & 0 & 0 \\
\hline Vol. 4 N. 22002 & 5 & 0 & 0 \\
\hline Vol. 5 N. 12003 & 6 & 0 & 0 \\
\hline Vol. 5 N. 22003 & 6 & 0 & 0 \\
\hline Vol. 6 N. 12004 & 5 & 0 & 0 \\
\hline Vol. 6 N. 22004 & 5 & 0 & 0 \\
\hline Vol. 7 N. 12005 & 5 & 0 & 0 \\
\hline Vol. 7 N. 22005 & 5 & 0 & 0 \\
\hline $\begin{array}{l}\text { Vol. } 7 \text { N. } 32005 \text { Edição } \\
\text { Especial }\end{array}$ & 5 & 0 & 0 \\
\hline Vol. 8 N. 12006 & 6 & 0 & 0 \\
\hline Vol. 8 N. 22006 & 6 & 0 & 0 \\
\hline Vol. 9 N. 12007 & 9 & 0 & 0 \\
\hline Vol. 9 N. 22007 & 9 & 1 & 0 \\
\hline Vol. 10 N. 12008 & 9 & 0 & 0 \\
\hline Vol. 10 N. 22008 & 9 & 0 & 0 \\
\hline Vol. 11 N. 12009 & 9 & 0 & 0 \\
\hline Vol. 11 N. 22009 & 9 & -1 & 0 \\
\hline Vol. 12 N. 12010 & 9 & 0 & 0 \\
\hline Vol. 12 N. 22010 & 15 & 0 & 0 \\
\hline Vol. 12 N. 32010 & 09 & 0 & 0 \\
\hline Total & 171 & 2 & 0 \\
\hline
\end{tabular}

Na revista Investigações em Ensino de Ciências (Investigações) foram publicados 186 artigos no período coberto pela pesquisa (1999-2010), dos quais dois haviam sido coletados, porém apenas um analisado por apresentar proximidade ao tema-problema no contexto aqui delimitado.

A-Investigações - GATTI, Sandra Regina Teodoro; NARDI, Roberto; SILVA, Dirceu da. História da Ciência no Ensino de Física: um estudo sobre o ensino de atração gravitacional desenvolvido com futuros professores. Investigações em Ensino de Ciências, v. 15, n. 1, p. 7-59, 2010.

Neste artigo A-Investigações os autorres apresentaram resultado de uma 
pesquisa em que analisaram a experiência didática de inclusão da HC na disciplina Prática de Ensino de Física, cujo tema foi: desenvolvimento histórico da atração gravitacional. Tratou-se de um estudo de caso, de enfoque qualitativo, cuja amostra consistiu em onze licenciandos em Física, na UNESP. A duração da pesquisa didática foi de um ano letivo.

Segundo Gatti, Nardi e Silva (2010, p. 7) o objetivo da pesquisa foi

[...] promover discussões sobre a existência e persistência das concepções alternativas, sobre a evolução história do tema atração gravitacional, além de leituras e debates de textos contemplando discussões recentes sobre a pesquisa em ensino de Ciências, de modo a gerar insatisfações com modelos tradicionais de ensino.

Procedimentalmente, houve um levantamento inicial das pré-concepções dos licenciandos sobre o tema, de tal modo que os pesquisadores tivessem um mapa orientador das atividades e um levantamento final das concepções. Os participantes elaboraram planos de ensino aplicados em situações reais de sala de aula, no ensino médio: um minicurso baseado em HC e nas concepções alternativas diagnosticadas nos discentes do ensino médio. $O$ enfoque dado no artigo restringese apenas à pesquisa junto aos licenciandos, dos quais se procurou entender se a "[...] experiência didática centrada na integração da História da Ciência no ensino, levando-se em conta as concepções e experiências didáticas de futuros docentes, poderia contribuir para a aceitação de novas metodologias de ensino" (GATTI; NARDI; SILVA, 2010, p. 8).

A proposta didática foi determinada a partir de quatro pontos fundamentais, a saber:

1. Preocupação com as concepções dos futuros docentes sobre os processos de ensino e aprendizagem;

2. Utilização da HC como "fio condutor das discussões" que permearam o curso;

3. Desenvolvimento de conhecimentos teóricos sobre a aprendizagem de Ciências foi considerado fundamental e integrado à proposta;

4. Desenvolvimento e aplicação de minicurso elaborado pelos licenciandos e realizado em salas de aula de ensino médio. 
Segundo Gatti, Nardi e Silva (2010, p. 9) "a participação dos futuros docentes em situações de ensino é importante para que se estabeleçam reflexões entre a explicitação de suas idéias, a teoria discutida durante o desenvolvimento do curso e a sua prática docente."

Para a coleta de dados, utilizaram o VOSTS ${ }^{86}$ em escala reduzida com apenas oito questões, as entrevistas (inicial e final) aplicadas foram do tipo grupo focal, cujos oito temas foram:

1. Definição de ciência;

2. Uniformidade do conhecimento científico;

3. Natureza do conhecimento científico;

4. Efeito do gênero nas carreiras científicas;

5. Natureza dos modelos científicos;

6. Métodos científicos;

7. Importância do consenso na ciência;

8. Produção do conhecimento.

$\mathrm{O}$ desenvolvimento da proposta de inclusão da $\mathrm{HC}$ ocorreu em quatro fases (GATTI; NARDI; SILVA, 2010, p. 12-13): 1르 fase, do levantamento inicial de concepções. Parece ter havido o uso de dois instrumentos de coleta de dados: a entrevista de grupo focal e o questionário respondido pelos licenciandos, porém o texto dos autores gera dúvida ao leitor sobre qual instrumento foi utilizado de fato ou se os dois; $2^{\mathrm{a}}$ fase, do curso: desenvolvimento histórico da atração gravitacional (leitura de textos e debates sobre evolução dos modelos de mundo para evidenciar a evolução do conceito de atração gravitacional); a $3^{\text {a }}$ elaboração de propostas de minicursos pelos licenciandos e aplicação em sala de aula de ensino médio e; a $4^{\text {a }}$ fase, do levantamento final das concepções dos licenciandos. A fase da abordagem história incluiu a discussão das tentativas iniciais de descrição do mundo, passando pelas ideias de Aristóteles, Ptolomeu, a Física da Idade Média, Copérnico, Kepler, Galileu, Descartes até chagar a Newton. Essa sequência histórica indica uma abordagem do conceito-tema (atração gravitacional) no seu contexto interno (Física),

${ }^{86}$ Baseado em AIKENEAD, G. S.; RYAN, A. G. Students' preconceptions about the epistemology of science. Science Education, v. 76, n. 6, p. 559-580, 1992. O VOSTS completo conta com 114 questões. 
localizando a pesquisa didática nas categorias Contextualização Interna e Instrumentação Didática, como veremos a seguir.

Quanto ao conceito de atração gravitacional constatou-se uma predominância e até persistência - entre os licenciandos - de concepções alternativas, sobretudo quanto ao estabelecimento da causa única dos movimentos terrestres e celestes. O que também tem sido já apontado pela literatura sobre concepções alternativas entre discentes.

As concepções dos licenciandos em relação a inclusão da HC no ensino foram divididas em vantagens e dificuldades, verificaram que os 11 participantes consideraram importante o uso da HC porque ela é motivacional (11 responderam), desmistificadora (11), mostra a ciência enquanto processo (10) e oferece cultura geral (3). Quanto às dificuldades foram apontadas as seguintes: falta de tempo nas aulas (11), preconceito dos alunos (4), falta de conhecimento sobre o tema (9), tempo para o professor preparar as aulas (8), falta de material didático adequado (8).

Esses dados demonstram o grau de receptividade e de complexidade envolvida no tema entre esse grupo de docentes em formação. As vantagens e as dificuldades estão praticamente ao mesmo nível. As vantagens já têm sido apontadas na literatura e algumas dificuldades também. O importante a reter é que tanto as vantagens como as dificuldades são indicativos de exigências de falta de planejamento estratégico e de propostas didáticas experimentais para a HFCrECN, os docentes interessados na inclusão procuram alternativas possíveis. A admissão teórica da relevância é simples. A elaboração de projetos experimentais e a consequente avaliação da aprendizagem que resulte significativa constitui a difícil equação metodológica e epistemológica para o movimento da HFCrECN.

A eliminação da bipolaridade entre vantagens e dificuldades começa a passar necessariamente na formação docente desde os primeiros semestres e que esta formação profissionalize de maneira proativa e empreendedora. O engajamento metodológico e epistemológico de qualquer mudança ou desenvolvimento cultural que se pretenda que surta efeitos significativos exige à altura uma mentalidade empreendedora proativa, analítica, crítica e criativa. A concepção da mudança como empreendimento e desenvolvimento - considerando que todo empreendimento e desenvolvimento requer planejamento estratégico para implementação das hipóteses na prática - exige o conhecimento da realidade em que se pretende alocar 
a mudança/desenvolvimento. E então estudar mecanismo de ação e de tomada de decisões estratégicas.

Dissemos isso porque a introdução de um elemento novo sempre encontra resistência, toda a mudança é dolorosa e os humanos não suportam a dor, é o que podemos perceber nos relatos que apresentaremos a seguir, feitas a partir da experiência de uma pesquisa didática que almejou mudança metodológica no ensino:

\begin{abstract}
Neste sentido, a longa vivência dos licenciandos nos cursos de formação, baseados na mera transmissão e recepção passiva de conteúdos contribuiu para limitar o desenvolvimento de uma prática de ensino inovadora durante o desenvolvimento de nossa proposta. Em muitos momentos da pesquisa, a necessidade da construção de uma metodologia inovadora que pudesse substituir o modelo tradicional foi questionada e encarada com ressalvas pelos futuros docentes. Mesmo discutindo e confrontado as idéias sobre os processos de ensino e aprendizagem de Ciências, buscando evidenciar que a mera transmissão de conhecimento não propiciava a evolução nas préconcepções dos indivíduos, nosso trabalho contrariava as experiências didáticas dos licenciandos e eles relutavam em aceitar novos conceitos. (GATTI; NARDI; SILVA, 2010, p. 53-54)
\end{abstract}

Pois bem, os novos conceitos, de fato, não são rejeitados meramente porque são novos, mas porque eles exigem novas práticas, novas formas de engajamento e empreendimento. Entenda-se prática no sentido lato: são praticas de pensamento (re/criação racional); de planejamento (re/criação estratégica); de ações didáticas (re/criação de ensinar e aprender); de avaliação do ensino e da aprendizagem (re/criação de novos instrumentos e medidas avaliativas); de publicar os resultados do processo didático (re/criação das formas de socialização significativa dos resultados do trabalho cumprido) e assim por diante.

\begin{abstract}
Assim, a pesquisa desenvolvida dentro da disciplina de Prática de Ensino [de Física] foi muito pontual dentro de um histórico de vivências tradicionais ao longo de toda a formação dos participantes.

Apensar de considerarem a importância das discussões e do desenvolvimento histórico que estudávamos, muitos licenciandos ainda esboçavam durante os debates a noção de que seria muito difícil seguir a carreira docente com um novo enfoque, não tradicional já que não se sentiam preparados para isso e afirmavam sentirem-se injustiçados por não terem tido a oportunidade de discutir esses temas durante toda a formação universitária. (GATTI; NARDI; SILVA, 2010, p. 54)
\end{abstract}

Ou ainda que

Apesar de algumas propostas mais centradas no aluno, ainda pesistiram 
resistências mesmo entre os indivíduos que procuraram desenvolver minicursos mais de acordo com as reflexões realizadas, como por exemplo: a falta de tempo para o professor preparar as aulas, falta de preparo durante a formação o que dificultaria o abandono da concepção tradicional; desinteresse dos alunos, limitações impostas pelo "entorno escolar", entre outras. (GATTI; NARDI; SILVA, 2010, p. 54)

Finalmente, não há como

[...] sustentar a existência de uma relação linear entre a evolução das concepções dos futuros docentes sobre a natureza da Ciência e seu comportamento em sala de aula, já que mesmo os licenciandos com bons resultados no questionário VOSTS aplicado ao final da proposta não conseguiram desenvolver um trabalho totalmente desvinculado do ensino tradicional, e relataram ainda uma incerteza com relação à possibilidade de seguirem a atividade docente com uma postura inovadora frente aos processos de ensino e aprendizagem. (GATTI; NARDI; SILVA, 2010, p. 54).

Estamos assim diante de uma situação séria. Percebe-se no relato a tamanha dificuldade de aceitar o desafio que o novo exige, chegando a ponto de colocar em risco a carreira profissional. Ao mesmo tempo em que os docentes consideram ser interessante, caso tivessem sido introduzidos à nova abordagem logo no início da formação. Cria-se assim um dilema, porém, parece provisório porque se reconhece a importância da nova abordagem, mas se nega a sua aplicação. O mesmo que dissessem é válido, mas não serve! O dilema é sério porque psicologicamente a decisão já está tomada: o não uso da abordagem nova.

As informações supracitadas são de extrema importância estratégica para o planejamento curricular dos cursos de formação, de tal forma a se criar um equilíbrio na distribuição das áreas de profissionalização: na formação de competências no conhecimento específico (em Física, Biologia, Química) e no conhecimento didático do ensino e da aprendizagem (da Física, Biologia, Química). Tanto que os autores ressaltaram que

Um aspecto diz respeito à necessidade de uma reestruturação dos cursos de graduação de forma a eliminar a dissociação entre as formações científica e pedagógica, que acabam transformando os cursos de licenciatura em algo parecido com bacharelados seguidos de uma complementação pedagógica ao final da formação. (GATTI; NARDI; SILVA, 2010, p. 54)

Por outro lado, a pontualidade da pesquisa didática de que os autores relatam anteriormente é plausível. É uma questão que encontramos em quase todos 
os trabalhos de pesquisa didática analisados. Sua duração tem sido apenas de um semestre a um ano letivo. As condições de sua realização nem sempre favorecem o desenvolvimento da pesquisa e a sua conclusão perfeita conforme metodologicamente planejado. Em todo caso, os resultados parciais trazem indicadores que merecem atenção para o movimento da HFCrECN, sobretudo.

Finalmente, verifica-se a permanência da distância entre o discurso/teoria e a prática. Verifica-se também a existência de estagnação no processo de ruptura com os obstáculos metodológicos e epistemológicos no processo de transformação educacional. Geralmente, os professores e as instituições em que trabalham (Escolas e Universidades) são mais tradicionais que os instrumentos normativos que regem sobre o sistema educacional geral ${ }^{87}$. É com razão que, em concordância com os autores, a formação inicial deveria preparar os indivíduos para uma base sólida de atividade profissional que pudessem desenvolver ao longo de sua vida, o que podemos chamar de biodocência, que agrega oportunidades de desenvolvimento profissional contínuo, questionamento da prática profissional e das diversas variáveis que nela interferem. A dialética é a guardiã da biodocência para não regredir às práticas tradicionais, sedutoras e obstaculizante.

Tabela 24 - Investigações em Ensino de Ciências ${ }^{88}$ ISSN 1518-8795 On Line Instituto de Física da Universidade Federal do Rio Grande do Sul (UFRGS)

Home Page: http://www.if.ufrgs.br/ienci/?go=home

\begin{tabular}{|c|c|c|c|}
\hline \multirow{2}{*}{$\begin{array}{c}\text { VOLUME, NÚMERO E } \\
\text { DATA }\end{array}$} & \multirow{2}{*}{$\begin{array}{l}\text { Total de Artigos } \\
\text { Publicados na } \\
\text { Revista }\end{array}$} & \multicolumn{2}{|c|}{$\begin{array}{l}\text { Artigos relacionados ao Tema da } \\
\text { Pesquisa }\end{array}$} \\
\hline & & $\begin{array}{l}\text { Referentes à } \\
\text { HFCrECN }\end{array}$ & $\begin{array}{ll}\text { Referentes } & \text { à } \\
\text { HFCrECN nos DO }\end{array}$ \\
\hline Vol. 4 N. 1 jan. 1999 & 3 & 0 & 0 \\
\hline Vol. 4 N. 2 mai. 1999 & 3 & 0 & 0 \\
\hline Vol. 4 N. 3 set. 1999 & 4 & 0 & 0 \\
\hline Vol. 5 N. 1 jan. 2000 & 3 & 0 & 0 \\
\hline Vol. 5 N. 2 mai. 2000 & 3 & 0 & 0 \\
\hline Vol. 5 N. 3 set. 2000 & 5 & 0 & 0 \\
\hline Vol. 6 N. 1 jan. 2001 & 5 & 0 & 0 \\
\hline Vol. 6 N. 2 mai. 2001 & 5 & 0 & 0 \\
\hline Vol. 6 N. 3 set. 2001 & 4 & 0 & 0 \\
\hline Vol. 7 N. 1 jan. 2002 & 4 & 0 & 0 \\
\hline
\end{tabular}

87 Apenas para exemplificar a lentidão em relação à mudanças, a Lei 9394/96 instituiu os chamados cursos seqüenciais ou cursos profissionais tecnológico de graduação, que as Universidade públicas resistem a oferecer essa modalidade de ensino superior, são cursos de formação profissionalizante, ao contrário mantêm os tradicionais cursos, às vezes, alegando a formação de pesquisadores.

${ }^{88} \mathrm{Na}$ revista Investigações (v.12, n. 3, p. 321-337, 2007) foi publicado um artigo que coletamos e estudamos, no entanto, não se aproximou ao objetivo da análise feita neste capítulo. Nele trata-se do estudo das opiniões acerca do uso da HFC na licenciatura em Física na Universidade Federal da Bahia. 


\begin{tabular}{|c|c|c|c|}
\hline Vol. 7 N. 2 mai. 2002 & 4 & 0 & 0 \\
\hline Vol. 7 N. 3 set. 2002 & 7 & 0 & 0 \\
\hline Vol. 8 N. 1 jan. 2003 & 4 & 0 & 0 \\
\hline Vol. 8 N. 2 ago. 2003 & 5 & 0 & 0 \\
\hline Vol. 8 N. 3 dez. 2003 & 4 & 0 & 0 \\
\hline Vol. 9 N. 1 mar. 2004 & 4 & 0 & 0 \\
\hline Vol. 9 N. 2 ago. 2004 & 4 & 0 & 0 \\
\hline Vol. 9 N. 3 dez. 2004 & 5 & 0 & 0 \\
\hline Vol. 10 N. 1 mar. 2005 & 5 & 0 & 0 \\
\hline Vol. 10 N. 2 ago. 2005 & 6 & 0 & 0 \\
\hline Vol. 10 N. 3 dez. 2005 & 6 & 0 & 0 \\
\hline Vol. 11 N. 1 mar. 2006 & 6 & 0 & 0 \\
\hline Vol. 11 N. 2 ago. 2006 & 6 & 0 & 0 \\
\hline Vol. 11 N. 3 dez. 2006 & 6 & 0 & 0 \\
\hline Vol. 12 N. 1 mar. 2007 & 6 & 0 & 0 \\
\hline Vol. 12 N. 2 ago. 2007 & 6 & 0 & 0 \\
\hline Vol. 12 N. 3 dez. 2007 & 6 & 0 & 0 \\
\hline Vol. 13 N. 1 jan. 2008 & 6 & 0 & 0 \\
\hline Vol. 13 N. 2 ago. 2008 & 6 & 0 & 0 \\
\hline Vol. 13 N. 3 dez. 2008 & 6 & 0 & 0 \\
\hline Vol. 14 N. 1 mar. 2009 & 8 & 0 & 0 \\
\hline Vol. 14 N. 2 ago. 2009 & 8 & 0 & 0 \\
\hline Vol. 14 N. 3 dez. 2009 & 8 & 0 & 0 \\
\hline Vol. 15 N. 1 mar. 2010 & 8 & 1 & 0 \\
\hline Vol. 15 N. 2 ago. 2010 & 7 & 0 & 0 \\
\hline Vol. 15 N. 3 dez. 2010 & $\sim P$ & 0 & 0 \\
\hline Total & 186 & 1 & 0 \\
\hline
\end{tabular}

Nas revistas Filosofia e História da Biologia (FHB, 2006-2010), História da Ciência e Ensino: construindo interfaces (HC\&E, 2010), Revista Brasileira de História da Ciência (RSBHC, 2003-2010) e Revista Brasileira de Pesquisa em Educação em Ciências (RBPEC, 2001-2010) havíamos coletado respectivamente: 1, 2, 0, 1. Depois de estudados, verificamos não guardarem aproximação ao tema-problema de pesquisa conforme delimitado. Na sequência seguem as tabelas ilustrativas.

Tabela 25 - Filosofia e História da Biologia (FHB) ISSN 2178-6224 On Line Associação Brasileira de Filosofia e História da Biologia - ABFHiB;

Home Page: http://www.abfhib.org/FHB/index.html / http://www.abfhib.org/

\begin{tabular}{|c|c|c|c|}
\hline \multirow{2}{*}{$\begin{array}{l}\text { VOLUME, } \\
\text { NÚMERO E } \\
\text { DATA }\end{array}$} & \multirow{2}{*}{$\begin{array}{l}\text { Total de Artigos } \\
\text { Publicados na } \\
\text { Revista }\end{array}$} & \multicolumn{2}{|c|}{$\begin{array}{l}\text { Artigos relacionados ao Tema da } \\
\text { Pesquisa }\end{array}$} \\
\hline & & $\begin{array}{l}\text { Referentes à } \\
\text { HFCrECN }\end{array}$ & $\begin{array}{l}\text { Referentes à } \\
\text { HFCrECN nos DO }\end{array}$ \\
\hline Vol. 12006 & 21 & 0 & 0 \\
\hline Vol. 22007 & 27 & 0 & 0 \\
\hline Vol. 32008 & 21 & 0 & 0 \\
\hline Vol. 4200 & 9 & 0 & 0 \\
\hline Vol. 5 N. 12010 & 9 & 0 & 0 \\
\hline Total & 87 & 0 & 0 \\
\hline
\end{tabular}


Tabela 26 - História da Ciência e Ensino: construindo interfaces ISSN 2178-2911 On Line

Programa de Pós-Graduação em História da Ciência

Pontifícia Universidade Católica de São Paulo - PUC-SP

Home Page: http://revistas.pucsp.br/index.php/hcensino/index

\begin{tabular}{|l|l|l|c|}
\hline $\begin{array}{l}\text { VOLUME, NÚMERO } \\
\text { E DATA }\end{array}$ & $\begin{array}{l}\text { Total de Artigos } \\
\text { Publicados } \\
\text { Revista }\end{array}$ & \multicolumn{3}{|l|}{$\begin{array}{l}\text { Artigos relacionados ao Tema da } \\
\text { Pesquisa }\end{array}$} \\
\cline { 3 - 4 } & $\begin{array}{l}\text { Referentes à } \\
\text { HFCrECN }\end{array}$ & $\begin{array}{l}\text { Referentes à } \\
\text { HFCrECN nos Do }\end{array}$ \\
\hline Vol. 1 2010 & $\mathbf{5}$ & 0 & 0 \\
\hline Vol. 2 2010 & $\mathbf{6}$ & 0 & 0 \\
\hline $\begin{array}{l}\text { Obs.: periódico } \\
\text { recente }\end{array}$ & & & \\
\hline Total & $\mathbf{1 1}$ & & \\
\hline
\end{tabular}

Tabela 27 - Revista Brasileira de História da Ciência (desde 2008) ISSN 2176-3275

[Revista da Sociedade Brasileira de História da Ciência (até 2007)]

Sociedade Brasileira de História da Ciência - SBHC

Pontifícia Universidade Católica de São Paulo - PUC-SP Home Page: http://www.sbhc.org.br/

\begin{tabular}{|c|c|c|c|}
\hline \multirow{2}{*}{$\begin{array}{c}\text { VOLUME, NÚMERO E } \\
\text { DATA }\end{array}$} & \multirow{2}{*}{$\begin{array}{l}\text { Total de Artigos } \\
\text { Publicados na } \\
\text { Revista }\end{array}$} & \multicolumn{2}{|c|}{$\begin{array}{l}\text { Artigos relacionados ao Tema da } \\
\text { Pesquisa }\end{array}$} \\
\hline & & $\begin{array}{l}\text { Referentes à } \\
\text { HFCrECN }\end{array}$ & $\begin{array}{l}\text { Referentes à } \\
\text { HFCrECN nos Do }\end{array}$ \\
\hline \multicolumn{4}{|l|}{ Vol. 1999 indisponível } \\
\hline Vol. 1 N. 12003 & 5 & 0 & 0 \\
\hline Vol. 1 N. 22003 & 5 & 0 & 0 \\
\hline Vol. 2 N. 12004 & 5 & 0 & 0 \\
\hline Vol. 2 N. 22004 & 6 & 0 & 0 \\
\hline Vol. 3 N. 12005 & 6 & 0 & 0 \\
\hline Vol. 3 N. 22005 & 5 & 0 & 0 \\
\hline Vol. 4 N. 12006 & 5 & 0 & 0 \\
\hline Vol. 4 N. 22006 & 5 & 0 & 0 \\
\hline Vol. 5 N. 12007 & 5 & 0 & 0 \\
\hline Vol. 5 N. 22007 & 5 & 0 & 0 \\
\hline Vol. 1 N. 12008 & 7 & 0 & 0 \\
\hline Vol. 1 N. 22008 & 6 & 0 & 0 \\
\hline Vol. 2 N. 12009 & 7 & 0 & 0 \\
\hline Vol. 2 N. 22009 & 8 & 0 & 0 \\
\hline Vol. 3 N. 12010 & 7 & 0 & 0 \\
\hline Vol. 1 N. 22010 & 9 & 0 & 0 \\
\hline Total & 96 & 0 & 0 \\
\hline
\end{tabular}


Tabela 28 - Revista Brasileira de Pesquisa em Educação em Ciências

ISSN: não divulgado

Associação Brasileira de Pesquisa em Educação em Ciências - ABRAPEC

Faculdade de Educação /Universidade Federal de Minas Gerais - UFMG

Home Page: http://www.fae.ufmg.br/abrapec/revista/index.html

\begin{tabular}{|c|c|c|c|}
\hline \multirow{2}{*}{$\begin{array}{c}\text { VOLUME, NÚMERO E } \\
\text { DATA }\end{array}$} & \multirow{2}{*}{$\begin{array}{l}\text { Total de Artigos } \\
\text { Publicados na } \\
\text { Revista }\end{array}$} & \multicolumn{2}{|c|}{$\begin{array}{l}\text { Artigos relacionados ao Tema da } \\
\text { Pesquisa }\end{array}$} \\
\hline & & $\begin{array}{l}\text { Referentes à } \\
\text { HFC-ECN }\end{array}$ & $\begin{array}{l}\text { Referentes à } \\
\text { HFC-ECN nos DO }\end{array}$ \\
\hline Vol. 1 N. 1 jan./abr. 2001 & 12 & 0 & 0 \\
\hline Vol. 1 N. 2 mai./ago. 2001 & 12 & 0 & 0 \\
\hline Vol. 1 N. 3 set./dez. 2001 & 12 & 0 & 0 \\
\hline Vol. 2 N. 1 jan./abr. 2002 & 6 & 0 & 0 \\
\hline Vol. 2 N. 2 mai./ago. 2002 & 8 & 0 & 0 \\
\hline Vol. 2 N. 3 set./dez. 2002 & 6 & 0 & 0 \\
\hline Vol. 3 N. 1 jan./abr. 2003 & 8 & 0 & 0 \\
\hline Vol. 3 N. 2 mai./ago. 2003 & 4 & 0 & 0 \\
\hline Vol. 3 N. 3 set./dez. 2003 & 4 & 0 & 0 \\
\hline Vol. 4 N. 1 jan./abr. 2004 & 8 & 0 & 0 \\
\hline Vol. 4 N. 2 mai./ago. 2004 & 8 & 0 & 0 \\
\hline Vol. 4 N. 3 set./dez. 2004 & 8 & 0 & 0 \\
\hline Vol. 5 N. 1 jan./abr. 2005 & 6 & 0 & 0 \\
\hline Vol. 5 N. 2 mai./ago. 2005 & 6 & 0 & 0 \\
\hline Vol. 5 N. 3 set./dez. 2005 & 5 & 0 & 0 \\
\hline Vol. 6 N. 1 jan./abr. 2006 & 4 & 0 & 0 \\
\hline Vol. 6 N. 2 mai./ago. 2006 & 4 & 0 & 0 \\
\hline Vol. 6 N. 3 set./dez. 2006 & 4 & 0 & 0 \\
\hline Vol. 7 N. 1 jan./abr. 2007 & 4 & 0 & 0 \\
\hline Vol. 7 N. 2 mai./ago. 2007 & 4 & 0 & 0 \\
\hline Vol. 7 N. 3 set./dez. 2007 & 4 & 0 & 0 \\
\hline Vol. 8 N. 1 jan./abr. 2008 & 6 & 0 & 0 \\
\hline Vol. 8 N. 2 mai./ago. 2008 & 6 & 0 & 0 \\
\hline Vol. 8 N. 3 set./dez. 2008 & 6 & 0 & 0 \\
\hline Vol. 9 N. 1 jan./abr. 2009 & 7 & 0 & 0 \\
\hline Vol. 9 N. 2 mai./ago. 2009 & 6 & 0 & 0 \\
\hline Vol. 9 N. 3 set./dez. 2009 & 7 & 0 & 0 \\
\hline Vol. 10 N. 1 jan./abr. 2010 & 8 & 0 & 0 \\
\hline $\begin{array}{l}\text { Vol. } 10 \text { N. } 2 \text { mai./ago. } \\
2010\end{array}$ & 7 & 0 & 0 \\
\hline Vol. 10 N. 3 set./dez. 2010 & $\sim \mathbf{P}$ & 0 & 0 \\
\hline Total & 190 & 0 & 0 \\
\hline
\end{tabular}

Finalmente, chegamos a um novo conjunto de Categorias de Análise, acrescidas ao longo das análises dos trabalhos oriundos das pesquisas: 
Tabela 29 - Artigos por Categorias de Análise

\begin{tabular}{|c|c|c|}
\hline \multicolumn{3}{|c|}{ CATEGORIZAÇÃO } \\
\hline № & ARTIGOS CATEGORIZADOS & CATEGORIA \\
\hline 1 & B-C\&Ed & Autoaperfeiçoamento* \\
\hline & & $\begin{array}{l}\text { (inclui argumentos de humanização e } \\
\text { aprendizagem) }\end{array}$ \\
\hline & & $\begin{array}{l}\text { *Este sinal caracteriza os termos } \\
\text { aproveitados de Maienschein, } 2000 .\end{array}$ \\
\hline 2 & & Elucidação \\
\hline & & (inclui argumentos de "Perspectiva"*) \\
\hline 3 & B-RBEF & Criticidade \\
\hline & $\begin{array}{l}\text { A-C\&Ed } \\
\text { B-C\&Ed } \\
\text { A-Ensaio } \\
\text { B-Ensaio }\end{array}$ & $\begin{array}{l}\text { (argumentos de Hermenêutica ou } \\
\text { interpretação, } \\
\text { Resignificação e "Eficiência"*) }\end{array}$ \\
\hline 4 & $\begin{array}{c}\text { A-CBEF } \\
\text { A-RBEF } \\
\text { B-RBEF } \\
\text { A-C\&Ed } \\
\text { B-C\&Ed } \\
\text { A-Ensaio } \\
\text { A-Investigacões }\end{array}$ & $\begin{array}{l}\text { Contextualização Interna } \\
\text { (argumentos vinculados ao contexto } \\
\text { interno, metodológico, conceitual e } \\
\text { cognitivo) }\end{array}$ \\
\hline 5 & $\begin{array}{l}\text { A-CBEF } \\
\text { A-Ensaio }\end{array}$ & $\begin{array}{l}\text { Contextualização Externa } \\
\text { (argumentos vinculados ao contexto } \\
\text { externo histórico, das relacõoses } \\
\text { socioculturais, econômicas, políticas, } \\
\text { etc.) }\end{array}$ \\
\hline 6 & $\begin{array}{l}\text { A-Ensaio } \\
\text { B-Ensaio }\end{array}$ & \begin{tabular}{l}
\multicolumn{1}{c}{ Sistemicidade } \\
(argumentos em que se expõe relações \\
de Inter/Multi/Transdisciplinaridade, \\
remetendo a um sistema integrado)
\end{tabular} \\
\hline 7 & $\begin{array}{l}\text { B-C\&Ed } \\
\text { B-Ensaio }\end{array}$ & $\begin{array}{l}\text { Falibilidade Epistêmica } \\
\text { (argumentos em que se ressaltam os } \\
\text { limites do conhecimento científico- } \\
\text { tecnológico) }\end{array}$ \\
\hline 8 & $\begin{array}{l}\text { - B-CBEF } \\
\text { A-Ensaio }\end{array}$ & $\begin{array}{l}\text { Motivacional } \\
\text { (argumentos em que se exprime a ideia } \\
\text { de que a HFC seria fonte de motivação, } \\
\text { inspiraçãol"imaginação"*) }\end{array}$ \\
\hline 9 & & $\begin{array}{l}\text { Socialização Epistêmica } \\
\text { (argumentos voltados para divulgação, } \\
\text { literacia científica, formação do cidadão } \\
\text { (cidadania)) }\end{array}$ \\
\hline 10 & $\begin{array}{c}\text { C-C\&Ed } \\
\text { A-Investigações }\end{array}$ & $\begin{array}{l}\text { Instrumentação Didática } \\
\text { (relacionada à propostas de pesquisa } \\
\text { didática em que se tenciona instruir } \\
\text { docentes em formação inicial ou } \\
\text { continuada a desenvolver determinadas } \\
\text { competências, e.g. abordagem da HFC) }\end{array}$ \\
\hline 11 & $\begin{array}{l}\text { D-C\&Ed } \\
\text { B-Ensaio }\end{array}$ & $\begin{array}{l}\text { Eticidade } \\
\text { (relacionada às propostas de pesquisa } \\
\text { didática em que se tenciona discutir } \\
\text { questões éticas relacionadas às ciência } \\
\text { e tecnologia) }\end{array}$ \\
\hline
\end{tabular}

Passamos agora para a análise dos dados coletados nos eventos da área de ensino de ciências naturais e algumas correlatas. 


\section{3 - Análise da HFCrECN nos Trabalhos de Eventos Científicos (1999 a 2010)}

Quanto aos eventos, procuramos analisar os eventos promovidos pelas sociedades científicas de Física, Biologia, Química e um evento da área de ECN, promovido pela Sociedade Brasileira de Pesquisa em Educação em Ciências (ABRAPEC), os demais critérios de seleção já foram mencionados anteriormente. Ao todo foram seis (6) eventos cujos trabalhos foram analisados, respectivamente:

1. Encontro de Pesquisa em Ensino de Física (EPEF) da SBF;

2. Simpósio Nacional de Ensino de Física (SNEF) da SBF;

3. Encontro Nacional de Ensino de Química (ENEQ) da SBQ;

4. Encontro Nacional de Ensino de Biologia (ENEBIO) da SBEnBio;

5. Encontro de Filosofia e História da Biologia - da ABFHiB;

6. Encontro Nacional de Pesquisa em Educação em Ciência (ENPEC) da ABRAPEC;

Foi constatado que a grande maioria dos trabalhos apresentados em eventos são partes de trabalhos de conclusão de cursos de mestrado ou doutorado ou iniciação científica, são raros os trabalhos de pesquisa que não fossem de caráter acadêmico-escolar.

A análise dos resumos segue a ordem cronológica de ocorrência dos eventos, na lista apresentada. Em virtude das características, em alguns resumos, constatamos a falta informações que indicassem o processo da pesquisa, da experimentação ou instrumentação didática realizada para inserção da HFC. Este fato levou-nos a criar - como consequência - uma nova categoria: insuficiência informativa em relação à HFCrECN. Esta categoria é apenas operacional, pois indica trabalhos em cujos resumos não foi possível identificar informações suficientes sobre a HFCrECN que possibilitassem localizá-los nas categorias de análise ou que cujo grau de significação permitisse a criação de novas categorias significativas.

Porém, da busca feita conseguimos obter trabalhos completos, não de todos, mas da grande maioria dos resumos, o que possibilitou obter informações mais precisas sobre os trabalhos. Além do problema de insuficiências de informações categorizáveis, encontramos outros problemas de redação que se refere ao marco temporal expresso pelos verbos, que dificultam entender se no momento da apresentação ou da escrita do trabalho, as propostas haviam sido já 
realizadas ou estavam para serem realizadas. Em alguns casos há conflitos entre os tempos verbais expressos nos textos, o que dificultou a compreensão da realização das ações investigativas dos autores, por exemplo: constatamos que em alguns momentos dos textos alguns autores anunciam que realizaram tal feito, porém, em outro momento, no mesmo trabalho, afirmam que realizarão ou aplicarão tão coisa, isto deixa o leitor em dúvidas em relação à pesquisa feita, se foi concluída ou não no momento da escrita do trabalho publicado em periódico ou apresentado em eventos.

\subsection{1 - Eventos da Área de Ensino de Física}

A área de Ensino de Física conta com uma contribuição crescente ao movimento internacional da HFCrECN, no âmbito nacional, em seus eventos tem havido uma participação e apresentação de propostas que vão desde decorrências de pesquisas posgraduacionais às didáticas (em sala de aula). Este fato não deve ser visto como fortuito à Física, pois nela começou a introdução da HC na formação universitária (até onde temos dados históricos, já referidos por nós neste e noutro trabalho anterior). O que também se vê pelo número de físicos a frequentar os cursos de $\mathrm{FC}$ e/ou HC. Este fenômeno nos faz pensar que, talvez, um macroprojeto de HFCrECN venha a surgir primeiro nesta área, no Brasil.

Os trabalhos coletados foram simbolizados com $\mathrm{T}$ designação de trabalho, seguida do número de ordem, da sigla do evento e do ano de divulgação, por exemplo: T1-EPEF-2000, isto para poder facilitar a inclusão na tabelas de categorias. A maioria dos trabalhos não apresenta paginação, daí que todas as citações se referem exclusivamente aos respectivos trabalhos em análise, em casos de referirmo-nos à algum conceito ou expressão dos autores o fizemos entre aspas apenas.

\subsubsection{1 - Encontro de Pesquisa em Ensino de Física - EPEF}

Em relação ao EPEF encontramos materiais apenas a partir do ano de 2000, em que foram coletados os trabalhos seguintes: 
T1-EPEF-2000 AMARAL, Elisabete Aparecida do; ZANETIC, João. Uma Abordagem Histórica da Teoria da Relatividade no Ensino Médio. In: ENCONTRO DE PESQUISA EM ENSINO DE FÍSICA, 7., 2000. Florianópolis: SBF, 2000. Resumos eletrônicos... Disponível em: <http://www.sbf1.sbfisica.org.br/eventos/epef/vii/programa1.htm>. Acesso em: 21 dez. 2010.

T2-EPEF-2000 PINTO, Alexandre Custódio; ZANETIC, João. Contribuições das Filosofias da Ciência para uma Reflexão sobre as (Re)Concepções do Ensino de Física. In: ENCONTRO DE PESQUISA EM ENSINO DE FÍSICA, 7., 2000. Florianópolis: SBF, 2000. Resumos eletrônicos... Disponível em: <http://www.sbf1.sbfisica.org.br/eventos/epef/vii/programa1.htm>. Acesso em: 21 dez. 2010.

T3-EPEF-2002 SILVA, Aparecida Valquiria Pereira da et al. A História e a Filosofia da Ciência Susidiando a Construção de Atividade Didáticas para o Ensino Médio de Física em Nível Médio. In: ENCONTRO DE PESQUISA EM ENSINO DE FÍSICA, 8., 2002. Águas de Lindóia, SP. Resumos eletrônicos... São Paulo: Sociedade Brasileira de Física, 2002. Disponível em: <http://www.sbf1.sbfisica.org.br/eventos/epef/viii/>. Acesso em: 21 jan. 2011.

T4-EPEF-2006 CARVALHO, Anna Maria Pessoa de. História e Filosofia da Ciência no Ensino de Física. In: ENCONTRO DE PESQUISA EM ENSINO DE FíSICA, 10., 2006. Londrina, PR. Caderno de Resumos... São Paulo: Sociedade Brasileira de Física, 2006. p. 26. Disponível também em: <http://www.sbf1.sbfisica.org.br/eventos/epef/x/>. Acesso em: 21 jan. 2011.

T5-EPEF-2008 SOUZA FILHO, Moacir Pereira de; BOSS, Sérgio L. Bragatto; CALUZI, João José. Diferenças e Semelhanças entre Eletricidade e Magnetismo: o diálogo histórico entre o erro e a verdade subsidiando o ensino de física. In: ENCONTRO DE PESQUISA EM ENSINO DE FÍSICA, 11., 2008. Curitiba, PR. Caderno de Resumos... São Paulo: Sociedade Brasileira de Física, 2008. Disponível também em: < http://www.sbf1.sbfisica.org.br/eventos/epef/xi/>. Acesso em: 21 jan. 2011.

T6-EPEF-2008 FORATO, Thais C. de Mello; MARTINS, Roberto de Andrade; PIETROCOLA, Maurício. Teorias da Luz e Natureza da Ciência: elaboração e análise de curso aplicado no ensino médio. In: ENCONTRO DE PESQUISA EM ENSINO DE FÍSICA, 11., 2008. Curitiba, PR. Caderno de Resumos... São Paulo: Sociedade Brasileira de Física, 2008. Disponível também em: < http://www.sbf1.sbfisica.org.br/eventos/epef/xi/>. Acesso em: 21 jan. 2011.

T7-EPEF-2008 BOSS, Sérgio L. Bragatto; SOUZA FILHO, Moacir P. de; LISBOA FILHO, Paulo N.; CALUZI, João José. História da Ciência e Aprendizagem Significativa: o conceito de carga elétrica. In: ENCONTRO DE PESQUISA EM ENSINO DE FÍSICA, 11., 2008. Curitiba, PR. Caderno de Resumos... São Paulo: Sociedade Brasileira de Física, 2008. Disponível também em: < http://www.sbf1.sbfisica.org.br/eventos/epef/xi/>. Acesso em: 21 jan. 2011.

T8-EPEF-2008 SOARES, Reginaldo Ribeiro; BORGES, Paulo de Faria. O Plano Inclinado de Galileu e a História da Ciência na Sala de Aula do Ensino Médio de Física. In: ENCONTRO DE PESQUISA EM ENSINO DE FÍSICA, 11., 2008. Curitiba, PR. Caderno de Resumos... São Paulo: Sociedade Brasileira de Física, 2008. Disponível também em: < http://www.sbf1.sbfisica.org.br/eventos/epef/xi/>. Acesso em: 21 jan. 2011.

T9-EPEF-2010 GATTI, Sandra R. Teodoro; NARDI, Roberto. Práticas Pedagógicas Realizadas em Atividades de Formação Continuada: a aproximação da História e Filosofia da Ciência ao ensino de Física. In: ENCONTRO DE PESQUISA EM ENSINO DE FÍSICA, 12., 2010. Águas de Lindóia, SP. Caderno de Resumos... São Paulo: Sociedade Brasileira de Física, 2010. Disponível também em: <http://www.sbfisica.org.br/ epef/xii/>. Acesso em: 21 jan. 2011.

T10-EPEF-2010 FORATO, Thaís C. de Mello; MARTINS, Roberto de A; PIETROCOLA, Maurício. A História e a Natureza da Ciência no Ensino de Ciências: obstáculos a superar ou contornar. In: ENCONTRO DE PESQUISA EM ENSINO DE FÍSICA, 12., 2010. Águas de Lindóia, SP. Caderno de Resumos... São Paulo: Sociedade Brasileira de Física, 2010. Disponível também em: $<$ http://www.sbfisica.org.br/ epef/xii/>. Acesso em: 21 jan. 2011. 
Paula B. da. A Natureza da Ciência através de um Episódio Histórico sobre a luz: adaptações metodológicas. In: ENCONTRO DE PESQUISA EM ENSINO DE FÍSICA, 12., 2010. Águas de Lindóia, SP. Caderno de Resumos... São Paulo: Sociedade Brasileira de Física, 2010. Disponível também em: <http://www.sbfisica.org.br/ epef/xii/>. Acesso em: 21 jan. 2011.

T12-EPEF-2010 REIS, José Claudio; GUERRA, Andreia; BRAGA, Marco. Da Necessidade de Valorizar a História e a Filosofia da Ciência na Formação de Professores. In: ENCONTRO DE PESQUISA EM ENSINO DE FÍSICA, 12., 2010. Águas de Lindóia, SP. Caderno de Resumos... São Paulo: Sociedade Brasileira de Física, 2010. Disponível também em: <http://www.sbfisica.org.br/ epef/xii/>. Acesso em: 21 jan. 2011.

Os autores do T1-EPEF-2000 tiveram por objetivo de estudo desenvolver uma proposta que possibilitasse a apresentação da Teoria da Relatividade Especial e Geral aos discentes da Escola média, servindo-se da noção de mudança paradigmática de Thomas Kuhn como referencial para descrever "episódios mais marcantes" da teoria de Einstein. A HC ou abordagem histórica é tida como instrumento de resgate do contexto dos cientistas que o influenciaram e dos problemas que motivaram Einstein a desenvolver a Teoria da Relatividade.

Afirmam também terem analisado uma "experiência educacional realizada na Escola Técnica Federal de São Paulo", durante a qual foi utilizada a leitura de textos em aula para possibilitar o entendimento histórico do conhecimento científico. Uma experiência que teria contado com as contribuições da literatura para abordagem interdisciplinar. Parece-nos que esta experiência educacional seja a aplicação da referida proposta de apresentação da teoria da relatividade einsteiniana, pois concluem que a análise dos resultados teria revelado "[...] uma grande receptividade nas atividades desenvolvidas, confirmando a viabilidade de utilização dessas diferentes abordagens" e despertado o entendimento das teorias físicas e sua contribuição cultural. Em virtude da falta de informações sobre o processo a inclusão da abordagem histórica tanto na proposta quanto na experiência educacional torna-se inviável a localização categórica do trabalho, neste sentido enquadra-se na categorial operacional de Insuficiência Informativa em Relação à HFCrECN.

Partindo da constatação de que na prática didática de ensino de física há ausência de abordagem de concepção geral de mundo, de física e da relação desta com a sociedade, os autores do T2-EPEF-2000 tiveram por objetivo identificar 'fragmentos das 'filosofias' da ciência presentes, explicita ou implicitamente, em cursos de física tanto do nível médio como do superior de ensino." Precisamente, trata-se de abordagens de Karl Popper, Thomas S. Kuhn, Gaston Bachelard e Paul 
Feyerabend.

Porém, mencionam rapidamente quatro exemplos de inserção de aspectos da FC no ensino de física, sem descrever o seu processo, tais seriam: o primeiro exemplo teria ocorrido no ensino médio em que se tratou de aspectos da física quântica com base na análise bachelardiana; o segundo e o terceiro exemplo teriam ocorrido no ensino superior e se referiram "às várias 'teorias gravitacionais' separadas dor revoluções científicas" analisadas sob a ótica de Kuhn e "à discussão do nascimento da mecânica quântica" com base em análise da FC; o quarto exemplo, teria sido de um curso de extensão universitária destinado aos docentes das escolas públicas, durante o qual teriam sido apresentadas "filosofias" às quais se vinculou temas de física clássica e moderna.

Do descrito no T2-EPEF-2000 é possível inferir apenas uma possibilidade de localização do trabalho em duas categorias: contextualização interna, por se tratar de temas conceituais da física (quântica, gravitação, clássica e moderna) e criticidade, por tencionar a abordagem epistemológica crítica dos temas.

O T3-EPEF-2002 refere-se à apresentação do trabalho consequente da execução do Projeto Pró-Ciências desenvolvido pelos autores numa cooperação entre Departamentos de Física e Educação da Faculdade de Ciências da UNESP em Bauru/SP. Participaram do projeto 33 docentes de ensino médio do município de Bauru e região, da área de Física e os que vindo de outras áreas lecionam física. Os autores tinham por objetivo: promover melhoria no ensino de física baseando-se na HFC e pesquisas atuais na área, abordando conteúdos da Proposta Curricular da Secretaria de Estado de Educação da São Paulo; estudar concepções espontâneas de discentes de nível médio; uso da HFC para planejamento de alternativas pedagógicas; elaborar material didático a ser usado em sala de aula, entre outros.

As atividades foram desenvolvidas em 440 horas distribuídas entre oferta de disciplinas, reuniões técnicas e seminários avaliativos. Ao analisar as disciplinas ${ }^{89}$ e atividades desenvolvidas podemos concluir que se trata de um trabalho localizável na categoria de Instrumentação Didática, pela inserção da abordagem de aspectos da HFC e estudos de concepções espontâneas dos discentes como elementos para

\footnotetext{
${ }^{89}$ Veja-se: Fundamentos Históricos e Filosóficos da Ciência para o Ensino de Física; Concepções Espontâneas, Mudança Conceptual e Ensino de Física; Instrumentação para o Planejamento/Construção de Atividades de Ensino de Física (mecânica, calor, óptica, eletricidade, magnetismo, temas moderno-contemporâneos da Física); Instrução para a Pesquisa, respectivamente.
} 
diagnóstico das condições de inserção da abordagem no ensino. A partir dos temas presentes no planejamento e construção de atividades didáticas podemos inferir uma Contextualização Interna já que não se faz referência a aspetos sociais, econômicos, culturais e político-religiosos que interferem no processo de produção científica.

Interessante a estratégia de avaliação do impacto do uso da HFC por meio de verificação do uso de conhecimento sobre concepções espontâneas por docentes escolares e pesquisadores participantes do projeto: uso de questionário para averiguar o conhecimento histórico presente na prática didática dos docentes escolares antes da disciplina relacionada à HFC, durante e depois do projeto.

Os autores afirmam que antes da participação efetiva do Projeto constataram que $40 \%$ dos docentes participantes haviam tentado incluir a HFC no ensino e que suas tentativas foram "pouco produtivas". Em relação à contribuição das atividades consideradas em si, os temas HFC (44\%), Concepções espontâneas/mudança conceitual (32\%) e HFC/Concepções espontâneas/mudança conceitual (8\%) foram considerados pelos participantes como os que mais contribuíram para as atividades. E que ao avaliarem o impacto do projeto em relação à prática didática $84 \%$ teria respondido que sua prática sofreu modificação em virtude da inserção de aspectos da HC e concepções espontâneas. Considerando a inserção da HC no ensino, ao final do projeto, $80 \%$ dos participantes teriam afirmado que passaram a usá-la no ensino de física.

Entretanto, o trabalho de inclusão em sala de aula

[...] parece ainda mostrar-se incipiente pois a novidade e o despreparo do docente na formação inicial, em relação aos temas, a organização escolar, as condições de trabalho (elevado número de horas aula e alunos, diversidade de escolas entre outras) e a cultura criada pelos textos didáticos não favorecem as mudanças.

[...]

Contudo [os docentes escolares participantes] mostraram também, que as mudanças na prática docente, em sala de aula, foram pontuais e pouco articuladas ao plano de trabalho já proposto no início do ano em cada escola.

A análise das atividades propostas, ao final deste Projeto, aponta ainda para uma inserção de História da Ciência, marcada por uma maior ênfase nos cientistas do que no processo de produção do conhecimento (lei, teoria ou conceito) enfocado.

[Mas, ainda assim,] Pode-se afirmar que o Projeto contribui para a formação do docente na medida que possibilitou novos conhecimentos, iniciação em atividades de pesquisa, o conhecimento de novas fontes de pesquisa e desenvolveu (ainda que não plenamente) as habilidades para lidar com essas fontes. (SILVIA et al. 2002) 
As 440 horas de instrumentação didática constituem uma iniciativa que propicia a capacitação em termos de formação continuada, o mínimo que pode ser feito com aqueles que em cuja formação não tiveram estudos de HFC, que pudesse Ihe dar algumas noções básicas, sobre as quais a formação continuada seria uma complementação e atualização. As dificuldades apontadas constituem obstáculos para o processo de inserção da HFC no ensino e é um fato que requisita o replanejamento dos programas de formação inicial docente.

Em 2006, o T4-EPEF-2006, foi apresentado durante a mesa redonda 3 HFC e o Ensino de Física, no resumo a autora diz que apresentaria uma discussão relacionada ao planejamento e inclusão de atividades de HFC no ensino e aprendizagem da física no ensino médio e, para tal, "Vamos apresentar o resultado de três trabalhos de pesquisa realizados em escolas estaduais da cidade de São Paulo." (CARVALHO, 2006). No entanto, verificando o enfoque (vertentes) dado ao conteúdo escolar de física "[...] pensado em suas três vertentes: conceitual, procedimental e atitudinal." (CARVALHO, 2006) é possível deduzir uma Contextualização Interna das atividades de inclusão da HFC e constatação de Insuficiência Informativa em Relação à HFCrECN, para os propósitos da análise.

A análise do erro também aparece incluída nas propostas da abordagem histórica, é o que podemos verificar no T5-EPEF-2008, em que os autores apresentam abordagem das diferenças e semelhanças entre a eletricidade e o magnetismo na $\mathrm{HC}$, como forma de contribuir com as discussões e estudo do papel do erro, em um grupo de estudantes de Licenciatura em Física. Os autores serviramse de pressupostos teóricos bachelardianos (psicanálise, teoria do erro, no Ensaio sobre o Conhecimento Aproximado ${ }^{90}$, Bachelard considera o erro como momento da temporalidade dialética a ser superado e por isso motor do conhecimento) conforme propostos por Santos ${ }^{91}$, tais como: conscientização, desequilibração e familiarização.

O objetivo foi o de: apresentar uma proposta didática apoiada na discussão textual e em experimentos histórico para contrastar os conhecimentos prévios dos discentes; discutir a importância do erro e mostrar que a HC propicia

${ }^{90}$ BACHELARD, Gaston. Ensaio sobre o Conhecimento Aproximado. Rio de Janeiro: Contraponto, 2004.

${ }_{91}$ Santos, M. E. V. M. Mudança Conceptual na Sala de Aula: um desafio pedagógico Epistemologicamente fundamentado. 2 ${ }^{\mathrm{a}}$ Ed. Lisboa: Livros Horizonte, 1998. 
momentos ou situações favoráveis para mobilização dos discentes para a aprendizagem.

Para materialização dos objetivos propostos os autores realizaram um curso denominado Fundamentos Históricos do Eletromagnetismo, com a duração de 60 horas e participação de quinze (15) licenciandos em Física. Partiu-se do estudo histórico (leitura de textos) da eletricidade e do magnetismo para chegar ao eletromagnetismo. Figuraram textos de autores como Bartholomews, Peregrinus, Gilbert, Gray, Du Fay e Franklin, Orsted, servindo-se de ferramentas audiovisuais para coleta de dados (abordagem qualitativa: gravação, transcrição e tratamento). Portanto, o enfoque no conteúdo histórico-conceitual da pesquisa faz com que esteja inscrito na categoria de Contextualização Interna.

Em relação aos resultados da investigação didática referente à aprendizagem por razões decorrentes da aplicada da HFC, os autores afirmam que:

\begin{abstract}
A pesquisa mostrou que nas duas questões formuladas as predições teóricas dos alunos não condiz com o observado experimentalmente. $\mathrm{Na}$ primeira questão, a hipótese de cargas elétricas em movimento próximo a um campo magnético influenciou fortemente a opinião dos alunos que acreditavam na interação do filete de água e o ímã. Eles imaginaram também que o movimento do ímã pudesse de alguma forma desviar o filete de água. Na segunda questão os alunos acreditavam que pelo fato das limalhas serem materiais ferromagnéticos, a atração elétrica não deveria ocorrer. Porém, vimos que a atração elétrica acontece com uma infinidade de materiais, inclusive com os ferromagnéticos. Diferentemente do que supôs um dos alunos, não é necessário que os corpos estejam carregados.

Estas predições equivocadas foram colocadas em processo de mobilização a fim de que o conhecimento científico seja discutido e pensado, e não simplesmente ensinado ao aluno. Os textos históricos constituem-se com [sic] fontes que fomentam este diálogo entre o professor e o aluno, entre 0 conhecimento do senso comum e o conhecimento científico. (Souza Filho; Boss; Caluzi, 2008)
\end{abstract}

As questões a que os autores se referem foram as que fizeram aos discentes antes da reprodução de experimentos historicamente conhecidos, ei-las, respectivamente: a) "Um filete de água é influenciado por um bastão atritado, mas será que um ímã exerce alguma influência sobre o filete de água?" e b) "Um bastão atritado atrai pequenos pedaços de papel. Será que este bastão atritado atrai limalhas de ferro?"

O uso de episódios históricos sobre a óptica, com ênfase em teorias da luz, como estratégia para introduzir a HFC o ensino médio foi o objetivo que tiveram os autores do T6-EPEF-2008. A sua pesquisa didática foi baseada também em um 
curso aplicado em escola pública de São Paulo, por meio da triangulação como estratégia metodológica para coleta dados (gravação de voz em vídeo, questionários e provas escritas, observação de campo durante as aulas).

Trata-se de uma pesquisa didática de Contextualização Interna, como pode ser percebido a partir do programa desenvolvido durante o curso de 20 horas (em 10 dias), realizado com 38 discentes do terceiro ano de uma escola média pública de São Paulo: a luz na antiguidade grega (conceito, mitos, atomistas, Empédocles, Aristóteles); Natureza da luz no século XVII (fenômeno da reflexão, refração e dispersão, Huygens e éter, Newton e teoria corpuscular, cor, imagem da ciência no séc. XVIII); Teorias da luz e éter luminífero, princípios do séc. XIX (fenômeno das sombras e difração, sobreposição e interferência, éter e teoria ondulatória, corpuscularismo e Fresnel, teoria de Fresnel e ondulatória).

A leitura de textos que tratavam dos aspectos históricos da óptica teria auxiliado a simulação do embate entre as teorias de Huygens e Newton, por meio do debate didático entre dois grupos, um representando a teoria da natureza da luz de Huygens e outro a corpuscular newtoniana. O restante da turma teria formado o júri, para conferir veredicto favorável à teoria que fosse "melhor fundamentada", durante o debate. Desta encenação didática resultou que "A teoria ondulatória foi vencedora do debate, mesmo com a maioria dos alunos 'preferindo' a sua rival. Na colocação do veredicto, o júri enfatizou que, embora preferissem a corpuscular, a argumentação do grupo da teoria ondulatória estava melhor" (FORATO; MARTINS; PIETROCOLA, 2008).

Mesmo não apresentando uma avaliação mensurativa, considerando a estratégia metodológica da triangulação de dados, para diagnosticar a interferência da abordagem dos aspectos históricos dos textos estudados no processo de aprendizagem da física, os autores afirmam que: "Os dados sugerem que essa seja uma estratégia adequada para inserir elementos de HFC no ensino médio, a despeito da necessidade de alguns ajustes" (FORATO; MARTINS; PIETROCOLA, 2008).

Ou ainda que:

A análise permitiu-nos repensar os dilemas na seleção de conteúdos, no recorte a adotar, em quais informações omitir e no nível de profundidade a tratar. Optamos por abordar apenas conceitos ligados à natureza da luz, excluindo, por exemplo, assuntos relacionados à questão levantada pelos alunos: "se ela agisse mesmo como som, como eles falam, ela não poderia produzir o calor, como o calor do Sol, o som não produz calor". Entretanto, 
fazer escolhas significa prescindir de outros caminhos possíveis.

[...]. O debate representou um marco no curso, pois a partir dele, os alunos que "dormiam" nas primeiras aulas passaram a participar ativamente do curso. Diversos aspectos formativos foram também contemplados, como a articulação de um novo conhecimento teórico para compor uma argumentação; o trabalho em equipe requerendo a colaboração entre os alunos; a compreensão de idéias rivais e a rápida seleção de concepções e exemplos que poderiam refutá-las, dentre muitos outros. (FORATO; MARTINS; PIETROCOLA, 2008).

Porém, embora a aceitação de uma teoria científica não ocorra à semelhança de decisões judiciais (i.e. teoria científica nos banco dos réus), no entanto, a simulação pedagógica encontra certo valor didático que pode consistir em despertar os discentes para a investigação, análise, interpretação e, sobretudo, o desenvolvimento da capacidade de argumentação para defesa ou refutação de ideias fundamentadas na consistência lógica, já que as evidências empíricas estão distantes para provar as teorias! O veredito dado, por discentes, constitui um desafio, uma demonstração do valor lógico da argumentação, para a tomada de decisão, em quaisquer empreitadas, inclusive as científicas. Essa estratégia pedagógica utilizada na investigação didática demonstra a intenção do desenvolvimento de capacidade e habilidades de Criticidade.

De certa forma, a ilustração de que em ciências se tomam decisões consequentes de embates de ideias pode contribuir para a dissipação das imagens ingênuas, que governam a percepção comum da atividade científica.

No EPEF de 2008, também foi apresentado um trabalho em que os autores discutiram a "pertinência da inserção de textos históricos (fontes primários) de Física em um curso de graduação em Licenciatura em Física", trata-se do T7EPEF-2008, resultante de pesquisa didática que teve por objetivo "[...] analisar se e como discussões com textos históricos podem auxiliar os alunos na aprendizagem dos conceitos." O conceito físico em causa foi a "carga elétrica". Os autores dizem ter coletado os dados via questionários qualitativos, em três momentos: no primeiro visavam à identificação de conhecimentos prévios dos discentes em relação à eletrostática; no segundo, identificação de conhecimento adquiridos pelos discentes após estudos de 3 textos $^{92}$ históricos $(\mathrm{HC})$ e no terceiro, verificar os conhecimentos

92 Os textos referidos são fragmentos de Gray, S. (A letter to Cromwell Mortimer, M.D. Secr. R.S. containing several experimets concerning electricity. In: Philosophical Transactions of the Royal Society, v. 37, p. 18-44, 1731); DU FAY, C. F. C. (Quantriéme Mémoire sur l'électricité: de l'attraction \& répulsion dês corps électriques. In: Mémoires de l'Academie Royale des Sciences, p. 457-476, 1733. A letter [...] concerning the Electricity. In: Philosophical Transactions of the Royal Society, v. 
adquiridos pelos discentes sobre o conceito de carga elétrica, após o estudo sobre "Lei de Gauss" (BOSS et al. 2008). Didaticamente, a Teoria da Aprendizagem Significativa de David Ausubel foi tida como referencial de abordagem pedagógica.

Trata-se de um trabalho de Contextualização Interna, em virtude do estudo conceitual dos textos históricos e também das questões conceituais dos questionários, referindo-se a temas como: "carga elétrica, eletrização, lei de Coulomb, campo elétrico e lei Gauss" (BOSS et al. 2008). A vinculação do trabalho à categoria analítica encontra outro apoio dos autores ao afirmarem que:

O nosso objetivo principal com os textos históricos era apresentar e discutir alguns experimentos de eletrostática, os quais demonstram importantes características e propriedades dos corpos carregados eletricamente, discutir duas teorias distintas que procuraram explicar a eletricidade no século XVIII, e discutir como se deu a proposição destas teorias, os problemas e/ou as necessidades que levaram a sua proposição e a lógica desta construção conceitual. (BOSS et al. 2008)

Percebe-se os aspectos da HC como âncoras para ilustrar os dilemas ou embates entre teorias científicas concorrentes para elucidação fenomênica. $O$ uso dos textos históricos como âncoras serviu para o tratamento conceitual, posição adequada à base teórica ausubeliana ou nas palavras dos autores:

[...] os textos históricos são organizadores prévios porque cumprem o papel de gerar condições cognitivas para a aprendizagem significativa. Desta forma, os textos históricos podem levar os alunos ao desenvolvimento de subsunçores que propiciem a aprendizagem significativa subseqüente. (BOSS et al. 2008)

Quando aos resultados de aprendizagem em virtude da inserção de aspectos da HC afirmam os autores que:

Os dados evidenciam a presença de elementos discutidos nos textos históricos nas respostas dos alunos quando eles escrevem sobre carga elétrica, questionário 03. Isto é um forte indício de que a discussão sobre os textos pode ter auxiliado os alunos no processo de aprendizagem do conceito de carga elétrica, na medida em que forneceu subsídios importantes para esta aprendizagem. No entanto, não é possível afirmar que houve de fato aprendizagem significativa, mas é possível afirmar que a maioria dos alunos possuía alguns subsunçores que os pesquisadores julgam necessários para isso. Esta afirmação é feita com base nas respostas dos graduandos quando questionados sobre as teorias de Du Fay e Franklin. Isto nos permite concluir que os textos históricos podem contribuir com a aprendizagem significativa na medida em que é um 
meio de fornecer subsunções aos alunos. (BOSS et al. 2008) (Destaque nosso)

O último trabalho do EPEF em 2008, T8-EPEF-2008, resultou da aplicação da $\mathrm{HC}$ e atividades experimentais enquanto elementos de mediação da aprendizagem da física em discentes do primeiro ano do ensino médio. Do ponto de vista da HC tratou-se da história do movimento desde Aristóteles, Ptolomeu, Copérnico, Brahe, Kepler até Galileu. E, é deste último que retiram a atividade experimental: "plano inclinado", utilizando recursos que Galileu teria usado e, depois, serviram-se de computador para coletar dados e construção de "tabelas de posição versus tempo e construir os respectivos gráficos" (SOARES; BORGES, 2008). O referencial teórico didático foi Piaget e Vigotski.

A atividade experimental foi feita em três turmas do Colégio Agrícola Nilo Peçanha da Universidade Federal Fluminense (Pinheiral-RJ), entre 2005 e 2006. Durante a primeira fase do trabalho os estudantes teriam estudado um texto e respondido a um questionário, ambos, referentes à $\mathrm{HC}$, que subsidiou o debate e a construção de modelos mentais. No segundo momento, os discentes estruturados em grupos desenvolveram atividade experimental no laboratório. Para os autores a HC e o laboratório serviram como recursos de intervenção didática sobre os discentes e que a discussão de textos de HC sobre o movimento (no céu e na superfície da terra) teria permitido o diagnóstico dos conceitos prévios e o desenvolvimento da zona proximal (Vigotski) e o laboratório serviu para criar conflitos cognitivos nos discentes.

Da análise das questões feitas aos discentes e referentes aos três textos estudados e as questões referentes à discussão do plano inclinado de Galileu pudemos perceber objetivamente e concluir que se trata de uma abordagem de Contextualização Interna. Não obstante, o resultado obtido com o trabalho permitiu concluir que "[...] a História da Ciência é um ótimo mediador para introduzir uma discussão sobre idéias e conceitos científicos e permite que as concepções prévias dos estudantes sejam conhecidas e consideradas no planejamento pedagógico do professor" (SOARES; BORGES, 2008).

Como se fosse para acompanhar o desenvolvimento profissional dos docentes, a formação continuada também tem sido alvo de proposta de pesquisa de intervenção para a HFCrECN. Este é o caso do T9-EPEF-2008 que é consequente do projeto "Práticas Pedagógicas e Processos Formativos de Professores na Área 
de Ensino de Ciências e Matemática" desenvolvido pelo Grupo de Pesquisa em Ensino de Ciências da UNESP-Bauru. Segundo Gatti e Nardi, o objetivo central do projeto teria sido:

[...] desenvolvimento de investigações articuladas que gerassem um conjunto de subsídios para a reflexão sobre os processos de formação docente na área de Ensino de Ciências naturais e Matemática. [E,] $O$ objetivo do trabalho [T9-EPEF-2008] foi o desenvolvimento de atividades de formação continuada com docentes de Física em exercício, inserindo a História e Filosofia da Ciência como fios condutores das discussões e foco das experiências didáticas realizadas por eles em sala de aula. (GATTI; NARDI, 2010)

Para alcançar o objetivo do trabalho, os autores, no primeiro semestre de 2008, desenvolveram um curso ("A História e a Filosofia da Ciência na prática pedagógica de professores de Física") de 40 horas. Do curso participaram docentes do ensino médio que lecionavam Física, num total de 22. Enquadrando-se como proposta de Instrumentação Didática, os docentes escolares foram submetidos ao desenvolvimento de propostas didáticas baseadas em HFC e diagnóstico das concepções alternativas dos estudantes da escola média. Isto é, desenvolvimento de proposta de minicursos que foram desenvolvidos em salas de aula pelos docentes escolares participantes da pesquisa e assessorados em reuniões de reflexão. Do total dos participantes, os autores acompanharam 5 docentes e no trabalho (T9-EPEF-2008) procuram apenas discutir propostas e percepções de duas docentes participantes.

A pesquisa de intervenção didática de que resulta do T9-EPEF-2008 foi de caráter qualitativo, cujo método de análise de dados foi a Análise de Conteúdo baseada em Bardin ${ }^{93}$. A teoria didática de base foi a construtivista e servindo de referências bibliográficas das pesquisa atuais da área de ensino de ciências naturais.

Os autores verificaram que, entre as docentes cujas propostas foram base de estudo, uma delas teve como fio condutor do seu planejamento "[...] a preocupação com as concepções alternativas dos estudantes, com a aproximação da História e Filosofia da Ciência e as relações entre Ciência, Tecnologia, Sociedade e Ambiente" (GATTI; NARDI, 2010). E, sua proposta teve como tema as "Leis de Newton", e, obteve sucesso na abordagem da HC ao demonstrar para os discentes que a ciência está em constante construção e reconstrução (evolução dos conceitos

${ }^{93}$ BARDIN, L. Análise de Conteúdo. Lisboa: Edições 70, 1994. 
da física), porém, o mesmo não ocorreu em relação à mudança de concepções dos seus discentes sobre 0 tema da atração gravitacional, conforme 0 relato apresentado por Gatti e Nardi. A segunda docente teve como tema "estrutura, propriedade e transformações da matéria" e obteve sucesso em relação a $\mathrm{HC}$, relatando que os discentes teriam gostado, por ter enfatizado a construção dinâmica da ciência.

Em termos gerais, quanto ao desenvolvimento do trabalho, os autores avaliam que:

\begin{abstract}
Apesar do reconhecimento da importância da aproximação da História da ciência no ensino, durante a entrevista de grupo focal as docentes revelaram uma série de obstáculos à sua utilização em sala de aula, tais como, por exemplo, a falta de interesse e de conhecimento prévios dos alunos, além de baixos salários e péssimas condições de trabalho para os professores. (GATTI; NARDI, 2010)
\end{abstract}

As afirmações das docentes participantes escondem também as suas próprias inseguranças em relação ao conhecimento de HFC, pois, segundo Gatti e Nardi todas as participantes nunca tiveram contato com HFC, o curso foi o primeiro momento de estabelecimento de contato epistêmico, justifica-se a insegurança e a timidez de aventurar-se a inclusão da HFC. Finalmente, segundo Gatti e Nardi (2010), embora tenha tido bons resultados e tenha havido participação ativa das docentes nas atividades durante o projeto, há diversos entraves da realidade escolar que, também, dificultam a efetivação da aproximação à prática didática, entre eles, estão: "[...] excesso de carga horária [atribuída a cada docente], classes superlotadas, pressão para o cumprimento integral da proposta curricular, entre outros." E, é neste sentido que os autores concluem, com certo pessimismo aceitável, que:

\footnotetext{
Ainda que as professoras tenham apontado a importância dos elementos discutidos durante o curso para o ensino de Ciências e sua intenção de seguir utilizando as inovações debatidas, não temos elementos que indiquem quais serão as repercussões da experiência desenvolvida para a carreira docente.

A formação de professores comprometidos com a construção do conhecimento científico representa um grande desafio, uma vez que, a formação continuada exige um empenho constante na reflexão e aperfeiçoamento da prática pedagógica. (GATTI; NARDI, 2010)
}

O desenvolvimento de curso de 20 horas sobre Física, para 38 discentes do ensino médio de uma escola pública da zona sul da cidade de São Paulo, com 
objetivo de introduzir aspectos históricos da óptica e discutir questões epistemológicas sobre a natureza da luz foi a finalidade da pesquisa didática (qualitativa) de que resultou o T10-EPEF-2010. Segundo Forato et al., houve uso de textos históricos (oito no total), montagem de um roteiro teatral e quase vinte atividades didáticas. A análise do conteúdo e das atividades desenvolvidas revela um desenvolvimento de capacidade de Criticidade e Contextualização Interna (não é possível reproduzir a íntegra do conteúdo em virtude da sua extensão). Finalmente, os autores perceberam que algumas das soluções propostas por eles foram "boas estratégias" e outras requerem do docente uma formação.

No T11-EPEF-2010, partindo de um curso piloto ${ }^{94}$ modificado, os autores, propuseram-se a pesquisar "como uma abordagem histórica e filosófica de um episódio da física poderia auxiliar na concepção que os alunos têm sobre a natureza da ciência”. O curso foi aplicado a 10 discentes do $2^{\circ}$ e $3^{\circ}$ ano de ensino médio. Entre as estratégias utilizadas estão: estudo de textos em grupos, apresentações em slides, gincana, experimentos, vídeos e discussões sobre a natureza da luz e da ciência.

A natureza da ciência $(\mathrm{NdC})$ foi estudada sob a ótica da $\mathrm{HC}$, foram estudados 3 episódicos históricos referentes a "gregos, modelo corpuscular e modelo ondulatório". O programa das atividades seguiu cinco momentos: 1ำ - um curso sobre o éter, a luz e a $\mathrm{NdC}$, apoiado num texto referente a filosofia e explicações sobre funcionamento da natureza; $2^{\circ}$ imagens de filósofos organizadas em linha temporal (cronologia) - para localizar os autores em discussão, baseada na leitura de um texto referente ao conceito de luz na antiguidade grega; o $3^{\circ}$ foi dedicado a fenômenos óticos (comportamento da luz), versando-se sobre Newton; $4^{\circ}$ predominou o debate Newton e Huygens (corpuscularimo) e, finalmente, no $5^{\circ} 0$ tema estudado foi luz e no século das luzes [iluminismo], seguindo de um debate entre dois grupos discentes representando posições de Newton e Huygens.

Portanto, embora haja uma referência à $\mathrm{NdC}$, que vincula o trabalho a uma dimensão epistemológica de Criticidade, tencionou-se também à historicidade que remete à Contextualização Interna, conforme o programa desenvolvido nos encontros descritos acima. Porém, segundo Ferreira, Forato e Silva (2010) "no geral,

94 O curso piloto fora realizado num âmbito da pesquisa doutoral de FORATO, Thaís. C. M. A Natureza da Ciência como saber Escolar: um estudo de caso a partir da história da luz. Tese (doutorado em Educação), São Paulo: FEUSP, 2009. 
as respostas dadas pelos alunos às questões propostas em cada texto, mostraram que de certa forma ocorreram modificações quanto à suas concepções sobre natureza da ciência."

Reis, Guerra e Braga (2010) em T12-EPEF-2010 apresentaram resultado de sua pesquisa didática desenvolvida com oito discentes de licenciatura em Física de uma universidade pública do Rio de Janeiro, "durante a disciplina Estágio Supervisionado II, sobre suas formações em História da Ciência e Filosofia da Ciência." A pesquisa de caráter qualitativa que os autores denominaram de "pesquisa-intervenção", baseada na construção de "diário de anotações" (observação de campo), filmagem das aulas dos discentes, registro audiovisual dos debates em sala de aula. A caracterização como pesquisa-intervenção parece justificar-se pelo fato de os autores terem tido também o objetivo de "[...] reorientação das atividades desenvolvidas durante o curso, com vistas a interferir na visão de NdC dos alunos" (REIS; GUERRA; BRAGA, 2010).

Porém, ao verificarmos as atividades desenvolvidas a qualificativo da pesquisa muda, a partir da percepção e perspectiva advinda de seguintes dados:

\footnotetext{
Quatro atividades foram propostas aos licenciados como forma de coletar as informações para análise:

1 - questionário inicial sobre ser professor de física e o que isso significa; 2 - questionário específico sobre a utilização da HFC no ensino de Física.

3 - atividade sobre introdução de temas de Física Moderna e Contemporânea (FMC) na escola básica;

4 - aula sobre um tema de Física Clássica onde cada licenciando escolheu livremente o tema da aula que ministrou para os outros licenciandos e 0 professor. (REIS; GUERRA; BRAGA, 2010)
}

Ora, a partir das quatro atividades e considerando que a pesquisa tencionou estudar sobre as formações dos discentes sobre HFC podemos inferir que se trata de uma pesquisa didática avaliativa ou, simplesmente, investigação avaliativa, cujo objetivo é verificar os conhecimentos aprendidos em disciplinas anteriores. A plausibilidade da nossa inferência é corroborada pelos próprios autores ao afirmarem que os dados teriam sido coletados em quatro momentos, aplicação de dois questionários, avaliação das aulas e dos trabalhos escritos como "forma de identificar como eles colocam em prática seus discursos sobre o tema [HFC]." E, sobretudo, o caráter avaliativo da investigação fica mais evidente ainda ao afirmar terem constatado que: 
[...] ter cursado algumas disciplinas de História da Ciência e de Filosofia da Ciência não instrumentalizou esse [sic] alunos de licenciatura. Eles pouco conhecem sobre História e Filosofia da Ciência, não têm segurança para tratar desse assunto, seja teoricamente seja em uma aula sobre um assunto escolhido por eles. (REIS; GUERRA; BRAGA, 2010)

Portanto, o caráter avaliativo do T12-EPEF-2010 não faz localizar este trabalho nas categorias da análise existentes até o momento, poderíamos dizer que se aproxima da Instrumentação Didática, mas se afasta dela o bastante. Outro aspecto que reforça nossa posição vem das perguntas feitas aos discentes, que traduzem o caráter avaliativo/diagnóstico. Assim sendo, somos impelidos a introduzir uma nova categoria: Diagnóstico da Aprendizagem em HFCrECN. Estão representados nela os trabalhos oriundos das investigações em que se avalia a aprendizagem em HFCrECN de indivíduos a ela submetidos.

Tal é o caso do T12-EPEF-2010, em que os autores afirmam que os discentes participantes apresentaram obstáculos de insuficiência de conhecimento em HFC: "Um dos obstáculos apontados para um curso de física com abordagem histórico-filosófica foi a constatação de que possuem conhecimento insuficiente de História e Filosofia da Ciência para desenvolverem práticas pedagógicas com esse enfoque" (REIS; GUERRA; BRAGA, 2010). Os autores concluem que o discurso sobre a inclusão da HFC não dá, aos docentes, segurança nenhuma que thes permita desenvolver e construir práticas didáticas com o perfil pretendido com a HFCrECN.

Este obstáculo de insuficiência gnosiológica descrita faz aproximar o T12EPEF-2010 ao T10-EPEF-2010, neste constamos que os obstáculos se referem à utilização da abordagem dos aspectos da HFC, apontados tanto pelos docentes escolares quanto pelos pesquisadores. Tais são obstáculos que necessitam ser levadas em consideração no planejamento tanto dos currículos dos programas de formação inicial e continuada quanto das políticas públicas de formação e trabalho docente. Em ambos os trabalhos estamos diante do que chamo de estado de insegurança profissional que impende a ação docente e a realização profissional. Os obstáculos remetem a pensar e materializar uma mudança séria no regime de trabalho dos docentes escolares, circunscrevendo a atividade docente a uma única escola e com tempo suficiente para ensino, acompanhamento aos discentes, pesquisa didática e planejamento educacional, entre outros benefícios de um labor significativo e salúbre. 
Portanto, foram ao todo 12 trabalhos coletados no Encontro de Pesquisa em Ensino de Física que apresentam propostas, além da discussão teórica, já predominante no movimento da HFCrECN. A seguir apresentamos a tabela com o período de coleta e a quantidade de trabalho por cada edição do EPEF.

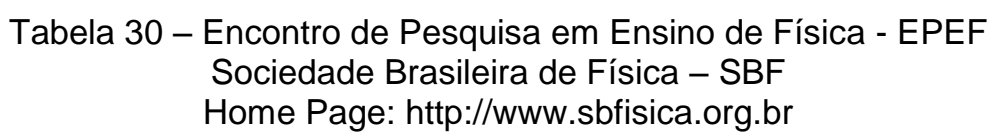

\begin{tabular}{|l|c|c|c|}
\hline $\begin{array}{c}\text { NÚMERO DE } \\
\text { EDIÇÃO E DATA DO } \\
\text { ENCONTRO }\end{array}$ & $\begin{array}{l}\text { Total de } \\
\text { Resumos } \\
\text { Apresentados }\end{array}$ & $\begin{array}{l}\text { Resumos } \\
\text { Abordagem do Tema da Pesquisa }\end{array}$ \\
\cline { 3 - 4 } & $\begin{array}{l}\text { Resumos à } \\
\text { Referentes à } \\
\text { HFCrECN }\end{array}$ & $\begin{array}{l}\text { Resumos } \\
\text { Referentes à } \\
\text { HFCrECN nos DO }\end{array}$ \\
\hline VII, 2000 & $\mathbf{+ 1 6 0}$ & $\mathbf{2}$ & 0 \\
\hline VIII, 2002 & $\mathbf{+ 9 2}$ & $\mathbf{1}$ & 0 \\
\hline IX, 2004 & $\mathbf{+ 1 4 6}$ & 0 & 0 \\
\hline X, 2006 & $\mathbf{+ 1 3 0}$ & $\mathbf{1}$ & 0 \\
\hline XI, 2008 & $\mathbf{+ 1 6 8}$ & $\mathbf{4}$ & 0 \\
\hline XII, 2010 & $\mathbf{+ 1 4 9}$ & $\mathbf{4}$ & 0 \\
\hline Total & $\mathbf{8 4 7}$ & $\mathbf{1 2}$ & 0 \\
\hline
\end{tabular}

\subsubsection{2 - Simpósio Nacional de Ensino de Física - SNEF}

O segundo evento representativo da área de ensino de Física é o Simpósio Nacional de Ensino de Física (SNEF), também promovido pela Sociedade Brasileira de Física. A seguir passamos a análise dos trabalhos apresentados nele durante o período de estudo. Eis a listagem dos trabalhos estudados:

T13-SNEF-1999 BARROS, Marcelo Alves. Uma Aproximação entre a História da Ciência e o Ensino de Física: o debate Huyghens-Newton em Sala de Aula. In: SIMPÓSIO NACIONAL DE ENSINO DE FÍSICA, 13., 1999. Brasília, DF. Caderno de Programação e Resumos... Brasília, DF: Universidade de Brasília, 1999. p. 134-135.

T14-SNEF-1999 NARDI, Roberto; TEODORO, Sandra Regina. Subsídios para a construção de Atividades de Ensino sobre o Conceito de Gravitação de Gravidade a partir das Concepções. In: SIMPÓSIO NACIONAL DE ENSINO DE FÍSICA, 13., 1999. Brasília, DF. Caderno de Programação e Resumos... Brasília, DF: Universidade de Brasília, 1999. p. 216-217.

T15-SNEF-2003 MATTOS, Rodrigo A.; FILHO, Jomar B.; SILVA, Dirceu. Estudo do Uso de Textos sobre História da Eletricidade para Cursos de Física do Nível Médio. In: SIMPÓSIO NACIONAL DE ENSINO DE FÍSICA, 13., 2003. Curitiba, PR. Programa e Resumos... Curitiba: CEET-PR/UFPR, 2003. P. 82.

T16-SNEF-2003 GEBARA, Maria José F. O Ensino e a Aprendizagem de Física; Contribuições da História da Ciência e do movimento das Concepções Alternativas. In: SIMPÓSIO NACIONAL DE ENSINO DE FÍSICA, 13., 2003. Curitiba, PR. Programa e Resumos... Curitiba: CEET-PR/UFPR, 2003. P. 91.

T17-SNEF-2003 LÙCIO, Veja A História da Física: uma nova perspectiva para o ensino de Física. In: SIMPÓSIO NACIONAL DE ENSINO DE FÍSICA, 13., 2003. Curitiba, PR. Programa e Resumos... Curitiba: CEET-PR/UFPR, 2003. P. 146. 
T18-SNEF-2003 SALES, Nilva L. L.; SANTOS, Renata R. A Ciência Através dos Tempos: uma integração entre física e história. In: SIMPÓSIO NACIONAL DE ENSINO DE FÍSICA, 13., 2003. Curitiba, PR. Programa e Resumos... Curitiba: CEET-PR/UFPR, 2003. Disponível em: <http://www.sbf1.sbfisica.org.br/eventos/snef/xv/>. Acesso em: 21 jan. 2011.

T19-SNEF-2003 IGARASHI, Ricardo N.; SANTOS, Ney S.; IRAMINA, Alice S.; BARROS, Marcelo A. As Contribuições da História da Ciência no Ensino da Óptica Física. In: SIMPÓSIO NACIONAL DE ENSINO DE FÍSICA, 13., 2003. Curitiba, PR. Programa e Resumos... Curitiba: CEET-PR/UFPR, 2003. P. 147.

T20-SNEF-2003 BARBOSA, Roberto G.; BARROS, Marcelo A.; IRANMINA, Alice Sizuko. Aprendendo Óptica Geométrica com base na História da Ciência e em Concepções Alternativas. In: SIMPÓSIO NACIONAL DE ENSINO DE FÍSICA, 13., 2003. Curitiba, PR. Programa e Resumos... Curitiba: CEET-PR/UFPR, 2003. P. 147.

T21-SNEF-2003 PEREIRA, Ricardo F.; FUKUI, Renato M.; BARROS, Marcelo; IRANMINA, Alice Sizuko. Utilizando Contextos Históricos como abordagem no Ensino Médio. In: SIMPÓSIO NACIONAL DE ENSINO DE FÍSICA, 13., 2003. Curitiba, PR. Programa e Resumos... Curitiba: CEET-PR/UFPR, 2003. P. 154.

T22-SNEF-2003 MANTOVANI, lara F.; Oliveira, Brno F.; BARROS, Marcelo A.; IRANMINA, Alice Sizuko. Buscando a História da Ciência para estudar o Conceito de Inércia. In: SIMPÓSIO NACIONAL DE ENSINO DE FÍSICA, 13., 2003. Curitiba, PR. Programa e Resumos... Curitiba: CEET-PR/UFPR, 2003. P. 148.

T23-SNEF-2003 GUERRA, Andreia; REIS, José Cláudio; BRAGA, Marco. Uma Abordagem Histórico-Filosófica para o Eletromagnetismo no Ensino Médio. In: SIMPÓSIO NACIONAL DE ENSINO DE FÍSICA, 13., 2003. Curitiba, PR. Programa e Resumos... Curitiba: CEET-PR/UFPR, 2003. P. 153.

T24-SNEF-2005 VIEIRA, Kátia M. Dias; BATISTA, Irinéa de Lourdes. A Abordagem Histórica no Ensino de Física e o Aprendizado do Conceito Físico de Movimento. In: SIMPÓSIO NACIONAL DE ENSINO DE FíSICA, 16., 2005. Rio de Janeiro, RJ. Programa e Resumos... Rio de Janeiro: $\quad$ CEET-RJ, $2005 . \quad$ p. $20 . \quad$ Disponível $\quad$ em: <http://www.sbf1.sbfisica.org.br/eventos/snef/xvi/cd/resumos/T0434-1.pdf >. Acesso em: Acesso em: 21 jan. 2011.

T25-SNEF-2005 SANTOS, Wilma M. Soares; DIAS, Penha M. Cardoso. A História da Física como "Organizador Prévio". In: SIMPÓSIO NACIONAL DE ENSINO DE FÍSICA, 16., 2005. Rio de Janeiro, RJ. Programa e Resumos... Rio de Janeiro: CEET-RJ, 2005. p. 116-117. Disponível em: <http://www.sbf1.sbfisica.org.br/eventos/snef/xvi/cd/resumos/T0370-1.pdf>. Acesso em: Acesso em: 21 jan. 2011.

T26-SNEF-2005 FERNANDES, Bruno Castilhos; DIAS, Penha M. Cardoso; SANTOS, Wilma M. Soares. Uma Prática de Ensino da 1aㅡ Lei de Newton utilizando a História da Física. In: SIMPÓSIO NACIONAL DE ENSINO DE FÍSICA, 16., 2005. Rio de Janeiro, RJ. Programa e Resumos... Rio de Janeiro: CEET-RJ, 2005. p. 117. Disponível em: $<$ http://www.sbf1.sbfisica.org.br/eventos/snef/xvi/sys/resumos/T0370-2.pdf>. Acesso em: Acesso em: 21 jan. 2011.

T27-SNEF-2005 FREITAS, Fábio $H$. de Alencar; FREIRE JR., Olival. O PLANO INCLINADO GALILEANO: notas sobre uma tomada de dados com estudantes do ensino superior. In: SIMPÓSIO NACIONAL DE ENSINO DE FÍSICA, 16., 2005. Rio de Janeiro, RJ. Programa e Resumos... Rio de Janeiro: CEET-RJ, 2005. p. 119-120. Disponível em: <http://www.sbf1.sbfisica.org.br/eventos/snef/xvi/sys/resumos/T0005-1.pdf>. Acesso em: Acesso em: 21 jan. 2011.

T28-SNEF-2005 SILVA, Luciano Fernandes; BOCANEGRA, Carlos Henrique; OLIVEIRA, Josely Kobal de. A Compreensão dos Alunos do Ensino Médio em Relação aos Aspectos da Natureza da Ciência. In: SIMPÓSIO NACIONAL DE ENSINO DE FÍSICA, 16., 2005. Rio de Janeiro, 
RJ. Programa e Resumos... Rio de Janeiro: CEET-RJ, 2005. p. 182. Disponível em: <http://www.sbf1.sbfisica.org.br/eventos/snef/xvi/sys/resumos/T0496-1.pdf>. Acesso em: Acesso em: 21 jan. 2011.

T29-SNEF-2007 SANCHEZ, Dario Ferreira, PAZ JÚNIOR, Emílio Merino de. Proposta de uma Aula com enfoque experimental sobre a Refração da Luz: o fenômeno e sua história. In: SIMPÓSIO NACIONAL DE ENSINO DE FÍSICA, 17., 2007. São Luiz, MA. Programa e Resumos... São Luiz: UEMA/UFMA/CEET-MA, 2007. p. 74. Disponível em: <http://www.sbf1.sbfisica.org.br/eventos/snef/xvii/>. $<$ http://www.sbf1.sbfisica.org.br/eventos/snef/xvii/programa/XVIISNEF_programa_e_resumos.pdf>. Acesso em: Acesso em: 22 jan. 2011.

T30-SNEF-2007 MONTEIRO, Maria Amélia; NARDI, Roberto. A Utilização da História da Ciência no Ensino de Física: investigação do espectroscópio de chamas. In: SIMPÓSIO NACIONAL DE ENSINO DE FÍSICA, 17., 2007. São Luiz, MA. Programa e Resumos... São Luiz:

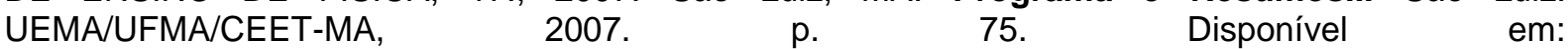
<http://www.sbf1.sbfisica.org.br/eventos/snef/xvii/>. $<$ http://www.sbf1.sbfisica.org.br/eventos/snef/xvii/programa/XVIISNEF_programa_e_resumos.pdf>. Acesso em: Acesso em: 22 jan. 2011.

T31-SNEF-2007 SANTOS, Alexssandro Ferraz dos; CARDOSO, Tereza Fachada Levy. Uma Proposta para Ensinar os Conceitos de Hidrostática: Santos Dumont e a História da Ciência. In: SIMPÓSIO NACIONAL DE ENSINO DE FÍSICA, 17., 2007. São Luiz, MA. Programa e Resumos... São Luiz: UEMA/UFMA/CEET-MA, 2007. p. 98. Disponível em: <http://www.sbf1.sbfisica.org.br/eventos/snef/xvii/>. $<$ http://www.sbf1.sbfisica.org.br/eventos/snef/xvii/programa/XVIISNEF_programa_e_resumos.pdf>. Acesso em: Acesso em: 22 jan. 2011.

T32-SNEF-2007 SOUZA, Roseli Ovale, ARAÚJO, Mauro S. Teixeira de; GUAZZELLI, lara R. Bocchese; MACIEL, Maria Delourdes. Concepções dos Estudantes sobre a Ciência, os Cientistas e o Método Científico: uma abordagem histórico-crítica como base de uma proposta de intervenção visando a resignificação destes conceitos. In: SIMPÓSIO NACIONAL DE ENSINO DE FíSICA, 17., 2007. São Luiz, MA. Programa e Resumos... São Luiz: UEMA/UFMA/CEET-MA, 2007. p. 99. Disponível em: <http://www.sbf1.sbfisica.org.br/eventos/snef/xvii/>. Ou <http://www.sbf1.sbfisica.org.br/eventos/snef/xvii/programa/XVIISNEF_programa_e_resumos.pdf>. Acesso em: Acesso em: 22 jan. 2011.

T33-SNEF-2007 BOCANEGRA, Carlos H.; SILVA, Luciano F.; ANDRADES, Agnaldo Aparecido F. A Natureza da Ciência e o Processo Educativo: relato de uma experiência de ensino realizada em uma Escola pública de ensino médio. In: SIMPÓSIO NACIONAL DE ENSINO DE FíSICA, 17., 2007. São Luiz, MA. Programa e Resumos... São Luiz: UEMA/UFMA/CEET-MA, 2007. p. 124. Disponível em: <http://www.sbf1.sbfisica.org.br/eventos/snef/xvii/>. Ou <http://www.sbf1.sbfisica.org.br/eventos/snef/xvii/programa/XVIISNEF_programa_e_resumos.pdf>. Acesso em: Acesso em: 22 jan. 2011.

T34-SNEF-2007 TEIXEIRA, Elder Sales; FREIRE JR, Olival Um Estudo sobre a Influência da História e Filosofia da Ciência na Formação de Estudantes de Física. In: SIMPÓSIO NACIONAL DE ENSINO DE FÍSICA, 17., 2007. São Luiz, MA. Programa e Resumos... São Luiz: UEMA/UFMA/CEET-MA, $2007 . \quad$ p. $146 . \quad$ Disponível em: $<$ http://www.sbf1.sbfisica.org.br/eventos/snef/xvii/>. $<$ http://www.sbf1.sbfisica.org.br/eventos/snef/xvii/programa/XVIISNEF_programa_e_resumos.pdf>. Acesso em: Acesso em: 22 jan. 2011.

T35-SNEF-2007 SILVA, Marcelo de Souza; TEIXEIRA, Elder Sales. Um Estudo de Caso acerca da Influência de uma Abordagem Contextual na Compreensão do Conceito de Inércia de Estudantes de Física. In: SIMPÓSIO NACIONAL DE ENSINO DE FÍSICA, 17., 2007. São Luiz, MA. Programa e Resumos... São Luiz: UEMA/UFMA/CEET-MA, 2007. p. 164. Disponível em: $<$ http://www.sbf1.sbfisica.org.br/eventos/snef/xvii/>. <http://www.sbf1.sbfisica.org.br/eventos/snef/xvii/programa/XVIISNEF_programa_e_resumos.pdf>. Acesso em: Acesso em: 22 jan. 2011. 
T36-SNEF-2009 GUERRA, Andreia; BRAGA, Marco; REIS, José Claudio. Um Curso de Cosmologia na Primeira Série do Ensino Médio com enfoque Histórico-Filosófico. In: SIMPÓSIO NACIONAL DE ENSINO DE FÍSICA, 18., 2009. Vitória, ES. Programa... Vitória, ES: UFES, 2009. Disponível em: <http://www.sbf1.sbfisica.org.br/eventos/snef/xviii/>. Acesso em: Acesso em: 22 jan. 2011.

T37-SNEF-2009 MEDINA, Márcio Nasser; BRAGA, Marco. Ensinar Física para os Alunos do Século XXI: uma proposta metodológica interdisciplinar que alia a História da Ciência, o Teatro e a Física. In: SIMPÓSIO NACIONAL DE ENSINO DE FÍSICA, 18., 2009. Vitória, ES. Programa... Vitória, ES: UFES, 2009. Disponível em: <http://www.sbf1.sbfisica.org.br/eventos/snef/xviii/>. Acesso em: Acesso em: 22 jan. 2011.

T38-SNEF-2009 QUINTAL, João Ricardo; MORAES, Andréa Guerra de. A História da Ciência no Processo Ensino-Aprendizagem. In: SIMPÓSIO NACIONAL DE ENSINO DE FÍSICA, 18., 2009. Vitória, ES. Programa... Vitória, ES: UFES, 2009. Disponível em: <http://www.sbf1.sbfisica.org.br/eventos/snef/xviii/>. Acesso em: Acesso em: 22 jan. 2011.

T39-SNEF-2009 SILVEIRA, Alessandro F. da; ATAÍDE, Ana R. P. de; SILVA, Ana Paula B. da; FREIRE, Morgana L. de Farias. Natureza da Ciência numa Proposta de Seqüencia Didática: explorando os pensamentos de Aristóteles e Galileu sobre o movimento relativo. In: SIMPÓSIO NACIONAL DE ENSINO DE FÍSICA, 18., 2009. Vitória, ES. Programa... Vitória, ES: UFES, 2009. Disponível em: <http://www.sbf1.sbfisica.org.br/eventos/snef/xviii/>. Acesso em: Acesso em: 22 jan. 2011.

T40-SNEF-2009 SILVA, Rafael H. Santos; LIMA, Uálace dos Santos; ARAUJO, Renato Santos. Uma Proposta de uso das Abordagens de Arte e História da Ciência para a Educação Básica. In: SIMPÓSIO NACIONAL DE ENSINO DE FÍSICA, 18., 2009. Vitória, ES. Programa... Vitória, ES: UFES, 2009. Disponível em: <http://www.sbf1.sbfisica.org.br/eventos/snef/xviii/>. Acesso em: Acesso em: 22 jan. 2011.

No SNEF de 1999 constatamos dois trabalhos apresentados que se apropinguam ao tema da investigação nesses meios de divulgação científica. Assim temos: o T13-SNEF-1999, cuja investigação didática de que resultou estava em andamento na altura do evento. Portanto, trata-se de apresentação de resultados parciais ou análises preliminares. O objetivo do autor consistia em "[...] apresentar uma atividade de ensino elaborada a partir da evolução da [sic] idéias sobre a natureza da luz" (BARROS, 1999). Tal atividade consistia em um curso ministrado a 30 discentes de duas turmas sob a sua gestão didática (em que lecionava). Também afirma que a atividade integrara a sua pesquisa doutoral.

As técnicas de coleta de dados foram gravação audiovisual das aulas, trabalhos escritos e desenhos feitos por discentes. As atividades programadas incluíram a discussão sobre a natureza da luz e o debate entre as ideias de Newton e as de Huyghens. Didaticamente, o autor baseou-se no pressuposto de conceber o ensino como investigação, ou seja,

[...] na apresentação de uma situação problemática que fosse interessante para os alunos, que envolvessem uma análise qualitativa da situação, a 
invenção de conceitos e emissão de hipóteses, o estabelecimento de estratégias de resolução e a análise dos resultados com possíveis situações de conflito cognitivo. (BARROS, 1999)

Na sequência, Barros define o papel do professor na atividade como orientador, selecionador de conteúdos e tarefas, coordenador das discussões, bem como introdutor ideias e indicador de conclusões. Na mesma ordem apresenta as três perguntas colocadas para discussão em grupos de discentes, após a leitura de um texto, no entanto, em nenhum momento o autor especificou o suposto texto que teria sido estudado.

Além do mais, não descreve como teria ocorrido ou ocorrerá a aproximação entre $\mathrm{HC}$ e ensino de Física, ou seja, não especificou como, metodológicamente e do ponto de vista da HFCrECN, teria sido reproduzido o debate do episódio histórico Newton versus Huyghens. Nem ao finalizar fez um anúncio de que seria feito em outro momento da pesquisa, apenas diz que na análise fará "transcrição das falas dos alunos gravadas em vídeo e do trabalho escrito", escolhendo certos "episódios de ensino" e não históricos (HC) que ilustrassem como os discentes teriam resolvidos o problema posto. As três questões apresentadas conotam uma abordagem epistemológica e não histórica, necessariamente. Em todo caso, a característica epistemológica das questões vincula o trabalho à categoria da Criticidade e pela falta de informação da vinculação da $\mathrm{HC}$ ao ensino, aproxima o trabalho da Insuficiência Informativa em Relação à HFCrECN.

No segundo trabalho apresentado no SNEF de 1999, os autores descrevem que tinham por finalidade estudar "[...] as concepções de estudantes de diversas faixas etárias sobre o conceito de gravidade e dados da História da Ciência como ponto de partida de uma investigação que possa subsidiar a ação docente" (NARDI; TEODORO, 1999). No T14-SNEF-1999 não há dados suficientes para inferir algo temático, os autores afirmam que o trabalho se encontra - à época do evento - na fase inicial de elaboração e coleta de dados, que naquele momento estariam na fase de discussão de modelos de mudança conceitual, para fazer uma opção pelo que contemple os novos debates, assim, a partir do modelo a ser escolhido serão programadas as atividades de ensino (NARDI; TEODORO, 1999), fato que localiza o artigo na categoria da Insuficiência Informativa em Relação à 


\section{HFCrECN.}

À semelhança do trabalho anterior, em termo de falta de informações sobre o uso da HC, está o T15-SNEF-2003 em que os autores afirmam terem enfocado "[...] o uso de textos com base na História das ciências, do desenvolvimento dos conceitos ligados à eletricidade, em um curso de nível médio regular" (MATTOS; FILHO; SILVA). Porém, sem apresentar dados sobre que textos teriam sido usados e como se procedeu durante a pesquisa didática com uso de textos de $\mathrm{HC}$, fato que o vincula a Insuficiência Informativa em Relação à HFCrECN.

O T16-SNEF-2003 é consequente de uma dissertação de mestrado, o objetivo do autor foi identificar concepções alternativas dos discentes da $2^{2}$ série do ensino médio sobre o fenômeno da queda dos corpos e com isso verificar

[...] até que ponto, procedimentos didáticos que levam em consideração a Histórica da Ciência como ferramenta didática, [são] capaz de estimular e motivar o estudo da Física e de auxiliar o professor, na identificação dos entraves ao desenvolvimento de conceitos científicos, muitas vezes semelhantes aos obstáculos à aprendizagem apresentados pelos alunos. (GEBARA, 2003)

Gebara concluiu que algumas formas de pensar do senso comum são extremamente arraigadas nos discentes e difíceis de superação. Faltaram também informações sobre como teriam sido identificadas as contribuições da $\mathrm{HC}$ no ensino, durante a proposta desenvolvida com os discentes do ensino médio, caracterizando o T16-SNEF-2003 ma categoria operacional de Insuficiência Informativa em Relação à HFCrECN, mas também é possível inferir uma Contextualização Interna, porque o autor se refere em seu objeto ao fenômeno da queda dos corpos (força gravitacional).

Lúcio (2003), no T17-SNEF-2003, afirma que, com o seu projeto, teve por objetivo "lecionar a física situando-a em seu contexto histórico e social" e que teria criado e aplicado livros didáticos desde 1996.

Este material passou por modificações no decorrer desses anos a fim de que a contextualização e a historicidade se aliassem ao princípio da autogestão para afastar de vez a fragmentação do conhecimento que tornao tão superficial e inadequado para as necessidades atuais. [...]. [E,] $O$ aumento da compreensão dos conteúdos, a maior participação em sala de aula e o alto nível de relações entre a física e os demais saberes são resultados que me levam a acreditar cada vez mais que a física deve caminhar junto à história, à filosofia e à sociologia. (LÚCIO, 2003) 
O descrito não caracteriza de modo compreensível como teria sido desenvolvida a aproximação da $\mathrm{HC}$ ao ensino da física, mas sugere a situar $\mathrm{o}$ trabalho na Contextualização Externa.

A concepção tradicional de HC linear e de "grandes feitos" e "gênios" aprece no projeto de "integração entre História e Física", desenvolvido em 2001 e 2002, cujo objetivo teria sido, segundo Sales e Santos (2003), o de "percorrer a história das idéias em evolução, relacionado as [sic] principais descobertas científicas aos grandes acontecimentos históricos, além de possibilitar conhecer a vida dos grandes nomes da ciência." A própria noção de "integração dentre História e Física" denota a ideia de não se tratar de $\mathrm{HC}$ ou História da Física - se assim for ter-se-á a concepção de junção de História mais Física, o que não é verdade porque à ciência inere, por natureza, a sua história. No entanto, os autores do T18-SNEF2003 teriam desenvolvido atividades em que integraram docentes das duas disciplinas como pode ser percebido no seguinte relato:

No início do projeto cada aluno deve pesquisar a vida de um cientista. Durante a pesquisa, a professora de História desenvolve uma linha do tempo histórica, caracterizando cada época e a [sic] suas respectivas estruturas e valores. Isso ajuda os alunos a inserirem o seu cientista na época em que viveu. Ao final, com a presença das professoras de História e Física, cada aluno apresenta para a sala a vida, época, obra e curiosidades sobre o cientista pesquisado, fixando o cartão biográfico deste na linha do tempo, que fica exposta na biblioteca.

A segunda etapa do projeto é a realização de um debate na aula de História sobre evolução do pensamento científico relacionando-o à sua época, e como cada época interferiu e influenciou o cientista. A última etapa é a leitura do paradidático: "Galileu e o nascimento da Ciência Moderna" de Andréia Guerra e outros, seguida de uma análise da obra, coordenada pela professora de Física. (SALES; SANTOS, 2003)

Embora numa concepção linearista de $\mathrm{HC}$ é possível reconhecer a tentativa de uma Contextualização Externa da física.

A HC como estratégia didática no ensino de física na escola média é o que podemos perceber no T19-SNEF-2003, cujos autores acreditam que a História da Física

[...] proporciona uma visão mais adequada da ciência enquanto processo de construção do conhecimento. Além disso, a abordagem histórica permite uma aproximação entre as situações de aprendizagem das características de um trabalho de investigação científica. Enfatizaremos, particularmente, o debate entre os dois modelos da luz: corpuscular e ondulatório. (IGARASHI 
et al., 2003)

Considerar a $\mathrm{HC}$ como estratégia didática no ensino é uma das concepções do movimento da HFCrECN, no entanto, ainda está longe de adquirir o estatuto ontológico, epistemológico e metodológico de estratégia didática, porque, dada a complexidade do ensino e da aprendizagem, uma estratégia didática não se resume ao uso de fragmentos e episódios esporádicos e sem uma razão metodológica que o sustente, num processo contínuo. A constituição da HFC como estratégia ou teoria didática é um desafio para o movimento da HFCrECN.

À época da apresentação do trabalho, ele estava em fase de realização, de desenvolvimento de atividades de ensino que posteriormente seriam desenvolvidas junto aos docentes do ensino médio, em sala de aula. Segundo Igarashi et al. (2003) para o desenvolvimento da atividade coletariam primeiro informações secundárias e elaborariam um texto com questões abertas apresentando argumentos favoráveis e contra cada modelo explicativo da luz (corpuscular e ondulatório). Após o trabalho em grupos, que seria feito pelos discentes, far-se-ia um debate geral para socializar as ideias e com isso, os autores, pretendiam buscar "[...] despertar a curiosidade nos alunos como também desenvolver suas competências cognitivas e habilidades de comunicação/argumentação na formulação de modelos e hipótese científicas" (IGARASHI et al., 2003). O que caracteriza o T19-SNEF-2003 como Motivacional.

No SNEF de 2003 encontramos também o trabalho de Barbosa, Barros e Iramina (2003), T20-SNEF-2003, em que descrevem ter apresentado uma proposta de ensino da óptica geométrica (conceitos de propagação, reflexão, refração e dispersão da luz) baseada na $\mathrm{HC}$ e no estudo das concepções alternativas/mudança conceitual dos discentes. A pesquisa didática seria realizado por meio de realização de um curso que ocorreria em cinco etapas: coleta de concepções alternativas dos discentes; uso da HC (leitura de textos históricos seguida de debate); realização das atividades de ensino; aplicação em sala de aula em um curso regular de física da escola média e; analisar e avaliar os resultados. O trabalho de que podemos inferir indícios de Contextualização Interna, ainda estava na fase de elaboração de atividades de ensino e seriam implementadas na escola média.

Também outros dois trabalhos que estavam em fase de desenvolvimento foram apresentados: o T21-SNEF-2003 em que a proposta apresentada visava o 
uso da História da Física, fonte de reflexão sobre a $\mathrm{NdC}$ e implicações sociais e tecnológicas da Física, que a princípio parecia tencionar a contextualização externa, porém, não é o que se percebe pelos temas programados para serem abordados. Eles anunciam uma Contextualização Interna da física ("modelos geocêntricos e heliocêntrico, Kepler e suas leis planetárias, Galileu e a defesa do modelo heliocêntrico, a luneta astronômica e a síntese newtoniana" (PEREIRA et al., 2003)).

E no T22-SNEF-2003, Mantovani et al. (2003), aparece uma proposta de Instrumentação Didática que estava dirigida aos docentes de ensino médio, para "transmitir uma visão geral para, docentes do ensino médio, da construção história [sic] do conceito de inércia e seu paralelismo com algumas das concepções alternativas mais comuns sobre o tema" (MANTOVANI et al., 2003). As atividades ocorreriam em dois momentos, a saber: o primeiro voltado para uso de fragmentos da obra de Galileu (Diálogo sobre os dois maiores sistemas do mundo), percebendo sobretudo a relação entre o conceito de força e o de movimento; no segundo, os autores dariam "[...] subsídios que dêem fundamentação para o professor refletir sobre os referenciais teóricos em relação ao ensino e aprendizagem, particularmente, o modelo de mudança conceitual e o construtivismo no ensino de ciências" (MANTOVANI et al. 2003).

Finalmente, o último trabalho coletado no SNEF-2003 (T23-SNEF-2003) refere-se a

[...] aprofundar as discussões a respeito da relação entre história, filosofia da ciência e ensino, a partir da apresentação e avaliação de um currículo com enfoque histórico-filosófico para um curso de eletromagnetismo implementado no nível médio de escolas do município do Rio de Janeiro ao longo do ano de 2001. [...], apresentar-se-á concretamente o currículo construído, destacando-se os conteúdos de física estudados, as práticas docentes efetivadas, os diferentes materiais didáticos elaborados ao longo do processo e resultados de avaliações realizadas junto com os alunos ao longo do processo. (GUERRA; REIS; BRAGA, 2003)

A partir do descrito na citação acima podemos concluir que se trata de um trabalho apresentado com o propósito de divulgar ações realizadas sobre a HFC-ECN, neste sentido surge uma nova categoria relacionada à divulgação de ações, resultados e materiais construídos em relação à HFCrECN: Socialização de Feitos em HFCrECN, esta é a categoria que nos parecer descrever o T23-SNEF2003.

$\mathrm{Na} 16^{\mathrm{a}}$ edição do SNEF foram coletados 5 trabalhos, no primeiro (T24- 
SNEF-2005) o objeto de estudo dos autores foi o conceito de movimento sob enfoque histórico, basicamente o conceito aristotélico e o galilaico-newtoniano de movimento, a partir dos "aspectos importantes" identificados e delineados para serem trabalhados durante a "adaptação didática para uma aplicação das análises histórica [sic] em sala de aula" o indica um programa de Contextualização Interna. A pesquisa de que resulta o trabalho estava em andamento à época do evento.

O segundo (T25-SNEF-2005), também de pesquisa em andamento, fora dedicado a apresentação parcial de resultados da pesquisa didática que consiste na produção de "material instrucional" a ser utilizado no ensino superior e médio, porém as atividades da pesquisa form previstas para serem desenvolvidas com licenciandos em Física no Instituto de Física da UFRJ. Partindo da Teoria de Aprendizagem Significativa de Ausubel, eles pretenderam usar a História da Física como "organizador prévio" conforme aquela teoria, ou seja, como fundamento de compreensão dos conceitos físicos (cosmologia, atrito, magnetismo, calor) e seus experimentos, um elo entre os conhecimentos prévios e os novos (científicos).

O acesso às concepções prévias foi possível por meio da aplicação de questionário aos estagiários do curso de licenciatura, em três momentos: antes, durante e depois das atividades. Pelos materiais instrucionais elaborados e descritos no trabalho é possível inferir uma Contextualização Interna. É de se considerar também que os autores dizem ter seguido os PCN, no que estes recomendam em relação ao ensino de Física. Afirmam os autores que o resultado parcial configura-se mais como indicador para escolha de temas de $\mathrm{HC}$ e sugerem o uso da $\mathrm{HC}$ como organizador prévio (SATOS; DIAS, 2005).

A HC como organizador prévio da teoria ausubeliana aprece no terceiro trabalho, T26-SNEF-2005, em que se trata de uma "proposta de estratégia pedagógica para o ensino da $1^{\text {a }}$ Lei de Newton no Ensino Médio." Também os autores elaboraram material instrucional de história da física para o tema didático a "1a Lei de Newton" e dando ênfase na construção conceitual. O material teria sido aplicado em duas instituições particulares de ensino para discentes de ensino fundamental e médio, aos quais também foram aplicados os questionários da investigação didática.

A análise dos temas do material instrucional elaborado indica uma Contextualização Interna, dos conceitos da física. Tendo, os autores, trabalhado com duas turmas, uma em que usaram método tradicional de ensino de física e 
outra em que utilizaram os procedimentos da pesquisa, verificaram que os discentes do procedimento tradicional atingiram índices menores em relação aos submetidos a procedimentos da pesquisa. Fernandes, Dias e Santos (2005) resumem então que os resultados teriam indicado a conclusão de que "quanto mais fundamentado é um assunto, no caso com seu contexto histórico, maior o rendimento apresentado pela turma" (FERNANDES; DIAS; SANTOS, 2005).

No quarto trabalho, T27-SNEF-2005, Freitas e Freire Jr (2005) apresentaram os resultados do trabalho anteriormente já apresentado durante o SNEF de 2003, sobre o Plano Inclinado enquanto experimento histórico. O experimento teria sido aplicado em uma turma de discentes que cursavam a disciplina Física Básica 1, de licenciatura em Física, da Universidade Federal da Bahia. A abordagem histórica foi dada ao conteúdo da mecânica e astronomia desde os gregos a Newton. Este trabalho também se localiza na categoria de Contextualização Interna, não só pela ênfase da abordagem - descrita anteriormente (história conceitual) -, mas também, pela análise do roteiro e dos dados coletados. Segundo os autores teriam obtidos resultados parcialmente significativos com aplicação do experimento histórico como estratégia didática: "os alunos participaram mais dos questionamentos e demonstraram ansiedade para 'ver' a teoria de Galileu na prática, de modo semelhante ao qual foi realizado no séc. XVI" (FREITAS; FREIRE JR, 2005).

No entanto, é preciso considerar que o uso ou a reprodução de experimento, por si só, não confere à atividade uma dimensão de uso de aspectos da $\mathrm{HC}$, por mais que o experimento seja histórico.

Finalmente, o sexto trabalho do SNEF-2005 (T28-SNEF-2005) é dedicado ao uso dos aspectos da HFC no ensino de Física e Química. Segundo Silva, Bocanegra e Oliveira (2005) seu objetivo era analisar a "compreensão dos alunos do Ensino Médio em relação aos aspectos da natureza da Ciência." Para tal fim, implementaram uma "intervenção planejada" a partir da ação interdisciplinar entre Física e Química.

Os autores teriam desenvolvido o trabalho em 2004 com 3 turmas (30 discentes cada) do $2^{\circ}$ ano de ensino médio noturno de uma Escola pública do município de Araraquara, em São Paulo. Os trabalhos escritos, os diálogos e as anotações de observação de campo serviram como técnicas de coleta de dados, indicando uma pesquisa de caráter qualitativa. 
Os aspectos temáticos trabalhados ("O que é a Ciência", "O Universo Mecanicista de Isaac Newton", "A construção da Matéria e as Ligações Químicas") circunscrevem-se basicamente em Epistemologia, Física e Química, somando-se os seus desmembramentos, podemos caracterizar o trabalho nas categorias de Contextualização Interna e Criticidade.

Durante as atividades os autores teriam percebido que

[...] os alunos do Ensino Médio estranhavam o fato de professores de Física e de Química abordarem aspectos históricos e filosóficos da Ciência Moderna. Entretanto, com o passar das aulas, notamos que eles passaram a assimilar melhor os conceitos básicos da Física e da Química a partir da compreensão de aspectos básicos da natureza da Ciência, tais como: modelo, comprovação empírica, hipótese, comunidade científica e história das idéias científicas. (SILVA; BOCANEGRA; OLIVEIRA, 2005)

E que, em consequência das atividades, os discentes teriam associado de forma coerente a noção de modelos científicos depois do debate sobre a "necessidade de comprovação empírica na atividade científica" e constataram ainda o "aumento sensível da compreensão dos alunos de aspectos conceituais da Física e da Química." (SILVA; BOCANEGRA; OLIVEIRA, 2005)

Monteiro e Nardi (2007) apresentaram, durante o SNEF-2007, o trabalho (T29-SNEF-2005) em que discutiram uma proposta metodológica de ensino que despertasse a curiosidade e interesse dos discentes, de ensino médio, em relação ao fenômeno da refração, baseada na apresentação de "experiência de baixo custo" e com ênfase no seu desenvolvimento histórico. Segundo os autores, pretendem com isso "instigar o aluno a desvendar aos poucos a teoria e a matemática por trás do fenômeno, encontrando-se a relação ou lei (a chamada Lei de Snell) que o rege" (MONTEIRO; NARDI, 2007), portanto, o trabalho é de caráter Motivacional, embora haja poucas informações em relação à HFCrECN.

O uso da HC aparece em outro trabalho: T30-SNEF-2005, em que os autores apresentaram resultado de investigação didática sobre o uso da HC, feita com 4 turmas de licenciatura em Física (de Universidade pública). O objetivo principal da investigação didática qualitativa (com entrevistas semiestruturadas) consistia em pesquisar as concepções dos licenciandos "[...] sobre o estudo do espectroscópio de chamas, a partir de uma perspectiva histórica e se tal abordagem influenciaria ou não os planejamentos de ensino dos mesmos, como também as visões de ciência" (MONTEIRO; NARDI, 2007). Afirmam os autores que os 
resultados obtidos teriam indicado que os licenciados participantes de pesquisa adquiriram uma visão mais crítica sobre a produção do conhecimento científico; perceberam também que os discentes tiveram compreensão melhor das

[...] disputas não harmoniosas ocorridas em torno da construção e da defesa de certas posições teóricas; notaram que a ciência é construída socialmente e recebe influência dos mais diversos matizes sociais; tornaram-se mais críticos, tanto em relação as [sic] formas de apresentação dos conteúdos pelos livros didáticos, como também em relação as [sic] omissões e distorções dos mesmos. (MONTEIRO; NARDI, 2007)

Os licenciandos teriam apontado também algumas limitações referentes à basearem suas atividades em referenciais históricos em virtude da ausência de materiais didáticos historicamente fundamentados ou contextualizados; assim como o fator tempo - necessário para realização de uma atividade com abordagem histórica - que é incompatível com a realidade dos licenciandos.

A ausência das informações desenvolvidas (programa) em relação à HFC-ECN, como em outros trabalhos estudados, nos força a fazer uma inferência inversa, isto é, a partir do descrito nos resultados e inferir o enquadramento categórico do trabalho nas categorias tais como: Contextualização Interna (estudo do espectroscópio) Contextualização Externa e Criticidade, mas com menor grau, considerando que o resultado - a partir do que se infere - é consequência e não a causa, portanto, era necessário analisar o programa das atividades.

No T30-SNEF-2005, Santos e Cardoso (2007) afirmam que o objetivo em seu trabalho era a "inserção da História da Ciência como elemento incentivador para o desenvolvimento da cultura científica, histórica e social." De maneira específica seria "elaborar estratégias para inserção da História da Ciência através de um tema gerado, que no caso temos Santos Dumont e os conceitos físicos relacionados à hidrostática em seus experimentos" (SANTOS; CARDOSO, 2007). Embora os objetivos tencionem a certa contextualização externa, não nos fornece indícios suficientes porque o trabalho apresenta insuficiência de informação sobre atividades e resultados em relação à abordagem histórica, daí localizá-lo na categoria de Insuficiência Informativa em Relação à HFCrECN.

Visando a uma intervenção didática que resultasse em resignificação conceitual por parte dos discentes levou Souza et al. (T32-SNEF-2005) a desenvolverem uma pesquisa-ação com 92 discentes da ensino fundamental de 
uma Escola de São Vicente, São Paulo. Para tal, implementavam à época um Projeto Piloto na Escola. Em foco estavam três conceitos: Ciência, Cientista e Método Científico, tendo recorrido ao questionário para diagnosticarem as percepções dos discentes sobre tais conceitos. Do resultado constataram que os discentes, no geral,

[...] que cientista é uma pessoa louca ou extremamente inteligente e imaginam que o Método Científico é uma seqüência de passos prédeterminados que leva a resultados incontestáveis, como se houvessem verdades absolutas nas Ciências. [...] os estudantes pensam que Ciência está relacionada à Física, Química e Biologia; que o cientista é um inventor ou descobridor [...]. (SOUZA et al. 2007)

À época do SNEF-2007, o projeto de investigação didática estava em desenvolvimento, assim os resultados descritos são parciais, correspondiam à primeira parte do projeto, da coleta das noções prévias dos discentes. A segunda fase consistiria na intervenção com o objetivo de "[...] criar condições para que os estudantes elaborem a resignificação dos seus conceitos, buscando proporcionar a eles uma nova visão a respeito da Ciência, do cientista e do Método Científico [...]" (SOUZA et al., 2007) e finalizariam com aplicação de um novo questionário avaliativo, para verificar até que ponto houve resignificação. A Criticidade é a categoria aproximada para caracterizar a proposta de Souza et al., pois, percebe-se que há uma análise conceitual (Epistemologia/FC), havendo também insuficiências de informações em relação ao plano da intervenção.

Em 2007 um resumo sobre experiência didática inclusionista foi relatada por três docentes de educação básica sobre HFCrECN, em uma Escola pública do interior do Estado de São Paulo. Trata-se de uma experiência de trabalho (T33SNEF-2005) conjunto entre os docentes de Física, Química e Filosofia, com objetivo de discutir o processo de produção científica e a NdC. Afirmam os autores que:

As diferentes visões de mundo, de cultura, de ciência formaram nossa maior riqueza em termos de trabalho educativo. Percebemos que trabalhos deste tipo podem contribuir para que se estabeleça um dialogo (sic) entre as diferentes áreas de conhecimento com a finalidade de estimular professores e alunos à prática permanente de debates e reflexões sobre a ciência, sua natureza e sua relação com a sociedade[.] [...] o trabalho contribuiu no sentido de ajudar a superar visões generalistas, absolutistas e deformadas da Ciência, da atividade científica e do cientista. (BOCANEGRA; SILVA; ANDRADE, 2007) 
Trata-se de uma experiência de trabalho interdisciplinar de desmistificação e resignificação da cultura científica escolar cuja característica é a Criticidade.

À semelhança do T32-SNEF-2005, os autores do T34-SNEF-2005 também desenvolveram uma intervenção didática, porém, antencedida de uma investigação das concepções dos estudantes de Física de duas Universidades públicas (a Estadual de Feira de Santa e a Federal da Bahia). O objetivo deles era investigar as influências e contribuições que a abordagem de ensino de Física baseada em HFC exercia na formação de estudantes de Física (licenciandos e bacharelandos) e a compreensão que os estudantes tinham dos conceitos referentes à "síntese newtoniana (gravitação universal, pêndulo, referenciais inerciais)" e à sua visão da NdC (TEIXEIRA; FREIRE JR, 2007).

A pesquisa realizada teria sido de caráter qualitativo e com uso de questionários abertos e entrevistas semiestruturadas para coleta de dados. A amostra estava composta por discentes das duas Universidades, aleatoriamente selecionados. Após o estudo das concepções prévias dos discentes sobre a "síntese newtoniana" teriam procedido a intervenção didática, para então fazer a "apreciação das transformações nas concepções". A abordagem da HFC foi discutida com base na teoria de aprendizagem significativa (Ausubel), da mudança conceitual e da NdC. Faltaram dados que dessem mais informações sobre como teriam procedido durante a intervenção didática para diagnosticar as influências e contribuições da abordagem contextual (HFC), a forma descritiva utilizada pelos autores não deu a entender se o trabalho estava ou não em andamento no momento da ocorrência do SNEF-2007. Enfim, os propósitos indicam um trabalho que pode ser alocado na categoria Diagnóstico da Aprendizagem em HFCrECN.

Os mesmos autores apresentaram outro trabalho (T35-SNEF-2005), em que afirmam ter realizado uma investigação para avaliação da influência da abordagem contextual com 13 estudantes de Física, desta feita, apenas da Universidade Estadual de Feira de Santana. O tema objeto de estudo seria o conceito newtoniano de inércia, aplicando um questionário qualitativo, para verificar as compreensões dos estudantes antes e depois de terem cursado a disciplina Física I, em que se faz contextualização dos conceitos da mecânica. Os autores afirmam que os resultados obtidos teriam indicado "[...] uma melhora substancial na qualidade das respostas conforme a literatura atualmente aceita, o que indica uma 
melhor compreensão acerca do conceito de inércia, que poder ser atribuída ao estudo contextualizado da mecânica newtoniana" (TEIXEIRA; FREIRE JR, 2007). Logo, o trabalho T35-SNEF-2005 também se caracteriza como de Diagnóstico da Aprendizagem em HFCrECN.

Finalmente, chegamos ao último SNEF do período de nossa análise, o SNEF é um encontro que ocorre de dois em dois anos, assim na época estudada, de 1999 a 2010, o último encontro ocorreu em 2009. Nele selecionamos 5 trabalhos que passamos a analisar a seguir.

No T36-SNEF-2009, Guerra, Braga e Reis (2009) apresentaram relato de experiência sobre a abordagem histórico-filosófica desenvolvida com estudantes do primeiro ano de ensino médio de uma Escola do Rio de Janeiro, sob o tema Cosmologia.

Ao analisar a proposta de atividades realizadas constatamos que o tema foi desenvolvido em forma de um curso de 1 hora aula semanal, num período de 4 bimestres e oferecido a 4 turmas, totalizando 120 discentes. O conteúdo ${ }^{95}$ desenvolvido indica uma Contextualização Interna do conteúdo da Cosmologia.

A experiência teria proporcionado trabalhar temas pouco estudados na Escola, mas que são abordados pela mídia. Finalmente, os autores afirmam que a HFC permitiria compreender a Física como "conhecimento vivo" e que "Sem que se tenha feito uma pesquisa para esse fim, nossa prática cotidiana permite inferir que tal abordagem teve uma ótima aceitação pelos alunos" (GUERRA, BRAGA e REIS, 2009).

Numa mobilização esporádica foi possível arregimentar vários meios para trabalhar aspectos da HC, é assim que "vemos" a HC no Teatro ou o Teatro na HC para ensinar Física! No T37-SNEF-2009, Medina e Braga (2009) apresentaram uma atividade que envolveu o teatro como forma de abordar questões históricas referentes ao ensino da Física. A peça teria ocorrido "[...] no bojo de um trabalho sobre a revolução científica, técnica, artística, econômica e social ocorrida durante os séculos XVI e XVII" (MEDINA; BRAGA, 2009). Trata-se de uma atividade que envolveu varias ações tais como debates, pesquisa, ensaio teatral, produção de cenários e figurinos, entre outras.

A motivação inicial dos autores parecia a de mudar perspectivas

\footnotetext{
${ }^{95}$ Pela sua extensão não é possível reproduzir o conteúdo.
} 
profissionais dos discentes, pois afirmam que:

[...] perceberam que as turmas da primeira série do Ensino Médio eram constituídas, em sua maioria, por alunos sem muito interesse nas áreas científicas e tecnológicas. Eram alunos com tendência para carreiras da área das Ciências Humanas e, em sua maioria, com poucas habilidades matemáticas. (MEDINA; BRAGA, 2009)

A proposta teria nascido depois de estudos sobre Gravitação Universal e Cosmologia nas aulas de Física, gerou a mobilização de outros docentes de forma a trabalhar interdisciplinarmente, unindo professores de Física, Filosofia, História da Arte, História Geral e Teatro. As atividades programadas consistiram em seminários sobre a revolução científico-cultural dos séculos 17 e 18, que culminaria com a apresentação de uma peça teatral adaptada: Galileo Galilei de autoria de Bertolt Bercht.

Do levantamento feito após o evento sobre a preferência profissional perceberam que, dos 27 estudantes que participaram das atividades, 16 estudantes responderam preferir seguir Ciências Humanas; 6 Tecnológicas; 3 Econômicas e 2 Biomédicas. A realização do diagnóstico por carreiras parece confirmar o objetivo subjacente de reverter aquela percepção inicial dos autores de que havia poucos discentes interessados pelas "áreas científicas e tecnológicas" conforme citado acima. A preferência maciça para as Ciências Humanas deve ter frustrado o objetivo da proposta realizada (com ausência completa para Ciências Naturais e Matemática) como pode ser percebido: "Percebeu-se, então, uma participação dos alunos, comumente desinteressados pelas Ciências, das chamadas Ciências Humanas, promovendo, assim, uma maior aproximação e, talvez, despertando um maior interesse pelo assunto" (MEDINA; BRAGA, 2009).

Agora resta saber para que assunto se despertou maior interesse, uma vez que - pelo que anunciaram - o assunto motivador foi Gravitação Universal e Cosmologia e o teatro girou em torno do contexto da Física.

No entanto, Medina e Braga (2009) avaliaram a proposta como sendo neutra, ao afirmarem que: "qualificou-se como um instrumento neutro, que não interferiu diretamente no processo de ensino-aprendizagem, mas forneceu informações sobre as competências e habilidades adquiridas pelos alunos."

O fornecimento de informação e os recortes temáticos de estudos - feitos sob títulos como: Revolução Filosófica, Científica, Político-Religiosa e Artística - 
caracterizam o trabalho como Motivacional e aproximação com a Contextualização Interna e Externa.

Quintal e Moraes, no T38-SNEF-2009, afirmam que seu objetivo foi "levantar questões a respeito do desenvolvimento do eletromagnetismo e motivar os alunos acerca das questões científicas abordadas em sala de aula" (QUINTAL; MORAES, 2009). O trabalho faz parte da pesquisa de conclusão do mestrado feito em 2008, cuja proposta inicial era

[...] realizar uma pesquisa em ensino para discutir relevância da implementação da História e Filosofia da Ciência, como agente influenciador no processo de ensino-aprendizagem dos conteúdos do eletromagnetismo, no Ensino Médio. A proposta pedagógica elaborada, de caráter históricofilosófico, utilizou a História da Ciência, como eixo condutor e apresentou o desenvolvimento do pensamento científico no estudo do eletromagnetismo, desde as principais descobertas sobre os fenômenos elétricos e magnéticos da Antiguidade Clássica até o conceito de campo criado por Maxwell em meados do século XIX. (QUINTA; MORAES, 2009)

Para materialização da proposta de que resultou o trabalho em estudo, foi necessário o desenvolvimento de um "curso histórico-filosófico, [que] visou despertar nos alunos um maior interesse pela ciência. Assim como, estabelecer uma aprendizagem significativa dos conteúdos do eletromagnetismo" (QUINTAL; MORAES, 2009). A proposta foi realizada com 90 discentes do $3^{\circ}$ ano de ensino médio. Foram componentes do curso:

[...] aulas expositivas sobre os conteúdos da eletricidade, do magnetismo e do eletromagnetismo, demonstração de experiências históricas confeccionadas pelo professor, realização de experiências históricas executadas pelos alunos, debate histórico com a turma e exercícios. Os exercícios foram elaborados abordando questões das experiências realizadas em sala de aula. (QUINTA; MORAES, 2009)

E que

[...] o eletromagnetismo foi discutido a partir da construção e análise, pelos alunos, de experimentos como o versorium de Gilbert, a garrafa de Leyden, a pilha de Volta, o experimento da agulha imantada de Oersted, os experiemntos [sic] de Ampére e os de indução de Faraday. (QUINTA; MORAES, 2009)

Do descrito acima sobre o curso e verificando a estrutura do curso - que não é possível reproduzir aqui pela sua extensão - é compreensível a localização do T38-SNEF-2009 nas categorias tais como Motivacional (considerando, sobretudo, o 
objetivo do curso), Contextualização Interna e Externa (considerando os procedimentos e o conteúdo/estrutura do curso).

No T39-SNEF-2009 Silveira et al. trataram de uma proposta de sequência didática pelo que traçaram um paralelo entre as concepções prévias (representações) dos discentes sobre movimento relativo e as ideias defendidas por Aristóteles e Galileu sobre o mesmo movimento. Para tal, foi necessário desenvolver algumas atividades práticas tais como: oficinas e estudos de fragmentos da obra Diálogos sobre os dois máximos sistemas do mundo, entre outros artigos sobre HC e ECN.

Os autores afirmam que

\begin{abstract}
A seqüência didática empregada permitiu explorar os parâmetros sobre a NDC através do episódio histórico sobre movimento relativo, contribuindo para o enriquecimento do assunto. De um modo geral, os alunos mostraram-se satisfeitos com a abordagem histórica utilizada para tratar do conteúdo estudado. Desta forma, consideramos que o uso da história apresentou um aspecto positivo, pois foi possível a desmistificação da física por parte do aluno, que passou a encará-la como algo em constante transformação. (SILVEIRA et al., 2009)
\end{abstract}

A sequência didática teria sido planejado para despertar a reflexão sobre a $\mathrm{NdC}$ e foi desenvolvida durante 8 horas, de que participaram 16 discentes licenciandos em Física, pela Universidade Estadual da Paraíba, em 2008. E, analisando os conteúdos e atividades dos 4 encontros desenvolvidos contata-se de uma Contextualização Interna. Para a qual, "De modo geral, os alunos mostraramse satisfeitos com a abordagem histórica utilizada parra tratar do conteúdo estudado" (SILVEIRA et al., 2009).

O último trabalho do SNEF, T40-SNEF-2009, refere-se à aproximação entre a $\mathrm{HC}$ o Teatro ou abordagem da $\mathrm{HC}$ via representação teatral. É assim que Silva, Lima e Araujo (2009) desenvolveram uma peça teatral não experimentada, que seria realizado com discentes da Escola Básica. A temática da peça foi Astronomia. Os autores justificaram a opção teatral por considerarem que

[...] a apresentação de livros de história da ciência não parece ser um dos melhores caminhos, seja pela falta de maturidade do público, seja pela profundidade dos mesmos. Neste contexto, faz-se necessário repensar 0 uso da história da ciência no ensino de Física, a qual pode ser feita por meio de uma peça de teatro. (SILVA; LIMA; ARAUJO, 2009) 
Mas também há que verificar se, necessariamente, este é também o meio adequado para fazer uma abordagem dos contextos das ciências que resulte no ensino e na aprendizagem científica significativa e não criar imagem distorcida e folclórica. O T40-SNEF-2009 sugere uma nova categoria, a que se refere a propostas não aplicadas na realidade escolar ou universitária, mas descritas apenas, isto é, são desejos sugestivos de abordagem histórica, como é o caso da peça teatral descrita neste trabalho, entre outros desenhos possíveis, como narrativas, a nova categoria pode ser denominada Propostas não Experimentadas em HFCrECN.

Tabela 31 - Simpósio Nacional de Ensino de Física - SNEF Sociedade Brasileira de Física - SBF Home Page: http://www.sbfisica.org.br

\begin{tabular}{|c|c|c|c|}
\hline \multirow{2}{*}{$\begin{array}{l}\text { NÚMERO DE } \\
\text { EDIÇÃO E DATA DO } \\
\text { ENCONTRO }\end{array}$} & \multirow{2}{*}{$\begin{array}{l}\text { Total de } \\
\text { Resumos } \\
\text { Apresentados }\end{array}$} & \multicolumn{2}{|c|}{$\begin{array}{l}\text { Resumos } \text { Relacionados à } \\
\text { Abordagem do Tema da Pesquisa }\end{array}$} \\
\hline & & $\begin{array}{l}\text { Resumos } \\
\text { Referentes à } \\
\text { HFCrECN }\end{array}$ & $\begin{array}{l}\text { Resumos } \\
\text { Referentes à } \\
\text { HFCrECN nos DO }\end{array}$ \\
\hline XIII, 1999 & $\begin{array}{l}\text { Não foi } \\
\text { possível } \\
\text { quantificar }\end{array}$ & 2 & 0 \\
\hline XIV, $2001^{*}$ & +264 & * & \\
\hline $\mathrm{XV}, 2003$ & +391 & 9 & 0 \\
\hline XVI, 2005 & +458 & 7 & 0 \\
\hline XVII, 2007 & +300 & 7 & 0 \\
\hline XVIII, 2009 & +492 & 5 & 0 \\
\hline Total & 1.905 & 28 & 0 \\
\hline
\end{tabular}

\subsection{2 - Eventos da Área de Ensino de Química}

Vejo que, nesse contexto, textos de caráter histórico, que abordam temas relevantes na educação Química tanto no ensino fundamental quanto no ensino médio podem e devem ser utilizados nas licenciaturas, a fim de que os futuros professores tenham a experiência da utilização de abordagens históricas. Além disso, a publicação de trabalhos envolvendo episódios históricos pode constituir um acervo de pesquisa para os professores.

Cristhiane Cunha Flôr ${ }^{96}$

96 FLÔR, Cristhiane Cunha. História da Ciência na Educação Química: síntese de elementos transurânicos e extensão da Tabela Periódica. In: ENCONTRO NACIONAL DE ENSINO DE QUÍMICA, 14., 2008. Resumos... Curitiba, PR. Disponível em: <http://www.quimica.ufpr.br/eduquim/eneq2008/resumos/R0590-1.pdf>. Acesso em: 20 jan. 2011. 


\subsubsection{1 - Encontro Nacional de Ensino de Química - ENEQ}

$\mathrm{Na}$ área de ensino de Química, apenas temos um evento de caráter nacional e representativo, trata-se do Encontro Nacional de Ensino de Química (ENEQ) e em virtude do seu caráter itinerante - como alguns outros eventos também, embora seja interessante e defensável a intinerância - há uma dispersão de material, por falta talvez de organização de um banco de dados junto à Sociedade Brasileira de Química (SBQ) e que fosse acessível para consulta. A própria SBQ tem já um exemplo interessante que é o da Reunião Anual desta sociedade, cujos dados estão armazenados on-line.

Pareceu-nos, então, em relação ao ENEQ, que os dados (Cadernos de Resumos ou Anais) de cada edição ficam nas instituições organizadoras e sua disponibilização on-line parece temporária ou não feita, ou talvez, resumos têm sido distribuídos em CDs. No entanto, após consultarmos as bibliotecas das Faculdades de Educação e de Química (USP), não encontramos materiais do ENEQ, então, resolvemos visitar a sede da SBQ (na USP) e fomos informados que a SBQ não dispõe de um banco de dados do ENEQ, não dispõe de arquivo com anais ou cadernos de resumos. Do ENEQ apenas conseguimos consultar resumos de 2008 e 2010 disponibilizados on-line pelas universidades organizadoras.

Eis os trabalhos coletados:

T41-ENEQ-2008 FERREIRA, Maira. História da Química e Problematização no Ensino de Reações Químicas. In: ENCONTRO NACIONAL DE ENSINO DE QUÍMICA, 14., 2008. Curitiba, PR. Resumos... Curitiba, PR: UFPR, 2008. Disponível em: <http://www.quimica.ufpr.br/eduquim/eneq2008/resumos/>. Acesso em: Acesso em: 20 jan. 2011.

T42-ENEQ-2008 MATOS, Kédima F. de Oliveira. História da Ciência X Ensino de Química: um estudo de caso a cerca da visão. In: ENCONTRO NACIONAL DE ENSINO DE QUÍMICA, 14., 2008. Curitiba, PR. Resumos... Curitiba, PR: UFPR, 2008. Disponível em: <http://www.quimica.ufpr.br/eduquim/eneq2008/resumos/>. Acesso em: Acesso em: 20 jan. 2011.

T43-ENEQ-2008 SILVA, Fausthon Fred da; NETO, José E. Simões; NAVARRO, Daniela M. do A. F. A História da Química como Elemento Motivador nas Aulas de Química Experimental. In: ENCONTRO NACIONAL DE ENSINO DE QUÍMICA, 14., 2008. Curitiba, PR. Resumos... Curitiba, PR: UFPR, 2008. Disponível em: <http://www.quimica.ufpr.br/eduquim/eneq2008/resumos/>. Acesso em: Acesso em: 20 jan. 2011.

T44-ENEQ-2008 VERZOTO, José Carlos; ROSSI, Adriana Vitorino. Favorecendo o Ensino e Estimulando a Aprendizagem de Equilíbrio Químico com Demonstração Experimental e Histórica da Ciência. In: ENCONTRO NACIONAL DE ENSINO DE QUÍMICA, 14., 2008. Curitiba, PR. Resumos... Curitiba, PR: UFPR, 2008. Disponível em: <http://www.quimica.ufpr.br/eduquim/eneq2008/resumos/>. Acesso em: Acesso em: 20 jan. 2011. 
T45-ENEQ-2010 MATEUS, Alfredo Luis; PORTO, Paulo Alves; FANTINI, Leandro H. A História Química da Radioatividade: incluindo fenômeno em uma abordagem histórica dos modelos atômicos. In: ENCONTRO NACIONAL DE ENSINO DE QUÍMICA, 15., 2010. Brasília, DF. Resumos... Brasília, DF: UnB, 2010. Disponível em: <http://www.quimica.ufpr.br/eduquim/eneq2008/resumos/>. Acesso em: Acesso em: 20 jan. 2011.

T46-ENEQ-2010 NASCIMENTO, Hemerson H. Ferreira do et al. A História da Ciência como Instrumento Humanizador no Ensino de Química. In: ENCONTRO NACIONAL DE ENSINO DE QUÍMICA, 15., 2010. Brasília, DF. Resumos... Brasília, DF: UnB, 2010. Disponível em: <http://www.quimica.ufpr.br/eduquim/eneq2008/resumos/>. Acesso em: Acesso em: 20 jan. 2011.

No ENEQ-2008 foram apresentados mais de 458 trabalhos, dos quais 4 foram selecionados por apresentarem aproximação ao tema de estudo. É o caso do T41-ENEQ-2008 em que Ferreira (2008) apresentou resultados de sua investigação didática "[...] sobre uma visão histórica do conteúdo Reações Químicas e a uma proposição de problematização envolvendo os combustíveis automotivos associando aspectos químicos, econômicos e ambientais" (FERREIRA, 2008). As atividades de tal investigação teriam sido desenvolvidas na disciplina Estágio Supervisionado oferecida ao curso de Licenciatura em Química, do Centro Universitário La Salle (Unilasalle), cujo objetivo teria sido "[...] propor aos acadêmicos pensarem formas de articulação dos conteúdos desenvolvidos no ensino médio, aos problemas da vida social" e o tema histórico se refere a "constituição histórica do tema reações química, a partir dos estudos de Lavoisier, no final do séc. XVIII" (FERREIRA, 2008) (destaque do original).

A opção da autora pela problematização parecer estar fundamentada na hipótese aventada por ela:

\footnotetext{
A problematização como estratégia de ensino, supõe um eixo integrador que é o objeto de conhecimento. Então, esse objeto precisa, de alguma forma, estar vinculado à "necessidade" do grupo/comunidade escolar de explicar, compreender, intervir, mudar, prever, algo que desafia uma disciplina isolada. (FEREIRA, 2008)
}

Daí a realização, em 2003, da pesquisa com 4 licenciandos, que estagiavam no terceiro ano do ensino médio trabalhando o conteúdos da Química Orgânica. Parece-nos que os licenciandos teriam sido instrumentalizados para utilizar a estratégias de problematização com o objetivo de significar os conteúdos escolares de química: reações químicas (objeto de estudo). E, que a $\mathrm{HC}$ seria o elemento para desenvolver a competência de contextualização como também previsto pelos PCN. Pois, 


\begin{abstract}
A análise dos relatórios de estágio desses alunos, que fui acompanhando ao longo do semestre, me permitiu ver que mesmo sendo orientados para fazer a a [sic] articulação das reações de combustão com a termoquímica, o resultado foi profícuo. Percebi que as ações que propunham como sendo problematizadoras, implicavam a inserção de exemplos de situações cotidianas que não utilizavam os conhecimentos químicos para resolver os problemas, apenas ilustravam e davam um "colorido" aos conteúdos escolares. Pude perceber, ainda, que o modo como os estagiários abordavam a História da Química era muito superficial, não Ihes dando a compreensão necessária para (re)significar os conhecimentos envolvidos. A construção desse trabalho foi, então, resultado das indicações dos acadêmicos de que não entendiam como os conhecimentos de História da Química poderiam ser utilizados para dar significado aos conteúdos escolares, ou como propor uma situação problema relevante para ensinar Química. (FERREIRA, 2008)
\end{abstract}

Portanto, podemos perceber que se trata de investigação didática que visava à Instrumentação Didática dos licenciandos para atuarem em situações problemas, no campo escolar, contextualizá-los e problematizá-los para resignificar os conteúdos de ensino e aprendizagem em Química ou, como diz Ferreira que: "a orientação aos estagiários para que abordem a História da Química ou criem situações problema no ensino de Química, implica que esses compreendam e signifiquem a História da Química ou a problematização nos conteúdos que irão desenvolver em sua prática docente" (FERREIRA, 2008).

No T42-ENEQ-2008, Matos (2008) descreve uma pesquisa didática em que avaliou o processo de compreensão dos conteúdos químicos após um tratamento histórico. A pesquisa teria sido feita em uma Escola particular na cidade de Osasco, São Paulo, da qual teriam participado 60 discentes do primeiro e segundo ano de ensino médio, com a participação de dois docentes. Teria subdividido os discentes em grupos para estudo e discussão de textos de $\mathrm{HC}$ e, segundo, os discentes teriam feito o levantamento de dúvidas e só assim teria a intervenção docente. Teria havido, também, a aplicação de questionário para sondar a compreensão dos discentes.

Porém, em nenhum momento a autora especifica um tema ou conteúdo químico ou histórico preciso que fora estudado. O que dificulta a localização ou mesmo a criação de nova categoria de análise. Finalmente, como resultado, afirma que $92 \%$ da amostra (60 discentes) teriam afirmado "[...] ter tido uma melhor compreensão da matéria dada pelo professor. Isto também foi possível ser 
observado nas avaliações realizadas pelos alunos" (MATOS, 2008). Portanto, verificamos que há no texto falta de informações sobre HFCrECN que nos assegurassem o enquadramento nas categorias de análise, identificando assim uma Insuficiência Informativa em Relação à HFCrECN.

Nos dois últimos trabalhos do ENEQ-2008 selecionados predomina a dimensão motivacional da HC. No T43-ENEQ-2008, Silva, Neto e Navarro (2008) demonstram sua preocupação com o ensino tradicional e expositivo em Química, então, tomaram por objetivo apresentar as vidrarias aos licenciandos em Química e Física da Universidade Federal de Pernambuco (UFPE), utilizando uma abordagem histórica das vidrarias, durante a disciplina Química Experimental comum aos licenciandos.

Teriam selecionado as seguintes vidrarias para abordagem contextual: "bico de Bunsen (Robert W. E. v. Bunsen), funil de Büchner (Eduard Büchner), pinça de Mohr (Karl F. Mohr), Erlenmeyer (Richard A. C. E. Erlenmeyer), condensador de Liebig (Justus v. Liebig) e a pipeta de Pasteur (Louis Pasteur)" (SILVA; NETO; NAVARRO, 2008). Durante as aulas teriam feito o histórico e as contribuições de cada cientista, cujos nomes designam as vidrarias.

No final, teriam aplicado um questionário qualitativo para verificação da receptividade da abordagem pelos discentes. Constataram que em relação aos cientistas, Pasteur e Bunsen foram os mais citados como conhecidos; a maioria teria dito interessada em HC como instrumento didático, motivador e facilitador de compreensão de ferramentas laboratoriais, no entanto, os discentes teriam dito ler pouco sobre HC. Portanto, é possível localizar o trabalho nas categorias Contextualização Interna e Motivacional, inferência reforçada pelos autores ao afirmarem que "A história da Química desempenha um papel motivador no ensino de química experimental, facilitando o entendimento dos processos históricos que fizeram parte do desenvolvimento dos aparatos de laboratórios, bem como os seus idealizadores" (SILVA; NETO; NAVARRO, 2008), sem portanto a consideração do contexto externo (social, cultural, econômico, político) em que se localiza o empreendimentos dos aparelhos laboratoriais.

Já no outro trabalho do ENEQ-2008, T44-ENEQ-2008, Verzoto e Rossi (2008) desenvolveram uma pesquisa didática com 134 estudantes do $3^{\circ}$ ano de ensino médio de uma Escola pública, na cidade de Cerquilho, São Paulo. O objetivo teria sido investigar "[...] o impacto de contextualização, uso de demonstração 
experimental e discussão de aspectos relevantes da História da Ciência como formas de despertar o interesse dos estudantes e favorecer a aprendizagem desse conceito" (VERZOTO; ROSSI, 2008).

O tema didático foi equilíbrio químico. Metodologicamente, os autores agiram como se aplicassem um plano experimental. Eles aplicaram duas propostas diferentes a dois grupos: a Proposta $A$ - evolveu "aulas contextualizadas, demonstrações experimentais e abordagem histórica" aplicada a 81 discentes de 3 turmas e a Proposta $B$ - envolveu apenas aulas com "aspectos teóricos tradicionais" e aplicada a 33 discentes de uma turma. E, ao final aplicaram um questionário para coletar as impressões dos discentes "sobre diversos aspectos relacionados com o ensino e a aprendizagem do conceito abordado nas aulas, além de questões específicas sobre o conteúdo" (VERZOTO; ROSSI, 2008).

No entanto, $81+33=114$, este número não corresponde aos 134 discentes anunciados como amostra total de participantes. Houve também, quantitativamente, desequilíbrio entre as amostras dos grupos, a proposta $A$ (81 discentes) e a B (33 discentes). Mas, mesmo assim tal fato não favoreceu a abordagem histórica em relação à abordagem teórica (dita tradicional) como pudemos verificar nos resultados apresentados na tabela comparativa pelos autores. Ao aplicar questionário, no aspecto que tange à $\mathrm{HC}$, solicitou-se dos discentes sobre:

"4) O que auxiliou seu aprendizado? (1) pouco a (5) muito".

Na proposta A: Experimentação $(4,2)$ e História da Ciência $(4,2)$.

E na proposta B: Aulas teóricas $(4,1)$.

Não houve esclarecimento do porque a opção "aulas teóricas" não constou da proposta $\mathrm{A}$, considerando que não há como desenvolver abordagem história e mesmo reproduzir experimentos sem teorizar, ainda que seja estudo dirigido. Assim, como os autores não esclareceram quantos discentes responderam em ambas as propostas, em relação à amostra ou se haviam outras opções além das apresentadas na tabela e reproduzidas acima. Se na Proposta B, 4,1 para aulas teóricas corresponde a totalidade dos discentes desta proposta ou não? 4,1 correspondem à média? $\mathrm{E}$, na proposta $\mathrm{A}$ os dois valores representam a amostra total $(81 / 2=40,5$ discentes para cada valor)? Qual foi a medida calculo estatística utilizada?

Em conformidade com a pergunta, a escala de valores aí representada 
(de 1 a 5), equivale a dizer aprendeu pouco ou muito por intermédio da "experimentação", "HC" ou "aulas teóricas". Se este raciocínio estiver correto e considerando a pontuação obtida, então, verifica-se que não houve diferença significativa, já que as aulas teóricas obtiveram uma avaliação extremamente próxima da obtida pela HC e experimentação. Mas também há outra questão, não foi dada, aos discentes, outra opção avaliativa, na proposta $B$, as aulas teóricas constituíram o único elemento que os discentes "tinham" como experiência de aprendizagem. Portanto, há problemas de compreensão da questão do questionário, em especial ao que se refere à $\mathrm{HC}$, porque a pergunta "o que auxiliou seu aprendizado?" não encontra amparo metodológico explicado no trabalho para diagnosticar a ocorrência ou não da aprendizagem com inclusão da reprodução de experimentos e abordagem histórica ou com aulas teóricas.

Em todo caso, os autores afirmam que:

Os resultados obtidos indicaram vantagens na aplicação da proposta $A$ que, certamente, demanda alguns esforços adicionais por parte do professor, principalmente no que diz respeito à realização das demonstrações experimentais e discussão de aspectos históricos. Este último aspecto acentua-se porque há deficiências relacionadas com abordagem histórica em livros didáticos brasileiros de química [...] (VERZOTO; ROSSI, 2008).

Embora, o procedimento não ofereça condições sólidas, metodologicamente, para estabelecer comparações entre as proposta A e B sobre se a HC proporcionou ou não aprendizagem do equilíbrio químico, fato é que está relatado que a abordagem história obteve uma pontuação significativa numa escala de 1 a 5, comparável a experimentação (empate). Portanto, por tencionarem a abordagem histórica como elemento de motivação, o T44-ENEQ-2008 pode ser inscrito como proposta de caráter Motivacional.

Apresentação de uma proposta não experimentada contemplando "a discussão do processo de construção do conhecimento científico, sem, contudo, dissociá-lo do ensino de conceitos de química" (MATEUS; PORTO; FANTINI, 2010) este foi o objetivo desses autores no T45-ENEQ-2010. Eles afirmam ter aliado um estudo em HC e as novas tecnologias de comunicação e informação, para produzir materiais descritos por eles: 
realizados pelos cientistas no início das pesquisas com radioatividade, de modo a mostrar quais eram as perguntas que os motivaram a realizar estes experimentos. Com essa abordagem esperamos mostrar que é possível evitar um tratamento histórico superficial, em que apenas nomes, datas e "descobertas" são apresentados. (Mateus; Porto; FANTINI, 2010)

O tema principal do material seria radioatividade e modelos atômicos. E, do material produzido constam dois episódios centrais: o primeiro refere-se ao experimento de Becquerel $^{97}$ com sais de urânio e, o segundo, às pesquisas de Rutherford $^{98}$ com as radiações do urânio.

Este trabalho (T45-ENEQ-2010) não se refere precisamente a HFCrECN, mas relacionado à produção de materiais paradidáticos (no caso, audiovisuais) que, de certa forma, auxiliam a abordagem da HFC-ECN, por esta razão exige a incorporação em nova categoria que pode ser a de Produção de Material Didático e Paradidático em HFCrECN.

No segundo trabalho do ENEQ-2010 (T46-ENEQ-2010) os autores apresentaram o desenvolvimento de uma atividade (cursos) durante a II Semana de Ciência e Tecnologia, da Unidade Acadêmica de Serra Talhada da Universidade Federal Rural de Pernambuco. Os autores, licenciando em Química desta universidade, teriam se despertado para abordagem contextual durante as discussões na disciplina Didática estudada no sexto semestre. Daí surgira a necessidade de aproximar a Química ao cotidiano. A atividade fora desenvolvida com 60 discentes do primeiro ano de licenciatura em Química na mesma universidade, servindo-se da História da Química para "contextualizar e humanizar esta ciência", assim,

A estratégia didática se constitui de uma dinâmica de diálogos acerca da
história e evolução da Química, seguida de algumas problematizações que
permitiram contextualizar na vida cotidiana as descobertas e inovações
trazidas pela Química ao longo da História. Foram abordados temas, como:
a Química na Pré-História, a Alquimia, a Química Moderna e a Química
Contemporânea. Esta última por meio das contribuições de grandes
cientistas. (NASCIMENTO et al., 2010)

Neste sentido, podemos inferir a localização em duas categorias:

${ }^{97}$ Trata-se do francês Antoine Henri Becquerel (1852-1908), engenheiro de pontes e calçadas, que lecionou física, descobriu a radioatividade dos sais de urânio e em 1903 recebeu, junto com o casal Curie (Pierre e Marie), o Nobel de Física.

${ }^{98}$ Refere-se ao neozelandês Ernest Rutherford (1871-1937), matemático e físico pela Universidade da Nova Zelândia. Nobel de Química, em 1908, em virtude das suas pesquisas sobre desintegração dos elementos e química das substâncias radioativas. 
Contextualização Interna e Autoaperfeiçoamento (fracamente). Contextualizar na vida cotidiana remete à transposição para o contexto vivencial dos discentes conforme consta nos PCN, que não significa, necessariamente, abordar as dimensões econômicas, políticas, ideológica da atividade científica. Contextualizar a química moderno-contemporânea restringindo-se às figuras de supostos "grandes cientistas" ou "gênios" é restringir-se ao âmbito que tende a reproduzir imagem errônea de percepção da ciência como construção coletiva.

Tabela 32 - Encontro Nacional de Ensino de Química - ENEQ. ISSN: 2179-5355

Home Page 2010: http://www.xveneq2010.unb.br/editorial.htm

Home Page 2008: http://www.quimica.ufpr.br/eduquim/eneq2008/resumos/

Sociedade Brasileira de Química (Divisão de Ensino) - SBQ;

Home Page: http://www.sbq.org.br/

\begin{tabular}{|l|l|l|l|}
\hline \multirow{2}{*}{$\begin{array}{c}\text { NÚMERO DE } \\
\text { EDIÇÃO E DATA DO } \\
\text { ENCONTRO }\end{array}$} & $\begin{array}{l}\text { Total de } \\
\text { Resumos } \\
\text { Apresentados }\end{array}$ & $\begin{array}{l}\text { Resumos } \\
\text { Abordagem do Tema da Pesquisa }\end{array}$ \\
\cline { 3 - 4 } & $\begin{array}{l}\text { Resumos } \\
\text { Referentes à } \\
\text { HFCrECN }\end{array}$ & $\begin{array}{l}\text { Resumos } \\
\text { Referentes à } \\
\text { HFCrECN nos Do }\end{array}$ \\
\hline X, 2000 & $\begin{array}{c}\text { Dados não } \\
\text { disponíveis }\end{array}$ & & \\
\hline XI, 2002 & $\begin{array}{c}\text { Dados não } \\
\text { disponíveis }\end{array}$ & & \\
\hline XII, 2004 & $\begin{array}{c}\text { Dados não } \\
\text { disponíveis }\end{array}$ & & \\
\hline XIII, 2006 & $\begin{array}{c}\text { Dados não } \\
\text { disponíveis }\end{array}$ & & \\
\hline XIV, 2008* & $+\mathbf{4 5 8}$ & $\mathbf{4}$ & 0 \\
\hline XV, 2010 & $\mathbf{+ 5 6 6}$ & $\mathbf{2}$ & 0 \\
\hline Total & $\mathbf{1 . 0 2 4}$ & $\mathbf{6}$ & $\mathbf{0}$ \\
\hline *Um artigo não foi verificado por quebra de link & \\
\hline
\end{tabular}

\subsection{3 - Eventos da Área de Ensino de Biologia}

Dois eventos foram selecionados como representativos desta área: 0 Encontro Nacional de Ensino de Biologia e o Encontro de História e Filosofia da Biologia.

\subsubsection{1 - Encontro Nacional de Ensino de Biologia - ENEBIO}

No ENEBIO-2005 foi selecionado o seguinte trabalho:

T47-ENEBIO-2005. SLONGO, lônes Inês Pinsson. História da Ciência, Ensino de Biologia e Formação de Professores. In: ENCONTRO NACIONAL DE ENSINO DE BIOLOGIA, 1., ENCONTRO REGIONAL DE ENSINO DE BIOLOGIA, 3., Rio Janeiro, RJ, 2005. Anais... Rio de 
Janeiro, RJ: SBENBIO, 2005. p. 794-798.

No trabalho referido Slongo (2005) teve por objetivo abordar o tema reprodução humana articulada à sua historicidade para proporcionar entendimento apropriado. Trata-se de uma investigação didática desenvolvida na disciplina Fisiologia Humana, de 30 horas, com 14 discentes do último ano de graduação em Biologia, da Universidade do Contestado em Concórdia, Santa Catarina, em 1995.

O texto histórico teria incluído, além da articulação epistemológica, os seguintes temas:

- Os modelos gregos (Hipócrates e Aristóteles);

- As observações de Harvey;

- A incessante busca pelo óvulo;

- A visualização do mundo microscópico;

- As teorias preformistas (ovistas e animalculistas);

- A retomada da epigênese;

- A teoria celular;

- Desvendamento da fecundação. (SLONGO, 2005)

Da análise do conteúdo do texto histórico elaborado e estudado inferimos a sua caracterização em Criticidade e Contextualização Interna e, de certa forma, anuncia-se ter havido uma Contextualização Externa do tema reprodução humana, que também pode ter sua compreensão ampliada pelo descrito a seguir:

O curso iniciou-se com a problematização do conhecimento sobre reprodução, seguindo a linha de tempo - desde os modelos gregos até o modelo atual. As questões utilizadas para a problematização foram as pontuadas pelos pesquisadores nos diferentes momentos da história e que o texto de Giordan $(1987)^{99}$ contempla com muita propriedade. Para viabilizar esta dinâmica da problematização, tendo em vista o enfoque histórico, fez-se necessário situar os alunos quanto ao contexto em que se desenvolveram os modelos em estudo. Para isso, excertos das obras de Bernal (1976) e Andrery (1988) ${ }^{100}$ foram fundamentais especialmente para contextualizar e caracterizar o pensamento aristotélico e suas implicações na Ciência da Idade Média, bem como a transição para a Ciência Moderna. (SLONGO, 2005)

A dimensão epistemológica teria sido razão de estimular a organização epistêmica e fonte de debates, indagações e resposta para compreensão histórica do processo construtivo do conhecimento científico.

\footnotetext{
${ }^{99}$ Nota nossa: Refere-se a GIORDAN, A. Historie de La Biologie. Paris: Lavoisier, 1987.

100 Nota nossa: ANDERY, M. A. et al. Para Compreender a Ciência. Espaço e Tempo: Rio de Janeiro, 1988. E, BERNAL, J. D. A Ciência na História. Lisboa: Livros Horizonte, 1976.
} 
A problematização estimulou os alunos à organização do conhecimento, realizada através da leitura e discussão dos textos apontados (histórico e atuais). Este momento pedagógico desencadeou-se naturalmente, gerando novos ciclos de problematização e promovendo resultados bastante satisfatórios. A peculiaridade desta dinâmica esteve na utilização do texto histórico para estruturar as demais atividades, inclusive gerando as discussões sobe aspectos pontuais da reprodução humana do modelo atual.

Uma característica marcante, oportunizada pela abordagem histórica, foi o fato de as aulas transformaram-se num constante debate, permeado por desafios - as questões problematizadoras. Essas questões introduziram no trabalho de sala de aula uma espécie de tensão positiva, aproximando o trabalho pedagógico de um processo investigativo. Com esta dinâmica, muitas questões suscitadas na problematização, propostas pelo texto histórico e ampliadas pelas discussões e atividades práticas que realizáramos, puderam ser respondidas. (SLONGO, 2005)

\section{E, finalmente,}

[...] na investigação realizada, a História da Ciência ao ser articulada ao ensino de Biologia, desempenhou duplo papel. Por um lado, constituiu-se na metodologia que estruturou o trabalho, uma vez que ao texto histórico foram agregadas as demais reflexões; por outro, a perspectiva histórica constituiu-se num dos conteúdos, proporcionado uma discussão sobre os mecanismos da produção científica, explicitando e exemplificando suas características. (SLONGO, 2005)

Portanto, percebe-se a descrição enfática da contribuição da abordagem histórico-filosófica ao estudo da reprodução humana, embora não tenha sido possível indicar mudanças ou graus de aprendizagem consequentes da aplicação da HFC.

Tabela 33 - Encontro Nacional de Ensino de Biologia - ENEBIO

Sociedade Brasileira de Ensino de Biologia - SBEnBio Home Page: http://www.sbenbio.org.br/enebio/

\begin{tabular}{|c|c|c|c|}
\hline \multirow{2}{*}{$\begin{array}{c}\text { NÚMERO DE } \\
\text { EDIÇÃO E DATA DO } \\
\text { ENCONTRO }\end{array}$} & \multirow{2}{*}{$\begin{array}{l}\text { Total de } \\
\text { Resumos } \\
\text { Apresentados }\end{array}$} & \multicolumn{2}{|c|}{$\begin{array}{ll}\text { Resumos } & \text { Relacionados } \\
\text { Abordagem do Tema da Pesquisa }\end{array}$} \\
\hline & & $\begin{array}{l}\text { Resumos } \\
\text { Referentes à } \\
\text { HFCrECN }\end{array}$ & $\begin{array}{l}\text { Resumos } \\
\text { Referentes à } \\
\text { HFCrECN nos DO }\end{array}$ \\
\hline $1^{\circ}, 2005^{*}$ & & 1 & 0 \\
\hline $2^{\circ}, 2007^{\star *}$ & +231 & & 0 \\
\hline 3ㅇ, 2010 & +421 & 0 & 0 \\
\hline Total & 652 & 1 & 0 \\
\hline
\end{tabular}




\subsubsection{2 - Encontro de Filosofia e História da Biologia - "EFHB"}

No Encontro de Filosofia e História da Biologia constatamos publicações em que se apresentam discussões teóricas importantes para a continuidade do debate da construção da interface e sua aproximação ao ensino de ciências naturais, neste caso, biológicas. Os trabalhos identificados no EFHB são importantes, por advirem da lavra de pesquisadores empenhados na História e Filosofia das Ciências Biológicas. O caráter historiográfico ou analítico de material didático faz dos trabalhos excelentes fontes de apoio aos docentes das Escolas da Educação Básica, sobretudo, quando introduzidos na abordagem contextualizadora crítica.

No entanto, para fins desta pesquisa, em virtude do recorte dado aos eventos, foi identificado um trabalho (T48-EHFB-2010) em que houve proposta de aplicação da HFC experimentadas no ensino de ciências naturais (Biologia).

T48-EHFB-2010. CORRÊA, André Luis; ARAUJO, Elaine S. Nicolini Nabuco de; MEGLHIORATTI, Fernanda Aparecida; CALDEIRA, Ana Maria de Andrade. História e Filosofia da Biologia como Ferramenta no Ensino de Evolução na Formação Inicial de Professores de Biologia. In: ENCONTRO HISTÓRIA E FILOSOFIA DA BIOLOGIA, [8]., São Paulo, SP, 2010. Resumos... São Paulo, SP: ABFHiB, 2010. p. 10-11. Disponível em: <http://www.abfhib.org/Eventos-antigos.html>. Acesso em: Acesso em: 20 jan. 2011.

No referido trabalho, Corrêa et al. (2010) partindo do pressuposto de que a teoria da evolução permite um ensino integrado da Biologia e que as dificuldades de sua compreensão seriam também decorrentes de "equívocos conceituais e históricos presentes nos livros didáticos" (CORRÊA et al., 2010), desenvolveram uma investigação didática cujo objetivo teria sido pesquisar qual entendimento os licenciandos em Ciências Biológicas e participantes da disciplina Evolução tinham sobre as teorias de Lamarck e Darwin. Para fazer jus a essa empreitada procederam da seguinte forma:

1) Verificação das concepções prévias; 2) Elaboração de um material pedagógico, contendo diversos textos históricos de fontes primárias e secundárias; 3) Discussões em dois módulos didáticos, utilizando o material pedagógico elaborado; 4 Análise das concepções construídas pelos alunos, a partir da intervenção didática. (CORRÊA et al., 2010)

E, os resultados obtidos teriam possibilitado compreender que 
[...] as concepções prévias dos entrevistados, acerca das teorias de Lamarck e Darwin, assemelham-se às explicações apresentadas nos livros didáticos, e que, a inserção de textos históricos nas aulas de Evolução pode ser uma estratégia interessante para construção do conhecimento dessa temática. (CORRÊA et al., 2010)

Embora também não tenha sido possível verificar o grau da contribuição da abordagem, há uma sinalização de compreensão da influência dos textos didáticos e da contribuição da $\mathrm{HC}$, confirmando as teorias do movimento da HFCrECN. Nesse sentido, o trabalho (T48-EHFB-2010) aproxima-se da Contextualização Interna.

Tabela 34 - Encontro de Filosofia e História da Biologia - "EHFB" Associação Brasileira de Filosofia e História da Biologia - ABFHiB Home Page: http://www.abfhib.org/Encontro.html

\begin{tabular}{|c|c|c|c|}
\hline \multirow{2}{*}{$\begin{array}{c}\text { NÚMERO DE } \\
\text { EDIÇÃO E DATA DO } \\
\text { ENCONTRO }\end{array}$} & \multirow{2}{*}{$\begin{array}{l}\text { Total de } \\
\text { Resumos } \\
\text { Apresentados }\end{array}$} & \multicolumn{2}{|c|}{$\begin{array}{lll}\text { Resumos } & \text { Relacionados } \\
\text { Abordagem do Tema da Pesquisa }\end{array}$} \\
\hline & & $\begin{array}{l}\text { Resumos } \\
\text { Referentes à } \\
\text { HFCrECN }\end{array}$ & $\begin{array}{l}\text { Resumos } \\
\text { Referentes à } \\
\text { HFCrECN nos DO }\end{array}$ \\
\hline $\mathrm{I}, 2003$ & +14 & 0 & 0 \\
\hline II, 2004 & +14 & 0 & 0 \\
\hline III, 2005 & +18 & 0 & 0 \\
\hline IV, 2006 & +32 & 0 & 0 \\
\hline$V, 2007$ & +42 & 0 & 0 \\
\hline $\mathrm{VI}, 2008$ & +37 & 0 & 0 \\
\hline $\begin{array}{l}\text { I Encontro Temático } \\
\text { da ABFHiB, } 2008\end{array}$ & +8 & 0 & 0 \\
\hline [VII?], 2009* & +41 & 0 & 0 \\
\hline [VIIII?], 2010* & +61 & 1 & 0 \\
\hline Total & 267 & 1 & 0 \\
\hline \multicolumn{4}{|c|}{ Sem número no material consultado. } \\
\hline
\end{tabular}

\section{3 - Eventos da Área de Ensino de Ciências Naturais}

$\mathrm{Na}$ área de Ensino de Ciências Naturais também existem eventos integradores em que têm sido apresentadas pesquisas provenientes das microáreas, conforme as especificidades das ciências naturais. Assim, o Encontro Nacional de Pesquisa em Educação em Ciência, evento representativo da área no Brasil, foi selecionado para coleta de dados referentes ao tema ora em estudo. 


\subsubsection{1 - Encontro Nacional de Pesquisa em Educação em Ciência - ENPEC}

Em relação ao ENPEC tivemos também dificuldades de encontrar o material, os resumos do $1^{\circ}, 2^{\circ}$ e $3^{\circ}$ não foram localizados; também não foi possível computador o total de trabalhos publicados no $4^{\circ}$ e $5^{\circ}$ ENPEC, mas foi possível obter os resumos referentes a temática de HFC, geralmente publicadas nas seções de HFC. Assim, no ENPEC-2003 havíamos obtido alguns trabalhos, depois de estudálos verificamos que não apresentavam aproximação ao tema, diferentemente dos resumos seguintes, dos dois últimos ENPEC. Eis os artigos coletados:

T49-ENPEC-2005. EL-HANI, Charbel Niño. Notas sobre o Ensino de História e Filosofia da Biologia na Educação Superior. In: ENCONTRO NACIONAL DE PESQUISA EM EDUCAÇÃO EM CIÊNCIAS, 5., Bauru, SP, 2005. Resumos... Bauru, SP: ABRAPEC, 2005. p. 67.

T50-ENPEC-2005. EDUZZI, Luiz O. Q. Do Átomo Grego ao Átomo de Bohr: receptividade inicial e perspectivas de pesquisa de um texto voltado para uma disciplina de evolução dos conceitos da física. In: ENCONTRO NACIONAL DE PESQUISA EM EDUCAÇÃO EM CIÊNCIAS, 5., Bauru, SP, 2005. Resumos... Bauru, SP: ABRAPEC, 2005. p. 67.

T51-ENPEC-2005. MENDES, Maria I. Porazza; FIGUEIROA, Silvia F. de Mendonça. A Terra sob Medida - debates de História da Ciência em espaços virtuais de aprendizagem. In: ENCONTRO NACIONAL DE PESQUISA EM EDUCAÇÃO EM CIÊNCIAS, 5., Bauru, SP, 2005. Resumos... Bauru, SP: ABRAPEC, 2005. p. 113.

T52-ENPEC-2005. MAIA, Dayane R. Andrade; MION, Fejane Aurora. Educação Científica e Tecnológica: a incorporação da curiosidade epistemológica no ensino de física. In: ENCONTRO NACIONAL DE PESQUISA EM EDUCAÇÃO EM CIÊNCIAS, 5., Bauru, SP, 2005. Resumos... Bauru, SP: ABRAPEC, 2005. p. 163.

T53-ENPEC-2005. PORTELA, Sebastião I. C.; LARANJEIRAS [sic], Cássio C. O Estudo de Casos de História da Ciência como estratégia de articulação da Dimensão Cultural da Ciência em Sala de Aula. In: ENCONTRO NACIONAL DE PESQUISA EM EDUCAÇÃO EM CIÊNCIAS, 5., Bauru, SP, 2005. Resumos... Bauru, SP: ABRAPEC, 2005. p. 216.

T54-ENPEC-2005. ROSA, Katemari; PENIDO, Maria C. Martins. A Inserção de História e Filosofia da Ciência no Ensino de Ciências e a Formação de Professores de Física. In: ENCONTRO NACIONAL DE PESQUISA EM EDUCAÇÃO EM CIÊNCIAS, 5., Bauru, SP, 2005. Resumos... Bauru, SP: ABRAPEC, 2005. p. 292.

T55-ENPEC-2005. GEBARA, Maria José. Questões Relativas à História da Ciência e ao Ensino de Ciências. In: ENCONTRO NACIONAL DE PESQUISA EM EDUCAÇÃO EM CIÊNCIAS, 5., Bauru, SP, 2005. Resumos... Bauru, SP: ABRAPEC, 2005. p. 422.

T56-ENPEC-2005. NEVES, Marcos C. Danhoni et al. Uma Discussão sobre o Mapeamento Conceitual da Relatividade e da Cosmologia para o Ensino de Física Moderna e Contemporânea. In: ENCONTRO NACIONAL DE PESQUISA EM EDUCAÇÃO EM CIÊNCIAS, 5., Bauru, SP, 2005. Resumos... Bauru, SP: ABRAPEC, 2005. p. 447.

T57-ENPEC-2007. STAUB, Ana Carolina. A História e a Filosofia da Ciência em uma Disciplina de Evolução dos Conceitos da Física. In: ENCONTRO NACIONAL DE PESQUISA EM EDUCAÇÃO EM CIÊNCIAS, 6., Florianópolis, SC, 2007. Resumos... Florianópolis, SC: ABRAPEC, 2007. Disponível em: <http://www.fae.ufmg.br/abrapec/viempec/7enpec/index.html>. Acesso em: 22 jan. 2011. 
T58-ENPEC-2009. BOSS, Sergio Luiz Bragatto; SOUZA FILHO, Moacir P. de; CALUZI, João José. História da Ciência e Aprendizagem Significativa: o experimento de Coloumb. In: ENCONTRO NACIONAL DE PESQUISA EM EDUCAÇÃO EM CIÊNCIAS, 7., Florianópolis, SC, 2009. Resumos... Florianópolis, SC: ABRAPEC, 2009. Disponível em: <http://www.fae.ufmg.br/abrapec/viempec/7enpec/index.html>. Acesso em: 22 jan. 2011.

T59-ENPEC-2009. CARVALHO, Letícia dos Santos; MARTINS, André Ferrer P. História da Ciência na Formação de Professores das Séries Iniciais: uma proposta com quadrinhos. In: ENCONTRO NACIONAL DE PESQUISA EM EDUCAÇÃO EM CIÊNCIAS, 7., Florianópolis, SC, 2009. Resumos... Florianópolis, SC: ABRAPEC, 2009. Disponível em: <http://www.fae.ufmg.br/abrapec/viempec/7enpec/index.html>. Acesso em: 22 jan. 2011.

T60-ENPEC-2009. RAPOSO, Washington; GUERRA, Andreia. Epistemologia na Educação Científica: um caminho para discutir a ciência em sala de aula? In: ENCONTRO NACIONAL DE PESQUISA EM EDUCAÇÃO EM CIÊNCIAS, 7., Florianópolis, SC, 2009. Resumos... Florianópolis, $\quad$ SC: $\quad$ ABRAPEC, $2009 . \quad$ Disponível em: <http://www.fae.ufmg.br/abrapec/viempec/7enpec/index.html>. Acesso em: 22 jan. 2011.

T61-ENPEC-2009. GATTI, Sandra R. Teodoro; NARDI, Roberto. História e a Filosofia da Ciência no Ensino de Física: análise de práticas pedagógicas realizadas em atividades de formação continuada de professores. In: ENCONTRO NACIONAL DE PESQUISA EM EDUCAÇÃO EM CIÊNCIAS, 7., Florianópolis, SC, 2009. Resumos... Florianópolis, SC: ABRAPEC, 2009. Disponível em: <http://www.fae.ufmg.br/abrapec/viempec/7enpec/index.html>. Acesso em: 22 jan. 2011.

No ENPEC-2005, El-Hani apresentou trabalho (T49-ENPEC-2005) em que tratou de duas propostas de inclusão da HFC que desenvolvia no ensino superior: em ciências biológicas, contribuindo para os debates referentes à "como ensinar sobre HFC". Então, afirma que:

\begin{abstract}
A primeira proposta utiliza exposições diálogas e discussões em sala de aula, partindo de estudos de casos históricos concretos para colocação e tratamento de questões epistemológicas. A segunda emprega metodologia de projetos para engajamento dos alunos em investigações nas áreas de história, filosofia e ensino de biologia. (El-Hani, 2005)
\end{abstract}

Embora haja insuficiência de informações no trabalho, é possível - a partir do descrito - inferir e tentar localizar, minimamente, o trabalho nas seguintes categorias: a primeira na Criticidade e, a segunda, na Instrumentação Didática.

Peduzzi em T50-ENPEC-2005 retrata uma experiência de inserção de um texto histórico ("Do Átomo Grego ao Átomo de Borh") em aula de uma disciplina de caráter histórico lecionada por ele (Evolução dos Conceitos da Física). A partir do objetivo da disciplina e do conteúdo dos cincos capítulos do texto trabalhado em sala de aula demonstra-se uma Contextualização Interna (própria das disciplinas de evolução dos conceitos), num percurso que vai desde os conceitos gregos de átomo, passando por Dalton, atomismo do séc. 19, espectroscopia, elétron, raio $X$, radioatividade, quantum de radiação até chegar ao modelo atômico de Bohr. 
A inclusão da HC também chega ao mundo cibernético da aprendizagem, foi o engajamento de duas professoras em oferecer um curso, entre 2004 e 2005, para docentes das Escolas médias e fundamentais. É o que ocorreu no que foi descrito em T51-ENPEC-2005 no qual as autoras afirmam que o tema principal fora a

[...] direção do achatamento terrestre ocorrido no século VXIII. [E que] Este curso fundamenta-se na importância da História da Ciência no ensino de Ciências e na possibilidade de se trabalhar com ambientes virtuais de aprendizagem sócio-construtivista da aprendizagem. Inicialmente preocupamo-nos em elaborar as estratégias de aprendizagem como simulações históricas. (MENDES; FIGUEIROA, 2005)

Verificamos, neste trabalho, que a situação de Insuficiência Informativa em Relação à HFCrECN se manifesta novamente, como em alguns outros.

Maia e Mion (T52-ENPEC-2005) desenvolveram uma pesquisa didática baseada na estratégia de pesquisa-ação no ensino de Física, com o objetivo de verificar a possibilidade de instigar e incorporar a "curiosidade epistemológica" nas aulas de Física e, ainda, "analisar se e como a incorporação da cultura científica e tecnológica por meio de atividades práticas e atividades teórico-experimentais" (MAIA; MION, 2005). E, afirmam ainda as autoras que os resultados da sua investigação didática teriam

[...] revelado que os alunos tornaram-se mais motivados pelas aulas devido às atividades propostas a utilização dos objetos tecnológicos proporcionou grande curiosidade possibilitando abrir o diálogo com os alunos. Mas o principal foi a real incorporação da consCiência [sic] crítica ou seja nós educadores nos tornamos mais curiosos. (MAIA; MION, 2005)

Os indícios de caráter Motivacional advêm dos objetivos e aparece na referência aos resultados, que a "curiosidade epistemológica" teria sido significada, para os âmbitos da aprendizagem e ensino. A esta curiosidade quando significativamente trabalhada conduz à criatividade e autonomia intelectual dos sujeitos como fautores da historicidade e da mudança dialética nos processos de organização cognitiva e social.

Portela e Laranjeiras no T53-ENPEC-2005 teria discutido a importância da HC no ensino considerando-a como portadora de uma "função constituinte do conhecimento científico" e por isso necessária à formação de cultura científica dos cidadãos. No mesmo trabalho, teriam proposta uma "estratégia didático-pedagógica 
baseada no uso de casos históricos onde o ensino de Ciências deve contemplar explicitamente" aspectos conceituais e os da $\mathrm{NdC}$, o que possibilitaria a ruptura com a abordagem caricatural e deformada das ciências (PORTELA; LARANJEIRAS, 2005). No entanto, não houve descrição estrutural e metodológica da proposta ou sua execução, apresentando assim uma Insuficiência Informativa em Relação à HFCrECN.

Porém, esta mesma insuficiência também aparece em outros trabalhos, tais como:

- o T54-ENPEC-2005, em que Rosa e Penido (2005) teriam apresentado reflexões como esboço parcial de um trabalho (T54-ENPEC-2005) em que tencionavam investigar a inclusão da HFC na formação de docentes de Física. Questionando o currículo atual de licenciatura em Física quanto à inserção da HFC e a indissociabilidade destas (HC e FC). Questionamento pertinente, pois, podemos compreender a indissociabilidade como conceito epistemológico da constituição do estatuto ontológico e epistemológica de um ente, conceito concorrente para a definição da identidade, e;

- o T55-ENPEC-2005, em que Gebara (2005) teria apresentado a importância, os aspecto favoráveis e contrários à inclusão da $\mathrm{HC}$ no ensino de ciências, a escolha do tema deveu-se a dois fatores: os PCN e à sua experiência docente com uso da $\mathrm{HC}$ no ensino médio como ferramenta didática;

- o T56-ENPEC-2005, no qual Neves et al. (2005) apresentaram um trabalho de pesquisa realizado com docentes de ensino médio, no âmbito de uma disciplina de mestrado. A pesquisa versava sobre a História da Relatividade (e Cosmologia). Segundo os autores o objetivo da sua pesquisa consistia em: "[...] analisar o comportamento dos professores [de ensino médio, participantes da pesquisa] a partir da leitura de textos críticos sobre a Teoria da Relatividade e a Cosmologia Moderna (teoria do 'Big Bang' e teorias reunidas sob o nome genérico de 'Teorias(s) do Estado Estacionário')" (Neves et al., 2005). Ainda que haja indicação do tema, tal fato não descreve nem oferece condições para enquadramento categórico preciso.

No 6ํㅡㄹ Encontro Nacional de Pesquisa em Educação em Ciência, ocorrido em 2007, coletamos um trabalho (T57-ENPEC-2007) de inclusão da FC em uma disciplina histórica na história da $\mathrm{HC}$ no Brasil: Evolução dos Conceitos da Física, no curso de Licenciatura em Física, da Universidade Federal de Santa Catarina, em 
2004. Especificamente, neste trabalho, Staub tratou do uso do texto denominado " $A$ Epistemologia Histórica de Bachelard no Estudo da Evolução da Óptica"101 na mencionada disciplina, com o objetivo de "analisar a pertinência e as possíveis contribuições da abordagem histórico-filosófica no estudo da ciência óptica em um contexto específico" (STAUB, 2007). Durante a investigação didática a autora teria aplicado um questionário, entrevistas semiestruturadas e observação livre que the teriam possibilitado "evidenciar o posicionamento dos alunos sobre a presença da filosofia da ciência" entre outros aspectos relacionados à HFC, naquela disciplina.

A análise do conteúdo programático, da descrição da abordagem dada e do contexto da aplicação do referido texto permite-nos identificar o T57-ENPEC2007 nas categorias de Contextualização Interna e Criticidade. Da experiência e investigação didática a autora concluiu que os discentes participantes da investigação teriam se mostrado "[...] bastante receptivos diante do estudo da história da óptica articulada à epistemologia bachelardiana" (STAUB, 2007). E de modo específico, no que se refere ao uso do texto inserido na atividade disciplinar, os discentes participantes teriam enfatizado

[...] vários conceitos da epistemologia bachelardiana para ilustrar a pertinência do estudo histórico da óptica à luz deste referencial. Afirmaram a natureza descontínua da ciência como uma das características mais relevantes da filosofia de Bachelard. As discussões sobre o uso equivocado das analogias, metáforas e imagens na ciência e no ensino, foram igualmente citados [sic] como discussões importantes, principalmente na formação inicial de professores. Conforme destacaram, o estudo crítico das analogias e metáforas repercute diretamente na prática da sala de aula. (STAUB, 2007)

A inserção do estudo de textos históricos durante as aulas tem sido utilizada como procedimento didático por alguns docentes, interessados na inclusão de HFC no ensino, em suas investigações didáticas. Neste mesmo sentido, Boss, Filho e Caluzi (2009), no T58-ENPEC-2009, teriam utilizado o texto "Primeira Memória de Charles A. Coulomb" em um curso de licenciatura em Física da UNESP e, didaticamente, referenciados na Teoria de Aprendizagem Significativa. Após o estudo do texto, cujo conceito chave é a força elétrica, os autores teriam aplicado um questionário qualitativo e cujos dados foram tratados por AC. Os resultados da atividade teriam permitido indícios de que os discentes teriam passado a ter

101 SATAU, Ana C. M.; PEDUZZI, Luiz O. Q. Contribuições da Epistemologia Bachelardiana no Estudo da História da óptica. In: Ciência \& Educação, Bauru, v. 13, n. 1, 2007, p. 99-126. 
"disponível, em sua estrutura cognitiva, alguns subsunçores importantes para a aprendizagem significativa do conceito de lei de Coulomb" (BOSS; FILHO; CALUZI, 2009).

A análise dos temas do questionário - que tinha 19 questões e aplicado a 33 discentes, tais são: "carga elétrica, eletrização, lei de Coulomb, campo elétrico e lei Gauss", bem como, o aparato e o procedimento experimentais utilizados por Charles Augustin Coulomb, o trabalho vincula-se a Contextualização Interna, pois, trata-se de uma abordagem conceitual, além da característica do texto estudado.

Por sua vez, Carvalho e Martins (2009), no T59-ENPEC-2009, apresentaram uma discussão, que envolveu três docentes dos anos iniciais do ensino fundamental que participavam de um projeto cujo objetivo teria sido o de "analisar as possíveis contribuições das histórias em quadrinhos na formação continuada de professores" (CARVALHO; MARTINS, 2009). No mesmo trabalho apresentam proposta de abordagem dos aspectos da HC "a partir de uma história em quadrinhos de Maurício de Sousa acerca da 'lenda da maçã de Newton', que se utiliza de elementos paródicos que são peculiares a esse gênero textual" (CAMPOS; NIGRO, 1999) e teriam ainda estudado o texto "professor-aluno-conhecimento" extraído da obra destes autores (Didática das Ciências ${ }^{102}$ ). As autoras reproduzem um episódio que teria ocorrido entre as três professoras participantes do ensino fundamental e uma história em quadrinhos "Magali em: Foi assim", que afirmam apresentar elementos associáveis à HC. O trabalho apresenta uma leve aproximação à Criticidade e à Contextualização Interna.

No T60-ENPEC-2009 Raposo e Guerra (2009) apresentaram parcialmente os resultados de uma investigação didática que estariam a desenvolver em uma Universidade pública do Rio de Janeiro, com discentes de licenciatura em Física. Sua investigação teria sido feita com aplicação de questionário misto (questões abertas e fechadas), entrevistas semiestruturadas e observação livre. Teriam solicitado aos discentes a construção de um plano de aula cujo tema foi "Lei da Inércia". Estes autores teriam desenvolvido um minicurso de 8 horas, para 13 discentes participantes, que já participavam da disciplina Instrumentação para o Ensino de Física.

Segundo Raposo e Guerra (2009), os temas envolvidos no minicurso

102 CAMPOS, Maria C. da Cunha; NIGRO, Rogério Gonçalves. Didática das Ciências: o ensinoaprendizagem como investigação. São Paulo: FTD, 1999. 
seriam: "a existência ou não de um método científico, a neutralidade nas observações científicas, o papel do empirismo, a questão da indução, o papel da criatividade na construção da ciência e o uso de idéias metafísicas no trabalho científico" (RAPOSO; GUERRA, 2009). Ao analisarem as respostas fornecidas pelos discentes, afirmam os autores, terem constatado que "[...] os alunos tinham dificuldade em delimitar o papel da experimentação, não conseguiam definir se a experimentação era geradora ou confirmadora de teorias", por outro lado, dizem os autores que

As intervenções dos alunos durante as atividades desenvolvidas [até a época do ENPEF-2009] mostram que o estudo de temas de epistemologia, a partir do conhecimento dos trabalhos de filósofos da ciência é um possível caminho para trazer aos futuros professores discussões sobre a ciência. (RAPOSO; GUERRA, 2009)

$\mathrm{E}$, então, concluem reconhecendo que

\begin{abstract}
Como o trabalho está em desenvolvimento, não podemos afirmar que a consciência do pensamento dos autores trabalhados, assim como, do significado de conceitos como empirismo, indução, dedução entre outros venham a construir uma visão sólida nesses alunos sobre o modo de produção científica. Porém o desenvolvimento do minicurso mostrou que o trabalho sistemático com temas de epistemologia, junto ao debate em torno aos trabalhos dos filósofos da ciência selecionados, possibilitou a construção de um rico espaço de reflexão em torno ao processo de construção do conhecimento científico. (RAPOSO; GUERRA, 2009)
\end{abstract}

Portanto, este trabalho além dos temas apresentados, envolveu a discussão de textos da FC de autores tais como: Thomas S. Kuhn, Irme Lakatos Paul Feyarabend, Gaston Bachelard e Edgar Morin, que o caracterizam na categoria

\title{
Criticidade.
}

Finalmente, o último trabalho (T61-ENPEC-2009) do ENPEC-2009, está relacionado à tentativa de inclusão da HFC na formação continuada de docentes de Física em serviço. Gatti e Nardi teriam tido por objetivo de sua investigação "[...] desenvolver atividades de formação continuada com docentes de Física em exercício, inserindo a História e Filosofia da Ciência como fios condutores das discussões e focos das experiências didáticas realizadas por eles em sala de aula" (GATTI; NARDI, 2009). Para alcançar tal objetivo, teriam procedido ao levantamento do perfil dos professores de Ciências, Física, Química, Biologia e Matemática do município de Bauru e região (em São Paulo). Então, só assim, puderam elaborar um 
curso para formação continuada, de 40 horas/aula, denominado: "A História e a Filosofia da Ciência na prática pedagógica de professores de Física".

Relatam que do curso haviam sido entrevistados 22 docentes, dos quais 7 haviam feito inscrição e destes 5 frequentaram todas as atividades do curso. A partir de estudos e discussões realizadas durando o curso (em 2008), as 5 docentes participantes teriam elaborado propostas de minicursos aplicados em situações didáticas reais (de sala de aula) e acompanhados em reuniões de reflexão (GATTI; NARDI, 2009). O curso teve como conteúdo desenvolvido:

1. Fundamentos teóricos sobre o ensino e aprendizagem de Física: a abordagem construtivista no ensino.

2. Filosofia, História da Ciência e Ensino de Física

3. Pesquisas recentes sobre o ensino de Física.

4. Formação de Professores e sua profissionalização.

5. Elaboração de atividades de ensino (GATTI; NARDI, 2009).

Da sua experiência e da entrevista focal que os autores fizeram com as docentes participantes consideram que as docentes que participaram do curso revelaram obstáculos ao uso da HFC em sala de aula, entre eles estariam: "a falta de interesse e de conhecimentos prévios dos alunos, além de baixos salários e péssimas condições de trabalho para os professores" (GATTI; NARDI, 2009). Em outro momento afirmam Gatti e Nardi que o curso foi o primeiro contato com a FC para as docentes participantes e que

Apesar dos bons resultados obtidos e da participação ativa das professoras no processo, as possibilidades de uma aproximação permanente da prática docente aos resultados de pesquisa estudados ainda são limitadas pelas condições adversas encontradas na realidade escolar, tais como excesso de carga horária, classes superlotadas, pressão para o cumprimento integral da proposta curricular, entre outros.

[...].

Apesar de considerarmos que as atividades selecionadas foram adequadas e bem desenvolvidas, isso não garante mudanças permanentes na ação docentes das participantes.

Ainda que as professoras tenham apontado a importância dos elementos discutidos durante o curso para o ensino de Ciências e sua intenção de seguir utilizando as inovações debatidas, não temos elementos que indiquem quais serão as repercussões da experiência desenvolvida para a carreira docente.

A formação de professores comprometidos com a construção do conhecimento científico representa um grande desafio, uma vez que, a formação continuada exige um empenho constante na reflexão e aperfeiçoamento da prática pedagógica. (GATTI; NARDI, 2009)

Portanto, o trabalho (T61-ENPEC-2009) desenvolvido por Gatti e Nardi é, 
evidentemente, uma proposta de Instrumentação Didática, não só pelo seu objetivo, mas como pode ser observado no conteúdo desenvolvido, exposto acima. Abaixo apresentamos a tabela do ENPEC, dos trabalhos coletados por ano de edição.

Tabela 35 - Encontro Nacional de Pesquisa em Educação em Ciência - ENPEC Associação Brasileira de Pesquisa em Educação em Ciências - SBPEC; Home Page: http://www.fae.ufmg.br/abrapec/

\begin{tabular}{|c|c|c|c|}
\hline \multirow{2}{*}{$\begin{array}{c}\text { NÚMERO DE } \\
\text { EDIÇÃO E DATA DO } \\
\text { ENCONTRO }\end{array}$} & \multirow{2}{*}{$\begin{array}{l}\text { Total de } \\
\text { Resumos } \\
\text { Apresentados }\end{array}$} & \multicolumn{2}{|c|}{$\begin{array}{lll}\text { Resumos } & \text { Relacionados } \\
\text { Abordagem do Tema da Pesquisa }\end{array}$} \\
\hline & & $\begin{array}{l}\text { Resumos } \\
\text { Referentes à } \\
\text { HFCrECN }\end{array}$ & $\begin{array}{l}\text { Resumos } \\
\text { Referentes à } \\
\text { HFCrECN nos DO }\end{array}$ \\
\hline \multicolumn{4}{|l|}{ I, não localizado } \\
\hline \multicolumn{4}{|l|}{ II, não localizado } \\
\hline III, não localizado & & & \\
\hline IV, 2003 & +248 & 0 & 0 \\
\hline $\mathrm{V}, 2005^{\star}$ & & 8 & 1 \\
\hline VI, 2007 & +846 & 1 & 0 \\
\hline VII, 2009 & +813 & 4 & 0 \\
\hline Total & 1.907 & 13 & 0 \\
\hline
\end{tabular}

A seguir apresentamos a localização de cada trabalho analisado em uma ou mais categorias, com mais ou menos aproximação em termos de abordagem da HFCrECN, a partir de apresentação de propostas inclusionistas.

Tabela 36 - Trabalhos de Eventos por Categorias de Análise

\begin{tabular}{|c|c|c|}
\hline \multicolumn{2}{|c|}{ CATEGORIZAÇÃO } \\
\hline No & TRABALHOS CATEGORIZADOS & CATEGORIA \\
\hline 1 & -T46-ENEQ-2010 & Autoaperfeiçoamento \\
\hline 2 & T6-EPEF-2008 & Criticidação \\
\hline 3 & T10-EPEF-2010 & \\
& $-T 11-E P E F-2010$ & \\
& - T30-SNEF-2005 & \\
& T32-SNEF-2005 & \\
& T33-SNEF-2005 & \\
& T47-ENEBIO-2005 & \\
& -T49-ENPEC-2005 & \\
& T57-ENPEC-2007 & \\
& -T59-ENPEC-2009 & \\
& T60-ENPEC-2009 & \\
\hline 4 & T2-EPEF-2000 & \\
& T3-EPEF-2002 & \\
& T4-EPEF-2006 & \\
& T5-EPEF-2008 & \\
& T6-EPEF-2008 & \\
& T7-EPEF-2008 & \\
\hline
\end{tabular}




\begin{tabular}{|c|c|c|}
\hline & $\begin{array}{c}\text { T8-EPEF-2008 } \\
\text { T10-EPEF-2010 } \\
\text { T11-EPEF-2010 } \\
\text { T16-SNEF-2003 } \\
\text {-T20-SNEF-2003 } \\
\text { T24-SNEF-2005 } \\
\text { T25-SNEF-2005 } \\
\text { T26-SNEF-2005 } \\
\text { T30-SNEF-2005 } \\
\text { T36-SNEF-2009 } \\
\text {-T37-SNEF-2009 } \\
\text { T38-SNEF-2009 } \\
\text { T39-SNEF-2009 } \\
\text { T43-ENEQ-2008 } \\
\text { T46-ENEQ-2010 } \\
\text { T47-ENEBIO-2005 } \\
\text { T48-EHFB-2010 } \\
\text { T50-ENPEC-2005 } \\
\text { T57-ENPEC-2007 } \\
\text { T58-ENPEC-2009 } \\
\text {-T59-ENPEC-2009 }\end{array}$ & \\
\hline 5 & $\begin{array}{l}\text {-T17-SNEF-2003 } \\
\text {-T18-SNEF-2003 } \\
\text { T30-SNEF-2005 } \\
\text { T37-SNEF-2009 } \\
\text { T38-SNEF-2009 } \\
\text {-T47-ENEBIO-2005 }\end{array}$ & Contextualização Externa \\
\hline 6 & & Sistemicidade \\
\hline 7 & & Falibilidade Epistêmica \\
\hline 8 & $\begin{array}{c}\text { T19-SNEF-2003 } \\
\text { T29-SNEF-2005 } \\
\text { T37-SNEF-2009 } \\
\text {-T38-SNEF-2009 } \\
\text { T43-ENEQ-2008 } \\
\text { T44-ENEQ-2008 } \\
\text { T52-ENPEC-2005 }\end{array}$ & Motivacional \\
\hline 9 & & Socialização Epistêmica \\
\hline 10 & $\begin{array}{c}\text { T3-EPEF-2002 } \\
\text { T9-EPEF-2008 } \\
\text { T41-ENEQ-2008 } \\
\text { T49-ENPEC-2005 } \\
\text { T61-ENPEC-2009 }\end{array}$ & $\begin{array}{l}\text { Instrumentação Didática } \\
\text { (relacionada à propostas de pesquisa didática } \\
\text { em que se tenciona instruir docentes em } \\
\text { formação inicial ou continuada a desenvolver } \\
\text { determinadas capacidades, e.g. abordagem da } \\
\text { HFC) }\end{array}$ \\
\hline 11 & & $\begin{array}{l}\text { Eticidade } \\
\text { (relacionada à propostas de pesquisa didática } \\
\text { em que se tenciona discutir questões éticas } \\
\text { relacionadas às ciência e tecnologia) }\end{array}$ \\
\hline 12 & $\begin{array}{c}\text { T1-EPEF-2000 } \\
\text { T13-SNEF-1999 } \\
\text { T14-SNEF-1999 } \\
\text { T15-SNEF-2003 } \\
\text { T16-SNEF-2003 } \\
\text { T30-SNEF-2005 } \\
\text { T42-ENEQ-2008 } \\
\text { T51-ENPEC-2005 } \\
\text { T53-ENPEC-2005 } \\
\text { T54-ENPEC-2005 } \\
\text { T55-ENPEC-2005 } \\
\text { T56-ENPEC-2005 }\end{array}$ & $\begin{array}{l}\text { Insuficiência Informativa em } \\
\quad \text { Relação à HFCrECN } \\
\text { (Esta categoria é apenas operacional, pois } \\
\text { indica trabalhos em cujos resumos não foi } \\
\text { possível identificar informações suficientes } \\
\text { sobre a HFCrECN que possibilitassem localizá- } \\
\text { los nas categorias de análise ou que cujo grau } \\
\text { de significação permitisse a criação de novas } \\
\text { categorias significativas). }\end{array}$ \\
\hline 13 & $\begin{array}{l}\text { T12-EPEF-2010 } \\
\text { T34-SNEF-2005 }\end{array}$ & $\begin{array}{c}\text { Diagnóstico da Aprendizagem em } \\
\text { HFCrECN }\end{array}$ \\
\hline
\end{tabular}




\begin{tabular}{|c|c|c|}
\hline & T35-SNEF-2005 & $\begin{array}{l}\text { (Esta relacionada aos trabalhos em que o foco } \\
\text { é a intervenção didática avaliativa, ou seja, os } \\
\text { objetivos entocam no diagnóstico, na avaliação } \\
\text { e verificação do conhecimento apreendido } \\
\text { sobre HFC, bem como, as capacidades de } \\
\text { transpô-lo para a realidade da prática docente). }\end{array}$ \\
\hline 14 & T23-SNEF-2003 & $\begin{array}{l}\text { Socialização de Feitos em } \\
\text { HFCrECN } \\
\text { (enquadra-se nesta categoria trabalhos } \\
\text { relacionados à divulgação de feitos - ações, } \\
\text { resultados e materiais construídos - em relação } \\
\text { à HFCrECN). }\end{array}$ \\
\hline 15 & T40-SNEF-2009 & $\begin{array}{l}\text { Propostas não Experimentadas em } \\
\text { HFCrECN } \\
\text { (trabalhos em que se apresentam propostas } \\
\text { não experimentadas na prática didática para a } \\
\text { HFCrECN, são peças teatrais, narrativas, entre } \\
\text { outros desenhos sugestivos). }\end{array}$ \\
\hline 16 & T45-ENEQ-2010 & $\begin{array}{l}\text { Produção de Material Didático e } \\
\text { Paradidático em HFCrECN } \\
\text { (trabalhos em que se trata de produção de } \\
\text { materiais didáticos e/ou paradidáticos que } \\
\text { podem auxiliar a HFCrECN). }\end{array}$ \\
\hline
\end{tabular}

Ademais, em relação aos eventos na área de Ensino de Ciências Naturais é necessário observar que existem outros eventos, nos quais há probabilidade de ocorrência de trabalhos em que, possivelmente, seus autores possam apresentar relações de aproximação com a abordagem do movimento da HFCrECN. Esses eventos são de consulta e participação interessante para docentes e pesquisadores interessados no debate e uso de aspectos de HFC no ensino. Tais eventos são nacionais e internacionais:

- Seminário Nacional de História da Ciência e da Tecnologia, da Sociedade Brasileira de História da Ciência (SBHC, www.sbhc.org.br), esta sociedade também publica um periódico próprio (Revista Brasileira de História da Ciência). O seminário mencionado já teve a $12^{\text {a }}$ edição, ocorrida em 2010, Salvador/BA.

- Congresso Latino-Americano de História da Ciência e da Tecnologia, da Sociedade Latino-Americana de História da Ciência e da Tecnologia (SLAHCT), que também teve, em 2010, a sua $7^{\text {ạ }}$ edição em Salvador/BA, paralelamente ao seminário da SBHC.

- Encontro de Filosofia e História da Ciência do Cone Sul, da Associação de Filosofia e História da Ciência do Cone Sul (AFHIC, www.afhic.org), sua $7^{a}$ edição ocorreu em Canela/RGS, Brasil, em maio de 2010. São países membros da AFHIC: Argentina, Brasil, Chile e Uruguay. 
- Conferencia Inter Americana de Educación en Física, do Consejo Inter Americano de Educación en Física (CIAEF), teve sua 10ª edição em julho de 2009, na Universidad de Antioquia, Medelin, Colombia. Ocorre de três em três anos.

- Encontro Latino Americano de Ensino de Química (ELEQ), sua $2^{\mathrm{a}}$ edição ocorreu em 2000, na Pontifícia Universidade Católica do Rio Grande do Sul Porto Alegre.

\section{- International Conference for the History of Science in Science} Education (ICHSSE), do International History, Philosophy and Science Teaching

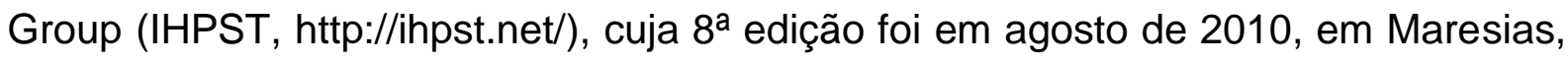
São Paulo. Este evento deu origem à versão latinoamericana daquela conferência: 1ํㅡㄹ Conferência Latino Americana do Grupo Internacional de História, Filosofia e Ensino de Ciências.

Finalmente, vale destacar e reconhecer que é muito valioso o esforço desses eventos - como também dos editores de periódicos e dos pesquisadores e docentes - em estabelecer e aproximar o diálogo, por vezes difícil, entre a HFC/HFSC e o ECN. Esperamos que os empreendimentos que têm sido levados a acabo se ampliem. E, que a zona de interface cresça e estabeleça seus estatutos. Que as críticas sirvam de elementos de ânimo para os que advogam e militam no movimento para HFCrECN ou HFSCrECN. 


\section{5 - HFCrECN NA FORMAÇÃO INICIAL DOCENTE: Caso USP}

As concepções de ensino escolar [ou universitário] são construções históricas que adquirem sentidos e significados próprios de acordo com o contexto.

(MEC, SEB, 2006, p. 103)

\section{1 - Apresentação}

Analisar a presença da HFCrECN nos planos curriculares das disciplinas da área de metodologia de ensino de ciências naturais e das de HFC nas Licenciaturas em Física, Biologia e Química da USP e; analisar as concepções de nove (9) docentes formadores, que atuam nas licenciaturas HFCrECN foram os objetivos determinados para este capítulo. Para o segundo objetivo, a técnica de coleta de dados utilizada foi a entrevista semiestruturada com especialista, cuja análise foi feita por meio da técnica de análise de conteúdo.

\section{2 - HFCrECN nos Planos Disciplinares}

Os planos disciplinares são instrumentos didáticos que apresentam um conjunto ordenado de descritores teórico-práticos (princípios coordenadores/ementários, objetivos, conteúdo operacionalizável e princípios de avaliação do alcance das metas propostas) necessários para tomar decisão de executar uma atividade de ensino, da qual se infere a aprendizagem, em uma determinada disciplina científica ou filosófica, no processo circunscrito a um determinado nível de formação, em dada instituição de ensino.

Dos planos analisados, na maioria deles, constatamos a presença de princípios coordenadores/ementários e conteúdos operacionalizáveis, porém alguns apresentam apenas tópicos de conteúdos operacionalizáveis. Coletamos todas as disciplinas relacionadas à metodologia de ensino, a HFC e aquelas que apresentam possibilidade de abordagem dos PCN, para verificar sob que aspecto os PCN são utilizados. Os nomes das disciplinas são antecedidos dos respectivos códigos, onde houver dois códigos, o primeiro é o antigo e, o segundo, o novo. Os códigos são de 
atribuição da instituição proprietária. Poder-se-á consultar em anexo os ementários/conteúdos completos de todas as disciplinas.

\subsection{1 - Na Licenciatura em Física}

Foram analisadas sete disciplinas do currículo, a saber:

Obrigatórias

1. EDM0425 - Metodologia do Ensino de Física I

2. EDM0426 - Metodologia do Ensino de Física II

\section{Optativas}

1. FAP0356/4300356 - Elementos e Estratégia para Ensino de Física;

2. FEP0390/4300390 - Práticas em Ensino de Física;

3. FMT0405/4300405 - Evolução dos Conceitos da Física;

4. FEP0353/4300353 - Tópicos de Histórica da Física Clássica;

5. FGE0454/4300454 - Tópicos de História da Física Moderna.

Veja-se que das cinco disciplinas ofertadas pelo Instituto de Física para a licenciatura em Física, três são da área de HC e todas são ofertadas na condição optativa, que é, estrategicamente, desfavorável porque a prática discente e docente tem demonstrado que nem sempre as humanidades são escolhidas por discentes, o que pode diminuir a contribuição dessas disciplinas.

Nas disciplinas metodológicas focaliza-se a vinculação entre a teoria e a prática pedagógica no ambiente escolar, em atividades de estágio didático, assim com o estudo de aspectos determinantes de aprendizagem e produção de conhecimento físico escolar. No entanto, alguns conteúdos operacionalizáveis merecem destaques tais como o estudo da "gênese histórica e individual do conhecimento físico" na EDM0425 - Metodologia do Ensino de Física l e do "papel do ensino de Física no nível médio" e; "O papel da História das Ciências no ensino de Física" na EDM0426 - Metodologia do Ensino de Física II, se os três temas ocuparem um sólido aprofundando nas respectivas disciplinas chegar-se-á aos contextos da produção do conhecimento em Física e à discussão e análise da contribuição da HC no ensino de Física.

As duas apresentam aspectos indiretos de vinculação ao tema da HFC-ECN, porque os seus temas, mesmo na segunda disciplina, remetem a uma abordagem teórica, a princípio, mas que o papel da HC no ensino de Física pode ser tratado de forma experimental, o que poderia aproximar mais ou menos a disciplina 
EDM0426 - Metodologia do Ensino de Física II à instrumentação didática. Porém, seria forçar demais diante da insuficiência de dados para podermos inferir a localização nas categorias de análise a partir dos dois enunciados apresentados. No entretanto, podemos agregá-las a uma nova categoria, qual seja, a da Inclusão Curricular de Aspectos da HFCrECN.

Na FAP0356/4300356 - Elementos e Estratégia para Ensino de Física os estudos estão voltados para um âmbito contextual em prol da abordagem históricofilosófica, isto é evidente ao percorrermos o seu programa, nele constatamos descritores que remetem:

$>$ ao estudo da construção histórica e individual do conhecimento;

$>$ aos contextos sócio-históricos;

$>$ à natureza da ciência;

$>$ ao formalismo matemático da física;

> às relações das ciências com as tecnologias e culturas;

$>$ às teorias de concepções alternativas e de mudança e perfil conceituais;

$>$ às diretrizes curriculares, no que tange ao ensino de física (embora sem mencionar sob que perspectiva seriam estudados as diretrizes) e;

> às propostas de melhoria de ensino de física, tais como: "a inserção da história e da filosofia no desenvolvimento do conteúdo, a utilização de atividades experimentais e/ou lúdicas em sala de aula, o papel do livro didático, a resolução de problemas, a divulgação científica [...]." (destaque nosso).

Como podemos observar essa disciplina caracteriza-se, de modo especial, na zona de interface entre a HFC e o ECN, no caso a Física, é tácita a inferência de que o objetivo aponta para desenvolver uma abordagem da HFCrECN. Neste sentido, é óbvia a presença de temas que remetem à aproximação, o que nos permite localizar a disciplina na categoria primária Inclusão Curricular de Aspectos da HFCrECN. E, posteriormente, nas outras categorias, tais como: Contextualização Externa; Contextualização Interna; Criticidade; Sistemicidade e; Instrumentação Didática.

O acompanhamento e desenvolvimento teórico-prático das atividades de estágio em ensino de Física constituem o foco da disciplina FEP0390/4300390 - 
Práticas em Ensino de Física.

No outro lado, estão as disciplinas da área de $\mathrm{HC}$, uma delas, relembra o episódio descrito sobre o cenário nacional na introdução deste trabalho. Trata-se da disciplina decorrente da divisão da História da Física ao vinculá-la ao Departamento de História, que foi recriada no Departamento de Física com o nome de "Evolução dos Conceitos de Física", hoje sob código: FMT0405/4300405 - Evolução dos Conceitos da Física; tanto nesta quanto nas outras duas disciplinas de HC, a saber: FEP0353/4300353 - Tópicos de Histórica da Física Clássica e FGE0454/4300454 Tópicos de História da Física Moderna, não há uma vinculação da abordagem histórica ao ensino da Física, elas estão estruturadas enquanto HC, sem fazer mensão a interface com o ECN.

A consistência dada nelas é sistemicamente historiográfica. Portanto, estas três disciplinas podem - de certa forma - serem incorporadas na categoria de Contextualização Interna. Os programas destas disciplinas não apontam expressamente para uma contextualização externa do desenvolvimento do conhecimento da Física. Mas, em todo caso, tendo em vista o que se convencionou - em alguns grupos - chamar de "currículo oculto", talvez, seja possível que o docente faça uma abordagem externalista, durante as aulas.

Porém, assim como não podemos julgar o que está oculto - porque os programas de ensinamento devem ser tornados evidentes nos seus planejamentos, não há razão para deixar para ocultismo a abordagem do contexto externo da produção do conhecimento - do mesmo modo não podemos condenar ou relegar estas disciplinas. Cremos que a introdução dessas disciplinas representa um grande passo para formação da cultura científica enriquecida e atualizada dos seus âmbitos e da sua historicidade. Neste sentido, no que concerne ao tema da pesquisa, constatamos que nas três disciplinas não há indícios tácitos que lhes aproxime do tema-problema da HFCrECN. A mesma situação foi constatada na disciplina Filosofia das Ciências Biológicas, como veremos.

Portanto, as três disciplinas de História da Física, vinculam-se a estratégias da grande área temática de inclusão da $H C$ e $F C$ enquanto disciplinas autônomas, em busca de um pleno gozo de identidade epistemológica. A característica de sua formação também não é, a princípio, integrativa da área de HFC, como os próprios substantivos adjetivados indicam: FC (Filosofia das Ciências Biológicas) e HC (História da Física). A adjetivação substantiva é colaboradora do 
processo de construção, estabelecimento de fronteira epistemológica e metodológica e definição de uma meso-identidade, embora não seja grande coisa o suficiente, quando se trata de construção de uma macroidentidade (HFSC), que permita estabelecer interface com os processos complexos de ensino e aprendizagem.

\subsection{2 - Na Licenciatura em Biologia}

Constatamos nove disciplinas, das quais seis obrigatórias e quatro optativas:

Obrigatórias

1. 0410115 - Filosofia das Ciências Biológicas

2. 0411206 - Introdução ao Ensino de Biologia

3. 0410515 - Ensino em Biologia

4. EDM0433 - Metodologia do Ensino de Ciências Biológicas I

5. EDM0434 - Metodologia do Ensino de Ciências Biológicas II

\section{Optativas}

1. BIO0449 - Estratégias para o ensino de genética e evolução no ensino médio

2. BIE0319 - Indagações ecológicas no ambiente escolar: aprendizagem e ensino

3. BIF0305 - Fisiologia para o ensino médio

4. 0410111 - Instrumentação para o Ensino de Ciências Biológicas

A 0410115 - Filosofia das Ciências Biológicas é uma disciplina cujos descritores foram planejados, especificamente, em conformidade com a consistência da FC (para Ciências Biológicas), com todo calibre analítico e crítico que tende a possibilitar nos estudos biológicos. A consistência dada nesta é filosófica (e histórica), o que faz com que se aproxime das seguintes categorias de análise: Criticidade, Elucidação, Eticidade, Falibilidade Epistêmica, Contextualização Interna. Aproximação às categorias não significa aproximação ao tema-problema da HFCrECN. O que não ocorre nesta disciplina.

$\mathrm{Na} 0411206$ - Introdução ao Ensino de Biologia o foco (eextremamente importante na formação docente) é dado à instrumentação para investigação em ensino de ciências, estudo teórico e prática de elaboração de projetos de pesquisa coletiva com ênfase no paradigma qualitativo. A investigação como fundamento formativo é de extrema importância e seria forte aliada da HFCrECN. Em 0410515 Ensino em Biologia, a ênfase é dada aos aspectos estratégicos e metodológicos de ensino e aprendizagem, focando a realidade do sistema público de ensino brasileiro 
e a teoria da transposição didática, complementadas com uma concepção de ensino e aprendizagem como ferramentas para formação crítica e cidadã.

Nas disciplinas EDM0433 - Metodologia do Ensino de Ciências Biológicas I e EDM0434 - Metodologia do Ensino de Ciências Biológicas II, respectivamente, na primeira a ênfase é dada aos estudos dos métodos básicos de ensino, às capacidades de condução de aulas/classe, motivação e das formas de comunicação e da natureza do diálogo entre docente e discente, bem como, o papel da biologia em questões de importância social e; na segunda, volta-se para análise do papel da biologia no currículo escolar, análise dos programas, documentos legais e livros didáticos e planejamento de unidades/modalidades didáticas.

Já nas disciplinas optativas, verificamos que na BI00449 - Estratégias para o ensino de genética e evolução no ensino médio destaca-se o estudo do desenvolvimento histórico dos conceitos de "evolução" e "herança" aplicado ao ensino de genética e evolução na Escola média e das diversas estratégias de ensino, bem como a identificação de dificuldades de entendimento conceitual e proposição de abordagens para solução de problemas. Inclui-se também a elaboração de planos de aula. Verificamos certa aproximação ao tema-problema da HFCrECN. Esta dimensão faz com que localizemos a disciplina nas seguintes categorias de análise: Contextualização Interna, Instrumentação Didática e Inclusão Curricular de Aspectos da HFCrECN.

Na BIE0319 - Indagações ecológicas no ambiente escolar: aprendizagem e ensino foca-se o estudo histórico da proposta pedagógico alicerçada no "método" denominado "Ciclo de Indagação" e "Ensino de Ecologia no Pátio da Escola", aquele parece uma espécie de retomada da maiêutica socrática conjugada com a indagação metodológica e este é um procedimento de ensino que tem sido ensaiado para ensinar Ecologia servindo-se do pátio da Escola como meio para estudar as relações entre os seres vivos, gerando motivação nos discentes, destaca-se também a visão interdisciplinar dos PCN e os esquemas conceituais para pesquisa ecológica na Escola.

Nas duas últimas disciplinas optativas o foco dos ementários está para um estudo a partir da revisão conceitual das DCN do ensino fundamental e médio no que diz respeito à Fisiologia, isto é na BIF0305 - Fisiologia para o ensino médio e; finalmente, a instrumentalização teórico-prática da discussão, elaboração de relatórios e de proposta de aulas e sua execução, para os níveis fundamental e 
médio e atividades como organização de excursões, feiras de ciências e montagem e manutenção de laboratórios de ciências, elaboração e execução de aulas com uso de audiovisuais e pesquisa bibliográfica, na disciplina 0410111 - Instrumentação para o Ensino de Ciências Biológicas.

Como podemos ver que não há uma vinculação com a temática da HFC $r E C N$ em nenhuma disciplina das analisadas, uma pequeníssima alusão aparece na BIO0449 - Estratégias para o ensino de genética e evolução no ensino médio, por referir-se ao estudo do desenvolvimento histórico de conceitos da evolução e genética mendeliana, o que remete a uma abordagem do contexto externo e a instrumentação didática para elaboração de planos de aula. E, na disciplina 0410115 - Filosofia das Ciências Biológicas não há, também, uma alusão a HFCrECN, a partir do exposto no seu ementário, fica compreensível que ela se enquadra na grande categoria temática do ensino da FC (HFC) enquanto disciplina acadêmica autônoma entre as demais ${ }^{103}$ e de fato está descrita com toda autonomia filosófica que lhe cabe, porém sem vínculo com o ensino do objeto de sua reflexão e análise. No entanto, ela se enquadra na categoria Criticidade.

Porém, já é significativa a existência da disciplina Filosofia das Ciências Biológicas como componente obrigatório do currículo, pelo menos, os discentes terão a oportunidade de refletir e analisar as questões filosóficas suscitadas pelas ciências biológicas, o que indiretamente pode contribuir para o ensino e para o desenvolvimento de mentalidade crítica e analítica dos processos internos e externos daquelas ciências. As disciplinas de HC ou FC não devem deixar ser o que são nos programas de formação, o que precisa ser feito seria complementar com outras disciplinas ou atividades específicas em se possa fazer integração das abordagens da HFC no ECN.

\subsection{3 - Na Licenciatura em Química}

Das nove disciplinas cujos ementários foram analisados, apenas uma é de HC, as oito são de metodologia de ensino, como podemos observar (todas são obrigatórias):

${ }^{103}$ Em conformidade com o que descrevemos no item iii, a), do 2º capítulo. 
1. EDM0431 - Metodologia do Ensino de Química I

2. EDM0432 - Metodologia do Ensino de Química II

3. QFL2505 - Instrumentação para o Ensino I

4. QFL2506 - Introdução para o Ensino de Química IV

5. QFL4610 - Introdução para o Ensino de Química I (Fundamentos)

6. QFL4620 - Introdução para o Ensino de Química II (Ensino e Atividades)

7. QFL4630 - Introdução para o Ensino de Química III (Currículo e Planejamento)

8. QFL3505 - Introdução para o Ensino de Química IV (Complementação)

9. FLH0640 - História das Ciências

As disciplinas EDM0431 - Metodologia do Ensino de Química I e EDM0432 - Metodologia do Ensino de Química II são ofertadas em esquema de continuidade e têm o mesmo ementário, salvo algumas alterações nos conteúdos operacionais. O foco delas está para um estudo teórico-prático que leve à elaboração de planos e instrumentalização para execução de aulas no desenvolvimento de estágio supervisionado. Porém, há um pequeno diferencial, no ementário da EDM0431, constata-se um enfoque para "Reflexões e discussões sobre cultura, ciência e processos de produção de conhecimento" e em seu programa consta o estudo de "Noções sobre cultura, ciência e formas de produção de conhecimento químico e conhecimento escolar". Esta menção pode caracterizar uma localização desta disciplina, mais ou menos, na Contextualização Externa.

No primeiro bloco de instrumentação (QFL2505 - Instrumentação para $O$ Ensino I e QFL2506 - Introdução para o Ensino de Química IV) o planejamento está voltado para estudo de tendências educacionais do ensino de ciências e química, das concepções sobre ciência e suas reverberações no ensino, experimentos didáticos para ensino médio e instrumentação para montagem de laboratório de ensino, na primeira. E, na segunda, trata-se a análise de livros didáticos, projetos, propostas curriculares e dos PCN (não especificada a perspectiva) e teorias de aprendizagem. Não consta, também, nenhuma vinculação ao uso de abordagem da HFC.

Quanto ao segundo bloco de instrumentação (QFL4610 - Introdução para o Ensino de Química I (Fundamentos)), constata-se um enfoque nos estudos de teorias (correntes) de ensino e aprendizagem e suas reverberações no ensino de ciências e química, das novas tendências, tais como: ciência, tecnologia, sociedade e ambiente (CTSA); contextualização e formação por competências e habilidades; resolução de problemas; bem como o estudo do "Papel da experimentação e da história da ciência no ensino da química" e; a análise de propostas curriculares e 
materiais didáticos. Há aqui uma aproximação expressa de forma significativa, diferentemente das outras disciplinas da mesma especialidade instrumental. Assim, ela pode incorporar-se na categoria Inclusão Curricular de Aspectos da HFCrECN e na Instrumentação Didática, em relação à HFCrECN.

$\mathrm{Na}$ QFL4620 - Introdução para o Ensino de Química II (Ensino e Atividades) a abordagem está voltada para o experimentalismo: estudo do "papel das atividades experimentais no ensino de química nas últimas décadas", a tipologia e o planejamento dessas atividades, seu embasamento teórico-metodológico; organização de espaço para realização das atividades didáticas experimentais e sua avaliação e observação das interações entre os atores envolvidos.

O estudo do projeto pedagógico e das fases de planejamento de aulas e avaliação, a elaboração de planos de aula e a atenção ao papel dos docentes e discentes são em síntese os objetos da QFL4630 - Introdução para o Ensino de Química III (Currículo e Planejamento). Na última disciplina instrumental - QFL3505 - Introdução para o Ensino de Química IV (Complementação) - enfoca-se a análise dos materiais didáticos de química e dos usos dados a eles em sala de aula, assim como a produção de textos e outros materiais didáticos. As disciplinas metodológicas são, por natureza, de instrumentalização didática.

A disciplina FLH0640 - História das Ciências é oferecida pelo Departamento de História (da FFLCH) para os Institutos de Biociências e Química, embora seja eminentemente histórica - como se prevê nos seus descritores, delinea-se a discussão do "desenvolvimento histórico da respectiva ciência (Biologia ou Química), inclusive suas controvérsias teóricas e práticas" e a natureza da ciência, as "relações entre a ciência, técnica e tecnologia", as questões de paradigmas científicos, a institucionalização das ciências e a relação dessas com a religião, ou o destaque às questões das relações entre biologia e sociedade (realçando questões como violência, hereditariedade, controvérsias entre evolucionismo e criacionismo) e à bioética diante dos dilemas da biotecnologia podemos constatar entre os seus conteúdos operacionalizáveis temas como a "História da ciência e ensino de ciências" o que caracteriza o desenvolvimento da interface HFC e ECN. Portanto, localiza-se nas seguintes categorias: Inclusão Curricular de Aspectos da HFCrECN, Contextualização Interna e Externa.

Ademais, há uma disciplina que não consta do programa (grade) curricular, mas consta no sistema júpiter - por isso não encontramos informações 
sobre sua condição de oferta se obrigatória ou optativa - denominada QFL4600 Introdução ao Ensino de Química, ela está direcionada para o estudo de uma variedade de temas; entre eles estão: as concepções sobre a natureza da Ciência, questões de metodologia de pesquisa, papel da experimentação, alfabetização científica, papel social da ciência, a LDBEN, os PCN e orientações e propostas curriculares entre outros, também não apresenta vinculação alguma com a HFCrECN, de forma direta.

Ora, acabamos de verificar que na unidade caso de estudo existe uma inserção de disciplinas da área HFC, enquanto HC ou FC e não integradas HFC. Constatamos também o caráter optativo destas disciplinas, o que desfavorece a opção dos discentes pelo estudo proporcionado por elas.

Do conjunto das disciplinas analisadas apenas em uma disciplina da área HFC e 6 das de caráter metodológico-didático constatamos a presença de aproximação com a HFCrECN, totalizando 7 disciplinas. Por um lado, tais aproximações são esporádicas em virtude de não ser o foco destas disciplinas fazer a abordagem da HFCrECN. Por outro, já é um passo significativo, pois é presumível que no futuro outras disciplinas também incorporem elementos de aproximação, ou mesmo que venham a existir, nos cursos de formação inicial, disciplinas integradas para promover a abordagem da HFCrECN.

A seguir apresentamos a tabela de localização das disciplinas nas categorias.

Tabela 37 - Disciplinas com Aproximação à HFCrECN por Categorias

\begin{tabular}{|c|c|c|}
\hline \multicolumn{2}{|c|}{ CATEGORIZAÇÃO } \\
\hline № & DISCIPLINAS CATEGORIZADAS & CATEGORIA \\
\hline 1 & 0410115 & Autoaperfeiçoamento \\
\hline 2 & FAP0356/4300356 & Criticidade \\
\hline 3 & 0410115 & \\
& 0410115 & Contextualização Interna \\
\hline 4 & FAP0356/4300356 & \\
& FMT0405/4300405 & \\
& FEP0353/4300353 & \\
& FGE0454/4300454 & \\
& 0410115 & Contextualização Externa \\
\hline 5 & BIO0449 & Sistemicidade \\
\hline 6 & FLH0640 & \\
\hline
\end{tabular}




\begin{tabular}{|c|c|c|}
\hline 7 & 0410115 & Falibilidade Epistêmica \\
\hline 8 & & Motivacional \\
\hline 9 & & Socialização Epistêmica \\
\hline 10 & $\begin{array}{c}\text { FAP0356/4300356 } \\
\text { BIO0449 } \\
\text { QFL4610 }\end{array}$ & Instrumentação Didática \\
\hline 11 & 0410115 & $\begin{array}{l}\text { Eticidade } \\
\end{array}$ \\
\hline 12 & & $\begin{array}{c}\text { Insuficiência Informativa em } \\
\text { Relação à HFCrECN }\end{array}$ \\
\hline & & $\begin{array}{c}\text { Diagnóstico da } \\
\text { Aprendizagem em HFCrECN }\end{array}$ \\
\hline & & $\begin{array}{c}\text { Socialização de Feitos em } \\
\text { HFCrECN }\end{array}$ \\
\hline & & $\begin{array}{c}\text { Propostas não } \\
\text { Experimentadas em } \\
\text { HFCrECN }\end{array}$ \\
\hline & & $\begin{array}{c}\text { Produção de Material } \\
\text { Didático e Paradidático em } \\
\text { HFCrECN } \\
\end{array}$ \\
\hline & $\begin{array}{c}\text {-EDM0425 } \\
\text { EDM0426 } \\
0410115 \\
\text { FAP0356/4300356 } \\
\text { BIO0449 } \\
\text { QFL4610 } \\
\text { FLH0640 } \\
\end{array}$ & $\begin{array}{l}\text { Inclusão Curricular de } \\
\text { Aspectos da HFCrECN } \\
\text { (Categoria das disciplinas em que se } \\
\text { constatam aspetos de aproximações da } \\
\text { HFCrECN). }\end{array}$ \\
\hline
\end{tabular}

\section{3 - HFCrECN vista pelos Docentes Formadores}

Para auscultar as concepções dos docentes formadores sobre a HFCrECN alguns critérios foram tomados:

- em virtude de o tema ser específico, optamos por aplicar uma entrevista semiestruturada com especialistas, isto é, com indivíduo com competência científica para responder ao problema (conforme já explicamos nos procedimentos metodológicos);

- igualmente, em virtude dessa especificidade temática, para seleção da amostra, alguns critérios foram necessários: o docente teria de estar vinculando (lecionando) a um programa de Licenciatura em Ciências Naturais (Biologia, Física e Química); lecionar disciplinas vinculadas ou aproximadas à HFCrECN, tais como as de Metodologia de Ensino; de HC e FC. A partir da identificação das disciplinas, procuramos verificar os docentes que ministravam tais disciplinas, para seleção;

- selecionados os docentes, estabelecemos o primeiro contato para solicitar-Ihes a vontade de participar da pesquisa. Inicialmente constatamos 12 docentes formadores, dos quais 10 responderam e participaram da pesquisa. Antes de serem entrevistados os docentes leram e assinaram o Termo de Consentimento 
Livre e Esclarecido, conforme a recomendações éticas do Comitê de Ética na Pesquisa, da Faculdade de Educação da Universidade de São Paulo.

Referimos-nos aos docentes formadores simbolicamente, como: DF-A, onde: $D F=$ Docente Formador, $A=$ indicativo de ordem alfabética.

As entrevistas basearam-se em três eixos temáticos (Roteiro):

Tema 1: Concepções acerca da aproximação entre a HFC e o ECN, em que solicitamos posicionamento sobre a aproximação da HFCrECN que aparece nos documentos oficiais, nas pesquisas em ECN e sobre a identificação de abordagens distintas acerca da HFCrECN.

Tema 2: Inclusão da HFC na formação inicial dos docentes de ciências naturais. Solicitamos opiniões sobre a presença e o papel da HFC na formação inicial dos docentes, se os docentes formadores discutiam em suas aulas a relação entre HFC e ECN, com que objetivo e que abordagem tem sido focada. As questões foram feitas relembrando aos docentes entrevistados as considerações das Diretrizes do CNE para formação inicial e dos currículos de licenciaturas que prevêem disciplinas da HC/FC, embora de forma distinta.

Tema 3: HFC no ensino de ciências naturais no ensino médio. Procuramos saber o posicionamento dos docentes formadores em relação a como percebiam o papel da HFC no ensino das ciências naturais em sala de aula da Escola média; sobre quais dificuldades seriam possíveis antever para implementar, na Escola, a aproximação da HFC ao ENC e o que poderia ser feito para facilitar essa aproximação, se for entendida como pertinente.

Ressaltamos ainda que para o tema HFCrECN algumas questões, durante as entrevistas, não foram respondidas na perspectiva da tese, isto é, em conformidade com o problema de investigação, de tal modo que consideramos aquelas respostas classificadas como pertinentes às perguntas dentro dos temas estabelecidos no roteiro da entrevista semiestruturada. Houve momentos em que os DF alongavam-se em história de suas vidas, contavam suas experiências, que são importantes, mas não para o problema da investigação. Essa fuga - que podemos chamar assim - é sempre possível de ocorrer na investigação qualitativa, exigindo controle do investigador. Neste sentido, para análise e discussão dos dados procedemos a uma abordagem por tema e identificando enquadramento categórico quando manifesto, para posterior indicação da frequência das categorias.

A aproximação da HFC ao ECN ou a HFCrECN não é algo tão simples 
como poderia ser presumível, de forma leiga e ingênua. Esta interface encerra um alto grau de complexidade nos diversos âmbitos constitutivos, tais como: 0 ontológico, da constituição do seu ser, enquanto campo científico/intelectual/investigativo; o epistemológico, da constituição de seu estatuto, sua fronteira e seus princípios de validação da sua produção do conhecimento; 0 lógico-metodológico, da criação de explicações coerentes e produção de um saber plausível, racional e materialmente evidenciado; o político, da garantia do espaço como circunscrição social no campo do conhecimento e do poder de agregar valores de sustentabilidade; o pedagógico, da divulgação significativa que gera e garante o aprimoramento da aprendizagem científica; entre outros âmbitos possíveis e concorrentes, tais como o ideológico. Todos eles constituem uma rede complexa que aumenta em virtude da complexidade do próprio fenômeno: a educação, ou precisamente, a formação escolar com todas as variáveis possíveis.

$\mathrm{Na}$ constituição de uma entidade e fronteira epistemológica, nem sempre as lutas são de caráter investigativo, a ocorrer entre o sujeito e o seu objeto de conhecimento e os meios disponíveis para conhecê-lo. Elas não têm sido travadas no campo da investigação ao tentar interpretar, numa relação dialética de face-aface com os fenômenos. A construção da interface HFCrECN tem passado também por tensões de várias ordens, o que pode ser compreendido, parcialmente, na visão dos docentes formadores.

\subsection{1 - Percepções acerca da Aproximação da HFC ao ECN}

Solicitados sobre a aproximação da HFC ao ECN, considerando o expresso nos documentos oficiais (DO) e nas pesquisas, afirmam alguns DF que as diretrizes atuais dos $\mathrm{DO}$, no que tange à aproximação da HFCrECN, são consequências de disputas ideológicas, políticas e teóricas diversas, no âmbito da concepção e constituição de política pública.

\footnotetext{
O que prevaleceu dentro dos documentos oficiais em relação à visão da nova FC como algo que possa ter espaço na formação de professores é consequência de disputas ideológicas, teóricas e políticas (enquanto políticas públicas), ... há prevalecimento de uma posição consequente de disputas de visões de mundo. (DF-A)
}

As disputas teóricas, políticas e ideológicas encontram espaço no campo 
educacional e adentram inclusive nas questões curriculares. Os currículos são, muitas vezes, objetos e consequências de tais disputas. E participar delas seria algo necessário já que, também, “É necessário levar temas humanísticos [para o interior dos currículos de ensino de ciências naturais] e a HC e a FC passam a ser vistas como importantes". (DF-A)

Ora, vimos aí, em DF-A, que a HFC é tida como fator de "humanização" das ciências naturais, a partir do processo de seu ensino, e mais, desde o planejamento curricular. A concepção da HFC como elemento de Autoaperfeiçoamento é enfática ao movimento da HFCrECN, em virtude dos interesses pessoais e das preocupações éticas, culturais e políticas; ênfase presente na literatura internacional (i. e. Matthews, 1992, 1994).

No entanto, no conjunto dos DF, percebemos que os PCN não são muito lidos ou levados em consideração. Entre os poucos DF que se posicionaram a respeito alguns falaram de forma genérica e outros fizeram observações críticas.

\begin{abstract}
Agora, o que está mencionado nos PCN que a dimensão sócio-histórica da ciência deveria ser contemplada, tudo bem, então quer dizer pegar a História ou, eventualmente, a Epistemologia e transformá-la em conteúdo escolar. Outra coisa é dizer: eu como formulador de currículo ou formador de professores de ciências preciso apoiar-me nos conhecimentos da História e Filosofia da Ciência para produzir melhores currículos ou para ser capaz de formar melhor os professores, esse é o trabalho mais interessante. (DF-E)
\end{abstract}

Os PCN são acusados de trazerem uma perspectiva conteudista da dimensão sócio-histórica ou da HFC, ao invés de uma perspectiva reflexiva, como elemento de desenvolvimento de Criticidade, que serviria como instrumento subjacente, para pensar tanto o planejamento didático e a formação docente quanto às estratégias didáticas, por exemplo.

No entanto, podemos perceber que, mesmo ao referirem-se aos PCN ou DO, o consenso entre os DF está longe também. Pois, há quem considere que os PCN deveriam fazer parte do conteúdo porque dele são por inerência (conceito ontológico que possibilita descrever e analisar a vinculação entre os entes e seus atributos e vice-versa). Assim, "a HFC deve fazer parte do conteúdo, é uma parte inerente ao conteúdo, esse tópico não traz dificuldade; é o contrário e se bem usado pode servir como estímulo para outros tipos de visões”. (DF-I). Esta percepção assim nos parece ser - remete a uma concepção ontológica das ciências pela qual a 
elas inere - por natureza - a sua história e a sua filosofia (epistemologia).

E, neste sentido, desvincular a HFC do conteúdo científico seria, então, uma espécie de "atentado" ontológico, talvez, daí resulte a defensabilidade da perspectiva de inclusão da dimensão histórico-filosófica no conteúdo científico, que, a priori, não é contrária à reflexão, esta, por sua vez, é inerente à filosofia, da qual a atual HC herda o seu caráter crítico, seja qual for a perspectiva historiográfica: história social da ciência ou história epistemológica da ciência, a criticidade é como fermento que deveria perpassar as duas perspectivas atuais, desde que buscada a "eliminação" de pseudoimagens e estereótipos na historiografia da ciência.

Paralelamente à questão HFC nos PCN, outra crítica apareceu ao longo da pesquisa, no caso específico dos PCN da Biologia, desta feita a crítica foi dirigida no sentido de omissão ou subtração de partes das ciências biológicas, a botânica, por exemplo:

\begin{abstract}
Eu considero que, por exemplo, os PCN e todos esses documentos oficiais estão mutilando o ensino, tirando coisas extremamente importantes, excluíram totalmente a História Natural, você não vê mais a Botânica, por exemplo. Acho que o aluno do colégio ou de uma Escola fundamental ele não está interessado em origem da vida, mas é importante que ele saiba o que é um tomate. Inclusive por razões de sobrevivência, o papel da agricultura, porque só se fala em ciência e tecnologia, inclusive fui convidada para uma conferência, se for fazer tal conferência, vou reclamar dessa ausência. (DF-I).
\end{abstract}

Embora não tenha sido nosso objeto de investigação a verificação de subtração de elementos do conteúdo interno das disciplinas, a crítica é plausível no sentido de que é necessário garantir aos cidadãos em formação o conhecimento da natureza o mais integrado possível.

No entanto, talvez, tais subtrações sejam explicadas pelas razões ideológicas e políticas que os grupos de planejadores curriculares carregam e das intenções políticas do momento social em que o país se encontra mergulhado. A identificação de que os PCN sejam consequências das pesquisas nacionais e internacionais pode fazer relembrar casos históricos em que as ideologias políticas e econômicas direcionam e determinam as linhas de investigação, o ensino e a aprendizagem científicas.

Os PCN, eles acabaram adotando, no caso a História e Filosofia da Ciência que você mencionou, essa recomendação de aproximação é fruto da pesquisa no ensino de ciências que ocorreram nas últimas décadas 
produzidas no país e, por conta disso, há essa recomendação. Creio que no exterior essa recomendação já é mais antiga. Se pensar que nos primeiros projetos de ensino de ciências (Física, Biologia e Química) produzidos no final da década 50, nos EUA, por conta da competição entre EUA e União Soviética, logo depois do Sputnik, eles criaram um projeto, por exemplo, de ensino de Física bem voltado para atrair os melhores estudantes de ciências americanos do ensino médio, para fazer os cursos universitários de ciências, porque eles [EUA], de uma certa forma, identificaram na deficiência do ensino médio a perca na corrida espacial. (DF-J).

Aí está um exemplo da dependência política e ideológica das perspectivas de formação científica.

Aquela observação de adoção da HFC consequente das pesquisas, parece encontrar consonância com outra observação que nos remete a pensar que tal adoção da HFC deve-se também aos tradicionais problemas da educação brasileira, pois,

\begin{abstract}
Tradicionalmente não há uma explicitação, qualquer proximidade maior entre ciências da natureza e História e filosofia, tradicionalmente eu digo na educação brasileira, mesmo ao logo do século $X X$ até três quarto do século presente, a tradição tem sido extremamente formalista e quando transborda do formal vai meramente em direção a uma aplicação com ou sem aspas em direção tecnológica. A relação com as ciências humanas, sequer a relação com a economia, o que seria mais natural, quando se pensa em termos tecnológicos, não se faz qualquer explicitação. Esse discurso que eu tomo parte, para mim, começa quando voltei do exterior, na segunda metade de 1970, quando percebi a enorme distância entre as áreas, estabelecendo relação, uma ponte com a economia e o cotidiano de vida dos alunos. (DF-C).
\end{abstract}

No entanto, nem tudo está perdido nos PCN, eles são visto como iniciativa que sinaliza para uma mudança que pode ocorrer a partir das pesquisas em ECN. Trata-se de uma ambientação histórico-social do currículo, com a perspectiva de que possa aparecer também nos manuais e na prática didática. Essa perspectiva de ambientação sócio-histórica do currículo, dos manuais e da prática docente, mas ao mesmo tempo em que o DF-C discorre de forma animada na sua explicação da relevância dos PCN, de repente, pára e diz que tal perspectiva está longe de ser aplicada na realidade educacional. Ele reconhece que uma década depois do lançamento dos PCN, ainda se mantém a rotina tradicional e conclui que a educação caminha a passos lentos. De fato, são passos muito lentos mesmo, de tão lento que há Escola e Universidade que não dispões desses PCN, há docentes que não leram esses instrumentos, logo, há programas curriculares não atualizados com a incorporação das orientações dos Parâmetros Curriculares Nacionais, então, é muita len-ti-dão! 
Quando a gente elaborou os PCN de ensino de ciências, ciências da natureza e matemática, essa sinalização [para HFC] estava mais explicita. Nos $\mathrm{PCN}+$ nós conseguimos que isso também se incorporasse na própria matriz curricular de certa maneira, aliás, nos $\mathrm{PCN}+$ você pode ver que era o nome que dei ao arquivo para distinguir dos PCN, conforme o tenho aqui no arquivo de meu computador, mas acabei enviando-o assim, para a capa e virou o nome das orientações complementares... [risos].

Nos PCN+, ao fazermos a proposta de divisão por semestre, demos uma sugestão organizada, a vida real aprece mais na Física, é uma Física do mundo real e o contexto, de certa maneira, convida a pensar a ciência como uma construção do ser humano. [portanto, pensar um Autoaperfeiçoamento] Toda vez que foi produzido um material com base nisso, a história deixa de ser pura e simplesmente um notazinha de rodapé, de data de nascimento e morte de um físico, etc., e [a HC] começa a ambientar o ensino de ciências em seus contextos diversos, em que posso ilustrar, por exemplo, com este livro produzido após os $\mathrm{PCN}+$, [pega o texto e mostra-mo folheando-o] em que a energia é pensada na sua presença e evolução histórica, ao longo da história desde o domínio do fogo, a importância disso; depois a agricultura, pega desde os 15 mil anos atrás até a passagem pela energética medieval, as rodas de vento, moinho de vento, roda da água; na vida moderna da maquina a vapor até chegar à modernidade; então, este enfoque em que se situa a ciência como uma construção história que desloca sua importância, seja na produção seja na guerra, já é uma coisa que decorre, por assim dizer, dos parâmetros curriculares, mas isso está longe de ser uma rotina, mesmo hoje, mais de uma década depois. Quero dizer que a educação caminha muito mais vagarosamente. (DF-C)

A leitura dos DO e a atualização em relação às pesquisas atuais constituem aspectos importantes para poder opinar sobre a sua relação com o ENC, para desenvolver projetos educativos e planejar propostas curriculares atualizados. Nesse sentido, percebemos que nem sempre os docentes formadores estão em dia com suas leituras dos DO, em especial os PCN, e novas pesquisas na área. Houve casos em que os DF afirmaram saber da existência do PCN, mas que não os leram (ex.: DF-B, foi categórico em afirmar isso, alguns outros indiretamente deram a entender em suas respostas, não fizeram referência aos $\mathrm{PCN}$, mesmo quando perguntados sobre).

Em todo caso, para que ocorra a HFCrECN seus defensores desenvolvem abordagens explicativas que concorrem para a materialização das perspectivas adotadas. Tais abordagens também não são unívocas, consensuais, são, muitas vezes, divergentes e conflitantes, por diversas razões teóricas, políticas, ideológicas ou de outra natureza. Mas, se houver coadunabilidade de objetivos as visões diferentes podem tornar-se complementares na busca de consecução das metas almejadas, que nesse caso seria o ECN contextualizado de forma crítica e criativa. Neste sentido, consideram-se as abordagens como partes de um sistema, 
distintos, mas integrados (Sistemicidade):

É uma questão interessante, em relação às abordagens [elas] variam de pessoa para pessoa, mas as abordagens diferentes não são necessariamente excludentes, elas podem ser complementares.

[...]

É importante situar a ciência no seu contexto, do desenvolvimento interno como contexto mais abrangente que leva em conta outras variáveis, como metodologias e teorias.

Convergem ao debate historiadores, filósofos, cientistas, mas, nesse debate ninguém é melhor que o outro, pois, as abordagens são complementares. (DF-B)

O que se percebe é que a distinção de abordagem também é diferente. Como essa concepção, digamos assim, subjetiva de abordagem que varia de pessoa para pessoa, parece-nos remeter mais a uma abordagem didática, que evidentemente tende a variar de professor para professor no âmbito de sala de aula. Essa situação, talvez, seja decorrente da concepção da própria noção "abordagem", que em alguns momentos pare ser entendida no sentido metodológicoepistemológico, em outros, no didático. Como uma postura intelectual, metodológicoepistemológica, a abordagem tende a ser mais objetiva e "universal" o possível e necessária, de tal modo que possa agregar defensores da mesma, identificados com ela:

\footnotetext{
Eu vejo com bons olhos, de fato muito influenciada por ser pesquisadora da área de ensino de ciências, passei a reconhecer a importância de introduzir na formação inicial dos alunos os elementos ligados à História e Filosofia das Ciências, quando comecei a me aproximar da literatura que fazia essa discussão da importância dessa discussão. Quero dizer com isso que não é uma coisa que está dada, que é óbvia essa aproximação, para mim, pelo menos, ela não era, acho na medida em que também fui me aproximando desses textos que discutiam essa possibilidade de articulação, comecei a ver uma série de justificativas que acho que são interessantes. No primeiro momento o que me chamou muita atenção ou uma das primeiras coisas que eu percebi como razão dessa aproximação da História e Filosofia das Ciências com o ensino tinha haver com toda aquela importância de formar um cidadão crítico, uma dimensão mais política e sociológica do ensino de ciências, bem no momento em que se discutia a questão as comunidades [científicas], como é que você pode fazer com que o aluno perceba uma ciência que tenha uma relação direta com a sociedade, uma ciência que não é neutra. Eu entrei em contato com isso no início dos anos 90 , foi quando comecei a me interessar por essas questões e logo depois de fazer o mestrado. Nesse momento, as leituras eram muito forte com essa perspectiva de um ensino de ciências mais crítico, acabei fazendo minha dissertação de mestrado com esse tema, o ensino de ciências numa perspectiva da didática crítica. A questão da História e Filosofia da Ciência aparece como uma possibilidade de discutir essa dimensão mais crítica, mais cidadã do ensino de ciências. Acho que no primeiro momento foi essa questão.
} 


\begin{abstract}
No segundo momento, tem a ver com as questões mais conceituais ou cognitivas, que é uma outra justificativa que, muitas vezes, também aparece com relação no uso da História e Filosofia da Ciência no ensino de ciências, que tem a ver com aquela ideia depois foi criticada, que os desenvolvimento cognitivo dos indivíduos de uma certa maneira repete a História da Ciência, alguns momentos que ocorreram na História da Ciência. Tinha toda uma discussão e algumas metodologias foram desenvolvidas nessa perspectivas de que as salas de aulas deveriam fazer com que os alunos passassem pelos mesmos processos ou situações semelhantes pelas quais os cientistas passaram, porque assim eles romperiam com as suas concepções espontâneas e intuitivas que também tiveram presença em alguns momentos da História da Ciência. Então veja são justificativas mais cognitivas do uso da História e Filosofia da Ciência no ensino. Foi assim que me aproximei da História e Filosofia da Ciência, tinha essas duas perspectivas e acho que essa segunda foi bastante criticada num certo momento. (DF-F)
\end{abstract}

De fato, essas duas perspectivas de abordagem existiram e ainda existem. A primeira, considerada como sociopolítica, é de fato a perspectiva de contextualização sociocultural das ciências, advêm do debate e visão externalista da ciência, de que é herdeira a História Social das Ciências e a Sociologia das Ciências. A segunda, parece estar mais ligada à epistemologia do desenvolvimento cognitivo de Piaget ${ }^{104}$ e seguidores, bem como, mais precisamente, às ideias de que ontogenia recapitula a filogenia, expressão da lei biogenética, do médico alemão Ernst Heinrich Philipp August Haeckel (fev. 1834 - ago. 1919), cujos estudos deram origem a união da ontogenia e filogenia, resultando no que se convencionou a chamar de "teoria da recapitulação" pelo que se argumentava que a evolução de um organismo refletia a evolução biológica da espécie. Tais ideias têm sua base na Sistemática Filogenética proposta pelo biólogo alemão Emil Hans Willi Hennig (abr. 1913 n nov. 1976) e nos trabalhos do cientista russo (biólogo, médico, geólogo e meteorologista), "criador" da embriologia, Karl (Maksimovich) Ernst Von Baer (fev. 1792 - nov. 1876). Porém, tais ideias estão em desuso atualmente. Parece-nos que tais ideias teriam influenciado os estudos psicológicos da personalidade (comportamentalistas e evolucionistas), em que se considerava que a personalidade de um indivíduo seria resultante das relações entre a filogenia, a ontogenia (histórico da evolução da aprendizagem) e meio (ambiente social e cultural), o que seria relevante para o ser humano modelar seu comportamento.

Sem designar as abordagens, parece que os DF reconhecem uma antiga e outra atual, mas alguém aventou denominar a última de construtivista.

104 O Trabalho de Piaget, Jean Piaget e Garcia, Rolando. Psychogenesis and the History of Science. USA: Columbia University, 1989, remete a essas ideias. 
Acho que é uma tendência [o movimento da HFCrECN] que tem sido mais forte dos anos noventa para cá, quando se questiona o que são conteúdos escolares, a tradição sempre foi a de pegar os produtos da ciência e essa mais atual e consensual nos anos noventa passa a olhar os processos da ciência como também portadores de interesse para formação básica, tem toda aquela história de ciência organizada, olhando da perspectiva do homem enquanto produtor do conhecimento. Acho que essa corrente que podemos dar o nome de construtivismo, mas que passa a olhar o papel do homem na construção daquilo que ele conhece, coloca o homem no centro da própria produção do conhecimento. (DF-E).

A perspectiva de levar em consideração o indivíduo e o meio nos processos de produções sociais, entre os quais a produção científica, sugere o reconhecimento do ser humano como fautor, sujeito sócio-histórico, portanto, concreto, que age em um determinado meio de que recebe influências e influenciando-o também. É um ser de relações, logo, suas produções resultam do estabelecimento de relações, nunca fechadas e acabadas, mas produções dinâmicas, construíveis e recontruíveis. A nova HFC leva em consideração as dimensões múltiplas da produção do conhecimento científico, para identificar os fatores que o influenciam, as causas e as consequências, as variáveis intervenientes. Portanto, trata-se de uma perspectiva ampla, que designa esse novo movimento da HFCrECN.

Porém, os DF percebem haver duas abordagens em relação à HFCrECN, são abordagens diferentes, mas complementares: uma que adota a HFC como conteúdo escolar (que seria a perspectiva dos PCN, conforme a crítica de alguns DF) e a outra, que considera a HFC como perspectiva reflexiva nos processos didáticos.

\begin{abstract}
A HFC é um ponto de reflexão para mim. Quero dizer que ter uma formação em HFC me permite ter clareza sobre quais os desafios que enfrentamos quando transformamos os conteúdos científicos em conteúdos escolares. Veja que estou pegando o produto e não o processo. Quando a gente olha a ideia dos conteúdos escolares, quem tem uma formação históricoepistemológica muito sólida se liberta: ah, é assim porque alguém em algum momento achou que tinha de ser assim, mas pode ser diferente! E eu posso me inspirar, por exemplo, quando a gente pega a ideia de obstáculos epistemológicos de Bachelard, é uma idéia maravilhosa não só para mim, mas quanta gente não se apropriou da idéia de Bachelard para interpretar os problemas de sala de aula e criam lá um estatuto didático ou fazer leitura de obstáculos epistemológicos na sala de aula, que os alunos também têm de enfrentar. (DF-E).
\end{abstract}

Para este DF a HFC deveria ser assumida como perspectiva de reflexão 
crítica subjacente, esta percepção remete a conceber a HFC como inerente às ciências naturais, como já fora ressaltado outrora, e, ainda, como elemento de 'libertação epistemológica': Criticidade.

A prevalência da perspectiva reflexiva da HFCrECN sobre a conteudista da HFCrECN (chamemos assim a perspectiva que considera a HFC como conteúdo escolar) aparece em outro momento em que o DF-E considera que a sua perspectiva crítica adveio de sua aprendizagem da HFC. Esta teria o libertado das amarras epistemológicas. Considera que HFC pode servir de conteúdo escolar, mas desde que atualizado pela perspectiva crítica, que é a mais esclarecedora, por desenvolver habilidade de reflexividade cujo objetivo é a capacidade de Criticidade, que podem ser constatada nos três momentos referenciados a seguir.

\begin{abstract}
Toda a perspectiva crítica que desenvolvi como pesquisador em ensino de ciências está baseada em duas âncoras: a primeira foi a minha experiência de 4 anos como professor da Escola média, que foi experiência muito intensa e; a segunda âncora foi a minha formação em HFC (doutorado), acho que isso me fez conhecer o subterrâneo das coisas, é como conhecer a cidade no seu mais subterrâneo, o que está por trás, quem frequenta que zona, conhecer a cidade numa dimensão mais profunda e isso quem em deu foi a HFC. É isso que acho que seja o interessante, então, a História e Epistemologia virarem conteúdos escolares é mais por causa dessa razão. Quando Osborn cita que eu sempre posso encontrar uma boa razão para garantir o direito ou a razão de uma coisa ser ensinada ou aprendida, eu diria que para HFC tem uma boa razão que é essa que aparece nos PCN, mas eu preciso encontrar outras razões, vou dar exemplo de um conteúdo da $\mathrm{HC}$ que acho muito válido: o debate sobre a natureza da luz, a polêmica entre Newton, Huyghens e Fresnel. Esse eu considero um episódio histórico, eu além de você como físico ou professor de Física deve conhecer, é sua obrigação conhecer isso histórica e epistemologicamente para conhecer as visões de mundo, é um conteúdo que na Escola deveria ser dado como conteúdo escolar, porque ele [o debate] envolve controvérsias, natureza da ciência, trabalha perspectivas de modelos, permite você perceber como é que uma coisa num momento histórico não é importante e em outro é, uma coisa que é proibida num momento histórico, no outro passa a ser aceitável, então, esse tipo de episódio ele é muito rico, não tem um bom motivo, tem vários bons motivos, então aí, eu penso que ele tem potencial para ser um bom conteúdo escolar. Enquanto que, do ponto de vista genérico como os PCN fazem, eu diria que ele é um ponto de reflexão importante para quem reformula o currículo e deveria ficar na cabeça das pessoas que: conhecer sobre História da Ciência, fornecer isso para os professores é tudo muito importante. (DF-E).
\end{abstract}

Do ponto de vista da perspectiva reflexiva a HFCrECN serviria, então, como elemento de libertação das formas tradicionais de ensino e do condicionamento dos livros didáticos que configuram como obstáculos para o desenvolvimento de uma postura reflexiva crítica. Assim, a abordagem de aspectos histórico-filosóficos utilizada como instrumento de reflexão didática permitiria fazer 
análise para além do que apresentam e postulam os livros didáticos, a HFC permitiria, então, ao indivíduo o desenvolvimento de uma cultura da autonomia intelectual. Neste sentido, o DF-E percebe que o movimento da HFCrECN estaria subdivido entre a inclusão da HFC enquanto conteúdo e enquanto elemento de reflexão.

\begin{abstract}
Um divisor de águas é esse: são aqueles que acreditam que a gente deve pegar a História da Ciência ou, eventualmente, a própria Filosofia da Ciência e transformá-la em conteúdo escolar, que é caso de pegar um episódio e fazer um debate que é apresentado dentro da visão Kuhn ou Popper, diria que isso é pegar a História e Filosofia da Ciência e transformála em conteúdo escolar. E, a outra é usá-la como ponto de reflexão para enfrentar os problemas escolares, problemas no ensino de ciências. Este é o divisor de águas. Não são incompatíveis as coisas tá, você pode usar as duas, mas elas são diferentes. Se você me perguntar qual é a mais importante? Eu acho que a segunda é a mais importante, a reflexão. Você como educador, seja como pesquisador ou como professor, ter uma formação histórico-filosófica, acho que é ai que você se liberta, porque a libertação do que podemos chamar de ensino tradicional, das amarras dos livros didáticos. Elas [HC e FC] vêm para nos dar autonomia, poder refletir sobre as perspectivas do que você está querendo ensinar e a História e Filosofia da Ciência é um dos elementos fundamental, não estou dizendo que é a única, mas nesse caso ela tem um papel fundamental.

O conhecimento escolar das ciências é uma versão do conhecimento científico (produto) que foi possível de ser transformado em conteúdo escolar, é um subproduto divulgado na Escola. (DF-E).
\end{abstract}

\title{
Esta mesma percepção é apontada por outro DF que mesmo não
}

pesquisando na área de interface entre a HFC e o ECN, percebeu essa relação:

Bom, eu não faço pesquisa nessa área, então não saberia caracterizar tendências ou perspectivas. O que eu vejo é assim: por um lado, algumas defesas com relação ao uso da História e Filosofia da Ciência na formação do professor, no sentido de que é uma maneira de instrumentalizar o professor, para que ele tenha informações sobre a produção do conhecimento científico, como a produção do conhecimento científico vem sendo feita ao longo do tempo, para ele a partir daí possa pensar, não necessariamente levar isso para sala de aula, mas no sentido de que ele tenha uma visão mais crítica dessa relação entre ciência e sociedade.

Uma outra perspectiva ou tendência, não sei como caracterizar, seria efetivamente desenvolver atividades de ensino de ciências com temáticas que abordam a dimensão histórica e filosófica da ciência. Nessa segunda perspectiva, o que tenho visto na literatura e mesmo os professores que tentam fazer isso têm falado é da dificuldade de ter materiais didáticos que possam auxiliar o professor a desenvolver essa perspectiva, na medida em que o acesso as esses textos originais ou clássicos é muito difícil, a estrutura e a linguagem desses textos também é de difícil compreensão, enfim é um pouco isso. (DF-F). [Destaque nosso]. 
conteúdo e a de inserção na formação docente versus aplicação de temas de HFC no ECN - possam parecer diferentes, elas não o são conceitualmente, pois, pode-se perceber na citação acima o destaque feito por nós, na primeira parte, destacada por nós, está indicada a abordagem da perspectiva de inserção da HFC como fundamento e fator de reflexão. E, no segundo destaque, sinaliza-se para inserção de abordagens de aspectos, isto é, conteúdos, da HFC no ECN.

Porém, no que se refere à aproximação da HFC ao ENC é compreendida como importante por várias razões, entre elas está a de prover aos discentes a possibilidade de entender as ciências como um conjunto processual de conhecimentos, como instituições, portanto, entender o estatuto ontológico, epistemológico e político-social.

\begin{abstract}
Eu acho que é fundamental. Em nenhuma fase de ensino de ciências, pelo menos mais recente, nos últimos 60 anos, se tratou de ciências, de aprendizagem de ciências sem se discutir a evolução do conhecimento como processo, por exemplo, no BSCS [Biological Sciences Curriculum Study, USA] era um dos princípios básicos que se analisa a História da Ciência, então, você não pode aprender a evolução sem entender todo o processo e o significado do darwinismo, neodarwinismo e assim por diante. Agora, me parece que a tendência atual é muito mais descritiva do que analítica. Eu penso que a mudança que seria necessária enfatizar é: que os alunos entendessem a ciência como conjunto de conhecimentos, como um processo e como uma instituição, ontem mesmo tinha uma reportagem no jornal sobre a Royal Academy ${ }^{105}$, quer dizer entender o papel que essas instituições desempenharam e continuam desempenhando na evolução da ciência. (DF-I).
\end{abstract}

Essa função de Contextualização Externa destas entidades chamadas ciências, institucionalizadas, também representa poder, não somente aquele poder epistemológico de que fala Francis Bacon (conhecimento é poder), mas também, trata-se de um poder sociopolítico e ideológico inclusive. As instituições científicas também interferem nos processos de evolução social de indivíduos e sociedades. Veja a seguir ao que se refere à inclusão da HFC na formação docente.

\title{
5.3.2 - Percepções acerca da HFCrECN na Formação Inicial Docente
}

Em 2005, já havíamos defendido a perspectiva reflexiva crítica da inclusão da HFC no ECN, que pudesse ser feita a partir da formação inicial docente, para que chegasse à educação básica via trabalho docente, em que estaria

${ }^{105}$ Talvez se refira à Royal Academy of Arts [ou Royal Society] (ambas da Inglaterra) 
subjacente a reflexividade crítica. Referindo-nos apenas a $\mathrm{HC}$ - conforme a delimitação daquela nossa pesquisa - escrevemos que para

[...] a HC possa atingir o âmago do processo da educação científica, ela deve ser introduzida na formação docente e fincar nela fundamentos necessários ou relevantes para seu uso na $\mathrm{EC}^{106}$, na elaboração de projetos pedagógicos e na reconstrução da imagem da ciência. (KAPITANGO-ASAMBA, 2005, p. 120)

O conhecimento da HFC, tanto da ciência como um todo quanto da ciência particular em que se habilitam os docentes para ensiná-la, não seria apenas de importância necessária para sua formação como cidadão, mas, sobretudo, como profissional e, portanto, para a sua prática profissional, considerando a historicidade do conhecimento científico, as suas limitações, a sua susceptibilidade às mudanças e influências. Portanto, vejamos a seguir as percepções dos docentes formadores em relação à presença da HFC na formação docente inicial.

A inclusão da HFC na formação inicial de docentes aparece referida nas Diretrizes Curriculares de Formação Inicial, promulgadas pelo Conselho Nacional de Educação, bem como a inclusão da HC e FC como disciplinas nas licenciaturas já são um fato, embora com alguns problemas de colocá-las como optativas, fato que gera uma reivindicação de mudanças, justa por sinal, da parte dos que advogam tal inserção.

$\mathrm{Na}$ investigação com os docentes formadores constatamos a defensabilidade da inclusão da HFC na formação inicial de docentes. Mas, também sua relevância é estendida à formação de bacharéis, o que sinaliza o reconhecimento da importância da HFC na formação básica universitária como um todo. Assim, defendem que a inclusão da HFC

\footnotetext{
É fundamental não só para formação dos professores, mais também dos pesquisadores. Existem alguns cursos que já incluem disciplinas de HFC. Por outro lado, existe certa resistência da parte de alguns alunos, eles já entram em cursos com grades definidas, as grades lembram prisões e isso se reflete nas concepções dos indivíduos. (DF-B).
}

De fato, essas "grades curriculares prisões" apresentam-se como obstáculos para inserção da HFC, sobretudo quando somadas às mentalidades tradicionais de alguns docentes que não enxergam possibilidades de mudança e de

${ }^{106}$ EC = Educação Científica. 
importância que a inserção da HFC possa trazer para a formação profissional dos discentes. Essas mentalidades tradicionais dos docentes são transmitidas aos discentes, que os herdam, passivamente, como uma herança de direito. Isso gera um preconceito em relação às disciplinas e estudos sociais ou de humanidades e linguagens, por parte das áreas de ciências naturais e tecnologias correlatas (engenharias).

Mas, a inserção da HFC não significa restringir-se a mera inclusão de disciplina da HFC/HFSC, que reproduza o modelo tradicional de ensino, é necessário o aprofundamento do significado das dimensões analíticas e críticas da HFC, o que remete, então, ao desenvolvimento das capacidades de reflexão e Criticidade. O que podemos verificar na defesa de que para inserção da HFC "não basta ter apenas algumas disciplinas nos cursos é preciso desempenhar mais um papel significativo" (DF-B).

A HFC permite a localização no mundo, o que evoca a compreensão do mundo como sistêmica (Sistemicidade) em que ocorrem interrelações entre os seres neles existentes e os processos produtivos realizados nele

\begin{abstract}
Acho fundamental, por um lado a Historia permite entender o seu lugar no mundo, se você tem a percepção da importância ciência e da tecnologia para sua vida cotidiana, você gostaria de entender porque que isto aconteceu e como aconteceu, independentemente de você ser um professor de alguma ciência ou ser um professor de português ou de qualquer outra disciplina, faz parte da formação entender esse processo de desenvolvimento da ciência, das técnicas e da tecnologia. (DF-D)
\end{abstract}

Isto justifica-se porque a localização no mundo é perceber as ciências no cotidiano cultural e ao recorrer à dimensão epistemológica da HC permite-se a Instrumentalização Docente em formação inicial e isso tende a repercutir na educação básica na Escola, assim se afirma ser, a HC, importante 
eles. (DF-D)

Ou ainda, que a importância da HFC se inscreve na formação universitária básica (espaço por excelência de Instrumentação Didática) como um todo.

\begin{abstract}
Acho que é fundamental. Acho que não só na questão da formação do professor, mas na formação do cientista, estou pensando na graduação como um todo. Acho que é muito importante que nos cursos de formação básica universitária, nas áreas científicas, se faça uma discussão sobre os aspectos filosóficos e históricos da ciência. Por que estou falando isso? Porque, quando a gente trabalha na licenciatura com os graduandos, meu caso os da biologia, que vão ser futuros professores, mesmo que naquele momento ele não quer fazer, mas é obrigatório, digo para aqueles que querem ser professor, mesmo para aqueles que não têm isso muito claro, mas acaba sendo mais uma opção profissional. Muitas vezes, o que a gente vê são visões de ciências bastante tradicionais, uma coisa que tenho percebido até pouco tempo, era óbvia essa coisa muito positivista, de querer ter uma ideia de verdade científica, de método único da ciência, isso aparecia, de um tempo para cá tenho percebido que não é tanto assim, de alguma maneira os alunos têm até apresentado outras perspectivas na hora de pensar a produção, a forma como o conhecimento é produzido. De qualquer maneira, ainda tem uma aposta muito grande, uma fé muito grande na ciência mesmo.

Acho que a inclusão desses temas, seja como uma disciplina específica, seja como um tema de discussão dentro das diferentes disciplinas da licenciatura são fundamentais para problematizar essas concepções de ciências, concepções entre ciência e sociedade que os alunos trazem. Eu vejo que os conteúdos de História e Filosofia da Ciência podem trazer uma contribuição muito grande: questionar, problematizar e discutir as relações de produção do conhecimento científico e entre ciência e sociedade. (DF-F)
\end{abstract}

A inclusão da HFC na graduação em ciências naturais e tecnologias ocorreria como uma forma de atenuar a designada "visão excessivamente positivista" da ciência, forma de introduzir uma perspectiva de Criticidade, porque seria necessário olhar criticamente que não existe método único e verdade absoluta e exata nas ciências, mas sim uma verdade aproximada e diversos métodos. Seria preciso também considerar a ciência nos seus contextos sociais e de produção.

A aprendizagem da HFC na formação inicial é, também, percebida como uma forma de iniciação, um pré-requisito para poder fazer abordagem históricofilosófica no ECN: "se o professor não for iniciado em HFC ele não vai saber usar, ele precisa aprender. Se faz parte do currículo é obrigatório, ele tem de aprender para poder dar aula" (DF-G).

Essa aprendizagem da HFC faria compreender não somente o produto da atividade científica, mais também, o seu processo. O processo é histórico e prenhe 
de problemas filosóficos, como podemos perceber a seguir:

Para mim, esse tipo de conhecimento é essencial para que se compreenda a Física, não dá para aprender apenas o produto sem aprender o processo. $E$, no processo a História tem muito a ver com isso, só para exemplificar porque que defendo a História e, posteriormente, a Epistemologia: a Epistemologia do século 20 que nasce com a decadência do positivismo clássico, já que a própria Física vai trazer o indeterminismo, a imprevisibilidade, vai trazer ideias novas que necessitam de uma epistemologia mais apropriada. E vão surgir o Thomas Kuhn, Popper, Lakatos, Feyarabend e Bachelard e, então, eu pego e faço associação entre História e Filosofia da Ciência em disciplinas que leciono. (DF-J)

De outra forma chega-se mesmo a defender a inclusão da HFC na formação docente com a perspectiva de fornecer uma espécie de segurança profissional, na esperança de que os futuros docentes possam saber lidar com as decisões didáticas, ou, compreendida como forma de fornecer subsídio daquilo que é, por natureza, inerente às ciências naturais tal qual elas são.

\begin{abstract}
Para mim é essencial, na verdade creio que deveria ser obrigatória e não apenas optativa, para oferecer inclusive ao professor opções de levar ou, digamos assim, dele não ter medo de enfrentar uma área que não conhece, então, pelo menos alguns elementos e alguns exemplares de História da Ciência devem estar presentes na formação dos futuros docentes da educação básica, nos cursos de licenciatura. Isso acontece aqui no Instituo de Física, embora a disciplina que tem o conteúdo de história ela também seja optativa, algo $[\mathrm{HC}]$ que eu creio ser essencial. Para mim, se nós vamos definir a compreensão do que é a ciência, a História e Filosofia não são apenas disciplinas auxiliares. Elas fazem parte da própria construção dessa área de conhecimento. Se nós pegarmos as grandes figuras que construíram em particular a Física, área que eu melhor conheço, as grandes figuras tanto da física clássica quanto da física contemporânea, em algum momento se debruçam em questões históricas e filosóficas. Eles próprios, de uma certa forma, são exemplares vivos de que a História e a Filosofia estão próximas da própria construção das grandes teorias da Física. Daí a razão de considerar as duas componentes essenciais. (DF-J)
\end{abstract}

Em relação ao Instituto de Física, verificamos que dispõem mais de disciplina da área de $\mathrm{HC}$, mas não no sentido das abordagens da HFCrECN, mas enquanto disciplinas da $\mathrm{HC}$ (historiografia).

O desenvolvimento da Criticidade nos docentes - pelo que a HFC é entendida como elemento estruturante da compreensão da historicidade da ciência estaria presente no enxergar e no apreender. Assim, a HFC deveria estar presente de dois modos na formação docente:

De duas maneiras deveria estar presente na formação de professores: primeiro no modo de enxergar e aprender a física propriamente dita, 
segundo, em cursos específicos de História e Filosofia da Ciência. [...]. Assim, a apresentação da física na formação dos professores pode sim fazer uso da história, como um elemento estruturante da compreensão do desenvolvimento da física.

Agora, é possível também fazermos um curso que atende a essa abordagem de história como estruturante, em que se revêem os momentos históricos complexos em que a física é a física na história e não a história na física, nos seus contextos como o advento da arte moderna, a emergência do fascismo, a guerra fria e as disputas entre os sistemas, entre outros aspectos, poderiam ser abordados em um curso.

Não se trata de História da Ciência pura e simplesmente, mas sim de uma História da Ciência e da Cosmologia ambientada na situação política, social e cultural de cada época ou período histórico científico. (DF-C)

Podemos verificar aqui a retomada daquelas duas abordagens para a HFCrECN: como perspectiva de reflexão e como conteúdo didático, mas também de uma forma integrada. Assim, por exemplo, os mapas roteiros dos manuais didáticos poderiam apresentar um modelo e uma abordagem argumentativa histórico-filosófica numa metodologia integrada de abordagem didática dos conteúdos científicos e seus contextos de produção e socioculturais gerais. Essa metodologia integrada de abordagem didática permitiria aos docentes em formação a percepção da dinâmica e pragmática não só do produto, mas sobretudo do processo produtivo, da sua historicidade e, a partir daí, inferir o modelo didático a ser implementado.

A Criticidade configura novamente na reflexividade como perspectiva para a introdução da HFC na formação docente e apresenta mais defensores. Quando questionado sobre a inclusão da HFC na formação docente o DF-E respondeu que sua

Importância está na perspectiva crítica. Acho que não teria mais o que acrescentar, é o que imagino que um bom físico deveria saber. Você dá pare ele uma noção de que aquilo está no livro é fruto de uma opção, porque a ciência é muito mais que aquilo. Se ele souber todo o processo envolvido na ciência, sem dúvida alguma, que ele terá autonomia inclusive de avaliar o "livro ruim", para dizer inclusive que esse autor teve essa opção, em minha opinião não é melhor, mas é uma opção possível. $\mathrm{E}$ mesmo que mude a opção pela linha a minha também não é a perfeita. É um compromisso, é o que a gente pode fazer. E sendo o que a gente pode fazer, então, vamos tentar fazer do melhor jeito possível. Eu acho que é nesse sentido que falo que [a HFC] liberta, porque liberta no sentido positivo da coisa, não é libertinagem, cada um fazer qualquer coisa, mas dá consciência dos limites das possibilidades do que é produzir um conteúdo escolar. Essa é a questão chave para mim. Existem limites e possibilidades no ato de ensinar e de aprender.

O problema me parecer que a maior dos professores tem uma visão muito ingênua sobre isso, ou jogam o problema no aluno, ou joga o problema no professor, isto é, nele mesmo: que ele é incapaz, ou ainda, joga o problema na Física, dizendo que a Física é complicada. E isso é a maneira de baratear o negócio. 
O Problema mais complicado é que, justamente, o conteúdo escolar necessário, que aparece nesse processo, ele é um compromisso entre eu professor, ele aluno e o conhecimento, esse compromisso gera versões do que seria a ciência ou o conhecimento escolar. São vários tipos de compromisso. É um casamento, que também parece um só, mas você olhar cada casal vive de um jeito, se acerta de um jeito, decide as coisas de um jeito, o que para um é absurdo para outro casal não é absurdo. (DF-E)

De fato isto demonstra e corrobora a ideia de que a relação em que se desenvolve o ensino e a aprendizagem é uma relação dialética, uma relação que envolve três ou mais entes: o docente (ensino), o discente (aprendizagem) e o conhecimento (aquilo que se ensino e aprende), podendo acrescentar a sociedade e as instituições.

Por outro lado, aprece uma crítica em virtude do tempo que o docente dispõe para construir a visão cética durante a formação básica universitária.

\begin{abstract}
Acho que o professor, apesar de ter tido uma formação científica especializada, eu não tenho certeza se ele tem tempo suficiente no curso para construir uma visão crítica da prática científica, que vai redundar na licenciatura para uns e em trabalho especializado de laboratórios e pósgraduação para outros. (DF-H)
\end{abstract}

De fato, o tempo de instrumentação para a abordagem de HFC na formação inicial é muito pouco, mas trata-se de introdução formativa em HFC, não se trata de formar um filósofo ou um historiador, mas de oferecer um subsídio para o licenciado sobre aquilo que é inerente à ciência de sua formação. Porque

Não dá para o professor entender realmente a ciência como um complexo e espaço social de desenvolvimento contemporâneo sem fazer essa análise empírica ao longo da história e os vários fatores históricos, políticos e sociais que influem na evolução das ciências, não só como causa das transformações, mas também como resultado das transformações, o aluno tem que entender como isso mudou as perspectivas do homem, um conjunto de sinergia. (DF-I)

A docente (DF-I) defende que não é justo não disponibilizar ao licenciando condições de noções básicas sobre a Contextualização Externa da ciência em que se forma e para poder ensiná-la. No entanto, essa mesma docente formadora afirma que a HFC não tem papel específico no ECN, exceto no contexto maior: "Especificamente não, só como parte de um complexo maior. Mas é imprescindível trabalhar com isso na formação de professores" (DF-I). Essa especificidade parece recair à formação específica singular (Física, Química, 
Biologia), mas, mesmo assim, a historicidade da química e os problemas epistemológicos fazem parte de sua especificidade também e não somente de sua extensão.

Mas, como será que os docentes formadores têm trabalhado a inclusão da HFC no ECN? Não tem sido fácil trabalhar temáticas ou abordagem HFC. Para alguns

\begin{abstract}
Integrar as abordagens HFC e conteúdos científicos é um problema sério. Por exemplo, qual é a concepção que os alunos têm de filosofia, o que é filosofia para os alunos de física, química, biologia? Qual é concepção de história que eles têm? Isso é interessante ser discutido. Eu tenho trabalhado isso no primeiro dia de aula, tenho aconselhado que precisam mudar as suas concepções em geral positivistas de ciência do século 19, que é muito restrita e que também aparece nos livros. É uma concepção de filosofia e história muito problemática.

Um dos objetivos é mudar a concepção de ciência, filosofia, história. Esta tem sido reduzida a cronologia dos fatos, isso é um problema sério, é preciso ressaltar que a história estuda a mudança, o passado, o presente e o futuro também. É preciso fazer esforços para mudar as concepções dos alunos dessas áreas ao lecionar HFC, qual a noção de filosofia e história que eles trazem da educação básica? Mas eles acabam se surpreendendo ao introduzir-Ihes numa nova concepção que não a cronológica da história, isso depende também da formação e habilidades do professor que leciona HFC. (DF-B).
\end{abstract}

De fato, não é algo tão simples lecionar HFC na formação em ciências experimentais, a concepção restrita de ciência ainda é muito forte nas mentalidades, está arraigada nelas e nas áreas experimentais e tecnologistas isso é muito evidente. As concepções ingênuas sobre História e Filosofia também existem, supondo que são áreas fáceis ou que basta fazer especialização em História ou Filosofia pronto já se é historiador ou filósofo ou que se sabe a História ou Filosofia. Esta é uma concepção ingênua vulgarizada.

A abordagem de HFC na formação docente em disciplinas não próprias para HFCrECN, gera sempre possibilidade de escolha que leva a relegar os assuntos da HFCrECN, como podemos ver no relato abaixo:

Não sempre. Mas em alguns momentos sim. Eu quero dizer com isso o seguinte, como qualquer currículo a gente tem uma possibilidade enorme conteúdos para trabalhar no curso de formação de professores e a gente tem que selecionar aquilo que vai trabalhar, em alguns momentos, a questão da História e Filosofia da Ciência apareceu como um tema que eu achei que era um tema importante para ser discutido e trabalhado, em alguns momentos ele acabou perdendo espaço para outros temas que também considero importantes para serem trabalhados. (DF-F) 
há que selecionar os conteúdos disciplinares, a HFC apareceu aí como conteúdo. Esse fato leva a pensar em disciplinas específicas da área de interseção (HFCrECN), em que a seleção de conteúdo não poderia desfavorecer a HFCrECN. HFC tem sido trabalhado na formação docente sob 0 aspecto Motivacional também, isto é, ela seria interessante para que os docentes pudessem despertar os interesses dos seus discentes. Interesse pelo que? Talvez interesse pela disciplina ou conteúdo científico que se ensina, pela ciência ou pelo simples pelo conhecimento.

Com isso, fazemos um esforço para que os futuros professores de Química e Biologia, principalmente, tenham o conceito de HFC como algo que os auxilie a despertar o interesse do aluno para as suas disciplinas. Nós sabemos - vendo os livros-textos utilizados no ensino médio, às vezes, também no Ensino Fundamental, em que é apresentado, em geral, para os alunos tanto das Escolas Públicas e quanto Particulares aqui no Brasil que há uma visão bastante reducionista e positivista das suas ciências. Normalmente, há uma página no máximo ou um pedacinho de uma página em capítulo de um livro-texto de Química, por exemplo, que fale sobre Lavoisier e aí são apresentados dados como datas, publicação, quando nasceu e quando e como morreu, mas não é nada contextualizado.

$E$, os alunos do curso superior, graduandos da USP, também não têm uma oportunidade de aprender o contexto social, filosófico e econômico em que se desenvolveu a sua disciplina. Então, é uma carência total quando eles chegam a um curso de um semestre, que é o que nós podemos dar, é muita coisa para ser dada, ao invés de ficar tendo também uma repetição exaustiva de conteúdo, a gente tenta pegar alguns casos mais isolados e significativos, para que o professor futuro entenda como ele pode usar essa informação contextualizada de HFC para fazer como que uma alavanca que desperte o interesse dos alunos.

$E$ isso tem funcionado, os alunos começam a perceber - quando o curso vai chegando ao final do semestre - que aquilo é um recurso bom. (DF-J)

Mas, também tem sido trabalhado na modalidade de projetos de intervenção, que remetem à Instrumentalização Didática.

E também, em forma de projetos durante o semestre, a gente tenta dar trabalhos, que sejam assim: se você for dar aula numa classe do ensino médio como você pensaria em utilizar, o que está aprendendo aqui na USP, numa sala com todos os problemas que normalmente você vai encontrar, que são problemas da educação hoje no Brasil e em outros países. E que você vai encontrar realidade nacional e, mais especificamente, paulista e paulistana. Como vocês acham que poderiam trabalhar isto? E tem saído até projetos com ideias interessantes, às vezes, recuperando, por exemplo, a história de uma ciência como a química, como foi a história da química no Brasil, por exemplo, no tempo da colônia, no tempo da metrópole portuguesa, o que se fazia de química, o que era possível, que industrias tinham no Brasil que mexiam com a química, porque que elas faziam isso, com todas essas 
informações o professor começa a perceber uma ligação entre a história e o seu objeto, que é ensinar a Química Orgânica ou Inorgânica e assim por diante. (DF-J)

A Instrumentação Didática aparece na prática didática dos docentes formadores em outros momentos, tais como:

\begin{abstract}
Vou te contar o que já fiz, teve um momento em que eu trabalhava as tendências no ensino de ciências, em que apresentava a História e Filosofia da Ciência como uma das tendências no ensino de ciências, a gente trazia algum texto para discutir, mas já fazia essa relação entre o ensino de ciências e a História e Filosofia da Ciência. Eventualmente, os alunos tinham de planejar atividades didáticas ou para estágio ou como atividade da disciplina baseada nessas tendências que eu apresentava, entre elas, a História e Filosofia da Ciência, então teve uma época que fiz dessa maneira.

Neste momento, eu não diria que isso é uma questão tanto da História da Ciência, mas eu tenho enfatizado questões da Sociologia da Ciência, como por exemplo, o texto de Latour, Vida de Laboratório, que descreve uma experiência do que ocorre no Laboratório e tem sido incrível como os alunos se apropriam daquilo, inclusive com representações teatrais. (DF-F)
\end{abstract}

A abordagem da HFC dentro de outras disciplinas surge sempre como um tema ou situação-problema esporádica, circunstancial, daí ora sim ora não poder trabalhar temas de HFC, porque há que cumprir os propósitos da disciplina que não são os de fazer HFCrECN, esta ocorre acidentalmente, o que nada impede o desenvolvimento da capacidade de Criticidade.

\begin{abstract}
Sim, um dos temas do meu curso de Metodologia [de Ensino] é o uso de História e Filosofia da Ciência. Tem uma aula especifica que faço isso, mas a aula específica é mais na primeira vertente de usar os aspectos história e epistemologia como conteúdo escolar, os alunos exercitam, escolhe episódios etc., mas a vertente de formação reflexiva ela perpassa toda a disciplina, porque essa não uma disciplina de História e Filosofia da Ciência, tem disciplina de História e Filosofia da Ciência eu não quero me sobrepor a essa disciplina que já existe no currículo, lá sim eles [discentes] vão aprende sobre História da Física, as ideias do Kuhn, de Bachelard e outros, eu não faço muito isso. (DF-E)
\end{abstract}

O respeito a não invasão de área de outra disciplina é importante no desenvolvimento do currículo de um programa de formação, a questão é quando o que se pretende abordar não é feito onde talvez devesse ser feito. A HFCrECN é tanto um tema e problema a ser abordado nas disciplinas de metodologia de ensino quanto nas de HFC constantes nos projetos curriculares. Mas, como verificamos isso está muito longe de ocorre de fato com frequência e efetividade.

Assim, os docentes formadores tendem a trabalhar como podem para 
poder tentar fazer alguma coisa, porque "numa disciplina não dá para fazer tudo. É uma ideia, você se sensibiliza com o tema" (DF-E):

Eu na verdade organizo todo meu curso de maneira a mostrar como é que ele [o discente] se apoiando numa perspectiva, muitas vezes, em epistemologia, ele entende os problemas de sala de aula, por exemplo, tem uma aula do meu curso que é problemas e problematização. Como é que começo a aula? Discutindo qual é a coisa que a gente mais faz na sala de aula como professor de Física? Começa resolvendo exercícios, que são problemas mais ou menos complexos, e dizemos qual é o problema um, etc. E digo, você vai passar $80 \%$ do seu tempo resolvendo problemas, por quê? Começo assim minha aula. Aí eles acham que não tem resposta, não tem resposta para isso. E pergunto, na aula de História o professor resolve problemas? Não. O professor de História faz outra coisa, debate, discute sobre questões de fundo, em geral ele faz uma questão que dura o semestre inteiro, por exemplo, para discutir a expansão comercial no século 16 ou 17 ou as navegações. Isso é um tema, não é uma pergunta. Tem muitas questões aí dentro. Aí começo a discutir com eles, e qual é a moral da história: a Física é um conhecimento baseado em problemas, isso não é uma questão natural. É uma questão epistemológica, a Física é baseada nisso. E, como a Física é baseada nisso é uma questão epistemológica que eu tenho de levar em conta quando preparo minhas aulas. Aí o que você faz, como professor de Física, você pega os mesmo problemas históricos que foram problemas para os cientistas, a gente já percebe que não dá, muitos dos problemas científicos são muito difíceis, então, já cai a ficha deles, que os problemas que têm de trabalhar na Escola não são exatamente os problemas científicos. Alguns podem ser, mas a gente vai ter que decidir quais são e quais não são.

Quando a gente pega o texto de Kuhn ou Zylbersztajn ${ }^{107}$ que fala dos problemas exemplares e dá mais uma pitada ele fala: olha, mas a gente aprende também teoria resolvendo problemas, mas não é qualquer problema, é problema tipo, discute a perspectiva do que são os problemas exemplares para Kuhn. Depois, discuto o que é problema aberto, problema fechado na perspectiva mais da Didática, falo de Gil Pérez, então veja, esse tema demora um mês. De que ele nasceu? Eles [discentes] acham que nasceu num problema de sala de aula, porque começo perguntando, mas é um problema que está sendo abordado numa perspectiva epistemológica. Da Epistemologia da Ciência e de alguma maneira da epistemologia do conhecimento que é produto da sala de aula. Eu faço esse trabalho, mas sei que não é minha área tá, eu sei que nessa grade curricular tem lá uma disciplina de História e Filosofia que é a Evolução dos Conceitos da Física. (DF-E)

Trata-se de uma abordagem mais epistemológica, do desenvolvimento da Criticidade do processo de produção de conhecimento, que é histórico. A historicidade que emerge aqui é uma historicidade crítica, epistemologizada. No entanto, a Criticidade e a Contextualização Externa aparecem também em outra abordagem de aspectos de HFC na prática didática na formação docente:

${ }^{107}$ Arden Zylbersztajn, docente da Universidade Federal de Santa Catarina. 
Tenho tentado fazer uma discussão com os alunos, depois de construir um percurso sobre a História mesmo, quais são os conceitos, quem são os personagens, como é que se constrói a ciência, como ela não é uma atividade unívoca, nem especial colocada num lugar separado da sociedade, como ela está misturada com todo dia, então, tenho tentado discutir para convencer os próprios alunos que a prática deles é uma prática social e não só uma prática técnica. $E$ que eles têm escolhas e carregam entendimentos, depois desse percurso a gente chega num debate sobre como divulgar, comunicar, alfabetizar e quais são os nossos entendimentos, qual é o público que eles vão encontrar, muitos deles já dão aulas, eles têm interesse sim. (DF-H)

Este é um relato animador para os defensores da HFCrECN, saber que há possibilidades de ocorrer com sucesso o desenvolvimento didático. A abordagem da HFC também faz com que se ultrapasse a dimensão formalista do ensino de ciências, os modelos formais no ensino são geralmente reproduzidos, eles não representam desafios, mas assimilação de processo de resolução já dado. Então, para ultrapassar a dimensão reprodutivista e criar e resolver novos problemas é necessário dominar os fundamentos conceituais com que se opera em determinada ciência, os conceitos estruturantes. Assim, ao mesmo tempo em que se possibilita o desenvolvimento de Criticidade, trabalha-se a Instrumentação Didática.

\begin{abstract}
Eu tenho discuto com meus alunos com objetivo de que eles tenham condições de levar para os seus futuros alunos de ensino médio ou alunos que eles já têm, porque alguns deles já lecionam como professor substituto, para que tenham condições de levar para sala de aula exemplares, claro que o ensino de ciências ele também necessita que as questões técnicas sejam experimentais, sejam elas conceituais, a resolução de problemas, tudo mais, tem que ser desenvolvidas também, eu não quero de forma alguma substituir o ensino [de ciência] pelo ensino de História da Ciência. Mas eu acredito que o ensino meramente de reprodução, resolução de exercícios de Física, não é suficiente para dar uma ideia para o aluno de ensino médio, principalmente para aquele aluno que vai para Universidade por opção própria ou por dificuldade de seguir seus estudos, ele só vai ter condições de ter uma ideia do que é Física, enquanto área de conhecimento, se alguns exemplares da História da Ciência e Filosofia da Ciência forem oferecidos da forma que ele possa continuar a ler sobre esses temas, depois que terminar o ensino médio. Ou mesmo quando ele vá para uma área de conhecimento que não seja a área científica. Que ele tenha uma formação. Que ele possa dizer para alguém que não estudou o que é a Física, explique-me a Física, porque não é simplesmente aplica $\mathrm{f}=\mathrm{m}$.a e inúmeros exercícios, mesmo que Le seja capaz de fazer isso que ele vai conseguir passar para alguém o que é Física. Porque $\mathrm{f}=\mathrm{m}$.a não é Física, pode ser traduzido com y=a.x, isso é Matemática. Para ter Física ele tem que discutir o que é o conceito de força, o que é conceito de massa, principalmente, o que é o conceito de aceleração, que é uma derivada segunda do espaço sobre tempo. Então, ele precisa dominar esse ferramental teórico mais rico para poder compreender o que é a Física. (DFJ)
\end{abstract}


um enfeite, muito menos como discurso docente, mas como 'instrumento essencial de aprendizagem', de desenvolvimento da Criticidade, do debate e neste sentido considera-se que

É preciso que o que se apresenta na sala de aula, primeiro não seja estritamente o discurso do professor, transformar a aula em discurso é uma perca de tempo grotesca, hoje em dia o professor não deve ser mais ser pensado como o transmissor de informações,... então, a primeira advertência que faria, sobretudo em tópicos como os de história, não se trata de contar essa história, se trata de a história sem discutida, ser debatida, então, quando num certo período histórico, por exemplo, período de Newton, teria o Newton de um lado da Europa propondo o modelo corpuscular da luz e do outro lado Huygens propondo o modelo ondulatório, esse embate que teve um sentido histórico, é tão importante quanto Einstein questionando a interpretação estatística de Copenhagen ${ }^{108}$ da física quântica, Einstein versus Bohr ou Newton versus Huygens, então é no debate de um contexto de um coisa história em sala de aula, que se consolida melhor o aprendizado da física e não no discurso do professor contando histórias, isso pode ser contraproducente, a mera falação do professor pode ser uma coisa muito chata, particularmente contando histórias, é preciso ambientar o debate, trazer de novo esse debate [histórico] e permitir aos alunos tomar partido e entender o que estava acontecendo. (DF-C)

Trata-se de discutir e debater a história e não simplesmente contá-la, transmiti-la. Trazer algo de novo para esse debate é problematizar a dimensão histórica, é ensinar a HFC enquanto perspectiva reflexiva, isto é, desenvolver a Criticidade, por exemplo:

[...] o debate do passado da física ambientada no momento histórico em que a física está sendo debatida, é a física na história e a história na física. A história como roteiro para entender a física.

Compreender a perplexidade de um Planck, que foi um grande físico clássico, por exemplo, ao se surpreender com sua percepção de que a luz que emergia de um buraco no forno (chamado de corpo negro) não correspondia a um continuo e perceber o que Planck buscava, o que estava interpretando (que era um espectro de frequências vindo de um forno), porque estava investigando isso, tinha havido antes um premio do Kaiser, porque isso era fundamental para aplicar calote, permite ao aluno compreender melhor a transição do pensamento clássico para o quântico, compreender como Einstein, cinco anos depois, com efeito fotoelétrico, introduz a ideia da luz como corpúsculo e, mais cinco anos depois ou oito, Bohr junta essas ideais e propõem a primeira ideia, o primeiro modelo de átomo, essas coisas ambientam a aprendizagem quântica, então, não é a história como enfeite, mais a história como instrumento essencial de conhecimento. (DF-C)

Percebemos também que há necessidade de disciplinas em que se

${ }^{108}$ Talvez, referência à Escola de Copenhagen. 
pudesse incluir aspectos de HFC no ECN ou criar novas disciplinas que tratem da HFCrECN, elas seriam importantes dentro de uma "perspectiva de rearranjo do currículo e redesenho dos cursos em relação à expansão do tempo de formação" (DF-A).

\begin{abstract}
Eu tendo a achar que o papel mais importante que a HFC tem, no ensino de ciências ou de Física, não é se transformar em conteúdos escolar como aparece nos PCN e nos documentos oficiais, o que me parecer mais interessante é a possibilidade que ela [HFC] oferece como ponto para você refletir sobre objetivos, conteúdos, currículos, sobre o que ensinar e o que aprender e isso vale tanto para quem formula currículos e o que forma professores quanto para quem é professor. (DF-E)
\end{abstract}

A relevância de repensar disciplinas específicas da HFC é uma questão latente entre os docentes formadores porque por intermédio delas se faria a Instrumentação Didática para a HFCrECN e a análise curricular. Neste sentido,

\begin{abstract}
O primeiro passo na formação docente de ciência é introduzir disciplinas que tratem de $\mathrm{FC}$ e $\mathrm{HC}$, esse é um passo importante. Acho que deveria haver uma integração maior entre essas áreas na universidade, onde os discentes já [estão] em áreas fechadas sem contatos com outras áreas, esse é um problema que negam até mesmo o papel da universidade. É um problema que está na origem da criação da própria universidade também. Falta integração entre as áreas, porém alguns grupos têm dado alguns passos criando programas e cursos interdisciplinares, em que pessoas de áreas diversas trabalham juntas. A própria HFC é uma área fundamentalmente interdisciplinar, embora todas as áreas - penso deveriam ser interdisciplinares e os profissionais deveriam ter essa experiência. Hoje o mundo todo está trabalhando nessa perspectiva e Brasil não pode escapar dessa perspectiva. (DF-B)
\end{abstract}

A inserção de disciplinas nos cursos de formação docente é uma estratégia de intervenção para capacitar docentes (Instrumentação Didática) desde tão cedo comecem a refletir e a praticar ações de sua carreira. Só que a estratégia teria de caminhar para a interface e não para inserção somente da HFC como conteúdo (disciplinas como tantas outras), mas que houvesse uma abordagem integrada da HFCrECN. Na abordagem integrada seria possível discutir a HFC como elemento de reflexão crítica do processo de produção do conhecimento científico e seus contextos, bem como do processo de ensino e aprendizagem.

Há um reconhecimento consensual de que há problemas na formação inicial docente e esta formação se reflete profundamente no desenvolvimento teórico-prático da profissionalidade, da autonomia intelectual e da identidade docente como um todo. Os formadores observam que os docentes licenciados não 
estão preparados para implementar as mudanças educacionais, nem mesmo implementar as coordenadas propostas pelos PCN e outras diretrizes educacionais, um dos problemas estaria na sua formação.

Boa parte dos professores ainda não está preparada para conduzir a mudança proposta pelos parâmetros [Curriculares], mais grave que isso, nos vestibulares das grandes universidades ou não, esses aspectos histórico-sociais nem sempre são contemplados. (DF-C)

Os docentes precisariam ser formados de tal modo que pudessem reconhecer que

\begin{abstract}
Ao trabalhar com os alunos é preciso levar em conta os aspectos históricos que devem fazer parte da própria metodologia de ensino e aprendizagem e não como notas de rodapé. Os conteúdos biológicos devem ser discutidos num contexto social real e histórico, por exemplo, sem seguir uma linearidade. (DF-C)
\end{abstract}

A crítica ao tratamento linear da HC é algo também constatado nos trabalhos da ID-PC, para o favorecimento do surgimento e desenvolvimento da

Criticidade e da mentalidade científica reflexiva, pois, a história linear oblitera a historicidade dos eventos e fenômenos.

\begin{abstract}
Acho importante não tentar associar História com cronologia, uma contação, com explicação linear que fuja das dificuldades, das incertezas que a ciência apresenta o tempo inteiro, do percurso do cientista individual, da comunidade a que ele pertence, dos projetos em que aquela comunidade se insere, então, a História não deve ser para esses currículos e profissionais mais apenas um complicador no sentido: aí eu tenho que decorar agora, além de tudo que eu já tenho de passar, uma lista de dados, fatos, nomes, personagens e ser ilustrativo, eu acho que não é isso. A questão é formar uma pessoa que tenha capacidade crítica, para ele mesmo como professor, para o que ele vai passar e para esse público que ele vai formar, como já falei, que tem objetivos diversos que, às vezes, vai escapar do professor, então é complicado, mas acho que o principal é não tomar como uma tarefa de um reprodutor de enciclopédia nem a filosofia, como um docente que identifica grupos de pensamento, representantes de uma determinada escola de pensamento e ele tem de reproduzir apenas essa descrição que alguém fez em algum lugar. É um procedimento difícil, tem que estar atento a esses limites senão ela [a HFC] não vai servir, vai ser mais uma disciplina para cumprir uma carga horária e, hoje, está cada vez mais difícil o aluno se interessar pelo curso médio, tem que aproximar essa Escola que pode ser muito interessante, mas que tem sido bastante inimiga do aluno, porque tem algumas dificuldades de erudição que, às vezes, ele não consegue ver de imediato, então, a sensibilidade desse professor vai ser posta à prova. (DFH)
\end{abstract}

E ainda, é durante a formação que os futuros docentes precisam saber e 
ter Elucidação sobre os fatores envolvidos no processo lento, difícil e coletivo de produção do conhecimento científico das ciências que ensinarão. Portanto, cabe à formação inicial fazer a Instrumentação Didática dos docentes em formação.

\begin{abstract}
Então, eu acho que, se o professor de ciências for introduzido na História e Filosofia da Ciência ele vai mudar a ideia dele de ciência, então, ele também vai ensinar de outro jeito para o aluno, que para mim é muito mais rico, que aquela ideia de que o cientista vai para o laboratório e faz com segurança o trabalho dele, o que para a História da Ciência é que o trabalho do cientista é um trabalho tateante, ele vai construindo aos pouquinhos o conhecimento e terá de convencer os outros que aquele caminho é válido, então tem etapas. (DF-G)
\end{abstract}

Reconhecendo os problemas da inexistência ou insuficiência de HFC na formação inicial dos docentes, há um recurso secundário que dependendo de como for feito pode ser eficiente: a formação continuada.

Primeira coisa, o cara que quer usar a perspectiva histórica como conteúdo escolar ou como perspectiva de reflexão ele vai ter que se formar para isso. $E$, isso é inevitável que essa formação é Pós-graduação. Quando falo de Pós-graduação não o mestrado tá, é que ele só vai conseguir depois que termina a graduação. O curso que ele fez lá [na graduação] dá uma pista para ele, ele vai ter que trabalhar na formação continuada. Estudar por conta própria, ter boas referências e quando aparecerem as sugestões de atividades históricas vai ter que se municiar e ir atrás de conhecimento para isso. A gente faz isso lá no Laboratório, quando a gente desenvolve atividades que envolvem história das ciências sempre tem um texto complementar, sempre tem uma orientação do professor que é bem reforçada do ponto de vista da História, esse é o primeiro problema.

O segundo problema, claramente quando você começa a trabalhar com atividades que envolvem História e Epistemologia, você muda a maneira que os alunos trabalham. Toda inovação de conteúdo implica em inovação metodológica. As duas coisas estão sempre amarradas. Aquilo que o aluno está acostumado a fazer quando você fornece para ele probleminhas para ele resolver é muito diferente do que ele terá de fazer quando você traz para ele o episódio do debate sobre a natureza da luz, ele vai ter que ler textos, vai ter que se colocar na perspectiva de Newton do século 18, vai ter de ver o Éter sem dar risada porque em algum momento vai ter que discutir sob a perspectiva de Fresnel, então, ele vai ter que entender que o jogo ali mudou. E o aluno vê que isso é difícil, ele está acostumado que a disciplina de História tem a mesma cara, que as regras são as mesmas e ele se atrapalha com isso. (DF-E)

A formação continuada é um recuso necessário para todos os docentes de todos os níveis de escolarização, faz parte do próprio ato de desenvolvimento profissional docente. Mas, ao se tratar de HFCrECN a complexidade aumenta, porém isso não deveria diminuir a motivação de autoaprendizagem e mesmo de profissionalização via especializações, mestrados, doutorados ou estágios de 
aperfeiçoamento. No entanto, isso não é tão simples assim para a realidade do trabalho docente no país. Os docentes escolares não têm as mesmas condições de trabalho que os seus colegas universitários, respeitadas as diferenças.

Por outro lado, na formação continuada a investigação emerge como elemento antecipador de situações fiáveis para trabalhar a HFCrECN, como podemos ver:

\begin{abstract}
Quando falo que o professor tem de fazer a formação continuada, é porque ele tem que adquirir um conhecimento que ele não tem. Agora, tem uma outra coisa que é importante, que o seguinte, tem alguns passos do caminho que ele não precisa sofrer na sala de aula. Por exemplo, quais são os bons episódios que têm mais de um atributo, não é só um bom motivo, têm vários motivos para você levar para sala de aula, esse tipo de coisas [HFC], a pesquisa pode antecipar isso para ele. Quais são os bons textos, qual é a boa sequência de atividades, quando ele quer fazer atividade que tenha um cunho histórico. Mas, isso aí eu acho que cai no mesmo tipo de pesquisa que agente faz com outros assuntos que é, necessariamente, usando a História. Se eu for usar um computador, uma ferramenta, literatura, qualquer tipo de estratégia ou recurso novo, eu acho que, o estágio que a gente se encontra, não deixaria o professor ser o piloto de teste dessas coisas, quer dizer não só ele sozinho que vai testar e ver se funciona ou não. Acho que a pesquisa pode ajudar nesse sentido, têm como controlar e fornecer algumas evidências de algumas coisas que têm mais chances de dar certo do que outras. Acho que nessa perspectiva é o que a gente tem trabalhado mais recentemente. (DF-E).
\end{abstract}

Vemos aí uma leve observação crítica, porém, profunda e necessária. O que significa fazer do docente escolar piloto de teste? E de que teste se trata? Ora, nesse caso, o teste seria da HFCrECN e os docentes escolar os "cobaias" (piloto de teste). Faz-se do docente escolar cobaia quando se prescreve, se dita e edita, sob várias formas, direitas e indiretas, o que ele deve fazer no ensino, no seu trabalho profissional. Isto é o que tem sido feito ao determinar-lhe o que tem de fazer para HFCrECN, sem contar - na maioria das vezes - com a sua anuência, sua colaboração decisória. E, o que quer dizer com a proposição "a pesquisa pode ajudar nesse sentido"? Significa dizer que a ID-PC, a partir de seu campo, pode fazer testes, experimentos, controlar, quantificar e qualificar, depois fornecer certas evidências daquilo que tem maior probabilidade de acerto em aprendizagem e ensino. Isto ocorre via implementação de macro projetos de investigação, é o que já temos nos referido em outros momentos. E, de outra forma também é ressaltado por outro docente formador - num reconhecimento de sistemicidade - ao afirmar que 
Acredito que nós deveríamos criar mais projetos interinstitucionais e interdisciplinares, isso que estou mencionando para a situação universitária acadêmica é o mesmo que aconteceu na Escola do nível básico e médio, ou seja, se você tiver professores que entendam que você pode pegar e fazer um projeto unindo, por exemplo, Química com Matemática, Química com Português, Química com História, um professor de Física com o de História e os dois trabalhem juntos e poderem usar esse potencial, a mesma coisa a gente poderíamos fazer na acadêmica, a HFC são por natureza interdisciplinares, não adianta você ficar confinado em uma área e não ter interação com as outras. (DF-D)

A HFC-ECN depende necessariamente de projetos interdisciplinares para poder ser efetivado no mínimo possível com eficiência plausível. Uma investigação conjunta e um material didático abordado interdisciplinarmente constituem meios para construção de uma metodologia de abordagem integrada.

\subsection{3 - Percepções acerca da HFCrECN no Ensino Médio}

Durante a pesquisa procuramos saber dos docentes formadores que papel eles previa da HFC no ECN no ensino médio e que dificuldades poderiam ser possíveis antever e o que poderia ser feito para facilitar a aproximação. O papel da HFC no ensino não é um consenso, encontra críticas na literatura e no campo educacional, em alguns discentes e alguns docentes que não a vêem como possível colaboradora da formação profissional nas licenciaturas ou nos bacharelados. Porém,

\footnotetext{
Esse é outro vetor da HFC importante, normalmente, a sociedade como um todo, portanto, os futuros professores e os próprios futuros alunos tendem a ver a $\mathrm{HC}$ como uma coisa pouco relevante, porque há ideia de que o mais importante é o mais recente, portanto, o que é histórico não interessa para a ciência em si, pode interessar como curiosidade, pode interessar na formação geral, mas não é vista como um auxiliar para a disciplina científica.

Então, outro trabalho que precisa ser feito é mostrar que isso não é verdade, ou seja, a História e a Filosofia da Ciência têm importância para a ciência de hoje. Que há uma grande continuidade e que há novas linhas de pesquisa mesmo de objetos de conhecimento mais antigo, ou seja, a ciência não está esgotada, mesmo essa ciência considerada mais antiga, como a mecânica ou qualquer dessas outras estabelecidas há mais tempo elas têm possibilidade de abrir novos caminhos, a partir do conhecimento da parte histórica e filosófica. Além disso, se você conhece quais são as circunstâncias em que foi feita uma experiência famosa, que todos os alunos ouvem falar, mais não sabem direito como isso foi feito, você percebe melhor o grau de dificuldade que esses cientistas no passado tiveram e com isso você pode pensar como as condições de hoje, dos seus laboratórios - quando eles existem - são também condições de desafios permanentes, tudo isso vai contribuindo para a formação científica mesmo. (DF-D)
} 
Em algum momento a HFCrECN foi considerada como importante no ensino médio como um todo e com particular atenção para o ECN, numa perspectiva de conceber a HFC como conteúdo escolar para atualizar (Elucidação) os discentes:

\begin{abstract}
Acho importante ter HC no ensino de ciências, no ensino médio em geral, mas no ensino de ciências porque esses alunos de alguma forma vão adentrar nesse campo sem informações, eu acho que os alunos - como o público em geral que não trabalho direto com ciências - têm informações muito generalizadas sobre como é o trabalho dos cientistas, como aconteceram as mudanças nas ciências, quais são os principais marcos, os principais nomes, as questões que envolvem gênios, descobertas elas são sempre em volta a muita nebulosidade e acho que esse tipo de abordagem possível é aquele que possa desconstruir essa mitologia e fazer com que os alunos pensem concretamente como é o trabalho do cientista. (DF-H)
\end{abstract}

Para alguns docentes formadores a HFC não apresenta, em princípio, dificuldades, mas estas podem aparecer se faltar instrumentos e formas de torná-la agradável aos discentes (Motivacional).

Acho que não, a História da Ciência não apresenta dificuldades, só se faltar instrumentas e as formas mais agradáveis de passar isso para o aluno, às vezes, os alunos gostam de ciências e não gostam de história, o professor vai ter que encontrar formas de juntar essas coisas, então, a única dificuldade seria essa: tornar agradável para o aluno, mas não a falta de laboratório ou usar experimentos. (DF-G)

Este tornar agradável a HFC aos discentes da Escola média não depende somente das capacidades dos docentes escolares, mas também de outras varáveis intervenientes e entre essas variáveis está a formação docente adequada.

A formação de professores tem que ter um enfoque que junte essas duas coisas, História da Ciência e ensino de ciências, no meu caso eu nunca me preocupei muito com ensino de ciências, trabalhei com História da Ciência, aqui na Universidade as coisas são um pouco separadas, então não fazia parte do meu universo, se houver essa diretriz de encaminhar mais a História da Ciência para o ensino, então o professor de História da Ciência precisa estar mais atento às essas dificuldades que possam ocorrer com os futuros professores. (DF-G)

A HFC é vista como importante no ECN porque ela é esclarecedora da $\mathrm{NdC}$, do Método Científico, portanto, portadora de Elucidação do processo de construção do conhecimento científico. 
Agora, acho que pensando em ensino de ciências, a História da Ciência é um tema muito importante porque ela esclarece sobre a natureza da ciência. Eu sou formada em Física, quando eu estudei Física minha ideia de ciência era completamente diferente do que tenho hoje, vim vendo a ciência muito ligada ao contexto histórico em que ela é constituída, vejo também a ciência ou o conhecimento científico como conhecimento certo, objetivo e seguro, mas como conhecimento que foi construído histórica e socialmente, então, ele não busca a verdade, mas busca constituir um tipo de compreensão sobre a natureza, digamos assim.

A História da Ciência também mexe muito com o método científico, não é só a Filosofia da Ciência que mexe com o método científico, a História da Ciência também é muito esclarecedora sobre como o método científico se dá na prática, como o cientista foi construindo o seu trabalho e a idéia que hoje a gente tem é que o método científico não é tão fechado como usualmente os professores ensinam. (DF-G)

\title{
Essa função de Elucidação que a HFC traz também é considerada por
}

outros formadores como forma de localizar o conhecimento científico no seu respectivo tempo e espaço.

\begin{abstract}
Então, eu acho que a História e Filosofia podem relocalizar, dizer quando aquele conhecimento foi situado num terminado tempo, num determinado espaço geográfico, o que ele respondeu naquele momento, isso é positivo, até para você dar criatividade para atividades de ciências, não achar que ela [a ciência] é só uma questão técnica, no máximo erudita que não tem pessoas lá dentro, que tem teorias que pairam no ar, que tem explicações genéricas que serve para tudo e para todo mundo de qualquer país e qualquer tempo.

Acho que a História pode localizar as origens desses conhecimentos porque, às vezes, mudam e é mais fácil para o aluno entender como um dado que ele próprio aprendeu, às vezes, no começo do ensino dele e quando ele já está saído já se modificou, e ele não tem parâmetro: como modificou porque estava errado? Não, estava certo enquanto ele foi proposto, agora foi modificado, é outra coisa, pode ter sido substituído, por várias razões não por erro, ou foi superado, não é mais suficiente e importante, não está mais nos planos do desenvolvimento do país, tem várias possibilidades, então acho que isso [HFC] fundamenta sim a aula do segundo grau ou licenciatura, é muito importante. (DF-H)
\end{abstract}

Em virtude, talvez, de pouco tempo dedicado aos estudos médios especulam que o ensino em período integral seria o ideal para que os discentes da Escola média tivessem tempo suficiente dedicado aos estudos das ciências naturais e assim os docentes tivessem tempo para poder fazer abordagem históricofilosófica.

Então, é a minha utopia, utopia é que em primeiro lugar nós deveríamos ter o ensino médio de tempo período integral e não ensino médio de três ou quatro horas, já que a formação de um jovem, para mim, e mais idealmente ainda pensando na realidade do meu país, é que os jovens até completarem o ensino médio não deveriam trabalhar, deveria apenas estudar, deveriam 
estar se preparando para via do trabalho, para continuar estudar, para diversas atividades que um jovem depois dos seus 17 ou 18 anos vai ter que desempenhar; então, a realidade que temos hoje, ela quase impossibilita que isso ocorra.

Aqui em São Paulo a Escola pública, que abriga quase $90 \%$ dos jovens no ensino médio, ela atualmente não chega a ter duas aulas de Física por semana, é quase nada, é muito pouco, tanto é que a Física dada ela se limita a resolução de exercícios típicos de cada área, muitas vezes se fica na mecânica, um pouco na eletricidade, mas não tem experimentos, uma Física sem experimentos não é Física, não é História e como disse a Física sem História não é Cultura e menos ainda Filosofia. (DF-J)

Ao criticar a pouca carga horária dedicada ao ensino e aprendizagem da Física no ensino médio (2h), comprando-a a carga horária antiga (4h) e à formação docente, afirma o docente formador que,

Então, nossos professores, infelizmente, são mal formados. A grande maioria do professores da rede pública do ensino, eu fico mais nela por conta do que disse anteriormente, que a grande maioria dos estudantes que frequenta os bancos escolares dessas Escolas, eles vão sair quase que analfabetos científicos, tendo apenas essas aulas. (DF-J)

A crítica dos docentes formadores aponta para uma mudança no cenário educacional ou mesmo mudança de cenário educacional, para (re) criar um novo cenário em que haja valorização profissional dos profissionais do ensino e proporcionalidade entre formação e condições de trabalho adequadas, para que possam, então, desenvolver projetos educacionais inovadores tanto os propostos pelos PCN quanto os tematizados pelas correntes ou tendências educacionais, tais como o movimento da HFCrECN.

Eu me lembro na época, eu terminei o ensino médio no começo da década de 60, tinha 4 aulas de Física por semana, o mesmo tanto de Biologia e Química. Me deram, naquela época, o pouco de História que se dava. Mas, o que eu acredito que nós temos que pensar no cenário que seja diferente desse, um cenário em que as ciências sejam valorizadas de forma adequada, que nós possamos levar para a sala de aula a História e a Filosofia, mesmo nessa realidade que nós temos no nosso país, aqui em São Paulo, em particular, alguns estudantes [licenciandos] procuram levar a História da Ciência, procuram de alguma forma driblar os projetos ou mesmo os textos que são adotados pelas escolas que, muitas vezes, reproduzem essa Física limitada à aplicação de formas matemáticas, então, o que acontece, às vezes, em algumas escolas, é os professores levarem os textos suplementares, falar algo sobre Galileu é muito pouco como exemplar de História da Ciência. Mas, de alguma forma é isso que acaba acontecendo, tanto é que algumas Escolas particulares que têm mais aulas de ciências, esse procedimento acaba ocorrendo, nas Escolas que visam não apenas os exames de vestibular, mas a formação cultural de seus estudantes - a elite que está estudando nessas Escolas não é a grande massa da população - e nossos estudantes formados nas licenciaturas da 
USP eles acabam abandonando as aulas nas Escolas estaduais, fazem concurso [para Escolas particulares], abandonam porque as condições de trabalho também não são adequadas, eles têm uma formação mais sofisticada do que aquilo que a Escola pública tem condições de permitir que eles desempenhem. Então, acabam indo para as Escolas particulares onde conseguem aplicar algo de História da Ciência, porque tem mais aulas de Física, seus alunos têm mais tempo de leitura. Então, o que eu vejo é que essas experiências elas têm de ser generalizadas para a Escola pública, nós não podemos continuar a oferecer um ensino em que a Física não aparece como algo cultura, pelo contrário, a Física é uma das área de conhecimento mais detestadas pelos estudantes da Escola do ensino médio. Então, eu acho que nós temos que reverter esta situação, eu acho que a História da Ciência tem um papel muito importante, para cumprir até, como você disse no começo, aquilo que os PCN orientam. Porque isso não está de fato levado, majoritariamente, para as nossas Escolas, então a formação do professor e a possibilidade dele levar isso para sala de aula depende também das condições de trabalho que os professores encontram lá. (DF-J)

A relação entre formação docente e possíveis dificuldades que podem surgir ao tentar incluir a HFC no ensino médio é apontada como consequência da insuficiência de conhecimento em História e Filosofia, e, eventualmente, insuficiência na própria área de formação:

Isso é fácil de perceber: primeira coisa é que eles [os docentes escolares] não sabem História e Filosofia o suficiente para terem essa desenvoltura e eles também não sabem tanta Física, não, mas isso é diferente. O que aprenderam de Física é suficiente para eles lidarem com a Física de sala de aula, o que eles sabem de História, em geral, é insuficiente. (DF-E)

\section{Percebemos aqui que a insuficiência na formação surge como a primeira}

dificuldade, também isto é apontando por outro docente formador, ao lado dos livros didáticos que representam a segunda dificuldade.

Dificuldade é o que não falta. Bom, para pensar na maioria dos professores e não exatamente em meus alunos, a principal dificuldade está em cultura, não só científica, mas também histórica. Esta dificuldade não tem a ver só com essa temática [HFCrECN], tem a ver com a falha de formação, no sentido mais amplo. Uma segunda dificuldade é que os livros-textos são normalmente concebidos para uma demanda, de uma certa Escola que pretende adestrar jovens para serem bem sucedidos em exames que the vão abrir certas portas ou fechar outras, e, esses exames têm pouca demanda do conhecimento de natureza histórica, epistemológica e filosófica, então, esse pragmatismo, por assim dizer, do adestrar para uma prova olímpica dos vestibulares competitivos é outro obstáculo para essa introdução [da HFC no ECN]. É bom que se diga também que os próprios alunos, às vezes, têm essa perspectiva competitiva e tomam coisas que os desvia do foco muito específico como perca de tempo, às vezes, não é só o aluno, mas também a própria Escola e família, então, tem havido resistências até ideológicas, ao tratar a história como algo importante no aprendizado de ciências. (DF-C) (destaque nosso). 
As resistências ideológicas são também, à nosso ver, consequentes de concepções de mundo e de cultura. Uns são mais adestrados para a cultura do imediatismo mecânico oferecido pelos sistemas de controle, outros menos. Mas, a maioria está! A formação docente é, muitas vezes, mais espaço de obliteração e "adestramento" das mentalidades que de reflexividade e libertação das amarras dos sistemas de controle. Estamos num verdadeiro cenário biopolítico, em que a vigilância e o engajamento na reflexividade crítica são necessários.

Em outro contexto, as dificuldades aprecem como limitações de tempo de trabalho didático e como conjunto de preconceitos internos do campo universitário. Isto é, preconceitos ligados às divisões de subculturas acadêmicas em que se encontra dividida a cultura universitária. De um lado, a tecnocientífica e, do outro, a humanística, são duas tribos sem paz perpétua e semeiam o tribalismo um do outro.

\begin{abstract}
Em primeiro lugar, uma dificuldade de tempo, você precisaria prever uma carga horária maior, tudo isso que falei fica muito mais fácil se você tem pelo menos um ano para ser dado, como aqui falei, a gente [trabalha] em um semestre e, sempre muito pouco, quando os alunos estão começando a perceber todos esses potenciais da HFC o semestre está acabando, então, seria útil termos pelo menos o dobro da carga horária. Outra dificuldade é que nem todas as unidades, e aqui eu vou falar no caso nosso da USP, nem todas as unidades percebem essa importância e se você for olhar, por exemplo, na Escola Politécnica seria importante termos também uma parte da História e Filosofia da Tecnologia, eles não têm essa disciplina. Várias vezes, nós tivemos a oportunidade de conversar tanto com alunos como com professores que falaram que acharam que isso é importante, mas nunca houve uma aprovação de que essas disciplinas fossem dadas. Então, você tem essas resistências de gente que acha que isso é perda de tempo, que é melhor você se concentrar em matérias mais técnicas do que em matérias humanísticas, infelizmente essa é uma dificuldade enorme, e um preconceito que está ligado à famosa divisão das duas culturas, a cultura chamada científica dum lado e a cultura humanística do outro lado. (DF-D)
\end{abstract}

Para facilitar a aproximação da HFC ao ensino médio, além das condições referidas ao tempo e à carga horária e a outras condições de trabalho docente e de gestão e políticas públicas educacionais, caberia também ao docente escolar alguns afazeres, tais como:

Primeiro é o professor pensar a sua prática, o que ele está fazendo, qual o objetivo dele no ensino, porque ele pode também imaginar que no ensino vai formar pessoas com uma visão generalizada do que é atividade de ciências. Qual seria essa alfabetização (como alguns discutem) necessária ao aluno? Mas, esse aluno num outro sentido, ele também não vai, muitas vezes, para área acadêmica, é muito complexo o público do ensino médio 
que esse professor vai tentar intermediar, você pode ter pessoas que vão por familiarizar-se e partir para áreas técnicas e científicas; você pode ter aquele que não vai ter uso imediato, mas vai ser, de alguma forma, replicador desses entendimentos, para o senso comum, para família ou para o próprio consumo dele, para leitura, para entendimento do mundo em que ele está. Então, esse professor tem um alcance maior do que apenas ilustrar o aluno, então, eu acho que esses tópicos [de HFC] quando aparecem, por vezes, não são muito explorados, eles são dados para o estudante de licenciatura como uma ilustração de toda uma prática, de questões teóricas que estariam além dos interesses dele, às veze, é só uma ilustração, acho que a gente ainda precisa aprofundar e melhorar a construção desses currículos pensando no público, nesses alunos, o que a gente acha essencial, são dados objetivos, são questões teóricas, é para formar alunos mais críticos ou com mais volume de dados informativos? (DF-H)

Percebe-se assim que a aproximação da HFC ao ensino médio depende da sua inserção na formação docente, isto é, depende da Instrumentação Didática pela qual passa a mudança do cenário intelectual que vai repercutir no campo escolar e nas jovens gerações. Uma formação baseada na reflexividade e Criticidade. Esse fato remete a refletir de forma crítica a própria prática da formação docente, portanto, uma autocrítica dos próprios docentes formadores, pois,

A gente [docentes formadores] precisa sempre ter esse público como objeto final do professor de História [HC], tem muitas passagens, o professor de nível superior especializado que nem a gente, que é da História e Filosofia Ciência e que vai formar alunos de licenciaturas diversas que não de historiadores [da ciência], [mas, de] química, física e biologia, que vai repassar para outro público que a gente ainda não sabe quem é e quais são os seus interesses. Será que a gente quer sensibilizar para que eles também vão para áreas científicas ou a gente quer formar um cidadão mais crítico ou a gente quer dar mais erudição, então tem várias questões aí para serem discutidas, é bom que a gente tenha essa sensibilização que os parâmetros trazem, mas isso é coisa que temos de continuar discutindo eu acho. (DF-H)

Disso resulta que há de se pensar e implementar uma mudança cultural significativa, como condição necessária para mudança nas estruturas e nos sistemas, nas mentalidades e práticas formativas de que redunda a HFCrECN.

Eu sou entusiasmado pela História como lhe disse antes de começarmos as perguntas, eu dizia no final do século vinte, eu falava para os meus colegas, o século vinte está acabando e nós não estamos levando a Física do século vinte para sala de aula, o século vinte já acabou e não estamos levando a Física do século vinte para sala de aula, então cadê a cultura? Cadê as revoluções científicas do século vinte? Porque sem isso o estudante, claro aprender uma boa mecânica newtoniana é um instrumento importante, mas é pouco, se nós pensarmos que a grande maioria dos estudantes que termina o ensino médio não vai para a universidade ou se vem para a universidade não vem para fazer física, vão fazer, por exemplo, Filosofia, 
então ter um bom curso de ciências ajuda a fazer um bom curso de Filosofia. (DF-J)

Os livros didáticos também são alvos de análises críticas dos pesquisadores da área de ECN, em relação ao tratamento dado aos aspectos históricos e filosóficos que não têm sido comentados. Essa crítica encontra apoio e consenso entre os docentes formadores, consideram que nos livros didáticos a HFC deveria ser apresentada permeando todo o material didático e não apenas restringirse a colocar boxes com informativos histórico-biográficos dos cientistas. Permear o material didático significa abordá-la enquanto perspectiva reflexiva crítica que não acomodasse a mente dos leitores.

O que aparece no livro didático de ciência usual é que o Newton teve um estalo lá e descobriu a lei da gravidade, a História da Ciência mostra que não foi bem assim e elucida como se constrói a ciência e isto é muito importante para o ensino, senão o que se ensina aí está errado, se passa uma visão errada de ciência. (DF-G)

A falta de material didático com abordagem histórico-filosófica tem sido uma reclamação constante para tentar fazer a HFCrECN, no entanto, já existe algum material aproximado que pode ser utilizado, mas que não dispensa a necessidade de existência de material com abordagem integrada - que seja facilitadora da metodologia integrada de ensino.

Alem da falta de material didático histórica e filosoficamente ambientada, lidar com textos históricos também constitui outra dificuldade enfrentada por docentes, tanto da Educação Básica como os próprios docentes formadores na Educação Superior.

Falta de material didático, dificuldade como transpor esses textos da época para o ensino de ciências de hoje, acho que são dificuldades verdadeiras mesmo. Mesmo a gente trabalhando na universidade eu tenho uma super dificuldade de usar esses textos e ter acesso a eles, acho que quem trabalha nesses temas tinha que produzir material didático, para a gente poder ter mais elementos para desenvolver esses temas. (DF-F)

Porém, embora haja uns que reclamam das dificuldades em lidar com os textos históricos (como a sua ausência) traduzidos para o português, em virtude de sua linguagem, entre outros aspectos, há outros que acreditam nesses textos e vêm neles os meios para aproximar a HFC ao ECN e com isso possibilitar o

\section{Autoaperfeiçoamento,}


Eu acredito que, hoje, no país de língua portuguesa, nós temos uma quantidade crescente de materiais produzidos, livros com traduções das obras clássicas da Física de Galileu, de Newton, de Einstein, de diferentes grandes figuras da Física, estão traduzidas para o português. O professor hoje tem também a possibilidade de usar a internet, embora não está universalizada, encontrar textos que o professor tem condições para seus estudantes, para reproduzir mais facilmente em sala de aula, então vejo, as condições reais que o professor encontra são esses experimentos, está falando da mecânica, então, levar alguns textos de Galileu, de Kepler, do Newton, para mim isso já é humanizar um pouco a perspectiva do olhar a Física de uma forma mais atraente, do que simplesmente uma matemática diferenciada como é ensinada. (DF-J)

Em decorrência do uso desses textos, para que haja melhor aproveitamento, o docente da Escola média assume o papel de tradutor, isto é, traduz para seus discentes os ensinamentos veiculados por meio daqueles textos históricos das ciências naturais, para fazer com que ocorra a HFCrECN.

Então, o que vejo é isso, a possibilidade de se levar textos clássicos para sala de aula, muitas vezes, nós vemos o próprio Einstein escrever um texto, é claro, ele diz no prefácio que é um texto voltado para o ensino médio, prefácio de um livro escrito a quase 100 anos, é claro que o ensino médio mesmo nos EUA onde ele morava na época era a elite que fazia ensino médio, mas de qualquer forma é um texto saboroso, se for acompanhado por um tradutor que possa fazer isso que é o professor. (DF-J)

O que é necessário para fazer a tradução epistêmica? Requer-se, do docente como tradutor epistêmico, uma formação sólida e contextualizada sobre o conhecimento a ser traduzido, para outros contextos diferentes dos contextos originais. A aprendizagem da tradução começa na formação inicial, o que significa oferecer aportes e ferramentas que possibilitem o exercício da tradutibilidade da gnose. Essa condição requer, condicionalmente, uma formação e autoformação para leitura: habito de leitura. O docente que não gosta de ler não será um profissional reflexivo, nem crítico nem criativo, mas atrofiado. Condição ressaltada como se segue:

Então, o professor bem formado que tenha, na sua licenciatura, tido oportunidade de ter acesso a elementos de História da Ciência, ele vai ter condições acredito eu, se for um bom leitor, que essa é uma outra necessidade. $O$ professor tem de gostar de ler, e eu acho que todo professor deveria gostar de ler, infelizmente, isso não ocorre, mas essa é a briga que nós temos de fazer também, que as pessoas gostem de ler, e gostem inclusive de ler os textos clássicos, trechos, agora mesmo até o jornal Folha de São publicou o terceiro volume da mecânica de Newton, e o terceiro volume do próprio Newton é um texto muito saboroso, então, não é 
um texto de difícil leitura para um bom aluno de ensino médio. E nós queremos que todos os alunos do ensino médio sejam bons alunos. Mas, também é um outro desafio. Eu creio que a leitura da Física ela até permite combater até duas coisas: o analfabetismo e analfabetismo científico. Então, a leitura essencial dos textos históricos podem favorecer. (DF-J)

Ou ainda que

Os professores precisam conhecer as outras coisas presentes em outras áreas, como literatura, ao aprender algo de História vai permitir que o estudante entenda Os Irmãos Karamazov, se for um bom leitor, e Dostoiévski ${ }^{109}$ já falava, no ano que nasceu Einstein, Os Irmãos Karamazov foram publicados como livro em 1879, é o ano que nasceu Einstein, e nos Irmãos a gente lê que o espaço tridimensional ele não suficiente sozinho para investigar as questões humanas, que é preciso o espaço de quatro dimensões, a quarta dimensão é o tempo [e o tempo é histórico], isto já está em Dostoiévski, um aprendizado que seja da ciência vai permitir que até o estudante de letras seja beneficiado, por uma boa educação de ciência, de física em particular. (DF-J)

Considerando a ideia de que a HFC oferece um referencial para poder discutir a questões internas e externas da produção do conhecimento científico, a falta de material didático com abordagem integrada - isto é, que traga incluída a perspectiva HFC - é apontada como dificuldade que precisar ser transposta para poder possibilitar a aproximação da HFC ao ECN.

Acho que outra coisa seria introduzir isso [HFC] na formação. Se o professor não tiver contato com essas discussões não tem como levar isso, seja na formação inicial ou continuada.

Mas, eu acho também que, pensando na Escola e no currículo, na mesma lógica que te falei que eu tenho monte de coisas para trabalhar e vou selecionar, a mesma situação o professor [da Educação Básica], ele tem muitos conteúdos, conceitos que tem de trabalhar no curso. E aí eu acho que tem que ter um trabalho de cooperação dos pesquisadores com os professores de selecionar, por um lado, conteúdos que sejam mais adequados para trabalhar numa abordagem histórico-filosófica, seja qualquer tema da biologia, por exemplo, que se preste tão bem para isso, seja porque você não tem o material histórico levantado, seja por questões da contemporaneidade dela, porque muitas coisas são recentes. Não se trata tanto de uma questão história, mas de uma discussão que é contemporânea, portanto, tem essa questão de pensar em bons temas para essa abordagem. (DF-F)

Por outro lado, requer-se, também, que didaticamente a abordagem da HFC seja de caráter motivacional de tal forma que instigue os discentes a estudar os textos históricos, para não correr o risco de não se alcançarem os objetivos da HFCrECN.

${ }^{109}$ Fiódor Mikhailovich Dostoiévski. 
E, uma maneira, mais de estratégias e metodologias, é que a História e Filosofia da Ciência seja instigante para os alunos senão não adiante chegar com os textos originais. Eu aprendi a trabalhar com História da Ciência com os textos de Galileu, um dos mais clássicos, a própria discussão sobre o sol que gira em torno da terra, quem gira em torno de quem. Na biologia agora é que temos uma comunidade de historiadores da ciência que têm preocupação com o ensino. (DF-F)

Além do mais, os docentes formadores observam também a necessidade de se abordar uma HFC crítica, não presa às supostas "grandes figuras", "gênios", "pais disso e daquilo", bem como, ao reducionismo geográfico das produções científicas e tecnológicas ou outras, que é uma concepção ingênua e acrítica da historicidade da ciência e tecnologia, além de ser ideológica e politicamente intencionada.

\begin{abstract}
Eu acho que a gente tem que pensar que temas seriam interessantes, para gente evitar aquelas abordagens mais personalistas, da História da Ciência centrada nas grandes descobertas, grandes figuras, cientistas, naturalistas e tem toda uma discussão dentro do campo da História da ciência que tem haver com essa História mais latinoamerica, não eurocêntrica, essa discussão está longe de chegar na Escola, muito longe ainda, na Escola a gente ainda vê nos livros didáticos aquela História de grandes figurais ainda. No caso da Biologia o tema que mais se fala é a evolução, porque tem o Darwin, mas ninguém fala do Wallace tem muito historiadores da Biologia que ficam reivindicando isso, tem alguns trabalhos de Pasteur que são clássicos que aparecem na História da Biologia voltada para o ensino. Enfim, é preciso acoplar isso, ter informações de História da Ciência e ao mesmo que façam sentido para Escola e que sejam abordados de uma maneira interessante dentro da Escola. (DF-F)
\end{abstract}

Pensar os temas possíveis e interessantes é pensar a HFC possível para o ensino e aprendizagem científica: que HFC se pretende ensinar? Com que objetivos e perspectivas? Quem vai ensinar HFC possui formação básica para tal? Qual o objetivo necessário da HFC na aprendizagem científica? Essas e outras questões poderão ser respondidas na medida em que a comunidade do movimento da HFCrECN for crescer e refletir de forma crítica (autocrítica) sobre suas preocupações e objetivos.

E tudo que tem sido feito até, de formas diversas e por diferentes grupos, já representa um passo importante, pois tempos atrás não se tinha nada do gênero no país, o estado atual da HFC pode ser considerado como um avanço, cuja tendência aponta para o crescimento, com abertura de cursos de especializações, mestrados e doutorados em HC e FC. 
A seguir apresentamos a tabela de incidência das percepções dos docentes formadores nas categorias de análise.

Tabela 38 - Incidência das Percepções dos Docentes Formadores nas Categorias

\begin{tabular}{|c|c|c|c|}
\hline \multicolumn{4}{|c|}{ CATEGORIZAÇÃO } \\
\hline № & DOCENTES FORMADORES & $\begin{array}{l}\text { CATEGORIA } \\
\end{array}$ & FREQUÊNCIA \\
\hline 1 & $\begin{array}{l}\text { DF-A } \\
\text { DF-C } \\
\text { DF-J }\end{array}$ & Autoaperfeiçoamento & 3 \\
\hline 2 & $\begin{array}{l}\text { DF-H } \\
\text { DF-G }\end{array}$ & Elucidação & 4 \\
\hline 3 & $\begin{array}{l}\text { DF-E } \\
\text { DF-F } \\
\text { DF-B } \\
\text { DF-C } \\
\text { DF-H } \\
\text { DF-J }\end{array}$ & Criticidade & 16 \\
\hline 4 & & Contextualização Interna & \\
\hline 5 & $\begin{array}{l}\text { DF-I } \\
\text { DF-H }\end{array}$ & Contextualização Externa & 3 \\
\hline 6 & $\begin{array}{l}\text { DF-B } \\
\text { DF-D }\end{array}$ & Sistemicidade & 2 \\
\hline 7 & & Falibilidade Epistêmica & \\
\hline 8 & $\begin{array}{l}\text { DF-J } \\
\text { DF-G }\end{array}$ & Motivacional & 2 \\
\hline 9 & & Socialização Epistêmica & \\
\hline 10 & $\begin{array}{l}\text { DF-J } \\
\text { DF-F } \\
\text { DF-G } \\
\text { DF-B } \\
\text { DF-H } \\
\text { DF-D }\end{array}$ & Instrumentação Didática & 9 \\
\hline 11 & & Eticidade & \\
\hline 12 & & $\begin{array}{c}\text { Insuficiência Informativa em Relação à } \\
\text { HFCrECN }\end{array}$ & \\
\hline 13 & & $\begin{array}{c}\text { Diagnóstico da Aprendizagem em } \\
\text { HFCrECN }\end{array}$ & \\
\hline 14 & & Socialização de Feitos em HFCrECN & \\
\hline 15 & & $\begin{array}{c}\text { Propostas não Experimentadas em } \\
\text { HFCrECN }\end{array}$ & \\
\hline 16 & & $\begin{array}{l}\text { Produção de Material Didático e } \\
\text { Paradidático em HFCrECN }\end{array}$ & \\
\hline 17 & & $\begin{array}{c}\text { Inclusão Curricular de Aspectos da } \\
\text { HFCrECN }\end{array}$ & \\
\hline
\end{tabular}




\section{CONSIDERAÇÕES, REFLEXÕES E PERSPECTIVAS}

Nesta seção apresentamos nossas considerações finais, fazemos algumas reflexões em virtude de algumas interpelações e perspectivas em relação ao tema-problema de investigação.

\section{a) - À Guisa de Considerações Finais}

Se ao tema HFCrECN concorrem quatro instâncias decisórias (ID), quais sejam: $4^{\mathrm{a}}-$ a dos regulamentos oficiais $(\mathrm{RO}) ; 3^{\mathrm{a}}-\mathrm{a}$ das pesquisas científicas (PC); $2^{\underline{a}}$ - a da formação docente (FD); $1^{\underline{a}}-$ a da prática didática escolar (PDE), então, delimitamos o nosso tema e problema de investigação às três posteriores $\left(4^{\mathrm{a}}, 3^{\mathrm{a}} \mathrm{e}\right.$ $2^{2}$ ), interpelou-nos saber como elas se relacionavam com o tema. Daí surgiu determinar o problema de investigação, considerando o consenso de que para essas ID a HFC interessa no ensino de ciências naturais, que consistiu em saber: em que as ID se distanciam entre si em relação à HFCrECN? E como cada ID responde à questão da HFC $-E C N$ ? Para responder a essas perguntas requereu de nós delimitar o objetivo para investigar as orientações teórico-empíricas de três instâncias decisórias envolvidas no tema da HFCrECN, por meio da análise dos documentos oficiais, trabalhos de pesquisas, ementários de formação básica e percepções dos docentes formadores.

Da pesquisa resulta que os $\mathrm{RO}$ apontam para a concepção da HFC como conteúdo curricular escolar - dentro da política de habilidades e competência gerais e específicas de contextualização sociocultural das ciências naturais e suas tecnologias -, a ser inserido no ECN. Mas, isso implica necessariamente:

- 1ำ na instrumentação didática dos docentes durante a formação inicial e continuada;

- 2ำ na definição metodológica básica dos procedimentos de abordagem integrada dos conteúdos científicos e histórico-filosófico;

- 3ำ na publicação de material didático contextualizado histórica e filosoficamente;

- 4ํ na definição do estatuto ontológico e epistemológico da HC ou HFC pretendida para o ensino; 
- 5ำ se se defende a HFCrECN como uma condição necessária na educação escolar - que confira como elemento de formação por habilidade e competências de contextualização sociocultural das ciências e tecnologias -, então, ela deve sê-la, antes, na educação universitária para formação docente.

A essas implicações os RO (4 ${ }^{\underline{a}}$ ID) não se referem, exceto alguns casos aproximados ao tema constantes das diretrizes curriculares de formação inicial docente (do CNE), em que se considera a HFC enquanto conteúdo a ser inserido, em forma de disciplinas nas licenciaturas, como tentativa de instrumentalização, mas demonstramos também que isso não converge necessariamente para a HFCrECN. Em alguns momentos ( $\mathrm{PCN}, \mathrm{PCN}+$ ) a $\mathrm{HC}$ aparece como subconteúdo dentro do conteúdo da disciplina História (BRASIL. MEC. SEMT, 2002, p. 18), já que a História é concebida como elemento de entendimento das descobertas científicas consequentes dos seus contextos históricos e sociais.

Tal entendimento ocorre mesmo quando se compreende a HFC como possível instrumento de compreensão do processo evolutivo das ciências que são construções humanas, considerando as relações das ciências e tecnologias com o desenvolvimento social, econômico, político e cultural das sociedades; ou como elemento de desenvolvimento de competência de contextualização sociocultural, enquanto dimensão inerente às ciências naturais. A HFC se configuraria como conteúdo disciplinar na formação docente, para possibilitar a compreensão dos contextos da produção do conhecimento científico e da ação ética.

Isso implica na concepção, no estabelecimento e na produção de recursos didáticos para contextualização do conteúdo, bem como, no estabelecimento de princípios metodológicos - o que não é apontado nos RO. Os $\mathrm{RO}$ destinam-se a apresentar prescrições de princípios teóricos gerais, que, por sua vez, também são importantes, pois, representam, de certo modo, um avanço na história da educação brasileira, no quesito específico da HFCrECN. Se os RO traçam princípios genéricos, não apontam para princípios que indicassem para as implicações de operacionalização, elas oferecem coordenadas imperativas.

$\mathrm{Na} 3^{a}$ ID constatamos que aparecem indicações que sempre apontam para pressupostos (justificações) teóricos da relevância da HFCrECN, da análise de concepções ou livros didáticos, ou ainda, da NdC. Os pressupostos teóricos implicam em sua experimentação para validação ou refutação. Nesse caso, em estabelecimento de um procedimento didático validado, plausível e "reprodutível" em 
outros contextos didáticos, que se tornaria uma realidade consensuada e um fato metodologicamente estabelecido.

No entanto, empiricamente, nas pesquisas nacionais sobre a HFCrECN veiculadas através de periódicos e eventos científicos, a partir de 1999 - apenas 11 artigos e 61 trabalho de eventos - de investigação didática em que se apresentaram propostas de intervenção didática para a HFCrECN - foram encontrados. Isto num período de uma década (1999-2010). A grande maioria dos 11 artigos enfoca a contextualização interna (7), a criticidade (5) e motivacional e contextualização externa (2 para cada). Dos 61 trabalhos de eventos, apresentam aspectos de contextualização interna (27); criticidade (11); motivacional (7); contextualização externa (6) e; Instrumentação Didática (5). Todos os trabalhos da ID-PC, somam 72, donde: contextualização interna: 34, criticidade: 16, motivacional: 9; contextualização externa: 8 e; Instrumentação Didática: 5. Os números indicam as incidências dos artigos e trabalhos nas categorias, portanto, um artigo ou trabalho pode incidir em mais de uma categoria. O importante é verificar o quanto uma categoria é freqüente (frequência).

Podemos verificar que a grande maioria dos trabalhos de pesquisa aponta para questões internas às ciências, questões de história conceitual e depois questões epistemológicas também relacionadas às questões dos conceitos científicos. Esse é indicativo de uma perspectiva distante da proposta e advogada nos $\mathrm{RO}$, que apontam para uma contextualização externa: sociocultural, como instrumento de inclusão da HFC como conteúdos de escolarização, porém não tem sob a mesma compreenão da contextualização externa em voga na HFC, mais ampla.

Todos os trabalhos e artigos analisados apresentam uma característica comum: apresentação de episódios temporários de inclusão ou da abordagem HFCrECN. Essa característica não garante continuidade dos trabalhos, assim como não garante resultados em que seja possível mensurar a melhora da aprendizagem em virtude da abordagem HFC, impossibilidade apontada por alguns autores. Alguns temas ocorrem com frequência, no caso da física, são temas de ocorrência comum: gravitação, luz, movimento, eletromagnetismo, etc.

Quando analisamos a ID-FD, para verificar como se configurava a HFCrECN nos ementários curriculares das disciplinas nos programas de formação inicial de docente, constatamos duas situações: a primeira é que nas disciplinas da 
área de HFC, existentes nos programas curriculares, não se estabelece relações com o ensino, portanto, não ocorre a HFCrECN. Algumas tentativas foram constatadas nas disciplinas didáticas, inclusão de temas apropinquados à HFCrECN. Verificamos também que a maioria das disciplinas analisadas aponta para contextualização interna (7) e contextualização externa, criticidade e instrumentação didática 3, para cada. Nesse aspecto, a ID-FD se aproxima da IDPC. A segunda situação diverge-se da primeira, as percepções dos docentes formadores apontam para instrumentação didática (6) e criticidade (6), a abordagem da HFC é vista não como conteúdo de escolarização, mas com perspectiva de reflexão crítica que deve perpassar toda a formação e então chegar a colaborar no ensino e na aprendizagem esclarecida histórica e filosoficamente.

Neste sentido, podemos responder ao problema da investigação que as ID se distanciam entre si quanto à $\mathrm{HFC}-\mathrm{ECN}$ em virtude das discrepâncias, isto é, distâncias de perspectivas existentes entre elas. Pois, cada ID aponta para perspectiva diferente, o que demonstra e confirma a tese de que embora haja consenso entre as ID, em considerar relevante a $H F C r E C N$, as suas orientações apontam para perspectivas diferentes, cuja convergência está longe de ocorrer na realidade material do sistema educacional, ou seja, nas práticas educativas. Tais discrepâncias consistem em desconexões de perspectivas metodológicas e epistemológicas entre as ID e constatamos que tal fato gera situações complexas que inviabilizam a materialização da HFCrECN, tanto na Educação Superior quanto na Básica, é o caso por exemplo da insegurança profissional dos docentes escolares em abordar temas de HFC, conforme verificado em alguns relatos de propostas analisadas.

Por outro lado, constatamos que as ID que concorrem para o campo temático da HFCrECN constituem seus próprios cenários, é no seu próprio cenário que cada instância se constrói e reconstrói numa dinâmica de intercomunicação complexa com outras instâncias. Essas ID formam uma constelação bicondicional com rupturas de sequência comunicativa e tomada de decisões. Eis a configuração geral das ID:

$4^{\mathrm{a}}-$ a dos regulamentos oficiais $(\mathrm{RO})$;

$3^{\mathrm{a}}-\mathrm{a}$ das pesquisas científicas (PC);

$2^{2}$ - a da formação docente (FD);

1 a - a da prática didática escolar (PDE). 
A ordem numérica representa a consistência relevante das instâncias em relação a tomar e efetivar decisões que influenciam o processo formativo: o ensino e a aprendizagem (no geral e para o caso em questão: a HFCrECN). A consistência relevante para efetivação (materialização) das decisões vai da $1^{\text {a }}$ em diante, contrariamente ao processo de decisão prescritiva que segue a ordem inversa. Assim, quanto à tomada de decisão prescritiva, as $4^{\text {a }}$ e $3^{\text {a }}$ instâncias tomam decisões teóricas prescritivas, cuja efetivação depende da tomada de decisão pelos formadores na 2aD-FD, campo universitário, início da tomada de decisão para construção do processo de operacionalização/materialização das prescrições. Tudo aquilo que for decidido teoricamente nas três instâncias anteriores (4⿳亠丷a, $3^{\underline{a}}$ e $\left.2^{\underline{a}}\right)$ sua materialização efetiva no ensino e na aprendizagem na educação básica depende, necessariamente, das decisões dos docentes escolares, no campo escolar (1 $\left.1^{\mathfrak{a}}\right)$.

Em termos de proporcionalidade, quanto maior for a extensão quantitativa (i. e. $4^{a}$ ) menor é a capacidade de materialização das decisões, quanto menor for a compreensão quantitativa (i. e. $\left.1^{\underline{a}}\right)$ maior é a capacidade de tomada de decisão prescritiva e maior é a decisão operacional na prática educativa.

Mas, ontologicamente, isto é, em relação à tomada de consciência de si enquanto entidade, cada ID constitui seu respectivo cenário ontológico, tais como:

$4^{\mathrm{a}}$ - RO - cenário governamental;

$3^{a}-\mathrm{PC}$ - cenário científico;

$2^{\mathrm{a}}$ - FD - cenário formação profissional;

$1^{a}$ - PDE - cenário formação básica.

Assim como do ponto de vista de tomada de decisões prescritivas, cada ID possui uma política própria que the é inerente enquanto ente político, constituindo um cenário político:

$4^{\mathrm{a}}-\mathrm{RO}$ - cenário macropolítico;

$3^{\mathrm{a}}$ - PC - cenário mesopolítico;

$2^{\text {a }}$ - FD - cenário micropolítico;

$1{ }^{a}$ - PDE - cenário infrapolítico.

E, finalmente, do ponto de vista de efetivação das decisões prescritivas, ordem de tomada de decisão operacional (materialização das decisões), muda-se a configuração de cenários, isto porque a consciência e o autoreconhecimento da posição ontológico e política levam ao estado de percepção da condição existencial no mundo dos cenários e ao reconhecimento das forças que 
cada ID pode mobilizar, assim como as suas estratégias de "sobrevivência". Assim, cada ID reconhece-se como um ente de decisão no cenário decisório:

$$
\begin{aligned}
& 4^{\text {a }} \text { - RO - cenário infradecisório; } \\
& 3^{\text {a }}-\mathrm{PC} \text { - cenário mesodecisório; } \\
& 2^{2} \text { - FD - cenário microdecisório; } \\
& 1^{\mathrm{a}}-\mathrm{PDE} \text { - cenário macrodecisório. }
\end{aligned}
$$

Esta metamorfose das ID é o que leva o campo escolar a estar na primazia das ID, como instituição primordial, e a mostrar o seu poder de decisão no processo de materializar as decisões prescritivas dos cenários prescritivos concorrentes ao sistema educacional, mas menos reconhecido e valorizado como tal. Como se as duas primeiras ID dissessem: nós prescrevemos para vocês, tomam e façam, as duas últimas respondessem: nós decidiremos sobre o cumprimentos de vossas decisões. Vocês - do seu lado - fingem que prescrevem; Nós - do nosso lado - fingimos que cumprimos. Coisas de sobrevivência nas relações de poder!

Podemos representar essa metamorfose do estatuto decisório das ID: poder prescritivo versus poder operacional, como se segue:

$$
\begin{array}{l:c}
4^{\mathrm{a}}-\mathrm{RO} \\
3^{\mathrm{a}}-\mathrm{PC} \\
2^{\mathrm{a}}-\mathrm{FD} \\
1^{\mathrm{a}}-\mathrm{PDE}
\end{array}
$$

As ID estabelecem uma relação bicondicional, em que a maior descontinuidade de comunicação e decisão recai sobre o campo escolar. A Escola é menos ouvida, a realidade escolar é menos considerada nas decisões e prescrições presentes tanto nos ordenamentos jurídico-políticos das $\mathrm{RO}$ quanto nos ordenamentos epistemológicos e metodológicos das investigações científicas.

Quanto à HFCrECN constatamos a existência de um consenso entre IDRO e ID-PC sobre a relevância da HFC no ECN, porém, nada ou muito poucas ações ocorrem nas ID-FD (e ID-PDE). Porém, entre as ID 4ํㅜ $3^{\underline{a}}$ e $2^{\underline{a}}$ tem havido uma intercomunicação ou interrelação de mútuas influências inconstantes e, às vezes, subliminares que direta ou indiretamente subjazem e impulsionam a tomada de suas decisões prescritivas. Assim, do ponto de vista de relações de influências mútuas de intercomunicação prescritiva das três últimas ID sobre uma, temos: 
Fluxograma 5 - Carga Prescritiva: processo decisório prescritivo das ID implicadas na HFCrECN.

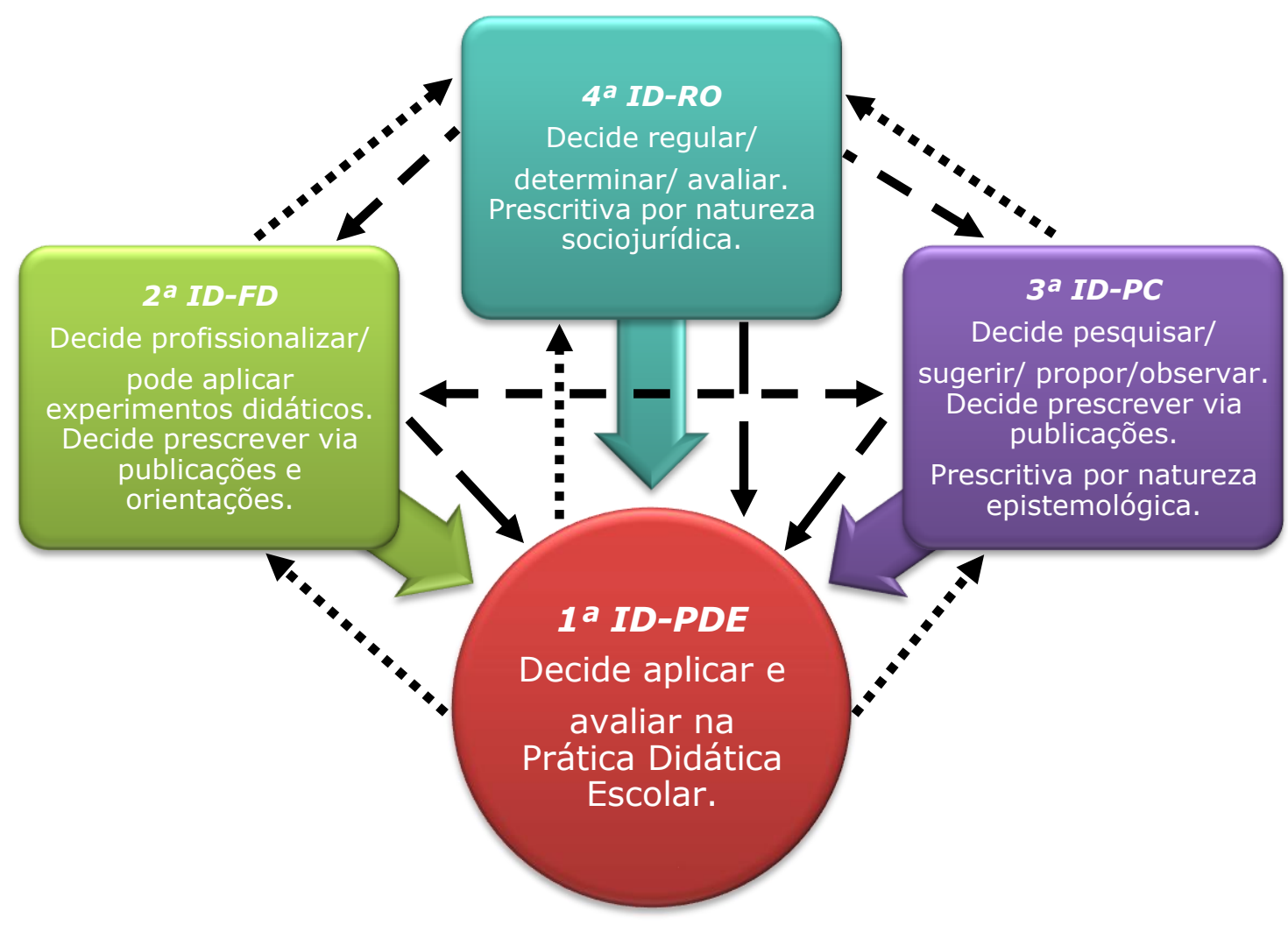

b) - Reflexões

O tema HFCrECN suscita-nos algumas interpelações. Em nosso trabalho anterior ${ }^{110}$ havíamos destacado que o que os docentes fazem na prática didática é pretérito, isto é, o ensino e aprendizagem de assuntos de/sobre física, química, biologia (ou outras disciplinas) é um ato de "reprodução" de assuntos que já contam com tempo de existência, portanto, são assuntos históricos em divulgação. Então, esse ato, há de ser um ato historicizante e crítico por tal razão. Apresentar/traduzir equações físicas ou químicas não é apresentar uma inovação ou criação física ou química senão apresentar (no sentido correto do verbo) elementos que têm uma longa história, traduzindo-os para gente e realidade de hoje.

Neste sentido, a discussão caminha para saber que perspectiva seria

${ }^{110}$ Vide KAPITANGO-A-SAMBA, 2005, p. 87-88. 
adequada ou plausível para resgatar a dimensão histórico-filosófica do conhecimento científico a ser divulgado na Escola e Universidade? Além do mais, considerando os processos de ensino e aprendizagem, até que ponto se sustenta a HFCrECN como uma necessidade nômica e não contingente? A HFCrECN satisfaz alguma relação causal no ensino e aprendizagem científica? Ora, considerando os resultados das pesquisas em ensino de ciências, propostas de intervenção ou investigações didáticas, em que se tenta utilizar aspectos histórico-filosóficos sem, no entanto, algum efeito controlável na melhora da aprendizagem científica consequente da abordagem da HFC, a resposta seria admitir que, talvez, não haja uma necessidade nômica da HFCrECN. Ao analisarmos o T12-EPEF-2010 nos deparamos com a seguinte constatação dos autores:

[...] ter cursado algumas disciplinas de História da Ciência e de Filosofia da Ciência não instrumentalizou esse [sic] alunos de licenciatura. Eles pouco conhecem sobre História e Filosofia da Ciência, não têm segurança para tratar desse assunto, seja teoricamente seja em uma aula sobre um assunto escolhido por eles. (REIS, GUERRA e BRAGA, 2010)

Outra constatação da dificuldade de fazer abordagem da HFC no ensino poder ser obtida a partir do relato de Sorpreso e Almeida (2010, p. 51), já referenciado, mas é relevante apresentá-lo:

[...] pudemos identificar conflitos nos imaginários dos estudantes. Por exemplo, nos momentos iniciais da disciplina, houve indícios de que ensinar História da Ciência não seria também um meio de ensinar Física, e esse aspecto tornou-se conflituoso no decorrer da disciplina, existindo momentos em que apareceram indícios de que, em seus imaginários, ensinar história da Ciência seria um meio para que os estudantes aprendessem Física. Notamos que esses aspectos pareceram se relacionar com a condição de produção de tratarem genericamente da abordagem ou do trabalho efetivo no Ensino Médio. Ou seja, quando falavam genericamente da abordagem, possivelmente recorrendo às publicações em ensino que revisaram, a História da Ciência seria meio para ensinar Física; já durante a apresentação do episódio de ensino, a Física não foi abordada através da História da Ciência. (SORPRESO; ALMEIDA, 2010, p. 51)

Logo, podemos identificar algumas situações que podem levar os docentes em formação à inação:

* as implicações metodológicas e epistemológicas da HFCrECN;

* a incoerência entre o discurso/teoria e a sua efetivação na prática;

* as dificuldades envolvidas no planejamento didático de uma aula de Física, Química ou Biologia, histórica e filosoficamente 
fundamentada;

* a necessidade da inserção da abordagem da HFCrECN na formação docente;

* o quão complexo é a mudança e o desenvolvimento da cultura experimental (científica);

* o quão complexo é a tomada de decisão didática nas práticas educativas;

* a inação serve de prelúdio para pensar, seriamente, - em termos de instâncias decisórias (ID) - como poderá ser a tomada de decisão para implementação dos pressupostos do movimento da HFCrECN no ambiente escolar;

* a inação server para despertar a visão do quanto há a ser feito pelo movimento da HFCrECN.

Ou ainda, como referido em outro trabalho, já mencionado anteriormente:

\begin{abstract}
Ainda que as professoras tenham apontado a importância dos elementos discutidos durante o curso para o ensino de Ciências e sua intenção de seguir utilizando as inovações debatidas, não temos elementos que indiquem quais serão as repercussões da experiência desenvolvida para a carreira docente. (GATTI; NARDI, 2010)
\end{abstract}

Esses problemas mencionados por esses autores ocorreram em outros trabalhos estudados, embora não ditos direitamente como aqui mencionados. Resulta, então, saber quais os resultados efetivos da aprendizagem científica decorrente da HFCrECN? O quanto e com que qualidade se aprende ciências com e sem a HFCrECN? Difícil de responder? Então, parecer tender a responder que a HFC não constitui uma condição necessária para haver aprendizagem científica significativa!

De fato, não podemos fazer da HFC a dententora de respostas para a resolução das crises de aprendizagem ou de ensino, mas pode ser um bom coadjuvante.

Se se adotar a HFC como conteúdo de escolarização não se satisfazem as interpelações apresentadas acima. Talvez, adotando a HFC enquanto perspectiva de reflexividade crítica seja possível responder àquelas indagações. $\mathrm{A}$ reflexividade e criticidade atualizadas, isto é situadas na historicidade do problema, podem fazer com que a HFC seja condição necessária para que haja reflexividade 
crítica situada historicamente. Ou, dito de outra forma, podemos dizer que a HFC é necessária para que haja uma aprendizagem reflexiva crítica, criativa e situada sócio-historicamente.

Por outro lado, a insistência e permanência na prescrição teórica sobre o que e como (poderia), hipoteticamente, a HFC contribuir para com o ensino e a aprendizagem das ciências naturais não é uma postura metodológica e estrategicamente salutar, em relação aos processos de ensino e aprendizagem, seria como se um médico cirurgião estivesse no púlpito da sua cátedra prescrevendo a colegas da saúde como deveriam proceder para fazer a cirurgia em andamento, mas sem ele mesmo nunca ter posto às suas mãos no bisturi e operar. Então, qual seria a base fundante de seu discurso? A mera imaginação ou intuição? Não. Não se opera nem se ensina com a imaginação.

A abordagem episódica ou esporádica da HFC-ECN também parece-nos que tende a torná-la como "folclórica" e "teatral", prelúdio de seu fracasso como linguagem metodológica para ensino e aprendizagem, isto é, está muito longe de se institucionalizar enquanto procedimento de ensino e aprendizagem. A História é algo que se encontra na fronteira do patológico com o normal crível. E, a vida e o trabalho na fronteira são lamacentos. Muitos alegam pertencer a muitos. Nesta mesma vida fronteiriça, também, tem sido lançada a Filosofia, pois notamos que há pouca ênfase no recorte de episódios ou aspectos que representariam a dimensão de análise filosófica, a ênfase é dada, majoritariamente em aspectos históricos.

Constatamos que o âmbito da realização da maioria das pesquisas didáticas intervencionistas ou inclusionistas (HFC-ECN) é o dos estudos pósgraduados, em nível de mestrado e doutorado. Este âmbito não é sempre apropriado para fazer pesquisas didáticas experimentais ou testes de que se possa inferir ou deduzir teorias ou metodologias de ensino e aprendizagem, em virtude do seu caráter e das vicissitudes e ideologias deste nível do campo acadêmico. Quaisquer pretensões de fazer a HFSC influírem nos processos de ensino e aprendizagem deveriam fazê-lo instituindo a HFSC como linguagem metodológica e epistemológica cujas hipóteses sejam comprovadas e os procedimentos de seu uso descrito e baseados em evidências ratificadoras das prescrições teóricas e políticas.

Há também, metodologicamente, os seguintes riscos: o de transformar o ensino e aprendizagem do conhecimento científico em ensino e aprendizagem do conhecimento histórico-filosófico e; o de fazer uma mistura que não tenha impacto 
significativo na aprendizagem discente, que gere mudança de mentalidade, ampliação da cultura e contribua para formação de mentalidade científica crítica.

O tema suscita outras indagações ainda, tais como: como introduzir a HFC no ECN em sala de aula? Quais, efetivamente, os procedimentos metodológicos da práxis didática que os docentes poderiam utilizar em suas aulas para inserir conteúdos da HFC na abordagem dos conteúdos científicos escolares? $\mathrm{Ou}$, quais procedimentos possibilitariam ensinar ciência contextualizada e depurada de vícios ideológicos pífios e pseudocientíficos? Esses problemas, entre outros, solicitam respostas de profunda severidade metodológica e engajamento investigativo-didático experimental que perpassa pela profissionalização docente, para tentar responder à altura aos problemas didáticos e aos supostos objetivos da HFC-ECN.

Segundo Matthews (1992, p. 32), uma vez que a HFC se tornar componente curricular na formação docente, então, é necessário levantar a seguinte questão: "que tipo de cursos de HFC são apropriados?" e continua afirmando que há, porém, um consenso de que, para que tais cursos sejam relevantes para os futuros docentes, eles devem ser cursos aplicados ou práticos e que tais cursos devem começar por explorar os problemas que os docentes consideram pertinentes ao desenvolvimento de sua práxis profissional.

Ora, isto implica dizer, necessariamente, que a HFC deve ser inserida e permanecer na profissionalização docente. Fincar nesta os fundamentos teóricopráticos (epistemológico-metodológico-didáticos) necessários, que justifiquem o seu uso no ensino e "motivem" a adesão crítica dos docentes (autoconvencimento), para fomentar a aprendizagem científica significativa e a adesão discente, a posteriori. Do contrário, não se passará de ações anódinas que não terão efetividade na práxis educativa de formação científica. A distância que surgir aí pode se transformar numa espécie de "patologia", pois,

Observadores da vida escolar preocupam-se com a distância, às vezes imensa, entre a pesquisa científica e a prática do ensino nas salas de aulas. Focalizando o ensino de Ciências, pode-se dizer que todo o imenso esforço de investigação e experimentação que levou às revoluções científicas dos últimos séculos, poucas vezes tem penetrado na prática escolar. É possível, no entanto, encontrarmos currículos e programas bastante atualizados, porém submetidos a tratamento didático absoleto, em desacordo com o processo de fazer e de pensar a Ciência, a busca da certeza e o lugar das incertezas que desafiam o futuro, enfim, avessos às condições próprias ao desenvolvimento da Ciência e às exigências de um processo de 
ensino/aprendizagem que faça justiça à inteligência do aluno.

Entre a pesquisa científica e a prática escolar, entretanto, não deveria haver senão aliança, acordo, cumplicidade, coordenação, nunca um vazio e muito menos oposição. (CASTRO, 2004, p. VII)

De fato, a afirmação de Castro é oportuna e acertiva, pois, entre as ID não poderia existir uma espécie de abismo, deveria haver uma intercomunicação e diálogo proativos e mútua sofoscopia ${ }^{111}$ permanente, para acabar com o desvinculamento reinante.

Ademais, os relatos que descrevem trabalhos interdisciplinares para fazer a HFC-ECN são interessantes, mas evidenciam a complexidade metodológica e epistemológica da HFCrECN, primeiro porque a inclusão ao exigir sempre um conjunto de profissionais dificulta repetir o evento em todas as aulas de Física, Química ou Biologia, durante o período letivo; segundo, não há ainda como mensurar a aprendizagem científica consequente da atividade com abordagem HFC, como alguns autores afirmam "como não utilizamos turma de controle, fica impossível dizer se nossos alunos aprenderam mais Física com essa abordagem" (GUERRA; REIS; BRAGA, 2004, p. 241). Porém, "em geral, os alunos mostraram-se bastante motivados com o trabalho. Conforme as aulas iam se desenvolvendo, eles discutiam mais o assunto, colocando inclusive questões que lhes afligiam pessoalmente, como as relações entre ciência e fé" (GUERRA; REIS; BRAGA, 2004, p. 244).

Mas, é dedutível que se pode adquirir informações culturais contextuais sobre produção científica, por sua vez, importantes, mas nem sempre motivadoras, inspiradoras ou instigadoras do aprender a aprender ciências, conforme as competências e habilidades prescritas nos PCN e orientações que os acompanham. Se considerarmos a mobilização feita, por exemplo, pelos autores acima, torna-se praticamente improdutivo e impossível ter de desenvolver todo aparato para cada aula ao longo do semestre letivo.

Percebe-se, então, que a HFC-ECN não proporciona mais ou menos aprendizagem científica, mas sim ampliação de informações sobre a produção científica, a instigação à curiosidade, mas se não for de domínio do docente

111 Sofoscopia introduzimos este conceito para significar saber observar e enxergar refletindo de forma crítica a realidade em sua amplitude possível para poder traçar metas, tomar decisões e estratégias de intervir nela. Sofo (do grego sophós/sophia, sábio/sabedoria) + scopia (do grego, skopein/skopéo, observar, olhar). 
(competência adquirida desde a formação inicial) pode atrapalhar o aprender a aprender ciência (fazendo ciência). A aprendizagem científica implica aprender a fazer ciência, a interpretar e resolver problemas científicos, sociais ou naturais aplicando conhecimentos científicos e tecnológicos, manipulando experimentos, bem como, a aprender a analisar e interpretar criticamente as variáveis intervenientes ao fazer ciência e à tomada de decisões (tais como questões políticas, econômicas, ideológicas, entre outras).

Assim, nossa mentalidade cética não fica sossegada, pois desconfiamos até que ponto teria aí uma relação causal! Mas ao menos nos parece plausível, a ponto de nos aventurarmos a dizer que uma abordagem dos aspectos da HFC sob a perspectiva reflexiva crítica contribuiria bastante para o entendimento das variáveis envolvidas e intervenientes ao processo e contextos da produção do conhecimento científico.

Ainda que cada instância decisória ofereça suporte com as suas decisões: uma oferece prescrições sugestivas (RO), motivações teóricas (PC), preocupação em instrumentação didática crítica (FD) e que HFC seja inserida no ECN, que os docentes sejam formados com uma visão de abordagem HFC, nada nos garante que isso seja, efetivamente, aplicado na sala de aula e chegue aos discentes das Escolas médias ou fundamentais. Uma formação profissional docente adequada e que ofereça visão crítica da produção, distribuição e consumo, relações contextuais do conhecimento científico é extremamente necessária, porém, não é garantia suficiente para fazer com que os discentes que serão ensinados, por docentes formados na abordagem em causa, obtenham também a visão crítica.

\section{c) - Perspectivas}

Entretanto, em nossa razão ainda sobra algo de otimismo. Afirma-se nos RO que "Pode-se dizer que alguém tem competência quando constitui, articula e mobiliza valores, conhecimentos e habilidades diante de situações e problemas não só rotineiros, mas também imprevistos em sua vida cotidiana" (BRASIL, 2006, p. 116). Isto pode ser dito para as ID e se enquadra bem também.

As pesquisas em ensino de ciências naturais, e não somente, apresentam uma distância em relação à prática docente e à realidade escolar, logo, apresentam uma influência reduzida. Seria necessário que as pesquisas e os programas de pós- 
graduação se articulassem com a formação inicial Escolas, que se apoiassem na realidade concreta do trabalho docente e das instituições de ensino para que houvesse houvesse ações significativas. É preciso romper o círculo vicioso que mantém as produções acadêmicas armazenadas nas bibliotecas cujo acesso é feito apenas pelos pesquisadores e estudantes universitários.

Assim, é necessário que no ensino se faça compreender os fenômenos, as formas, os processos e procedimentos, os produtos e os contextos e ideias subjacentes a todos eles. Tradicionalmente esses conhecimentos, compreensões e domínios inerentes, vinculados de forma íntima e necessária, têm sido ignorados nos sistemas de escolarização básica e superior, contribuindo assim para uma inépcia profissional. Para transpor ou romper com tal situação, talvez, o caminho eficiente que dispomos seja pela profissionalização docente, da formação básica universitária à formação permanente. Este engajamento é conjugado com a: reformulação curricular e didática (integração teoria e prática, Escola e Universidade e Sociedade); a mudança comportamental (atitudes proativas); a mudança nas mentalidades (no pensar que guia as ações); a flexibilidade normativa e a salubridade no trabalho docente decente (condições).

Nossa observeção é que a HFCrECN requer, fundamentalmente, que os docentes possuam um arcabouço teórico-prático (empírico-racional) contínuo no desenvolvimento profissional, que perpassa pela sua formação inicial e continuada e chegue à prática docente investigativa. Este arcabouço asseguraria aos docentes um engajamento profissional com base em uma metodologia dinâmica, interativa e sistêmica que Ihes permitiria a análise e seleção de conteúdos, material didático e paradidático, planejamento de estratégias didáticas e comunicativas alicerçadas na análise histórico-filosófico-sociológica integrada e sistêmica do conhecimento científico e seus contextos de produção, expansão e consumo, bem como, os contextos didáticos da escola, dos discentes e dos próprios docentes. Assim, ter-seia uma cultura analítica, crítica e criativa que liberta as práticas educativas das prisões dos livros didáticos e dos engodos das burocracias.

Em outras palavras, é necessário introduzir os docentes de ciências naturais a um estudo fundamental da análise filosófica, histórica e sociológica dos contextos, das situações e dos problemas postos pela tecnociência, de tal modo que seja possível pensar estratégias de abordagem integrada no ensino em sala de aula, no laboratório ou campo. É preciso 
Dotar o professor de uma formação mais ampla do conhecimento científico tornou-se imprescindível para a melhoria do ensino. Isto passou a significar aperfeiçoar sua capacidade de analisar: os problemas na origem da proposição dos conceitos; os embates entre as novas e antigas concepções científicas; a função dos obstáculos epistemológicos no processo de produção de conhecimento. Essa tarefa se constitui numa busca de aproximação entre a natureza, o conteúdo e a organização do saber que se pretende ensinar. (OLIVEIRA, 2003, p. 141-142)

A inclusão da HFC no ECN encontrará vários empecilhos práticos, não obstante sua relevância teórica. O primeiro obstáculo a ser vencido é a sua inserção e permanência na formação inicial e adesão docente; o segundo, a comprovação de que seu uso seja catalisador da aprendizagem científica; terceiro, a produção de materiais didáticos de abordagem integrada; quarto, as condições curriculares (distribuição e gestão do tempo curricular); quinto, as condições escolares e políticas; entre outros.

Que a HFC seja sempre incluída como perspectiva de reflexão crítica na formação docente porque nela está a garantia de sua contribuição nos processos de ensino e aprendizagem, que na formação continuada se atualize 0 instrumental oferecido na formação básica. A formação inicial constitui o espaço inicial da atualização ontológica, epistemológica e metodológica do ser profissional, é, então, como se fosse o "núcleo atômico" do desenvolvimento profissional, núcleo a ser atingido, nesse caso, pela substância da abordagem dos aspectos da HFC para fazer com que esta se esparrame como "prótons" e, dialeticamente, como "nêutrons" na prática da atuação profissional docente.

Preocupanos ainda o fato de os docentes estarem cercados de uma rede complexa de obstáculos que vão desde a formação inicial (lacunas formativas) até a vida profissional, essa rede de obstáculo imobiliza o engajamento docente numa prática didática significativa, em que se possa pensar mudanças diversas, entre as quais, a HFCrECN.

A ausência da atualização de que nos referimos pode ser percebida em relatos como esse apresentado por docente participante da pesquisa de Silva et al. (2002): "É importante ressaltar que na nossa graduação (Física) estes tópicos [de HFC] não são abordados, o que gerou uma grande lacuna na minha formação." 
Então, as autoras descrevem o estado obstaculizante:

Quanto à inserção nas salas de aula, parece ainda mostrar-se incipiente pois a novidade e o despreparo do docente na formação inicial, em relação aos temas, a organização escolar, as condições de trabalho (elevado número de horas aula e alunos, diversidade de escolas entre outras) e a cultura criada pelos textos didáticos não favorecem as mudanças. (SILVA et al., 2002)

Porém, essa inserção não deve se restringir a oferta de disciplinas de HC ou FC, já constatamos que nem sempre nestas disciplinas tradicionais se estabelecem relações com o ensino, o que implica dizer que em termos disciplinares seria necessários disciplinas próprias dedicados a abordar estratégias de ensino usando várias ferramentas, recursos, entre os quais a HFC, como recurso de problematização situada na historicidade, pois "[...] a opção didática pela História da Ciência deve acontecer de forma articulada com a Filosofia da Ciência, a fim de ajudar na análise crítica do conhecimento científico produzido e na transposição didática dos conteúdos" (OKI e MORADILLO, 2008, p. 70).

As referidas disciplinas seriam eminentemente práticas e investigativa, a pesquisa, o planejamento didático curricular e as propostas de aulas e de produção materiais didáticos deveriam ser o centro da instrumentação didática, para inserir HFCrECN e outros recursos ou linguagens, tais como: construção de estratégias didáticas, de propostas de aulas, de análises comparativas, de tal forma que mesmo que venham a faltar fundamentos da formação filosófica e historiográfica, supomos que, pelo menos, a instrumentação didática em HFCrECN, será um começo plausível para vislumbrar resultados significativos, que possam contribuir para a construção identitária, a resignificação do labor docente e a contextualização crítica no ensino das ciências.

Aliás, ao falar em identidade, esta é também um problema que se reflete no processo da construção e consolidação do movimento HFCrECN. A questão identitária merece nossa reflexão. Durante a pesquisa percebemos que não é uma questão resolvida. Uns acreditam e falam em HC outros HFC, outros ainda ficam ao meio. Surgindo várias histórias, ora História Social da Ciência ora História Filosófica da Ciência e assim em diante. Ora vinculada à departamentos de História ou de Filosofia ou de Ciências, ou então, formam-se departamentos próprios. Há quem defenda, "para mim a História da Ciência é importante porque é minha área de 
pesquisa e por ser uma das vertentes da História, da pesquisa histórica e hoje a História trabalha com uma variedade de temas inclusive a História da Ciência" (DFG). A questão da Identidade é outra que também está muito longe de ser resolvida e ela influi decisivamente nas propostas de HFCrECN. Os problemas de identidade estão longe de serem resolvidos, mas são urgentes, podem anteceder ao estabelecimento de quaisquer relações de interface ou serem resolvidos durante.

Finalmente, é notório o esforço teórico - internacional e nacionalmente de reconhecimento da relevância da HFC no ensino de ciências naturais (e até sociais e linguagens), para introduzir discussões dos variados contextos materiais e imateriais que confluem na produção, comercialização e consumo dos produtos da atividade científico-tecnológica (conhecimentos, artefatos e conseqüências plausíveis ou não). No entanto, em termos nacionais, é bom verificar que há uma preocupação cada vez mais crescente entre os pesquisadores docentes com a temática. Nos eventos cada vez mais se criam mesas redondas e eixos temáticos de HFSC, além dos próprios RO, tudo isso constitui uma mudança histórica e um reconhecimento da importância da HFSC ao ECN. Bem como existem programas de pós-graduação que contribuem para formação de pesquisadores na área de HFSC, reconhecendo que a Sociologia da Ciência ainda é muito pouco explorada em nossa realizada nacional. 


\section{REFERÊNCIAS}

ALFONSO-GOLDFARB, Ana Maria. O que é História da Ciência. São Paulo: brasiliense, 1994.

AMARAL, Elisabete Aparecida do; ZANETIC, João. Uma Abordagem Histórica da Teoria da Relatividade no Ensino Médio. In: ENCONTRO DE PESQUISA EM ENSINO DE FíSICA, 7., 2000. Florianópolis, SC. Resumos eletrônicos... São Paulo: Sociedade Brasileira de Física, 2000. Disponível em: < http://www.sbf1.sbfisica.org.br/eventos/epef/vii/programa1.htm>. Acesso em: 21 jan. 2011.

ARBOLEDA, Luis Carlos. Historia y enseñanza de las matemáticas. In: Quipu Revista Latinoamericana de Historia de las Ciencias y la Tecnologia, Mexico, v. 1, n. 2, may.-ago., 1984.

BACHELARD, Gaston. A Epistemologia. Tradução de Fátima L. Godinho e Mário C. Oliveira. Lisboa: Edições 70, 2001.

BACHELARD, Gaston. A Formação do Espírito Científico: contribuição para uma psicanálise do conhecimento. Tradução de Estela dos Santos Abreu. Rio de Janeiro: Contraponto, 1996. 316p.

BASTOS, Fernando. História da Ciência e pesquisa em ensino de ciências: breves considerações. In: NARDI, Roberto (Org.). Questões Atuais no Ensino de Ciências. São Paulo: Escrituras, 1998. p. 43-52. (Série Educação para a Ciência, vol. 2).

BARBOSA, Roberto G.; BARROS, Marcelo A.; IRANMINA, Alice Sizuko. Aprendendo Óptica Geométrica com base na História da Ciência e em Concepções Alternativas. In: SIMPÓSIO NACIONAL DE ENSINO DE FÍSICA, 13., 2003. Curitiba, PR. Programa e Resumos... Curitiba: CEET-PR/UFPR, 2003. P. 147.

BARROS, Marcelo Alves. Uma Aproximação entre a História da Ciência e o Ensino de Física: o debate Huyghens-Newton em Sala de Aula. In: SIMPÓSIO NACIONAL DE ENSINO DE FÍSICA, 13., 1999. Brasília, DF. Caderno de Programação e Resumos... Brasília, DF: Universidade de Brasília, 1999. p. 134-135.

BAUER, Martin W.; GASKELL, George (Ed.). Pesquisa Qualitativa com Texto, Imagem e Som: um manual prático. $7^{a}$ Ed. Tradução de Pedrinho A. Guareschi. Petrópolis: Vozes, 2008.

BOCANEGRA, Carlos H.; SILVA, Luciano F.; ANDRADES, Agnaldo Aparecido F. A Natureza da Ciência e o Processo Educativo: relato de uma experiência de ensino realizada em uma Escola pública de ensino médio. In: SIMPÓSIO NACIONAL DE ENSINO DE FÍSICA, 17., 2007. São Luiz, MA. Programa e Resumos... São Luiz: UEMA/UFMA/CEET-MA, 2007. p. 124. Disponível em: $<$ <ttp://www.sbf1.sbfisica.org.br/eventos/snef/xvii/>. $\quad O u$ 
<http://www.sbf1.sbfisica.org.br/eventos/snef/xvii/programa/XVIISNEF_programa_e_ resumos.pdf>. Acesso em: Acesso em: 22 jan. 2011.

BOSS, Sergio Luiz Bragatto; SOUZA FILHO, Moacir P. de; CALUZI, João José. História da Ciência e Aprendizagem Significativa: o experimento de Coloumb. In: ENCONTRO NACIONAL DE PESQUISA EM EDUCAÇÃO EM CIÊNCIAS, 7., Florianópolis, SC, 2009. Resumos... Florianópolis, SC: ABRAPEC, 2009. Disponível em: <http://www.fae.ufmg.br/abrapec/viempec/7enpec/index.html>. Acesso em: 22 jan. 2011.

BOSS, Sérgio L. Bragatto; SOUZA FILHO, Moacir P. de; LISBOA FILHO, Paulo N.; CALUZI, João José. História da Ciência e Aprendizagem Significativa: o conceito de carga elétrica. In: ENCONTRO DE PESQUISA EM ENSINO DE FÍSICA, 11., 2008. Curitiba, PR. Caderno de Resumos... São Paulo: Sociedade Brasileira de Física, 2008. Disponível também em: <http://www.sbf1.sbfisica.org.br/eventos/epef/xi/>. Acesso em: 21 jan. 2011.

BRASIL. Lei no 10.172, de janeiro de 2001. Aprova o Plano Nacional de Educação e dá outras providências. Brasília: MEC, 2001. Disponível em: <https://www.planalto.gov.br/ccivil_03/leis/leis_2001/l10172.htm>. Acesso em: $31 / 08 / 2010$.

BRASIL. Lei no 9.394, de 20 de dezembro de 1996. Estabelece as diretrizes e bases da educação nacional. Brasília: MEC, 1996. Disponível em: <http://www.planalto.gov.br/ccivil_03/Leis/L9394.htm>. Acesso em: 31 jun. 2010.

BRASIL. Ministério da Educação. Conselho Nacional de Educação, Câmara de Educação Básica. Resolução no 3 de 26 de junho de 19998. Dispões sobre as Diretrizes Curriculares Nacionais para o Ensino Médio. Brasília: MEC/CNE/CEB, 1998. Disponível em: <http://portal.mec.gov.br/cne/arquivos/pdf/rceb03_98.pdf>. Acesso em: 20 set. 2010.

BRASIL. Ministério da Educação. Conselho Nacional de Educação, Câmara de Educação Básica. Parecer CEB/CNE, no 15/98. Brasília: MEC, CNE/CEB, 1998a. Disponível em: <http://portal.mec.gov.br/index.php?option=com_content\&view=article\&id=13254:par ecer-ceb-1998\&catid=323:orgaos-vinculados\&ltemid=866>. Acesso em: 31/08/2010.

BRASIL. Ministério da Educação. Conselho Nacional de Educação, Câmara de Educação Básica. Resolução CEB/CNE, no 3/98. Brasília: MEC, CNE/CEB, 1998 b. Disponível em: $<$ http://portal.mec.gov.br/index.php?option=com_content\&view=article\&id=13204:res olucao-ceb-1998\&catid=323:orgaos-vinculados\&ltemid=866>. Acesso em: $31 / 08 / 2010$.

BRASIL. Ministério da Educação. Instituto Nacional de Estudos e Pesquisas Educacionais Anísio Teixeira (INEPE). Matriz de Referência para o ENEM 2009. Disponível em: <http://enem.inep.gov.br/enem.php>. Acesso em: 30 nov. 2010.

BRASIL. Ministério da Educação. Secretaria de Educação Básica. Orientações Curriculares para Ensino Médio. Volume 2 - Ciências da Natureza, Matemática e 
suas Tecnologias. Brasília: MEC/SEB, 2006.

BRASIL. Ministério da Educação. Secretaria de Educação Média e Tecnológica. Parâmetros Curriculares Nacionais (Ensino Médio). Parte I - Bases Legais. Brasília: $\quad$ MEC/Semtec, $2000 . \quad$ Disponível em: <http://portal.mec.gov.br/index.php?option=com_content\&view=article\&id=12598:pub licacoes\&catid=195:seb-educacao-basica>. Acesso em: 21 jun. 2010.

BRASIL. Ministério da Educação. Secretaria de Educação Média e Tecnológica. Parâmetros Curriculares Nacionais (Ensino Médio). Parte III - Ciências da Natureza, Matemática e suas Tecnologias. Brasília: Ministério da Educação, [1999 ou 2000]. Disponível em: $<$ http://portal.mec.gov.br/index.php?option=com_content\&view=article\&id=12598:pub licacoes\&catid=195:seb-educacao-basica>. Acesso em: 21 jun. 2010.

BRASIL. Ministério da Educação. Secretaria de Educação Média e Tecnológica. Orientações Educacionais Complementares aos Parâmetros Curriculares Nacionais (PCN+) - Ciências da Natureza, Matemática e suas Tecnologias. Brasília: Ministério da Educação, 2002. Disponível em: $<$ http://portal.mec.gov.br/index.php?option=com_content\&view=article\&id=12598:pub licacoes\&catid=195:seb-educacao-basica>. Acesso em: 21 jun. 2010.

BRASIL. Ministério da Educação. Secretaria de Educação Média e Tecnológica. PCN+Ensino Médio: orientações educacionais complementares aos Parâmetros Curriculares Nacionais - Ciências da Natureza, Matemática e suas Tecnologias. Brasília: MEC/Semetec, 2002.

BOGDAN, Robert C.; BIKLEN, Sari Knopp. Investigação Qualitativa em Educação. Tradução de Maria João Alvarez, Sara Bahia dos Santos e Telmo Mourinho Baptista. Porto: Porto Editora, 1994.

CARVALHO, Anna Maria Pessoa de. História e Filosofia da Ciência no Ensino de Física. In: ENCONTRO DE PESQUISA EM ENSINO DE FÍSICA, 10., 2006. Londrina, PR. Caderno de Resumos... São Paulo: Sociedade Brasileira de Física, 2006. $\quad$ p. $26 . \quad$ Disponível também em: <http://www.sbf1.sbfisica.org.br/eventos/epef/x/>. Acesso em: 21 jan. 2011.

CARVALHO, Letícia dos Santos; MARTINS, André Ferrer P. História da Ciência na Formação de Professores das Séries Iniciais: uma proposta com quadrinhos. In: ENCONTRO NACIONAL DE PESQUISA EM EDUCAÇÃO EM CIÊNCIAS, 7., Florianópolis, SC, 2009. Resumos... Florianópolis, SC: ABRAPEC, 2009. Disponível em: <http://www.fae.ufmg.br/abrapec/viempec/7enpec/index.html>. Acesso em: 22 jan. 2011.

CASTRO, Amelia Domingues de. Prefácio. In CARVALHO, Anna Maria Pessoa de (Org.). Ensino de Ciências: unindo a pesquisa e a prática. São Paulo: Pioneira Thomson Learning, 2004. p. VII-XI.

CHASSOT, Attico. Alfabetização Científica: questões e desafios para educação. $3^{\underline{a}}$ ed. ljuí: Editora Unijuí, 2003.

CHASSOT, Attico. Sete Escritos sobre Educação e Ciência. São Paulo: Cortez, 
2008.

CORRÊA, André Luis; ARAUJO, Elaine S. Nicolini Nabuco de; MEGLHIORATTI, Fernanda Aparecida; CALDEIRA, Ana Maria de Andrade. História e Filosofia da Biologia como Ferramenta no Ensino de Evolução na Formação Inicial de Professores de Biologia. In: ENCONTRO HISTÓRIA E FILOSOFIA DA BIOLOGIA, [8]., São Paulo, SP, 2010. Resumos... São Paulo, SP: ABFHiB, 2010. p. 10-11. Disponível em: <http://www.abfhib.org/Eventos-antigos.html>. Acesso em: Acesso em: 20 jan. 2011.

CRESWELL, John W. Projeto de Pesquisa: métodos qualitativo, quantitativo e misto. Tradução de Luciana de Oliveira da Rocha. 2ª ed. Porto Alegre: Artmed, 2007.

CUNHA, Ana Maria de Oliveira; KRASILCHIK, Myriam. A FORMAÇÃO CONTINUADA DE PROFESSORES DE CIÊNCIAS: percepções a partir de uma experiência.

<http://www.anped.org.br/reunioes/23/textos/0812t.PDF>. Acesso em: 3 mar. 2011.

DEBUS, Allen G. Ciência e história: o nascimento de uma nova área. In ALFONSOGOLDFARB, Ana Maria; BELTRAN, Maria Helena R. (Orgs). Escrevendo a história da ciência: tendências, propostas e discussões historiográficas. São Paulo: Educ/Livraria da Física/FAPESP, 2004. p. 13-36.

EL-HANI, Charbel Niño. Notas sobre o Ensino de História e Filosofia da Biologia na Educação Superior. In: ENCONTRO NACIONAL DE PESQUISA EM EDUCAÇÃO EM CIÊNCIAS, 5., Bauru, SP, 2005. Resumos... Bauru, SP: ABRAPEC, 2005. p. 67.

FERNANDES, Bruno Castilhos; DIAS, Penha M. Cardoso; SANTOS, Wilma M. Soares. Uma Prática de Ensino da $1^{\underline{a}}$ Lei de Newton utilizando a História da Física. In: SIMPÓSIO NACIONAL DE ENSINO DE FÍSICA, 16., 2005. Rio de Janeiro, RJ. Programa e Resumos... Rio de Janeiro: CEET-RJ, 2005. p. 117. Disponível em: <http://www.sbf1.sbfisica.org.br/eventos/snef/xvi/sys/resumos/T0370-2.pdf>. Acesso em: Acesso em: 21 jan. 2011.

FERRAZ, Márcia H. Mendes; HINO, H.; SICCA, Natalina Ap. Laguna. História da Ciência no ensino de Química no $2^{\circ}$ grau. Revista da Sociedade Brsileira de História da Ciência, Rio de Janeiro, v. 3, p. 78-79, 1989.

FERREIRA, Maira. História da Química e Problematização no Ensino de Reações Químicas. In: ENCONTRO NACIONAL DE ENSINO DE QUÍMICA, 14., 2008. Curitiba, PR. Resumos... Curitiba, PR: UFPR, 2008. Disponível em: <http://www.quimica.ufpr.br/eduquim/eneq2008/resumos/>. Acesso em: Acesso em: 20 jan. 2011.

FLICK, Uwe. Introdução à Pesquisa Qualitativa. 3ª ed. Tradução de Joice Elias Costa. Porto Alegre: Artmed, 2009.

FORATO, Thais C. de Mello; MARTINS, Roberto de Andrade; PIETROCOLA, Maurício. Teorias da Luz e Natureza da Ciência: elaboração e análise de curso aplicado no ensino médio. In: ENCONTRO DE PESQUISA EM ENSINO DE FÍSICA, 11., 2008. Curitiba, PR. Caderno de Resumos... São Paulo: Sociedade Brasileira de Física, 2008. Disponível também em: 
<http://www.sbf1.sbfisica.org.br/eventos/epef/xi/>. Acesso em: 21 jan. 2011.

FORATO, Thaís C. de Mello; MARTINS, Roberto de A; PIETROCOLA, Maurício. A História e a Natureza da Ciência no Ensino de Ciências: obstáculos a superar ou contornar. In: ENCONTRO DE PESQUISA EM ENSINO DE FÍSICA, 12., 2010. Águas de Lindóia, SP. Caderno de Resumos... São Paulo: Sociedade Brasileira de Física, 2010. Disponível também em: <http://www.sbfisica.org.br/ epef/xii/>. Acesso em: 21 jan. 2011.

FREIRE, Paulo. Pedagogia da Autonomia: saberes necessários à prática educativa. 36aㅡ ed. São Paulo: Paz e Terra, 1996. (Col. Leitura).

FREITAS, Fábio $H$. de Alencar; FREIRE JR., Olival. O PLANO INCLINADO GALILEANO: notas sobre uma tomada de dados com estudantes do ensino superior. In: SIMPÓSIO NACIONAL DE ENSINO DE FÍSICA, 16., 2005. Rio de Janeiro, RJ. Programa e Resumos... Rio de Janeiro: CEET-RJ, 2005. p. 119-120. Disponível em: <http://www.sbf1.sbfisica.org.br/eventos/snef/xvi/sys/resumos/T00051.pdf>. Acesso em: Acesso em: 21 jan. 2011.

GASKELL, George. Entrevistas Individuais e Grupais. In BAUER, Martin W.; GASKELL, George (Ed.). Pesquisa Qualitativa com Texto, Imagem e Som: um manual prático. $7^{\underline{a}}$ ed. Tradução de Pedrinho A. Guareschi. Petrópolis, RJ: Vozes, 2008.

GATTI, Sandra R. Teodoro; NARDI, Roberto. História e a Filosofia da Ciência no Ensino de Física: análise de práticas pedagógicas realizadas em atividades de formação continuada de professores. In: ENCONTRO NACIONAL DE PESQUISA EM EDUCAÇÃO EM CIÊNCIAS, 7., Florianópolis, SC, 2009. Resumos... Florianópolis, SC: ABRAPEC, 2009. Disponível em: <http://www.fae.ufmg.br/abrapec/viempec/7enpec/index.html>. Acesso em: 22 jan. 2011.

GATTI, Sandra Regina Teodoro; NARDI, Roberto. Práticas Pedagógicas Realizadas em Atividades de Formação Continuada: a aproximação da História e Filosofia da Ciência ao ensino de Física. In: ENCONTRO DE PESQUISA EM ENSINO DE FíSICA, 12., 2010. Águas de Lindóia, SP. Caderno de Resumos... São Paulo: Sociedade Brasileira de Física, 2010. Disponível também em: <http://www.sbfisica.org.br/ epef/xii/>. Acesso em: 21 jan. 2011.

GATTI, Sandra Regina Teodoro; NARDI, Roberto; SILVA, Dirceu da. A História da Ciência na Formação do Professor de Física: subsídios para um curso sobre o tema atração gravitacional visando às mudanças de postura na ação docente. Ciência \& Educação, Bauru-SP, v. 10, n.3, p. 491-500, 2004.

GATTI, Sandra Regina Teodoro; NARDI, Roberto; SILVA, Dirceu da. História da Ciência no Ensino de Física: um estudo sobre o ensino de atração gravitacional desenvolvido com futuros professores. Investigações em Ensino de Ciências, v. 15, n. 1, p. 7-59, 2010.

GEBARA, Maria José. Questões Relativas à História da Ciência e ao Ensino de Ciências. In: ENCONTRO NACIONAL DE PESQUISA EM EDUCAÇÃO EM 
CIÊNCIAS, 5., Bauru, SP, 2005. Resumos... Bauru, SP: ABRAPEC, 2005. p. 422.

GEBARA, Maria José F. O Ensino e a Aprendizagem de Física; Contribuições da História da Ciência e do movimento das Concepções Alternativas. In: SIMPÓSIO NACIONAL DE ENSINO DE FÍSICA, 13., 2003, Curitiba, PR. Programa e Resumos... Curitiba: CEET-PR/UFPR, 2003. p. 91.

GIL, Antonio Carlos. Como Elaborar Projetos de Pesquisa. 5 ed. São Paulo: Atlas, 2010.

GUERRA, Andréa et al. Uma Perspectiva Histórico-Filosófica para o Ensino das Ciências. In: Seminário Nacional de História da Ciência e da Tecnologia, 5. Reunião da Rede de Intercâmbios para a História e a Epistemologia das Ciências Químicas e Biológicas, 3. 1995, Ouro Preto, MG. Anais. São Paulo: Sociedade Brasileira de História da Ciência, 1998. p. 190-198.

GUERRA, Andreia; BRAGA, Marco; REIS, José Claudio. Um Curso de Cosmologia na Primeira Série do Ensino Médio com enfoque Histórico-Filosófico. In: SIMPÓSIO NACIONAL DE ENSINO DE FÍSICA, 18., 2009, Vitória, ES. Programa... Vitória, ES: UFES, 2009. Disponível em: <http://www.sbf1.sbfisica.org.br/eventos/snef/xviii/>. Acesso em: Acesso em: 22 jan. 2011.

GUERRA, Andreia; REIS, José C.; BRAGA, Marco. Uma Abordagem HistóricoFilosófica para o Eletromagnetismo no Ensino Médio. Caderno Brasileiro de Ensino de Física, Florianópolis, v. 21, n. 2, p. 224-248, ago., 2004.

GUERRA, Andreia; REIS, José Cláudio; BRAGA, Marco. Uma Abordagem HistóricoFilosófica para o Eletromagnetismo no Ensino Médio. In: SIMPÓSIO NACIONAL DE ENSINO DE FÍSICA, 13., 2003. Curitiba, PR. Programa e Resumos... Curitiba: CEET-PR/UFPR, 2003. p. 153.

GUIMARÃES, Márcio T.; CARVALHO, Washington I. P. de; OLIVEIRA, Mônica Santos. Raciocínio Moral na Tomada de Decisões em Relação a Questões Sociocientíficas: o exemplo do melhoramento genético. Ciência \& Educação, Bauru-SP, v. 16, n. 2, p. 465-477, 2010.

HÜLSENDEGER, Margarete J. V. C. A História da Ciência no Ensino da Termodinâmica: um outro olhar sobre o ensino de Física. Ensaio - Pesquisa em Educação em Ciências, Belo Horizonte, v. 9, n. 2, p. 191-205, 2007.

IGARASHI, Ricardo N.; SANTOS, Ney S.; IRAMINA, Alice S.; BARROS, Marcelo A. As Contribuições da História da Ciência no Ensino da Óptica Física. In: SIMPÓsIO NACIONAL DE ENSINO DE FÍSICA, 13., 2003. Curitiba, PR. Programa e Resumos... Curitiba: CEET-PR/UFPR, 2003. P. 147.

IRISH COUNCIL FOR SCIENCE, TECNOLOGY AND INNOVATION-ICSTI. Ensino da Ciência no Nível Fundamental a Médio. Forfás/lrlanda, outubro,1999. Tradução de Sylvio de Queirós Mattoso. In: TECBAHIA Revista Baiana de Tecnologia, Bahia, v. 19, n. 1, jan.-abr., p. 26-39, 2004.

JENKINS, E. W. The history of science in British schools: retrospect and prospect. Intenational Journal of Science Education, London, v. 12, n. 3, p. 274-281, 1990. 
KAPITANGO-A-SAMBA, K. kya. Papel da História da Ciência nas Licenciaturas em Ciências Naturais e Matemática. Dissertação (Mestrado em História da Ciência). São Paulo: Pontifícia Universidade Católica de São Paulo - PUC-SP, 2005.

KUHN, Thomas Samuel. Tensão Essencial. Tradução de Rui Pacheco. Lisboa: Edições 70, 1989.

LAKATOS, Imre. História da Ciência e suas Reconstruções Racionais e Outros Ensaios. Tradução de Emília Picado T. M. Mendes, Lisboa: Edições 70, [1998?].

LONGHINI, Marcos D.; NARDI, Roberto. Como age a pressão atmosférica? Algumas situações-problemas tendo como base a História da Ciência e pesquisa na área. Caderno Brasileiro de Ensino de Física, Florianópolis, v. 26, n. 1, p. 7-23, abr., 2009.

LÚCIO, Veja A História da Física: uma nova perspectiva para o ensino de Física. In: SIMPÓSIO NACIONAL DE ENSINO DE FÍSICA, 13., 2003. Curitiba, PR. Programa e Resumos... Curitiba: CEET-PR/UFPR, 2003. P. 146.

LÜDKE, Menga. Pesquisa em Educação: abordagens qualitativas. São Paulo: EPU, 1986. (Temas básicos de educação e ensino).

MAGALHÃES, Murilo de F.; SANTOS, Wilma M S.; DIAS, Penha M. C. Uma Proposta para Ensinar os Conceitos de Campo Elétrico e Magnético: uma aplicação da História da Física. Revista Brasileira de Ensino de Física, v. 24, n. 4, p. 489496, dez., 2002.

MAIA, Dayane R. Andrade; MION, Fejane Aurora. Educação Científica e Tecnológica: a incorporação da curiosidade epistemológica no ensino de física. In: ENCONTRO NACIONAL DE PESQUISA EM EDUCAÇÃO EM CIÊNCIAS, 5., Bauru, SP, 2005. Resumos... Bauru, SP: ABRAPEC, 2005. p. 163.

MAIENSCHEIN, Jane. Why Study History for Science? Biology and Philosophy, Netherlands, n. 15, p. 339-348, 2000.

MARTINS, Roberto de Andrade. Que tipo de História da Ciência Esperamos ter nas próximas Décadas? Episteme, Porto Alegre, v. 10, p. 39-56, jan.-jun., 2000.

MARTINS, Gilberto de Andrade; THEÓPHILO, Carlos Renato. Metodologia da Investigação Científica para Ciências Sociais Aplicadas. São Paulo: Atlas, 2007.

MATOS, Kédima F. de Oliveira. História da Ciência X Ensino de Química: um estudo de caso a cerca da visão. In: ENCONTRO NACIONAL DE ENSINO DE QUÍMICA, 14., 2008. Curitiba, PR. Resumos... Curitiba, PR: UFPR, 2008. Disponível em: <http://www.quimica.ufpr.br/eduquim/eneq2008/resumos/>. Acesso em: Acesso em: 20 jan. 2011.

MATTOS, Rodrigo A.; FILHO, Jomar B.; SILVA, Dirceu. Estudo do Uso de Textos sobre História da Eletricidade para Cursos de Física do Nível Médio. In: SIMPÓSIO NACIONAL DE ENSINO DE FÍSICA, 13., 2003. Curitiba, PR. Programa e Resumos... Curitiba: CEET-PR/UFPR, 2003. p. 82. 
MANTOVANI, lara F.; Oliveira, Brno F.; BARROS, Marcelo A.; IRANMINA, Alice Sizuko. Buscando a História da Ciência para estudar o Conceito de Inércia. In: SIMPÓSIO NACIONAL DE ENSINO DE FÍSICA, 13., 2003. Curitiba, PR. Programa e Resumos... Curitiba: CEET-PR/UFPR, 2003. p. 148.

MATEUS, Alfredo Luis; PORTO, Paulo Alves; FANTINI, Leandro H. A História Química da Radioatividade: incluindo fenômeno em uma abordagem histórica dos modelos atômicos. In: ENCONTRO NACIONAL DE ENSINO DE QUÍMICA, 15. 2010. Brasília, DF. Resumos... Brasília, DF: UnB, 2010. Disponível em: <http://www.quimica.ufpr.br/eduquim/eneq2008/resumos/>. Acesso em: Acesso em: 20 jan. 2011.

MATTHEWS, Michael R. History, Phylosophy, and Science Teaching: the present rapprochement. Science \& Education, Netherlands, v. 1, n. 1, p. 11-47, 1992.

MATTHEWS, Michael R. History, Philosoph, and Science Teaching. [Science Teaching: the Role of History and Philosophy of Science]. New York/London: Routledge, 1994.

MATTHEWS, Michael R. James T. Robinson's Account of Philosophy of Science and Science Teaching: some lessons for today from the 1960s. Science Education, London, v. 81, n. 3, jun., 1997.

MATTHEWS, Michael R. History, Philosophy, and Science Teaching: the new engagement. Asia-Pacific Forum on Science Learning and Teaching, Hong Kong, v. $10, \quad$ n. 1 , p. 1-14, Jun. 2009. Disponível em: <http://www.ied.edu.hk/apfslt/v10_issue1/foreword/>. Acesso em: 08 dez 2009.

McGINN, Colin. Como se faz Filosofia. Lisboa: Bizâncio, 2007. Disponível em: <http://criticanarede.com/fm_01.html>. Acesso em: 08 dez 2009.

MEDINA, Márcio Nasser; BRAGA, Marco. Ensinar Física para os Alunos do Século $\mathrm{XXI}$ : uma proposta metodológica interdisciplinar que alia a História da Ciência, o Teatro e a Física. In: SIMPÓSIO NACIONAL DE ENSINO DE FÍSICA, 18., 2009. Vitória, ES. Programa... Vitória, ES: UFES, 2009. Disponível em: <http://www.sbf1.sbfisica.org.br/eventos/snef/xviii/>. Acesso em: Acesso em: 22 jan. 2011.

MENDES, Maria I. Porazza; FIGUEIROA, Silvia F. de Mendonça. A Terra sob Medida - debates de História da Ciência em espaços virtuais de aprendizagem. In: ENCONTRO NACIONAL DE PESQUISA EM EDUCAÇÃO EM CIÊNCIAS, 5., Bauru, SP, 2005. Resumos... Bauru, SP: ABRAPEC, 2005. p. 113.

MONTEIRO, Maria Amélia; NARDI, Roberto. A Utilização da História da Ciência no Ensino de Física: investigação do espectroscópio de chamas. In: SIMPÓSIO NACIONAL DE ENSINO DE FÍSICA, 17., 2007. São Luiz, MA. Programa e Resumos... São Luiz: UEMA/UFMA/CEET-MA, 2007. p. 75. Disponível em: <http://www.sbf1.sbfisica.org.br/eventos/snef/xvii/>. Ou <http://www.sbf1.sbfisica.org.br/eventos/snef/xvii/programa/XVIISNEF_programa_e_ resumos.pdf>. Acesso em: Acesso em: 22 jan. 2011.

MOREIRA, M. A.; MASINI, E. F. S. A Aprendizagem Significativa. A Teoria de 
David Ausubel. São Paulo: Editora Moraes, 1982.

NASCIMENTO, Hemerson H. Ferreira do et al. A História da Ciência como Instrumento Humanizador no Ensino de Química. In: ENCONTRO NACIONAL DE ENSINO DE QUÍMICA, 15., 2010. Brasília, DF. Resumos... Brasília, DF: UnB, 2010. Disponível em: <http://www.quimica.ufpr.br/eduquim/eneq2008/resumos/>. Acesso em: Acesso em: 20 jan. 2011.

NARDI, Roberto; TEODORO, Sandra Regina. Subsídios para a construção de Atividades de Ensino sobre o Conceito de Gravitação de Gravidade a partir das Concepções. In: SIMPÓSIO NACIONAL DE ENSINO DE FÍSICA, 13., 1999. Brasília, DF. Caderno de Programação e Resumos... Brasília, DF: Universidade de Brasília, 1999. p. 216-217.

NEVES, Marcos C. Danhoni et al. Uma Discussão sobre o Mapeamento Conceitual da Relatividade e da Cosmologia para o Ensino de Física Moderna e Contemporânea. In: ENCONTRO NACIONAL DE PESQUISA EM EDUCAÇÃO EM CIÊNCIAS, 5., Bauru, SP, 2005. Resumos... Bauru, SP: ABRAPEC, 2005. p. 447.

NIELSEN, Henry e THOMSEN, Poul V. History and Philosophy of Science in Physics Education. International Journal of Science Education, London, v. 12, n. 3, p. 308316, 1990.

NIETZSCHE, Friedrich Wilhelm. Segunda Consideração Intempestiva: da utilizadade e desvantagem da história para a vida. Tradução de Marco Antônio Casanova. Rio de Janeiro: Relume Dumará, 2003. (Col. Conexões, 20).

NUCLEAR TECNOLOGIA E CONSULTORIA. A Energia Nuclear no Brasil. Disponível em: <http://www.nuctec.com.br/educacional/enbrasil.html>. Acesso em: 30 nov. 2010.

OKI, Maria da C. Marinho; MORADILLO, Edílson Fortuna de. O Ensino de História da Química: contruindo para a compreensão da natureza da ciência. Ciência \& Educação, Bauru-SP, v. 14, n. 1, p. 67-88, 2008.

OLIVEIRA, Maurício Pietrocola de. A História e a Epistemologia no Ensino de Ciências: dos processos aos modelos de realidade na educação científica. In ANDRADE, Ana Maria Ribeiro de (Org.). Ciência em Perspectiva. Estudos, Ensaios e Debates. Rio de Janeiro: MAST:SBHC, 2003. (Coleção História da Ciência - Série Estudos da Ciência, v. 1). p. 133-149.

PEDUZZI, Luiz O. Q. Do Átomo Grego ao Átomo de Bohr: receptividade inicial e perspectivas de pesquisa de um texto voltado para uma disciplina de evolução dos conceitos da física. In: ENCONTRO NACIONAL DE PESQUISA EM EDUCAÇÃO EM CIÊNCIAS, 5., Bauru, SP, 2005. Resumos... Bauru, SP: ABRAPEC, 2005. p. 67.

PEREIRA, Jaene Guimarães; FORATO, Thaís C. de Mello; SILVA, Ana Paula B. da. A Natureza da Ciência através de um Episódio Histórico sobre a luz: adaptações metodológicas. In: ENCONTRO DE PESQUISA EM ENSINO DE FÍSICA, 12., 2010. Águas de Lindóia, SP. Caderno de Resumos... São Paulo: Sociedade Brasileira de Física, 2010. Disponível também em: <http://www.sbfisica.org.br/ epef/xii/>. Acesso em: 21 jan. 2011. 
PEREIRA, Ricardo F.; FUKUI, Renato M.; BARROS, Marcelo; IRANMINA, Alice Sizuko. Utilizando Contextos Históricos como abordagem no Ensino Médio. In: SIMPÓSIO NACIONAL DE ENSINO DE FÍSICA, 13., 2003. Curitiba, PR. Programa e Resumos... Curitiba: CEET-PR/UFPR, 2003. p. 154.

PINTO, Alexandre Custódio; ZANETIC, João. Contribuições das Filosofias da Ciência para uma Reflexão sobre as (Re)Concepções do Ensino de Física. In: ENCONTRO DE PESQUISA EM ENSINO DE FÍSICA, 7., 2000. Florianópolis, SC. Resumos eletrônicos... São Paulo: Sociedade Brasileira de Física, 2000. Disponível em: < http://www.sbf1.sbfisica.org.br/eventos/epef/vii/programa1.htm>. Acesso em: 21 jan. 2011.

PORTELA, Sebastião I. C.; LARANJEIRAS [sic], Cássio C. O Estudo de Casos de História da Ciência como estratégia de articulação da Dimensão Cultural da Ciência em Sala de Aula. In: ENCONTRO NACIONAL DE PESQUISA EM EDUCAÇÃO EM CIÊNCIAS, 5., Bauru, SP, 2005. Resumos... Bauru, SP: ABRAPEC, 2005. p. 216.

PRADO, Fernando D. A Graduação em Física na USP. Dissertação (Mestrado em Educação). São Paulo: Universidade de São Paulo-USP, 1980.

PROJETO HIPST - History and Philosophy in Science Teaching. Disponível em: <http://hipst.eled.auth.gr/index.htm>, ou ainda, em: <http://didaktik.physik.unikl.de/hipst/about\%20HIPST.html>. Acesso em: 11 mar. 2010.

QUINTAL, João Ricardo; MORAES, Andréa Guerra de. A História da Ciência no Processo Ensino-Aprendizagem. In: SIMPÓSIO NACIONAL DE ENSINO DE FÍSICA, 18., 2009. Vitória, ES. Programa... Vitória, ES: UFES, 2009. Disponível em: <http://www.sbf1.sbfisica.org.br/eventos/snef/xviii/>. Acesso em: Acesso em: 22 jan. 2011.

RAPOSO, Washington; GUERRA, Andreia. Epistemologia na Educação Científica: um caminho para discutir a ciência em sala de aula? In: ENCONTRO NACIONAL DE PESQUISA EM EDUCAÇÃO EM CIÊNCIAS, 7., Florianópolis, SC, 2009. Resumos... Florianópolis, SC: ABRAPEC, 2009. Disponível em: <http://www.fae.ufmg.br/abrapec/viempec/7enpec/index.html>. Acesso em: 22 jan. 2011.

REIS, José Claudio; GUERRA, Andreia; BRAGA, Marco. Da Necessidade de Valorizar a História e a Filosofia da Ciência na Formação de Professores. In: ENCONTRO DE PESQUISA EM ENSINO DE FÍSICA, 12., 2010. Águas de Lindóia, SP. Caderno de Resumos... São Paulo: Sociedade Brasileira de Física, 2010. Disponível também em: <http://www.sbfisica.org.br/ epef/xii/>. Acesso em: 21 jan. 2011.

RICARDO, Elio Carlos. Competências, Interdisciplinaridade e Contextualização: dos Parâmetros Curriculares Nacionais a uma compressão para o ensino das ciências. Tese (Doutorado em Educação Científica e Tecnológica). Florianópolis, SC: UFSC, 2005.

ROCHA, José F. Moura. O Conceito de «campo» em sala de aula: uma abordagem histórico-conceitual. Revista Brasileira de Ensino de Física, v. 31, n. 1, p. 489-496, 
dez., 2002.

ROSA, Katemari; PENIDO, Maria C. Martins. A Inserção de História e Filosofia da Ciência no Ensino de Ciências e a Formação de Professores de Física. In: ENCONTRO NACIONAL DE PESQUISA EM EDUCAÇÃO EM CIÊNCIAS, 5., Bauru, SP, 2005. Resumos... Bauru, SP: ABRAPEC, 2005. p. 292.

SALES, Nilva L. L.; SANTOS, Renata R. A Ciência Através dos Tempos: uma integração entre física e história. In: SIMPÓSIO NACIONAL DE ENSINO DE FÍSICA, 13., 2003. Curitiba, PR. Programa e Resumos... Curitiba: CEET-PR/UFPR, 2003. Disponível em: <http://www.sbf1.sbfisica.org.br/eventos/snef/xv/>. Acesso em: 21 jan. 2011.

SANCHEZ, Dario Ferreira, PAZ JÚNIOR, Emílio Merino de. Proposta de uma Aula com enfoque experimental sobre a Refração da Luz: o fenômeno e sua história. In: SIMPÓSIO NACIONAL DE ENSINO DE FİSICA, 17., 2007. São Luiz, MA. Programa e Resumos... São Luiz: UEMA/UFMA/CEET-MA, 2007. p. 74. Disponível em: $<$ http://www.sbf1.sbfisica.org.br/eventos/snef/xvii/>.

$<$ http://www.sbf1.sbfisica.org.br/eventos/snef/xvii/programa/XVIISNEF_programa_e_ resumos.pdf>. Acesso em: Acesso em: 22 jan. 2011.

SANTOS, Alexssandro Ferraz dos; CARDOSO, Tereza Fachada Levy. Uma Proposta para Ensinar os Conceitos de Hidrostática: Santos Dumont e a História da Ciência. In: SIMPÓSIO NACIONAL DE ENSINO DE FÍSICA, 17., 2007. São Luiz, MA. Programa e Resumos... São Luiz: UEMA/UFMA/CEET-MA, 2007. p. 98. Disponível em: <http://www.sbf1.sbfisica.org.br/eventos/snef/xvii/>. Ou <http://www.sbf1.sbfisica.org.br/eventos/snef/xvii/programa/XVIISNEF_programa_e_ resumos.pdf>. Acesso em: Acesso em: 22 jan. 2011.

SANTOS, Wilma M. Soares; DIAS, Penha M. Cardoso. A História da Física como "Organizador Prévio". In: SIMPÓSIO NACIONAL DE ENSINO DE FÍSICA, 16., 2005. Rio de Janeiro, RJ. Programa e Resumos... Rio de Janeiro: CEET-RJ, 2005. p. 116-117. Disponível

em: <http://www.sbf1.sbfisica.org.br/eventos/snef/xvi/cd/resumos/T0370-1.pdf>. Acesso em: Acesso em: 21 jan. 2011.

SAMPIERI, Roberto Hernández. Metodologia de Pesquisa. Tradução de Fátima Conceição Murad, Melissa Kassner e Sheila Clara Dystyler Ladeira. 3a ed. São Paulo: McGraw-Hill, 2006.

SLONGO, lônes Inês Pinsson. História da Ciência, Ensino de Biologia e Formação de Professores. In: ENCONTRO NACIONAL DE ENSINO DE BIOLOGIA, 1., ENCONTRO REGIONAL DE ENSINO DE BIOLOGIA, 3., Rio Janeiro, RJ, 2005. Anais... Rio de Janeiro, RJ: SBENBIO, 2005. p. 794-798.

SICCA, Natalina Aparecida Laguna; FERRAZ, Márcia Helena Mendes. História da Ciência e Ensino de Química: da Legislação à Formação do Profissional. In: SOCIEDADE BRASILEIRA DE HISTÓRIA DA CIÊNCIA. Seminário Nacional de História da Ciência e Tecnologia, 5, 1995. Reunião da Rede de Intercâmbios para a História e a Epistemologia das Ciências Químicas e Biológicas, 3, 1995. Caderno de Resumos. Ouro Preto: Sociedade Brasileira de História da Ciência, 1995. p. 97-98. 
SILVEIRA, Alessandro F. da; ATAíDE, Ana R. P. de; SILVA, Ana Paula B. da; FREIRE, Morgana L. de Farias. Natureza da Ciência numa Proposta de Seqüencia Didática: explorando os pensamentos de Aristóteles e Galileu sobre o movimento relativo. In: SIMPÓSIO NACIONAL DE ENSINO DE FÍSICA, 18., 2009. Vitória, ES.

Programa... Vitória, ES: UFES, 2009. Disponível em: <http://www.sbf1.sbfisica.org.br/eventos/snef/xviii/>. Acesso em: Acesso em: 22 jan. 2011.

SILVERMAN, David. Interpretação de Dados Qualitativos: métodos para análise de entrevistas, textos e interações. $3^{\underline{a}}$ ed. Tradução de Magda França Lopes. Porto Alegre: Artmed, 2009.

SILVA, Aparecida Valquiria Pereira da et al. A História e a Filosofia da Ciência Susidiando a Construção de Atividade Didáticas para o Ensino Médio de Física em Nível Médio. In: ENCONTRO DE PESQUISA EM ENSINO DE FÍSICA, 8., 2002. Águas de Lindóia, SP. Resumos eletrônicos... São Paulo: Sociedade Brasileira de Física, 2002. Disponível em: <http://www.sbf1.sbfisica.org.br/eventos/epef/viii/>. Acesso em: 21 jan. 2011.

SILVA, Fausthon Fred da; NETO, José E. Simões; NAVARRO, Daniela M. do A. F. A História da Química como Elemento Motivador nas Aulas de Química Experimental. In: ENCONTRO NACIONAL DE ENSINO DE QUÍMICA, 14., 2008. Curitiba, PR. Resumos... Curitiba, PR: UFPR, 2008. Disponível em: $<$ http://www.quimica.ufpr.br/eduquim/eneq2008/resumos/>. Acesso em: Acesso em: 20 jan. 2011.

SILVA, Luciano Fernandes; BOCANEGRA, Carlos Henrique; OLIVEIRA, Josely Kobal de. A Compreensão dos Alunos do Ensino Médio em Relação aos Aspectos da Natureza da Ciência. In: SIMPÓSIO NACIONAL DE ENSINO DE FÍSICA, 16., 2005. Rio de Janeiro, RJ. Programa e Resumos... Rio de Janeiro: CEET-RJ, 2005. p. $182 . \quad$ Disponível em: <http://www.sbf1.sbfisica.org.br/eventos/snef/xvi/sys/resumos/T0496-1.pdf>. Acesso em: Acesso em: 21 jan. 2011.

SILVA, Marcelo de Souza; TEIXEIRA, Elder Sales. Um Estudo de Caso acerca da Influência de uma Abordagem Contextual na Compreensão do Conceito de Inércia de Estudantes de Física. In: SIMPÓSIO NACIONAL DE ENSINO DE FíSICA, 17., 2007. São Luiz, MA. Programa e Resumos... São Luiz: UEMA/UFMA/CEET-MA, 2007. p. 164. Disponível em: <http://www.sbf1.sbfisica.org.br/eventos/snef/xvii/>. Ou $<$ http://www.sbf1.sbfisica.org.br/eventos/snef/xvii/programa/XVIISNEF_programa_e_ resumos.pdf>. Acesso em: Acesso em: 22 jan. 2011.

SILVA, Paulo Sérgio Araújo da; CHAVES, Sílvia Nogueira. Epistemologia, Ética e Política na Formação de Professores de Ciências. Ensaio - Pesquisa em Educação em Ciências, Belo Horizonte, v. 11, n. 2, p. 230-244, 2009.

SILVA, Rafael H. Santos; LIMA, Uálace dos Santos; ARAUJO, Renato Santos. Uma Proposta de uso das Abordagens de Arte e História da Ciência para a Educação Básica. In: SIMPÓSIO NACIONAL DE ENSINO DE FÍSICA, 18., 2009. Vitória, ES. Programa... Vitória, ES: UFES, 2009. Disponível em: <http://www.sbf1.sbfisica.org.br/eventos/snef/xviii/>. Acesso em: Acesso em: 22 jan. 
2011.

SOARES, Reginaldo Ribeiro; BORGES, Paulo de Faria. O Plano Inclinado de Galileu e a História da Ciência na Sala de Aula do Ensino Médio de Física. In: ENCONTRO DE PESQUISA EM ENSINO DE FÍSICA, 11., 2008. Curitiba, PR. Caderno de Resumos... São Paulo: Sociedade Brasileira de Física, 2008. Disponível também em: <http://www.sbf1.sbfisica.org.br/eventos/epef/xi/>. Acesso em: 21 jan. 2011.

SORPRESO, Thirza P.; ALMEIDA, Maria José P. Monteiro de. Discursos de Licenciandos em Física sobre a Questão Nuclear no Ensino Médio: foco na abordagem histórica. Ciência \& Educação, Bauru-SP, v. 16, n. 1, p. 37-60, 2010.

SOUZA, Roseli Ovale, ARAÚJO, Mauro S. Teixeira de; GUAZZELLI, lara R. Bocchese; MACIEL, Maria Delourdes. Concepções dos Estudantes sobre a Ciência, os Cientistas e o Método Científico: uma abordagem histórico-crítica como base de uma proposta de intervenção visando a resignificação destes conceitos. In: SIMPÓSIO NACIONAL DE ENSINO DE FÍSICA, 17., 2007. São Luiz, MA. Programa e Resumos... São Luiz: UEMA/UFMA/CEET-MA, 2007. p. 99. Disponível em: $<$ http://www.sbf1.sbfisica.org.br/eventos/snef/xvii/>. $<$ http://www.sbf1.sbfisica.org.br/eventos/snef/xvii/programa/XVIISNEF_programa_e_ resumos.pdf>. Acesso em: Acesso em: 22 jan. 2011.

SOUZA FILHO, Moacir Pereira de; BOSS, Sérgio L. Bragatto; CALUZI, João José. Diferenças e Semelhanças entre Eletricidade e Magnetismo: o diálogo histórico entre o erro e a verdade subsidiando o ensino de física. In: ENCONTRO DE PESQUISA EM ENSINO DE FÍSICA, 11., 2008. Curitiba, PR. Caderno de Resumos... São Paulo: Sociedade Brasileira de Física, 2008. Disponível também em: <http://www.sbf1.sbfisica.org.br/eventos/epef/xi/>. Acesso em: 21 jan. 2011.

STAUB, Ana Carolina. A História e a Filosofia da Ciência em uma Disciplina de Evolução dos Conceitos da Física. In: ENCONTRO NACIONAL DE PESQUISA EM EDUCAÇÃO EM CIÊNCIAS, 6., Florianópolis, SC, 2007. Resumos... Florianópolis, SC: ABRAPEC, 2007.2 Disponível em: <http://www.fae.ufmg.br/abrapec/viempec/7enpec/index.html>. Acesso em: 22 jan. 2011.

STAUB, Ana C. M.: PEDUZZI, Luiz O. Q. O Papel da Epistemologia em uma Disciplina de Evolução dos Conceitos da Física. In: SIMPÓSIO NACIONAL DE ENSINO DE FÍSICA, 13., 2003. Curitiba, PR. Caderno de Programação e Resumos... Curitiba: CEET-PR/UFPR, 2003. p. 151.

TEIXEIRA, Elder Sales; FREIRE JR, Olival Um Estudo sobre a Influência da História e Filosofia da Ciência na Formação de Estudantes de Física. In: SIMPÓSIO NACIONAL DE ENSINO DE FÍSICA, 17., 2007. São Luiz, MA. Programa e Resumos... São Luiz: UEMA/UFMA/CEET-MA, 2007. p. 146. Disponível em: $<$ http://www.sbf1.sbfisica.org.br/eventos/snef/xvii/>.

$\mathrm{Ou}$ <http://www.sbf1.sbfisica.org.br/eventos/snef/xvii/programa/XVIISNEF_programa_e_ resumos.pdf>. Acesso em: Acesso em: 22 jan. 2011.

THEORETICAL BASIS OF THE HIPST PROJECT. Material em PDF recebido, no 
dia 18/03/2009, por e-mail enviado pelo Professor Dr. Ricardo Lopes Coelho, da Secção Autónoma de História e Filosofia das Ciências, da Universidade de Lisboa e integrante do Projeto HIPST.

VERZOTO, José Carlos; ROSSI, Adriana Vitorino. Favorecendo o Ensino e Estimulando a Aprendizagem de Equilíbrio Químico com Demonstração Experimental e Histórica da Ciência. In: ENCONTRO NACIONAL DE ENSINO DE QUÍMICA, 14., 2008. Curitiba, PR. Resumos... Curitiba, PR: UFPR, 2008. Disponível em: <http://www.quimica.ufpr.br/eduquim/eneq2008/resumos/>. Acesso em: Acesso em: 20 jan. 2011.

VIEIRA, Kátia M. Dias; BATISTA, Irinéa de Lourdes. A Abordagem Histórica no Ensino de Física e o Aprendizado do Conceito Físico de Movimento. In: SIMPÓSIO NACIONAL DE ENSINO DE FíSICA, 16., 2005. Rio de Janeiro, RJ. Programa e Resumos... Rio de Janeiro: CEET-RJ, 2005. p. 90. Disponível em: <http://www.sbf1.sbfisica.org.br/eventos/snef/xvi/cd/resumos/T0434-1.pdf >. Acesso em: Acesso em: 21 jan. 2011.

WINCH, Christopher. Dicionário de Filosofia da Educação. Tradução de Renato Marques de Oliveira, São Paulo: Contexto, 2007. 
ANPÊNDICES E ANEXOS 


\section{APÊNDICE - TERMO DE CONSENTIMENTO LIVRE E ESCLARECIDO}

Concordo em participar, como voluntário, do projeto de pesquisa intitulado História e Filosofia da Ciência no Ensino de Ciências Naturais entre o Consenso e as Perspectivas que tem como pesquisador responsável Kilwangy kya Kapitango-aSamba, doutorando do Programa de Pós-Graduação em Educação (Ensino de Ciências e Matemática), da Faculdade de Educação da Universidade de São Paulo, orientado por Prof. Dr. Elio Carlos Ricardo, que podem ser contatados pelo e-mail kskamba1@gmail.com ou telefone (065) 9931-4262 e cujos objetivos são:

1. Analisar as orientações teóricas dos documentos oficiais brasileiros para o ensino médio e a formação docente, no que se refere a inclusão da História e Filosofia da Ciência no Ensino de Ciências Naturais (ex.: LDB; PCN; PCN+; Matrizes Curriculares de Referência para o SAEB; Orientações Curriculares para o Ensino Médio; Matrizes de Referência do ENEM; Diretrizes Curriculares dos Cursos de Graduação);

2. Analisar as orientações teóricas das pesquisas acadêmicas da área de ensino de ciências naturais;

3. Analisar os ementários curriculares das disciplinas da área de metodologia de ensino de ciências naturais (Física, Biologia e Química) e das de HFC nos cursos de formação inicial docente (caso USP);

4. Analisar as concepções dos docentes formadores dos cursos de licenciaturas em ciências naturais (caso USP);

5. Contribuir para os estudos sobre a interface entre História e Filosofia da Ciência e Ensino de Ciências Naturais (ênfase na Formação Docente).

E minha participação consistirá em apresentar as minhas ideias oriundas da minha experiência docente.

Compreendo que este estudo possui finalidade de pesquisa, que os dados obtidos serão divulgados seguindo as diretrizes éticas da pesquisa, com a preservação do anonimato dos participantes, assegurando, assim minha privacidade. Sei que posso abandonar a minha participação na pesquisa quando quiser e que não receberei nenhum pagamento por esta participação.

Nome e Assinatura

São Paulo, /2010. 


\section{ANEXO $1^{\circ}$ - EMENTÁRIOS DE LICENCIATURA EM FÍSICA}

Obrigatórias

EDM0425 - Metodologia do Ensino de Física I

EDM0426 - Metodologia do Ensino de Física II

\section{Disciplina optativa}

FAP0356/4300356 - Elementos e Estratégia para Ensino de Física

FEP0390/4300390 - Práticas em Ensino de Física

FMT0405/4300405 - Evolução dos Conceitos da Física

FEP0353/4300353 - Tópicos de Histórica da Física Clássica

FGE0454/4300454 - Tópicos de História da Física Moderna

\section{DISCIPLINAS OBRIGATÓRIAS}

\section{EDM0425 - Metodologia do Ensino de Física I}

\section{Faculdade de Educação}

Metodologia do Ensino e Ed Comparada

\section{Disciplina: EDM0425 - Metodologia do Ensino de Física I}

Créditos Aula: 4

Créditos Trabalho: 2

Carga Horária Total: 120 h ( Estágio: 60 h )

Tipo:

Semestral

Ativação: $\quad 01 / 01 / 2011$

\section{Objetivos}

a) Fornecer subsídios teóricos e vivências de situações práticas para que o licenciando integre os conhecimentos científicos da área, os conhecimentos didáticos gerais sobre educação, os conhecimentos específicos sobre o ensino da física no nível médio e os conhecimentos sobre os contextos de atuação. b) Desenvolver autonomia docente que possibilite uma atitude de permanente avaliação e aprimoramento dos conhecimentos teóricos e práticos. 


\section{Docente(s) Responsável(eis) $)^{112}$}

\section{Programa Resumido}

Problemas e perspectivas atuais da organização curricular do ensino de física no nível médio. Caracterização do ensino veiculado nas escolas e re-conhecimento da sala de aula. Desenvolvimento, aplicação e análise de intervenções em atividades de estágio em situação escolar. Reconhecimento de potencialidades do ensino de Física em contextos não-formais.

\section{Programa}

a) Práticas e abordagens vigentes na escola e as propostas oficiais para o ensino de física no nível médio: organização curricular; concepções sobre ensino, aprendizagem e ciências e suas relações com procedimentos pedagógicos; estratégias didáticas utilizadas nas aulas do Ensino Médio. b) As relações didáticas entre professor e alunos e entre alunos: relações discursivas na sala de aula; contrato didático c) Atividades de estágio em uma perspectiva investigativa e inovadora: observação e reconhecimento da escola e das práticas educativas relativas ao Ensino de Física; elaboração, implementação e análise de propostas didáticas; observação de situações de atendimento em instituições de educação não-formal (museus e centros de ciências, observatórios, etc)

Obs: As atividades de estágio ocorrerão concomitantemente e de forma integrada ao demais temas do programa

\section{Avaliação \\ Método}

Aulas expositivas e de discussão, trabalhos em grupo, laboratório didático, entrevista e trabalho de campo, micro ensino e simulação de aulas

\section{Critério}

Provas, trabalhos em classe e relatórios.

\section{Norma de Recuperação}

Prova escrita e/ou trabalho (somente para aqueles que tenham realizado os estágios).

$1^{\circ}$ semestre: $1^{\text {a }}$ quinzena de julho.

\section{Bibliografia}

ABIB, M. L. V. dos S. Uma Abordagem Piagetiana para o Ensino da Flutuação dos Corpos. Textos Pesquisa para o Ensino de Ciências, no 2, Faculdade de Educação da Universidade de São Paulo, 1988. ABD ABDALLA, Maria Cristina B.. O discreto charme das partículas elementares. São Paulo: Editora UNESP, 2006. ARAÚJO, M. S. T.; ABIB, M. L. V. S. Atividades Experimentais no Ensino de Física: Diferentes Enfoques, Diferentes Finalidades. Revista Brasileira de

\footnotetext{
${ }^{112}$ Em todas as Disciplinas, preferimos retirar os nomes dos docentes, por questões éticas e mesmo porque nem sempre são os mesmo docentes a lecionarem as disciplinas sempre.
} 
Ensino de Física, v. 25, n. 2, p. 176-194, 2003. ASTOLFI, Jean-Pierre. A didática das ciências Trad. Magda S. S. Fonseca. Campinas-SP:

ASTOLFI, Jean-Pierre et al. As palavras-chave da didática das ciências. Lisboa: Instituto Piaget, 2002. AQUINO, J. G. A indisciplina e a escola atual. Revista da Faculdade de Educação, São $\quad$ Paulo, $\quad$ v.24, $\quad$ n.2, 1998. BACHELARD, Gaston. A formação do espírito científico: contribuição para uma psicanálise do conhecimento. Trad. Estela dos Santos Abreu. Rio de Janeiro: Contraponto, 1996.

BORGES, M.R.R. Em debate: Cientificidade e educação em ciências. Porto Alegre: $\quad$ SE/CECIRS, 1996.p.9 a p.73,1996. BRASIL. PCN+ Ensino Médio, Orientações Educacionais Complementares, aos Parâmetros Curriculares Nacionais, FÍSICA. MEC/SENTEC. CACHAPUZ, A., GIL- PEREZ, D., CARVALHO, A.M.P., PRAIA, J., VILCHES, A. (2005). A Necessária Renovação do Ensino das Ciências. São Paulo, Editora Cortez.

CARVALHO, A. M. P. de; GIL-PEREZ, D. Formação de Professores de Ciências. São Paulo, Cortez, 1993. CHALMERS, A.F. O que é Ciência, afinal? São Paulo: Brasiliense, 2003. DELIZOICOV, Demétrio; ANGOTTI, José A. P.. Física. São Paulo: 1992. EINSTEIN, Albert; INFELD, Leopold. A evolução da física. Trad. Giasone Rebuá. Rio de Janeiro: Jorge Zahar Ed., 2008. FEYNMAN, Richard Philips. Física em 12 lições. Trad. Ivo Korytowski. Rio de Janeiro: Ediouro, 2005. GIL-PEREZ, A. VILCHES, M. EDWARDS, J. F. PRAIA, P. VALDÉS, M. L. VITAL, H. TRICÁRIO E C. RUEDA, A. Educação científica e a situação do mundo: um programa de atividades dirigido a professores. Revista Ciência \& Educação. V.9, n.3, 2003. LEMKE, J. Investigar para el futuro de la educación científica: nuevas formas de aprender, nuevas formas de vivir, University of "Investigación Didátida", Enseñanza de las ciencias, v.24, n.1, 2006. MATEUS, Alfredo Luis. Ciência na tela: experimentos no retroprojetor. Belo Horizonte: Editora UFMG, 2009. MEIRIEU, Philippe. Aprender... sim, mas como. Trad. Vanise Dresch. Porto Alegre: Artes Médicas, 1998. MIZUKAMI, M. G. N. Ensino: as abordagens do processo. São Paulo, E. P. U., 2000.

MOREIRA, M.A. (1985). Ensino e Aprendizagem: Enfoques Teóricos. São Paulo. Editora

Moraes.

PERRENOUD, Philippe. A prática reflexiva no ofício de professor: profissionalização e razão pedagógica. Trad. Cláudia Schilling. Porto Alegre: Artmed Editora, 2002. PERRENOUD, Philippe. Dez novas competências para ensinar. Trad. Patrícia Chittoni Ramos. Porto Alegre: Artes Médicas Sul, 2000. PIETROCOLA, Maurício (org.). Ensino de Física: conteúdos, metodologia e epistemologia numa concepção integradora. Florianópolis: Ed. da UFSC, 2001. SILVA, Cibelle Celestino (org.). Estudos de história e filosofia das ciências: subsídios para aplicação no ensino. São Paulo: Editora Livraria da Física, 2006. TARDIF, Maurice. Saberes Docentes e Formação Profissional. Petrópolis-RJ: 
Vozes, 2002. VILLANI, A. Reflexões Sobre o Ensino de Física no Brasil: Práticas, Conteúdos e Pressupostos. Revista de Ensino de Física, São Paulo, v. 6, n. 2., 1984.

Obs: Serão também utilizados livros didáticos de Física para o Ensino Médio e artigos diversos de periódicos da área de ensino de ciências, como: Revista Brasileira de Ensino de Física. Caderno Catarinense de Ensino de Física. $\begin{array}{lllll}\text { Investigações no } & \text { nnsino } & \text { Ciências }\end{array}$

Ensaio

Ciência

$\&$

Educação

Enseñanza de las Ciencias.

\section{EDM0426 - Metodologia do Ensino de Física II}

\section{Faculdade de Educação}

Metodologia do Ensino e Ed Comparada

Disciplina: EDM0426 - Metodologia do Ensino de Física II

Créditos Aula: 4

Créditos Trabalho: 2

Carga Horária Total: $120 \mathrm{~h}$ (Estágio: $120 \mathrm{~h}$ )

Tipo:

Semestral

Ativação: $\quad 01 / 01 / 2000$

\section{Objetivos}

1. Analisar as opções curriculares do ensino de Física em função de seu desenvolvimento

histórico.

2. Identificar as concepções sobre ensino de Física presentes em materiais didáticos.

3. Interpretar, definir temas e percursos curriculares relevantes ao ensino médio.

4. Vivenciar e analisar atividades que incluam materiais curriculares inovadoras.

5. Elaborar, implementar e avaliar programas de ensino em situação de estágio,

\section{Docente(s) Responsável(eis)}

\section{Programa Resumido}

Tem por meta estabelecer a integração entre os conteúdos de física e os pedagógicos e entre os trabalhos teóricos e as práticas nas escolas de $1^{\circ}$ e $2^{\circ}$ graus. As atividades em aulas e em estágios pretendem levar os alunos, futuros professores, a estudarem tanto as condições determinantes da aprendizagem, do ensino e da produção de conhecimento físico em ambiente escolar como desenvolver, adaptar e avaliar material didático. 
1. O papel do ensino de Física no nível médio.

2. O papel da História das Ciências no ensino de Física.

3. Resolução de problemas abertos no ensino de Física.

4. Propostas para o planejamento curricular para o ensino médio

5. Avaliação do desempenho do aluno.

6. Avaliação das atividades de ensino.

\section{Avaliação}

Método

Aulas expositivas e de discussão, trabalhos em grupo e laboratório didático, entrevista e trabalhos de campo, micro ensino e simulação de aulas.

\section{Critério}

Provas, trabalhos em classe e relatórios.

\section{Norma de Recuperação}

Prova escrita e/ou trabalho (somente para aqueles que tenham realizado os estágios).

2ํㅗㄹ semestre: 1a Quinzena de Dezembro

\section{Bibliografia}

ASTOLFI, Jean-Pierre; Develay, M. (1989) - La Didactique des Sciences Presses Universitaires de France. BENLLOCH, M.; (1984) - Por um aprendizaje constructivista de las ciencias. Propuesta didactica para el ciclo superior de basica. Visur Libros. CARRASCOSA ALIS, J. e outros (1990) - Formacionde Formadores en Didactica de las Ciencias, Universitat de valencia. Nau Libres. DRIVER, R., GUESNE, E. y TIBERGHIEN, A. (1985). Chisdre's ideas in science. (Open University Press: Milton Keynes) Trad. Cast. De P. Manzano, 1989 - Ideas científicas en la infancia y la adolescencia (Morata/MEC:Madrid).. GIL D.; CARRASCOSA, J.; FURIO, C.y. M. Torregrosa (1991) - La Ensenanza de las Ciencias en la Education Secundarie, Ice - Harsori, Universitat de Barcelona.

CARVALHO, A. M. P. (1987) - Prática de Ensino: os estágios na formação do professor. $2^{\text {a }}$ edição, Livraria Pioneira ed., São Paulo. CARVALHO, A. M. P. (1989) - Física: Proposta para um Ensino Cosntrutivista.

Ed. Pedagógica Universitária, PORLAN, R.; GARCIA, J.E. y CANAL, P. (1989) - Cosntrutuvismo y ensenanza de las ciencias. Diada Ed., Sevilha. POZO, J. I. (1987) - Aprendizage de la Ciencia y Pensamiento Causall. Visor Libros Ed. Madrid. PROYECTO CURRICULAR "INVESTIGACION Y RENOVACION ESCOLAR"(IRES), Volumes: I, II e II, Diada Editoras S. L. (1991). GIORDAN, A.; VECCHI, G. (1988) - Los Origenes del Saber, Diada Editoras Sevilha.

ABIB, M. L. V. dos S. (1988). Uma Abordagem Piagetiana para o Ensino da Flutuação dos Corpos. Textos Pesquisa para o Ensino de Ciências, no 2 , Faculdade de Educação da Universidade de São Paulo. CARVALHO, A. M. P. de (1985). Prática de Ensino. Os Estágios na Formação do Professor. São Paulo, Pioneira. CARVALHO, A. M. P. de; GIL-PEREZ, D. (1993). Formação de Professores de 
Ciências.

São

Paulo,

Cortez.

CARVALHO, A. M. P. de; VANNUCCHI, A. I.; BARROS, M. A.; GONÇALVES, M. A. R.; REY, R. C. de (1998). Ciências no Ensino Fundamental. São Paulo, Escrituras

Editora.

NARDI, R. (org.) (1998). Pesquisas em ensino de Física. São Paulo, Escrituras Editora.

SILVA, D. (1990). O ensino construtivista da velocidade angular. Textos Pesquisa para o ensino de Ciências № 3, São Paulo, Faculdade de Educação. TIBERGHIEN A., JOSSEM, E. L.; BAROYAS, J.; (Ed.) (1998); Research in Physics Education with Teacher Education, ICPE book. 15 NARDI, R. (1992) Subsídios para o Ensino de Campo, Texto Pesquisa para o Ensino de Ciências, Faculdade de Educação. Livros Didáticos de Física para o Ensino Médio. Artigos diversos dos seguintes periódicos:

Revista

Caderno

Brasileira

Catarinense

de

Revista

Enseñanza

Investigacioón en la Escuela. de Ensino de Física. de Ensino de Física. Ensino de Ciências. las Ciencias.

\section{DISCIPLINAS OPTATIVAS}

FAP0356/4300356 - Elementos e Estratégia para Ensino de Física

Instituto de Física

Disciplinas Interdepartamentais do Instituto de Física

Disciplina: 4300356 - Elementos e Estratégia para o Ensino de Física

Créditos Aula: $\quad 4$

Créditos Trabalho: 0

Carga Horária Total: $60 \mathrm{~h}$ ( Práticas como Componentes Curriculares $=60 \mathrm{~h}$ )

Tipo:

Semestral

Ativação: $\quad 01 / 01 / 2011$

\section{Objetivos}

Identificar e analisar os principais elementos que compõem o Ensino de Física, visando abordar com maior profundidade e abrangência as várias questões envolvidas no processo pedagógico. Promover a identificação e o entendimento articulado dos elementos que compõem a totalidade do processo envolvido no Ensino de Física. Esta disciplina pretende fornecer uma base para o estudo de outras questões abordadas nas disciplinas que compõem 0 bloco INSTRUMENTAÇÃO do Curso de Licenciatura do IFUSP e das disciplinas de Metodologia de Ensino de Física I e II ministradas na FEUSP. 


\section{Programa Resumido}

\section{Programa}

Construção histórica e individual do conhecimento científico. I) Natureza do conhecimento científico: o papel da ciência; os contextos histórico-sociais de seus desenvolvimentos. A estrutura do conhecimento físico; o significado das teorias, leis e modelos; o papel do formalismo matemático na física. A relação entre ciência, cultura e tecnologia. II) O papel da educação científica e os objetivos da física no Ensino Médio de Física. Diretrizes e propostas curriculares para o Ensino de Física. III) A construção do conhecimento científico no processo de aprendizagem. Concepções alternativas, mudança conceitual e perfil conceitual. IV) Propostas de melhoria do Ensino de Física, na perspectiva da pesquisa e das implicações no ambiente escolar: a inserção da história e da filosofia no desenvolvimento do conteúdo, a utilização de atividades experimentais e/ou lúdicas em sala de aula, o papel do livro didático, a resolução de problemas, a divulgação científica, o cotidiano e o emprego de novas tecnologias no Ensino de Física.

\section{Avaliação}

Método

Aulas expositivas, trabalhos em grupos, discussões coletivas, realização de atividades práticas e Seminários apresentados pelos alunos sobre estratégias de ensino de física.

\section{Critério}

Participação e envolvimento nas leituras, discussões e trabalhos ao longo do curso. Apresentação de seminário sobre estratégia de ensino de física. Apresentação de um relatório final. Prova com consulta aos textos.

\section{Norma de Recuperação}

Disciplina com $2^{a}$ avaliação.

\section{Bibliografia}

Alves, R. Filosofia da Ciência :introdução ao jogo e suas regras. SP:Brasiliense,1981. BRASIL. PCN. Brasília: MEC, 2000. BRASIL. PCN+. Brasília: MEC, 2002. Bunge, M. Filosofia da Física. Lisboa: Edições 70, 1973. Bunge, M. Física e Filosofia. São Paulo: Ed. Perspectiva, 2000. Davis, C.; Oliveira, Z.. Psicologia na educação. São Paulo: Cortez. pp. 16-34. 1994. Freire, P. Pedagogia do oprimido. São Paulo: Paz e Terra, 2005. Heisenberg, W. (1958). Física e filosofia. Brasília: UNB. pp 141-154. 1987. Kneller, G. Ciência como atividade humana. São Paulo: Ed. Zahar/Edusp, 1978. Kuhn, T. (1962). Estrutura das revoluções científicas. São Paulo: Perspectiva. 29-66. 1982. Menezes, L.C.. Projeto Pedagógico: Rever o quê, mudar por quê. Revista Educação e Informática. São Paulo: FDE, v. 10, n. 14, p. 29-34, dez. 2000. Mortimer, E.. Linguagem e formação de conceitos no ensino de ciências. BH: UFMG,35-58,2000 Mortimer, E.F. Construtivismo, mudança conceitual e ensino de ciências: para onde vamos? Investigações em Ensino de Ciências. V(1), pp20-39, 1996. Oliveira, M.K.. Vygotsky: aprendizado e desenvolvimento: um processo histórico. São Paulo: Scipione, 1997. Poincaré, H. (1902) A ciência e a hipótese. Brasília: UNB, 1985. Robilotta, M.R.Construção e Realidade no Ensino 
de Física. São Paulo: IFUSP, 1985. Salém, S. Estruturas conceituais no Ensino de Física. São Paulo: Dissertação de mestrado, IF/FE - USP, 1986. Snyders, G.. A alegria na escola. São Paulo: Manole, 1988. Tayle, Y. A construção do conhecimento. São Paulo: Secretaria de Educação de São Paulo, 1992. Villani, A. Idéias Espontâneas e o Ensino de Física. São Paulo: IFUSP, 1987. Artigos de periódicos, dissertações e teses da área de Ensino de Física/Ciências. Artigos apresentados em eventos da área de Ensino de Física/Ciências.

\section{FEP0390/4300390 - Práticas em Ensino de Física}

\section{Instituto de Física}

\section{Disciplinas Interdepartamentais do Instituto de Física}

\section{Disciplina: 4300390 - Práticas em Ensino de Física}

$\begin{array}{ll}\text { Créditos Aula: } & 2 \\ \text { Créditos Trabalho: } 3\end{array}$

Carga Horária Total: 120 h ( Estágio: 120 h )

$\begin{array}{ll}\text { Tipo: } & \text { Anual } \\ \text { Ativação: } & 01 / 01 / 2009\end{array}$

\section{Objetivos}

Capacitar os alunos para desenvolver, com autonomia, a integração dos conteúdos de Física e pedagógicos, iniciando-os em práticas profissionais. Promover, planejar, organizar e acompanhar atividades de ensino de Física, a serem realizadas pelos alunos do Curso de Licenciatura, como momentos de iniciação profissional. Essas atividades podem incluir, por exemplo, a proposição de seminários, mini-cursos, oficinas, mini-simpósios ou outros eventos, em escolas, centros de formação e/ou atividades vinculadas a projetos de formação continuada de professores. O objetivo da disciplina é, portanto, o de acompanhar as atividades de estágio em um total de 120 horas, distribuidas em horas-aula e horas-atividade. As características das atividades de estágio deverão corresponder às orientações apresentadas do Programa de Formação de Professores da USP.

\section{Programa Resumido}

\section{Programa}

Elementos para um planejamento pedagógico em Ensino de Física. Procedimentos para o desenvolvimento e acompanhamento das atividades. Métodos e práticas de avaliação em Ensino de Física.

\section{Avaliação \\ Método}

As aulas semanais de planejamento conjunto das atividades a serem realizadas. Atividades de discussão e acompanhamento, em grupos, das práticas em desenvolvimento pelos alunos. Atividades Discentes: Realização de atividades 
de Ensino de Física que configurem atividades de estágio e formação profissional. Elaboração de planejamento, desenvolvimento, reflexão crítica e avaliação dessas atividades, assim como relatório em que compareçam esses elementos.

\section{Critério}

Aprovação dos relatórios sobre as atividades desenvolvidas, com comprovação de realização das atividades práticas correspondentes.

Norma de Recuperação

Essa disciplina não inclui segunda avaliação.

\section{Bibliografia}

Livros didáticos de Física para o Ensino Médio. Artigos diversos dos seguintes periódicos: Revista Brasileira de Ensino de Física, Caderno Catarinense de Ensino de Física, Revista de Ensino de Ciências, Enseñanza de las Ciencias, Investigación en la Escuela. Artigos diversos de revistas de divulgação científica.

\section{FMT0405/4300405 - Evolução dos Conceitos da Física}

\section{Instituto de Física}

\section{Disciplinas Interdepartamentais do Instituto de Física}

\section{Disciplina: 4300405 - Evolução dos Conceitos da Física}

Créditos Aula: 2

Créditos Trabalho: 0

Carga Horária Total: $30 \mathrm{~h}$

Tipo:

Ativação:

\section{Objetivos}

1. Proporcionar uma introdução básica sobre a história da ciência e seus diferentes enfoques, metodologias e objetos de estudo. 2. Proporcionar uma introdução básica sobre diferentes correntes epistemológicas que surgiram em função da revolução científica do início do século XX. 3. Exemplificar essa abordagem históricoepistemológica com temas da física clássica e/ou da física contemporânea. 4. Proporcionar uma análise da função social da ciência com base em estudo de temas da física clássica e/ou da física contemporânea.

\section{Programa Resumido}

\section{Programa}

A Física da Antiguidade. A descrição do sistema planetário: Ptolomeu e Copérnico. A Renascença. Galileu, Newton e a Revolução Científica. A Física e a Revolução Industrial. As Revoluções científicas modernas: Einstein e Planck. A Física do mundo Contemporâneo. O papel social da Física. 


\section{Avaliação}

\section{Método}

1. aula expositiva 2. discussão em classe com base em roteiro previamente distribuído.

\section{Critério}

Provas e listas trabalhos extra classe.

\section{Norma de Recuperação}

Com 2a avaliação.

\section{Bibliografia}

1. Textos de evolução dos conceitos especialmente preparados para a disciplina.

2. Max Jammer. "The conceptual development of quantum mechanics". McGraw-Hill, 1966. 3. Jun'ichi Osada. "Evolução das idéias da física". ed. E. Blücher e Edusp, 1972. 4. Mário Schemberg. "Pensando a física". Ed. Brasiliense, 1984. 5. George Gamow. "Treinta años que conmovieron la física". Ed. Universitária de Buenos Aires, 1974. 6. Thomas S. Kuhn. "A estrutura das revoluções científicas". Ed. Perspectiva, 1998. 7. Paul Feyerabend. "Contra o método". Ed. Francisco Alves, 1977. 8. Gaston Bachelard. "O novo espírito científico". Ed. Tempo Brasileiro, 1985.

\section{FEP0353/4300353 - Tópicos de Histórica da Física Clássica}

\section{Instituto de Física}

\section{Disciplinas Interdepartamentais do Instituto de Física}

\section{Disciplina: 4300353 - Tópicos de História da Física Clássica}

Créditos Aula: 2

Créditos Trabalho: 0

Carga Horária Total: $30 \mathrm{~h}$

Tipo:

Semestral

Ativação:

01/01/2009

\section{Objetivos}

- Apresentar o processo de construção das principais teorias físicas, com ênfase na evolução de conceitos, abordando o desenvolvimento da Física até o final do século XIX.

\section{Programa Resumido}

\section{Programa}

O nascimento da Mecânica. A Mecânica Newtoniana. O conceito vis-viva. Euler e Lagrange. A Revolução Industrial e as máquinas a vapor. O calórico e o surgimento 
da Termodinâmica. A indução de Faraday e a construção do eletromagnetismo. A Física Clássica no final do século XIX.

\section{Avaliação}

Método

Aulas expositivas, incluindo eventualmente realização de seminários.

\section{Critério}

Média ponderada de provas, exercícios ou trabalhos, segundo critério a ser especificado pelo docente responsável no início do semestre.

\section{Norma de Recuperação}

Com 2 a avaliação.

\section{Bibliografia}

1) KOYRE, Do mundo fechado ao universo infinito, São Paulo, Edusp, 1979.

2) NEWTON, I., Principia, São Paulo, EDUSP/Nova Stella, 1979.

3) MACH, E., The Science of Mechanics, London, Open Court, 1942.

4) WHITTAKER, A, History of Theories of aether and electricity, London, Nelson, 1951.

5) Artigos originais e de periódicos da área.

\section{FGE0454/4300454 -Tópicos de História da Física Moderna}

\section{Instituto de Física}

\section{Disciplinas Interdepartamentais do Instituto de Física}

\section{Disciplina: 4300454 - Tópicos de História da Física Moderna}

Créditos Aula: 2

Créditos Trabalho: 0

Carga Horária Total: $30 \mathrm{~h}$

Tipo:

Semestral

Ativação:

01/01/2009

\section{Objetivos}

Apresentar e discutir o desenvolvimento conceitual das duas grandes vertentes da física contemporânea: a Mecânica Relativística e a Mecânica Clássica.

\section{Programa Resumido}

\section{Programa}

A crise da Mecânica Clássica no final do século XIX. Surgimento, desenvolvimento e formalização da Mecânica Quântica. Desenvolvimento da Física Nuclear. Desenvolvimento da Física das Partículas Elementares. Partículas Elementares e 
Cosmologia.

\section{Avaliação}

Método

Aulas expositivas, incluindo eventualmente realização de seminários.

\section{Critério}

Média ponderada de provas, exercícios ou trabalhos, segundo critério a ser especificado pelo docente responsável no início do semestre.

\section{Norma de Recuperação}

Com 2 a avaliação.

\section{Bibliografia}

1) JAMMER, M., The Conceptual Development of Quantum Mechanics. McGraw-Hill Book Company,

2) Artigos originais e de periódicos da área.

1966. 


\title{
ANEXO 2ㅇ - EMENTÁRIOS DE LICENCIATURA EM BIOLOGIA
}

\author{
Biologia Ementários Analisados \\ http://www.ib.usp.br/gra/ \\ 09/09/2010
}

\section{Obrigatórias \\ 0410115 - FILOSOFIA DAS CIÊNCIAS BIOLÓGICAS - 2.0}

Introdução à Filosofia das Ciências. - como se alcança como se estabelece e como muda o conhecimento científico; - como a ciência explica os fatos empíricos e que espécie de compreensão nos é dada por suas explicações; - características que distinguem a indagação científica de outros tipos de investigação e conhecimento; a "objetividade" do discurso científico; - que condições devem ser satisfeitas para uma explicação científica ser aceitável; - predisposições dos cientistas e avaliação das teorias científicas; - a ciência como uma forma de conhecimento; - teorias, indução e dedução; - o sucesso do modelo hipotético-dedutivo nas ciências biológicas; - a estratégia científica como atitude de vida; Limites e pressupostos da investigação, do conhecimento e da compreensão científica nas Ciências Biológicas. - os conceitos de comprobabilidade e reprodutibilidade nas Ciências Biológicas; limites da generalização nas Ciências Biológicas; - o sucesso do modelo hipotéticodedutivo nas Ciências Biológicas; O papel das entidades teóricas nas Ciências Biológicas. - função e valor adaptativo; - aptidão; - metas e planos; - teleologia e teleonomia nas Ciências Biológicas; - seleção natural; - unidades de seleção; relações entre ambiente e evolução; - adaptação; - os conceitos de espécie; desenvolvimento em ontogenia; - filogenia; - desenvolvimento em filogenia; progresso e evolução; - complexidade e evolução; - sistemática; - estrutura das diferentes versões da teoria evolucionista; - estrutura da teoria evolucionista Darwiniana; - a teoria genética da evolução; - natureza estatística da teoria evolucionista; - natureza dedutiva da teoria evolucionista; O conceito de ser vivo organicismo versus reducionismo; - a concepção mecanicista da vida; - a concepção sistêmica da vida; - níveis de organização e propriedades emergentes; - as fronteiras entre o inanimado e o vivente; Evolução cultural. - natureza humana; - "memética"; evolução, sociabilidade e ética.

\section{Instituto de Biociências}

\section{Disciplinas Interdepartamentais do Instituto de Biociências}

\section{Disciplina: 0410115 - Filosofia das Ciências Biológicas}

Créditos Aula: 2

Créditos Trabalho: 0

Carga Horária Total: $30 \mathrm{~h}$

Tipo:

Semestral 
Ativação: $\quad$ 01/01/2009 Desativação: 31/12/2009

\section{Objetivos}

O objetivo desta disciplina é estimular a compreensão e avaliação crítica dos métodos, conceitos e teorias da área de Ciências Biológicas por meio da (1) discussão dos pressupostos e limites da explicação, do conhecimento e da compreensão científicas na área de Ciências Biológicas, (2) instrumentação dos alunos para a avaliação de teorias e suas relações com observações,

(3) discussão dos conceitos de ser vivo e de espécie, (4) reflexão sobre as abordagens sistêmica e reducionista nas Ciências Biológicas,

(5) distinção entre teleologia e teleonomia em ciências biológicas, (6) análise crítica dos principais elementos da teoria evolucionista. (7) discussão da aplicabilidade de raciocínios indutivo-dedutivos em ciências biológicas.

\section{Docente(s) Responsável(eis)}

\section{Programa Resumido}

1-Introdução à Filosofia das Ciências

2- Limites e pressupostos da investigação, do conhecimento e da compreensão científica nas Ciências Biológicas

3-O papel das entidades teóricas nas Ciências Biológicas

4-O conceito de ser vivo

5-Evolução cultural

\section{Programa}

Introdução à Filosofia das Ciências

- como se alcança, como se estabelece e como muda o conhecimento científico;

- como a ciência explica os fatos empíricos e que espécie de compreensão nos é dada por suas explicações;

- características que distinguem a indagação científica de outros tipos de investigação e conhecimento;

- a "objetividade" do discurso científico;

- que condições devem ser satisfeitas para uma explicação científica ser aceitável;

- predisposições dos cientistas e avaliação das teorias científicas;

- a ciência como uma forma de conhecimento;

- teorias, indução e dedução;

- o sucesso do modelo hipotético-dedutivo nas ciências biológicas;

- a estratégia científica como atitude de vida;

Limites e pressupostos da investigação, do conhecimento e da compreensão científica nas Ciências Biológicas

- os conceitos de comprobabilidade e reprodutibilidade nas Ciências Biológicas;

- limites da generalização nas Ciências Biológicas;

- o sucesso do modelo hipotético-dedutivo nas Ciências Biológicas;

O papel das entidades teóricas nas Ciências Biológicas.

- função e valor adaptativo; 
- aptidão;

- metas e planos;

- teleologia e teleonomia nas Ciências Biológicas;

- seleção natural;

- unidades de seleção;

- relações entre ambiente e evolução;

- adaptação;

- os conceitos de espécie;

- desenvolvimento em ontogenia;

- filogenia;

- desenvolvimento em filogenia;

- progresso e evolução;

- complexidade e evolução;

- sistemática;

- estrutura das diferentes versões da teoria evolucionista;

- estrutura da teoria evolucionista Darwiniana;

- a teoria genética da evolução;

- natureza estatística da teoria evolucionista;

- natureza dedutiva da teoria evolucionista;

O conceito de ser vivo

- organicismo versus reducionismo;

- a concepção mecanicista da vida;

- a concepção sistêmica da vida;

- níveis de organização e propriedades emergentes;

- as fronteiras entre o inanimado e o vivente;

Evolução cultural

- natureza humana;

- "memética";

- evolução, sociabilidade e ética.

\section{Avaliação}

\section{Método}

Serão sugeridos textos para leitura prévia, antes de cada aula, juntamente com o fornecimento de uma lista de questões para reflexão. Então, durante as aulas propriamente ditas, os alunos serão estimulados a discutir as questões propostas, contando sempre com o direcionamento da discussão por parte dos professores. Quando oportuno, serão utilizadas aulas expositivas, estudo dirigido acompanhado da redação de ensaios, discussões em pequenos grupos e seminários.

\section{Critério}

A aprendizagem será avaliada por meio de provas dissertativas, de ensaios redigidos ao longo do curso, de trabalhos e de seminários

\section{Norma de Recuperação}

A recuperação envolverá a redação de um ensaio sobre tema definido pelo professor em conjunto com o aluno, e de uma prova dissertativa; o trabalho deverá ser entregue no dia da realização da prova dissertativa. Ensaio e prova 
deverão ser realizados até o final da primeira semana de aulas do semestre letivo seguinte. Para ser aprovado o aluno deverá obter nota igual ou superior a 5 (cinco) na média entre as notas obtidas no trabalho e na prova dissertativa.

\section{Bibliografia}

Campos A, Santos AMG, Xavier GF (1997) A consciência como fruto da evolução e do funcionamento do sistema nervoso. Psicologia USP, 8(2), 181226.

Cavalli-Sforza L, Feldman M (1981) Cultural Transmission and Evolution: A Quantitative Approach. Princeton, NJ: Princeton University Press.

Dawkins R (1979) O gene egoísta, Imprenta, Belo Horizonte, Ed Itatiaia.

Dawkins R (1982) The Extended Phenotype. Oxford: Oxford University Press.

Dawkins R (1996) O rio que saía do Éden. Uma visão darwiniana da vida, Ed

Rocco, São Paulo.

Dawkins R (2001) O relojoeiro cego, Ed Companhia das Letras, São Paulo.

Dawkins R. (1997) 'Human Chauvinism: A Review of S.J. Gould's Full House'.

Evolution 51(3): 1015-20.

Dennett D (2001) A idéia perigosa de Darwin: evolução e sentido da vida, Ed

Temas e Debates.

Dupré J (1981) 'Natural Kinds and Biological Taxa', Philosophical Review 90: 6690.

Ereschefsky M (ed) (1992) The Units of Evolution: Essays on the Nature of Species, Cambridge, MIT Press.

Ghiselin M (1974) 'A Radical Solution to the Species Problem', Systematic Zoology 23: 536-44.

Gould SJ (1996) Full House: The Spread of Excellence from Plato to Darwin, New York, Harmony Press.

Gould SJ (1997) 'Self-help for a Hedgehog Stuck on a Molehill', Evolution 51(3): 1010-24

Gould SJ (2002) Pilares do tempo: ciência e religião na plenitude da vida, Ed Rocco, São Paulo.

Gould SJ; Lewontin R (1979) 'The Spandrels of San Marco and the Panglossian Paradigm: A critique of the Adaptationist Programme', Proceedings of the Royal Society of London B 205: 581-98.

Gray R (1992) 'Death of the Gene: Developmental Systems Strike Back' in Griffiths, P (ed) Trees of Life: Essays in the Philosophy of Biology, Dordrecht, Kluwer.

Griffiths P, Gray R (1994) 'Developmental Systems and Evolutionary

Explanation' Journal of Philosophy 91: 277-304.

Griffiths P (1996) 'The Historical Turn in the Study of Adaptation' British Journal for the Philosophy of Science 47: 511-532.

Hempel CG (1966) Filosofia da ciência natural, Ed Zahar, Rio de Janeiro. Hull (1975) Filosofia da ciência biológica, Ed Zahar, Rio de Janeiro.

Hull D (1988) Science as a Process, Chicago: University of Chicago Press.

Hull D (1978) 'A Matter of Individuality', Philosophy of Science 45: 335-60.

Hull D (1981) 'Units of Evolution: A Metaphysical Essay' In The Philosophy of

Evolution R. Jensen and R. Harre (eds), Brighton, Harvester.

Hull D (1986) 'On Human Nature' PSA: 3-13.

Hull D (1997) 'The Ideal Species Concept - And Why We Can't Get It.' In Species: The Units of Biodiversity, edited by M.F. Claridge, H.A. Dawah, and 
M.R. Wilson New York: Chapman and Hall.

Kuhn T (1975). A estrutura das revoluções científicas. Ed Perspectiva, São Paulo.

Lakatos I, Musgrave AE (1970) (eds.) Criticism and the Growth of Knowledge. Cambridge, England, Cambridge University Press.

Lewontin R (2000) Biologia como ideologia: a doutrina do DNA, Ed FUNCEP, Ribeirão Preto.

Lewontin R (1985) 'Adaptation' in The Dialectical Biologist, edited by R. Levins and R.C. Lewontin. Cambridge, Harvard University Press.

Lloyd E (1993) 'Unit of Selection' In Keywords in Evolutionary Biology E. FoxKeller and E. Lloyd (eds) Cambridge, Harvard.

Maienshein J, Ruse M (eds) (1998) Evolution and Ethics, Cambridge, Cambridge University Press.

Matthen M (1997) 'Teleology and the Product Analogy' Australasian Journal of Philosophy 75: 21-37.

Mayr E (1982) Systematics and the Origin of Species, New York, Columbia University Press.

Mayr E (1988) Towards a New Philosophy of Biology, Cambridge, Harvard University Press.

Mayr E (2005) Biologia, ciência única: reflexões sobre a autonomia de uma disciplina científica. Ed Companhia das Letras.

McShea D (1991) 'Complexity and Evolution: What Everybody Knows' Biology and Philosophy 6: $303-234$.

Newton-Smith WH (1981) The Rationality of Science, Boston, Routledge \& Kegan Paul.

Nitecki M (ed) (1988) Evolutionary Progress, Chicago, University of Chicago

Press.

Oyama S (2000) Evolution's Eye, Duke University Press.

Oyama S (2000) The Ontogeny of Information, 2nd Edition, Duke University

Press.

Popper K (1975) Lógica da pesquisa científica, Ed Cultrix, São Paulo.

Rose M, Lauder G (eds) (1996) Adaptation, San Diego, Academic Press.

Ruse M (1996) Monad to Man: The Concept of Progress in Evolutionary Biology. Cambridge, Harvard University Press.

Ruse M, Wilson EO (1986) 'Moral Philosophy as Applied Science: A Darwinian

Approach to the Foundations of Ethics' Philosophy 61: 173-92.

Schaffner K (1993) Discovery and Explanation in Biology and Medicine.

Chicago, University of Chicago Press.

Sober E (1998) 'Six Sayings about Adaptationism' in D. Hull and M. Ruse (eds)

The Philosophy of Biology Oxford, Oxford University Press.

Sober E (1984) The Nature of Selection: Evolutionary Theory in Philosophical

Focus. Cambridge, MIT Press.

Sober E (1988) 'What is Evolutionary Altruism?' Canadian Journal of Philosophy suppl. vol. 14: 75-99.

Sober E (1992) 'Models of Cultural Evolution' in Griffiths, P (ed) Trees of Life:

Essays in the Philosophy of Biology. Dordrecht: Kluwer.

Sober E (1993) The Philosophy of Biology. Boulder, Westview.

Sober E, Wilson DS (1998) Unto Others: The Evolution of Altruism. Cambridge, Harvard University Press.

Sober E, Lewontin RC (1982) 'Artifact, Cause and Genic Selection' Philosophy 
of Science 49: 157-180.

Sober E (ed) (1994) Conceptual Issues in Evolutionary Biology (2nd Edition). Cambridge MA: MIT Press.

Sterelny K, Kitcher P (1988) 'The Return of The Gene' Journal of Philosophy 85: 339-60.

Sterelny K, Griffiths PE (1999) Sex and Death: An Introduction to Philosophy of Biology. Chicago, IL: University of Chicago Press.

Thompson P (ed) (1995) Issues in Evolutionary Ethics. Albany, NY: SUNY Press.

Walsh DM (1996) 'Fitness and Function' British Journal for the Philosophy of Science 47: 553-574.

Williams GC (1966) Adaptation and Natural Selection. Princeton, NJ: Princeton University Press.

\section{6 - INTRODUÇÃO AO ENSINO DE BIOLOGIA - 4.0}

O estudante será levado a conhecer diferentes aspectos relacionados ao ensino da Biologia. Um deles é o campo conceitual, no qual os conceitos biológicos são transpostos para a realidade de sala de aula e reintroduzidos no âmbito do cotidiano das pessoas. Outro aspecto diz respeito às estratégias e metodologias para a aprendizagem de tais conceitos. Um terceiro nível de abordagem deve refletir a realidade do ensino de Biologia principalmente no sistema público brasileiro. A Biologia, seu aprendizado e ensino devem ser entendidos, a partir desta disciplina, como ferramentas importantes na formação de personalidades críticas e cidadãs.

\section{Instituto de Biociências}

\section{Disciplinas Interdepartamentais do Instituto de Biociências}

\section{Disciplina: 0411206 - Introdução ao Ensino de Biologia}

$\begin{array}{ll}\text { Créditos Aula: } & 4 \\ \text { Créditos Trabalho: } & 1\end{array}$

Carga Horária Total: 90 h ( Práticas como Componentes Curriculares $=45$ h )

Tipo:

Semestral

Ativação: $\quad 01 / 01 / 2011$

\section{Objetivos}

Reconhecer o Ensino de Ciências e Biologia como um campo promissor de atuação profissional que integra a prática da pesquisa com a atividade docente. Refletir criticamente sobre aspectos introdutórios relacionados à prática docente. Adquirir subsídios teóricos e metodológicos para o planejamento, execução e apresentação de um projeto de pesquisa em Ensino de Ciências. Obter instrumentos para a busca de dados de pesquisa junto a instituições de Ensino Básico, de modo a promover a aproximação do futuro professor a diferentes realidades do sistema de ensino. Analisar criticamente trabalhos da área de Ensino de Ciências, discernindo sobre sua potencial aplicação em situações concretas de ensino-aprendizagem. 


\section{Docente(s) Responsável(eis)}

\section{Programa Resumido}

Teórico: Reflexões sobre atividade docente (conceito de bom professor, características dos estudantes, estratégias gerais de ensino-aprendizagem). Subsídios básicos para a construção coletiva de projeto de pesquisa em Ensino de Ciências. Discussão e seleção de temas geradores da Biologia. Introdução as principais linhas de pesquisa em Ensino de Ciências. Introdução às principais metodologias de pesquisa em educação, com ênfase em abordagens qualitativas. Estudo sobre os procedimentos de preparação e execução da pesquisa de campo. Abordagem dos fundamentos metodológicos para análise e apresentação de resultados. Prático: Trabalho em grupo para desenvolvimento de projeto de pesquisa na área de Ensino de Ciências. Comunicações orais dos grupos sobre os projetos de pesquisa desenvolvidos ao longo da disciplina.

\section{Programa}

Teórico: Reflexões sobre atividade docente (conceito de bom professor, características dos estudantes, estratégias gerais de ensino-aprendizagem). Subsídios básicos para a construção coletiva de projeto de pesquisa em Ensino de Ciências. Discussão e seleção de temas geradores da Biologia. Introdução as principais linhas de pesquisa em Ensino de Ciências. Introdução às principais metodologias de pesquisa em educação, com ênfase em abordagens qualitativas. Estudo sobre os procedimentos de preparação e execução da pesquisa de campo. Abordagem dos fundamentos metodológicos para análise e apresentação de resultados. Prático: Trabalho em grupo para desenvolvimento de projeto de pesquisa na área de Ensino de Ciências. Comunicações orais dos grupos sobre os projetos de pesquisa desenvolvidos ao longo da disciplina.

\section{Avaliação}

\section{Método}

Aulas expositivas dialogadas. Painel integrado. Atividades teórico-práticas. Leitura e interpretação de textos. Recursos multimídia (softwares, vídeos). Integração aluno-professor por meio de atividades em ambiente virtual de aprendizagem (Plataforma Moodle).

\section{Critério}

Avaliação diagnóstica e continuada composta por: avaliação escrita sobre linhas, metodologias e interpretações em Ensino de Ciências (individual), projeto de pesquisa em Ensino de Ciências (grupo), comunicação oral do projeto desenvolvido (grupo), auto-avaliação (individual e grupo).

\section{Norma de Recuperação}

A nota da recuperação será o resultado da média aritmética entre a nota final obtida na disciplina e a nota obtida na prova/trabalho de recuperação. Os instrumentos serão uma prova e apresentação escrita de projeto individual de pesquisa em Ensino de Ciência.

\section{Bibliografia}

Básica: 
ANASTASIOU, L.G.C., ALVES L.. Processos de Ensinagem na Universidade pressupostos para as estratégias de trabalho em aula. Joinville: UNIVILLE, 2009.

BIZZO, N. Ciência: Fácil ou difícil? São Paulo: Ática, 2000.

BRASIL. Parâmetros Curriculares Nacionais: ciências da natureza. Brasília: MEC/SEMTEC, 1999.

BRASIL. Parâmetros Curriculares Nacionais: Ensino Médio. Brasília: MEC/SEMTEC, 1999.

BRASIL. PCN+ Ensino Médio: orientações educacionais complementares aos Parâmetros Curriculares Nacionais. Ciências da Natureza, Matemática e suas Tecnologias. Brasília: MEC/SEMTEC, 2002.

BELL, J. Projeto de Pesquisa. Guia para pesquisadores iniciantes em educação, saúde e ciências sociais. Artmed, Porto Alegre, 2008

CACHAPUZ A., GIL-PEREZ D., CARVALHO A. M. P., PRAIA J., VILCHES A. A necessária renovação do ensino das ciências. São Paulo: Cortez, 2005.

LANKSHEAR C., KNOBEL M. Pesquisa pedagógica. Do projeto à implementação. Porto Alegre: Artmed, 2008.

LUDKE M., ANDRÉ M. Pesquisa em educação: abordagens qualitativas. São Paulo: EPU, 1986.

PERRENOUD P. Avaliação: da excelência à regulação das aprendizagens, entre duas lógicas. Porto Alegre: Artmed, 1999.

STRAUSS A., CORBIN J. Pesquisa qualitativa. Técnicas e procedimentos para o desenvolvimento de teoria fundamentada. Artmed, 2008.

KRASILCHIK M. Práticas de Ensino de Biologia. São Paulo: EDUSP, 2004. Complementar:

FRASER, Barry J. \& TOBIN, Kenneth G. (orgs.). International handbook of science education. Dordrecht: Kluwer, 2003. 2 vols.

GABEL, Dorothy L. (Ed.). Handbook of research on science teaching and learning. New York: MacMillan, 1994.

TOBIN, Kenneth \& KINCHELOE, Joe, eds. Doing educational research: a

handbook. Rotterdam: Sense Publishers, 2006.

\section{5 - ENSINO EM BIOLOGIA - 4.4}

O estudante será levado a conhecer diferentes aspectos relacionados ao ensino da Biologia. Um deles é o campo conceitual, no qual os conceitos biológicos são transpostos para a realidade da sala de aula e re-introduzidos no âmbito do cotidiano das pessoas. Outro aspecto diz respeito às estratégias e metodologias para a aprendizagem de tais conceitos. Um terceiro nível de abordagem deve refletir a realidade do ensino de Biologia principalmente no sistema público brasileiro. A Biologia, seu aprendizado e ensino devem ser entendidos, a partir desta disciplina, como ferramentas importantes na formação de personalidades críticas e cidadãs.

Instituto de Biociências

Disciplinas Interdepartamentais do Instituto de Biociências

Disciplina: 0410515 - Ensino em Biologia

Créditos Aula: 4 
Créditos

Trabalho:

Carga

Total:

Tipo:

Ativação:

Horária $180 \mathrm{~h}$ ( Estágio: $120 \mathrm{~h}$, Práticas como Componentes Curriculares $=60 \mathrm{~h}$ )

Semestral

$01 / 01 / 2007$

\section{Objetivos}

A disciplina tem por objetivo iniciar os alunos em questões voltadas ao ensino de Biologia, propiciando-lhes um contato mais íntimo com a licenciatura como possibilidade atuação profissional.

\section{Docente(s) Responsável(eis)}

\section{Programa Resumido}

\section{Programa}

O estudante será levado a conhecer diferentes aspectos relacionados ao ensino da Biologia. Um deles é o campo conceitual, no qual os conceitos biológicos são transpostos para a realidade de sala de aula e re-introduzidos no âmbito do cotidiano das pessoas. Outro aspecto diz respeito às estratégias e metodologias para a aprendizagem de tais conceitos. Um terceiro nível de abordagem deve refletir a realidade do ensino de Biologia principalmente no sistema público brasileiro. A Biologia, seu aprendizado e ensino devem ser entendidos, a partir desta disciplina, como ferramentas importantes na formação de personalidades críticas e cidadãs.

\section{Avaliação}

\section{Método}

Análise, observação, participação em discussões e em aulas teóricas, elaboração de sínteses (escritas ou orais)

\section{Critério}

A avaliação final constará de trabalho final na forma escrita ou como apresentação oral.

\section{Norma de Recuperação}

\section{Bibliografia}

BARBIERI, M. R; SICCA,N. L; CARVALHO, C. P. de. A construção do conhecimento do professor - uma experiência de parceria entre professores do ensino fundamental e médio da rede pública e a universidade . Ribeirão Preto: Holos, 2001, p. 98. CAMPOS, M. C. da C.; NIGRO, R. G. Didática das Ciências: o ensino aprendizagem como investigação. São Paulo: FTD, 1999. p. 192.

DELIZOICOV , D. ; ANGOTTI J. A. Metodologia do Ensino de Ciências. 2. ed. São Paulo: 
Cortez, 2000. p. 11-27.

52

DELORS, J. Os quatro pilares da educação. In: Educação um tesouro a descobrir. Relatório

da comissão internacional sobre a Educação para o séc. XXI. Portugal: ASA, 1996. Cap.4. p.

89-102.

DEMO, P. Desafios Modernos da Educação. Petrópoles - RJ: Vozes, 1993. p. 79-120.

"Lei de Diretrizes e Bases da Educação Nacional" - (LDB). São José dos

Campos:

Universidade do Vale do Paraíba - UniVap, 1996.

LIBÂNEO, J. C. Adeus Professor, Adeus Professora? Novas exigências educacionais e

profissão docente. 2. ed. São Paulo: Cortez, 1998. p. 35- 43.

53

MEC, SEB. Orientações Curriculares para o Ensino de Biologia. MEC. 2006.

MORIN, E. Os Sete Saberes necessários à Educação do Futuro. 8. ed. São

Paulo: Cortez;

Brasília, DF: UNESCO, 2003. p. 14-39.

PENTEADO, J. A. Didática e prática de ensino. São Paulo: Mc Graw - Hill, 1979.

p.175-179.

SERAFINI, G. As Inquietações do Sr. K. sobre o Rigorismo dos Conteúdos escolares. In:

WEISSMANN, H. Didática das Ciências Naturais: Contribuições e reflexões.

Porto

Alegre: ArtMed, 1998. Cap. 4. p. 91-126.

WEISSMANN, H. O que Ensinam os Professores quando Ensinam Ciências

Naturais e o que

Dizem Querer Ensinar. In: Didática das Ciências Naturais:Contribuições e reflexões. Porto

Alegre: ArtMed, 1998. Cap. 2. p. 31-32; 37; 47.

WERNWCK, H. Se você finge que ensina, Eu finjo que aprendo . 6. ed.

Petrópolis-RJ:

Vozes, 1994. p. 45-54.

\section{EDM 0433 - METODOLOGIA DO ENSINO DE CIÊNCIAS BIOLÓGICAS I - 4.2}

Este curso examinará os métodos básicos de instrução para as Ciências Biológicas. Formas de comunicação, realização de atividades didáticas e a natureza do diálogo professor-aluno serão analisadas e praticadas. O Curso pretende prover os alunos com competência em habilidades básicas de condução de aula, incluindo manejo de classe e motivação pela familiarização com amplo espectro de modalidades didáticas, sua elaboração e aplicação. Atenção especial será dada ao papel da Biologia em tópicos de relevância social. 


\section{Metodologia do Ensino e Ed Comparada}

\section{Disciplina: EDM0433 - Metodologia do Ensino de Ciências Biológicas I}

Créditos Aula: 4

Créditos Trabalho: 2

Carga Horária Total: 120 h ( Estágio: 120 h )

Tipo:

Semestral

Ativação: $\quad 01 / 01 / 2000$

\section{Objetivos}

. Analisar a situação do ensino das Ciências Biológicas na escola de $1^{\circ}$ e $2^{\circ}$ graus 2. Analisar as tendências atuais do ensino de Ciências Biológicas. 3. Selecionar, analisar, planejar e executar várias modalidades didáticas adequadas ao ensino de Ciências Biológicas. 4. Selecionar utilizar e conservar equipamento e organismos necessários ao desenvolvimento de cursos práticos de Ciências Biológicas. 5. Selecionar, manter e usar recursos audio-visuais.

\section{Docente(s) Responsável(eis)}

\section{Programa Resumido}

Este curso examinará os métodos básicos de instrução para as Ciências Biológicas. Formas de comunicação, realização de atividades didáticas e a natureza do diálogo professor-aluno serão analisadas e praticadas. O curso pretende prover os alunos com competência em habilidades básicas de condução de aula, incluindo manejo de classe e motivação pela familiarização com amplo espectro de modalidades didáticas, sua elaboração e aplicação. Atenção especial será dada ao papel da Biologia em tópicos de relevância social.

\section{Programa}

1. O ensino de Ciências Biológicas - tendências e perspectivas.

2. Objetivos do ensino de Ciências Biológicas.

3. Modalidades didáticas.

4. O laboratório - sua organização e manutenção.

5. Comunicação entre o professor e aluno

\section{Avaliação}

\section{Método}

1. Exposição dialogada.

2. Trabalhos em grupo.

3. Trabalhos individuais.

4. Jogos e simulações.

5. Aulas práticas.

\section{Critério}

1. Trabalhos escritos em grupos individuais. 
2. Participação nos debates em classe, aulas e seminários.

3. Relatórios de estágio incluindo projetos de ensino

\section{Norma de Recuperação}

1. Realização integral dos estágios e apresentação de relatório.

2. Trabalho escrito sobre os conteúdos desenvolvidos

\section{Bibliografia}

BSCS, Biology Teachers Handbook. John Wiley and Sons, 1970.

CARVALHO, Anna Maria e GIL-PEREZ, Daniel. Forma,cão de Professores de Ciências. Cortez, 1995.

FEUSHAW, P. Development and Dilemmas in Science Education, Falner Press, 1988.

HENDERSON, J. and KRUITON, S. Biotechonology in Schools. Open University Press, 1990.

KRASILCHIK, Myriam. Prática de Ensino de Biologia, Harbra, 1986.

KRASILCHIK, Myriam. O professor e o currículo das ciências, E. P. U., São

Paulo, 1986.

McWethy,Patricia J. Basic Biological Concepts: What should the world's children know? Proceedings from the IUBS/CBE Symposium, 1994.

MILLAR, Robin (edit.) Doing Science - Images of Science in Science Education.

Falmer Press, 1989.

NARDI, Roberto. Pesquisas em Ensino de Ciências e Matemática. UNESP, 1996.

OLIVEIRA, D. L. Ciências das salas de aula. Mediação, 1997.

ROMEY, Willians. Inquiry Techniques for Teaching Sciences, Prentice Hall, 1968.

SHULMAN, Lee. Learning by Discovery, Mac Nally, 1969.

SUTTON, C. (Coodenador). Science Teacher Education Project, Mac Graw Hill, 1976.

VOSS, Buton - Biology as Inquiry, C. U. Mos by Co., 1968.

HASSARD, Jack. Minds on Science. Middle and Secondary School Methods. Harper Collins, 1992.

JORGE, V. Crisci, McINERNEY, Joseph D. e McWETHY, Patricia J. Order \& Diversity in the Living Word: Teaching Taxonomy \& Systematics in Schools, NABT, 1993.

AMERICAN FEDERATION OF TEACHERS.. What College-Bound Sudents Abroad Are Expected to Know About Biology. National Center for Improving Science Education, 1994.

\section{EDM 0434 - METODOLOGIA DO ENSINO DE CIÊNCIAS BIOLÓGICAS II - 4.2}

Esse curso examinará a evolução do papel das Ciências Biológicas no currículo escolar e propiciará uma análise dos programas em vigor, documentos legais e livros didáticos. Os processos de avaliação serão discutidos através de análise e preparação de diferentes instrumentos de verificação da aprendizagem. Peculiaridades do ensino de diferentes tópicos serão consideradas através da apresentação de sugestões de estruturação de unidades e organização de modalidades didáticas. Especial consideração será dada aos métodos e resultados 
de pesquisa em ensino e aprendizagem de Biologia.

\title{
Faculdade de Educação
}

\section{Metodologia do Ensino e Ed Comparada}

\section{Disciplina: EDM0434 - Metodologia do Ensino de Ciências Biológicas II}

\author{
Créditos Aula: $\quad 4$
}

Créditos Trabalho: 2

Carga Horária Total: 120 h ( Estágio: 120 h )

Tipo: Semestral

Ativação: $\quad 01 / 01 / 2000$

\section{Objetivos}

1. Analisar os currículos de Ciências Biológicas e disciplinas correlatas em vigor na

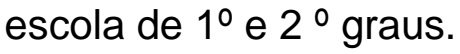

2. Realizar e executar planejamentos curriculares.

3. Analisar e elaborar instrumentos e material para avaliação.

4. Analisar e selecionar recursos necessários a execução de cursos de Ciências Biológicas

\section{Docente(s) Responsável(eis)}

\section{Programa Resumido}

Esse curso examinará a evolução do papel das Ciências Biológicas no currículo escolar e propiciará uma análise dos programas em vigor, documentos legais e livros didáticos. Os processos de avaliação serão discutidos através de análise e preparação de diferentes instrumentos de verificação da aprendizagem. Peculiaridades do ensino de diferentes tópicos serão consideradas através da apresentação de sugestões de estruturação de unidades e organização de modalidades didáticas. Especial consideração será dada aos métodos e resultados de pesquisa em ensino e aprendizagem de Biologia.

\section{Programa}

1. A situação da Biologia no currículo escolar.

2. Planejamento curricular no ensino de Biologia.

3. Avaliação.

4. O ambiente - atividades e segurança no laboratório e no campo.

5. Estrutura do conhecimento nas Ciências Biológicas.

6. Pesquisas em ensino e aprendizagem de Biologia.

7. O tratamento pedagógico de tópicos especiais de Biologia, entre outros, genética, Fisiologia, Ecologia, Educação Ambiental e Biotecnologia.

\section{Avaliação}

\section{Método}

1. Exposição dialogada. 
2. Trabalhos em grupo.

3. trabalhos individuais.

4. Jogos e simulações.

5. Aulas práticas.

\section{Critério}

1. Trabalhos escritos em grupos e individuais.

2. Participação nos debates em classe, aulas e seminários.

3. Relatórios de estágio incluindo projetos de ensin

Norma de Recuperação

1. Realização integral dos estágios e apresentação de relatório.

2. Trabalho escrito sobre os conteúdos desenvolvidos

\section{Bibliografia}

BSCS, Biology Teachers Handbook. John Wiley and Sons, 1970.

CARVALHO, Anna Maria e GIL-PEREZ, Daniel. Forma,cão de Professores de

Ciências. Cortez, 1995.

FEUSHAW, P. Development and Dilemmas in Science Education, Falner Press, 1988.

HENDERSON, J. and KRUITON, S. Biotechonology in Schools. Open University Press, 1990.

KRASILCHIK, Myriam. Prática de Ensino de Biologia, Harbra, 1986.

KRASILCHIK, Myriam. O professor e o currículo das ciências, E. P. U., São

Paulo, 1986.

McWethy,Patricia J. Basic Biological Concepts: What should the world's children know? Proceedings from the IUBS/CBE Symposium, 1994.

MILLAR, Robin (edit.) Doing Science - Images of Science in Science Education.

Falmer Press, 1989.

NARDI, Roberto. Pesquisas em Ensino de Ciências e Matemática. UNESP, 1996.

OLIVEIRA, D. L. Ciências das salas de aula. Mediação, 1997.

ROMEY, Willians. Inquiry Techniques for Teaching Sciences, Prentice Hall, 1968.

SHULMAN, Lee. Learning by Discovery, Mac Nally, 1969.

SUTTON, C. (Coodenador). Science Teacher Education Project, Mac Graw Hill, 1976.

VOSS, Buton - Biology as Inquiry, C. U. Mos by Co., 1968.

HASSARD, Jack. Minds on Science. Middle and Secondary School Methods. Harper Collins, 1992.

JORGE, V. Crisci, McINERNEY, Joseph D. e McWETHY, Patricia J. Order \& Diversity in the Living Word: Teaching Taxonomy \& Systematics in Schools, NABT, 1993.

AMERICAN FEDERATION OF TEACHERS.. What College-Bound Sudents Abroad Are Expected to Know About Biology. National Center for Improving Science Education, 1994 


\section{DISCIPLINAS OPTATIVAS}

\section{BIO0449 ESTRATÉGIAS PARA O ENSINO DE GENÉTICA E EVOLUÇÃO NO ENSINO MÉDIO}

Pensando em voz alta durante a solução de problemas de genética e evolução. Aprendendo a entender a Genética. O papel da história e da linguagem no ensino e aprendizado da Genética e da Evolução. A utilização de modelos interativos. Resolução de problemas funciona? Mapas de conceito. Grupos de discussão e resolução de problemas de Genética e Evolução. Leitura, interpretação de textos e formulação de perguntas e problemas.

\section{Instituto de Biociências}

\section{Genética e Biologia Evolutiva}

\section{Disciplina: BIO0449 - Estratégias para o Ensino de Genética e Evolução no Ensino Médio}

Créditos Aula: $\quad 4$

Créditos Trabalho: 1

Carga Horária Total: $90 \mathrm{~h}$ ( Práticas como Componentes Curriculares $=45 \mathrm{~h}$ )

Tipo:

Semestral

Ativação: $\quad 01 / 01 / 2011$

\section{Objetivos}

Apresentar o desenvolvimento histórico de conceitos da Genética e da Evolução sob a ótica do ensino dessas disciplinas no ensino médio. Discutir e planejar estratégias diversificadas de ensino de tópicos específicos de Genética e Evolução. Oferecer condições para que os alunos identifiquem as dificuldades de compreensão de conceitos específicos da Genética e da Evolução, e proponham abordagens metodológicas que possam ajudar na solução desses problemas. Promover a elaboração de planos de curso de Genética e Evolução para o Ensino Médio.

\section{Docente(s) Responsável(eis)}

\section{Programa Resumido}

Teórico:

Desenvolvimento histórico de conceitos de evolução e herança. Temas de Evolução e Genética relevantes para o Ensino Médio. Estratégias de ensino para o ensinoaprendizagem de Evolução e Genética do Ensino Médio. Planejamento de cursos de Evolução e Genética no Ensino Médio.

\section{Programa}

Teórico:

Desenvolvimento histórico de conceitos de evolução e herança. Temas de Evolução e Genética relevantes para o Ensino Médio. Estratégias de ensino para o ensino- 
aprendizagem de Evolução e Genética do Ensino Médio. Planejamento de cursos de Evolução e Genética no Ensino Médio.

\section{Avaliação}

Método

Atividades em grupo. Estudo dirigido. Animações digitais, filmes e documentários. Exposições dialogadas.

\section{Critério}

Atividades em grupo + Plano de Curso de Genética e Evolução para o Ensino Médio + Miniaulas

\section{Norma de Recuperação}

A nota da recuperação será o resultado da média aritmética entre a nota final obtida na disciplina e a nota obtida na prova/trabalho de recuperação. A recuperação será oferecida na época estabelecida pelo Calendário Escolar da USP.

\section{Bibliografia}

Griffiths, A J F, Wessler, S R, Lewontin, R C, Gelbart, W M, Suzuki, D T, Miller, J H (2006) Introdução à Genética. 8ae ed., Guanabara Koogan, Rio de Janeiro.

Stearns, S C, Hoekstra R F (2003). Evolução: uma introdução. Atheneu, São

Paulo.

Bowler, P J (1989) Evolution: the history of an idea. The University of Chicago Press, Chicago.

Martins, L AC P (2007) A teoria da progressão dos animais, de Lamarck.

Booklink / Fapesp / GHTC, Rio de Janeiro.

Matthews, M (1994) Science teaching: the role of history and philosophy of science. Routledge, New York.

Mayr, Ernst. The growth of biological thought: diversity, evolution and inheritance. Cambridge, MA: Belknap, 1982. / O desenvolvimento do pensamento biologic: diversidade, evolução e herança. Editora da Universidade de Brasília, 1998.

Olby, R (1985) Origins of Mendelism. 2ª ed., The University of Chicago Press, Chicago.

Revista Genética na Escola.

\section{BIE 0319 INDAGAÇÕES ECOLÓGICAS NO AMBIENTE ESCOLAR:}

\section{APRENDIZAGEM E ENSINO}

O desenvolvimento histórico da proposta pedagógica baseada no Ciclo de Indagação e o Ensino de Ecologia no Pátio da Escola, Questionamentos acerca de uma micro-paisagem: a arte de fazer perguntas, segundo algumas pautas universais. Classes de Indagações: guiadas, semi-guiadas e livres. O delineamento 
da Indagação em uma peça de teatro. PCNs e a Indagação Interdisciplinar. Esquema conceitual de temas adequados ao desenvolvimento de investigações ecológicas no ambiente escolar. O papel do educador: dar respostas ou fomentar reflexões? Aplicação da proposta metodológica. Outras aplicações do Ciclo de Indagação. A declaração de princípios da proposta pedagógica EEPE: compromissos, ética e aplicações.

\section{Instituto de Biociências}

\section{Ecologia}

\section{Disciplina: BIE0319 - Indagações Ecológicas no Ambiente Escolar: Aprendizagem e Ensino}

Créditos Aula: 4

Créditos Trabalho: 1

Carga Horária Total: $90 \mathrm{~h}$ ( Práticas como Componentes Curriculares $=45 \mathrm{~h}$ )

Tipo:

Semestral

Ativação: $\quad 01 / 01 / 2007$

\section{Objetivos}

. Objetivos: 1) apresentar a proposta pedagógica, baseada no Ciclo de Indagação, como um caminho para a educação ecológica; 2)exercitar o uso do Ciclo de Indagação, explorando os elementos naturais presentes no ambiente escolar, a fim de conhecer e compreender processos ecológicos a partir de experiências próprias; 3) apresentar e exercitar os tipos de indagação: guiada, semi-guiada e livre; 4) desenvolver a habilidade de aprender com autonomia e pensar criticamente, integrando áreas de conhecimento, a fim de encontrar soluções para os problemas locais; 5) prover aos educadores uma ferramenta que possibilite formar membros ativos de uma comunidade que pensem e decidam crítica e conscienciosamente sobre o uso e conservação do meio ambiente em geral e da biodiversidade em particular.

\section{Docente(s) Responsável(eis)}

\section{Programa Resumido}

1. O desenvolvimento histórico da proposta pedagógica baseada no Ciclo de Indagação e o Ensino de Ecologia no Pátio da Escola;

2. Questionamentos acerca de uma micro-paisagem: a arte de fazer perguntas, segundo algumas pautas universais;

3. Classes de Indagações: guiadas, semi-guiadas e livres; 
4. O delineamento da Indagação em uma peça de teatro;

5. PCNs e a Indagação Interdisciplinar;

6. Esquema conceitual de temas adequados ao desenvolvimento de investigações ecológicas no ambiente escolar;

7. O papel do educador: dar respostas ou fomentar reflexões?

8. Aplicação da proposta metodológica;

9. Outras aplicações do Ciclo de Indagação;

A declaração de princípios da proposta pedagógica EEPE: compromissos, ética e aplicações.

\section{Programa}

1. O desenvolvimento histórico da proposta pedagógica baseada no Ciclo de Indagação e o Ensino de Ecologia no Pátio da Escola;

2. Questionamentos acerca de uma micro-paisagem: a arte de fazer perguntas, segundo algumas pautas universais;

3. Classes de Indagações: guiadas, semi-guiadas e livres;

4. O delineamento da Indagação em uma peça de teatro;

5. PCNs e a Indagação Interdisciplinar;

6. Esquema conceitual de temas adequados ao desenvolvimento de investigações ecológicas no ambiente escolar;

7. O papel do educador: dar respostas ou fomentar reflexões?

8. Aplicação da proposta metodológica;

9. Outras aplicações do Ciclo de Indagação;

A declaração de princípios da proposta pedagógica EEPE: compromissos, ética e aplicações.

\section{Avaliação}

Método

- Aulas práticas e expositivas.

\section{Critério}

- Notas para a Indagações elaboradas (grupo e individual);

- Nota para o Relatório sobre a aplicação da proposta pedagógica.

\section{Norma de Recuperação}

\section{Bibliografia}

Arango, N., Chaves, M.E y Feinsinger, P. 2002. Guia metodológica para la enseñanza de ecología em el pátio de la escuela. Audubon - Programa para a América Latina y el Caribe.

\section{BIF0305 FISIOLOGIA PARA O ENSINO MÉDIO}

Disciplina voltada à revisão dos conceitos das diretrizes curriculares do MEC abordados no Ensino (Fundamental e Médio): Metabolismo e Fisiologia Celular; Consumo de oxigênio; Termogênese e Termorregulação; Sistema cardiovascular; Sistema respiratório; Metabolismo energético; Locomoção; Fibras musculares; 
Sistema digestório; Alimentação, digestão e absorção; Distúrbios alimentares;

Nutrição; Ingestão de água e sais; Sistema excretório; Sistema nervoso; Órgãos dos sentidos; Sistema endócrino; Reprodução; Gravidez e lactação.

Instituto de Biociências

Fisiologia

Disciplina: BIF0305 - Fisiologia para o Ensino Médio

Créditos Aula: 3

Créditos Trabalho: 1

Carga Horária Total: $75 \mathrm{~h}$ ( Práticas como Componentes Curriculares $=45 \mathrm{~h}$ )

Tipo:

Semestral

Ativação: $\quad 01 / 01 / 2007$

\section{Objetivos}

Capacitar o aluno a compreender os conceitos básicos de fisiologia que o habilite a atuar como profissional no ensino fundamental e médio bem como para ser uma referencia para a comunidade estudantil na área.

\section{Programa Resumido}

Disciplina voltada à revisão dos conceitos das diretrizes curriculares do MEC (Parte do possível conteúdo desta disciplina está contemplado no momento na atual disciplina inter-departamental de Instrumentação para o Ensino de Ciências.

\section{Programa}

Disciplina voltada à revisão dos conceitos das diretrizes curriculares do MEC (Parte do possível conteúdo desta disciplina está contemplado no momento na atual disciplina inter-departamental de Instrumentação para o Ensino de Ciências.

\section{Avaliação}

Método

Aulas teóricas, discussões e atividades teórico-práticas.

\section{Critério}

\section{Norma de Recuperação}

\section{Bibliografia}

Guyton, A.C. \& Hall, J.E. Tratado de Fisiologia Médica, 10a ed., 2002.

Guanabara-Koogan, 973

pp.

Aires, M.M; Fisiologia, 2 ed, 1999. Guanabara-Koogan, 934 pp 


\section{INSTRUMENTAÇÃO PARA O ENSINO DE CIÊNCIAS BIOLÓGICAS}

PROGRAMA TEÓRICO - Planejamento, elaboração e execução de aula de Ciências e de Biologia. Discussão sobre escolha e adequação de Temas de aulas para os ensinos fundamental e médio. Discussão e elaboração de relatórios referentes ao planejamento e organização de excursões, feiras de Ciências e montagem e manutenção de laboratórios de ciências, destinados aos ensinos fundamental e médio. Discussão sobre elaboração de materiais de apoio ao professor. Uso de recursos audiovisuais como instrumentos didáticos.

PROGRAMA PRÁTICO 1 - Planejamento, elaboração e execução de aula prática: pesquisa bibliográfica, adequação do conteúdo, do tempo de aula, das estratégias didáticas e dos recursos materiais; 2 - Desenvolvimento de aulas práticas de Ciências e Biologia de acordo com os itens da ementa abrangendo os seguintes tópicos: a) matéria e energia: ar, água, calor, luz, eletricidade, estrutura atômica, reações químicas; b) o ambiente: solo, sistema solar, biosfera, noções de ecologia; c) caracterização dos seres vivos; d) anatomia e fisiologia humanas, noções de higiene. e) citologia e genética. 3 - Visita e execução de atividades ligadas ao ensino de Ciências em outros Institutos na USP.

\section{Instituto de Biociências}

\section{Disciplinas Interdepartamentais do Instituto de Biociências}

\section{Disciplina: 0410111 - Instrumentação para o Ensino de Ciências Biológicas}

Créditos Aula: $\quad 4$

Créditos Trabalho: 1

Carga Horária Total: $90 \mathrm{~h}$ ( Práticas como Componentes Curriculares $=45 \mathrm{~h}$ )

Tipo: Semestral

Ativação: $\quad 01 / 01 / 2011$

\section{Objetivos}

Promover reflexões sobre temas pertinentes à formação do professor que atuará em Ciências para o Ensino Fundamental e Biologia para o Ensino Médio. Desenvolver 
no aluno habilidades como criatividade, organização e senso crítico para planejamento, execução e avaliação de seqüências didáticas utilizando instrumentos práticos e lúdicos, bem como para atividades de campo e outros tipos de excursões didáticas apropriadas para tais segmentos educacionais.

\section{Docente(s) Responsável(eis)}

\section{Programa Resumido}

Programa Teórico

- Introdução às estratégias didáticas

- Introdução à metodologia dialética de ensino

- Utilização de material biológico em sala de aula

- Feiras de Ciências e o ensino por investigação

- Direitos autorais e criação de instrumentos didáticos

- Planejamento de laboratório de Ciências

- Planejamento de excursões didáticas

- Museus e suas possibilidades no ensino de Ciências

Programa Prático

- Planejamento e elaboração de instrumentos didáticos, realização de aulas simuladas utilizando tais instrumentos, elaboração de roteiros explicativos e realização de avaliações críticas sobre tais aulas.

- Elaboração de roteiro para visita didática a um museu de ciência e para trabalho de campo em um local apropriado para excursão didática (ex. Jardim Botânico, Zoológico, Aquário, Parque)

\section{Programa}

Programa Teórico

- Introdução às estratégias didáticas

- Introdução à metodologia dialética de ensino

- Utilização de material biológico em sala de aula

- Feiras de Ciências e o ensino por investigação

- Direitos autorais e criação de instrumentos didáticos

- Planejamento de laboratório de Ciências

- Planejamento de excursões didáticas

- Museus e suas possibilidades no ensino de Ciências

Programa Prático

- Planejamento e elaboração de instrumentos didáticos, realização de aulas simuladas utilizando tais instrumentos, elaboração de roteiros explicativos e realização de avaliações críticas sobre tais aulas.

- Elaboração de roteiro para visita didática a um museu de ciência e para trabalho de campo em um local apropriado para excursão didática (ex. Jardim Botânico,

Zoológico, Aquário, Parque)

\section{Avaliação}

Método

Aulas expositivas dialogadas

Elaboração e apresentação por parte dos alunos de seqüências didáticas utilizando instrumentos práticos e lúdicos de ensino-aprendizagem

Discussões sobre aulas apresentadas por alunos 
Interação alunos-equipe docente utilizando ambiente virtual

Atividades discentes: - Participar das aulas dialogadas e reflexões sobre temas pertinentes à formação do professor

- Planejar e elaborar de instrumentos didáticos, realizar aulas simuladas utilizando tais instrumentos, elaborar de roteiros explicativos e realizar de avaliações críticas sobre tais aulas.

- Elaborar roteiro para visita didática a um museu de ciência e para trabalho de campo

\section{Critério}

- Aulas simuladas utilizando os instrumentos desenvolvidos e roteiros a elas referentes.

- Roteiro para visita didática a um museu de ciência e para trabalho de campo em um local apropriado para excursão didática

- Participação em discussões em aula e no ambiente ambiente virtual

\section{Norma de Recuperação}

Não há.

\section{Bibliografia}

Básica

ANASTASIOU, L.G.C., ALVES L. Processos de Ensinagem na Universidade pressupostos para as estratégias de trabalho em aula. Joinville: UNIVILLE, 2009.

BRASIL. Parâmetros Curriculares Nacionais: ciências da natureza. Brasília: MEC/SEMTEC, 1999.

BRASIL. Parâmetros Curriculares Nacionais: Ensino Médio. Brasília: MEC/SEMTEC, 1999.

BRASIL. PCN+ Ensino Médio: orientações educacionais complementares aos Parâmetros Curriculares Nacionais. Ciências da Natureza, Matemática e suas Tecnologias. Brasília: MEC/SEMTEC, 2002.

CACHAPUZ, A, GIL-PEREZ, D., CARVALHO, A.M.P., PRAIA, J, VILCHES, A. A necessária renovação do ensino das ciências. São Paulo: Cortez. 2005.

HINO, H., HANAZAKI, R.T. Organização e segurança no laboratório de química no Ensino Médio. São Paulo, Secretaria de Estado da Educação, 1997. PEREIRA, A. B.; OAIGEN E. R.; HENNING, G. J. Feiras de Ciência. Canoas: ULBRA. 2000.

PERRENOUD P. Avaliação: da excelência à regulação das aprendizagens, entre duas lógicas. Porto Alegre: Artmed, 1999.

KRASILCHIK M. Práticas de Ensino de Biologia. São Paulo: EDUSP, 2004. MATEUS, A.L. Química na cabeça. Belo Horizonte, Editora UFMG. 2001.

VALADARES, E.C. Física mais que divertida. Belo Horizonte, Editora UFMG. 2000.

Complementa

CHASSOT, A. Alfabetização científica: uma possibilidade para a inclusão social. Revista Brasileira de Educação. v. 23, p. 89-100, 2003.

DINIZ, R., DUARTE, A.L.A., OLIVEIRA, C.A.S., ROMITI, M. Animais em aulas práticas: podemos substituí-los com a mesma qualidade de ensino? Revista Brasileira de Educação Médica. v. 2, n. 30, p. 31-41, 2006.

ROSE, MA. Russell and Burch Revisited. ACCART News. V. 5, n. 4, p.1-7. 1992. 
SANTOS, W.L.P. D. Educação científica na perspectiva de letramento como prática social: funções, princípios e desafios. Revista Brasileira de Educação, v.12, n.36, p.474-491. 2007.

SASSERON, L.H. E CARVALHO, A.M.P.D. Almejando a alfabetização científica no ensino fundamental: a proposição e a procura de indicadores do processo. Investigações em Ensino de Ciências.v. 13, p. 333-352. 2008.

URSI, S. Elaboração de relatórios científicos: informações básicas para jovens investigadores dos ensinos fundamental e médio. São Paulo: Departamento de Botânica, Instituto de Biociências, Universidade de São Paulo, 2008. 


\section{ANEXO 3 EMENTÁRIO DAS DISCIPLINAS DE LICENCIATURA EM QUÍMICA}

\section{Obrigatórias Analisadas Química}

EDM0431 - Metodologia do Ensino de Química I

EDM0432 - Metodologia do Ensino de Química II

QFL2505 - Instrumentação para o Ensino I

QFL2506 - Introdução para o Ensino de Química IV

QFL4610 - Introdução para o Ensino de Química I (Fundamentos)

QFL4620 - Introdução para o Ensino de Química II (Ensino e Atividades)

QFL4630 - Introdução para o Ensino de Química III (Currículo e Planejamento)

QFL3505 - Introdução para o Ensino de Química IV (Complementação)

FLH0640 - História das Ciências

Não Caracterizada se Obrigatória ou Optativa

QFL4600 - Introdução ao Ensino de Química

EDM0431 - Metodologia do Ensino de Química I

Faculdade de Educação

Metodologia do Ensino e Ed Comparada

Disciplina: EDM0431 - Metodologia do Ensino de Química I

Créditos Aula: 4

Créditos Trabalho: 2

Carga Horária $120 \mathrm{~h}$ (Estágio: 60 h, Práticas como Componentes Curriculares

Total: $=60 \mathrm{~h}$ )

Tipo: Semestral $\quad$ S

Ativação: $\quad 01 / 01 / 2005$

\section{Objetivos}

1. Fomentar o senso crítico do licenciando, que propicie uma atuação sistêmica nos diversos espaços profissionais de seu domínio, repercutindo em tomadas de decisão responsáveis

por

parte

do

mesmo. 
2. Introduzir o licenciando em práticas pedagógicas para ministrar disciplinas de Química no $1^{\circ}$ e $2^{\circ}$ graus, através do estágio supervisionado e de reflexões teóricas. 3. Embasar o licenciando com elementos teóricos, metodológicos e técnicos sobre as principais vertentes do processo de ensino-aprendizagem: relações sócioculturais no ambiente escolar; habilidades cognitivas e atitudinais; planejamento e desenvolvimento de conteúdo; avaliação.

\section{Programa Resumido}

12. Ementa (programa resumido):

As disciplinas de Metodologia do Ensino de Química I e II são oferecidas a partir de uma visão de continuidade e integração entre ambas. Reflexões e discussões sobre cultura, ciência e processos de produção de conhecimento, sobre a organização e planejamento das atividades e módulos temáticos de ensino de Química de Ensinos Fundamental e Médio, sobre o papel da linguagem e meios mediacionais no ensino e na aprendizagem de ciências antecipam o desenvolvimento de projetos de planejamento e realização de atividades e módulos temáticos de ensino, que são sistematicamente analisados por meio de técnicas de análise de episódios de ensino, subsidiando a reflexão sobre as ações mediadas em sala de aula, de modo permitir a instauração de práticas e a apropriação de fundamentos teóricos sobre a avaliação e o replanejamento do ensino. Concertadamente, ocorrem os estágios supervisionados a partir de projetos individuais e coletivos.

\section{Programa}

13. Conteúdo (programa):

1. A prática de ensino na formação docente e o papel do estágio supervisionado.

2. Projetos de estágios supervisionados.

3. Noções sobre cultura, ciência e formas de produção de conhecimento químico e conhecimento

escolar.

4. Sobre a linguagem, medição e o processo de elaboração de significado.

5. Análise de episódios de ensino.

6. Sobre a noção de atividade de ensino.

7. Os eixos conceitual, temático e da atividade na organização e planejamento do ensino/

\section{Avaliação \\ Método}

15. Métodos utilizados:

Discussão em grupo; seminários, aulas expositivas e práticas

\section{Critério}

16. Critérios de avaliação de aprendizagem:

Elaboração de resenhas, projetos, relatórios e provas escritas.

\section{Norma de Recuperação}

17. Normas de recuperação (critérios de aprovação e épocas de realização das provas ou trabalhos):

Provas e trabalhos escritos realizados na primeira semana do próximo semestre. 


\section{Bibliografia}

21. Bibliografia Básica:

LAZLO Pierre. "A Palavra das Coisas ou A Linguagem da Química". Coleção Ciência Aberta 74, ed. Gradiva, Lisboa, 1995.

VYGOTSKY Lev S. "A formação social a mente". 48 ed., Ed. Martins Fontes; São Paulo, 1991.

VYGOTSKY Lev S. "Pensamento e linguagem" 18 ed., Ed. Martins Fontes; São Paulo, 1993.

CHASSOT, Attico e OLIVEIRA, Renato J. (org.). "Ciência, ética e cultura na educação". Ed. UNISINOS, São Leopoldo, 1998.

MALDANER, Otávio A. " A formação inicial e continuada de professores de Química". Ed. UNIJUÍ, ljuí, 2000.

MACHADO, Andréa H. "Aula de Química: discurso e conhecimento". Ed. UNIJUÍ, Ijuí, 1999.

MORTIMER, Eduardo F. "Linguagem e formação de conceitos no ensino de ciências". Ed. UFMG, Belo Horizonte, 2000.

LOPES, Alice R.C. "Conhecimento escolar: ciência e cotidiano". Ed. UERJ, Rio de Janeiro, 1999.

SANTOS, Wildson L.P. e SCHNETZLER, Roseli, P. "Educação em Química: compromisso com a cidadania". Ed. UNIJUÍ, ruí, 1997.

OLIVEIRA, Renato J ." A escola e o ensino de ciências". Ed. UNISINOS, São Leopoldo, 2000.

PERIÓDICOS

Química Nova, Química Nova na Escola e Cadernos Temáticos de Química Nova na Escola: revistas de divulgação do ensino de Química da Sociedade Brasileira de Química.

Enseõanza de Las Ciências: revista de investigação e experiências didáticas da Universidade Autônoma d Barcelona.

Journal of Chemical Education: revista da divisão de ensino de Química da

American Chemical Socie:ty .

URLS:

http://www.sbq.org.br/ensino Página da Divisão de Ensino da Sociedade Brasileira de Química.

http://químicafe.usp.br Página do Laboratório de Pesquisa em Ensino de Química e Telemática

Educacional da Faculdade de Educação da USP .

EDM0432 - Metodologia do Ensino de Química II

\section{Faculdade de Educação}

\section{Metodologia do Ensino e Ed Comparada}

Disciplina: EDM0432 - Metodologia do Ensino de Quimica II

Créditos Aula: 4

Créditos Trabalho: 2 
Carga Horária $120 \mathrm{~h}$ ( Estágio: $60 \mathrm{~h}$, Práticas como Componentes Curriculares

Total:

Tipo:

Ativação:
$=60 \mathrm{~h}$ )

Semestral

$01 / 01 / 2005$

\section{Objetivos}

1. Completar a introdução do licenciando em práticas pedagógicas para ministrar disciplinas de Química no $1^{\circ}$ e $2^{\circ}$ graus, através do estágio supervisionado e de reflexões

teóricas.

2. Estabelecer os limites de continuidade, aplicação e objetivos entre os conteúdos apreendidos pelo seu domínio, dando ênfase ao papel da linguagem e da experimentação na construção do conhecimento químico. 3. Propiciar ao licenciando condições para o desenvolvimento de projetos sobre planejamento e desenvolvimento curricular, bem como sobre elaboração de materiais didáticos e instrucionais.

\section{Programa Resumido}

12

Ementa

(programa

resumido):

As disciplinas de Metodologia do Ensino de Química I e II são oferecidas a partir de uma visão de continuidade e integração entre ambas. Reflexões e discussões sobre cultura, ciência e processos de produção de conhecimento, sobre a organização e planejamento das atividades e módulos temáticos de ensino de Química de Ensinos Fundamental e Médio, sobre o papel da linguagem e meios mediacionais no ensino e na aprendizagem de ciências antecipam o desenvolvimento de projetos de planejamento e realização de atividades e módulos temáticos de ensino, que são sistematicamente analisados por meio de técnicas de análise de episódios de ensino, subsidiando a reflexão sobre as ações mediadas em sala de aula, de modo permitir a instauração de práticas e a apropriação de fundamentos teóricos sobre a avaliação e o replanejamento do ensino. Concertadamente, ocorrem os estágios supervisionados a partir de projetos individuais e coletivos.

\section{Programa}

13. Conteúdo (programa):

I. A prática de ensino na formação docente e o papel do estágio supervisionado.

2. Projetos de estágios supervisionados.

3. Análise de episódios de ensino.

4. Planejamento de módulos temáticos de ensino.

5. Elaboração de material de apoio às atividades de ensino.

6. Avaliação e reflexão sobre a prática de ensino.

\section{Avaliação}

Método

15. Métodos utilizados:

Discussão em grupo; seminários, aulas expositivas e práticas

\section{Critério}

16. Critérios de avaliação de aprendizagem:

Elaboração de resenhas, projetos, relatórios e provas escritas. 


\section{Norma de Recuperação}

17. Normas de recuperação (critérios de aprovação e épocas de realização das provas ou trabalhos):

Provas e trabalhos escritos realizados na primeira semana do próximo semestre.

\section{Bibliografia}

21. Bibliografia Básica:

CHASSOT, Attico e OLIVEIRA, Renato J. (org.). "Ciência, ética e cultura na educação". Ed. UNISINOS, São Leopoldo, 1998.

LAZLO Pierre. "A Palavra das Coisas ou A Linguagem da Química". Coleção Ciência Aberta 74, ed. Gradiva, Lisboa, 1995.

LOPES, Alice R.C. "Conhecimento escolar: ciência e cotidiano". Ed. UERJ, Rio de Janeiro, 1999.MALDANER, Otávio A. "A formação inicial e continuada de professores de Química". Ed. UNIJUÍ, ljuí, 2000. , MACHADO, Andréa H. "Aula de Química: discurso e conhecimento". Ed. UNIJUI, Ijuí, 1999.

MORTIMER, Eduardo F. "Linguagem e formação de conceitos no ensino de ciências". Ed. UFMG, Belo Horizonte, 2000.

OLIVEIRA, Renato J ."A escola e o ensino de ciências". Ed. UNISINOS, São Leopoldo, 2000.

SANTOS, Wildson L.P. e SCHNETZLER, Rose1i, P. "Educação em Química: compromisso com a cidadania". Ed. UNIJUÍ, ljuí, 1997.

VYGOTSKY Lev S. "A formação social a mente". 4a ed., Ed. Martins Fontes; São Paulo, 1991.

VYGOTSKY Lev S. "Pensamento e linguagem" la ed., Ed. Martins Fontes; São Paulo, 1993.

\section{PERIÓDICOS}

Química Nova, Química Nova na Escola e Cadernos Temáticos de Química Nova na Escola: revistas de divulgação do ensino de Química da Sociedade Brasileira de Química.

Ensefianza de Las Ciências: revista de investigação e experiências didáticas da Universidade Autônoma d Barcelona.

Joumal of Chemical Education: revista da divisão de ensino de Química da American Chemical Society .

URLS:

http://www.sbq.org.br/ensino Página da Divisão de Ensino da Sociedade Brasileira de Química.

http://química.fe.usp.br Página do Laboratório de Pesquisa em Ensino de Química e Telemática Educacional da Faculdade de Educação da USP .

QFL2505 - Instrumentação para o Ensino I

\section{Instituto de Química}




\section{Disciplina: QFL2505 - Instrumentação para O Ensino I}

Créditos Aula: $\quad 4$

Créditos Trabalho: 0

Carga Horária Total: $60 \mathrm{~h}$ ( Práticas como Componentes Curriculares $=60 \mathrm{~h}$ )

Tipo:

Semestral

Ativação: $\quad 01 / 01 / 2009$

\section{Objetivos}

Reconhecer e avaliar concepções das diversas correntes educacionais, sobre Ciência e ensino-aprendizagem em Ciência. Desenvolver e aperfeiçoar o conhecimento sobre construção, manutenção e uso de laboratório de ensino da Química. Aperfeiçoar as habilidades na utilização dos laboratórios de ensino da Química. Conhecer fontes de informações úteis para o professor de química.

\section{Docente(s) Responsável(eis)}

\section{Programa Resumido}

Estudo das principais tendências educacionais para o ensino de Ciências e de Química. Estudo das concepções sobre Ciências e suas implicações para o ensino. Estudo de experimentos para ensino no $2^{\circ}$ grau - teste, adaptação de experiências e planejamento de aulas onde estão inseridos os experimentos estudados. Laboratórios para ensino: normas sobre construção e segurança, equipamento, material de consumo. Elaboração e aplicação de aulas para alunos do $2^{\circ}$ grau. As fontes de informação para o professor: livros, periódicos e outras mídias.

\section{Programa}

Estudo das principais tendências educacionais para o ensino de Ciências e de Química. Estudo das concepções sobre Ciências e suas implicações para o ensino. Estudo de experimentos para ensino no $2^{\circ}$ grau - teste, adaptação de experiências e planejamento de aulas onde estão inseridos os experimentos estudados. Laboratórios para ensino: normas sobre construção e segurança, equipamento, material de consumo. Elaboração e aplicação de aulas para alunos do $2^{\circ}$ grau. As fontes de informação para o professor: livros, periódicos e outras mídias.

\section{Avaliação}

Método

Seminários, discussão em grupo, aulas de laboratório, pesquisa bibliográfica.

\section{Critério}

Será feita através de relatórios sobre textos, trabalhos de laboratório, das contribuições nos seminários, participação nas aulas, da análise, em conjunto com os colegas, da aula oferecida e de questões propostas.

\section{Norma de Recuperação}

Nota da $2^{\mathrm{a}}$ Avaliação $=$ Nota da $1^{\mathrm{a}}$ Avaliação $+2 \times$ (Nota da prova de recuperação) dividido por 3 . 


\section{Bibliografia}

Textos selecionados de livros e periódicos.

S. Educação - CENP - Subsídios para a implementação da proposta Curricular de Química para o 2ํgrau, 1979.

São Paulo (estado) Secretaria de Educação, CENP. Organização e segurança no laboratório de química no ensino médio. São Paulo, SE/CENP, 1997.

W. PENTEADO (org) - "Psicologia e Ensino", Ed. Papelivros, 1980

M. A. Moreira - "Ensino e Aprendizagem: Enfoques Teóricos", Ed. Moraes, 1988

N. Beltran \& C. A. Ciscato - "Química", Ed. Cortez, 1991

J. Bordenave \& A. M. Pereira - "Estratégias de Ensino-Aprendizagem", Ed. Vozes, 1988

A. M. P. de Carvalho - "Prática de Ensino", Ed. Pioneira", 1985

D. Gil-Peréz \& A. M. P. de Carvalho - "Formacao de Professores de Ciências :Tendências e Inovações" Coleção Questões da Nova Época, v.26, Ed. Cortez, 1995

Journal of Chemical Education

Enseñanza de las Ciencias

Journal of Research in Science Teaching

Química Nova

Química Nova na Escola

Education in Chemistry

International Journal of Science Education

Science Education

QFL2506 - Introdução para o Ensino de Química IV

Instituto de Química

Química Fundamental

Disciplina: QFL2506 - Instrumentação para O Ensino IV

Créditos Aula: 12

Créditos Trabalho: 0

Carga Horária Total: $180 \mathrm{~h}$ ( Práticas como Componentes Curriculares $=180 \mathrm{~h}$ ) 
Tipo: Semestral

Ativação: $\quad 01 / 01 / 2005$

\section{Objetivos}

Avaliar os fundamentos psicológicos e dos processos de ensino-aprendizagem de Química. Análise de materiais instrucionais. Elaborar programas de ensino de Química.

\section{Docente(s) Responsável(eis)}

\section{Programa Resumido}

Concepções construtivistas aplicáveis ao processo de ensino-aprendizagem . Estudo crítico de livros-textos e projetos de Química. Estudo crítico da Proposta Curricular de Química (1988) e dos Parâmetros Curriculares Nacionais (1999). Interação entre programas de ensino e teorias de aprendizagem. Programa de ensino fundamentado em alguma Teoria de Aprendizagem.

\section{Programa}

Concepções construtivistas aplicáveis ao processo de ensino-aprendizagem . Estudo crítico de livros-textos e projetos de Química. Estudo crítico da Proposta Curricular de Química (1988) e dos Parâmetros Curriculares Nacionais (1999). Interação entre programas de ensino e teorias de aprendizagem. Programa de ensino fundamentado em alguma Teoria de Aprendizagem.

\section{Avaliação}

\section{Método}

Concepções construtivistas aplicáveis ao processo de ensino-aprendizagem . Estudo crítico de livros-textos e projetos de Química. Estudo crítico da Proposta Curricular de Química (1988) e dos Parâmetros Curriculares Nacionais (1999). Interação entre programas de ensino e teorias de aprendizagem. Programa de ensino fundamentado em alguma Teoria de Aprendizagem.

\section{Critério}

Será feita através de trabalhos realizados de laboratório, de análise de livros e do planejamento, das contribuições nos seminários, da participação em aula, e respostas às questões propostas.

\section{Norma de Recuperação}

Nota da $2^{\mathrm{a}}$ Avaliação $=$ Nota da $1^{\mathrm{a}}$ Avaliação $+2 \times$ (Nota da prova de recuperação) dividido por 3 .

\section{Bibliografia}

Artigos em Periódicos sobre Educação, tais como: J. Chem. Ed., Educacion Química ( México), Education in Chemistry, International J. of Science Education, Enseñanza de las Ciências, J. Research Science Teaching, Química Nova na escola, etc.

D. GIL-PERÉZ \& A. M. P. de CARVALHO - "Formação de Professores de Ciências :Tendências e Inovações",Coleção Questões da Nova Época, v.26, Ed. 
Cortez, 1995

Brasil, Ministério da Educação. Parâmetros Curriculares Nacionais: ensino médio. Ministério da educação, 1999.

Projetos para Ensino de Química.

Livros de Química para o ensino médio.

QFL4610 - Introdução para o Ensino de Química I (Fundamentos)

\section{Instituto de Química}

\section{Química Fundamental}

Disciplina: QFL4610 - Instrumentação para o Ensino de Química I (Fundamentos)

Créditos Aula: 4

Créditos Trabalho: 0

Carga Horária Total: $60 \mathrm{~h}$ ( Práticas como Componentes Curriculares $=60 \mathrm{~h}$ )

Tipo:

Semestral

Ativação: $\quad$ 01/01/2009

\section{Objetivos}

A disciplina tem como objetivo principal introduzir o estudante na reflexão crítica sobre o ensino de química na escola básica, identificando problemas de ensino e aprendizagem, as tendências atuais do ensino de química, analisando e propondo iniciativas para o trabalho docente.

\section{Docente(s) Responsável(eis)}

\section{Programa Resumido}

Concepções sobre ensino e aprendizagem. Concepções construtivistas. Conteúdos de ensino. Tendências e estratégias de ensino. Propostas curriculares. Livros didáticos.

\section{Programa}

Principais concepções das diversas correntes sobre ensino e aprendizagem de Ciências (Comportamentalismo, Humanismo, Costrutivismo e Sócio-Construtivismo). Concepções construtivistas do aprendizado (Piaget, Vygotsky e Ausubel) e suas conseqüências para o ensino de ciências/ química. Conteúdos para o ensino de química, dimensões conceitual, procedimental e atitudinal do conteúdo, níveis macro, micro e representacional do conhecimento químico. Tendências e estratégias atuais do ensino: Ciência, Tecnologia, Sociedade e Ambiente (CTSA); contextualização; competências e habilidades; ensino por abordagem temática; ensino por problemas e projetos. Papel da experimentação e da história da ciência 
no ensino da química. Propostas curriculares de Química para o Ensino Médio. Os livros e outros materiais didáticos. Critérios para ; análise de textos, atividades e outros materiais utilizados no ensino.

\section{Avaliação}

Método

Seminários, discussão em grupo, pesquisa bibliográfica.

\section{Critério}

Será feita através de relatórios sobre textos, de análise de livros, apresentação de seminários, participação nas atividades propostas.

\section{Norma de Recuperação}

Aprovação obtida por nota mínima 5,0 (cinco). Nota da $2 a$ avaliação = Nota da 1a avaliação $+2 \times$ (Nota da prova de recuperação) dividido por 3.

\section{Bibliografia}

Textos selecionados de livros e periódicos.

BRASIL. Ministério da Educação, EC, Secretaria de Educação Básica, SEB, Departamento de Políticas de Ensino Médio. "Orientações Curriculares do Ensino Médio". Brasília, MEC/SEB, 2006.

BRASIL. Ministério da Educação (MEC), Secretaria de Educação Média e Tecnológica (Semtec). Parâmetros Curriculares Nacionais para o Ensino Médio. Brasília: MEC/Semtec, 1999.

BRASIL. Ministério da Educação (MEC), Secretaria de Educação Média e Tecnológica (Semtec). PCN + Ensino médio: orientações educacionais complementares aos Parâmetros Curriculares Nacionais - Ciências da Natureza, Matemática e suas Tecnologias. Brasília: MEC/Semtec, 2002.

SÃO PAULO (Estado) Secretaria da Educação. Coordenadoria de Estudos e Normas Pedagógicas. "Oficinas temáticas no ensino público: formação continuada de professores" coordenação de Maria Eunice Ribeiro Marcondes. São Paulo: FDE, 2007. 108 p.

W. PENTEADO (org) - "Psicologia e Ensino", Ed. Papelivros, 1980

M. A. MOREIRA - "Teorias de Ensino-Aprendizagem," São Paulo: Ed. Pedagógica Universitária, 1999.

N. BELTRAN \& C. A. CISCATO - "Química", Ed. Cortez, 1991

J. BORDENAVE E A. M. PEREIRA - "Estratégias de Ensino Aprendizagem, Ed. Vozes, 1988.

D. GIL-PERÉZ \& A. M. P. DE CARVALHO - "Formacão de Professores de Ciências :Tendências e Inovações" Coleção Questões da Nova Época, v.26, Ed. Cortez, 1995. 
MIZUKAMI, M.G.N. "Ensino: as abordagens do processo" São Paulo: Ed.

Pedagógica Universitária, 1986.

DAVIS, C.; Oliveira, Z. "Psicologia na Educação" São Paulo: Editora Cortez, 2a . Ed., 1999.

MINGUET, P.A.(org.) "A construção do conhecimento na educação" Porto Alegre: ArtMed, 1998.

REGO, T.C. "Vygotsky: uma perspectiva histórico-cultural da educação".

Petrópolis, RJ: Editora Vozes, 12ª Ed., 2001.

Artigos selecionados dos periódicos:

Journal of Chemical Education

Enseñanza de las Ciencias

Journal of Research in Science Teaching

Química Nova

Química Nova na Escola

Education in Chemistry

International Journal of Science Education

Science Education

Science \& Education

Livros de Química para o Ensino Médio

QFL4620 - Introdução para o Ensino de Química II (Ensino e Atividades)

Instituto de Química

Química Fundamental

Disciplina: QFL4620 - Instrumentação para o Ensino de Química II (Ensino e Atividades)

Créditos Aula: 6

Créditos Trabalho: 0

Carga Horária Total: 90 h (Práticas como Componentes Curriculares $=90$ h )

Tipo:

Semestral

Ativação: $\quad 01 / 01 / 2009$

\section{Objetivos}

A disciplina tem como principais objetivos: dar subsídios ao estudante para saber utilizar atividades experimentais como recurso didático e possibilitar o desenvolvimento de ações em situações reais de ensino. Assim, objetiva-se dotar o estudante de um instrumental que lhe permita conhecer os vários tipos de atividades experimentais, analisar suas funções e adequação a diferentes realidades educacionais; desenvolver atividades experimentais fundamentadas em 
pressupostos teóricos e metodológicos; saber planejar e organizar o espaço físico para o desenvolvimento de atividades, considerando aspectos pedagógicos, de segurança e ambientais.

\section{Docente(s) Responsável(eis)}

\section{Programa Resumido}

Ensino experimental. Experimentos em Ciências e no ensino de Ciências.

\section{Programa}

Importância e papel das atividades experimentais no ensino de química nas últimas décadas. Experimentos em Ciências e no ensino de Ciências. Tipos de atividades experimentais, suas funções e adequação a diferentes realidades educacionais.Planejamento de atividades experimentais fundamentadas em pressupostos teóricos e metodológicos; planejamento e organização do espaço físico para o desenvolvimento de atividades, considerando aspectos pedagógicos, de segurança e ambientais. Avaliação da aula experimental, interação professor aluno, conteúdo, competências, atitudes dos alunos.

\section{Avaliação}

\section{Método}

Seminários, discussão em grupo, aulas de laboratório, pesquisa bibliográfica.

\section{Critério}

Será feita através de relatórios sobre textos; trabalhos de laboratório; participação nas aulas; da análise, em conjunto com os colegas,das aulas oferecidas; projeto de laboratório para escola e de questões propostas.

\section{Norma de Recuperação}

Aprovação obtida por nota mínima 5,0 (cinco). Nota da $2 \mathrm{a}$ avaliação $=$ Nota da 1 a avaliação $+2 \times$ (Nota da prova de recuperação) dividido por 3 .

\section{Bibliografia}

SÃO PAULO (estado) Secretaria de Educação, CENP. Subsídios para a implementação da proposta Curricular de Química pra o 20 grau, 1979.

SÃO PAULO (estado) Secretaria de Educação, CENP. Organização e segurança no laboratório de química no ensino médio. São Paulo, SE/CENP, 1997.
A.M.P. DE CARVALHO - Prática de Ensino, Ed. Pioneira", 1985
R. MORAES \& R. MANCUSO (orgs.). Educação em Ciências - Produção de Currículos e Formação de Professores. ljuí, Editora Unijuí, 2004.
D. HODSON. "Experiments in Science and Science Teaching", Educational Philosophy and Theory 20 (1988), $53-66$.
N. BELTRAN \& C. A. CISCATO. Química. São Paulo, Cortez, 1991. 
L. B. ZANON \& MALDANER, O. A. (Orgs.). Fundamentos e Propostas de Encino de Química para a Educação Básica no Brasil. ljuí, Editora Unijuí, 2007.

Artigos extraídos dos periódicos:

Química Nova na Escola

Química Nova

Enseñanza de las Ciencias

International Journal of Science Education

Journal of Research in Science Teaching

Science Education

Journal of Chemical Education

Education in Chemistry

QFL4630 - Introdução para o Ensino de Química III (Currículo e Planejamento)

Instituto de Química

Química Fundamental

Disciplina: QFL4630 - Instrumentação para o Ensino de Química III (Currículo e Planejamento)

Créditos Aula: 4

Créditos Trabalho: 0

Carga Horária Total: $60 \mathrm{~h}$ ( Práticas como Componentes Curriculares $=60 \mathrm{~h}$ )

Tipo:

Semestral

Ativação: $\quad 01 / 01 / 2009$

\section{Objetivos}

A disciplina tem como objetivo principal trazer subsídios e reflexões ao estudante para que ele possa desenvolver um planejamento e plano de ensino de Química para o Ensino Médio, levando em consideração os objetivos da educação, as relações interativas em sala de aula, a seleção e seqüência de conteúdos, a organização e a gestão da sala de aula e a avaliação.

\section{Docente(s) Responsável(eis)}

\section{Programa Resumido}

Níveis de planejamento de ensino. Projeto Político pedagógico. Objetivos, seleção e organização de conteúdos. Avaliação. Plano de aula.

\section{Programa}

Níveis de planejamento educacional e de ensino.Projeto Político PedagógicoEtapas para elaboração de um planejamento de ensino: objetivos, seleção e organização dos conteúdos, metodologias e avaliaçãoOs planos de aula - as relações interativas 
na sala de aula, o papel dos professores e alunos, a distribuiçção do tempo, a organização dos conteúdos, a organização das atividades do professor e dos alunos, a avaliação

\section{Avaliação}

Método

Seminários, discussão em grupo, pesquisa bibliográfica.

\section{Critério}

Será feita através de trabalhos realizados, elaboração de um planejamento, das contribuições nos seminários, da participação em aula, e respostas às atividades questões propostas.

\section{Norma de Recuperação}

Aprovação obtida por nota mínima 5,0 (cinco).

Nota da 2 a avaliação = Nota da 1a avaliação $+2 \times$ (Nota da prova de recuperação) dividido por 3 .

\section{Bibliografia}

D. GIL-PERÉZ \& A. M. P. de CARVALHO - "Formação de Professores de

Ciências :Tendências e Inovações", Coleção Questões da Nova Época, v.26,

Ed. Cortez, 1995

SACRISTÁN, J.G., GÓMEZ, A.I.P. Compreender e transformar o ensino. 4aㅡ Ed. Porto Alegre: ArtMed, 2000.

ZABALA, A. A Prática Educativa: como ensinar, Porto Alegra: Artmed, 1998.

COLL, C. - Psicologia e Currículo, uma Aproximação Psico-pedagógica à Elaboração do Currículo Escolar, Ática,1996. Questões Atuais no Ensino de Ciências. São Paulo: Escrituras Ed., 2001.

MENEGOLLA M., SANT'ANNA, I.M., Por que planejar? Como planejar? 13를 Ed. Petrópolis: Vozes, 2003.

Livros de Química para o ensino médio.

Artigos em Periódicos sobre Educação, tais como:

Química Nova na Escola

Química Nova

Educación Química

Enseñanza de las Ciencias

International Journal of Science Education

Journal of Research in Science Teaching

Investigações em Ensino de Ciências

Science Education

Journal of Chemical Education

Education in Chemistry 


\section{Instituto de Química}

\section{Química Fundamental}

Disciplina: QFL3505 - Instrumentação para o Ensino de Química IV (complementação)

Créditos Aula: $\quad 4$

Créditos Trabalho: 0

Carga Horária Total: $60 \mathrm{~h}$ ( Práticas como Componentes Curriculares $=60 \mathrm{~h}$ )

Tipo:

Semestral

Ativação: $\quad 01 / 01 / 2006$

\section{Objetivos}

A disciplina tem como objetivo principal dar subsídios para que o aluno possa produzir materiais didáticos para o ensino de química, dentro de certos princípios norteadores, definidos pelo próprio estudante.

\section{Docente(s) Responsável(eis)}

\section{Programa Resumido}

Papel do livro didático no ensino de química e a dinâmica de sua utilização em sala de aula; análise de textos, atividades e outros materiais utilizados no ensino. Produção de textos: objetivo, metodologia e avaliação. Produção de outros materiais: jogos, experimentos, painéis. Exposições e feiras de ciências: planejamento, preparação, utilização.

\section{Programa}

Papel do livro didático no ensino de química e a dinâmica de sua utilização em sala de aula; análise de textos, atividades e outros materiais utilizados no ensino. Produção de textos: objetivo, metodologia e avaliação. Produção de outros materiais: jogos, experimentos, painéis. Exposições e feiras de ciências: planejamento, preparação, utilização.

\section{Avaliação}

\section{Método}

Seminários, discussão em grupo, aulas de laboratório, pesquisa bibliográfica.

\section{Critério}

Será feita através de trabalhos realizados, de análise de materiais didáticos, das contribuições nos seminários, da participação em aula, material didático elaborado.

\section{Norma de Recuperação}

Nota da $2^{\mathrm{a}}$ Avaliação $=$ Nota da $1^{\mathrm{a}}$ Avaliação $+2 \times$ (Nota da prova de recuperação) dividido por 3 .

\section{Bibliografia}

Livros didáticos de química.


Livros para-didáticos e de divulgação científica.

Revistas de divulgação científica.

FLH0640 - História das Ciências

Faculdade de Filosofia, Letras e Ciências Humanas

História

Disciplina: FLH0640 - História das Ciências

Créditos Aula: 4

Créditos Trabalho: 0

Carga Horária Total: $60 \mathrm{~h}$

Tipo:

Semestral

Ativação: $\quad 01 / 01 / 2011$

\section{Objetivos}

Esta disciplina é ministrada para unidades da USP fora da FFLCH (como por exemplo, Biociências e Química) e busca discutir o desenvolvimento histórico da respectiva ciência, inclusive suas controvérsias teóricas e práticas. Entre seus tópicos se incluem: a representação da natureza e o processo de formação do campo científico específico, bem como sua relação com o conhecimento em geral; as relações entre a ciência, técnica e tecnologia; formação e crise dos paradigmas científicos; institucionalização da ciência, ciência local e universal; relações entre ciência e religião, entre outras variáveis do processo histórico. Os temas podem ser discutidos em diversas épocas determinantes para a formação histórica do campo científico específico, inclusive no caso brasileiro.

\section{Docente(s) Responsável(eis)}

\section{Programa Resumido}

Estudo e análise das visões sobre a natureza e a constituição de uma ciência dos seres vivos: descontinuidades e permanências. Compreensão e análise das relações entre biologia, sociedade e cultura.

\section{Programa}

História da ciência e ensino de ciências

A historicidade da ciência

A Revolução Científica

Filosofia mecânica e história natural

A evolução e a "nova" biologia

A genética e os (ab)usos da hereditariedade

A evolução dos germes e as doenças na história

Biologia e sociedade: I. a questão da violência 
Biologia e sociedade: II. a controvérsia evolução x criação

A revolução biotecnológica e os dilemas da bioética

\section{Avaliação}

\section{Método}

1.MÉTODOS UTILIZADOS

Aulas teórico-expositivas

Análise de textos

Apresentação e análise de filmes e/ou documentários

Seminários

\section{ATIVIDADES DISCENTES}

Leituras programadas

Seminários

Participação nas aulas e demais atividades relacionadas ao curso.

\section{Critério}

A avaliação terá por base a realização de seminário e de prova escrita sobre os temas e textos trabalhados ao longo do curso.

\section{Norma de Recuperação}

Prova escrita e/ou oral sobre o conteúdo trabalhado no curso.

\section{Bibliografia}

BIOLOGIA

CARON, Joseph A. "Biology' in the Life Sciences: A Historiographical Contribution", History of Science,XXVI (1988), pp. 223-268. MAGALHÃES, Gildo - Introdução à metodologia da pesquisa: caminhos da ciência e tecnologia (Ática, GOULD, Stephen Jay. Pilares do Tempo: Ciência e Religião na Plenitude da Vida. Tradução de F. Rangel; Rio de Janeiro: Rocco, 2002. . Viva 0 brontossauro (Cia. das Letras, 1992). HELLMAN, Hal- Grandes debates na ciência (UNESP, 1999). HÖSLE, Vittorio e Illies, Christian - Darwinism \& philosophy (University of Notre Dame, 2005). JACOB, François. A Lógica da Vida: Uma História da Hereditariedade. Trad. de Ângela Loureiro de Souza; Rio de Janeiro: Edições Graal, 1983. KELLER, Evelyn Fox. O Século do Gene. Tradução de Nelson Vaz; Belo Horizonte: Crisálida, 2002. . Refiguring life (Columbia University, 1995). MARGULIS, Lynn e Sagan, Dorion - O que é vida? (J. Zahar, 2002). MAYR, Ernst. Biologia, Ciência Única. Tradução de Marcelo Leite; São Paulo: Companhia das Letras, 2005. MOTOYAMA, Shozo (Org.). Prelúdio para uma História: Ciência e Tecnologia no Brasil. São Paulo: 2004. ROSE, Steven et al. - Not in our genes (Penguin, 1984). ROSEN, George - Uma história da saúde pública (Unesp, 1994). SERRES, Michel (Dir.). Elementos para uma História das Ciências. Lisboa: Terramar, vols., 1996. THOMAS, Keith. O Homem e o Mundo Natural: Mudanças de Atitude em Relação às Plantas e aos Animais (1500-1800). Trad. de João Roberto Martins 
Filho; São Paulo: Companhia das Letras, 1989. THUILLIER, Pierre. De Arquimedes a Einstein: A Face Oculta da Invenção Científica. Trad. de Maria Inês Duque-Estrada; Rio de Janeiro: Jorge Zahar Ed., 1994.

QUÍMICA

LEICESTER, Henry. The historical background of chemistry (Dover, 1971). MAAR, Juergen. Pequena História da Química (Papa-livro, 1999). MAGALHÃES, Gildo. Uma introdução à metodologia de pesquisa (Ática, 2005). BELL, Madison.. Lavoisier no Ano Um ( Cia. das Letras, 2007). BERNAL, John. Ciencia e industria en el siglo XIX (Martínez Roca, 1973). CARRARA, Ernesto e MEIRELLES, Hélio. A Indústria Química e o Desenvolvimento do Brasil (Metalivros, 1996). DJERASSI, Carl e HOFFMANN, Roald. Oxigênio (Vieira \& Lent, 2004). FARADAY, Michael. A história química de uma vela. (Contraponto, 2003). HECHT, Laurence, "Mysterium Microcosmicus: the geometric basis for the periodicity of the elements", 21st Century vol1, $\mathrm{n}^{\circ} 2,1988$. HOFFMANN, Roald. O mesmo e o não mesmo (UNESP, 2007). LE COUTEUR, P. e BURRESON, J.. Os botões de Napoleão (J. Zahar, 2006). LEVI, Primo. A Tabela Periódica (Relume Dumará, 1994). RHEINBOLDT, Heinrich. História da Balança (Edusp, 1988). SACKS, Oliver. Tio Tungstênio (Cia. das Letras, 2002). SERRES, Michel (org.). Elementos para uma História das Ciências (3 vol. Terramar, 1996).

THUILLIER, Pierre. De Arquimedes a Einstein: A Face Oculta da Invenção Científica. Trad. de Maria Inês Duque-Estrada; Rio de Janeiro: Jorge Zahar Ed., 1994.

\section{Instituto de Química}

\section{Química Fundamental}

Disciplina: QFL4600 - Introdução ao Ensino de Química

Créditos Aula: 4

Créditos Trabalho: 0

Carga Horária Total: $60 \mathrm{~h}$ ( Práticas como Componentes Curriculares $=30 \mathrm{~h}$ )

Tipo:

Semestral

Ativação: $\quad 01 / 01 / 2009$

\section{Objetivos}

1. Introduzir o estudante na reflexão crítica sobre o ensino de química na escola básica. 2. Refletir sobre o papel da educação científica frente às atuais necessidades e complexidade da sociedade moderna. 3.Proporcionar a compreensão do desenvolvimento científico como um processo de produção histórico/social. 


\section{Programa Resumido}

Natureza da Ciência e Metodologia Científica. Questões atuais sobre o ensino de ciência/ química. Parâmetros e orientações curriculares oficiais. Aspectos do conhecimento químico. Concepções alternativas. Fontes de informação ao trabalho docente.

\section{Programa}

Concepções sobre a natureza da Ciência. A pesquisa científica e a metodologia científica. O papel da experimentação e da teoria no desenvolvimento das idéias científicas. Estudo de casos ilustrativos do "fazer ciência". Questões atuais sobre o ensino de ciência/ química: alfabetização científica; conteúdos necessários para o exercício da cidadania; temas químicos sociais; o papel social da ciência. Lei de Diretrizes e Bases; Parâmetros Curriculares Nacionais (PCN, PCN+, OCEM, Proposta Curricular do Estado de SP): objetivos para o ensino médio, ensino de química para a formação do cidadão. Aspectos do conhecimento químico: observação dos fenômenos, níveis de representação e modelos teóricos explicativos. Características e problemas atuais do ensino de química: abordagem do conteúdo e a articulação entre os níveis macroscópico e microscópico do conhecimento químico; concepções alternativas dos conceitos científicos/ químicos. Fontes de informação ao trabalho docente; contribuição da pesquisa em ensino de química para o ensino médio.

\section{Avaliação}

\section{Método}

Seminários, discussão em grupo, pesquisa bibliográfica, trabalhos escritos.

\section{Critério}

Será feita através de relatórios sobre textos, apresentação de seminários, participação nas atividades propostas.

\section{Norma de Recuperação}

Aprovação obtida por nota mínima 5,0 (cinco). Nota da 2a avaliação $=$ Nota da 1 a avaliação +2 x (Nota da prova de recuperação) dividido por 3 .

\section{Bibliografia}

Textos selecionados de livros e periódicos.

DELIZOICOV, D., et. al, Ensino de Ciencias: fundamentos e métodos, São Paulo: Cortez Editora, 2002.

D. GIL-PERÉZ \& A. M. P. de CARVALHO - "Formacão de Professores de Ciências :Tendências e Inovações"Coleção Questões da Nova Época, v.26, Ed. Cortez, 1995

H. COLLINS e T. PINCH, O Golem - O Que Você Deveria Saber Sobre a Ciência, São Paulo, Edunesp, 2003.

A. CHALMERS, O Que é Ciência Afinal? São Paulo, Brasiliense, 1993.

A. J. ALVES-MAZZOTI e GEWANDSZNAJDER, F., O Método nas Ciências Naturais e Sociais. São Paulo: Pioneira Thomson Learning, 2004. 
CACHAPUZ, A., et. al. (org), A Necessária Renovação do Ensino das Ciências, São Paulo: Cortez Editora, 2005.

ZIMAN, J. Conhecimento Publico, Belo Horizonte: Editora Itatiaia, 1979.

BRASIL. Ministério da Educação, EC, Secretaria de Educação Básica, SEB, Departamento de Políticas de Ensino Médio. "Orientações Curriculares do Ensino Médio". Brasília, MEC/SEB, 2006.

BRASIL. Ministério da Educação (MEC), Secretaria de Educação Média e Tecnológica (Semtec). Parâmetros Curriculares Nacionais para o Ensino Médio. Brasília: MEC/Semtec, 1999.

BRASIL. Ministério da Educação (MEC), Secretaria de Educação Média e Tecnológica (Semtec). PCN + Ensino médio: orientações educacionais complementares aos Parâmetros Curriculares Nacionais - Ciências da Natureza, Matemática e suas Tecnologias. Brasília: MEC/Semtec, 2002.

SÃO PAULO (Estado) Secretaria da Educação. Coordenadoria de Estudos e Normas Pedagógicas. "Oficinas temáticas no ensino público: formação continuada de professores" coordenação de Maria Eunice Ribeiro Marcondes. São Paulo: FDE, 2007. 108 p.

Artigos selecionados dos periódicos:

Química Nova na Escola

Química Nova

International Journal of Science Education

Journal of Research in Science Teaching

Enseñanza de las Ciencias

Science Education

Journal of Chemical Education

Education in Chemistry 